\title{
Desarrollo de recubrimientos híbridos osteoinductores para implantes dentales
}

Tesis Doctoral presentada por

Miriam Hernández Escolano

para optar al grado de Doctor

por la Universidad Politécnica de Valencia

Directores de Tesis Doctoral:

Julio J. Suay Antón

Antonia Jiménez Morales 


Agradecimientos 

No se me ocurría cómo empezar los agradecimientos, así que he recurrido a una herramienta que me enseñó mi mama...

La primera definición que da la R.A.E de Tesis es "Conclusión, proposición que se mantiene con razonamientos." Pero nada pone del esfuerzo, constancia y dedicación que conlleva alcanzar esos razonamientos que soportan la conclusión, tanto del doctorando como de las personas que se encuentran a su alrededor. Por eso quería con estas líneas acordarme de cada una de esas personas que me han acompañado durante estos años.

De todos en primer lugar quería citar a mis directores de tesis, Julio y Toñi. A los dos daros las gracias por transmitirme vuestros conocimientos, haberme ayudado en cada obstáculo y hacerme ver el camino para llegar a la solución. Por confiar y creer en mí. Por escucharme y aconsejarme. Por enseñarme a valorar mi trabajo y a mí misma. Por recordarme la suerte que tengo de tener una Tesis tan bonita.

Nunca olvidaré las primeras palabras que intercambié con Julio en el descanso de una de las clases de Polimeros para aplicaciones especiales (por cierto, tenemos pendiente la nota) “¿cuánto has dicho...?”, desde ese día supe que tendríamos una relación, cuanto poco, especial. Después empezaron los rituales de persuasión para hacer la tesis, con lo joven que eres, buenas notas... y el siguiente septiembre ya estaba en el CBIT en "mi cuarto oscuro" haciendo ensayos. Quería darte las gracias por haberme dado la oportunidad de trabajar en distintas líneas de investigación, por contar conmigo, por haberme puesto en contacto con el mundo industrial, llevándome a grandes empresas Nacionales e Internacionales, a congresos, que me han ayudado enormemente tanto personal como profesionalmente.

Toñi, quería agradecerte el enorme apoyo que me has transmitido desde "la lejanía" de Madrid. Has sido mi mentora. Gracias por enseñarme todo cuanto sabes de sol-gel, sin ti esta Tesis Doctoral no hubiera sido posible. Gracias por transmitir en el trabajo del día a día esa alegría que te caracteriza. Por escucharme y apoyarme ante cualquier problema. Por todas las reuniones amenas y divertidas que hemos tenido y esas llamadas de teléfono interminables. 
Agradecer a los profesores José Luis Gómez, Manuel Monleón, Manuel Salmerón, José Antonio Tejedor, y al resto de profesores que forman parte del CBIT vuestra ayuda desinteresada que tanto me ha aportado en la elaboración de esta Tesis Doctoral.

A mis compañeros y amigos del CBIT, en especial Amparo, Carmen, Cristina, Harmony, Marco, Myriam y Pachi. Quería deciros que habéis sido mi familia en Valencia. Habéis sido la rama a la que cogerme cada día para no caerme (aunque me habéis enseñado que cada uno tiene que ser su propia rama), habéis sido mis confidentes y cada uno de vosotros me habéis aportado un granito de sabiduría que llevaré conmigo para siempre.

Al resto de compañeros y amigos (las viejas y nuevas generaciones CBIT) gracias por los consejos y ayudas en los momentos de desesperación. Por todos esos momentos de risas en las comidas, en los laboratorios, habéis hecho que el trabajo del día a día sea divertido, ameno y simplemente mejor.

A mi amiga y compañera Marije que me ha ayudado tantísimo en la realización de esta tesis y con la que he podido contar en todo momento, aunque la prefería cuando estaba en Valencia. Y siguiendo con Donostia quería agradecer a María su dedicación, su ayuda y desearle suerte en sus próximos 4 años de sol-gel.

A toda la gente de Castellón, en especial a María José con la que compartí mis inicios al lado de Julio y con la que he compartido tantas cosas. A las nuevas generaciones PIMA: Montse, Ane, Sara e Irene gracias por vuestra ayuda en este último tramo y os deseo mucha suerte en los años futuros.

Quería agradecer a todos los profesores con los que Julio me ha dado la oportunidad de trabajar, que me han enseñado tanto y con los que he compartido grandes momentos. Mariló Gurruchaga e Isabel Goñi, gracias por ayudarme sin ningún impedimento, brindando siempre una sonrisa. Angels Serra, gracias por tu dedicación y por acogerme en tu centro como a una más. A Xavier Ramis por enseñarme con paciencia el mundo isoconversional y el apoyo prestado en la elaboración de mi primer artículo. También quería acordarme de Juan Carlos Galván por sus clases de electroquímica en Madrid y por sus grandes aportaciones en reuniones y post-reuniones. 
Por último, quería agradecer a mi familia, cada día más grande y llena de nuevas luces, a mis amigas y a Luis, por apoyarme en los momentos buenos y en los malos, por hacerme reír cuando lo necesitaba, por cuidarme, porque sois mi todo y $\sin$ vosotros no sería yo. 



\section{Índice}

RESUMEN

RESUM

ABSTRACT

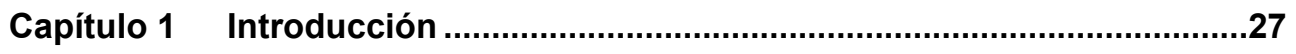

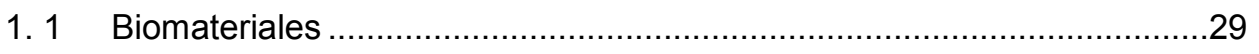

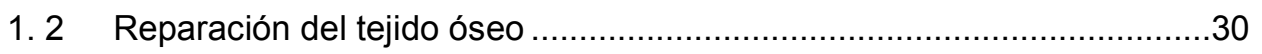

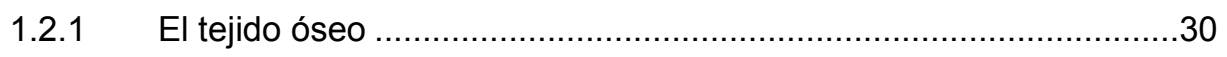

1.2.2 Reparación ósea: Comportamiento celular ....................................31

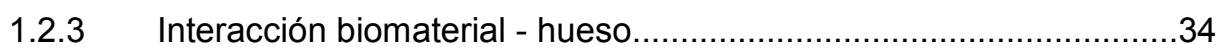

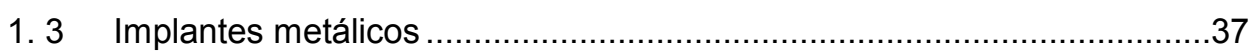

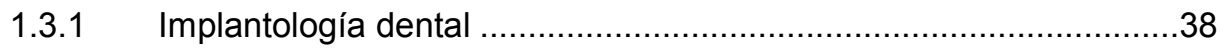

1.3.2 El titanio en implantes dentales ................................................. 40

1.4 Introducción al proceso sol-gel .....................................................4

1.4.1 Reacciones del proceso sol-gel................................................ 47

1.4.2 Factores que afectan a la hidrólisis y condensación ........................49

1. 5 Recubrimientos sol-gel sobre aleaciones metálicas ............................51

1.5.1 Métodos de deposición ...............................................................54

1.5.2 Protección frente a la corrosión de recubrimientos híbridos orgánico-

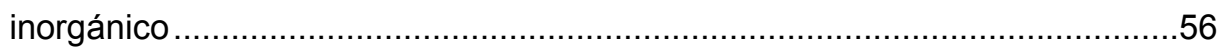

1. 6 Recubrimientos sol-gel para aplicaciones biomédicas ..........................57

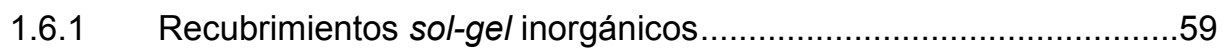

1.6.2 Recubrimientos híbridos orgánico-inorgánicos ..............................60 
1.6.3 Recubrimientos híbridos orgánico-inorgánicos como vehículo de

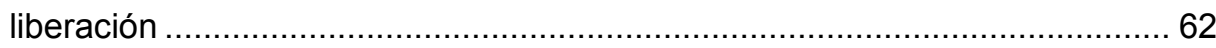

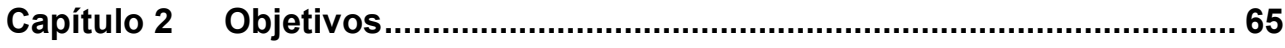

Capítulo 3 Materiales y métodos .................................................................. 71

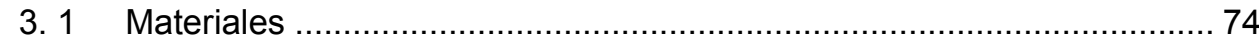

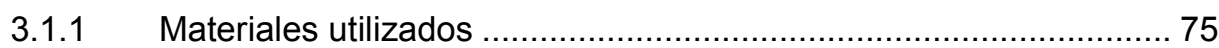

3.1.2 Método de obtención de los geles ...................................... 77

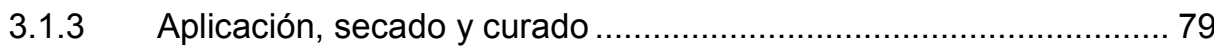

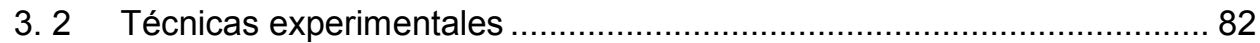

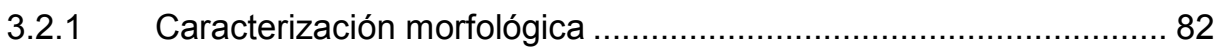

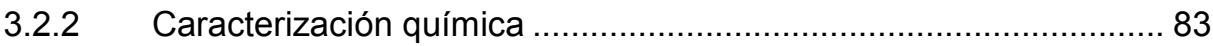

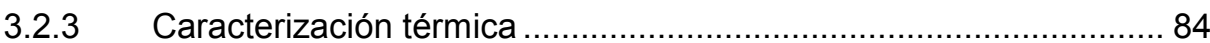

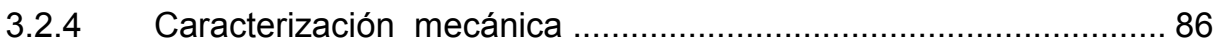

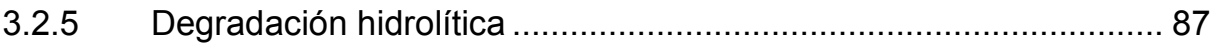

3.2.6 Protección frente a la corrosión. Medidas impedancia electroquímica 87

3.2.7 Medidas de ángulo de contacto ............................................ 97

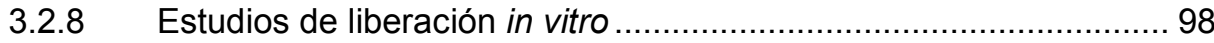

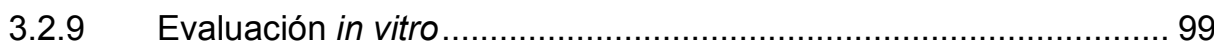

\section{Capítulo 4 Selección del precursor base para aplicaciones biomédicas 105}

4. 1 Síntesis de los materiales a partir de los precursores MTMOS, VTES y

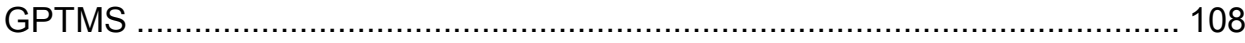

4. 2 Caracterización química de los recubrimientos ............................. 110

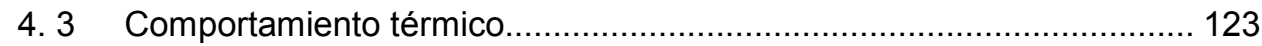

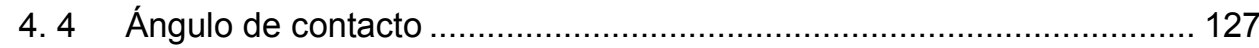




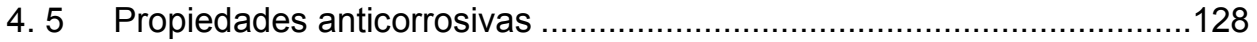

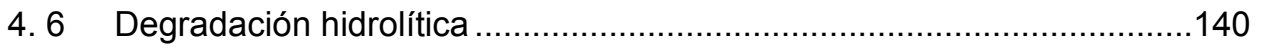

4. $7 \quad$ Liberación de agentes terapéuticos............................................142

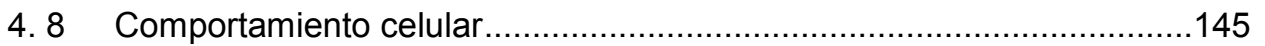

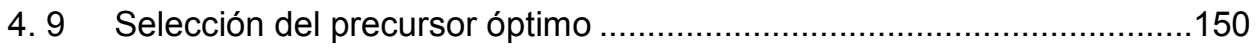

Capítulo 5 Síntesis y optimización de series de recubrimientos sol-gel con propiedades diferenciadas

5. 1 Recubrimientos con distinto contenido inorgánico .........................156

5.1.1 Síntesis de la serie de materiales VTES-TEOS ........................156

5.1.2 Caracterización química de la serie de recubrimientos VTES-TEOS.. 159

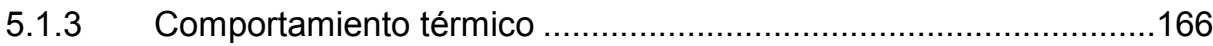

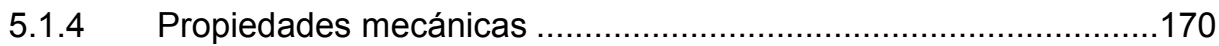

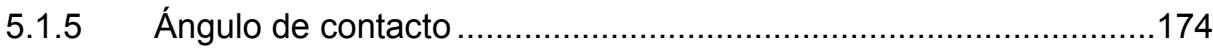

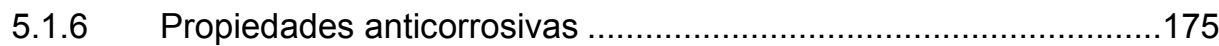

5.1.7 Degradación hidrolítica .................................................188

5.1.8 Liberación de agentes terapéuticos........................................190

5.1.9 Comportamiento celular............................................... 192

5. 2 Recubrimientos con grupo funcional epoxi...................................197

5.2.1 Síntesis de la serie de materiales VTES-GPTMS ......................198

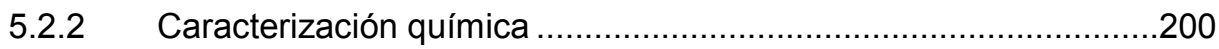

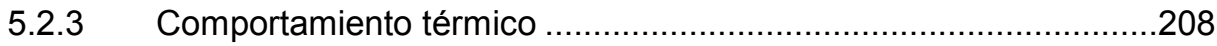

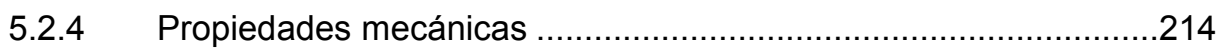

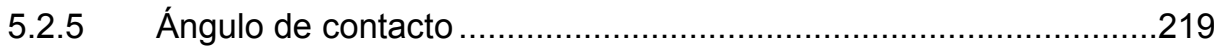

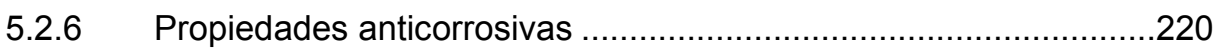




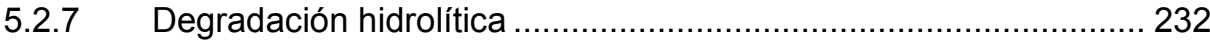

5.2.8 Liberación de agentes terapéuticos ...................................... 234

5.2.9 Comportamiento celular ............................................... 236

5. 3 Selección del recubrimiento óptimo para la aplicación biomédica........ 242

\section{Capítulo 6 Diseño a medida del recubrimiento (nivel bioactividad, control} de la velocidad de degradación y de la liberación de fármacos) .................. 247

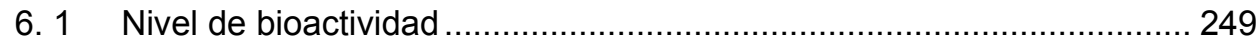

6.1.1 Síntesis de recubrimiento con HAp .................................... 249

6.1.2 Comportamiento térmico con distintas cargas de HAp ............... 253

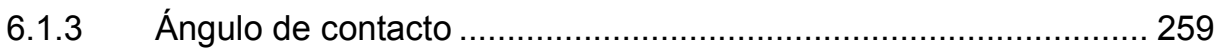

6. 2 Control de la velocidad de degradación y la liberación de fármacos .... 260

6.2.1 Estudio mediante FTIR del efecto de las condiciones (tiempo y

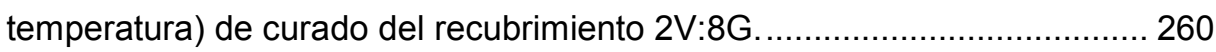

6.2.2 Caracterización de la formación de red mediante DSC ................ 263

6.2.3 Ángulo de contacto con distintos tratamientos de curado ............. 267

6.2.4 Degradación hidrolítica con distinto tratamiento de curado........... 268

6.2.5 Estudio de la influencia del grado de entrecruzado en la liberación de agentes terapéuticos

6.2.1 Estudio de la influencia en la cantidad de fármaco incorporado en la liberación

6. 3 Discusión del diseño a medida del recubrimiento $2 \mathrm{~V}: 8 \mathrm{G} \ldots \ldots \ldots \ldots \ldots \ldots . . \ldots \ldots$

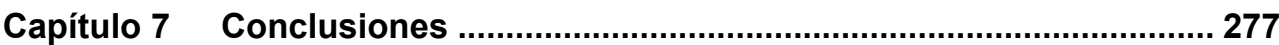

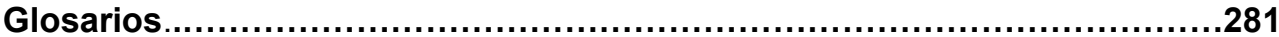

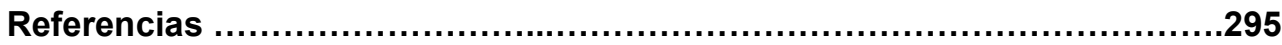

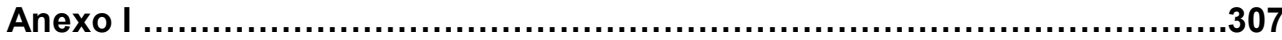




\section{RESUMEN}

En la actualidad, en el desarrollo de implantes metálicos y, en particular el de los dentales, se necesitan métodos innovadores que permitan desarrollar nuevos procesos y materiales con mayor velocidad de osteointegración, para conseguir una unión hueso-implante óptima en todo tipo de pacientes, incluso en aquellos donde el uso de implantes dentales se desaconseja por tener mermada la capacidad para la regeneración ósea.

El titanio y algunas de sus aleaciones son materiales reconocidos como biocompatibles y los más empleados para la fabricación de implantes dentales. Sin embargo, en algún tipo de pacientes, los tiempos necesarios para la osteointegración son más elevados de lo deseable. Así pues, poder reducir los tiempos de cirugía requeridos en este tipo de operaciones, así como poder abarcar un mayor abanico de posibles pacientes tiene una gran relevancia clínica.

Una vía innovadora e incipiente para solucionar este inconveniente consiste en desarrollar nuevos recubrimientos osteoinductores que mejoren las propiedades de los implantes metálicos dentales.

El objetivo principal de esta Tesis Doctoral se centra en desarrollar recubrimientos con propiedades osteoinductoras para implantes dentales metálicos que mejoren su osteointegración, de forma que se reduzcan los tiempos para su integración. Se pretende dotar además a estos recubrimientos de una propiedad añadida, como es la capacidad de liberación de agentes terapéuticos cuando la situación lo requiera, evitando, por un lado las infecciones o procesos inflamatorios y, por otro lado, la ingesta de medicamentos por cualquier otra vía.

Para alcanzar estos objetivos, se propone la preparación de un recubrimiento híbrido orgánico-inorgánico obtenido mediante procesos de tipo sol-gel. La idea base subyacente en los desarrollos efectuados se centra en conseguir que el contacto del implante metálico con los tejidos vivos pueda establecerse a través de un material degradable con el tiempo que potencie la adhesión y proliferación celular, y la posterior mineralización. 
Para tal fin, se ha desarrollado un protocolo que permite realizar la selección de recubrimientos que sean óptimos para esta aplicación concreta. El procedimiento consiste en un estudio integral en el que se han pre-seleccionado cuatro precursores de silicio formadores de una red de naturaleza polisiloxánica: el tetraetil-ortosilicato (TEOS), el metil-trimetoxisilano (MTMOS), el vinil-trietoxisilano (VTES) y el 3glicidoxipropil-trimetoxisilano (GPTMS). A partir de estos precursores se han preparado nuevos recubrimientos híbridos órgano-inorgánicos diseñados a medida, sobre los que se ha realizado una caracterización físico-química en profundidad. Mediante estudios realizados sobre el comportamiento in vitro de estos recubrimientos en contacto con fluidos biológicos simulados se ha analizado los fenómenos de degradación hidrolítica. Por otra parte, en las matrices órgano-silícicas se ha introducido un fármaco modelo (procaína), con el propósito de diseñar recubrimientos con propiedades de liberación lenta y controlada de fármacos. Por último, se han analizado tanto la citotoxicidad de los recubrimientos resultantes como la proliferación de osteoblastos humanos sobre los mismos.

Tras los resultados obtenidos en una primera etapa de esta Tesis Doctoral, se ha seleccionado como precursor de referencia el vinil-trietoxisilano. En la siguiente etapa, el estudio se ha centrado en la caracterización y estudio del comportamiento in vitro de dos tipos de recubrimientos, uno de ellos se ha preparado a partir de mezclas de vinil-trietoxisilano y tetraetil-ortosilicato (VTES:TEOS) y el otro a partir de mezclas de vinil-trietoxisilano y 3-glicidoxipropil-trimetoxisilano (VTES:GPTMS) con el propósito de conseguir nuevos materiales de interés físico-químico y biológico.

En esta etapa, en la investigación se han contemplado los siguientes cuatro aspectos:

(1) Estudio de las propiedades físico-químicas, mecánicas y anticorrosivas.

(2) Evaluación de la degradación hidrolítica.

(3) Análisis de la liberación de fármacos en medio acuoso.

(4) Evaluación de la osteoinducción de los recubrimientos mediante ensayos de proliferación de células madre mesenquimales y de capacidad de diferenciación de éstas a osteoblastos sobre los recubrimientos. 
Los resultados obtenidos durante este estudio han mostrado que los recubrimientos basados en mezclas de VTES y TEOS son de carácter hidrófilo y degradable hidrolíticamente. Si estas propiedades son importantes también lo son las que se han obtenido con los recubrimientos basados en las mezclas de VTES y GPTMS. Gracias al carácter activo de los grupos epoxi de estos recubrimientos, se puede conseguir una mayor unión química con péptidos y proteínas. No obstante, tras calibrar y optimizar los resultados obtenidos en esta fase del estudio se ha seleccionado el recubrimiento basado en mezclas de VTES y GPTMS, concretamente la formulación de un 20\% en peso de VTES y un $80 \%$ de GPTMS (2V:8G).

Con este recubrimiento se ha realizado un estudio en profundidad para optimizar sus propiedades. En primer lugar, se han introducido partículas bioactivas con la intención de mejorar la osteointegración del implante. Por otro lado, se ha llevado a cabo un estudio que ha permitido variar el grado de entrecruzamiento de la red de forma controlada y repetitiva, a fin de tener un mayor control sobre el tiempo de degradación y la posible liberación de fármacos y moléculas activas. El estudio se ha basado en la variación de las condiciones de curado del recubrimiento, para lo cual se ha analizado el estado de la red formada mediante la aplicación de espectroscopia infrarroja (FTIR) y calorimetría diferencial de barrido (DSC). Finalmente, con el control de los tiempos y temperaturas de curado se han conseguido recubrimientos con grados de entrecruzamiento diseñados a la medida, pudiéndose así obtener redes con bajo o con alto entrecruzamiento para controlar a voluntad las propiedades de degradación y de la liberación de fármacos de los recubrimientos resultantes. 



\section{RESUM}

En l'actualitat el desenvolupament d'implants metàl-lics i, en particular el dels implants dentals necessita incorporar alguns mètodes innovadors per desenvolupar nous processos i materials amb una major velocitat d'osteointegració i aconseguir que la unió entre l'os i l'implant siga òptima en tot tipus de pacients, inclòs en aquells en què l'ús d'implants dentals no s'aconsella per tindre minvada la capacitat de regeneració òssia.

El titani i alguns dels seus aliatges són materials reconeguts com a biocompatibles i els més utilitzats per a la fabricació d'implants dentals. Ara bé, en alguns pacients el temps requerit per a l'osteointegració és més elevat que el desitjat. Poder reduir els temps de cirurgia necessaris en aquest tipus d'operacions i així poder abastar un major ventall de possibles pacients, té una gran rellevància clínica.

Una via innovadora i incipient per tal de solucionar aquest inconvenient consisteix a desenvolupar nous recobriments osteoinductors que milloren, en aquest sentit, les propietats dels nous implants metàl-lics dentals.

L'objectiu principal d'aquesta Tesi Doctoral es centra en el desenvolupament de recobriments amb propietats osteoinductores per a implants dentals metàl-lics que milloren la seua osteointegració, de forma que es reduïsquen els temps per a la seua integració. Es pretén, a més a més, dotar a aquests recobriments d'una propietat afegida, com és la capacitat d'alliberar agents terapèutics quan la situació ho requerisca i evitar, per una banda, les infeccions o processos inflamatoris i, per l'altra, la ingesta de medicaments per qualsevol altra via.

Per aconseguir aquests objectius es proposa la preparació d'un recobriment híbrid orgànic-inorgànic obtingut mitjançant processos de tipus sol-gel. La idea base subjacent en els desenvolupaments efectuats se centra en aconseguir que el contacte de l'implant metàl-lic amb els teixits vius puga establir-se a través d'un material degradable amb el temps que potencie l'adhesió i proliferació cel·lular i la posterior mineralització.

Per a tal fi s'ha desenvolupant un protocol que permet realitzar la selecció de recobriments que siguen òptims per a aquesta aplicació en concret. El procediment 
consisteix en un estudi integral en què s'han preseleccionat quatre precursors de silici formadors d'una xarxa de naturalesa polisiloxànica: el vinil-trietoxisilà (VTES), el tetraetil-ortosilicat (TEOS), el 3-glicidoxipropil-trimetoxisilà (GPTMS) i el metiltrimetoxisilà (MTMOS). A partir d'aquests precursors s'han preparat uns nous recobriments híbrids orgànics-inorgànics dissenyats a mida, sobre els quals s'ha realitzat una caracterització físico-química en profunditat. Mitjançant estudis realitzats sobre el comportament in vitro d'aquests recobriments en contacte amb fluids biològics simulats, s'ha analitzat la quantitat d'aigua que absorbeixen, la qual s'ha correlacionat amb els fenòmens de degradació hidrolítica que experimenten al llarg del temps d'assaig en els fluids biològics. Per altra banda, en les matrius organosilíciques s'ha introduït un fàrmac modèlic (procaïna), amb el propòsit de dissenyar recobriments amb propietats d'alliberació lenta i controlada de fàrmacs. Per últim, s'han analitzat tant la citotoxicitat dels recobriments resultants com la proliferació d'osteoblasts humans sobre ells.

Després d'obtindre els resultats de la primera etapa d'aquesta Tesi Doctoral, s'ha seleccionat com a precursor de referència el vinil-trietoxisilà. A la següent etapa, s'ha caracteritzat i estudiat el comportament in vitro de dos tipus de recobriments, un d'ells s'ha preparat a partir de mescles de vinil-trietoxisilà i tetraetil-ortosilicat (VTES:TEOS) i l'altre a partir de mescles de vinil-trietoxisilà i 3- glicidoxipropil-trimetoxisilà (VTES:GPTMS) amb el propòsit d'aconseguir nous materials d'interès fisico-químic $i$ biològic.

En aquesta etapa de la investigació s'han considerat els cinc aspectes següents:

(1) L'estudi de les propietats fisico-químiques, mecàniques i anticorrosives.

(2) L’avaluació de la degradació hidrolítica.

(3) L'anàlisi de l'alliberament de fàrmacs en medi aquós.

(4) L'avaluació de l'osteoinducció dels recobriments mitjançant els assajos de proliferació de cèllules mare mesenquimals i de la capacitat de diferenciació a osteoblasts sobre els recobriments.

Els resultats obtinguts en aquest estudi han mostrat que els recobriments basats en mescles de VTES i TEOS són de caràcter hidròfil i degradable hidrolíticament. Si 
aquestes propietats són importants també ho són aquelles que s'han obtingut amb els recobriments basats en les mescles de VTES i GPTMS. Gràcies al caràcter viu dels grups epoxi s'ha aconseguit major unió química amb els pèptids i les proteïnes. Tanmateix, una vegada calibrats i optimitzats els resultats d'aquesta fase de l'estudi, s'ha seleccionat el recobriment basat en mescles de VTES i GPTMS, concretament la formulació amb un $20 \%$ de VTES i un $80 \%$ de GPTMS (2V:8G).

Amb aquest recobriment s'ha realitzat un estudi en profunditat per optimitzar les seues propietats. En primer Iloc, s'han introduït unes partícules bioactives amb la intenció de millorar l'osteointegració de l'implant. Per altra banda, s'ha efectuat un estudi que ha permès variar el grau d'entrecreuament de la xarxa de forma controlada i repetitiva, per tal de tindre més control sobre el temps de degradació i el possible alliberament dels fàrmacs i molècules actives. L'estudi s'ha basat en la variació de les condicions de curat del recobriment, i per a tal s'ha analitzat l'estat de la xarxa formada a través d'espectroscòpia infraroja (FTIR) i calorimetria diferencial de rastreig (DSC). Finalment, amb el control dels temps i de les temperatures de curat s'han aconseguit recobriments amb uns graus d'entrecreuament dissenyats a mida que han permès obtindre unes xarxes $a m b$ un baix 0 alt entrecreuament per controlar voluntàriament les propietats de degradació i de l'alliberament de fàrmacs dels recobriments resultants. 



\section{ABSTRACT}

The development of metal implants and, particularly in the field of the dental ones, innovator methods are needed to allow the progress of new processes and materials with a higher osseointegration speed, so that a best implant-bone bond can be achieved in all type of patients, even for those who have problems to use dental implants due to have a reduced bone regeneration.

Titanium and some of its alloys are materials admitted as biocompatible and their use is wide spread in the manufacture of dental implants. Nevertheless, some patients need times longer than the desirable to complete osseointegration. So, to reduce the time requires in this type of surgery as well as to widen the range of possible patients has a great clinical relevance.

An innovating and incipient method to solve the above mentioned problems consist of the development of new osteoinductor coatings which will improve the properties of dental metallic implants.

The aim of this Thesis Dissertation is focused on the development of new coatings with ostinductor properties to be used in metallic dental implants, the aim is to reduce integration times. On top of that, a new property is added to the coating to get better results such as the capacity to drug release when the situation requires it; avoiding on the one hand, infections or inflammatory process and on the other hand, to take medicaments by any means.

To reach those goals a new organic-inorganic hybrid coating got through the solgel route is proposed. The grounds, that underlies in the carried out processes, is to get that the contact between metal implant and alive tissue is done through a degradable material which promotes the cell adhesion and proliferation, and the subsequent mineralization process.

To get the best coating selection for this specific application a new protocol has been developed. The procedure consists of an integral study in which four silicon precursors were pre-selected: the tetraethyl-orthosilicate (TEOS), the methyltrimethoxysilane (MTMOS), the vynil-triethoxysilane (VTES) and the 3-glycidoxypropiltrimethoxysilane (GPTMS). From those precursors new organic-inorganic hybrid 
coatings have been designed to meet all the requirements. A complete physicalchemical characterization was done in all the coatings obtained. In vitro testes were carried out in order to obtain the hydrolytic degradation of the films. Besides this, a model drug (procaine) was added into the hybrid network, with the aim of design coatings with the property to slow and control drug release. Cytotoxicity essay and human osteoblast cell proliferation were done to determine the biological behavior of the coatings.

After the results got in the first stage of this Doctoral Dissertation, a vyniltriethoxysilane was selected as reference precursor. In the following stage, this study has been centered in the characterization and study of the behavior in vitro of two kinds of coatings. One of them have been prepared from mixtures of vyniltriethoxysilane and tetraethyl-orthosilicate (VTES: TEOS) and the other from mixtures of vynil-triethoxysilane and 3-glycidoxypropil-trimethoxysilane (VTES: GPTMS), with the aim to get new materials of physical-chemical and biological interest.

At this level, during investigation, the following four aspects have been taken into account:

(1) The physical-chemical, mechanical and anticorrosive properties.

(2) Evaluation of the hydrolytic degradation.

(3) Analysis of the drug release.

(4) Evaluation of the osseinductuion of the coatings through essays of mesenchymal stem cells proliferation and osteogenic differentiation of cultured onto the coatings.

The results obtained along these study have shown that the coatings based on VTES:TEOS are hydrophilic and hydrolytic degradable. If these properties are important, those obtained from VTES:GPTMS coatings are also important. Thanks to the active character of the epoxy groups of these coatings, a better chemical bond with proteins and peptides is achieved. Nevertheless, after measuring and optimizing the obtained results at this stage of the study, it has been selected the coating based on the VTES:GPTMS, specially the formulation with a $20 \%$ wt VTES and a $80 \%$ wt of GPTMS (2V: 8G). 
With the elected coating a study in depth to optimize its final properties has been done. To start with, bioactive particles have been introduced with the aim of improving the osteointegración of implants. On the other hand, along the essays done, it has been possible to vary the cross-linking density of the coatings in a control and repetitive way, in order to have a higher control on the degradation time and the possible drug and active molecules release. The study has been based on the variation of the cure conditions, to do that, the network state has been analyzed using infrared spectroscopy (FTIR) and differential scanning calorimetry (DSC).

Finally, with the control of the times and cure temperatures, new coatings have been achieved with cross-linking rates designed to the required measure. Therefore to get networks with low or high bond density to control the degradation properties and drug release of the coatings obtained as required. 

Capítulo 1 Introducción 



\section{1 Biomateriales}

En el último cuarto de siglo se ha producido un aumento de la esperanza de vida. Este fenómeno se debe principalmente a todos los avances que se han conseguido en el campo de la medicina. En el pasado cuando un órgano vital del cuerpo humano fallaba, el riesgo de muerte era muy elevado y en caso de solventar el problema quedaban graves secuelas. Sin embargo, ahora existen un gran número de actuaciones que se pueden llevar a cabo para solucionar el problema y, que además, el paciente quede con una calidad de vida buena o muy buena. Cuando los problemas tienen lugar en un órgano vital la vía que actualmente se utiliza es la de efectuar trasplantes de órganos procedentes de donantes, quedando todavía lejos las propuestas efectuadas por el campo del conocimiento de la ingeniería tisular en cuanto a la creación de órganos artificiales. Por otro lado, cuando la raíz del problema es traumatológica, dermatológica, odontológica, etc. el uso de trasplantes está limitado, por lo que se recurre al uso de implantes sintéticos basados en biomateriales. Un biomaterial es un material sintético, natural o natural modificado, destinado a estar en contacto e interactuar con el sistema biológico [1].

El momento actual se caracteriza por el auge en el desarrollo de biomateriales. Son numerosos los grupos de investigación que se dedican al desarrollo y perfeccionamiento de nuevos materiales capaces de simular el comportamiento del tejido dañado, dispensar fármacos de manera controlada, etc. Una de las vertientes en el perfeccionamiento de nuevos materiales es utilizar aquellos avances en otros campos de la ingeniería y modificarlos para su uso en biomedicina. Un ejemplo de esto es el uso de nanomateriales, composites o híbridos orgánico-inorgánicos como los que se desarrollan en la presente Tesis Doctoral.

Los materiales que van a ser implantados deben cumplir una serie de especificaciones dada su aplicación final, por ello tanto los componentes como los productos derivados de su posible degradación deben ser biocompatibles. Se considera que un material es biocompatible cuando tiene una respuesta apropiada dentro del cuerpo humano para la aplicación para la que ha sido diseñado [1-2]. En función de la aplicación final se especificarán una serie de parámetros que serán los que definan la biocompatibilidad del material. En general existen unos factores 
intrínsecos del material que modulan la respuesta del organismo. Alguno de ellos son su naturaleza, composición química, geometría o morfología, y estos serán los parámetros necesarios para poder diseñar nuevos materiales para nuevas aplicaciones.

Los biomateriales se pueden clasificar en función de la respuesta que crean en el cuerpo humano a su implantación: tóxico, biotolerantes, bioinertes, bioactivos o biodegradables. Esta clasificación se profundizará en el apartado 1.2.3.

\section{2 Reparación del tejido óseo}

\subsubsection{El tejido óseo}

Una de las líneas de investigación más incipientes en la actualidad y que presenta grandes retos es la reparación de tejido óseo. Son muchas las patologías o accidentes traumatológicos que llevan a la pérdida de parte de tejido o a la necesidad de extracción del mismo, con el agravante de que el tejido óseo no es capaz de regenerarse por sí mismo cuando existe una distancia superior a $1 \mathrm{~mm}$ entre las dos zonas de hueso contiguas [3]. Además el tejido óseo es un material con una composición y estructura muy compleja (Figura. 1.1), capaz de soportar grandes cargas cíclicas. Por todo ello, conseguir un material capaz de sustituirlo y/o que permita su regeneración constituye uno de los grandes retos presentes para la ingeniería de materiales.

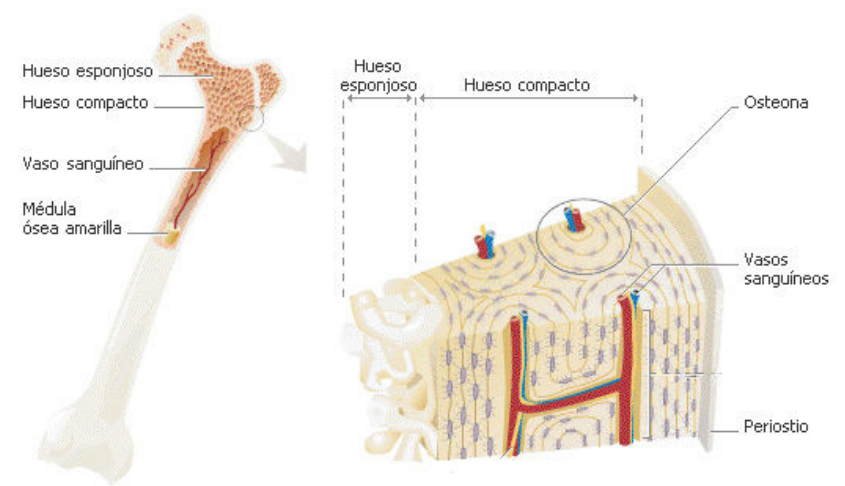

Figura. 1.1 Composición y estructura de hueso maduro[4]. 
En la Figura. 1.1 se muestra la estructura típica de un hueso maduro o lamelar. Se caracteriza por estar formado por láminas ordenadas, con dos distribuciones bien diferenciadas: esponjosa o compacta

El hueso esponjoso deja espacios entre sus láminas, que será ocupado por la médula ósea y se sitúa en la zona más profunda del hueso. El hueso compacto se encuentra superficialmente y posee láminas muy tupidas entre sí. Está cubierto por el periostio osteogénico [3].

Por otro lado, también se puede localizar hueso inmaduro o trabecular. En éste no existe un orden determinado y se puede encontrar en el feto o cuando se está regenerando hueso, el hueso inicial se va sustituyendo por tejido lamelar con el paso del tiempo [3].

El hueso está compuesto por un $35 \%$ de matriz orgánica y un $65 \%$ de matriz inorgánica. La matriz inorgánica está formada por hidroxiapatita cálcica $\left[\mathrm{Ca}_{10}\left(\mathrm{PO}_{4}\right)_{6}(\mathrm{OH})_{2}\right.$ ] que es la encargada de dar la resistencia y dureza al hueso [5]. Por otro lado, la matriz orgánica está formada por células óseas (mayoritariamente osteoblastos y osteocitos) y proteínas de la matriz extracelular. La matriz extracelular está formada en un $90 \%$ por colágeno (tipo I en un $97 \%$ y tipo $V$ en un $3 \%$ ) y un $10 \%$ de proteínas no colágenas ( $20 \%$ osteocalcina, $20 \%$ osteocina, $12 \%$ sialoproteinas de hueso, $10 \%$ proteoglicanos, fibronectina, factores de crecimiento, proteínas morfogenéticas de hueso, etc.) Todas estas proteínas están sintetizadas por los osteoblastos [6].

\subsubsection{Reparación ósea: Comportamiento celular}

Los tejidos cuando son dañados tienden a repararse o regenerarse. La regeneración es la formación del mismo tejido nuevo en la zona dañada. La reparación consiste en formar tejido conectivo que constituye la cápsula fibrótica o la necrosis de la zona. Que se produzca un proceso u otro depende en mayor medida de la capacidad regenerativa de las células que forman el tejido. Se puede clasificar las células en función de esta propiedad en: lábiles, estables y permanentes. Las células lábiles tienen la capacidad de proliferar durante toda su vida, las células estables retienen esta capacidad pero no se replican normalmente, las células 
permanentes no pueden reproducirse por sí mismas. Por tanto, se podrá obtener una regeneración buena en tejidos con células estables y lábiles, mientras que en tejidos compuestos por células permanentes formarán fibrosis o una cápsula fibrótica, con muy poca restitución del tejido normal.

La regeneración de tejido óseo es un proceso complejo en el que intervienen varios tipos celulares y factores. Al igual que en el resto de tejidos, la formación de los mismos nace de células madre. El tejido óseo está formado por células estables, con capacidad para regenerarse.

Las células madre involucradas en la regeneración del tejido óseo son las células madre mesenquimales (MSCss, siglas en inglés). Estas células son multipotenciales, lo cual significa que en función del entorno se pueden diferenciar y dar lugar a tejidos como hueso, cartílago, tendón, musculo, médula ósea, dermis y grasa [7].

En el caso del tejido óseo, las MSCss se diferencian en células osteoprogenitoras. Las células osteoprogenitoras son capaces de diferenciarse a osteoblastos, hecho esencial para la formación de hueso. Los osteoblastos sintetizan, transportan y organizan las proteínas de la matriz orgánica del hueso, y también activan el proceso de mineralización (el indicador de este proceso es, entre otros, la actividad de la enzima alcalina fosfatasa [8]). Las células segregan matriz extracelular mineralizada (hidroxiapatita). Una vez los osteoblastos se encuentran rodeados totalmente por matriz orgánica se denominan osteocitos y son las células más numerosas en el hueso (Figura. 1.2). Por otro lado, existen otro tipo de células que tienen un papel fundamental en la regeneración de tejido óseo, los osteoclastos. Estas células se encargan de la reabsorción ósea y gracias a este proceso de descomposición se liberan sustancias (factores de crecimiento) que inician la renovación de hueso [5], siendo un tejido en continua renovación y vivo. 


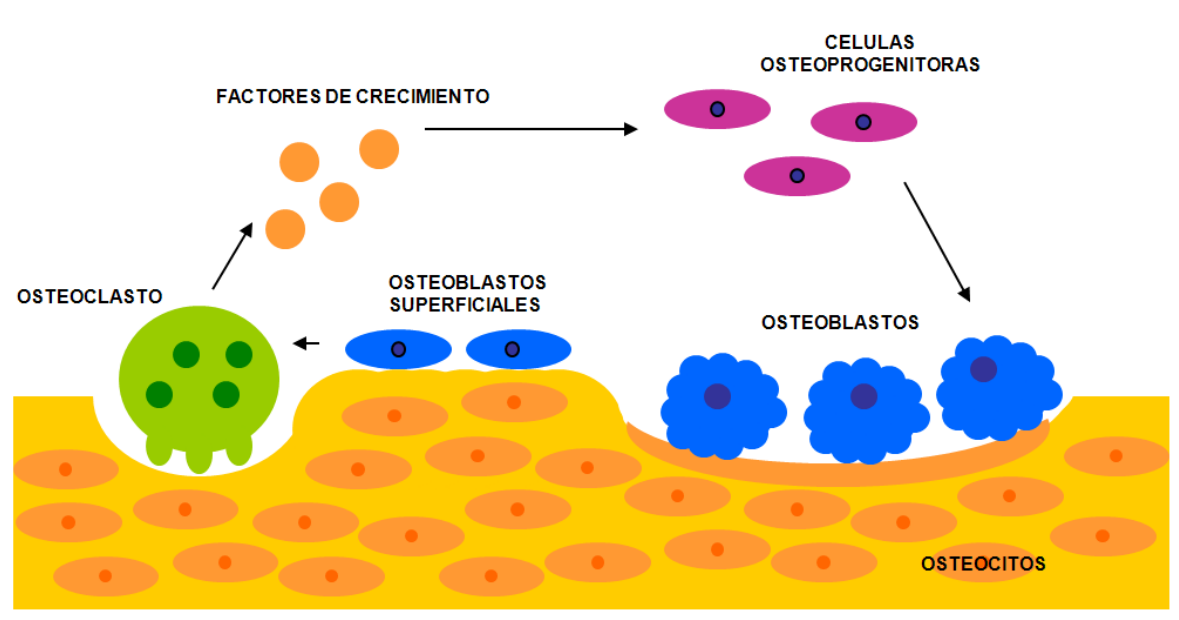

Figura. 1.2 Proceso celular para la formación de hueso.

Cuando se produce una rotura en el hueso, el tejido tiene una respuesta específica que se puede dividir en tres etapas: inflamación, reparación y remodelación. En el primer estadio se produce un hematoma y una reacción inflamatoria. En el hematoma se produce una acumulación de proteínas (como las citocinas) y plaquetas formando un coágulo de gran atractivo para las MSCss que migran a la zona dañada. El hematoma condensa formando un soporte a través del cual se puede producir la migración de las MSCss encargadas de la regeneración, la migración se produce a través de los primeros capilares que se forman en el hematoma. Las MSCss proliferan y siguen el proceso de diferenciación hacia osteoblastos y condrocitos. Las células osteoprogenitoras crean hueso inmaduro formado por osteoide y cartílago que se denomina callo de fractura. El osteoide mineraliza, aumentando su rigidez, y el cartílago se osifica formando el hueso hasta que se restablece la continuidad entre los extremos con hueso nuevo. Una vez que el callo endurece se produce la remodelación con la sustitución de hueso inmaduro por hueso lamelar y simultáneamente se produce la resorción del callo (Figura. 1.3) [810]. 


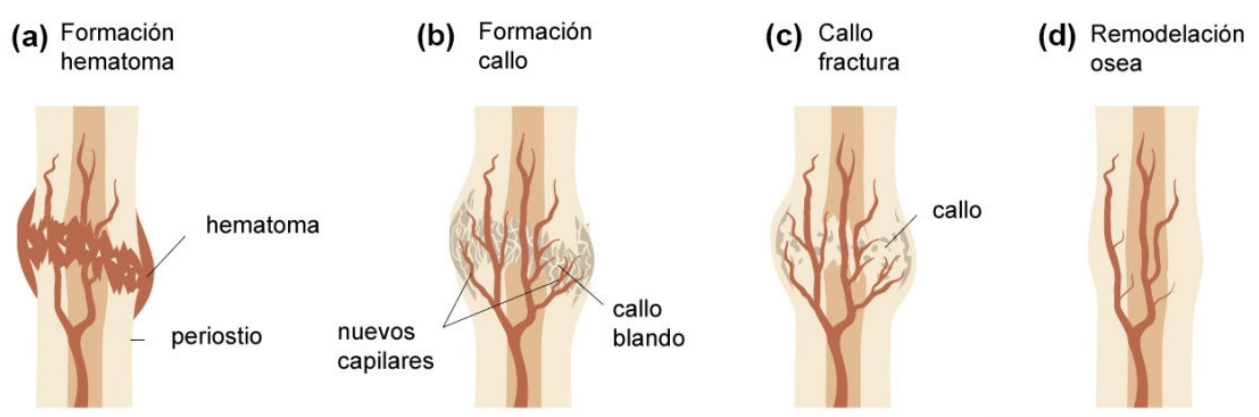

Figura. 1.3 Esquema de regeneración ósea tras fractura (adaptada de [10]).

\subsubsection{Interacción biomaterial - hueso}

En las cirugías en la que se introduce un implante dentro de un tejido, el biomaterial del cual se ha fabricado el implante, interacciona con el tejido donde es implantado. Se produce entonces una respuesta del organismo con el fin de mantener el equilibrio homeostático [11], en función del grado de perturbación que cree el material en el tejido, éste determinará su biocompatibilidad. El término biocompatibilidad se define como la habilidad del material para llevar a cabo una función específica con una respuesta del tejido apropiada [2, 12]. En general, se producen una cascada de reacciones: herida, inflamación aguda, inflamación crónica, tejido granuloso y reacción a cuerpo extraño o fibrosis [11]. El tamaño, forma, propiedades físicas y químicas del biomaterial variarán la respuesta del tejido al implante, cambiando la intensidad y duración de la respuesta inflamatoria.

Al igual que en la reparación del tejido óseo explicada anteriormente, cuando se introduce un implante se produce un daño en el tejido, produciéndose la rotura de vasos sanguíneos y permitiendo la salida de proteínas y células del torrente sanguíneo a la zona dañada, formándose un coágulo y/o trombo. Se produce una absorción de proteínas sanguíneas en la superficie del biomaterial, formándose una matriz de soporte provisional para el anclaje, proliferación y migración de los distintos tipos celulares que intervienen en la reparación. El coágulo consiste principalmente en una red de fibrina, que es de vital importancia en el proceso de formación de tejido vascular nuevo, en él se anclan otras proteínas y existen factores de crecimiento que mediarán la respuesta celular. El efecto del biomaterial en el plasma o células sanguíneas puede producir cambios químicos que medien la respuesta posterior, 
pudiéndose dar dos situaciones: formación de la cápsula fibrótica (de mayor o menor espesor o ninguna) o la reacción a cuerpo extraño (Figura. 1.4).

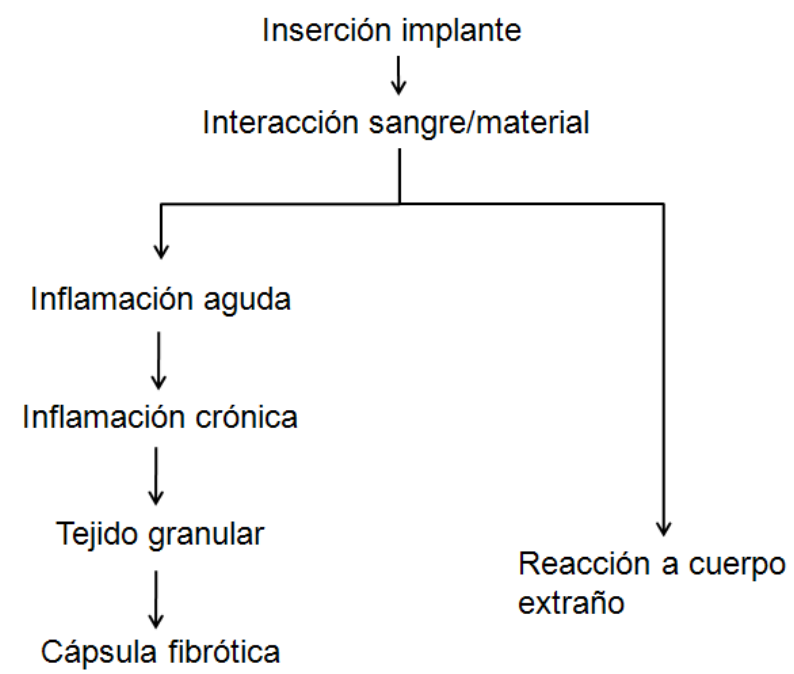

Figura. 1.4 Cascada de reacciones que se dan en el cuerpo humano cuando se introduce un implante.

La formación de la cápsula fibrótica es una indicación del grado de biocompatibilidad del implante. Se dice que un material es tóxico cuando no se crea la cápsula fibrótica, produciéndose reacción a cuerpo extraño y fracasa el proceso reparador. Cuando el material no es tóxico y es inactivo biológicamente se forma una cápsula fibrótica gruesa, denominándose biotolerante. En el caso que la cápsula fibrosa sea menos consistente se designa el término bioinerte. Cuando el material implantado crea unión interfacial entre el material y el tejido circundante el material es clasificado como bioactivo. Por último, hay que considerar la existencia de materiales biodegradables que desaparecen paulatinamente en contacto con el medio circundante y son remplazados por el tejido adyacente [12-13].

Así la primera respuesta rápida y de corta duración al contacto del implante con el tejido es la denominada inflamación aguda. Se caracteriza principalmente por la formación del coágulo anteriormente descrito y la migración de células blancas del torrente sanguíneo a la zona afectada. Se produce una acumulación de leucocitos, en particular neutrófilos y monocitos. El cometido de los neutrófilos es fagocitar los 
microorganismos que pudieran haber entrado durante la cirugía e intentar fagocitar el biomaterial del implante. En el caso del implante este proceso no se va a poder llevar a cabo debido principalmente a la diferencia de tamaño que existe entre la célula y el dispositivo. El proceso que puede ocurrir es que los leucocitos comiencen a segregar matriz extracelular con la intención de degradar el biomaterial [14].

Tras la inflamación aguda se produce una inflamación crónica, es de corta duración y se concentra en la región del implante. Esta etapa se caracteriza por la presencia sobre todo de macrófagos, además de monocitos y linfocitos, junto con la proliferación de vasos sanguíneos y tejido conectivo (proliferación de fibroblastos y células endoteliales vasculares). Esta etapa es imprescindible y se conoce como angiogénesis, ya que es preciso desarrollar una red de vasos sanguíneos tan pronto como sea posible para proveer nutrientes al tejido en crecimiento, para eliminar los residuos celulares, y transportar los distintos tipos celulares que intervienen en la reparación hacia la zona del implante. Una vez iniciada la recuperación por medio de la proliferación de fibroblastos y células endoteliales vasculares en la zona del implante, se produce la formación de tejido granular. Toma este nombre por la apariencia irregular y rosácea. Los fibroblastos proliferan y sintetizan distintas proteínas de la matriz extracelular como por ejemplo colágeno tipo III, tipo I, glicosaminglicanos y polisacáridos [11, 14].

En el último estadio del proceso de reparación del tejido en presencia de un implante se pueden dar dos procesos distintos: la regeneración, que es la reconstitución del tejido por células del mismo tipo que había previo al daño, o el remplazo por tejido conectivo formando la cápsula fibrótica, cuando los fibroblastos se convierten en fibrocitos inactivos. Estos procesos están controlados por la capacidad de proliferación de las células del tejido (lábil, estables o permanentes, ver sección 1.2.2), por la extensión del daño generado, y por la permanencia del andamiaje en la superficie del implante $[11,14]$.

Como se citó anteriormente, la reparación perfecta sólo se conseguirá con tejidos con células lábiles o estables, mientras en tejidos con células permanentes producirán fibrosis o formación de cápsula fibrótica con poca restitución del tejido dañado independientemente del material utilizado para fabricar el implante. 
Por otro lado, cuando la presencia del implante hace posible retener la estructura formada durante las etapas iniciales del daño la formación de la estructura del tejido normal es posible, mientras que en los casos donde no se mantenga se producirá fibrosis de la zona, ya que no habrá un soporte para el transporte de nutrientes y el paso de células.

Cuando el implante no es aceptado, se considera material tóxico porque se produce la reacción a un cuerpo extraño. Los monocitos y los macrófagos forman células gigantes multinucleadas en un intento de fagocitar el implante, por medio de la secreción de agentes oxidantes. Estas células persisten alrededor del material aislándolo del resto del tejido, formando un granuloma. Con el paso del tiempo pueden reabsorberse o puede darse un proceso infeccioso.

\section{3 Implantes metálicos}

El uso de metales como implantes es una práctica relativamente nueva que data de principios del siglo $X X$. Su uso se centra en implantes óseos, donde los requerimientos mecánicos prevalecen frente a otros, ya que los metales tienen un alto módulo y límite elástico y son materiales dúctiles. Alrededor de 1920 se desarrolló el acero 316L y se descubrió que tenía una buena resistencia a la corrosión (en comparación con los metales utilizados anteriormente). En 1930 se desarrollaron las aleaciones de Cr-Co para aeronáutica y se demostró que tenían un mejor comportamiento en contacto con el cuerpo humano que el acero AISI 316L. A mitad del siglo pasado el titanio puro se desmarcó del resto de metales por tener una excelente biocompatibilidad, sin embargo sus propiedades mecánicas eran peores al resto de aleaciones. Se desarrollaron distintas aleaciones, hasta encontrar que la aleación Ti6Al4V mejoraba las propiedades mecánicas sin disminuir su biocompatibilidad. Todas las aleaciones metálicas usadas en implantes son susceptibles de corrosión en mayor o menor medida, dependiendo de las propiedades del material, de las condiciones en servicio, de la historia térmica y del tratamiento superficial final aplicado previo a la implantación [15]. Durante los procesos de corrosión se reducen las propiedades mecánicas del implante y además se pueden desprender productos derivados de la corrosión de naturaleza tóxica. 
El acero AISI 316L se ha utilizado durante décadas por tener una buena biocompatibilidad y una buena resistencia a la corrosión por formación de una fina capa de óxido de cromo en su superficie. Sin embargo, puede llegar a producirse su corrosión, siendo los productos de ésta potencialmente peligrosos para el cuerpo humano. Por eso su uso se está limitando a implantes no permanentes [16].

Las aleaciones de Cr-Co también tienen unas buenas propiedades anticorrosivas por la formación de una capa da óxido de cromo en su superficie. Tiene mejor comportamiento frente a la corrosión que el acero y mejores propiedades mecánicas [16].

El titanio es el más inerte de los presentados aquí, debido a la formación de una capa de óxido de titanio. Además es un buen candidato porque es más ligero y tiene una excelente biocompatibilidad [16]. Sin embargo, tiene unas bajas propiedades mecánicas que se remedian por medio de aleaciones como la Ti6Al4V. Sus propiedades mecánicas específicas, la resistencia a fática y la mayor similitud de su módulo elástico respecto al que posee el hueso, hacen que esta aleación sea una de las mejores para implantación en hueso. Recientemente se ha estudiado que esta aleación puede desprender pequeñas cantidades de $\mathrm{Al}$ y $\mathrm{V}$ que pueden tener efectos negativos en el cuerpo humano.

\subsubsection{Implantología dental}

En el campo de cirugía maxilofacial el implante tiene la función de sustituir la raíz dental creando así una pieza sólida sobre la cual poder colocar la prótesis o corona dental. El objetivo, al igual que el resto de implantes es restaurar la función perdida.

Las causas principales para que un paciente necesite un implante son varias, entre ellas la más importante es por enfermedad periodontal (proceso inflamatorio de las encías que ocasiona daños en los tejidos de los dientes), que supone un $48 \%$ de las intervenciones [17]. Existen otras causas como son las caries (27\%) o traumatismos o fracturas $(9,4 \%)$.

El uso de implantes dentales se ha extendido mucho en los últimos años, se calcula que mundialmente el numero de cirugías que se realizan al año es de un millón. Sin embargo, hay pacientes que no pueden ser intervenidos por diversas 
causas, como por ejemplo, pacientes con enfermedades metabólicas, hematológicas, cardiológicas o enfermedades del metabolismo óseo. Estos pacientes tienen mermada su capacidad para regenerar hueso y por tanto el proceso de osteointegración del implante se ve comprometido, por lo que los odontólogos desaconsejan la intervención. Otros problemas que derivan en el fracaso del implante son el déficit en la calidad y/o cantidad ósea, como mujeres de avanzada edad, o pacientes fumadores (factor de riesgo alto de fracaso del implante) [17].

Los materiales más utilizados son de naturaleza metálica, siendo el titanio puro el de mayor consumo. En este campo de la implantología quirúrgica puede variar la pureza del material, la forma y topografía del implante, así como los tratamientos superficiales aplicados. La finalidad es siempre obtener una buena unión mecánica con el hueso de forma que se reduzcan al mínimo los movimientos que se puedan producir entre el implante y el hueso periimplantario con el objetivo final de minimizar la reacción a cuerpo extraño [18].

Los implantes dentales están compuestos por una parte roscada que será la que se encuentre en contacto con el tejido óseo y un pilar de soporte que será la zona de unión con la corona dental, como se muestra en la Figura. 1.5. En ella también se muestra el modo en el que se fija el implante al maxilar así como la dirección y el sentido de las cargas a las que se ve sometido el implante durante su vida en uso [19].

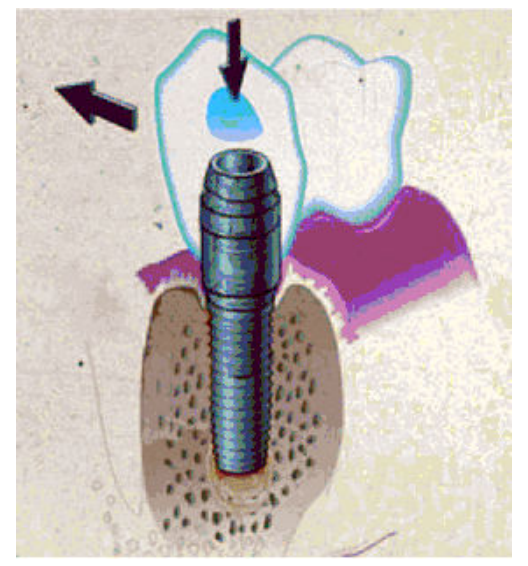

Figura. 1.5 Esquema de fijación de implante dental y orientación de las cargas [19]. 
Las fuerzas que soporta el implante dental son de gran magnitud debido al masticado, hecho que motiva el desgaste del implante dental. En adultos, la fuerza media por bocado se encuentra entre $100-150 \mathrm{~N}$, siendo la carga máxima registrada de $443 \mathrm{~N}$ [20]. Sin embargo, hay que tener en cuenta que no todas las fuerzas son iguales entre individuos, ni entre distintas regiones de la boca. Estas fuerzas hacen que se pueda romper la unión hueso-implante, produciéndose a partir de ese momento micromovimientos entre ellos.

\subsubsection{El titanio en implantes dentales}

Las propiedades que debe de cumplir un biomaterial para uso como implante dental son: poseer un módulo elástico lo más parecido al hueso, tener una elevada resistencia a corrosión, excelente biocompatibilidad (indicativo de un óptimo grado de osteointegración) y una adecuada resistencia mecánica para soportar cargas cíclicas [13].

A pesar del gran desarrollo llevado a cabo en los últimos años orientado al diseño de implantes metálicos, la principal causa de fracaso del implante es la mala interacción entre el implante y el hueso, debido a una baja osteointegración (33.1\% de los casos registrados) [17]. El fenómeno de osteointegración está relacionado con las propiedades superficiales del implante, siendo las más importantes la composición química, hidrofilia y rugosidad [21].

La composición química y las cargas superficiales que pueden soportar los implantes de titanio dependen de la composición de la aleación seleccionada y del tratamiento superficial. El titanio puro comercial tiene distintos grados de pureza, desde pureza 1 a 4 . La pureza está determinada por el contenido en oxígeno, carbono y hierro. En la Tabla 1.1 se recoge la composición de los distintos grados. Existe una relación directa entre el contenido de estos elementos y las propiedades mecánicas. 
Tabla 1.1 Composición química de los distintos grados de Titanio puro.

\begin{tabular}{|c|c|c|c|c|}
\hline Elemento & Grado 1 I\% & Grado 2 I\% & Grado 3 /\% & Grado 4 /\% \\
\hline Nitrógeno & 0.03 & 0.03 & 0.05 & 0.05 \\
\hline Carbono & 0.10 & 0.10 & 0.10 & 0.10 \\
\hline Hidrogeno & 0.015 & 0.015 & 0.015 & 0.015 \\
\hline Hierro & 0.20 & 0.30 & 0.30 & 0.50 \\
\hline Oxigeno & 0.18 & 0.25 & 0.35 & 0.40 \\
\hline
\end{tabular}

En cuanto a la rugosidad, se puede dividir en tres categorías: macro-, micro- y nano-. El nivel macro se define para topografías que están en el intervalo de milímetros a micras, la microtopografía es una rugosidad superficial de 1 a 10 micrómetros. Con estas topografías se consigue un mejor anclaje mecánico del implante con el hueso [21]. Rugosidades superficiales del orden de nanómetros influyen en la absorción de proteínas, la adhesión de osteoblastos y, por tanto, en el proceso de osteointegración del implante. Sin embargo, es difícil obtener superficies reproducibles, aunque se han reportado distintos métodos como "titanium plasmaspray" [22], granallado [23], tratamientos ácidos [24-25] o anodización [26] capaces de conseguir nanotopografías con buen comportamiento osteointegrador.

Otro factor importante a tener en cuenta es la selección del material, e incluso el diseño del implante a fin de reducir al máximo los procesos corrosivos por los que se pueden ver afectados. Existen distintos tipos de corrosión en implantes: ataque uniforme, galvánica, aireación diferencial, por picaduras, intragranular, por tensión residual, y por desgaste. Los implantes dentales sufren predominantemente corrosión por desgaste, debido a las cargas mecánicas a las que se ven sometidos, que provocan micromovimientos entre el implante y el hueso [27]. El implante de titanio debido a este desgaste pierde la capa pasiva protectora favoreciéndose los procesos corrosivos en la superficie. Debido a la presencia en el medio fisiológico de iones activos como iones hidrógeno $\left(\mathrm{H}^{+}\right)$, compuestos de sulfito $\left(\mathrm{S}^{2-}\right)$, oxígeno disuelto $\left(\mathrm{O}_{2}\right)$ y cloruros $\left(\mathrm{Cl}^{-}\right)$se favorecen los procesos corrosivos en los que se obtienen iones como $\mathrm{Ti}^{+4}[28]$.

La degradación de los implantes es desaconsejable tanto por la pérdida de la integridad estructural del implante como por el desprendimiento de productos derivados de su corrosión, que pueden provocar reacciones adversas en el tejido 
circundante. De hecho, son muchos los autores que han descrito incrementos locales de concentración de trazas de metal relacionados con la presencia de un implante en la zona. La corrosión de implantes metálicos puede afectar al entorno de tres maneras diferentes: corrientes eléctricas que afecten al comportamiento celular, cambios en el estado electroquímico $\left(\mathrm{pH}\right.$, concentración $\left.\mathrm{O}_{2}\right)$, y con efectos negativos en el metabolismo celular por la presencia de iones metálicos [15]. Estos procesos pueden aumentar la probabilidad de la denominada reacción a cuerpo extraño y el posterior fallo del implante.

Una solución para que estos materiales de naturaleza metálica cumplan las exigencias requeridas en cuanto a desgaste y corrosión, así como mejorar la osteointegración, puede llevarse a cabo por la modificación de la superficie metálica mediante recubrimientos.

Se pueden encontrar distintas técnicas para recubrir implantes metálicos [29-30], como las basadas en la obtención de recubrimientos de hidroxiapatita, alúmina, titania, recubrimientos vítreos, etc. Las de mayor aplicación son los recubrimientos con cerámica tipo hidroxiapatita, pertenecientes a los fosfatos cálcicos, que gracias a su similitud con la parte orgánica del hueso tienen una alta bioactividad.

Existen distintas técnicas para depositar recubrimientos cerámicos en la superficie metálica. La más extensamente utilizada es la proyección térmica o plasma spray [21, 30]. Mediante esta técnica se pueden crear recubrimientos de HAp [31], de espesores que oscilan de 50 a 200 micras [30]. La principal desventaja que tienen es la poca adherencia entre la capa creada y el titanio. Además, durante la fabricación se necesitan altas temperaturas (cercanas al punto de fusión de la cerámica) y la HAp proyectada se puede descomponer y formar otras fases con distinta cristalinidad y distinta relación $\mathrm{Ca} / \mathrm{P}$ siendo algunas indeseables por su mal comportamiento in vivo. Otra desventaja es, la posible alteración de las propiedades mecánicas y de la protección frente a la corrosión del material metálico, debido a las altas temperaturas que se alcanzan para su aplicación, pudiendo producir un fallo acelerado del implante [12]. También se puede obtener capas de silicato cálcico $\left(\mathrm{CaO}-\mathrm{SiO}_{2}\right)$, óxido de titanio u óxidos como de circonio o aluminio con esta técnica [30]. 
Otra técnica novedosa para incrementar la osteointegración de la superficie del titanio, es la modificación bioquímica. Esta técnica tiene como objetivo la modificación de la superficie para inducir un comportamiento celular específico por medio de la inmovilización de péptidos, proteínas y factores de crecimiento. El titanio no tiene capacidad para anclar estas moléculas a su superficie, por lo que esta técnica propone el anclaje de órgano-silanos, órgano-fosfatos o productos químicos fotosensibles con grupos terminales activos (Tiol-, amino-, carboxil-, o epoxi-) con capacidad para reaccionar con las biomoléculas. Se pueden encontrar distintos métodos como la silanización (Figura. 1.6) [32-33], la fotoquímica [34] o las capas autoensambladas (SAM's)[35]. Estas capas funcionan muy bien en cultivos in vitro, sin embargo, para la aplicación final tienen la desventaja de que los recubrimientos son de escala nanométrica, y no existe control sobre la permanencia de los mismos en la superficie del implante.
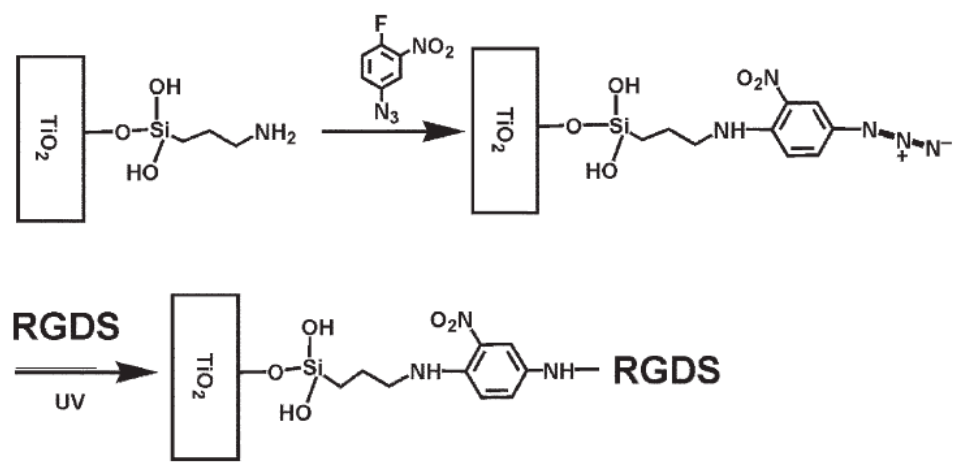

Figura. 1.6 Ejemplo de silanización para el anclaje de RGD en la superficie del titanio[32].

En este contexto, se ha detectado una interesante e innovadora línea de investigación para dar solución a las limitaciones respecto a la biocompatibilidad de los implantes dentales. Por un lado, se trataría de mejorar el comportamiento que tienen, reduciendo el tiempo de recuperación del paciente promoviendo la osteointegración del implante. Por otro lado, se estudiaría la viabilidad para conseguir una mayor osteoinducción de forma que pacientes con limitaciones en su regeneración ósea puedan someterse a este tipo de cirugías. Para ello, en la presente Tesis Doctoral, se ha desarrollado un recubrimiento orgánico-inorgánico 
sintetizado con un método de química suave, concretamente vía sol-gel, que tiene un alto porcentaje de éxito frente a las limitaciones indicadas, es decir, está diseñado para que sea apto frente a la mejora de la bioactividad y capacidad de osteintegracion y osteoinducción del implante. Además, gracias a la versatilidad de esta vía de obtención de recubrimientos se han podido introducir agentes terapéuticos, como fármacos. Aunque no se abarca en la presente Tesis Doctoral, en los recubrimientos desarrollados se pueden introducir otro tipo de moléculas como proteínas, péptidos y/o factores de crecimiento.

\section{4 Introducción al proceso sol-gel}

Los materiales sol-gel engloban un gran número de materiales inorgánicos u orgánico/inorgánicos que comparten las bases de la reacción de síntesis, reacciones tipo sol-gel [36]. El proceso sol-gel se define como aquel en el cual una solución monofásica de varios componentes miscibles, llamada sol, evoluciona a un sistema, denominado gel, donde el sólido tiene poros embebidos de líquido, dando lugar a una transición irreversible [37]. El sol está formado por una dispersión de partículas coloidales, con un tamaño entre $1 \mathrm{~nm}$ y $1 \mu \mathrm{m}$, en un fluido [36]. Un gel es una red rígida, interconectada mediante poros de dimensiones submicrométricas y cadenas poliméricas cuya longitud media es mayor de $1 \mu \mathrm{m}$. Esta red se expande a través del medio líquido y se limitará por el tamaño del contenedor.

Básicamente el proceso sol-gel se fundamenta en la hidrólisis y condensación de precursores metálicos. El más común es el precursor de silicio, capaz de formar una red inorgánica tipo $\mathrm{Si}-\mathrm{O}-\mathrm{Si}$, con ramificaciones orgánicas dependiendo del resto de la cadena del precursor. Este tipo de síntesis tiene una serie de ventajas que la hacen atractiva desde el punto de vista industrial: 
* Versatilidad del proceso.

* Bajas temperaturas de síntesis.

* Condiciones de química suaves.

* Obtención de materiales con elevada pureza y homogeneidad.

* Posibilidad de preparación de materiales porosos, con control en el tamaño de poro.

* Posibilidad de usar precursores funcionalizados y anclar covalentemente otras especies orgánicas.

* Posibilidad de polimerización de redes orgánicas interpenetradas con la red inorgánica.

* Posibilidad de atrapar especies orgánicas que creen poros con forma y tamaño controlado.

También existen algunas limitaciones, como el precio elevado de algunos precursores, que el proceso sea sensible a condiciones ambientales de humedad y calor o la existencia de problemas de agrietamiento durante el secado [38].

La técnica sol-gel permite obtener una gran variedad de materiales con propiedades a medida variando parámetros relacionados con la síntesis del material (apartado 1.4.2). La primera publicación sobre procesos sol-gel se atribuye a J. Ebelmen, científico francés que en 1846 describió la síntesis de monolitos de silicato a partir de un precursor de tetraetoxisilano, preparado a partir de tetraclorosilano y etanol [37]. Pero esta técnica se desarrolló extensamente alrededor de 1990 por C.J. Brinker y G.W Scherer [39]. Se ha utilizado en numerosos campos dada su versatilidad (desarrollo de baterías recargables de litio y de ion litio [40-41], materiales ópticos [42-43], ferroeléctricos [44] y magnéticos [45-46], sensores [47-48], recubrimientos anticorrosivos [49-50]). 
Se han propuesto muchas clasificaciones de este tipo de materiales, en función de su morfología final, en función de la red formada, etc. En esta Tesis Doctoral se ha diferenciado entre: inorgánicos (sinterizados o no) e híbridos orgánico-inorgánicos.

Los materiales inorgánicos están basados en una red Si-O-Si y no está incluida en su composición componentes orgánicos. Se pueden obtener con esta formulación gracias a la selección del precursor de partida (TEOS o TMOS) o a la realización de un tratamiento térmico de sinterización $\left(\mathrm{T}^{\mathrm{a}}>500^{\circ} \mathrm{C}\right)$, que elimina todo componente orgánico de la red.

Los materiales híbridos orgánico-inorgánicos están compuestos por la red inorgánica Si-O-Si y por una red orgánica. Estos híbridos se clasificaron, en 1994, por Sánchez y colaboradores en dos grandes grupos. Los primeros, clase I, son aquellos cuyas interacciones entre las partes orgánicas e inorgánicas se producen a través de puentes de hidrógeno y fuerzas de van der Waals. El segundo grupo, clase II, la partes orgánicas e inorgánicas están fuertemente ligadas a través de enlaces covalentes [51-52]. Los híbridos del tipo II (desarrollados en la presente Tesis Doctoral) se preparan a partir de alcóxidos orgánicamente modificados que contienen uno o más enlaces covalentes que no intervienen durante las reacciones sol-gel (el enlace $\mathrm{Si}-\mathrm{C}$ es hidrolíticamente estable [53]). Tienen una estructura tipo $\mathrm{X}_{n} \mathrm{Si}(\mathrm{OR})_{4-n}$, donde $\mathrm{R}$ es un radical alquil y $\mathrm{X}$ una cadena orgánica. Este grupo $\mathrm{X}$ introduce nuevas propiedades a la red inorgánica de los materiales sintetizados, tales como hidrofilia, flexibilidad, respuesta óptica, etc. El grupo orgánico $X$ se puede introducir de dos formas distintas: como un modificador de la red o como un formador de red. Si X es una cadena orgánica no hidrolizable ni reaccionante, la cadena orgánica permanece sin reaccionar ocupando espacio dentro de la red inorgánica, y el grupo orgánico $X$ actuará como un modificador de la red inorgánica. Si X puede reaccionar por sí mismo (contiene grupos vinil, epoxi, metracrilatos) o con otros monómeros polimerizables, se formará una red de polímero orgánico en combinación con la red inorgánica, y actuará como formador de red [52-53]. 


\subsubsection{Reacciones del proceso sol-gel}

El proceso sol-gel se basa en dos reacciones básicas de hidrólisis y condensación. El procedimiento sol-gel es un proceso complejo que incluye varias etapas. A continuación se presentan las principales características de cada una de ellas.

\section{a) Hidrólisis y condensación}

Las reacciones de hidrólisis y condensación se pueden resumir en las ecuaciones (ec. 1.1, ec. 1.2, ec 1.3). Los alcóxidos de silicio hidrolizan su cadena alcoxi en presencia de agua para formar un silanol con al menos un grupo $\mathrm{OH}$ (ec. 1.1), éste grupo $\mathrm{OH}$ será capaz de condensar de dos formas distintas, o bien reaccionará con otro silanol (ec. 1.2) o reaccionará con un grupo no hidrolizado -OR para producir un alcohol ROH (ec.1.3). Las reacciones de hidrólisis y condensación se dan de forma simultánea.

$$
\begin{aligned}
& \mathrm{M}(\mathrm{OR})_{4}+\mathrm{n} \mathrm{H}_{2} \mathrm{O} \rightarrow \mathrm{M}(\mathrm{OR})_{m}(\mathrm{OH})_{n}+\mathrm{nROH} \\
& M(\mathrm{OR})_{m}(\mathrm{OH})_{n}+\mathrm{M}\left(\mathrm{OR}^{\prime}\right)_{m^{\prime}}(\mathrm{OH})_{n^{\prime}} \rightarrow(\mathrm{OR})_{m}(\mathrm{OH})_{n-1} \mathrm{M}-\mathrm{O}-\mathrm{M}\left(\mathrm{OR}^{\prime}\right)_{m^{\prime}}(\mathrm{OH})_{n^{\prime}-y}+\mathrm{H}_{2} \mathrm{O} \\
& \text { (ec. 1.2) } \\
& M(\mathrm{OR})_{m}(\mathrm{OH})_{n}+\mathrm{M}(\mathrm{OR})_{m^{\prime}}(\mathrm{OH})_{n^{\prime}} \rightarrow(\mathrm{OR})_{m}(\mathrm{OH})_{\mathrm{n}-1} \mathrm{M}-\mathrm{O}-\mathrm{M}(\mathrm{OR})_{m^{\prime}-1}(\mathrm{OH})_{n^{\prime}}+\mathrm{R}^{\prime} \mathrm{OH}
\end{aligned}
$$

Siendo $M$ generalmente $\mathrm{Si}$ y $\mathrm{R}$ un grupo orgánico (típicamente alquil). Cuando las reacciones se dan entre alcóxidos orgánicamente modificados, de fórmula tipo $X_{n} \operatorname{Si}(O R)_{4-n}$ (siendo $X$ una cadena orgánica cualquiera), las reacciones son las mismas pero al existir un enlace $\mathrm{Si}-\mathrm{C}$ que no es hidrolizable la cadena $\mathrm{X}$ permanece en la red final.

Las condiciones químicas de hidrólisis y condensación son suaves, y pueden estar catalizadas por ácidos o por bases (apartado 1.4.2). Existen dos métodos para llevar a cabo las reacciones de hidrólisis y condensación. El método "one step" en el cual se realiza toda la síntesis con un pH seleccionado. El método "two step" en el que inicialmente se utiliza un pH extremo que en un paso posterior a la hidrolisis se neutraliza. 
b) Gelificación

Con el tiempo los intermedios de reacción van condensando hasta que forman una red tridimensional, produciéndose un fuerte aumento de la viscosidad y peso molecular, creándose un gel. Si se deja que las reacciones de condensación sigan durante un tiempo (que depende de varios factores que afectan a la formación de red) la viscosidad sigue aumentando hasta que se forma un sólido. En el punto de gel, no existe un cambio térmico (exotérmico o endotérmico).

\section{c) Envejecimiento}

La etapa de envejecimiento ocurre si el gel se deja reposar. El tiempo de envejecimiento que puede variar de horas a días, aumentando la conectividad de la red y produciéndose una contracción de la misma. Se caracteriza por una contracción del gel debido a la salida de líquido de sus poros.

d) Secado

Durante esta etapa se produce la eliminación del líquido de los poros interconectados en la red. Este proceso puede crear tensiones dentro del entramado por diferencia entre la velocidad de secado de las caras exteriores e interiores, produciéndose grietas superficiales.

e) Densificación o sinterizado

En esta etapa se aplica un tratamiento térmico para completar la densificación de la red. Si el tratamiento aplicado es a temperaturas inferiores a $200^{\circ} \mathrm{C}$ se produce la pérdida de agua y alcohol, produciéndose una contracción mínima.

Cuando se aplica un tratamiento de temperaturas comprendidas entre $200^{\circ} \mathrm{C}$ a $700^{\circ} \mathrm{C}$ las muestras muestran tanto pérdida de peso como contracción. Ocurren tres procesos: pérdidas de cadenas orgánicas, continuación de la condensación (asociada con pérdida de peso y contracción) y una relajación estructural (contracción sin pérdida de peso). Con la pérdida de las cadenas orgánicas se crean poros en los espacios donde previamente se situaban. 
Estas son las etapas generales que envuelven el proceso, pero no todas tienen por qué usarse en la síntesis. En función del tipo de material que se quiera obtener se aplicarán unas u otras. En el caso de querer obtener recubrimientos híbridos orgánico-inorgánicos como los que se han diseñado en la presente Tesis Doctoral, no se llevará a cabo una gelificación ni envejecimiento completos. Esto es debido a que el material debe estar fluido para su aplicación sobre la superficie metálica del implante.

\subsubsection{Factores que afectan a la hidrólisis y condensación}

\section{a) Influencia del $\mathrm{pH}$}

La reacción de hidrólisis y condensación de los precursores de silicio se puede realizar utilizando un catalizador ácido o básico. Cuando estas dos reacciones se dan en medio ácido, la hidrólisis del primer radical alquil es más rápida que la condensación. El producto de este primer paso tiene una condenación rápida, es decir, $(\mathrm{RO})_{3} \mathrm{SiOH}$ condensa más rápido que $(\mathrm{RO})_{2} \mathrm{Si}(\mathrm{OH})_{2}$ que a su vez, condensa más rápido que $(\mathrm{OR}) \mathrm{Si}(\mathrm{OH})_{3}$, etc. Por este motivo, la reacción ácida favorece la formación de una estructura abierta, que una vez formada continuará hidrolizando y condensando lateralmente (Figura. 1.7). Por el contrario, si las reacciones se dan en medio básico, una vez sustituido el primer $\mathrm{OH}$, se favorece la hidrólisis del producto de este primer paso, $(\mathrm{RO})_{3} \mathrm{SiOH}$ hidroliza más rápido que $(\mathrm{RO})_{2} \mathrm{Si}(\mathrm{OH})_{2}$ que a su vez, hidroliza más rápido que $(\mathrm{OR}) \mathrm{Si}(\mathrm{OH})_{3}$, etc. Se generan especies totalmente hidrolizadas $\mathrm{Si}(\mathrm{OH})_{4}$ que condensan rápidamente obteniéndose agrupaciones de redes entrecruzadas que se unen unas a otras formando una red menos compacta con distancias entre agrupaciones (estructuras porosas, Figura. 1.7) [36]. 

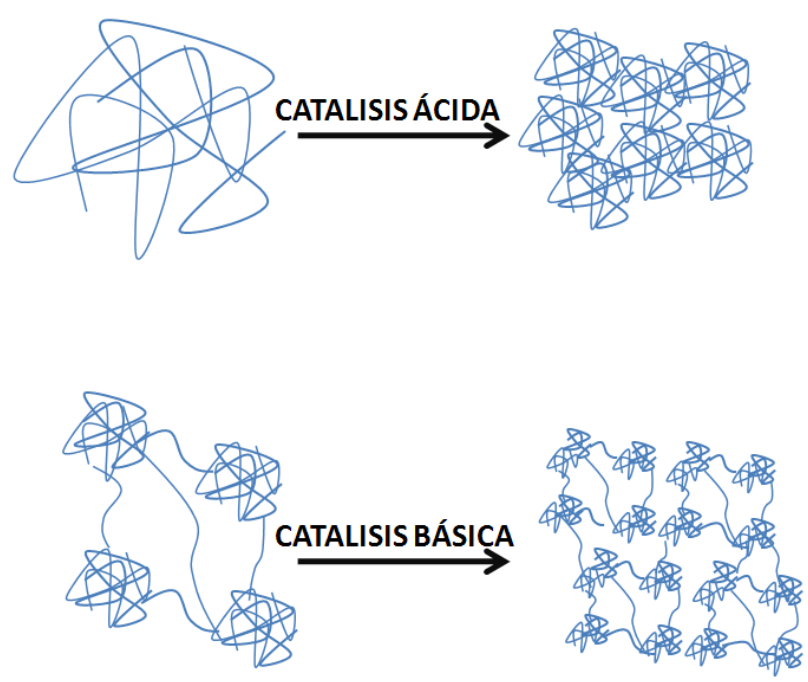

Figura. 1.7 Esquema influencia del pH en la formación de red

b) Efecto hidrófobo y el solvente

Debido a la naturaleza hidrófoba de los grupos etoxi, algunos precursores son inmiscibles con agua y también pueden serlo entre ellos en mezclas, por tanto, es necesario añadir un solvente para mejorar la miscibilidad y favorecer el proceso de hidrólisis. La elección de un disolvente u otro es importante ya que al producirse alcohol durante la reacción de hidrólisis se puede provocar una reacción de transesterificación. Esta elección también influirá en el proceso de secado.

c) Efecto de la relación agua: alcóxido

La relación molar agua:alcóxido también tiene influencia en la velocidad de hidrólisis y condensación. El ratio óptimo dependerá del precursor seleccionado, por ejemplo, si se trata de TEOS al tener 4 grupos hidrolizables, el ratio será 4 . Si se selecciona un precursor con 3 grupos hidrolizables como el VTES, el ratio será 3.

Se pueden utilizar cantidades inferiores de agua, ya que, como se indicó en el punto 1.4.1 se produce agua en la reacción de hidrólisis y condensación. Sin embargo, si se utiliza cantidades muy bajas, la velocidad de hidrólisis disminuye debido a una reducción de la concentración de reactivo (agua). Si se utilizan cantidades altas de agua, el alcóxido queda diluido y aumenta el tiempo de reacción. 


\section{5 Recubrimientos sol-gel sobre aleaciones metálicas}

Son muchos los tipos de materiales que se pueden obtener mediante la técnica sol-gel. Uno de los más interesantes y que ha tenido y tiene un gran desarrollo en las últimas décadas son los recubrimientos sobre metales [54].

La principal aplicación que se ha dado, y por la que se han desarrollado extensamente, es para la protección frente a la corrosión, como capas de conversión para substratos, fundamentalmente aleaciones de aluminio, ya que se pueden obtener capas protectoras de pocas micras de espesor mediante un método no contaminante (sustitución de cromatos).

En función de la naturaleza del recubrimiento, se puede dividir los recubrimientos sol-gel en dos grandes grupos:

* Recubrimientos inorgánicos o recubrimientos de óxido de metal: obtenidos a partir de las reacciones de hidrólisis y condensación de alcóxidos metálicos, recubrimientos de $\mathrm{SiO}_{2}, \mathrm{ZrO}_{2}, \mathrm{~B}_{2} \mathrm{O}_{3}, \mathrm{Si}-\mathrm{O}_{2}-\mathrm{B}_{2} \mathrm{O}_{3}, \mathrm{SiO}_{2}-\mathrm{Zr}-\mathrm{O}_{2}, \mathrm{ZrO}_{2-}$ $\mathrm{Y}_{2} \mathrm{O}_{3}$, etc. $\mathrm{O}$ bien, obtenidos mediante temperaturas de densificación por encima de $200^{\circ} \mathrm{C}$.

* Recubrimientos híbridos orgánico-inorgánico: obtenidos por la incorporación de grupos orgánicos a la red inorgánica con el fin de obtener una mayor flexibilidad y espesor.

El método sol-gel de obtención de recubrimientos se esquematiza en la Figura. 1.8. 


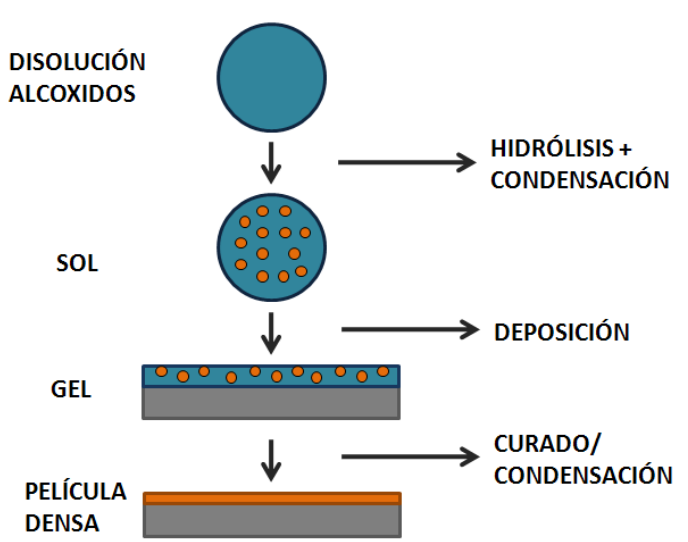

Figura. 1.8 Esquema de obtención de recubrimientos híbridos orgánico-inorgánico sol-gel.

El primer paso en la síntesis consiste en la obtención del sol a partir de la hidrólisis de precursores de silicio mediante la adición de agua y opcionalmente de un catalizador, produciéndose a su vez las reacciones de condensación tal y como se describió en el punto anterior. Posteriormente, la fase sol se deposita sobre la superficie metálica mediante métodos de inmersión (dip-coating), giro a alta velocidad (spin-coating) o pulverización (apartado 1.5.1), formándose una capa inicial que se denomina ge/ unida a la base metálica por puentes de hidrógeno. La formación de la película densa se produce por la continuación de las reacciones de condensación en la superficie del metal. Este proceso puede llevarse a cabo a temperatura ambiente o a una temperatura superior. El resultado es la obtención de una película densa o xerogel unida al metal químicamente por medio de enlaces covalentes $\mathrm{y}$, por tanto, con una muy buena adherencia [54].

Cuando se sumerge el metal en la disolución de silanos, los grupos silanol ( $\mathrm{Si}-\mathrm{OH})$ se absorben en la superficie metálica a través de enlaces tipo puente de hidrógeno. Durante la etapa de curado/densificación, en la que se suceden las reacciones de condensación, los grupos $\mathrm{Si}-\mathrm{OH}$ y $\mathrm{Me}-\mathrm{OH}$ se condensan para formar un enlace fuerte de tipo covalente (Figura. 1.9). 

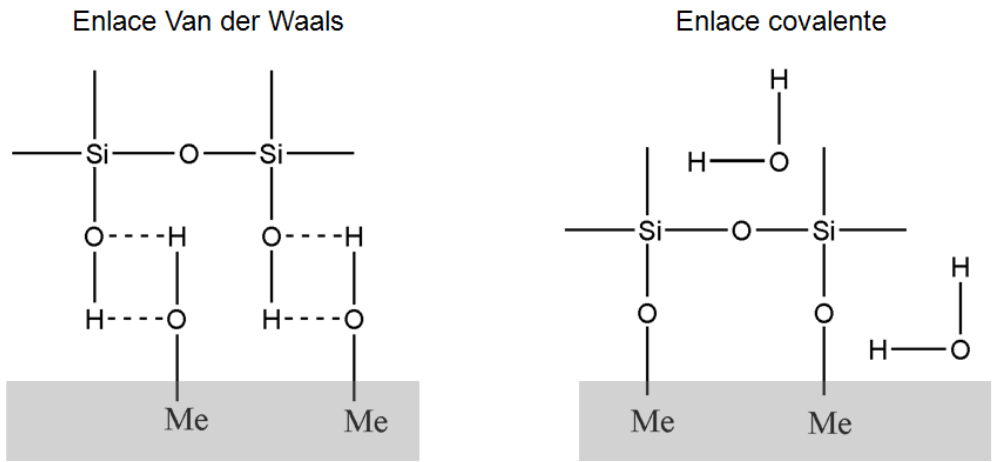

Figura. 1.9 Representación esquemática de la formación de enlace covalente entre el sustrato metálico y el film sol-gel antes y después de la densificación producido durante el curado.

La red de silicio se forma tal y como se describió en apartados anteriores. Cuando los recubrimientos son híbridos orgánico-inorgánicos, las partes orgánicas permanecen en el recubrimiento final, tal y como se muestra en la Figura. 1.10. El grupo de investigación de Juan Carlos Galván del CENIM (CSIC) junto al grupo de investigación de Antonia Jiménez-Morales de la Universidad Carlos III de Madrid ha desarrollado una metodología adecuada para la obtención de este tipo de recubrimientos. Han desarrollado recubrimientos sol-gel como capas de conversión para protección anticorrosiva [55-58]. 


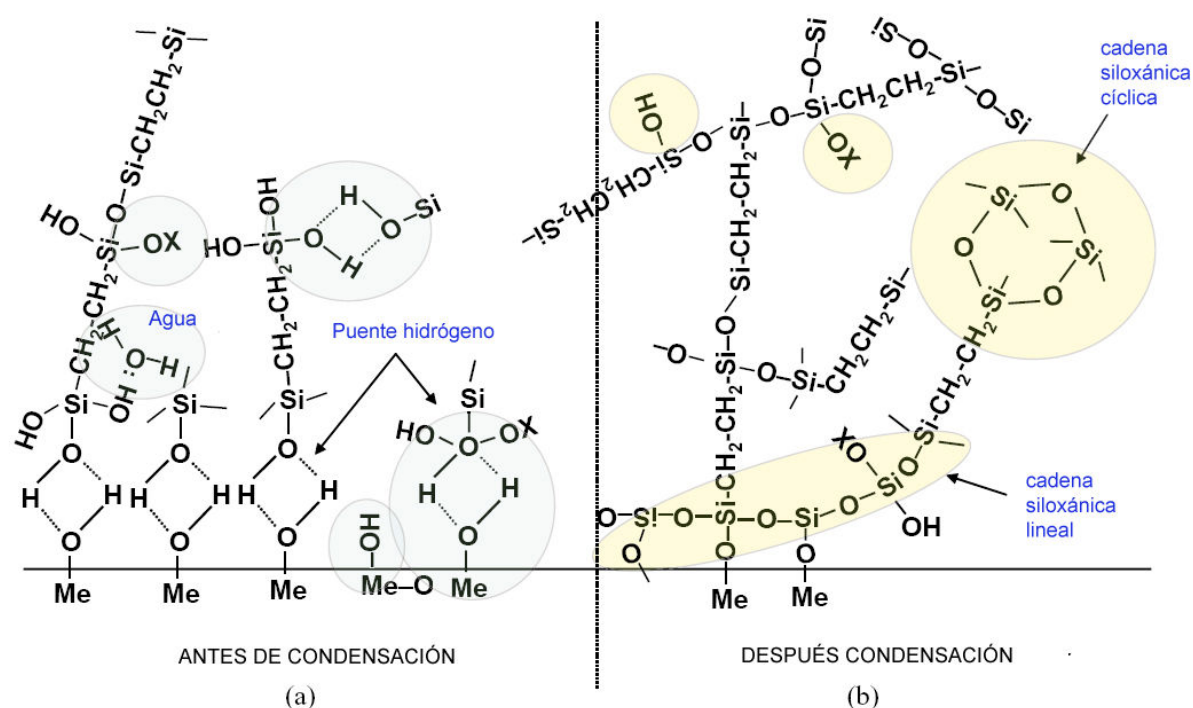

(a)

(b)

Figura. 1.10 Esquema formación de red sol-gel sobre metal (a) inmediatamente después de la aplicación y (b) después del tratamiento de curado (adaptada de [59]).

\subsubsection{Métodos de deposición}

Como se ha comentado en el apartado anterior, tras la preparación del sol, éste se deposita sobre la superficie metálica. Son varias las técnicas que se pueden utilizar para la deposición, entre las que destaca la aplicación por inmersión (dip-coating). Otras técnicas como la aplicación por giro a alta velocidad (spin-coating) o pulverización también se han utilizado para este tipo de recubrimientos.

\section{a) Deposición por inmersión o Dip- Coating}

La técnica dip-coating consiste básicamente en la inmersión y extracción de la pieza a una velocidad controlada dentro del sol. Durante la extracción debido al drenaje de la pieza por acción de la gravedad y la evaporación de los disolventes, así como la continuación de las reacciones de condensación se produce la deposición de una película sobre la superficie del metal (Figura. 1.11). 


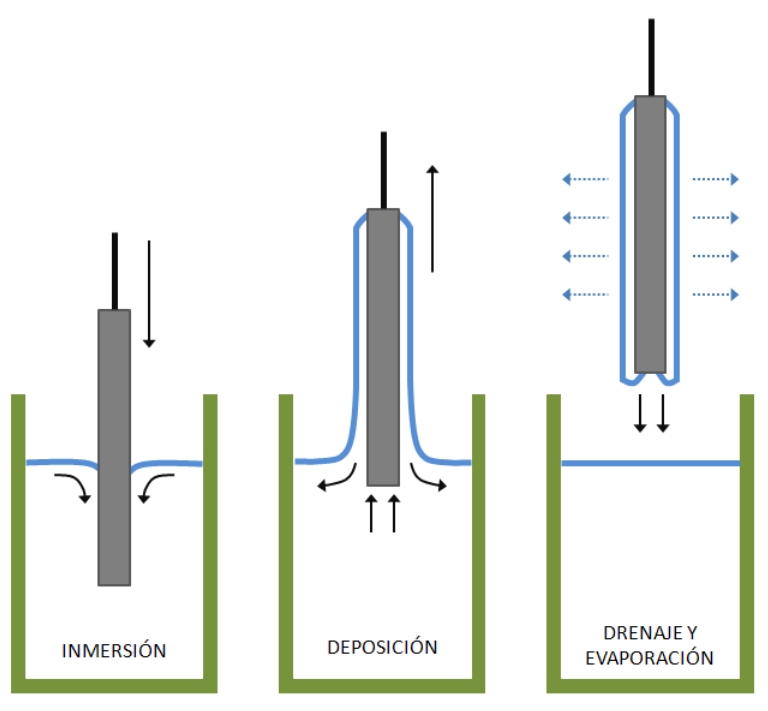

Figura. 1.11 Esquema de la deposición por inmersión o dip-coating.

El espesor de la película formada depende de la velocidad de extracción, así como del contenido en sólidos y de la viscosidad del sol. Si la velocidad de extracción y la viscosidad del sol elegidos se mantienen dentro del régimen newtoniano, el espesor de la película se puede calcular usando la ecuación de Landau-Levich (ec. 1.4) [60].

$$
h=0.94 \cdot \frac{(\eta \cdot v)^{2 / 3}}{\gamma_{L V}^{1 / 6}(\rho \cdot g)^{1 / 2}}
$$

siendo $h$ el espesor de la película, $\eta$ la viscosidad del sol, $\chi_{L V}$ la tensión superficial liquido-vapor, $\rho$ la densidad y $g$ la gravedad. Esta ecuación se ajusta bien a los espesores calculados cuando se ha realizado una catálisis ácida del sol. Lo más interesante de esta técnica es que eligiendo una viscosidad apropiada, el espesor de la película se puede variar con precisión [61].

Son muchos los autores que utilizan esta técnica para obtener los recubrimientos, porque permite recubrir piezas de manera homogénea con distintas topografías. 
b) Deposición por giro a alta velocidad o Spin-Coating

En la deposición por spin-coating el sustrato a recubrir gira sobre un eje perpendicular a la superficie. Un exceso de sol es depositado sobre el sustrato que se hace girar a una alta velocidad de modo que por acción de la fuerza centrífuga el exceso de material es expulsado formándose una capa homogénea sobre el sustrato (Figura. 1.12).
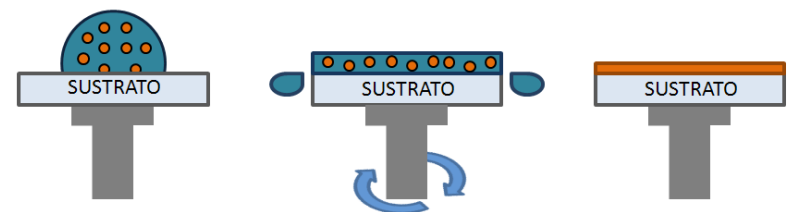

Figura. 1.12 Esquema deposición por giro o spin-coating.

El espesor de la película se ajusta variando la viscosidad del sol, o bien ajustando la velocidad de rotación, el tiempo de rotación o la aceleración de giro.

1.5.2 Protección frente a la corrosión de recubrimientos híbridos orgánicoinorgánico

Las propiedades protectoras de los recubrimientos sol-gel se basan en el establecimiento de una barrera física entre el medio agresivo y el metal base. Por lo tanto, la eficacia protectora está directamente relacionada con el grado de densificación alcanzado durante el curado. Sin embargo, se ha demostrado que la principal ventaja de este tipo de recubrimientos se debe a que actúan como promotores de la adhesión mediante la formación de los enlaces covalentes entre el recubrimiento y el metal (descritos anteriormente). Además estos recubrimientos permiten la incorporación de diversos agentes.

Son muchas las publicaciones sobre las propiedades protectoras de este tipo de recubrimientos sobre distintos tipos de sustratos metálicos [54], tales como, aceros [62-63], aluminio [64-65], zinc [66], aleaciones de titanio [30]. La presencia de componentes inorgánicos potencia la resistencia al rayado así como su durabilidad, y aumenta la adhesión con el metal. La incorporación de los componentes orgánicos 
favorece la flexibilidad y permiten incorporar grupos funcionales que pueden ser reactivos con sucesivas capas (como por ejemplo pinturas) o con distintos agentes.

Estos recubrimientos con notables características anticorrosivas se han utilizado en aeronáutica y automoción con el fin de sustituir las capas de conversión basadas en compuestos de cromo VI que tiene un alto poder contaminante. Sin embargo, también se pueden utilizar como capas de protección de prótesis metálicas que van a estar en contacto con fluidos biológicos (altamente corrosivos por la presencia de sales de distinta naturaleza). Como se verá en el siguiente apartado, la utilización de estos materiales en el campo biomédico abre un gran abanico de posibilidades muy atractivas e innovadoras.

\section{6 Recubrimientos sol-gel para aplicaciones biomédicas}

Son pocos los materiales que pueden anclar directamente con el hueso. En el caso de metales, el problema de anclaje con el hueso es mayor ya que, además de no ser un material bioactivo, se pueden desprender iones que inhiban la osteoinducción e incluso de partículas que favorezcan la reacción a cuerpo extraño tras su implantación debido a fenómenos de corrosión electroquímica. Como resultado no se produce una completa fijación de la prótesis, produciéndose micromovimientos o migraciones originando dolor, sangrado, inflamación y otros inconvenientes. Sin embargo, los metales son una buena opción para implantes de tejido óseo, ya que son los únicos capaces de soportar las cargas mecánicas de esta aplicación. Además del problema de la corrosión, los implantes metálicos no pueden ser dopados fácilmente con fármacos que puedan liberarse, partículas bioactivas o incluso ser modificados mediante la adicción de biomoléculas (proteínas o péptidos). Por ello, se considera adecuado plantear la posibilidad de recubrir estos materiales con una película delgada de otro material que tenga un comportamiento bioactivo, o incluso osteoinductor, de forma que se mejore notablemente su comportamiento biológico. Este recubrimiento podría utilizarse como vehículo de liberación controlada de moléculas bioactivas y fármacos.

Estudios sobre los mecanismos de unión entre el hueso y el implante han demostrado que la presencia de una capa de apatita semejante a la composición mineral del hueso favorece la osteintegración. Los iones calcio y los grupos silanol 
(Si-OH) son componentes esenciales para la formación de esta capa biológicamente activa. Por esto, se espera que los materiales obtenidos con la tecnología sol-gel a partir de alcoxisilanos tengan unas buenas propiedades en cuanto a bioactividad se refiere.

La versatilidad del proceso sol-gel permite controlar el grado de grupos hidrófobos presentes en la superficie por medio de la selección de los precursores utilizados para la síntesis, y en definitiva graduar las propiedades finales del recubrimiento en varios aspectos, tales como las propiedades anticorrosivas, la degradación hidrolítica o la viabilidad celular [67]. Como se citó anteriormente las propiedades superficiales de los materiales a implantar in vivo son de vital importancia para el éxito o el fracaso de la biocompatibilidad de la prótesis, por tanto, poder controlar parámetros como la hidrofilia, velocidad de degradación o propiedades mecánicas proporciona una potente herramienta para obtener un recubrimiento con las mejores propiedades de biocompatibilidad posibles, es decir, "hecho a medida" para esta aplicación.

Además se ha observado que durante la degradación hidrolítica del sol-gel en el fluido biológico se producen ácido ortosilícico, por medio de la reacción:

$$
\mathrm{SiO}_{2}(\mathrm{~s})+2 \mathrm{H}_{2} \mathrm{O} \rightarrow \mathrm{Si}(\mathrm{OH})_{4}(\mathrm{aq})
$$

Estas moléculas en bajas concentraciones no solo no son tóxicas sino que además son osteoinductoras [68-72]. Por un lado, varios investigadores referidos en la bibliografía han detectado que los iones de silicio favorecen la bioactividad del material, favoreciendo la formación de la capa de hidroxiapatita biomimética en contacto con el fluido humano [71-72]. Por otro lado, son capaces de activar la producción de colágeno tipo I en los osteoblastos y promover la diferenciación de los mismos [69]. Por tanto, de manera crítica, se pueden clasificar los materiales como biodegradables.

Al igual que en recubrimientos sol-gel anticorrosivos aplicados sobre aleaciones metálicas, los recubrimientos biomédicos también se pueden clasificar en dos grandes grupos: inorgánicos e híbridos orgánicos-inorgánicos. Además, dentro del grupo de híbridos orgánicos-inorgánicos se pueden encontrar un gran grupo donde se han introducido agentes orgánicos como fármacos o péptidos con la finalidad de incorporar nuevas funciones a los implantes metálicos. En los siguientes apartados se 
presenta la situación actual de cada uno de los tipos de recubrimientos tipo sol-gel para aplicaciones biomédicas.

\subsubsection{Recubrimientos sol-gel inorgánicos}

Los recubrimientos inorgánicos tipo sol-gel han tenido gran desarrollo en un intento de sintetizar hidroxiapatita cristalina lo más parecida posible a la que se encuentra en el hueso. Son numerosos los trabajos, en los que utilizando la vía de síntesis sol-gel, se han obtenido capas de hidroxiapatita sobre prótesis metálicas con el fin de mejorar el anclaje de osteoblastos. Peon y colaboradores sintetizaron, a partir de precursores de fósforo, de calcio trietilfosfito y de nitrato cálcico tetrahidratado, hidroxiapatita homogénea, fuertemente adherente al metal y cristalina [73].

Mediante la técnica sol-gel se pueden sintetizar recubrimientos de fosfato cálcico, como los desarrollados por Nguyen y colaboradores [29] que depositaron por dip-coating una capa de fosfato cálcico sobre Ti-6Al-4V. Obtuvieron una capa adherida a la superficie de la prótesis y obtuvieron un contacto directo entre el hueso y la capa, además encontraron numerosos osteocitos en la superficie recubierta, muestra de una mejora de la osteoconductividad del recubrimiento.

Advincula y colaboradores [74] desarrollaron recubrimientos de óxido de titanio sobre Ti-6Al-4V. Evaluaron la bioreactividad de los sustratos desarrollados evaluando el comportamiento de osteoblastos y la formación de matriz mineralizada. Las películas creadas tienen una gran densidad de $\mathrm{Ti}-\mathrm{OH}$ en superficie, indicativo de buena mojabilidad, son rugosas y porosas. Observaron que las células se adhieren muy bien a la capa de sol-gel y tienen núcleos de mineralización. Hoffmann y colaboradores [32] presentan dos tipos de recubrimiento a base de óxido de titanio obtenido por sol-gel. Cuando evalúan la citocompatibilidad de los recubrimientos desarrollados obtienen una notable mejora a la viabilidad celular en comparación con los sustratos sin recubrir.

También se pueden obtener recubrimientos de óxido de titanio e hidroxiapatita, como los descritos por Milella y colaboradores [30], estos recubrimientos recogen las ventajas de los recubrimientos de óxido de titanio que son altamente adherentes al 
titanio pero que tienen baja bioactividad y las optimas propiedades respecto a la bioactividad de la hidroxiapatita. Milella y colaboradores obtienen recubrimientos homogéneos, rugosos y porosos, en los que se detectan en la superficie grupos hidróxido como Ti-OH, promotores de osteointegración.

Existen otro tipo de recubrimientos inorgánicos, como los descritos por Duran y colaboradores [75-79], que utilizan una red inorgánica Si-O-Si como matriz para insertar partículas bioactivas como hidroxiapatita, bioglass ${ }^{\circledR}, \mathrm{u}$ otros cristales bioactivos. Mediante esta técnica son capaces de recubrir de forma homogénea acero quirúrgico $316 \mathrm{~L}$, así como titanio y sus aleaciones y conseguir una buena dispersión de las partículas introducidas. Obtienen buena protección frente a la corrosión y han estudiado la bioactividad por inmersión en suero fisiológico (SBF) en donde obtuvieron buenos resultados, formándose una capa de hidroxiapatita biomimética en la superficie. Sin embargo, no se han realizado estudios biológicos para evaluar el comportamiento celular sobre estos materiales.

\subsubsection{Recubrimientos híbridos orgánico-inorgánicos}

Las líneas actuales para conseguir una mejor osteointegración del implante se están centrando en introducir agentes orgánicos [80] como péptidos/proteínas [68, 8182] o fármacos[83-85]. Los implantes metálicos tienen limitada la introducción de este tipo de cargas ya que no pueden anclarse directamente a la superficie metálica. Por tanto, el uso de recubrimientos híbridos orgánico-inorgánico donde las temperaturas de síntesis se encuentran por debajo de $150^{\circ} \mathrm{C}$ y las condiciones de síntesis no pueden degradar los agentes incorporados $[80,86]$ son una opción interesante y viable. Además, los recubrimientos obtenidos ofrecen un gran número de ventajas: buenas propiedades mecánicas y térmicas, se pueden variar las condiciones de síntesis, se pueden obtener distintos grados de porosidad, y son biológicamente viables [87-91].

Beganskine y colaboradores [87] han desarrollado películas de TEOS modificadas con otros precursores que le aportan el carácter orgánico a las películas como metiltimetoxisilano (MTMOS), hexametildisilizano (HMDS) y (3-aminopropil) trietoxisilano (APTES). El interés de introducir un grupo amina radica en la posibilidad de anclar químicamente proteínas a la superficie del implante, mejorando la formación 
de la película de proteínas y, por tanto, favorece la posterior adhesión celular. Han estudiado la viabilidad celular (utilizando una línea comercial) y han depositado una capa de distintas proteínas (por ejemplo, Laminina-I, Fibronectina, Colageno-I) en la superficie del recubrimiento. De esta forma han conseguido obtener recubrimientos con distintas características de mojabilidad, y distintas absorciones de proteínas en superficie. En todos los recubrimientos lograron una buena respuesta celular en comparación con los controles.

Manso-Silván y colaboradores [88] presentan en su trabajo un híbrido cuya red inorgánica está compuesta por óxido de titanio obtenido a partir de tetraisopropilortotitanato (TIPT) y lo combinan con (3-aminopropil)trietoxisilano (APTES). Estudiaron la viabilidad celular de células mesenquimales, obteniendo buenos resultados con estos híbridos, detectando un buen anclaje celular. Adicionalmente, realizaron un cultivo con medio de diferenciación osteogénico detectando unas diferencias de comportamiento mayores en los recubrimientos en comparación con el material control.

La posibilidad de polimerizar las cadenas orgánicas introducidas con los precursores de silicio es una opción viable que desarrollaron Hosseinalipour y colaboradores [90]. En este estudio prepararon híbridos a base de TEOS y metacriloxipropiltrimetoxisilano (MAPTS) e introdujeron un agente iniciador de la polimerización de acrilatos, el benzoil peróxido (BPO). Determinaron distintos ángulos de contacto para la serie de materiales con distintas cantidades de MAPTS obteniendo el menor ángulo para la mayor cantidad de TEOS. En este caso, sólo se realizó un test de citotoxicidad con células L929 (del tejido adiposo de ratón) sobre los materiales desarrollados detectando que en ningún caso eran citotóxicos.

Otra opción para desarrollar híbridos es introducir una red polimérica. Dentro de los polímeros, una opción interesante es introducir polímeros de origen natural como la gelatina o el quitosano. Tsuru y colaboradores [89] introdujeron gelatina a una red de GPTMS y TEOS. En este trabajo estudiaron la liberación de silicio, controlada por el contenido en TEOS, de tal manera que a mayor contenido del precursor, mayor liberación de silicio que a su vez promueve la regeneración de hueso. Estos autores también estudiaron la proliferación celular de osteoblastos y la mineralización de los 
mismos, y para todos los casos obtuvieron un buen comportamiento, sin deferencias significativas entre las distintas composiciones.

\subsubsection{Recubrimientos híbridos orgánico-inorgánicos como vehículo de liberación}

La posibilidad de incorporar fármacos en recubrimientos orgánico-inorgánicos capaces de actuar como vehículos de liberación es muy interesante para minimizar el riesgo de infección sobre todo en las primeras etapas del proceso de respuesta a cuerpo extraño, debido a la existencia de bacterias capaces de adherirse a la prótesis.

La síntesis de este tipo de recubrimientos permite introducir el fármaco antes o después de la hidrólisis de los precursores, siendo en muchos casos la estructura y la dispersión del fármaco parecida en los dos procesos, ya que la encapsulación se produce durante la etapa de secado/curado [80, 92]. El proceso de liberación de fármacos desde películas sol-gel se rige por fenómenos de degradación por erosión así como difusión a través de la matriz de sol-gel [80, 83, 85, 92-99].

La literatura describe distintos métodos para añadir fármacos en los film de solge. Por ejemplo, Radin y colaboradores [83-85, 93, 100] incorporaron fármacos solubles en agua, como la vancomicina, en la etapa sol. El procedimiento que siguieron para controlar la liberación se basó en la incorporación distintas concentraciones de fármaco adicionado al sol y la posterior deposición de distintas capas. Por medio de la adicción de diversas capas lograron alargar el tiempo durante el cual se produjo la liberación del fármaco, sin embargo, no llegaron a conseguir un control óptimo de la cinética de liberación. Böttcher y colaboradores [80, 94] estudiaron la influencia de distintos factores en la relación de liberación, concluyendo que ésta depende de la relación entre los silicios y el fármaco, del espesor de la película y del peso y tamaño molecular del fármaco. Cuanto mayor es la relación silicio:fármaco más lenta es la liberación. A mayor tamaño del fármaco, más complicada es su difusión a través de la película y así la cinética de liberación disminuye. Morpurgo y colaboradores [95] subrayan la importancia de las posibles interacciones químicas entre los precursores seleccionados y el fármaco introducido, 
el componente orgánico tiende a retrasar y disminuir la salida del fármaco y este efecto se ve acentuado con la longitud de la cadena orgánica del alcoxisilano [92].

Por otro lado, la inclusión de moléculas biológicas en una matriz de sol-gel ha despertado gran interés por la posible creación de nuevos materiales biocompuestos que presenten las funcionalidades de enzimas, proteínas u otros biocomponentes [80]. Las biomoléculas embebidas retienen su conformación, propiedades físicas y químicas, y mantienen una actividad cercana a la molécula libre, es decir, la matriz sol-gel estabiliza las proteínas embebidas evitando la desnaturalización térmica y química. La porosidad de la matriz puede hacer que las moléculas embebidas en la matriz sean fácilmente accesibles a los reactivos externos y se puedan producir reacciones químicas con la película inorgánica a gran velocidad, siendo la velocidad de reacción con las enzimas embebidas incluso comparables con las que se producirían en medio acuoso. Se han inmobilizado proteínas como la gelatina y el colágeno comercial hidrolizado en el recubrimiento sol-gel evitando altas concentraciones de alcohol en el sol [101]. 

Capítulo 2 Objetivos 

A raíz de los antecedentes presentados en la introducción, para la realización de la presente Tesis Doctoral se planteó el siguiente objetivo general:

Síntesis de nuevos recubrimientos híbridos tipo sol-gel hechos a medida para la mejora de la osteointegración de implantes dentales metálicos, con dos fines muy concretos: (1) reducir los tiempos de integración del implante y, (2) permitir su uso en pacientes con una deficiente regeneración ósea.

Como objetivos parciales se plantea:

- Síntesis de recubrimientos órgano-inorgánicos vía sol-gel sobre superficies metálicas de forma homogénea y reproducible.

- Caracterización físico-químicamente de los recubrimientos obtenidos.

- Modulación de las propiedades de los recubrimientos para obtener una osteoinducción óptima del implante.

- Estudio de la degradación hidrolítica de los recubrimientos.

- Estudio de las propiedades anticorrosivas de los recubrimientos.

- Prevención de infecciones o procesos inflamatorios introduciendo agentes terapéuticos y estudio de su liberación para mejorar la osteointegración del implante.

- Estudio de la biocompatibilidad de los recubrimientos.

- Realización de cultivos in vitro para determinar la capacidad de osteoinducción de los recubrimientos.

Los objetivos marcados se alcanzaron mediante el establecimiento de una metodología de trabajo que se esquematiza en la Figura. 2.1. 


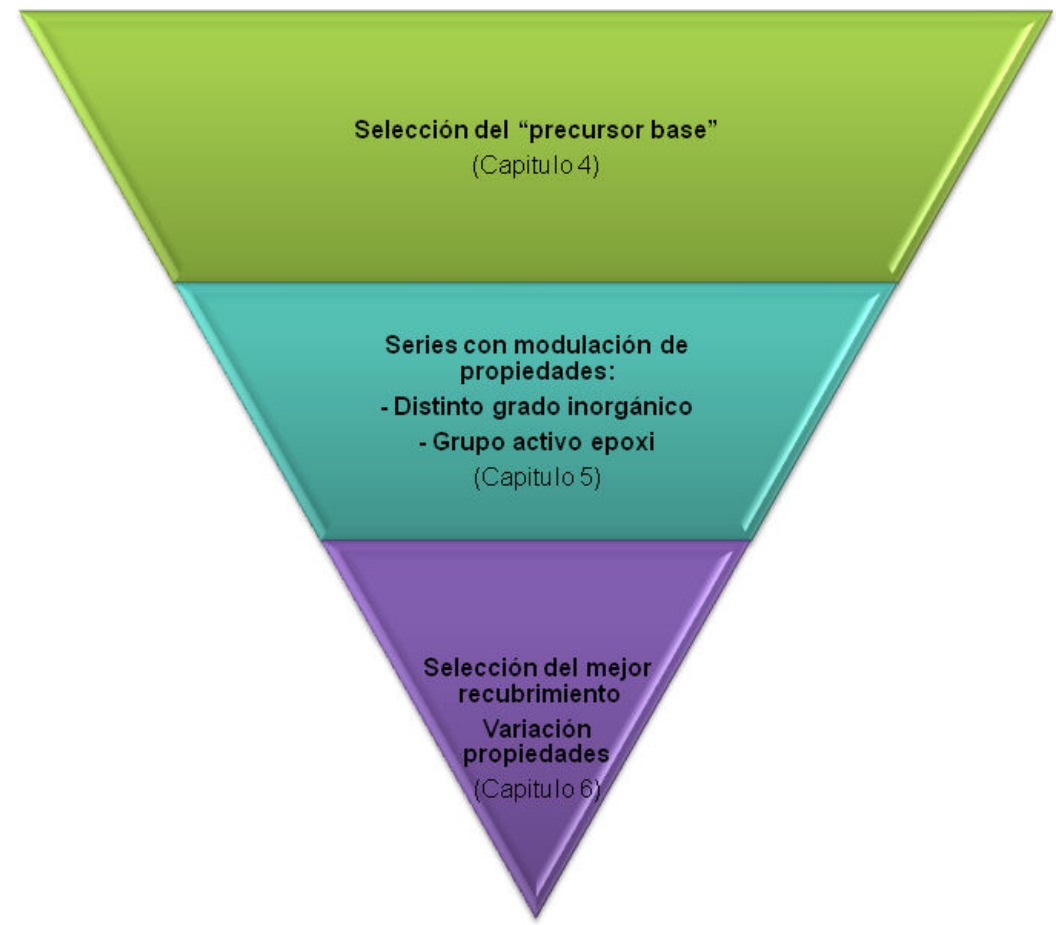

Figura. 2.1 Esquema de la metodología desarrollada para la obtención de los objetivos y su correspondencia con los capítulos de la presente Tesis Doctoral.

En primer lugar, se han pre-seleccionado 4 precursores de silicio: tetraetilortosilicato (TEOS), metil-trimetoxisilano (MTMOS), vinil-trietoxisilano (VTES) y 3glicidoxipropil-trimetoxisilano (GPTMS). A continuación, se han desarrollado y ajustado los parámetros de síntesis de los recubrimientos obtenidos a partir de estos cuatro precursores y se ha realizado un estudio sistemático del comportamiento de los materiales obtenidos. Para realizar este estudio se han evaluado sus propiedades superficiales, el tipo de red formada, así como la protección frente a la corrosión y la velocidad de degradación en fluidos biológicos simulados.

En la siguiente fase del estudio, se han preparado recubrimientos en cuya red organopolisiloxánica se ha introducido un fármaco modelo, con el objetivo de evaluar las posibles propiedades de liberación sostenida y controlada del agente incorporado desde los recubrimientos diseñados a medida, para tal fin, en base a los conocimientos adquiridos en etapas anteriores de esta Tesis Doctoral. 
Finalmente, se ha evaluado el comportamiento biológico de estos nuevos materiales, analizándose la citotoxicidad y la proliferación de osteoblastos humanos.

Todo este estudio se ha realizado con el fin de seleccionar el precursor que permita producir y optimizar materiales multifuncionales que ofrezcan la mejoría de las propiedades o la mejoría del comportamiento en servicio, desde un punto de vista global. Así, el estudio nos ha permitido seleccionar un "precursor base" y tomarlo como referencia en las siguientes etapas de esta Tesis Doctoral.

Una vez seleccionado el "precursor base", se han modulado distintas propiedades de interés en el comportamiento del material así como en la respuesta biológica del mismo.

Por un lado, se ha variado la hidrofilia del recubrimiento (factor clave en la adhesión celular) por medio de la creación de una red con un carácter más inorgánico, mediante la adicción de distintas cantidades del precursor TEOS. Se ha desarrollado y ajustado los parámetros de síntesis de esta serie de materiales. Se han estudiado sus propiedades superficiales, el tipo de red formada, la protección frente a la corrosión y la velocidad de degradación en función de la relación molar "precursor base"/TEOS. Así mismo, se ha evaluado la proliferación de células mesenquimales del tejido adiposo humano sobre la serie de materiales y su capacidad para diferenciarse a osteoblastos humanos.

Por otro lado, se ha añadido al "precursor base" distintas cantidades de GPTMS que aporta al recubrimiento un contenido mayor orgánico $\mathrm{y}$, además, introduce un grupo reactivo epoxi, que será de interés para la creación de una superficie más activa. Al material resultante se le ha aplicado la misma sistemática que habíamos desarrollado para el estudio y evolución de los materiales desarrollados en las etapas anteriores.

Finalmente, una vez seleccionado el recubrimiento óptimo, se realizan variaciones tanto en la adición de distintos agentes, que puedan resultar de interés para la aplicación final, así como variaciones en la propia red por medio de modificaciones en los parámetros de síntesis con el fin de controlar el nivel de bioactividad, la velocidad de degradación y liberación de fármacos. 

Capítulo 3 Materiales y métodos 

La presente Tesis Doctoral ha seguido la metodología presentada en la Figura.

3.1

\section{Sintesis}

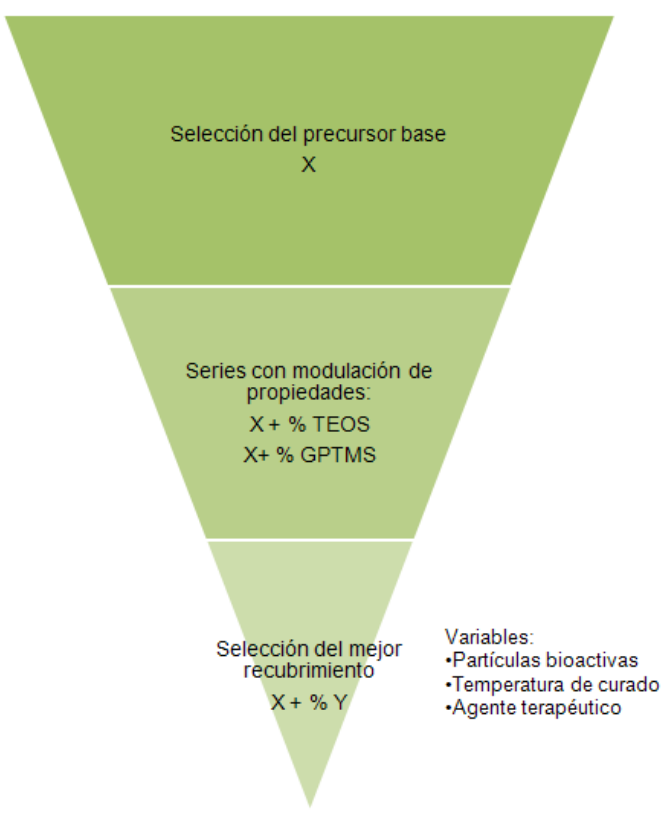

Caracterización

- Ensayos básicos

-Morfológicas. SEM

-Físicas. TMA

-Químicas. FTIR, RMN

- Térmicas. TGA DSC

- Biológicas. Citotoxicidad y proliferación osteoblastos

-Ensayos básicos

- Morfológicas. SEM

-Físicas. TMA

-Químicas. FTIR, RMN

-Térmicas. TGA, DSC

- Biológicas. Proliferación y diferenciación de células mesenquimales.

Morfológicas. SEM

- Físicas TMA, DMA

-Químicas. FTIR, FTIR "in situ", RMN

- Térmicas. TGA + Estudio cinético de degradación

DSC Evolución de

DSC + Evolución de

- Degradación

- Liberación de fármacos

Protección anticonosiva EIS

- Biológicas. Citotoxicidad, proliferación osteoblastos

y mesenquimales, diferenciación de mesenquimales a osteoblastos.

Figura. 3.1 Diagrama del plan de trabajo seguido en la presente Tesis Doctoral para la selección de un recubrimiento óptimo. 


\section{1 Materiales}

Se propone la síntesis de recubrimientos híbridos orgánico-inorgánicos tipo sol-gel que aumenten la biocompatibilidad y osteointegración de implantes metálicos, y en específico de implantes dentales. Los recubrimientos deben reunir al menos los siguientes requisitos:

- versatilidad

- capacidad de incorporación de partículas bioactivas

- capacidad de incorporación de fármacos o biomoléculas.

- gran adherencia al substrato metálico

- homogeneidad y libre de grietas o poros

- biocompatiblilidad y capacidad osteoinductiva

- biodegradabilidad

Para la síntesis de recubrimientos sol-gel se parte de precursores de silicio. Todos los precursores de silicio tienen una fórmula química semejante, del tipo $\mathrm{X}_{n} \mathrm{Si} \mathrm{OR}_{(4-n)}$, siendo X una cadena orgánica y $\mathrm{R}$ una cadena alcoxi. Por tanto, el átomo de silicio se encuentra rodeado por una o varias cadenas alcoxi (de distinta longitud) que serán las que reaccionaran en la primera etapa de la síntesis (hidrólisis). La estructura de las cadenas orgánicas $\mathrm{X} y$, por tanto, del propio precursor son muy variadas con lo que en función de la selección que se realiza se obtendrán diferentes tipos de red.

Los materiales utilizados en esta Tesis Doctoral se han obtenido por síntesis ácida "one step" (en un paso), utilizando en el proceso de hidrólisis de los precursores de silicio agua destilada y como catalizador ácido nítrico. Durante la hidrólisis el sistema se mantiene en agitación 1 hora y se deja estabilizar durante otra hora para obtener el sol.

Los distintos materiales se pueden obtener bien aplicados sobre distintos sustratos (en esta Tesis Doctoral sobre acero inoxidable AISI 316L y titanio puro grado 4) o bien en película libre. Para la aplicación sobre sustratos se pueden utilizar distintas técnicas como flow-coating, dip-coating, etc. 
El material necesita ser secado y curado para promover las reacciones de condensación y la salida de disolventes de la red. Las condiciones a utilizar serán especificadas para cada tipo de material en el apartado 3.1.3. Una vez curado el material estará listo para su uso.

\subsubsection{Materiales utilizados}

Se han sintetizado los nuevos materiales para su aplicación como recubrimiento a partir de un precursor de silicio o una combinación de dos de ellos. Se tomaron como precursores de partida metil-trimetoxisilano MTMOS (Sigma-Aldrich Ref.M6420), viniltrietoxisilano VTES (Sigma-Aldrich Ref.75560), glicidoxipropil-trimetoxisilano GPTMS (Sigma-Aldrich Ref.440167) y tetraetil- ortosilicato TEOS (Sigma-Aldrich Ref.333859), en la Figura. 3.2 se muestra un esquema de la estructura molecular de cada uno de ellos.

(a)<smiles>CCO[Si](OCC)(OCC)OCC</smiles>

(c)<smiles>C=C[Si](OC)(OC)OC</smiles>

(b)<smiles>CO[Si](C)(OC)OC</smiles>

(d)

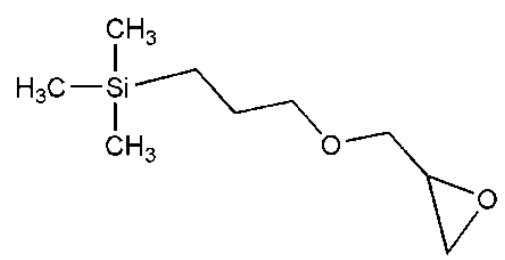

Figura. 3.2 Esquema de la estructura molecular de los precursores de silicio (a) TEOS (b) MTMOS (c) VTES (d) GPTMS. 
Adicionalmente en algunas formulaciones se han sintetizado recubrimientos cargados con partículas bioactivas de hidroxiapatita $(\mathrm{HAp})$ de fórmula $\mathrm{Ca}_{5}(\mathrm{OH})\left(\mathrm{PO}_{4}\right)_{3}$ con tamaño de partícula >200nm (Sigma-Aldrich, Ref. 677418).

Por otro lado, se desarrollaron formulaciones a los que se ha adicionado procaína (Pr) (Sigma-Aldrich Ref. P9879) como fármaco modelo, su estructura molecular se muestra en Figura. 3.3.<smiles>CCN(CC)CCOC(=O)c1ccc(N)cc1</smiles>

Figura. 3.3 Esquema de la estructura molecular de la procaína.

Los materiales se han obtenido como recubrimientos sobre distintos sustratos (acero inoxidable, titanio, vidrio e implantes) o como film libre en función del tipo de ensayo de caracterización a utilizar.

Los sustratos utilizados fueron los siguientes:

* Acero inoxidable austenítico tipo AISI-316L calidad de acabado 2B (suministrado por Ramón Navarrete Aceros Inoxidables, S.L.)

* Titanio de pureza grado 4 (suministrado por llerimplant, S.L.)

* Portas de vidrio diámetro 18mm (Afora Ref. LA550012C)

* Implantes dentales titanio grado 1 (Ilerimplant, S.L. modelo Phoenix-3) (Figura. 3.4)

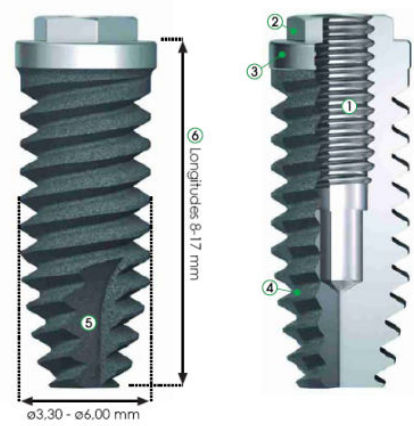

Figura. 3.4 Esquema implante Phoenix-3. (1) rosca interior, (2) hexágono externo, (3) plataforma, (4) rosca exterior, (5) fresadas autoroscantes. 


\subsubsection{Método de obtención de los soles}

Para realizar el recubrimiento se ha preparado una disolución del precursor o los precursores en isopropanol con una relación en volumen 1:1 (Tabla 3.1). Esta disolución se agita magnéticamente. Se añade gota a gota agua destilada en cantidad estequiométrica para la hidrólisis de los grupos alcoxi presentes en los precursores. Con el fin de acelerar el proceso de hidrólisis el agua añadida está acidificada hasta $\mathrm{pH}=1$ gracias a la adición de ácido nítrico. Esta disolución se deja en agitación (150r.p.m) durante una hora para permitir la completa hidrólisis de todos los grupos. Para estabilizar el sistema se deja en reposo durante otra hora. Posteriormente el sistema está preparado para realizar los siguientes pasos del proceso de síntesis bien como recubrimiento o como película libre.

Tabla 3.1 Relaciones volumétricas alcohol:precursor cuando se utiliza un solo precursor para la síntesis del nuevo material (tabla superior) y cuando se parte de distintas mezclas molares de dos precursores distintos (tabla inferior). La relación precursor:agua de hidrólisis siempre es la estequiométrica.

\begin{tabular}{|c|c|c|c|c|c|c|}
\hline & \multicolumn{2}{|c|}{ VTES } & \multicolumn{2}{|c|}{ MTMOS } & \multicolumn{2}{|c|}{ GPTMS } \\
\hline Alcohol:precursor & \multicolumn{2}{|c|}{$1: 1$} & \multicolumn{2}{|c|}{$1: 1$} & \multicolumn{2}{|c|}{$1: 1$} \\
\hline Agua hidrólisis $\mathrm{pH}=1$ & \multicolumn{2}{|c|}{ Esteq. } & \multicolumn{2}{|c|}{ Esteq. } & \multicolumn{2}{|c|}{ Esteq. } \\
\hline & \multicolumn{3}{|c|}{ VTES : TEOS } & \multicolumn{3}{|c|}{ VTES : GPTMS } \\
\hline Relación en moles & $9: 1$ & $8: 2$ & $7: 3$ & $8: 2$ & $1: 1$ & $2: 8$ \\
\hline Alcohol:precursores & $1: 1$ & $1: 1$ & $1: 1$ & $1: 1$ & $1: 1$ & $1: 1$ \\
\hline Agua hidrólisis $\mathrm{pH}=1$ & Esteq. & Esteq. & Esteq. & Esteq. & Esteq. & Esteq. \\
\hline
\end{tabular}

Las formulaciones dopadas con HAp se sintetizan siguiendo la misma metodología que la descrita anteriormente hasta la etapa de hidrólisis, es decir, la etapa de dopado se inicia inmediatamente después de la hidrólisis.

En esta Tesis Doctoral se han sintetizado recubrimientos con 2,5\% HAp y 5\% HAp en peso respecto a los silanos precursores. Inicialmente se realiza una dispersión de las partículas en isopropanol por medio de ultrasonidos (2-4 minutos a 30W con ultrasonidos Sonoplus HD 3200) para evitar la aglomeración de dichas partículas. Posteriormente a la etapa de hidrólisis realizada a los precursores se añade esta suspensión gota a gota manteniendo agitación (150 r.p.m) durante 5 minutos. Por último, se mantiene sin agitación durante una hora para estabilizar el sistema. 
Los recubrimientos dopados con fármaco se sintetizan siguiendo la misma metodología que para el recubrimiento sin cargas. Se han añadido distintas cantidades de fármaco a los recubrimientos, en concreto, $5 \%, 7,5 \%$ y $10 \%$ de fármaco respecto a silanos. En el caso de tratarse de un fármaco soluble en agua, el agente se disuelve en el agua de hidrólisis sin que esto afecte al resto del protocolo de síntesis.

El esquema completo del proceso de síntesis se muestra en la Figura. 3.5

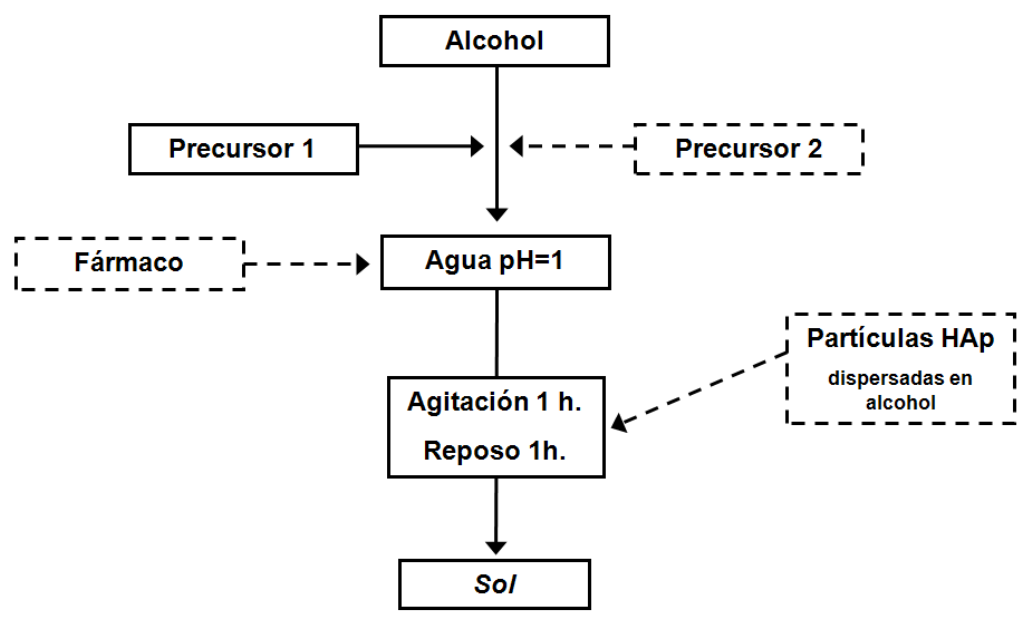

Figura. 3.5 Esquema de síntesis de sol-gel. 


\subsubsection{Aplicación, secado y curado}

Una vez obtenida la fase sol del sistema, éste se encuentra preparado para su aplicación sobre los distintos sustratos, o bien, para introducirlo en el molde para la obtención de un film libre.

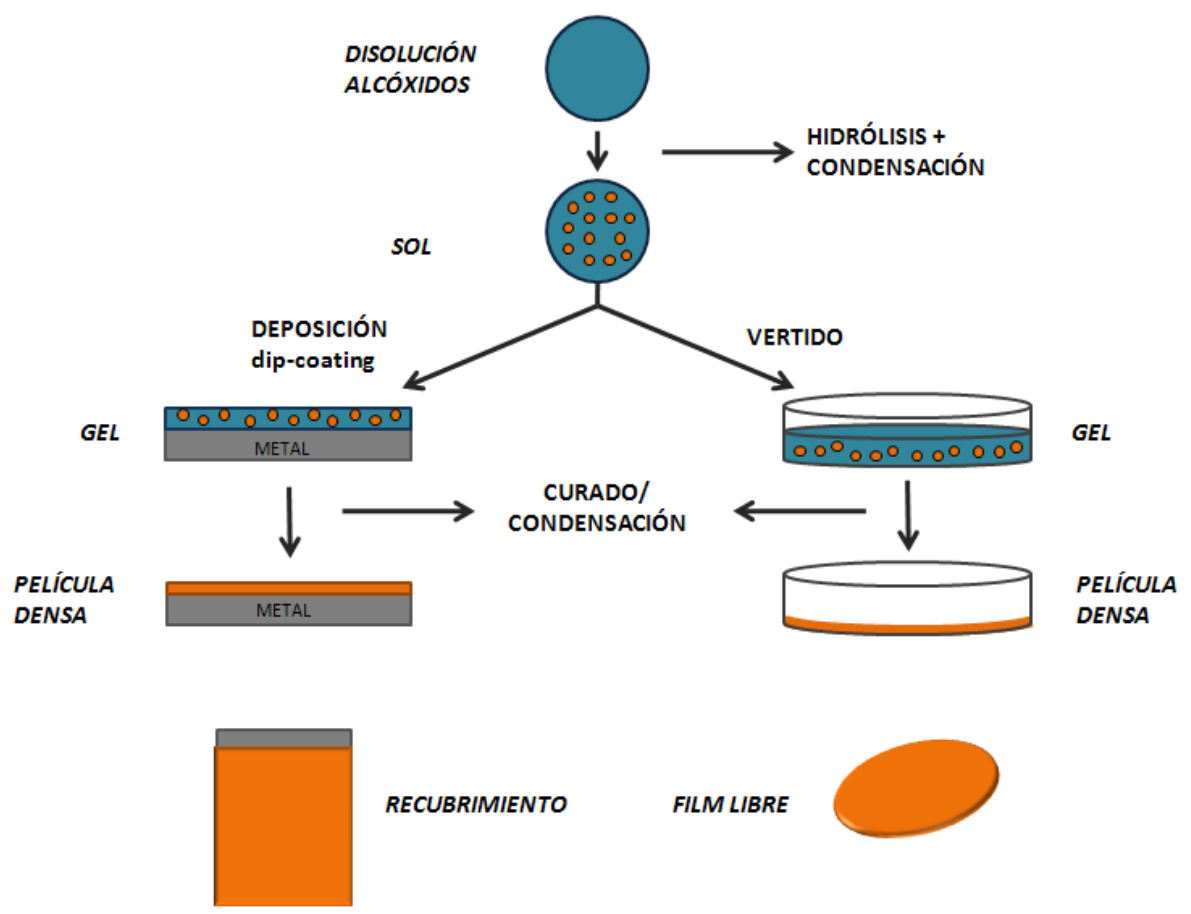

Figura. 3.6 Esquema del método de obtención de las distintos tipos de materiales.

a) Preparación de la superficie

Todos los sustratos deben encontrarse desengrasados y limpios de impurezas. Cada sustrato tiene un protocolo de limpieza distinto.

Para las planchas metálicas (tanto acero como titanio) se procede a realizar un proceso de desbaste convencional hasta 1000p. Este desbaste se realiza en 4 direcciones en forma de cruz y aspa. Posteriormente se limpia en repetidas ocasiones con agua destilada y, por último, se limpia con acetona para eliminar los posibles restos de grasas. Se secan al aire y se utilizan inmediatamente. 
Cuando se ha requerido recubrir vidrios, éstos se han limpiado introduciéndolos en un baño de ultrasonidos en etanol durante 5 minutos a $30 \mathrm{~W}$ de potencia utilizando Sonoplus HD 3200, acabando el proceso con la inmersión, en repetidas ocasiones, del sustrato con agua destilada y por último en etanol. Posteriormente, los sustratos de vidrio se secan en estufa a $150^{\circ} \mathrm{C}$. Para obtener recubrimientos sobre vidrio es necesario activar la superficie para que el recubrimiento este presente de forma uniformemente en toda la superficie. El tratamiento se realiza por medio de plasma de Argón que aumenta la mojabilidad de la superficie. Se realiza un tratamiento en cámara de plasma con flujo de Argón de $200 \mathrm{sscm}$ durante 300 segundos a presión de 50Pa y $300 \mathrm{~W}$ de energía.

\section{b) Método de aplicación sobre superficies}

Para recubrir superficies metálicas se ha utilizado la técnica "dip-coating". Esta técnica consta de tres etapas: (1) inmersión a velocidad controlada de la pieza en la fase sol y una vez inmersa, se deja un tiempo controlado de residencia, (2) extracción de la pieza a una velocidad controlada, que suele ser la misma que la de inmersión y (3) drenaje de la pieza (Figura. 3.7).
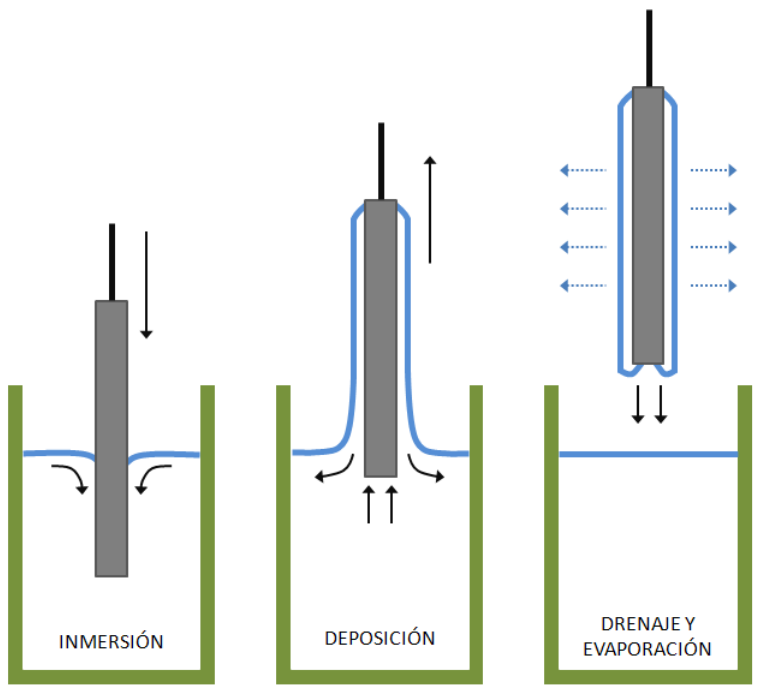

Figura. 3.7 Esquema de método de recubrimiento de superficies mediante la técnica "Dipcoating". 
Para realizar la inmersión de la muestra metálica en la fase sol en condiciones controladas y constantes, se ha optado por la utilización de un sistema ascensor de la marca KSV Instruments modelo KSVDC. Se ha utilizado una velocidad de inmersión de $100 \mathrm{~cm} / \mathrm{min}$ y el tiempo de inmersión de un minuto, siendo la velocidad de extracción es $100 \mathrm{~cm} / \mathrm{min}$.

Para recubrir superficies de vidrio se ha optado por el "método de la gota". Una vez activada la superficie del vidrio, se consigue un recubrimiento homogéneo y continuo de gel dejando caer una gota de 10 microlitros de sol sobre la superficie.

c) Obtención de película o film libre.

Para obtener film libre se utilizan moldes de teflón antiadherentes de $50 \mathrm{ml}$ de volumen y diámetro $65 \mathrm{~mm}$ (LineaLab, SL Ref. 45705) a los que se les añade la cantidad adecuada de sol para obtener espesores homogéneos y films sin grietas ni imperfecciones (fundamentalmente burbujas de aire) (Tabla 3.2).

Tabla 3.2 Volumen de material incorporado al molde de teflón para la obtención de films libres homogéneos de cada formulación.

\begin{tabular}{|c|c|c|c|c|c|c|}
\hline sol & \multicolumn{2}{|c|}{ VTES } & \multicolumn{2}{|c|}{ MTMOS } & \multicolumn{2}{|c|}{ GPTMS } \\
\hline Cantidad de gel $(\mu \mathrm{l})$ & \multicolumn{2}{|c|}{10} & \multicolumn{2}{|c|}{10} & \multicolumn{2}{|c|}{7.5} \\
\hline sol & \multicolumn{3}{|c|}{ VTES : TEOS } & \multicolumn{3}{|c|}{ VTES : GPTMS } \\
\hline Formulaciones & $9: 1$ & $8: 2$ & $7: 3$ & $8: 2$ & $1: 1$ & $2: 8$ \\
\hline Cantidad de gel $(\mu \mathrm{l})$ & 10 & 10 & 10 & 9 & 7.5 & 7.5 \\
\hline
\end{tabular}

Los recubrimientos que utilizan TEOS como precursor, dada la fragilidad y contracción que le atribuye éste, se desmoldan del teflón cuando llevan 1 hora de curado y se sitúan entre dos planchas metálicas lo suficientemente pesadas como para evitar la curvatura del film.

d) Secado y curado de los recubrimientos.

Una vez depositado el recubrimiento sobre el sustrato seleccionado o dispuesto sobre el molde se hace un tratamiento de secado en estufa. El tratamiento inicialmente consiste en una isoterma a $50^{\circ} \mathrm{C}$ durante 15 minutos y una rampa de temperatura hasta la temperatura de curado a una velocidad de $3^{\circ} \mathrm{C} / \mathrm{min}$. Este 
tratamiento permite la eliminación gradual del agua y de los disolventes evitando la aparición de grietas o burbujas.

Posteriormente se realiza un segundo tratamiento que, en función de la formulación, implicará la utilización de tiempos y temperaturas según se especifican en la tabla Tabla 3.3. Con este tratamiento se consigue una total densificación del recubrimiento y el secado completo del mismo.

Tabla 3.3 Cuadro de muestras y tratamientos de curado estándar.

\begin{tabular}{|c|c|c|c|c|c|c|}
\hline & \multicolumn{2}{|c|}{ VTES } & \multicolumn{2}{|l|}{ MTMOS } & \multicolumn{2}{|c|}{ GPTMS } \\
\hline Temperatura $\left({ }^{\circ} \mathrm{C}\right)$ & \multicolumn{2}{|c|}{100} & \multicolumn{2}{|l|}{80} & \multicolumn{2}{|c|}{140} \\
\hline Tiempo (min) & \multicolumn{2}{|c|}{105} & \multicolumn{2}{|l|}{105} & \multicolumn{2}{|c|}{90} \\
\hline & \multicolumn{3}{|c|}{ VTES : TEOS } & \multicolumn{3}{|c|}{ VTES : GPTMS } \\
\hline & $9: 1$ & $8: 2$ & $7: 3$ & $8: 2$ & 1:1 & $2: 8$ \\
\hline Temperatura $\left({ }^{\circ} \mathrm{C}\right)$ & 50 & 50 & 50 & 100 & 140 & 140 \\
\hline Tiempo (min) & 120 & 120 & 120 & 90 & 90 & 90 \\
\hline
\end{tabular}

\section{2 Técnicas experimentales}

\subsubsection{Caracterización morfológica}

Para el análisis superficial y de acabado de las muestras dopadas o sin dopar con partículas se utilizó la técnica de Microscopía Electrónica de Barrido (SEM, en siglas inglesas).

Además, con este equipo se puede determinar, de modo orientativo, el espesor del recubrimiento observando un corte transversal de las muestras. Para poder visualizar este corte se ha diseñado un protocolo de corte y preparación de la muestra que se describe a continuación:

1. Realización de corte transversal en la muestra (sustrato/recubrimiento) con una cortadora de precisión con disco de punta de diamante (Disque Diamant LM de la marca PRESI) y lubricación con agua a 300r.p.m. para se evita el deterioro del recubrimiento.

2. Embutición de la muestra por su cara transversal con una resina con contención de bordes (Durocit Kit de marca Struters). 
3. Desbastado en platos de distinto tamaño de partícula (320p, 600p, 1000p) siempre en dirección perpendicular al recubrimiento

4. Pulido con polvo de diamante de 1micrómetro.

La superficie obtenida es la que se analiza. Gracias a herramientas del software del SEM se ha medido el espesor de capa obtenida.

\subsubsection{Caracterización química}

Con el objetivo de conocer la formulación química de los materiales y hacer un seguimiento de las reacciones de hidrólisis y condensación, así como del curado del proceso sol-gel se realizaron estudios por medio de la Espectroscopia de Infrarrojo por Transformada de Fourier (FTIR, en siglas inglesas) y Resonancia Magnética Nuclear (RMN).

\section{a) Espectroscopia de infrarrojo}

El análisis químico de los recubrimientos obtenidos se ha realizado utilizando un accesorio de reflexión atenuada (ATR en siglas inglesas, Thermo Nicolet) en un espectrofotómetro FT-IR Thermo Nicolet NEXUS. Las medidas se realizaron en un intervalo de $4000-500 \mathrm{~cm}^{-1}$ con una resolución de $4 \mathrm{~cm}^{-1}$ en absorbancia.

Adicionalmente, se han evaluado las reacciones de condensación que ocurren durante el curado del recubrimiento por medio de medidas "in situ" en FTIR-ATR con control de temperatura. Para ello se ha utilizado un espectofotómetro FTIR-680PLUS de la marca JASCO con una resolución de $4 \mathrm{~cm}^{-1}$ en absorbancia equipado con accesorio ATR con control de temperatura y cristal de diamante (Golden Gate heated single-reflection diamond ATR de la marca Specac-Teknokroma). En este caso se situó, sobre el cristal del accesorio ATR que se encuentra a la temperatura fijada para el ensayo, una gota del material en estado sol. Se programa el equipo para que realice la toma de datos cada 10 segundos durante 4 horas, para asegurar que el material está totalmente curado. 
b) Resonancia Magnética Nuclear

Para completar la caracterización química del material se ha realizado un estudio mediante Resonancia Magnética Nuclear RMN del átomo de ${ }^{29} \mathrm{Si}$ en estado líquido y sólido.

La espectroscopia de RMN es una técnica empleada principalmente en la determinación de estructuras moleculares. En nuestro caso, esta técnica se ha empleado para optimizar el proceso de hidrólisis y además realizar un estudio cualitativo del grado de reticulación de las muestras.

Mediante el RMN de ${ }^{29} \mathrm{Si}$ en estado líquido se ha realizado el seguimiento de las reacciones de hidrólisis y condensación. El estudio se ha llevado a cabo en un equipo FT-NMR Bruker Avance de $300 \mathrm{MHz}$ modelo DPX-300. Se ha realizado un RMN antes y después de añadir el agua ácida de hidrólisis. Así se han determinado las posiciones base de las bandas de cada precursor antes y después de la hidrólisis. Mediante la adquisición de un espectro cada hora durante 5 horas de ensayo se ha podido analizar la variación de las bandas durante la reacción.

La técnica más empleada a la hora de realizar ensayos de ${ }^{29} \mathrm{Si}$ en estado sólido es la denominada Si-H polarización cruzada/rotación en ángulo mágico (CP/MAS). La estructura final del recubrimiento se ha caracterizado mediante RMN de sólido en un espectrómetro Bruker Avance $300 \mathrm{MHz}$ modelo DSX- 300. Se realizan RMN de sólidos al mismo recubrimiento tras el tratamiento de curado.

\subsubsection{Caracterización térmica}

Por medio de la utilización de técnicas calorimétricas se pueden extraer valiosos datos sobre el estado de la red formada. Además permiten estudiar el proceso de secado-curado de la red sol-gel.

\section{a) Calorimetría Diferencial de Barrido}

La Calorimetría Diferencial de Barrido (DSC, en siglas inglesas) es una técnica que permite obtener información de la temperatura a la cual tienen lugar cambios energéticos y del calor involucrado en un proceso. Efectos térmicos como fusión, cristalización, transición vítrea,... se traducen en diferencias en el flujo de calor que será medido por los sensores de temperatura del equipo. 
En esta Tesis Doctoral se ha utilizado un DSC Mettler-Toledo $823 \mathrm{e}$ que es un calorímetro diferencial de flujo de calor. El principio de funcionamiento de este tipo de calorímetros se basa en la medida de la variación entre el flujo de calor de la muestra a medir y la de referencia cuando dicha muestra se somete a un programa de temperatura en una atmósfera controlada. Con este equipo se determina la temperatura de transición vítrea $\left(T_{g}\right)$ de los materiales obtenidos. Las medidas se realizaron sobre materiales curados y se les aplicó barridos consistentes en una rampa de enfriamiento de $25^{\circ} \mathrm{C}$ a $-120^{\circ} \mathrm{C}$ a una velocidad de $30^{\circ} \mathrm{C} / \mathrm{min}$, seguido de una isoterma de 2 minutos a $-120^{\circ} \mathrm{C}$. Tras la isoterma se realiza una rampa de calentamiento a una velocidad de $10^{\circ} \mathrm{C} / \mathrm{min}$ hasta $200^{\circ} \mathrm{C}$ todo ello refrigerado con un flujo de nitrógeno de $30 \mathrm{ml} / \mathrm{min}$.

Por otro lado, por medio de esta técnica se pueden detectar cambios en la temperatura de transición vítrea de los materiales durante el curado de los mismos. Al ir creándose enlaces durante el curado, se van limitando grados de libertad en la red, lo que se traduce en un aumento de la energía necesaria para que se produzcan y, por tanto, un aumento en la $T_{g}$ del material. Cuando el material se encuentra totalmente entrecruzado, la $T_{g}$ deja de evolucionar estabilizándose a una cierta temperatura. Para realizar este estudio se mide $T_{g}$ y $\Delta C p$ para distintos tiempos y temperaturas de curado. Para ello se sintetizaron muestras a una determinada temperatura de curado, cambiando el tiempo desde 0 min hasta uno suficientemente largo para asegurar la total formación de la red (tomado como fondo de escala).

\section{b) Estabilidad térmica. Análisis termogravimétrico}

Se ha estudiado la estabilidad térmica de los sistemas obtenidos, de forma que se ha podido evaluar la influencia de la formulación, así como de las cargas, en esta propiedad. Para realizar el ensayo se utilizó un Termogravímetro SDTQ600 TA Instruments. Se estudiaron muestras de masa de $7 \mathrm{mg}$, con un ciclo de degradación que comienza en $30^{\circ} \mathrm{C}$ y aumenta la temperatura a una velocidad de $10^{\circ} \mathrm{C} / \mathrm{min}$ hasta $700^{\circ} \mathrm{C}$, todo ello con un flujo de nitrógeno de $100 \mathrm{ml} / \mathrm{min}$. Tras la medida la muestra se deja enfriar.

Para completar el estudio de la degradación de los materiales, y detectar los procesos que se dan durante la degradación los residuos producidos en el ensayo 
anterior se analizaron con FTIR a distintas temperaturas de degradación, así se analizaron residuos después de cada pico de degradación detectado con el TGA.

A fin de conocer el proceso de degradación térmica de los materiales obtenidos, se han realizado estudios cinéticos. Gracias a la utilización de métodos isoconversionales, como Coats-Redfern o el IKR puede obtenerse tanto el triplete cinético (factor pre-exponencial $A$, energía de activación $E_{a}$ y la integral del modelo cinético en función del grado de conversión $g(\alpha)$ de cada sistema) como realizar cálculos teóricos de los procesos de degradación isoterma a una temperatura y un tiempo determinados.

Para realizar esta experimentación se utilizó una termobalanza Mettler-Toledo TG50. Se estudiaron muestras de $7 \mathrm{mg}$. El programa de degradación comienza en $30^{\circ} \mathrm{C}$ y termina en $700^{\circ} \mathrm{C}$ con un flujo de nitrógeno $(100 \mathrm{ml} / \mathrm{min})$. La metodología exigió la realización de ensayos no-isotermos, éstos se realizaron a distintas velocidades de calentamiento $2,5,10,25^{\circ} \mathrm{C} / \mathrm{min}$, para obtener los datos necesarios para la realización del estudio cinético.

\subsubsection{Caracterización mecánica}

Las diferentes formulaciones y la adición de partículas bioactivas o fármacos, hace que las formulaciones tengan propiedades mecánicas muy diferentes. Para obtener estas propiedades se realizarán ensayos de tensión-deformación a temperatura controlada.

Los ensayos tensión-deformación se realizaron a fin de obtener información sobre el comportamiento mecánico a compresión de los distintos materiales. Este tipo de ensayos se utilizan para determinar los parámetros ingenieriles del material (módulo elástico, límite elástico, tenacidad, etc. )

Para la realización de estos ensayos se sintetizaron muestras libres de sustrato (film libre) de $1 \mathrm{~mm}$ de espesor máximo y un diámetro de $12 \mathrm{~mm}$, sin grietas e imperfecciones en la zona a ensayar. El ensayo se realiza a $37^{\circ} \mathrm{C}$ en seco, utilizando un intervalo de deformaciones pequeño. Para realizar el ensayo se empleó un dilatómetro Seiko TMA/SS6000 con palpador de cuarzo de diámetro $3,6 \mathrm{~mm}$, este equipo aplica una carga programable y mide la dilatación de la muestra. El programa 
de cargas aplicado para la obtención de las curvas tensión-deformación es desde 0 a $1400 \mathrm{mN}$ a compresión con una velocidad de carga de $50 \mathrm{mN} / \mathrm{min}$.

\subsubsection{Degradación hidrolítica}

Los recubrimientos sol-gel formulados tienen características de materiales reabsorbibles una vez implantados en el cuerpo humano. La degradación ocurre mediante reacción de hidrólisis como la que se detalla en la ecuación 3.1.

$$
\mathrm{SiO}_{2}+2 \mathrm{H}_{2} \mathrm{O} \rightarrow \mathrm{Si}(\mathrm{OH})_{4}(a q) \text {. }
$$

Los productos de degradación basados en sílice, según la literatura, resultan tener propiedades osteoinductivas [68-72]. El fenómeno de degradación es determinante en la cinética de la liberación de fármacos, ya que gran parte de la liberación se produce asociada a este fenómeno.

El ensayo se lleva a cabo manteniendo los films en un buffer de fosfato salino (PBS, siglas en inglés), se ajusta el medio de disolución al $\mathrm{pH}$ bucal, $\mathrm{pH}=6,8$, y se mantiene una temperatura constante de $37^{\circ} \mathrm{C}$ (en estufa). El PBS está preparado a partir de fosfato de sodio monobásico monohidratado $\mathrm{NaH}_{2} \mathrm{PO}_{4} \cdot \mathrm{H}_{2} \mathrm{O}$ (Sigma-Aldrich ref.: S9638 ) y fosfato di-sodio 7-hidratado $\mathrm{Na}_{2} \mathrm{HPO}_{4} \cdot 7 \mathrm{H}_{2} \mathrm{O}$ (Panreac ref. 132656).

Las muestras se introducen en un bote con $500 \mathrm{ml}$ de PBS y se cierran para evitar su evaporación. Una vez por semana se procede a la extracción de la muestra y se secan en una estufa de vacío a $37^{\circ} \mathrm{C}$ durante 24 horas, pasado este tiempo se pesan para determinar la pérdida de peso. La cinética se expresa como pérdida de peso en función del tiempo de inmersión en PBS.

3.2.6 Protección frente a la corrosión. Medidas impedancia electroquímica [102-104]

\section{a) Fundamentos de la técnica}

Una de las técnicas electroquímicas que ha experimentado un mayor auge en los últimos años es la espectroscopia de impedancia electroquímica (EIS, siglas en inglés). Esta técnica se basa en el análisis de la respuesta de un sistema electroquímico a una perturbación provocada por una función conocida de voltaje, corriente o carga. El registro de la señal de la respuesta del sistema perturbado 
permite el análisis de los procesos que se desencadenan simultánea y/o consecutivamente, de una forma no destructiva. Cada proceso genera una respuesta que se relaciona con una frecuencia característica (ec. 3.2).

$$
f=\frac{1}{2 \pi \tau}
$$

Donde $\tau$ es la constante de tiempo, es decir, el tiempo que emplea el sistema en volver a recuperar el estado estacionario. Por lo tanto, procesos con $\tau$ altas son procesos lentos que tienen lugar a bajas frecuencias (como los procesos de corrosión en las superficies metálicas), mientras que los procesos con $\tau$ bajas serán procesos rápidos que se desarrollan a valores de frecuencia elevados (como los relacionados con las propiedades dieléctricas de recubrimientos).

La respuesta se obtiene mediante la perturbación del sistema en estado estacionario, al aplicar una señal eléctrica, por ejemplo una señal de corriente alterna sinusoidal, del tipo que aparece en la ecuación 3.3, en el caso de trabajar en régimen potenciostático.

$$
E=E_{0} \cdot \operatorname{sen} \omega t
$$

Variando la frecuencia, $\omega$, de la señal de potencial, $E$ (voltios), se obtiene la respuesta del sistema en forma de corriente, $i$ (amperios). La respuesta en régimen estacionario de un sistema lineal a este tipo de señal de excitación, será otra señal sinusoidal, de la misma frecuencia que la primera, pero que difiere en los valores de amplitud y ángulo de fase (ec. 3.4).

$$
i=i_{0} \cdot \operatorname{sen}(\omega t+\varphi)
$$

Siendo $E_{o}$ e $i_{0}$ las amplitudes máximas de la señal de entrada y su respuesta, respectivamente, mientras que $\varphi$ es la diferencia de fase de dichas señales. Por lo general, para conseguir respuestas lineales y que no se altere irreversiblemente el sistema con la medida, la señal de entrada, $E$, se aplica sobre el potencial de equilibrio del electrodo y su amplitud $E_{0}$ suele ser muy baja, del orden de $10 \mathrm{mV}$.

La relación entre la señal del potencial aplicado y la corriente de respuesta se conoce como la impedancia del sistema, $Z$, de igual forma que en corriente continua 
la relación entre el voltaje y el flujo de corriente defina la resistencia en función de la ley de Ohm. Sin embargo, la impedancia es una magnitud vectorial con una dirección o argumento $\varphi$ (ec.3.5) y un módulo $|Z|$ que vendrá definido por el cociente de las amplitudes de la señal de voltaje y la señal de corriente. Donde $Z$ ' y $Z$ ' ' serán las componentes real e imaginaria del vector impedancia (ec. 3.6).

$$
\begin{aligned}
& \varphi=\arctan \left(Z^{\prime \prime} / Z^{\prime}\right) \\
& Z=\left[\left(Z^{\prime}\right)^{2}+\left(Z^{\prime \prime}\right)^{2}\right]^{1 / 2}
\end{aligned}
$$

Los datos obtenidos se representan mediante los diagramas de Bode o de Nyquist. Puesto que la impedancia del sistema es función de la frecuencia, para cada valor de la frecuencia se obtiene un par de valores, $Z$ ' y $Z$ ', que definen un nuevo vector impedancia. La envolvente resultado de la unión de todos los extremos de estos vectores, para los diferentes valores de frecuencia $\omega$ de la onda aplicada, constituye el diagrama de Nyquist (Figura. 3.8)

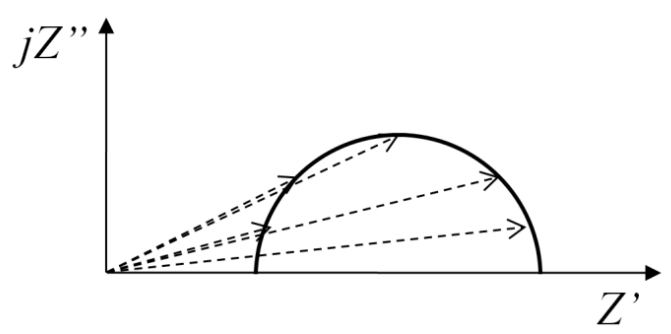

Figura. 3.8 Variaciones de la impedancia con la frecuencia. Diagrama de Nyquist.

Existen diferentes variantes de gráficos de Bode, que son el resultado de la representación de diferentes parámetros de la impedancia en función de la frecuencia. Los gráficos de Bode más comunes se muestran en la Figura. 3.9, donde se representa, en uno de los ejes de ordenadas el logaritmo en base 10 del módulo de la impedancia $(|Z|)$ y en el secundario el ángulo de fase, ambos respecto al logaritmo base 10 de la frecuencia $(f)$. 


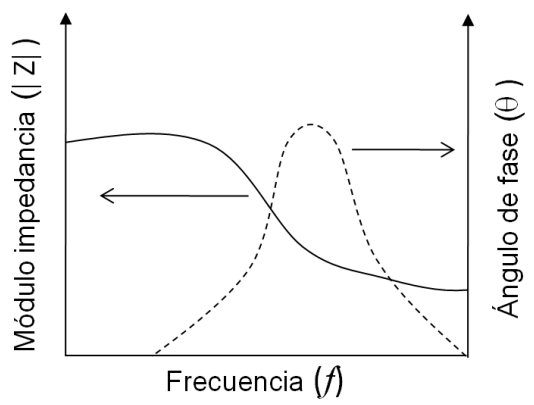

Figura. 3.9 Diagrama de Bode

El análisis de los resultados se realiza a través del empleo de circuitos equivalentes, siempre y cuando se cumplan determinadas condiciones experimentales, tales como, linealidad, causalidad, estabilidad y continuidad de la función de transferencia.

Linealidad: el sistema es lineal cuando existe una relación univoca entre perturbación y la respuesta al sistema, de forma que se pueda describir por un conjunto de ecuaciones diferenciales lineales.

Causalidad: la respuesta del sistema solamente depende de la perturbación aplicada.

Estabilidad: el sistema debe volver a su estado de estabilidad inicial en cuanto la perturbación desaparezca.

Continuidad de la función transferencia: las componentes real e imaginaria de la impedancia deben tener valores finitos y poseer valores discretos y continuos en todo el intervalo de frecuencias.

De esta forma un sistema electroquímico se puede representar como la suma de diversos componentes eléctricos que se combinan de forma que el conjunto global sea representativo de los procesos físicos y/o químicos que se desarrollan en el sistema a estudio. A continuación se presentarán una serie de ejemplos para conocer la respuesta del sistema en función de los elementos presentes en el circuito y su combinación. 
La resistencia es un elemento del circuito en que el valor de potencial es directamente proporcional a la corriente que lo atraviesa, de forma que su impedancia se define por la ecuación 3.7.

$$
Z_{R}=R
$$

Por lo tanto, este elemento solo presenta componente real, con lo que su respuesta será independiente de la frecuencia, tal como se muestra en la Figura. 3.10 .
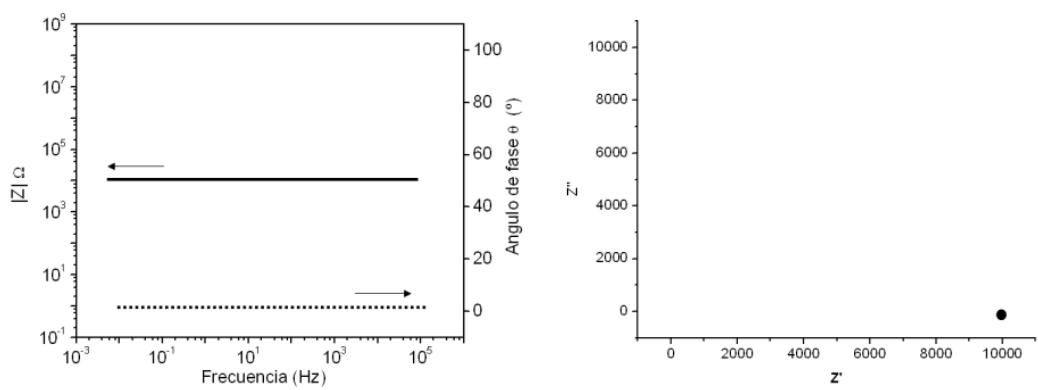

Figura. 3.10 Diagrama de Bode (izquierda) y diagrama de Nyquist (derecha) de una resistencia de $10^{4} \Omega$.

Un condensador es un dispositivo constituido por 2 armaduras metálicas separadas por un material dieléctrico, que son capaces de almacenar carga eléctrica. Se caracteriza por presentar una proporcionalidad directa entre el calor de potencial y carga almacenada. La impedancia asociada al condensador se expresa en la ecuación 3.8 .

$$
Z_{C}=\frac{1}{j \omega C}
$$

La impedancia de este elemento es un número puramente imaginario, función de la frecuencia de trabajo (Figura. 3.11). 

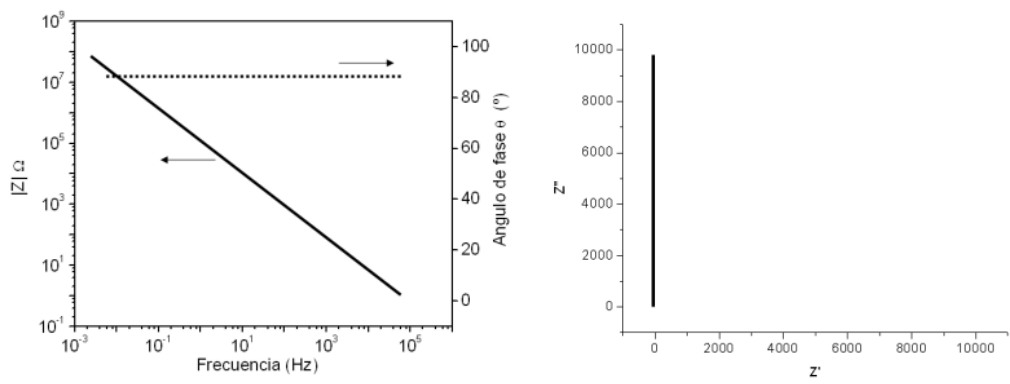

Figura. 3.11 Diagrama de Bode (izquierda) y diagrama de Nyquist (derecha) de una capacidad de $1 \mu \mathrm{F}$.

Las señales de respuesta de un circuito constituido por una resistencia en paralelo a un condensador se representan en la Figura. 3.12, cuyo valor de impedancia se rige por la ecuación 3.8. El valor de la capacidad se determina en el máximo de $Z$ ', $f_{\max }$ en el diagrama de Nyquist (ec 3.10 y 3.11).

$$
\begin{aligned}
& Z=\frac{R}{1+\omega^{2} C^{2} R^{2}}-\frac{\omega C R^{2}}{1+\omega^{2} C^{2} R^{2}} j \\
& C=\frac{1}{2 \pi f_{\text {max }} R} \\
& f_{\text {max }}=\frac{1}{2 \pi R C}=\frac{1}{2 \pi \tau}
\end{aligned}
$$
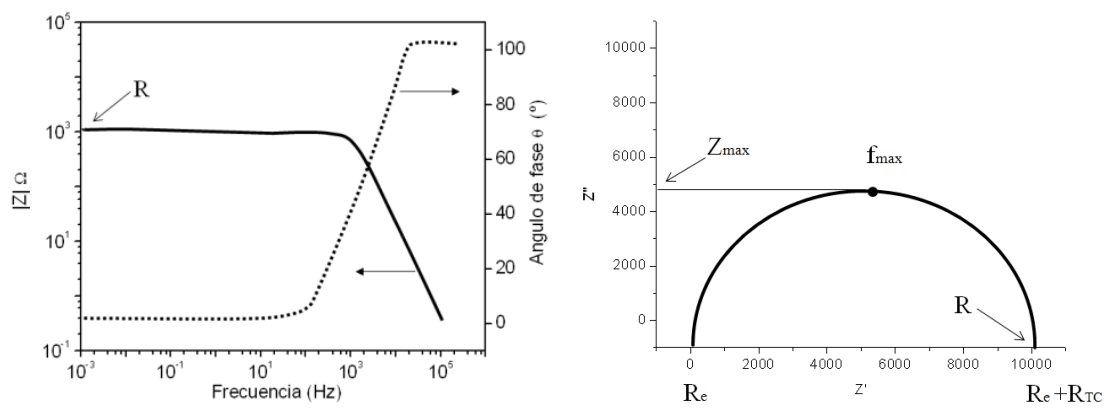

Figura. 3.12 Diagrama de Bode (izquierda) y diagrama de Nyquist (derecha) de un circuito RC en paralelo.

En la Figura. 3.12 se representa la respuesta de un sistema simple compuesto por una resistencia en paralelo con un condensador (que simula la intercara electrodo electrolito) que a su vez está en serie con una segunda resistencia. Este circuito fue compuesto por Randles y explica satisfactoriamente el comportamiento de un gran número de sistemas electroquímicos. 
$R_{e}$ representa la resistencia óhmica entre el electrodo de trabajo y el electrodo de referencia y engloba a la resistencia del electrolito y de películas superficiales (resistencia del cableado...). $C_{D L}$ es la capacidad de la doble capa electroquímica que se forma en la interfase electrodo/electrolito y, por último y en paralelo a $C_{D L}$ se encuentra $R_{T C}$, que será la resistencia de transferencia de carga ión/electrón.

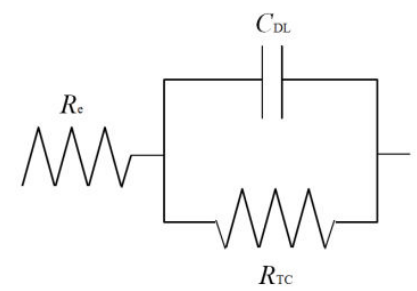

Figura. 3.13 Modelo del circuito equivalente simplificado propuesto por Randles.

Mediante el empleo de la técnica EIS no sólo se obtiene información sobre los aspectos cinéticos, relacionados con los procesos de corrosión que tienen lugar sobre la superficie del metal, sino también sobre los mecanismos de reacción que gobiernan dichos procesos que se deducen a partir de la forma del espectro.

El empleo de esta técnica experimental para evaluar las capacidades protectoras ante la corrosión de diversos tipos de recubrimientos, permite una observación más detallada y no destructiva de los procesos involucrados en el deterioro de dichas películas. Además de permitir un análisis cuantitativo de los datos experimentales, a través del cálculo de determinados parámetros que ayudan a la caracterización de la película (resistencia, capacidad, etc.). Sin embargo, la selección del circuito equivalente adecuado resulta a veces un proceso dificultoso que requiere de especial cuidado para evitar en toda medida el cálculo de resultados erróneos.

La heterogeneidad de los recubrimientos es otro factor a tener en cuenta, ya que la elevada sensibilidad de esta técnica normalmente deriva en la falta de reproducibilidad de los datos experimentales.

En la Figura. 3.14 se representa el circuito equivalente general empleado para el estudio del deterioro de los recubrimientos orgánicos aplicados sobre sustratos metálicos. 


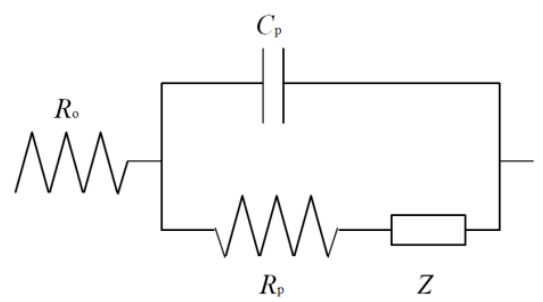

Figura. 3.14 Modelo del circuito equivalente general para metales pintados.

Donde $R_{o}$ representa la resistencia entre el electrodo de referencia y el de trabajo (metal pintado). Normalmente el electrolito empleado es muy conductor por lo que

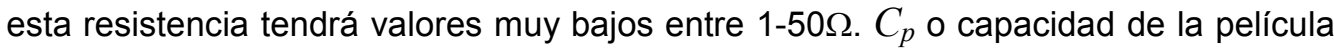
permite conocer la constante dieléctrica del recubrimiento mediante el empleo de la ecuación 3.12. Cabe destacar que también nos permite estudiar la absorción de agua de la película durante el proceso de deterioro teniendo en cuenta la relación de Brasher-Kinsbury (ec.3.13). Esta ecuación supone que la distribución del agua es aleatoria en toda la capa de recubrimiento, sin embargo, cuando la fracción de agua es elevada este parámetro es semicuantitativo.

$$
C_{p}=\frac{\varepsilon \cdot \varepsilon_{0} \cdot A}{d}
$$

Donde $\varepsilon$ es la constante dieléctrica, $\varepsilon_{0}$ es la permitividad del vacío $\left(8,854 \cdot 10^{-12}\right.$ $\mathrm{F} / \mathrm{m}), A$ es el área superficial del electrodo de trabajo y $d$ es la distancia entre el electrodo de referencia y el de trabajo.

$$
X_{V}(\%)=\frac{\log \left(\frac{C_{t}}{C_{0}}\right)}{\log \varepsilon_{H_{2} O} O} \cdot 100
$$

Donde $X_{v}$ es la fracción, en porcentaje, del volumen de agua que entra en la película, $C_{0}$ es la capacidad de la película al comienzo de la exposición, $C_{t}$ es la capacidad de la película al tiempo t, $\varepsilon_{\mathrm{H}_{2} \mathrm{O}}$ es la constante dieléctrica del agua pura (su valor es 80 a temperatura ambiente)

$R_{p}$ es la resistencia de los poros del recubrimiento al paso del electrolito, por ello, este parámetro se relaciona con la entrada de electrolito. Su valor disminuye a 
medida que aumenta el tiempo de exposición y se van creando más caminos a través del recubrimiento

$Z$ es la impedancia faradaica que hace referencia a los procesos electroquímicos que se producen en la interfase metal-recubrimiento. Los distintos modelos de circuitos equivalentes se diferencian entre sí, en función de los elementos por los que se sustituya $Z$. De esta forma, en la Figura. 3.15 se representa el modelo de circuito más ampliamente utilizado, que se emplea cuando el sistema está dominado por el proceso de transferencia de carga, donde $Z$ se sustituye por una capacidad en paralelo a una resistencia.

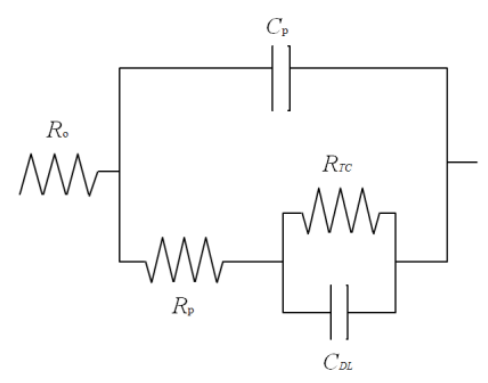

Figura. 3.15 Modelo de circuito equivalente para un sistema dominado por el proceso de transferencia de carga.

Donde $C_{D L}$ es la capacidad de la doble capa que se establece en la interfase metal-solución, y hace referencia a los procesos de corrosión originados debajo del recubrimiento. Permite conocer el área deslaminada del metal en contacto con el electrolito. $R_{T C}$ es la resistencia de la transferencia de carga, que está asociada a la cinética del proceso de corrosión.

b) Análisis de las propiedades anticorrosivas mediante espectroscopía de impedancia electroquímica

Con el fin de caracterizar las propiedades anticorrosivas de los recubrimientos obtenidos se han realizado medidas de espectroscopia de impedancia electroquímica (EIS). Se realizaron medidas a lo largo del tiempo desde el instante inicial hasta un total de 48 horas.

Los ensayos se han realizado con un equipo potenciostato - galvanostato IM6/6eX de Zahner - elektrik en control potenciostático y sobre el potencial libre de corrosión. 
Las medidas de impedancia se efectuaron aplicando barridos de frecuencias comprendidos entre $10 \mathrm{mHz}$ y $100 \mathrm{kHz}$. La amplitud de la señal sinusoidal aplicada ha sido de $\pm 10 \mathrm{mV}$, con un barrido logarítmico de 5 puntos por década y en el interior de una celda de Faraday para evitar interferencias ajenas a la experimentación.

Las muestras se montaron dentro de una celda electroquímica convencional, como la de la Figura. 3.16 Esta celda de medida permite la distribución de tres electrodos: un electrodo de referencia de $\mathrm{Ag} / \mathrm{AgCl}$, un contraelectrodo (hoja grafito de $10 \times 40 \times 5 \mathrm{~mm}$ ) y electrodo de trabajo (substrato metálico recubierto en estudio). Estos elementos se encuentran sumergidos en un medio acuoso denominado electrolito. En esta Tesis Doctoral se ha empleado una disolución $\mathrm{NaCl}$ al 3,5\% (en peso) que simula el agua de mar. Cabe destacar que el cloruro de sodio debe ser blanco, con una pureza mínima de 99'6 \% (en peso), prácticamente exento de cobre y níquel y con un contenido máximo de $0,1 \%$ (en peso) de yoduro sódico.

La celda se introduce dentro de una celda de Faraday y se conecta a las terminales correspondientes del potenciostato. Una vez programado el equipo electroquímico, la adquisición de los datos de medida es automática, gracias al software que acompaña al equipo. El tiempo total estimado para la ejecución de cada ensayo es de 25 minutos dependiendo de la estabilidad del potencia a cada frecuencia. 


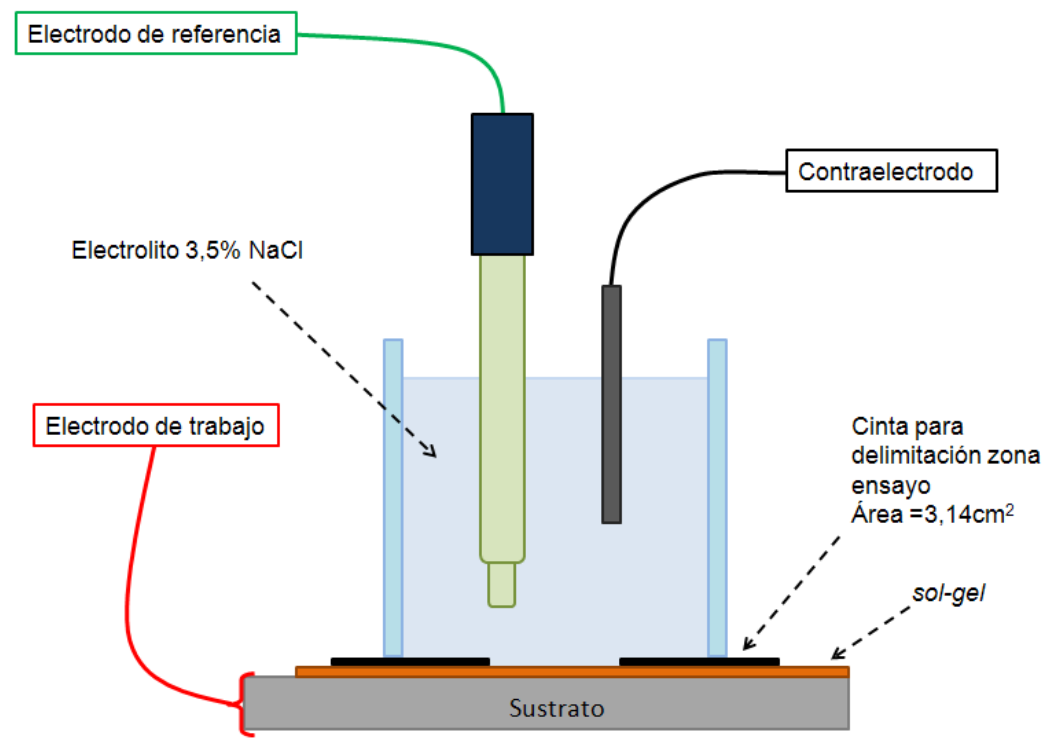

Figura. 3.16 Celda electroquímica de tres electrodos. Electrodo de referencia $(\mathrm{Ag} / \mathrm{AgCl})$, contraelectrodo (hoja grafito) y electrodo de trabajo (sustrato metálico).

\subsubsection{Medidas de ángulo de contacto}

Una propiedad importante de los materiales para aplicaciones biomédicas es la hidrofilia de las superficies, ya que de ella puede depender la absorción de proteínas en la superficie y por consiguiente el comportamiento celular. También es una propiedad que influye en los fenómenos de degradación y por tanto en la liberación de los agentes terapéuticos introducidos.

La medida comparativa de la hidrofilia/hidrofobia de los distintos films obtenidos se determina mediante la obtención del ángulo de contacto que se forma entre una gota de agua y el sustrato estudiado (Figura. 3.17). 


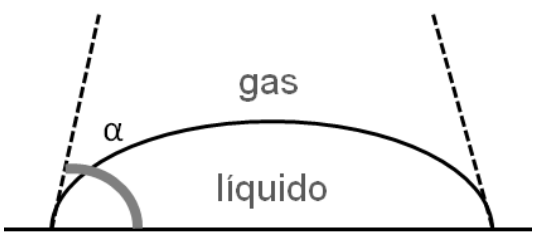

muestra

Figura. 3.17 Esquema de medida del ángulo de contacto entre un líquido y un material.

Para ello se ha utilizado un equipo DATAPHYSICS OCA20 que cuantifica el ángulo formado entre el perímetro de la gota dispensada y el recubrimiento. Los ensayos se realizaron con agua destilada a temperatura ambiente y con un volumen de gota constante de $10 \mu \mathrm{l}$. Se realizaron 11 replicas de medida por material.

\subsubsection{Estudios de liberación in vitro}

Los recubrimientos obtenidos se pueden emplear como sistemas de liberación controlada de fármacos. Esta propiedad puede resultar de gran importancia ya que la liberación local disminuye el riesgo de efectos secundarios derivados de la administración por vía oral, además puede mejorar la eficacia del medicamento al administrarse localmente en la zona dañada.

En el ensayo in vitro se intenta reproducir, de la forma más aproximada posible, las condiciones fisiológicas en las que va a tener aplicación el material. Así, se emplea un buffer de fosfato salino (PBS, siglas en inglés) para ajustar el medio de disolución al $\mathrm{pH}$ bucal, $\mathrm{pH}=6,8$, y se mantiene una temperatura constante de $37^{\circ} \mathrm{C}$. El PBS está preparado a partir de fosfato de sodio monobásico monohidratado $\mathrm{NaH}_{2} \mathrm{PO}_{4} \cdot \mathrm{H}_{2} \mathrm{O}$ (Sigma-Aldrich ref. S9638) y fosfato di-sodio 7-hidratado $\mathrm{Na}_{2} \mathrm{HPO}_{4} \cdot 7 \mathrm{H}_{2} \mathrm{O}$ (Panreac ref. 132656).

Para la realización del ensayo se toma un reactor de fondo semiesférico al que se le introducen $500 \mathrm{ml}$ de PBS a una temperatura de $37^{\circ} \mathrm{C}$ (temperatura mantenida por medio de baños termostatizados). La muestra se mantiene en agitación a una velocidad de $60 \mathrm{rpm}$ dentro del baño. Se toman muestras cada hora durante las primeras 8 horas de ensayo y a las 24,48 y 72 horas. La toma de muestra se hace tomando PBS de una zona equidistante entre la superficie del reactor y la parte 
inferior del cestillo. El volumen de muestra extraído es de $5 \mathrm{ml}$, y tras la extracción se añade $5 \mathrm{ml}$ de PBS nuevo.

La cantidad de principio activo liberado se determina mediante un espectrofotómetro UV (Helios-Omega) a una longitud de onda de 290nm, característica de la procaína. La cantidad de principio activo liberado en el medio se expresa como $M_{t} / M_{\infty}$, es decir, como la cantidad de fármaco liberado en cada tiempo por lo liberado a tiempo infinito (liberación total).

\subsubsection{Evaluación in vitro}

Los recubrimientos se han evaluado in vitro con el fin de conocer su comportamiento una vez dispuestos en contacto con células. Estos ensayos funcionales pueden indicar la idoneidad del recubrimiento para uso biomédico.

a) Esterilización y acondicionamiento de los materiales.

Todos los materiales deben ser esterilizados previamente al cultivo (independientemente del tipo celular). Para ello, los materiales se disponen sobre una superficie estéril y se exponen a radiación UV durante 30 minutos en cada una de sus caras.

Adicionalmente, se realiza un acondicionamiento de los materiales, consistente en sumergirlos en el medio de cultivo (en concordancia con el tipo celular) durante las 16 horas previas al cultivo, se retira el medio y se procede a la siembra normal sobre el material. Durante este acondicionamiento se produce una primera absorción de proteínas del medio sobre la superficie del material favoreciendo el posterior anclaje celular.

\section{b) Ensayo de citotoxicidad}

Los ensayos de toxicidad celular se han realizado siguiendo la norma ISO-10993. Esta norma regula los ensayos para determinar la toxicidad de productos y materiales sanitarios. En ella se describe el procedimiento para la realización de los ensayos de citotoxicidad por contacto directo con el material, por extractos y por contacto indirecto. De entre ellos se ha realizado el test de citotoxicidad por extractos que da 
una medida cuantitativa de la viabilidad celular. La línea celular utilizada es fibroblastos de ratón L-929 (European collection of cell cultures, ref. 85011425).

Para realizar el ensayo se incuban las L-929 (25.000 células/pocillo) a $37^{\circ} \mathrm{C}$ en recipientes sin muestra, utilizando como medio de cultivo Dulbelcco's Modified Eagles Medium (DMEM, Sigma) con 10\% Suero bovino fetal (SBF, Biochrom). Por otro lado, se obtiene un extracto de los materiales manteniéndolos sumergidos en medio de cultivo (DMEM + 10\%SBF) sin células 24 horas. Pasado este tiempo el extracto de los materiales se pipetea sobre los cultivos y se incuba durante 24,48 y 72 horas. Se determina cuantitativamente la toxicidad utilizando el Kit MTT (Roche). Para ello, transcurrido el tiempo de cultivo se añade el reactivo hasta obtener una concentración final de $0.5 \mathrm{mg} / \mathrm{ml}$, se incuban las células durante 24horas, se añade $100 \mu \mathrm{l}$ de solución "Solubilization" y se deja "overnight" (termino que indica un tiempo superior a 10 horas en reposo). Posteriormente se analiza con espectrofotométrico utilizando un lector multiplacas (multiskan Ascent) midiendo a una longitud $(\lambda)$ de $550 \mathrm{~nm}$.

El análisis MTT mide la viabilidad celular a través de su actividad metabólica. El MTT soluble en agua y de color amarillo se reduce metabólicamente en las células viables dando un producto de desecho (formazano) de color azul-violeta insoluble en agua. El número de células viables se correlaciona con la intensidad de color que se determina por mediciones fotométricas después de disolver el formazano en alcohol. Un descenso en el número de células vivas da como resultado un descenso en la actividad metabólica de las células. Para calcular la reducción de la viabilidad comparada con las células control se emplea la (ec. 3.14).

Viabilidad celular $\%=\frac{\text { DO muestra }}{\text { DO control }} \cdot 100$

Siendo DO550 Muestra ensayo el valor medio de la densidad óptica medida de los extractos de la muestra. DO550 Control es el valor medio de la densidad óptica medida del control (pocillo sin material).

Cuanto más bajo es el valor de Viabilidad \% tanto mayor es el potencial citotóxico del material analizado. Si la viabilidad se reduce $<70 \%$ en el período de tiempo analizado respecto al control se concluye que el material es citotóxico. 
Para la realización de este ensayo, se prepararon muestras de titanio liso $(12 \mathrm{~mm}$ diámetro, suministrado por llerimplant, S.L.) recubiertos con los materiales por el método de deposición dip-coating, siguiendo el protocolo descrito en 3. 1. En este caso no se realiza acondicionamiento de las muestras. El ensayo se realiza por triplicado.

c) Ensayo proliferación de fibroblastos L-929.

Se ha evaluado la capacidad in vitro de proliferación de osteoblastos sobre los biomateriales desarrollados. Se analizan dos condiciones experimentales. Por un lado, se estudia la proliferación de las células en adhesión sobre la placa de cultivo en condiciones normales de crecimiento $y$, por otro, se estudia la proliferación celular sobre los biomateriales dispuestos en una placa de plástico antiadherente de manera que impida la adhesión y crecimiento celular en el soporte de plástico. Se han utilizado fibroblastos de ratón L-929 (European collection of cell cultures, ref. 85011425)

Para realizar el ensayo se incuban las células L-929 (25.000 células/pocillo) a $37^{\circ} \mathrm{C}$ sobre los materiales, utilizando como medio de cultivo $1 \mathrm{ml}$ de Dulbelcco's Modified Eagles Medium (DMEM, Sigma) con 10\% Suero bovino fetal (SBF, Biochrom), durante 24, 48 y 72 horas. Se determina cuantitativamente la actividad mitocondrial utilizando el Kit MTT (Roche). Para ello, transcurrido el tiempo de cultivo se añade el reactivo hasta obtener una concentración final de $0.5 \mathrm{mg} / \mathrm{ml}$, se incuban las células durante 24 horas, se añade $100 \mu \mathrm{l}$ de solución "Solubilization" y se deja "overnight". Posteriormente se analiza con espectrofotométrico utilizando un lector multiplacas (Multiskan Ascent) midiendo a una longitud $(\lambda)$ de $550 \mathrm{~nm}$.

Para la realización de este ensayo, se prepararon muestras de titanio liso (12mm diámetro, llerimplant) recubiertas con los materiales por el método de deposición dipcoating, siguiendo el protocolo descrito en 3. 1. En este caso no se realiza acondicionamiento de las muestras. 
d) Ensayo de proliferación de osteoblastos

Se ha evaluado la capacidad in vitro de proliferación de osteoblastos sobre los biomateriales desarrollados. Se analizan dos condiciones experimentales. Por un lado, se estudia la proliferación de las células en adhesión sobre la placa de cultivo en condiciones normales de crecimiento $\mathrm{y}$, por otro, se estudia la proliferación celular sobre los biomateriales dispuestos en una placa de plástico antiadherente de manera que impida la adhesión y crecimiento celular en el soporte de plástico. Los osteoblastos utilizados están obtenidos de tejido óseo humano por la empresa Histocell S.L..

Para realizar el ensayo se incuban los osteoblastos (25.000 células/pocillo) a $37^{\circ} \mathrm{C}$ sobre los materiales, utilizando como medio de cultivo $1 \mathrm{ml}$ de Osteoblast Growth Medium (Promocell), durante 1 día, 7 y 15 días. Se determina cuantitativamente la actividad mitocondrial utilizando el Kit MTT (Roche). Para ello, transcurrido el tiempo de cultivo se añade el reactivo hasta obtener una concentración final de $0.5 \mathrm{mg} / \mathrm{ml}$, se incuban las células durante 24 horas, se añade $100 \mu$ de solución "solubilization" y se deja "overnight". Posteriormente se analiza con espectrofotométrico utilizando un lector multiplacas (Multiskan Ascent) midiendo a una longitud $(\lambda)$ de $550 \mathrm{~nm}$.

Para la realización de este ensayo, se prepararon muestras de titanio liso (12mm diámetro, llerimplant) recubiertos con los materiales por el método de deposición dipcoating, siguiendo el protocolo descrito en 3 . 1. Se realiza acondicionamiento de las muestras. Cada uno de los materiales se ha ensayado por triplicado, y al mismo tiempo, de cada uno de los triplicados se ha tomado muestras por cuadriplicado de la medida de absorbancia

e) Ensayo de proliferación de células mesenquimales del tejido adiposo humano

Se ha evaluado la capacidad in vitro de proliferación de las AMSCss sobre los biomateriales desarrollados. Se estudia la proliferación de las células en adhesión sobre la placa de cultivo (soporte plástico) en condiciones normales de crecimiento y, por otro lado, se estudia la proliferación de las AMSCss sobre los biomateriales. Las AMSCss utilizadas en este estudio están obtenidas de tejido adiposo humano por la empresa Histocell S.L.. 
Para realizar el ensayo se incuban las AMSCss (47.500 células/pocillo) a $37^{\circ} \mathrm{C}$ sobre los materiales, utilizando como medio de cultivo 1,5 ml de DMEM - Glutamax (Gibco), durante 1 día, 7 y 14 días. Se determina cuantitativamente la actividad mitocondrial utilizando el Kit MTT (Roche). Para ello, transcurrido el tiempo de cultivo se añade el reactivo hasta obtener una concentración final de $0.5 \mathrm{mg} / \mathrm{ml}$, se incuban las células durante 24horas, se añade $100 \mu$ l de solución "solubilization" y se deja "overnight". Posteriormente se analiza con espectrofotométrico utilizando un lector multiplacas (Multiskan Ascent) midiendo a una longitud $(\lambda)$ de 550nm.

Para la realización de este ensayo, se prepararon muestras de vidrio $(12 \mathrm{~mm}$ diámetro, portas vidrio Marienfeld $\mathrm{GmbH} \&$ Co.KG) recubiertos con los materiales por el método de deposición solving-casting, siguiendo el protocolo descrito en 3. 1. Se realiza acondicionamiento de las muestras. Cada uno de los materiales se ha ensayado por triplicado, y al mismo tiempo, de cada uno de los triplicados se ha tomado muestras por cuadriplicado de la medida de absorbancia

f) Ensayo de diferenciación de células mesenquimales del tejido adiposo humano a osteoblastos. Rojo alizarina.

Se ha evaluado la capacidad osteogénica de las AMSCss dispuestas sobre los biomateriales mediante la cuantificación de los depósitos de calcio formados por las AMSCss diferenciadas a células óseas en un medio de diferenciación osteogénico. Se estudia la osteogénesis de las AMSCss sobre los biomateriales cultivados con el medio de diferenciación a células de hueso. Las AMSCss utilizadas en este estudio están obtenidas de tejido adiposo humano por la empresa Histocell S.L.

Para realizar el ensayo se incuban las AMSCss (7.600 células/pocillo) a $37^{\circ} \mathrm{C}$ sobre los materiales, utilizando como medio de cultivo 1,5 ml de DMEM - Glutamax (Gibco) con 10\% FBS, durante 7 días. Transcurridos estos 7 días de cultivo, las células se cultivan con medio de diferenciación osteogénico StemPro. Osteoblast Differentiation médium (Gibco) durante 14 días más, renovando el medio cada 72-96 horas. Finalmente, a los 7 y 14 días de cultivo diferenciador, el calcio extracelular producido se analiza mediante Rojo Alizarina (Sigma-Aldrich). Para ello se lava el cultivo con PBS, se fijan las células con formaldehido al $10 \%$, se lavan de nuevo con PBS. Se procede a la tinción con Rojo Alizarina al 2\% con pH 4,1-4,3 durante 15 min en oscuridad, se lava con AguaMiliQ. Se realizan las fotos con el microscopio óptico. 
Extracción del rojo alizarina con cloruro de cetilpiridinio durante 3 horas a RT con agitación. Analizar con espectrofotométrico utilizando un lector multiplacas (Multiskan Ascent) midiendo a una longitud $(\lambda)$ de $570 \mathrm{~nm}$. 
Capítulo 4 Selección del precursor base para aplicaciones biomédicas 

En este capítulo se realiza la selección de aquellos precursores que serán la base para la síntesis de recubrimientos con propiedades moduladas y distintos tipos de funcionalidades para su aplicación en implantes dentales. La metodología a llevar a cabo consistirá en fabricar series de recubrimientos a partir de distintos precursores y realizar su caracterización fisicoquímica, mecánica y biológica a fin de determinar aquellos que puedan cumplir mejor con los requisitos de la aplicación (osteoinducción, capacidad de reabsorción, adherencia al substrato, posibilidad de poder ser funcionalizados, etc.) Así se presentan las propiedades de los recubrimientos obtenidos a partir de precursores de silicio tales como MTMOS, VTES y GPTMS. Se comprobó en primer lugar la formación de recubrimiento y su morfología sobre la superficie metálica a nivel macro así como micrométrico por medio de SEM. Se caracteriza la formación de red con los parámetros de síntesis utilizados por medio de RMN de líquidos y se caracteriza químicamente la red formada por medio de FTIR y RMN en sólido. Con el fin de profundizar en el conocimiento de la estructura de las redes formadas se realiza un estudio de DSC para obtener la $T_{g}$ de los materiales y se caracteriza la degradación térmica por TGA.

Para evaluar la adecuación de estos materiales a aplicaciones biomédicas se realizaron ensayos de citotoxicidad bajo la norma ISO-10993. Se realizó, adicionalmente, un ensayo de proliferación de fibroblastos de la línea L-929 y de proliferación de osteoblastos humanos sobre los recubrimientos aplicados en titanio.

Finalmente, a partir de las propiedades de los recubrimientos formulados y de su adecuación a los requisitos fisicoquímicos y biológicos, se realiza la selección del recubrimiento ( $\mathrm{y}$ por tanto del precursor) óptimo, en este caso el VTES, para posteriormente, utilizarlo como precursor base para la obtención de distintos tipos de recubrimientos con propiedades moduladas. Las series de materiales con propiedades moduladas se obtienen a partir del material base, que se seleccionará en el presente capítulo, introduciendo por mezcla dos tipos de precursores: el TEOS (que consigue disminuir la temperatura de curado y el ángulo de contacto, así como aumentar la degradabilidad) y el GPTMS (fundamentalmente para aumentar el número de grupos epoxi presentes y permitir un mayor número de enlaces con distintos tipos de péptidos o proteínas). 


\section{1 Síntesis de los materiales a partir de los precursores MTMOS, VTES y GPTMS}

Se han sintetizado tres recubrimientos distintos partiendo de los precursores MTMOS, VTES y GPTMS utilizando las condiciones de síntesis descritas en 3.1.2. En todos los casos se ha obtenido un sol transparente y sin precipitados, con una viscosidad adecuada para obtener una correcta aplicación sobre el metal.

A la hora de obtener recubrimientos sobre metales es importante que recubran toda la superficie y que no presenten imperfecciones como grietas o poros derivadas de las condiciones aplicadas en el curado. Todos los recubrimientos se han aplicado de manera homogénea en toda la superficie, dando como resultado una película continua y sin imperfecciones (Figura. 4.1(izq.)). Se comprueba el acabado de los recubrimientos aplicados sobre metal mediante una prueba que consiste en comparar visualmente la reflexión de un rayo luminoso y la formación de la imagen en la superficie, obteniéndose que los recubrimientos son transparentes y tienen un acabado brillante en todos los casos, con una reflexión tipo espejo (Figura. 4.1 (dcha.)).
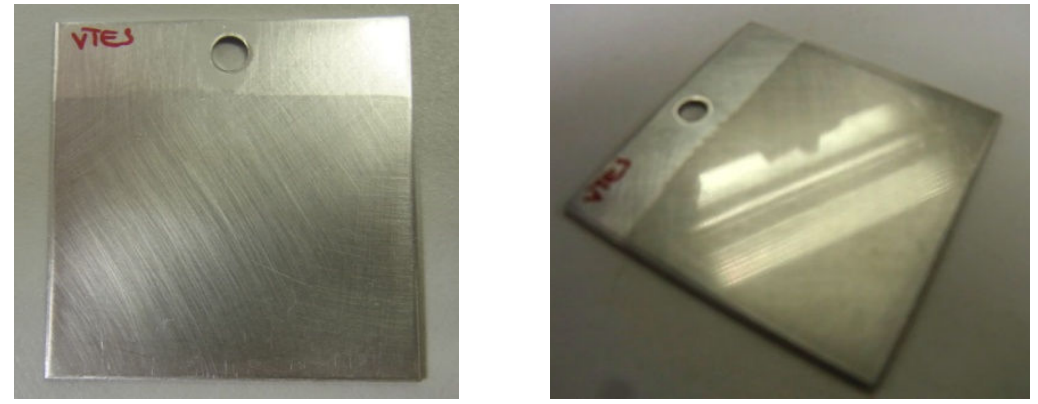

Figura. 4.1 (Izq.) Ejemplo de plancha recubierta con el recubrimiento VTES mediante la técnica dip-coating. (Dcha.) reflejo tipo espejo sobre la superficie del recubrimiento VTES.

Por otro lado, se ha caracterizado la adherencia de los recubrimientos al metal por medio de la técnica de corte enrejado. Se han obtenido para todos los casos recubrimientos adherentes, sin desprendimiento del recubrimiento en ningún caso.

Para comprobar las características superficiales micrométricas de los materiales obtenidos se evaluó con SEM la superficie de los recubrimientos aplicados sobre acero AISI 316L (Figura. 4.2). 

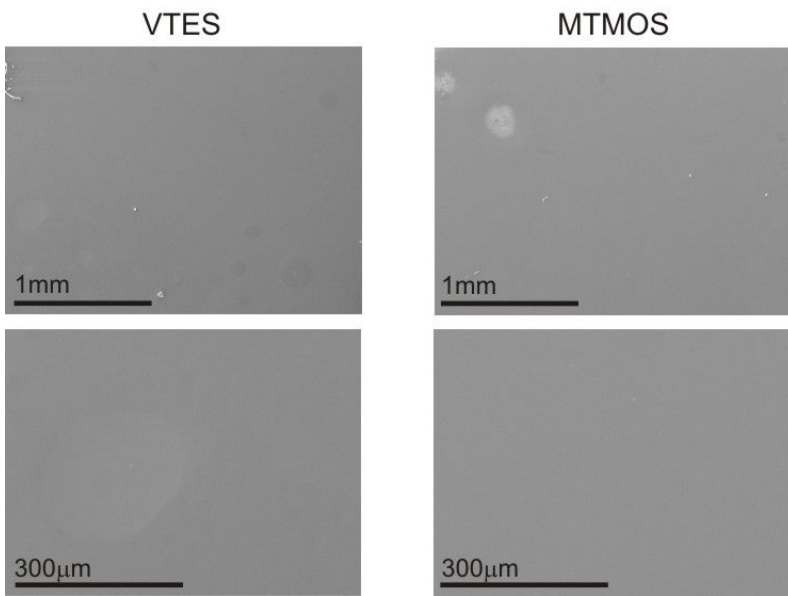

GPTMS

Figura. 4.2 Micrografías obtenidas con SEM de los recubrimientos VTES, MTMOS y GPTMS aplicados sobre acero $316 \mathrm{~L}$ (primera fila a 50X aumentos, segunda fila a 200X aumentos).

Las imágenes muestran para todas las formulaciones obtenidas con cada precursor (MTMOS, VTES y GPTMS) recubrimientos homogéneos, continuos, sin grietas ni poros.

Además, se han conseguido obtener de cada recubrimiento muestras en forma de película libre (sin sustrato) con un espesor aproximado de $1 \mathrm{~mm}$ como se muestran en la Figura. 4.3. Estas películas se obtienen vertiendo una cantidad apropiada de sol (especificada en 3.1.3) en moldes de teflón y se aplica el mismo tratamiento de curado que el aplicado en las planchas metálicas. Posteriormente se desmoldan y se obtienen películas consistentes y no presentan grietas ni poros. Estas películas libres se utilizarán para la caracterización del material en aquellos experimentos en los que no se pueda utilizar el material como recubrimiento aplicado en metal, como por ejemplo en técnicas calorimétricas o en algunas propiedades mecánicas.

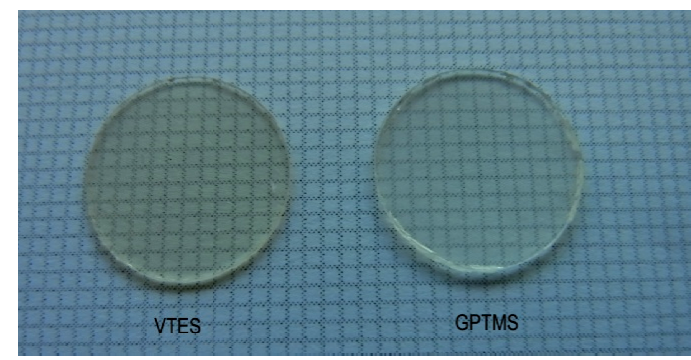

Figura. 4.3 Ejemplo de los recubrimientos en película libre obtenidos a partir de los precusores VTES y GPTMS. 


\section{2 Caracterización química de los recubrimientos}

Para la obtención de este tipo de materiales, tal y como se explicó en 1.4 se parte de precursores de silicio de formula $\mathrm{X}^{\prime} \mathrm{Si}(\mathrm{OX})_{3}$ donde $\mathrm{X}$ es una cadena metil o etil en los precursores que en esta Tesis Doctoral se presentan. Esta ramificación OX tiene capacidad para hidrolizarse en presencia de agua y un catalizador (en nuestro caso ácido nítrico), dando lugar a un grupo hidroxi $\mathrm{OH}$ y posteriormente condensar, para formar la cadena polisiloxánica Si-O-Si. Estas reacciones se pueden estudiar por medio de distintas técnicas de caracterización química como son la resonancia magnética nuclear del átomo de ${ }^{29} \mathrm{Si}\left({ }^{29} \mathrm{Si}-\mathrm{RMN}\right)$, tanto en líquidos como en sólidos, y la espectroscopia de infrarrojos con transformada de Fourier (FTIR). Se han utilizado estas técnicas para fijar parámetros de síntesis como pueden ser el tiempo de reacción para la hidrólisis y condensación de los precursores, o las condiciones de curado óptimas para la formación de la red polisiloxánica. Por otro lado, las técnicas de caracterización química permiten caracterizar las cadenas orgánicas presentes en los precursores de silicio $X^{\prime}$ y si éstas se ven afectadas durante la reacciones de síntesis de la red sol-gel. Se presentan los resultados para dos técnicas: ${ }^{29}$ Si-RMN y FTIR.

a) Resonancia magnética nuclear de silicio ( ${ }^{29}$ Si-RMN)

La formación de la red de sol-gel depende de las reacciones de condensación de $\mathrm{Si}-\mathrm{OH}$ (obtenidos tras la hidrolisis de los grupos alcóxidos de los precursores) para formar enlaces Si-O-Si. Dependiendo de diversos factores como el $\mathrm{pH}$, la relación molar agua:precursor y la duración y condiciones establecidas en la reacción de hidrólisis y condensación se obtendrán redes más o menos entrecruzadas.

En nuestro caso, el pH utilizado ha sido 1 y se ha mantenido constante en todos los casos. La cantidad de agua añadida para la hidrólisis ha sido la estequiométrica para la hidrólisis de todos las grupos alcoxi (OX).

Se busca optimizar el tiempo de hidrólisis/condensación de cada uno de los precursores con el fin de obtener sistemas con el máximo grado de condensación. Para ello, se ha estudiado por medio de RMN en líquidos el proceso de hidrólisis y condensación durante las dos primeras horas tras la adición del agua acidificada promotora de estas reacciones. 
El proceso de hidrólisis se ha seguido mediante el uso de la técnica RMN en líquidos del núcleo ${ }^{29} \mathrm{Si}$. Este tipo de espectroscopia permite estudiar el entorno de los átomos de silicio de los sistemas, es decir, permite obtener información acerca del grado de hidrólisis y entrecruzamiento. Como los precursores tienen 3 grupos hidrolizables en el caso del MTMOS, VTES, GPTMS, y cuatro en el caso del TEOS, se deben esperar picos de desplazamientos químicos tipo $\mathrm{T}^{\mathrm{n}}$ entre -40 y $-80 \mathrm{ppm}$ y tipo $Q^{n}$ entre -80 y -120 [105].

Las señales tipo $T$ corresponden a átomos de silicio que están enlazados directamente a un grupo orgánico, quedando solamente 3 posibilidades de unión por puentes de oxigeno con otros átomos de silicio. El superíndice se refiere al número de uniones a otros átomos de silicio a través de puentes siloxanos, y puede ser como máximo igual a 3 (Figura. 4.4). Si un átomo de silicio se une por un oxigeno a otro grupo distinto como, por ejemplo, a un grupo $\mathrm{OH}$ para dar un silanol (hidrólisis) o a un grupo orgánico formando un alcóxido, el número " $n$ " es tantas veces menor como número de enlaces tenga. Así, una señal $\mathrm{T}^{3}$ se asocia a átomos de silicio que están unidos mediante puente siloxano a tres átomos de silicio.<smiles>[R][Si]([O])([O])O[Na]</smiles>

$\mathbf{T}_{\mathbf{0}}$<smiles>[R][Si]([O])([O])[O]</smiles>

$\mathrm{T}_{1}$<smiles>[R][Si]([O])([O-])[O-]</smiles>

$\mathbf{T}_{2}$<smiles>[R][Si]([O-])([O-])[O-]</smiles>

$\mathbf{T}_{3}$

Figura. 4.4 Nomenclatura seguida en RMN para el estudio de los precursores GPTMS, VTES y MTMOS.

En el caso de evaluar el precursor TEOS que tiene 4 grupos alcoxi hidrolizables la señal es tipo Q. En esta situación el átomo de silicio puede unirse por puente siloxano a 4 átomos de silicio (Figura. 4.5). 
<smiles>[O][Si]([O])([O-])O[Na]</smiles>

$\mathbf{Q}_{0}$<smiles>[O][Si]([O-])([O-])[O-]</smiles>

$\mathbf{Q}_{1}$<smiles>[O-][Si]([O-])([O-])[Os]</smiles>

$\mathbf{Q}_{2}$<smiles>[O-][Si]([O-])(O)[Os]</smiles>

$\mathbf{Q}_{3}$<smiles>[O-][Si]([O-])([O-])O</smiles>

$\mathbf{Q}_{4}$

Figura. 4.5 Nomenclatura seguida en RMN para el estudio del precursor TEOS.

Inicialmente se ha obtenido el espectro correspondiente a los diferentes alcoxisilanos disueltos únicamente en isopropanol. Posteriormente se registraron los espectros en el instante inicial tras haber añadido el agua acidificada (20minutos tras la adición) y tras 1 y 2 horas de de la adición. En la Figura. 4.6 se muestran los espectros de ${ }^{29} \mathrm{Si}-\mathrm{RMN}$ en líquidos obtenidos durante las reacciones de hidrólisis/condensación del precursor TEOS, en la Figura. 4.7 las del precursor MTMOS, en la Figura. 4.8 las del VTES y en la Figura. 4.9 las correspondientes a GPTMS.

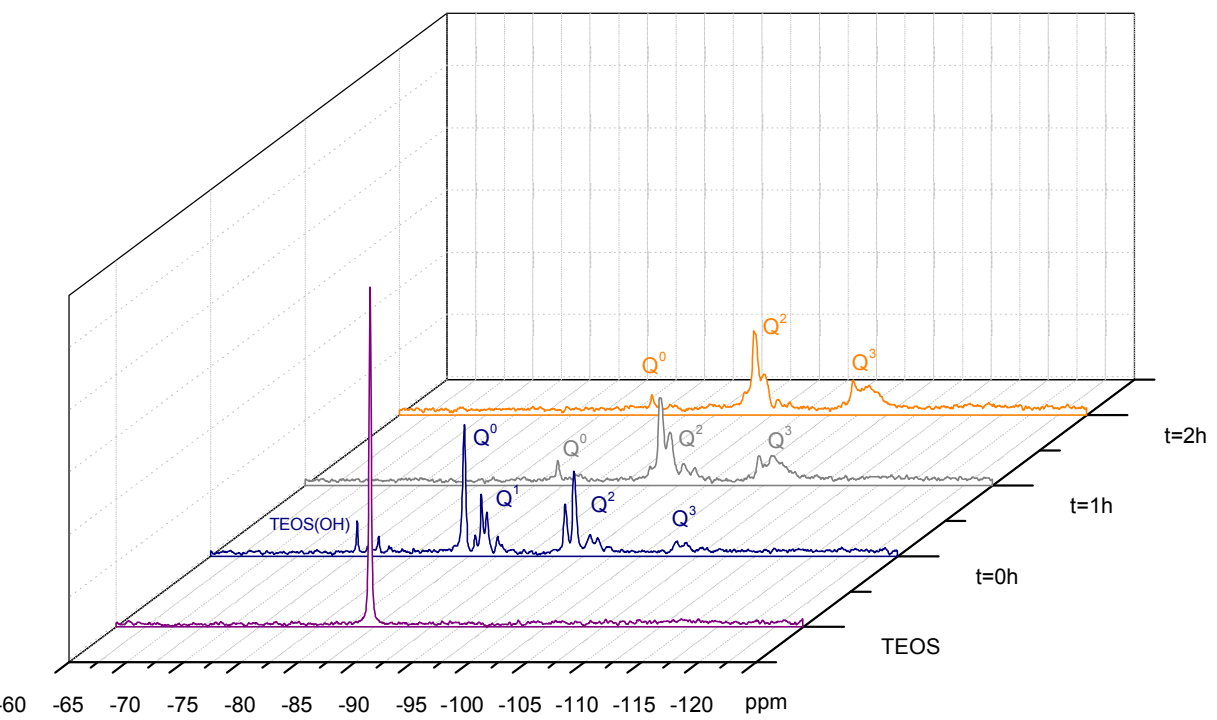

Figura. 4.6 Espectro ${ }^{29} \mathrm{Si}-\mathrm{RMN}$ liquido de TEOS

El espectro de la mezcla del precursor TEOS con el alcohol muestra un desplazamiento químico a $-82 \mathrm{ppm}$. Al adicionar el agua $(\mathrm{t}=0)$ se detecta un pico a 72ppm correspondiente a la presencia de especies hidrolizadas. Se detectan 
igualmente picos de desplazamientos de especies $Q^{0}, Q^{1}, Q^{2}$ y $Q^{3}$, cuyos valores se resumen en la Tabla 4.3. Pasada 1 hora tras la adición del agua desaparece el pico asociado a especies hidrolizadas y disminuye la intensidad del pico asociado a $Q^{0}$ y $Q^{1}$ desaparece, aumentando la intensidad relativa del pico $Q^{3}$. A las 2 horas ha aumentando la intensidad relativa del pico $Q^{2}$ y $Q^{3}$, disminuyéndose a su vez la intensidad del pico $Q^{0}$. Se ha producido una buena hidrólisis y condensación del precursor con las condiciones de síntesis utilizadas, llegándose a detectar especies $Q^{3}$.

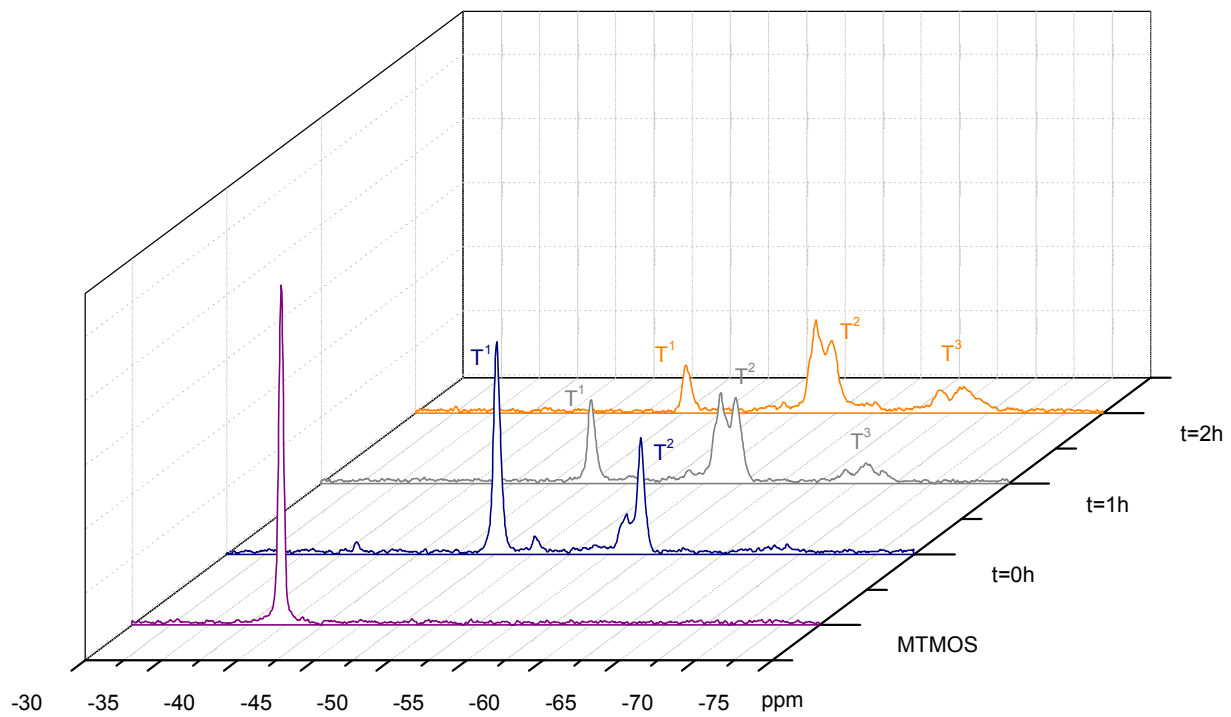

Figura. 4.7 Espectro ${ }^{29} \mathrm{Si}-\mathrm{RMN}$ liquido de MTMOS

En este caso el pico de desplazamiento de la mezcla del precursor MTMOS con el alcohol se encuentra a $-39 \mathrm{ppm}$. En el instante inicial $(\mathrm{t}=0)$ se detectan picos de desplazamientos de especies $\mathrm{T}^{1}, \mathrm{~T}^{2}$ cuyos valores se resumen en la Tabla 4.1. Pasada 1 hora tras la adición del agua disminuye la intensidad del pico asociado a $\mathrm{T}^{1}$ y aumenta la intensidad relativa del pico $\mathrm{T}^{2}$ y aparece el pico de desplazamiento asociado a especies $\mathrm{T}^{3}$. A las 2 horas prácticamente no se ven diferencias en el espectro, tan solo una ligera disminución del pico $\mathrm{T}^{1} \mathrm{y}$ un aumento del pico $\mathrm{T}^{3}$. El precursor MTMOS consigue, con las condiciones fijadas y a 1 hora del inicio de la reacción, establecer los primeros enlaces para la formación de la red de silicio. 


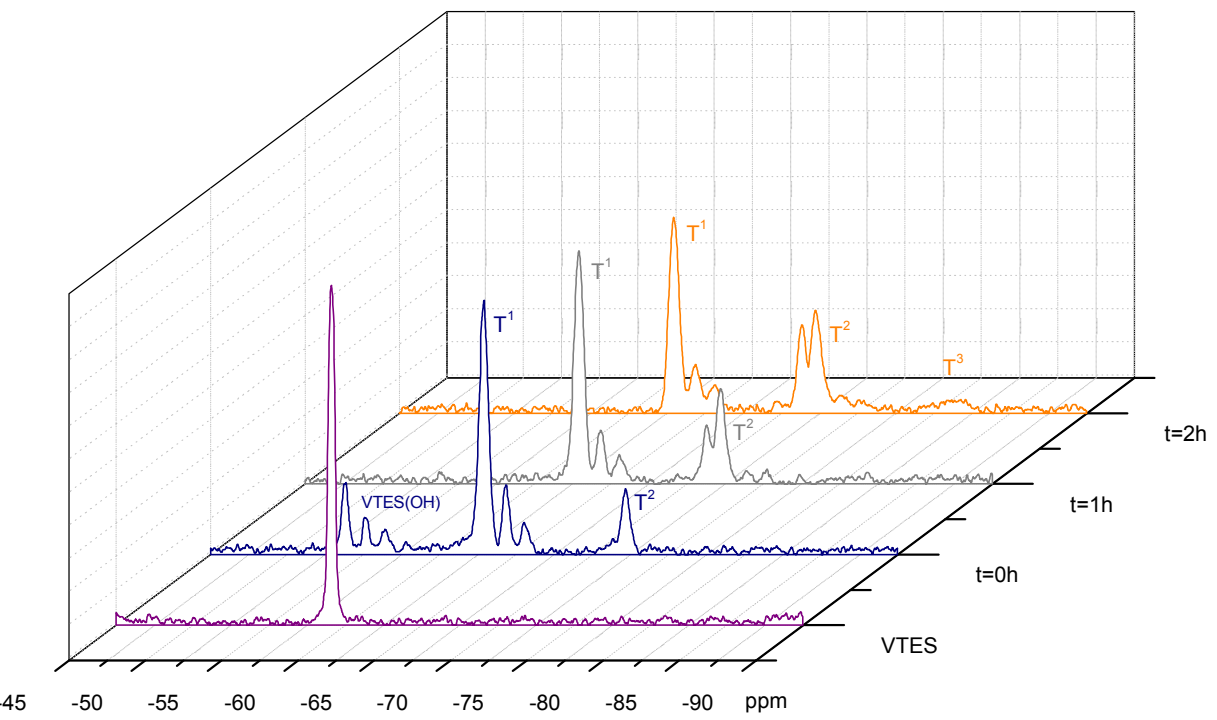

Figura. 4.8 Espectro ${ }^{29} \mathrm{Si}-\mathrm{RMN}$ liquido de VTES

El pico de desplazamiento de la mezcla del precursor VTES con el alcohol se encuentra a $-59 \mathrm{ppm}$. En el instante inicial $(\mathrm{t}=0)$ se detectan picos de desplazamientos de especies hidrolizadas y picos asociados a especies $T^{1}, T^{2}$ cuyos valores se resumen en la Tabla 4.3. Pasada 1 hora tras la adición del agua desaparece el pico de especies hidrolizada y se registra una ligera disminución de la intensidad relativa del pico asociado a $T^{1}$. Se produce un aumento considerable de la intensidad relativa del pico $T^{2}$. A las 2 horas de la adición del agua aparece el pico de desplazamiento asociado a especies $\mathrm{T}^{3}$ y una disminución del pico $\mathrm{T}^{1}$. Se ha conseguido una correcta hidrólisis del precursor VTES y a las dos horas del comienzo de las reacciones de hidrólisis y condensación se detectan especies entrecruzadas tipo $\mathrm{T}^{2}$ y $\mathrm{T}^{3}$. 


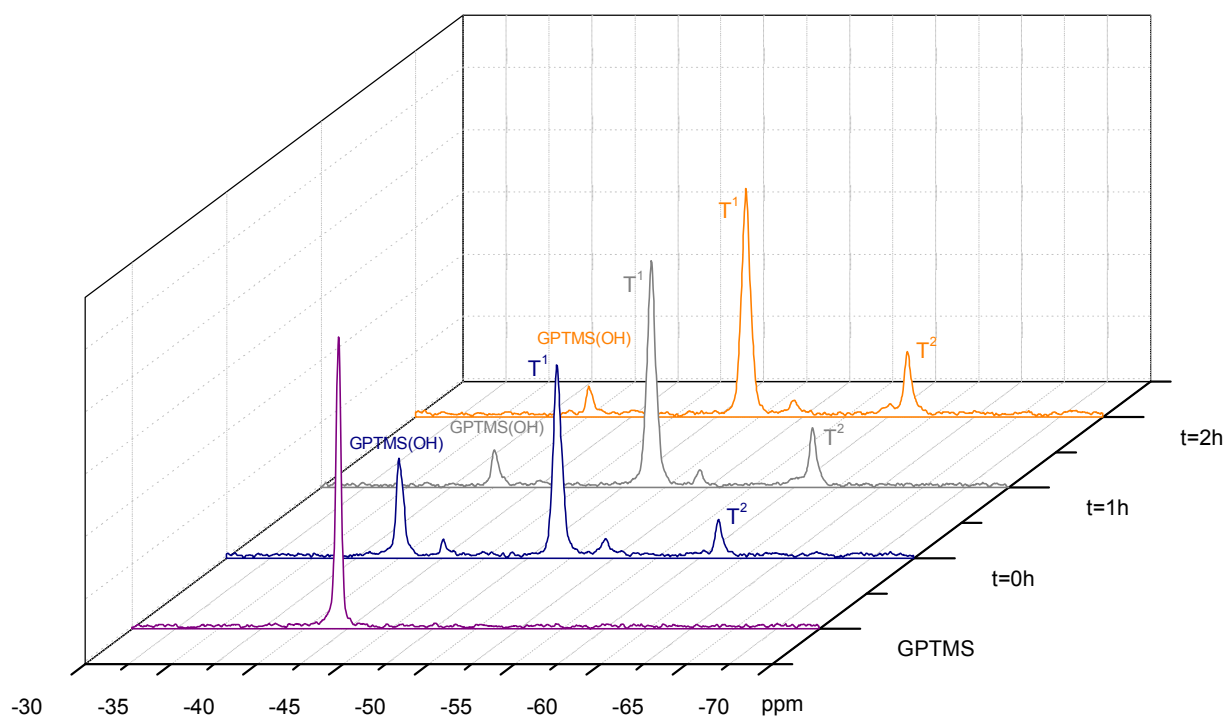

Figura. 4.9 Espectro ${ }^{29} \mathrm{Si}-\mathrm{RMN}$ liquido de GPTMS

En el caso del precursor GPTMS, la mezcla de éste con alcohol produce un pico de desplazamiento a $-41 \mathrm{ppm}$. En el instante inicial $(\mathrm{t}=0)$ se detectan, con una intensidad relativa alta, picos de desplazamientos de especies hidrolizadas y picos asociados a especies $T^{1}, T^{2}$ cuyos valores se resumen en la Tabla 4.1. Pasada 1 hora tras la adición del agua disminuye la intensidad del pico de especies hidrolizadas y se registra un ligero aumento de la intensidad relativa del pico asociado a $\mathrm{T}^{1} \mathrm{y} \mathrm{T}^{2}$. A las 2 horas de la adición del agua no se observan cambios apreciables en el espectro registrado, probablemente debido a que las posibilidades de enlaces de esta red en medio acuoso se han completado.

Tabla 4.1 Valores del desplazamiento químico de las señales de ${ }^{29} \mathrm{Si}-\mathrm{RMN}$ líquidos.

\begin{tabular}{|c|c|c|c|c|c|c|c|c|c|}
\hline Form & \multicolumn{8}{|c|}{ Desplazamiento } \\
\hline & & $\mathrm{OH}$ & $\mathrm{Q}^{0}$ & $\mathrm{Q}^{1}$ & $\mathrm{Q}^{2}$ & $\mathrm{Q}^{3}$ & $\mathrm{~T}^{1}$ & $\mathrm{~T}^{2}$ & $\mathrm{~T}^{3}$ \\
\hline TEOS & -82 & -72 & -82 & -84 & -91 & -100 & - & - & - \\
\hline MTMOS & -39 & $-37^{*}$ & - & - & - & - & -47 & -57 & -65 \\
\hline VTES & -59 & -53 & - & - & - & - & -63 & -72 & -81 \\
\hline GPTMS & -41 & -40 & - & - & - & - & -49 & -58 & - \\
\hline
\end{tabular}


Al tratarse de una hidrólisis ácida, tal y como se mencionó en la introducción, se produce rápidamente la hidrólisis de uno de los grupos alquil del precursor, teniendo este alcóxido una mayor tendencia a condensar que a hidrolizar de nuevo.

Cuando se analiza la hidrólisis del MTMOS, VTES y GPTMS se observa esta secuencia de reacciones típicas de las reacciones ácidas. Para el instante $t=0$ el espectro muestra a una señal predominantemente $\mathrm{T}^{1}$, al tener una mayor tendencia a condensar que a hidrolizar de nuevo, la señal $(\mathrm{OH})$ asociada a especies que no han condensado pero sí hidrolizado es más débil. Tras 1 hora de hidrólisis se promueven reacciones de hidrólisis y condensación de otro de los alquil hidrolizables, haciendo que la intensidad relativa de la señal $\mathrm{T}^{2}$ aumente. Es importante remarcar que pasada la primera hora de reacción no se observan cambios significativos en los espectros registrados. No llegan a registrarse señales tipo $\mathrm{T}^{3}$ asociadas al máximo entrecruzamiento.

En el caso del TEOS, el comportamiento es algo diferente. Para el instante inicial $(t=0)$ se observa señal asociada a especies hidrolizadas TEOS $(\mathrm{OH})$, las especies predominantes son $Q^{0}$ y $Q^{1}$ aunque se observan picos asociados a las especies tipo $Q^{2}$ y $Q^{3}$ mostrando que el proceso de hidrólisis y condensación es muy rápido con el $\mathrm{pH}$ seleccionado. Con el paso del tiempo el proceso de hidrólisis y condensación continua, observándose un aumento en la intensidad de las bandas tipo $Q^{2}$ y $Q^{3}$. No se observan señales tipo $Q^{4}$ de máximo entrecruzamiento. En este caso, tras dos horas siguen observándose cambios en los espectros de RMN. Al tratarse de un precursor que forma una red totalmente inorgánica, frágil y que se caracteriza por curar a temperatura ambiente se decidió que una hora era un tiempo razonable para que se produzcan las reacciones de hidrólisis y condensación sin un aumento excesivo de la viscosidad que impediría una correcta aplicación de la película sobre el metal.

El proceso de hidrólisis se establece en todos los sistemas a un tiempo fijo de una hora ya que no se aprecian cambios significativos en las intensidades relativas de los picos registrados. En el MTMOS, VTES y GPTMS se aprecia de forma clara como después del proceso de hidrólisis el avance de la condensación es muy pequeño (señales de entornos tipo $\mathrm{T}^{2} \mathrm{y} \mathrm{T}^{3}$ ) siendo necesaria la aplicación de un proceso de secado/curado con temperatura para asegurar la formación de la red. En el caso del 
TEOS las reacciones de hidrólisis y condensación evolucionan con el paso del tiempo, sin embargo se fijan como en el resto de recubrimientos en 1 hora para evitar el aumento de la viscosidad y permitir una correcta la aplicación del recubrimiento sobre la superficie a recubrir.

También se han estudiado los materiales obtenidos tras la aplicación del tratamiento de curado (donde realmente se dan los procesos de condensación para la formación de red polisiloxánica) mediante RMN de sólidos del núcleo de ${ }^{29} \mathrm{Si}$. El tratamiento de curado se aplica para permitir la evaporación de los disolventes incorporados así como promover las reacciones de condensación. Se ha registrado en los espectros ${ }^{29} \mathrm{Si}-\mathrm{RMN}$ de líquidos que durante la primera etapa de hidrólisis aunque han tenido lugar reacciones de condensación, éstas no han sido suficientes para que se logre el máximo de entrecruzamiento de la red, ya que no se detectan señales tipo $T^{3}$ (en MTMOS, VTES y GPTMS) o $Q^{4}$ (en TEOS). En este estudio se pretende comprobar si con los tratamientos térmicos aplicados se consigue el mayor grado de condensación de los precursores empleados, por tanto, un máximo entrecruzamiento de la red. Como consecuencia se obtendrá una caracterización de la red obtenida con las condiciones de síntesis aplicadas.

En la Figura. 4.10 se representan los espectros Si-RMN de sólidos de los precursores TEOS, MTMOS, VTES y GPTMS tras haberles aplicado el tratamiento de secado y curado (Tabla 4.2). Las muestras ensayadas se obtienen en película libre y posteriormente se trituran para permitir una correcta adquisición de los espectros.

Tabla 4.2 Tratamiento de curado aplicado para cada recubrimiento.

\begin{tabular}{|c|c|c|c|}
\hline & VTES & MTMOS & GPTMS \\
\hline Temperatura $\left({ }^{\circ} \mathbf{C}\right)$ & 100 & 80 & 140 \\
\hline Tiempo $(\mathbf{m i n})$ & 105 & 105 & 90 \\
\hline *Tratamiento de secado común en todas las muestras: $50^{\circ} \mathrm{C} / 15 \mathrm{~min}+$ rampa $\mathrm{V}=3^{\circ} \mathrm{C} / \mathrm{min}$ hasta Tc
\end{tabular}




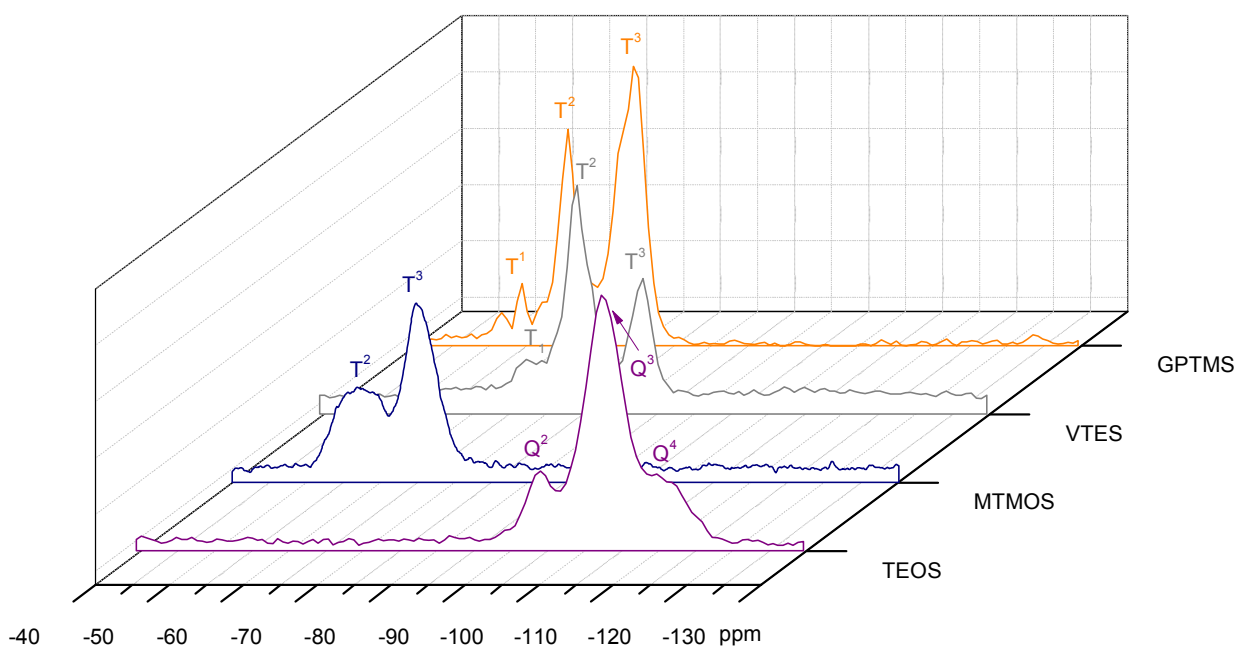

Figura. 4.10 Espectro RMN de ${ }^{29} \mathrm{Si}$ de TEOS, MTMOS, VTES y GPTMS.

El espectro de ${ }^{29} \mathrm{Si}-\mathrm{RMN}$ de sólidos muestra para el recubrimiento sintetizado a partir de TEOS señales asociadas a silicios en entornos $Q^{2}, Q^{3}$, y $Q^{4}$, la relación de intensidades de las señales $Q^{2} / Q^{3} / Q^{4}$ de 18/66/17 (Tabla 4.3), lo que indica un elevado número de silanoles terminales, que no han condensado totalmente.

En el caso de MTMOS aparecen señales asociadas a entornos $\mathrm{T}^{2}$ y $\mathrm{T}^{3}$, con una mayor intensidad de $T^{3}$ siendo la relación de intensidades de las señales $T^{2} / T^{3}$ de 33/67 (Tabla 4.3), lo que indica que se ha generado una red con alto entrecruzamiento. En este caso los picos son asimétricos y anchos, lo que indica heterogeneidad de situaciones de los entornos de estos silicios. La presencia de la cadena metil del precursor no interfiere en la polimerización de la red $\mathrm{Si}-\mathrm{O}-\mathrm{Si}$, ya que no se detecta ningún átomo de silicio con un único puente siloxano, si no que en su mayoría (el $67 \%$ de los átomos de silicio presentes) han conseguido establecer tres puentes siloxano para la formación de la red.

En el espectro del recubrimiento VTES aparecen señales $T^{1}, T^{2}$ y $T^{3}$, siendo la relación de intensidades de estas señales de 11/57/32 (Tabla 4.3), lo que indica que tanto la presencia del grupo vinil, como el tratamiento de curado utilizado, hacen que la red no se encuentre totalmente entrecruzada quedando grupos silanoles por 
reaccionar. Existen especies $\mathrm{T}^{1}$ al final del curado y la intensidad relativa de especies $\mathrm{T}^{2}$ es mayor a $\mathrm{T}^{3}$. Se obtiene una red menos entrecruzada que la obtenida en MTMOS.

Por último, el recubrimiento basado en GPTMS muestra señales asociadas a entornos de silicio tipo $T^{1}, T^{2} y T^{3}$. La relación de intensidades de los picos $T^{1} / T^{2} / T^{3}$ es 9/39/52 (Tabla 4.3). En este caso se produce un comportamiento como en el recubrimiento sintetizado a partir de VTES, la presencia del grupo orgánico así como el tratamiento de curado utilizado impide la completa condensación de los silanoles. En este caso la influencia del el grupo orgánico presente en el precursor es mayor a la obtenida en VTES por tener este un mayor tamaño impidiendo la condensación de grupos hidróxido contiguos dando lugar a una red más abierta que la obtenida en MTMOS [106-107].

Tabla 4.3 Valores del desplazamiento químico de las señales de ${ }^{29} \mathrm{Si}-\mathrm{RMN}$ sólidos.

\begin{tabular}{|c|c|c|c|c|c|c|c|c|}
\hline \multirow[t]{2}{*}{ Form. } & \multicolumn{8}{|c|}{ Desplazamiento químico $\delta / p p m$} \\
\hline & $Q^{2}$ & $Q^{3}$ & $Q^{4}$ & $Q^{2} / Q^{3} / Q^{4}$ & $\mathrm{~T}^{1}$ & $\mathrm{~T}^{2}$ & $\mathrm{~T}^{3}$ & $T^{1} / T^{2} / T^{3}$ \\
\hline TEOS & -93 & -102 & -109 & $18 / 66 / 17$ & - & - & - & - \\
\hline MTMOS & - & - & - & - & - & -56 & -65 & $33 / 67\left(T^{2} / T^{3}\right)$ \\
\hline VTES & - & - & - & - & -57 & -74 & -82 & $11 / 57 / 32$ \\
\hline GPTMS & - & - & - & - & -54 & -60 & -69 & $9 / 39 / 52$ \\
\hline
\end{tabular}

A la vista de los resultados obtenidos queda patente que si bien las redes obtenidas para cada uno de los precursores están formadas con un grado de condensación, establecido por la relación existente entre las señales de cada una de las especies, es claro que el grado de curado podría aumentarse mediante la aplicación de condiciones más severas de curado en cuanto a tiempo y temperatura. A pesar de aplicar un tratamiento de curado más severo, no podría llegarse a la formación de una red totalmente entrecruzada en aquellos recubrimientos donde la presencia del grupo orgánico impide el contacto entre dos grupos silanoles contiguos e impidiendo la condensación. No obstante ha jugado papel fundamental a la hora de seleccionar el tratamiento final a aplicar criterios adicionales como la fragilidad encontrada en las redes tanto al aplicar como recubrimiento como al ser obtenidos como película libre, e incluso la selección de tiempos que fueran factibles de poder ser utilizados en futuras aplicaciones de tipo industrial. Los tratamientos de curado optimizados tras este estudio se recogen en la Tabla 4.4. 
Tabla 4.4 Tratamiento de curado aplicado para cada recubrimiento.

\begin{tabular}{cccc} 
& VTES & MTMOS & GPTMS \\
\hline Temperatura $\left({ }^{\circ} \mathrm{C}\right)$ & 100 & 80 & 140 \\
\hline Tiempo $(\mathbf{m i n})$ & 105 & 105 & 90 \\
\hline *Tratamiento de secado común en todas las muestras: $50^{\circ} \mathrm{C} / 15 \mathrm{~min}+$ rampa $\mathrm{V}=3^{\circ} \mathrm{C} / \mathrm{min}$ hasta Tc
\end{tabular}

\section{b) Espectroscopia infrarroja}

La técnica de FTIR es una de las técnicas más extensamente utilizadas para investigar las reacciones tipo sol-gel, ya que permite caracterizar la estructura química de los materiales obtenidos. Con este ensayo se caracteriza la red polisiloxánica, así como las cadenas orgánicas presentes en los precursores y que no han hidrolizado durante los procesos de síntesis. Además se puede evaluar si las condiciones de síntesis aplicadas han afectado a estas cadenas orgánicas y en qué forma en caso de que se encuentren afectadas. Las muestras para realizar este ensayo se obtienen en film libre aplicándoles los tratamientos de curado optimizados tras el estudio de RMN, posteriormente se trituraron y se prepararon cápsulas de $\mathrm{KBr}$ con un $5 \%$ de muestra. En la Figura. 4.11 se muestran los espectros adquiridos para cada una de las formulaciones TEOS, MTMOS, VTES y GPTMS.

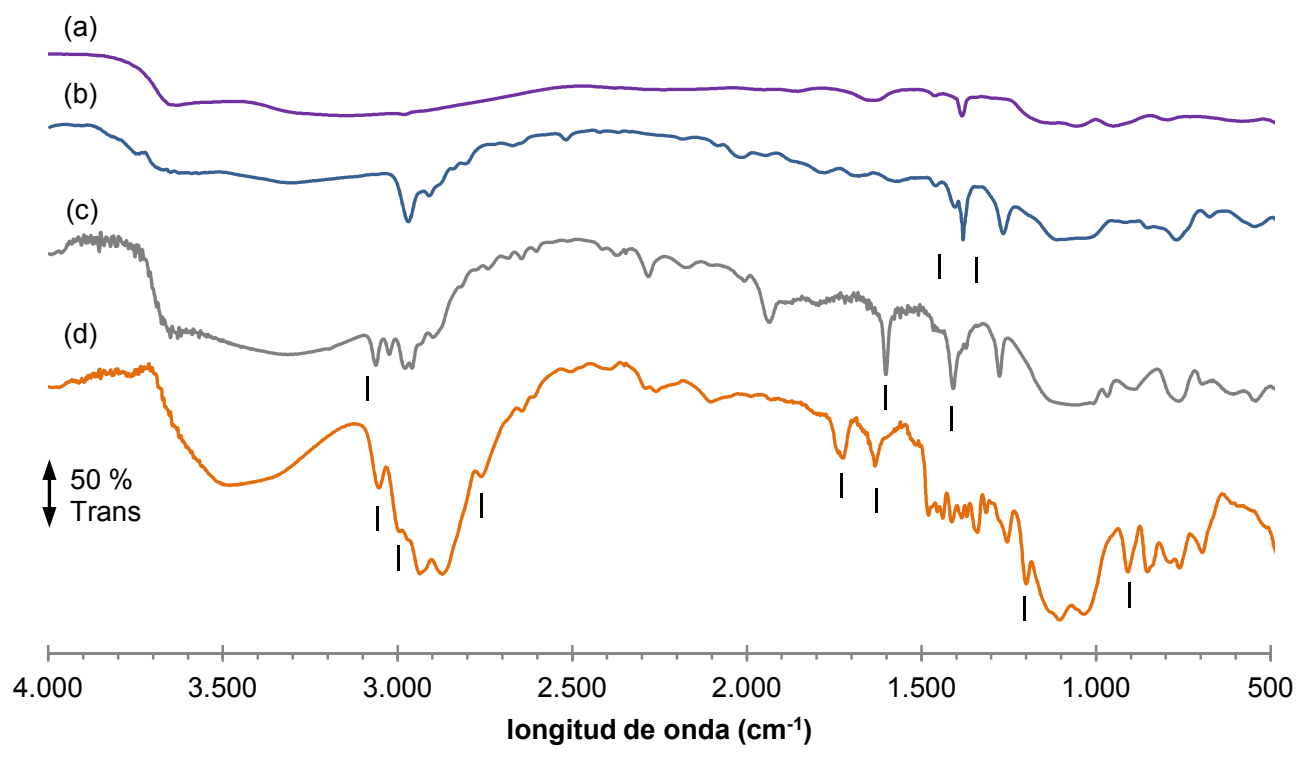

Figura. 4.11 Espectros infrarrojos (región $4000-500 \mathrm{~cm}^{-1}$ ) de los materiales basado en: (a) TEOS, (b) MTMOS, (c) VTES, (d) GPTMS. 
Se observa como todas las muestras tienen dos bandas en común asociada a la vibración asimétrica del enlace Si-O-Si alrededor de $1075 \mathrm{~cm}^{-1}$ y de $1163 \mathrm{~cm}^{-1}$. Además tienen una banda asociada a la vibración simétrica de los átomos de oxígeno del enlace Si-O-Si $\left(\sim 800 \mathrm{~cm}^{-1}\right)$. Estas bandas son características de la formación de la red inorgánica Si-O-Si [52, 108].

Por otro lado, se encuentran las bandas asociadas a productos residuales de la reacción sol-gel. En los espectros aparecen bandas asociadas a vibraciones de grupos $\mathrm{OH}\left(\sim 3300-3500 \mathrm{~cm}^{-1}\right)$ que pueden deberse a presencia de grupos terminales $\mathrm{Si}-\mathrm{OH}$, restos de agua y alcohol. En el entorno de $3740 \mathrm{~cm}^{-1}$ se aprecia en todos los casos un hombro dentro de la banda de $\mathrm{OH}$ asociado a la vibración de grupos terminales $\mathrm{Si}-\mathrm{OH}$, correspondientes a hidroxilos que no han condensado durante el tratamiento térmico $[52,108]$. A bajas longitudes de onda $\left(\sim 840\right.$ y $\left.894 \mathrm{~cm}^{-1}\right)$ aparecen dos bandas asociadas también a la vibración de grupos terminales $\mathrm{Si}-\mathrm{OH}$.

En la Tabla 4.5 se asignan las bandas representativas de las cadenas orgánicas de cada uno de los recubrimientos formulados marcadas en los espectros $[37,52$, 108-111].

Tabla 4.5 Tabla asignación bandas representativas de cada formulación.

\begin{tabular}{|c|c|c|}
\hline Formulación & Frecuencia característica $\mathbf{( c m}^{-\mathbf{1}} \mathbf{)}$ & Asignación \\
\hline MTMOS & 1450 & Si-C \\
\hline \multirow{2}{*}{ VTES } & 1275 & Si-CH3 \\
& 3060 & $=\mathrm{CH} 2$ \\
\hline GPTMS & 1600 & $\mathrm{C}=\mathrm{C}$ \\
& 1450 & Si-C \\
& $3050,2955,2758$ & $\mathrm{CH} 2$ anillo epoxi \\
& 1710 & $\mathrm{C}-\mathrm{C}$ \\
& 1620 & $\mathrm{C}-\mathrm{O}$ epoxi \\
& 1205 & $\mathrm{CH}-\mathrm{O}-\mathrm{CH} 2$ \\
\hline
\end{tabular}

El recubrimiento a base de TEOS solo muestra las bandas características de la formación de la red inorgánica, ya que no cuenta con parte orgánica. Se observa que quedan grupos residuales silanoles por reaccionar. La banda alrededor de $1400 \mathrm{~cm}^{-1}$ se debe a presencia de isopropanol atrapado en la red. 
El recubrimiento obtenido partiendo de MTMOS se caracteriza por tener, a parte de la red polisiloxánica, una cadena orgánica corta metilo cuya banda de vibración se encuentra entorno a $1275 \mathrm{~cm}^{-1}$.

Cuando se parte del precursor VTES el espectro se complica apareciendo adicionalmente a las bandas de la red $\mathrm{Si}-\mathrm{O}-\mathrm{Si}$, las bandas características de la vibración del grupo vinil. El pico de mayor importancia es el asociado a la vibración simétrica del enlace $\mathrm{C}=\mathrm{C}$. Se observa en el espectro una mayor intensidad de la banda característica de silanoles terminales a $3750 \mathrm{~cm}^{-1}$, asociada a la presencia de

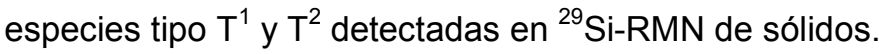

El último espectro es el del recubrimiento obtenido a partir del precursor GPTMS. En este caso las bandas características son varias, asociadas a la cadena carboxílica $\left(\sim 1200 \mathrm{~cm}^{-1}\right)$ y al grupo epoxi $\left(\sim 3050,2955,2758 \mathrm{~cm}^{-1}\right)[110,112]$. En este espectro, se observa como la banda de $\mathrm{OH}$ es mucho mayor que en casos anteriores, este fenómeno se puede deber a la apertura de parte de los anillos epoxi presentes en la formulación [110], ya que, según el espectro de RMN, la cantidad de especies con entornos tipo $T^{1} y T^{2}$ no es mayor que para el resto de formulaciones, teniéndose que deber a la presencia de grupos hidroxilo procedentes de la apertura parcial de los grupos epoxi. Los anillos epoxi son altamente reactivos ya que el ángulo de enlace entre los carbonos se reduce a $60^{\circ}$, cuando el valor más favorable energéticamente es de $104^{\circ}$, este hecho hace que se acumule tensión y tenga tendencia a abrirse. Además existe un desplazamiento de las cargas hacia el oxígeno que también hace aumentar su reactividad. El anillo epoxi puede abrirse por distintos procesos, pero dadas las condiciones de síntesis como es la presencia de agua y $\mathrm{pH}$ bajo probablemente se produce por hidrolisis de la forma representada en la Figura. 4.12 $[52,113]$. La apertura del anillo es interesante ya que una mayor presencia de grupos hidroxi en la superficie del material hace que este material tenga un carácter más hidrófilo y hace disminuir las propiedades anticorrosivas del recubrimiento[113]. Por otro lado, la presencia de estos grupos activos permitirá (en trabajos futuros) el anclaje de factores de alto interés biológico como son péptidos (RGD, colágeno, etc.) o factores de crecimiento. 


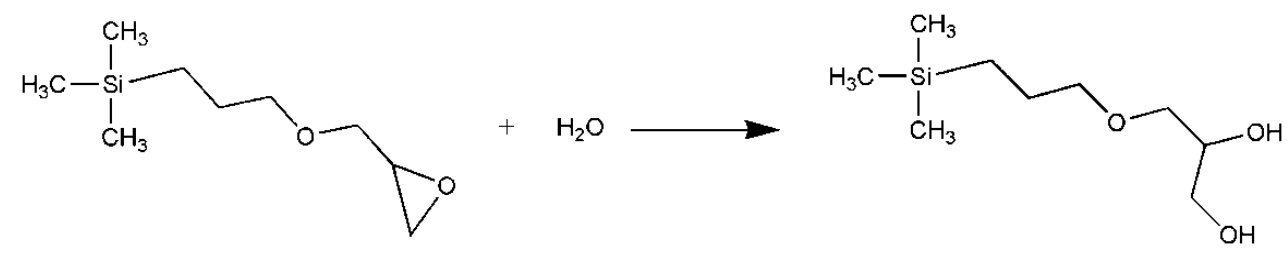

Figura. 4.12 Apertura por hidrólisis de anillo epoxi en GPTMS.

Se observa mediante la técnica FTIR que con las condiciones de síntesis aplicadas $(\mathrm{pH}=1$, cantidad de agua estequimétrica, duración de reacciones de hidrólisis) así como los tratamiento de curado aplicados se han conseguido obtener redes polisiloxánicas en todos los casos. Se confirma mediante esta técnica que existen grupos reactivos silanoles por condensar, debido tanto a los tratamientos de curado obtenidos como al tamaño de las cadenas orgánicas de los precursores seleccionados. Por último se ha confirmado que las condiciones de síntesis no han afectado a las cadenas orgánicas de los precursores MTMOS y VTES, y permanecen en el recubrimiento final. En el caso del GPTMS se ha detectado una apertura de parte de los anillos epoxi del precursor, quedando grupos hidroxi activos procedentes de dicha apertura en el recubrimiento final.

\section{3 Comportamiento térmico}

En este apartado se estudia las propiedades térmicas de los materiales obtenidos en función de su composición. En concreto, se estudiará la existencia o no de transición entre un estado gomoso a un estado vítreo $\left(T_{g}\right)$ por medio de calorimetría diferencial de barrido (DSC), siendo esta propiedad valiosa para la determinación del tipo de red formada. Por otro lado, se analizarán los procesos de degradación que sufre el material con la temperatura, que nos permitirán determinar si los tratamientos de curado son los adecuados para no degradar la cadena formada. Dependiendo de la estructura química de los precursores, así como los tratamientos térmicos de secado/curado aplicados a cada uno de los materiales, las propiedades térmicas como la temperatura de transición vítrea y los fenómenos de degradación serán unos u otros. 
La temperatura de transición vítrea $\left(\mathrm{T}_{\mathrm{g}}\right)$ de los recubrimientos obtenidos se ha determinado por medio de medidas DSC. Mediante esta técnica se pretende obtener una caracterización del tipo de red formada, en este caso con técnicas calorimétricas, por medio de la determinación de la temperatura de transición vítrea. La Figura. 4.13 representa las curvas calorimétricas de un barrido de temperaturas entre $-100^{\circ} \mathrm{C}$ hasta $200^{\circ} \mathrm{C}$ bajo flujo de nitrógeno de los tres recubrimientos estudiados MTMOS, VTES y GPTMS obtenidos en film libre y posteriormente triturados para permitir un flujo de calor homogéneo por toda la muestra. El criterio seguido en los termogramas representados conlleva que los picos hacia arriba corresponden a procesos exotérmicos.

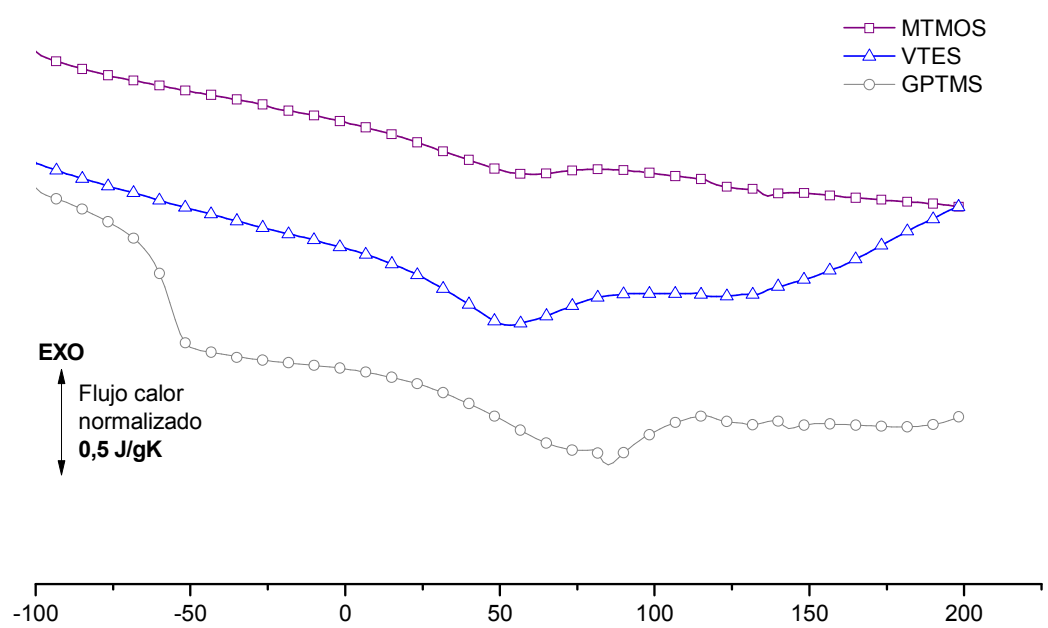

Figura. 4.13 Curvas DSC de los materiales MTMOS, VTES y GPTMS. Velocidad de calentamiento $10^{\circ} \mathrm{C}$ con un flujo de $\mathrm{N}_{2}$ de $30 \mathrm{ml} / \mathrm{min}$.

El valor de temperatura denominado $T_{g}$ se relaciona con la movilidad molecular de la parte amorfa de la red formada, por eso, sólo se registrará en aquellas formulaciones donde el peso molecular asociado a ésta sea suficiente para que la señal registrada sea nítida. Por este motivo el recubrimiento que presenta una $\mathrm{Tg}$ clara a $-56^{\circ} \mathrm{C}$, con un $\Delta \mathrm{Cp} 0,45(\mathrm{~J} / \mathrm{gK})$ es el GPTMS. Este recubrimiento cuenta con cadenas orgánicas con posibilidad de movimientos conformacionales. Los recubrimientos MTMOS y VTES tienen las posibilidades de movimientos 
conformacionales muy pequeños debido a la formación de red por parte del silicio y al pequeño peso molecular de las cadenas orgánicas laterales motivo por el cual $T_{g}$ no se registra. El pico endotérmico detectado entre $50^{\circ} \mathrm{C}-100^{\circ} \mathrm{C}$ se debe a la evaporación de especies volátiles remanentes en los recubrimientos, como agua y alcohol [114$115]$.

Adicionalmente, y para completar el estudio de estabilidad térmica se ha realizado un estudio de degradación térmica de los recubrimientos por TGA. Este estudio permite cuantificar la carga inorgánica de los recubrimientos y además asegurar que las temperaturas de curado son las óptimas, es decir, no se produce pérdida de la parte orgánica introducida en los alcoxisilanos. La Figura. 4.14 representa las curvas de degradación térmica obtenidas entre temperatura ambiente y $700^{\circ} \mathrm{C}$ a $10^{\circ} \mathrm{C} / \mathrm{min}$ en flujo de nitrógeno de los recubrimientos TEOS, MTMOS, VTES y GPTMS obtenidos en película libre y posteriormente triturados para favorecer la correcta dispersión del calor por la muestra.

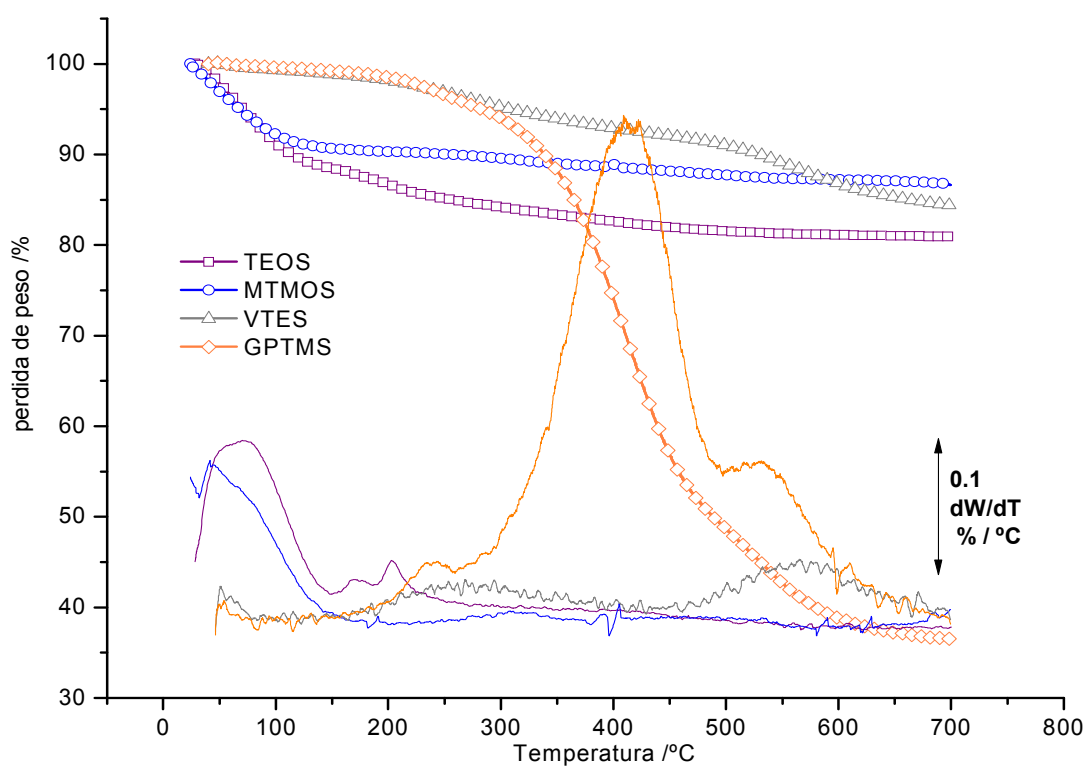

Figura. 4.14 Curvas TGA y derivada de la pérdida de peso de los materiales TEOS, MTMOS, VTES y GPTMS, Velocidad de calentamiento $10^{\circ} \mathrm{C} / \mathrm{min}$ en atmosfera $\mathrm{N}_{2}$. 
El recubrimiento TEOS y MTMOS registran una pérdida de un $10 \%$ por debajo de $100^{\circ} \mathrm{C}$ hecho que se atribuye a la evaporación de agentes volátiles como alcohol y agua, fenómeno que se corrobora con los datos obtenidos en DSC. Tras esta pérdida el recubrimiento MTMOS, registra una pequeña pérdida de $3 \%$ en peso entre $150^{\circ} \mathrm{C}$ y $400^{\circ} \mathrm{C}$ debida a la pérdida del grupo metilo.

El recubrimiento TEOS tiene una pérdida gradual y constante de peso hasta $200^{\circ} \mathrm{C}$, que se puede deber a un proceso de continua condensación ya que este recubrimiento se ha curado a temperatura ambiente y puede tener grupos silanoles sin condensar, tal y como se interpretó con los espectros de ${ }^{29} \mathrm{Si}-\mathrm{RMN}$. Cuando se produce la condensación de dos grupos silanoles se produce agua que se evapora por encima de $100^{\circ} \mathrm{C}$, registrándose por tanto pérdida de peso. Por encima de $200^{\circ} \mathrm{C}$ no se registra pérdida de peso ya que la degradación de la cadena inorgánica Si-O-Si no se produce en el intervalo de temperaturas estudiado.

El recubrimiento VTES presenta tres pérdidas de peso. Una primera pequeña por debajo de $100^{\circ} \mathrm{C}$ asociada a la evaporación de alcohol y agua residuales presentes en la red. La segunda alrededor de $240^{\circ} \mathrm{C}$ que puede deberse a la existencia de reacciones de curado por tener el recubrimiento grupos silanol no condensados con el tratamiento térmico aplicado. La pérdida de peso se debe a la pérdida de agua producida en la condensación de dos grupos silanol. La degradación que aparece a altas temperaturas $\left(526^{\circ} \mathrm{C}\right)$ y se puede relacionar con la degradación de grupo vinil presente en la cadena.

El recubrimiento que presenta mayor pérdida de peso por degradación térmica es el GPTMS por contar con un mayor contenido orgánico. Si se analiza la derivada de la pérdida de peso se observa claramente como la mayor degradación se registra entre $300^{\circ} \mathrm{C}-500^{\circ} \mathrm{C}$, con su máximo a $415^{\circ} \mathrm{C}$, apareciendo otra degradación más pequeña alrededor de $534^{\circ} \mathrm{C}$ relacionada ambas con la pérdida de las cadenas orgánicas [115-116]. Además presenta una degradación a baja temperatura $\left(150^{\circ} \mathrm{C}\right)$, de menor intensidad que las registradas a altas temperaturas, que se atribuye (como en el caso del VTES) a pérdida de compuestos volátiles por la continuación del proceso de condensación de grupos silanoles no condensados. 
Se observa como las propiedades térmicas de los materiales dependen de su composición, así redes donde la cadena orgánica incorporada es corta las transiciones entre estado gomoso y vítreo no se pueden detectar debido a que las posibilidades de movimientos conformacionales se ven impedidos por la formación de la red de silicio, así como al pequeño peso molecular de estas cadenas, como ocurre en VTES y MTMOS. Por el mismo motivo los procesos de degradación de estos recubrimientos conllevan una pérdida de peso baja. En el caso de fórmulas partiendo del precursor GPTMS, las posibilidades de movimientos conformacionales de sus cadenas es mayor y la red formada tiene un carácter mayor orgánico. En este caso la degradación del recubrimiento es mayor al perder estas cadenas entorno a $300^{\circ} \mathrm{C}$ $500^{\circ} \mathrm{C}$. Por último se ha podido confirmar que los tratamientos de curado aplicados en todos los casos se encuentran por debajo de la temperatura de degradación de los recubrimientos, ya que no se registra pérdida de peso por debajo de $200^{\circ} \mathrm{C}$, y las temperaturas de curado no superan los $140^{\circ} \mathrm{C}$.

\section{4 Ángulo de contacto}

Una propiedad importante relacionada con el comportamiento que tienen los materiales en medio acuoso es la hidrofilia. En general un material hidrófilo absorberá más fácilmente agua, y por lo tanto, tendrá peores propiedades anticorrosivas. Un método sencillo para caracterizar la hidrofilia de los films es la medida del ángulo de contacto que crea una gota de agua sobre el material. Los valores obtenidos para los films se presentan en la Tabla 4.6.

Tabla 4.6 Medida ángulo de contacto de agua extrapura con los materiales TEOS, MTMOS, VTES y GPTMS aplicados por dip-coating a $100 \mathrm{~mm} / \mathrm{min}$ sobre acero AISI $316 \mathrm{~L}$.

\begin{tabular}{|c|c|c|c|c|}
\hline Nomenclatura & TEOS & MTMOS & VTES & GPTMS \\
\hline $\begin{array}{c}\text { Angulo de } \\
\text { contacto / }\end{array}$ & $66 \pm 1$ & $82 \pm 3$ & $80 \pm 1$ & $61 \pm 1$ \\
\hline
\end{tabular}

Los resultados muestran que el recubrimiento más hidrófilo es el GPTMS, propiedad que se debe a una mayor presencia de grupos $\mathrm{OH}$ terminales en la superficie del material. Estos grupos provienen tanto de la apertura parcial del anillo epoxi como a la formación de una red más abierta con enlaces $\mathrm{Si}-\mathrm{OH}$ sin reaccionar. Este resultado concuerda con los espectros de ${ }^{29} \mathrm{Si}-\mathrm{RMN}$ y FTIR registrados para este 
material donde la banda asociada a la vibración de enlaces - $\mathrm{OH}$ aparecía con una intensidad elevada EI TEOS al tratarse de un recubrimiento con mayor carácter inorgánico tiene gran capacidad para absorber agua en su superficie hecho recogido en bibliografía [67]. EI VTES y MTMOS tienen un carácter más hidrófobo debido a la presencia de los grupos vinil y metilo en la red formada.

\section{5 Propiedades anticorrosivas}

Los materiales desarrollados están diseñados para cumplir una serie de requerimientos, entre los que se encuentra la protección frente a la corrosión del substrato metálico sobre el que están aplicados. Esta protección evita la salida de iones desde la prótesis al entorno sobre todo en los momentos iniciales, lo cual puede favorecer la osteointegración ya que se ha demostrado que éstos pueden afectar a la captación de células osteoinductoras y, por tanto, la regeneración del tejido óseo [32, 90].

Se ha evaluado la capacidad de los recubrimientos sintetizados para proteger frente a la corrosión el sustrato metálico. Para ello se han introducido las planchas de acero AISI 316L recubiertas mediante la técnica dip-coating con cada formulación en una solución acuosa de $\mathrm{NaCl}$ al 3,5\% en peso y se ha evaluado el comportamiento frente a la corrosión mediante la técnica de espectroscopia de impedancia electroquímica. El equipo empleado fue un Zahner - elektrik, el intervalo de frecuencias estudiado comprende desde $100 \mathrm{kHz}$ hasta $10 \mathrm{mHz}$, con una amplitud de la señal de entrada de $\pm 10 \mathrm{mV}$. Se han registrado espectros de impedancia a diferentes tiempos de exposición al electrolito y durante un tiempo máximo de inmersión de 24 horas.

En la Figura. 4.16 y Figura. 4.15 se representan los diagramas de Nyquist y de Bode al principio de la exposición de cada recubrimiento. 


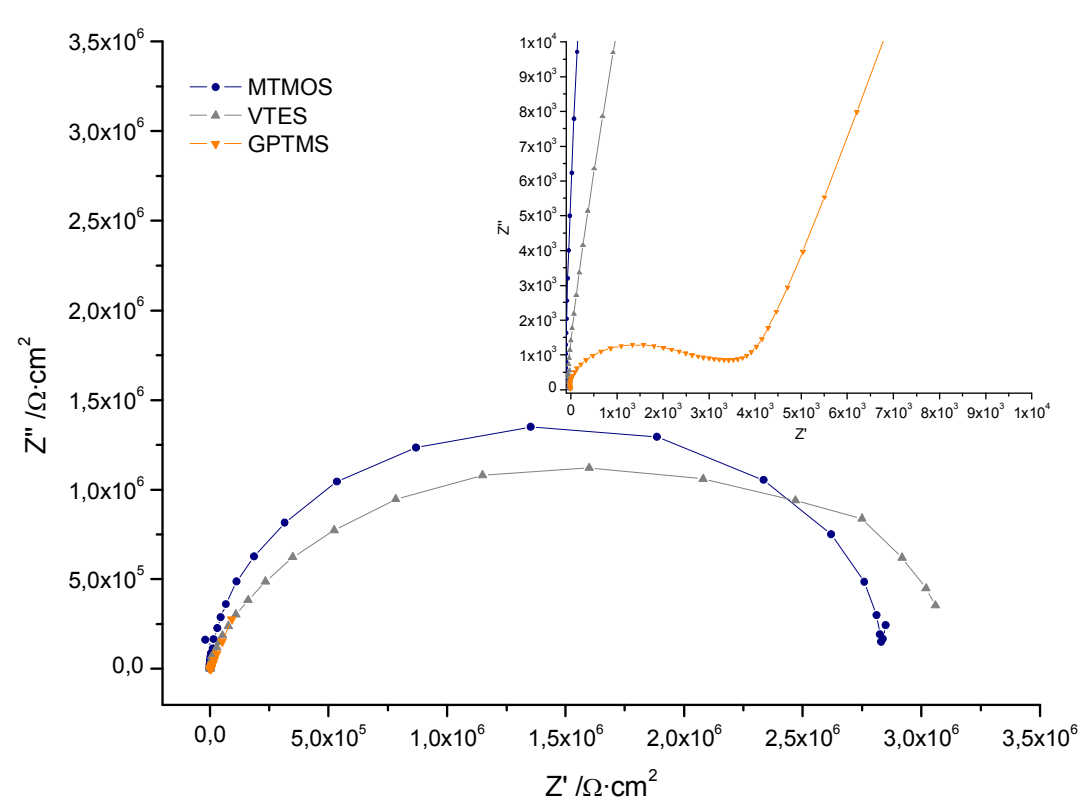

Figura. 4.15 Diagrama de Nyquist de los recubrimientos MTMOS, VTES y GPTMS aplicados sobre acero AISI 316-L a tiempo cero, en una disolución de $\mathrm{NaCl}$ al $3,5 \%$ en peso.

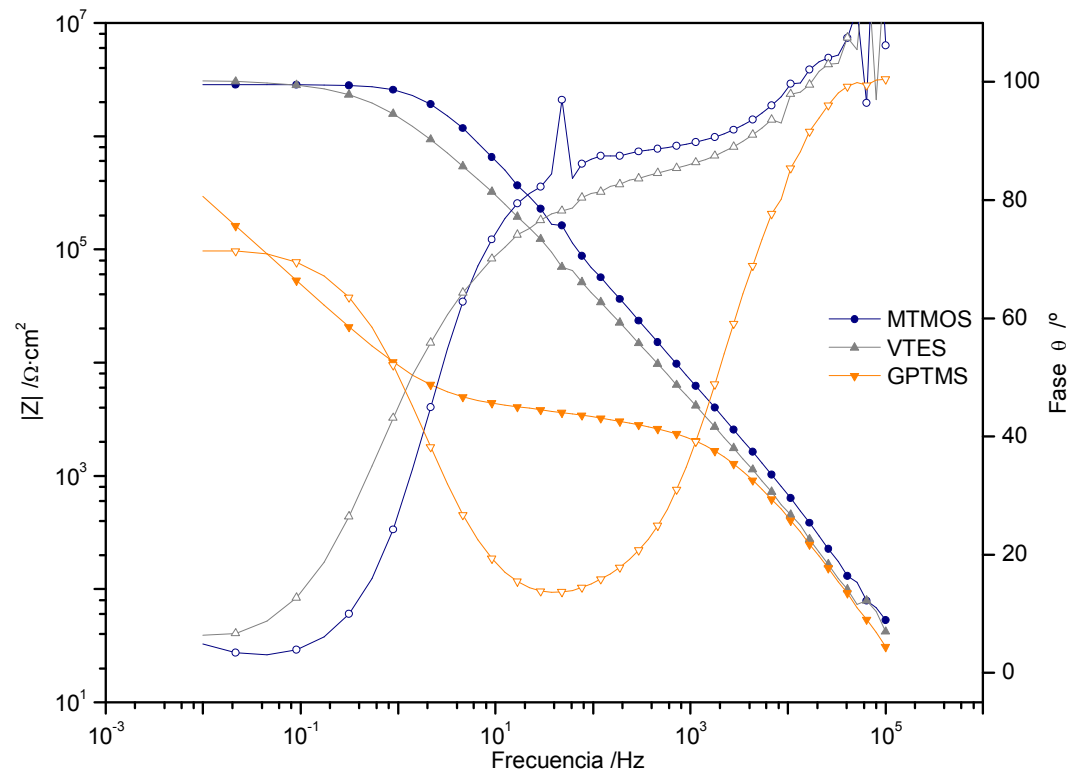

Figura. 4.16 Diagrama de Bode de los recubrimientos MTMOS, VTES y GPTMS aplicados sobre acero AISI 316-L a tiempo cero, en una disolución de $\mathrm{NaCl}$ al 3,5\% en peso. 
Los espectros de impedancia frente a frecuencia de los recubrimientos de MTMOS y VTES tienen un aspecto similar. Ambos muestran en el diagrama de Nyquist un único arco poco simétrico y achatado. Analizando el diagrama de Bode se consigue distinguir la presencia de dos constantes de tiempo, la primera se desarrolla a altas frecuencias y se asocia a las propiedades dieléctricas del recubrimiento sol-gel y la segunda tiene lugar a bajas frecuencias y se asocia a procesos electroquímicos que tiene lugar en la interfase (fenómenos de respuesta mucho más lenta que los procesos de relajación dieléctrica que tienen lugar en el recubrimiento).

En el espectro del recubrimiento basado en GPTMS se aprecia claramente la presencia de dos arcos en el diagrama de Nyquist. Cuando se analiza el diagrama de Bode, se distinguen tres constantes de tiempo una a altas frecuencias que se relaciona con la respuesta del recubrimiento al contacto con el electrolito y, por tanto, proporciona información sobre las propiedades del recubrimiento, otra asociada a la respuesta de la interfase (valores de frecuencia intermedios) y la tercera asociada a la capa de óxido formada en la superficie del metal (valores de frecuencia bajos). El arco descrito a bajas frecuencias y correspondiente a la capa de óxido formada no está totalmente definido dentro del intervalo de frecuencias estudiado. La respuesta en frecuencia está asociada a constantes de tiempo demasiado grandes para el ensayo realizado, por lo que la información obtenida sobre estos procesos es muy limitada.

Se observa que los valores del módulo de impedancia de los recubrimientos basados en las formulaciones VTES y MTMOS son superiores a las de GPTMS en una amplia región del espectro de frecuencias, mostrando los dos primeros un comportamiento más capacitivo, esto es, mayores valores de ángulo de fase y un menor decrecimiento de éste a bajas frecuencias. Este hecho probablemente se deba a la distinta naturaleza de cada uno de los nuevos recubriminetos sintetizados. Desde el punto de vista del material se ha determinado, con diversas técnicas descritas en diferentes apartados, la formación de una red más compacta y menos permeable por parte de los precursores VTES y MTMOS en comparación con el GPTMS. El recubrimiento GPTMS al contar con una cadena orgánica de mayor tamaño crea una red menos conectada y, por tanto, una estructura más abierta [107] que permite el paso del electrolito a su través. 
Se ha analizado el comportamiento de los recubrimientos con el paso del tiempo de exposición al electrolito hasta 24 horas. En la Figura. 4.17 y Figura. 4.18 se muestra la evolución de los diagramas de impedancia (representación de Nyquist) de los recubrimientos MTMOS y VTES, respectivamente.

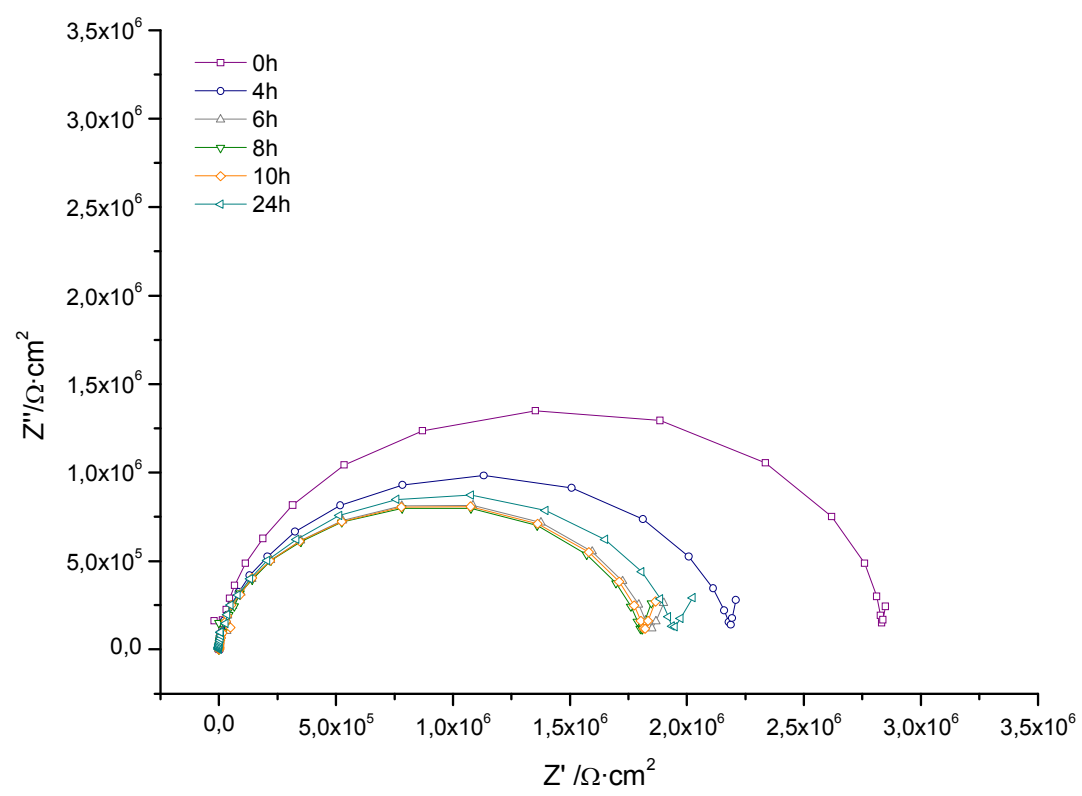

Figura. 4.17 Evolución de los diagramas de Nyquist obtenidos para el recubrimiento MTMOS durante 24 horas de exposición a una disolución $\mathrm{NaCl}$ al 3,5\% en peso. 


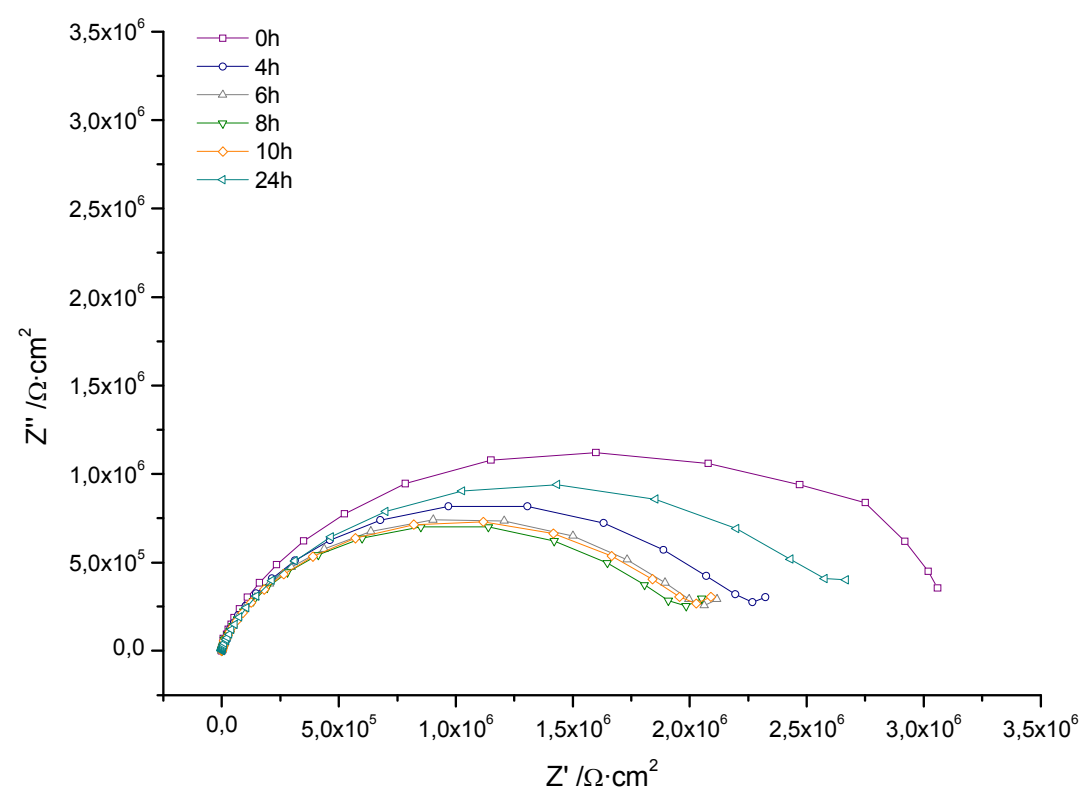

Figura. 4.18 Evolución de los diagramas de Nyquist obtenidos para el recubrimiento VTES durante 24 horas de exposición a una disolución $\mathrm{NaCl}$ al 3,5\% en peso.

Ambos recubrimientos presentan un comportamiento muy similar, se observa un descenso progresivo de los valores de impedancia a medida que aumenta el tiempo de exposición durante las primeras 10 horas y a las 24 horas se observa una ligera recuperación de las impedancias del sistema.

La evolución del recubrimiento GPTMS (Figura. 4.19) muestra un importante descenso de los valores de impedancia con la exposición al electrolito, el diámetro del arco de altas frecuencias disminuye su diámetro drásticamente a las 4 horas de exposición. El comportamiento de este recubrimiento es mucho menos resistivo. Este hecho puede ser debido a que el recubrimiento GPTMS tiene una mayor cantidad de canales interconectados que además aumentan con la exposición al electrolito por la degradación de éste. 


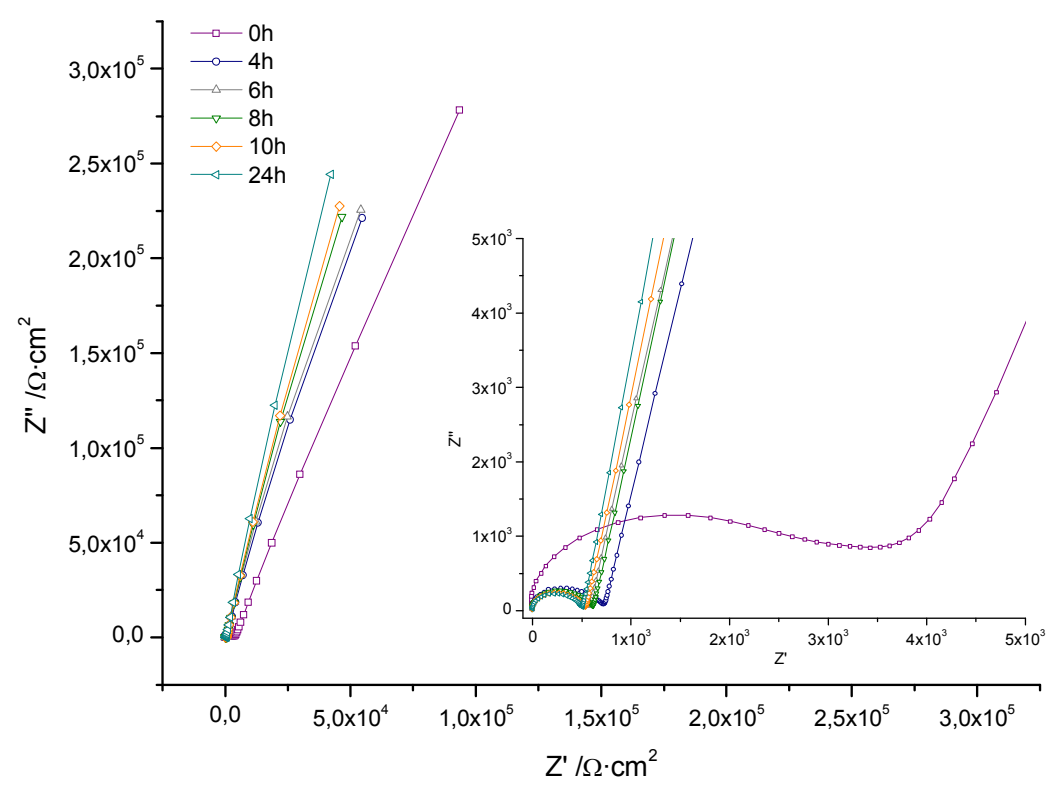

Figura. 4.19 Evolución de los diagramas de Nyquist obtenidos para el recubrimiento GPTMS durante 24 horas de exposición a una disolución $\mathrm{NaCl}$ al 3,5\% en peso.

Se realiza la modelización de los valores de impedancia compleja mediante circuitos equivalentes. En los recubrimientos obtenidos a partir de MTMOS y VTES se utiliza un circuito con dos constantes de tiempo (Figura. 4.20 (izq.)) formado por los elementos pasivos $R_{p o}$ (resistencia del electrolito dentro de los poros del recubrimiento), $\mathrm{CPE}_{\mathrm{c}}$ (capacidad de las zonas intactas del recubrimiento), ambos elementos guardan relación con las propiedades eléctricas intrínsecas del recubrimiento. Por otro lado se encuentran $R_{p}$ (resistencia a la polarización) y $C P E_{d l}$ (capacidad de doble fase), que guardan relación con las propiedades electroquímicas de la interfase metal/electrolito en la base de los poros del recubrimiento. En el recubrimiento obtenido a partir de GPTMS se utiliza un circuito con tres constantes de tiempo (Figura. 4.20 (dcha.)) formado con dos elementos pasivos adicionales característicos de la capa de óxido $\mathrm{CPE}_{\mathrm{ox}}$ (capacidad de la capa de óxido) y $\mathrm{R}_{\mathrm{ox}}$ (resistencia a la capa de óxido)[117-118]. 

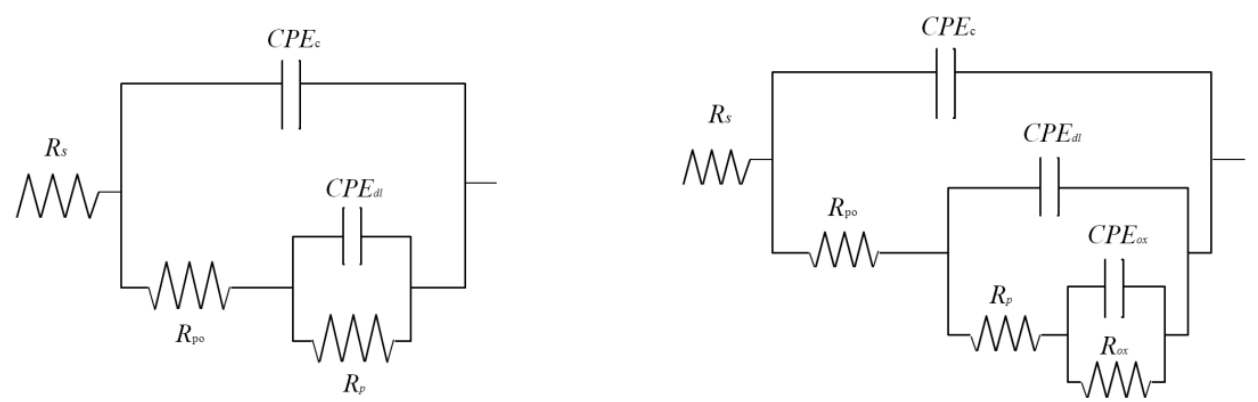

Figura. 4.20 Circuito equivalente de (izq.) con constantes de tiempo y (dcha.) contres constantes de tiempo usado en la modelización de los datos electroquímicos [117].

En la Tabla 4.7 se recogen las siglas y las correspondencias con los fenómenos existentes en el sistema metal/recubrimiento de los elementos pasivos de los circuitos usados para la simulación.

Tabla 4.7 Elementos pasivos del circuito equivalente y su interpretación física dentro de los procesos del sistema recubrimiento/metal.

\begin{tabular}{|c|c|c|c|}
\hline \multirow[t]{2}{*}{ Recubrimiento } & \multirow[t]{2}{*}{$\begin{array}{l}1^{\text {a }} \text { cte. tiempo } \\
\text { alta frecuencia }\end{array}$} & $\mathrm{R}_{\mathrm{po}}$ & $\begin{array}{l}\text { Resistencia de los poros del } \\
\text { recubrimiento }\end{array}$ \\
\hline & & $\mathrm{CPE}_{\mathrm{c}}$ & $\begin{array}{c}\text { Capacidad de las zonas intactas } \\
\text { del recubrimiento }\end{array}$ \\
\hline \multirow[t]{2}{*}{ Interfase } & \multirow[t]{2}{*}{$2^{\mathrm{a}}$ cte. tiempo } & $\mathrm{R}_{\mathrm{p}}$ & $\begin{array}{c}\text { Resistencia de polarización en la } \\
\text { base de los poros }\end{array}$ \\
\hline & & $\mathrm{CPE}_{\mathrm{dl}}$ & $\begin{array}{c}\text { Capacidad de la doble capa } \\
\text { electroquímica en la base de los } \\
\text { poros }\end{array}$ \\
\hline \multirow[t]{2}{*}{ Capa óxido } & \multirow{2}{*}{$\begin{array}{l}3^{\text {a }} \text { cte. tiempo } \\
\text { baja frecuencia }\end{array}$} & $\mathrm{R}_{\mathrm{ox}}$ & Resistencia eléctrica del óxido \\
\hline & & $\mathrm{CPE}_{\mathrm{ox}}$ & Capacidad de la capa óxido \\
\hline
\end{tabular}

En la Figura. 4.21 se representan, a modo de ejemplo, los datos experimentales obtenidos para el recubrimiento MTMOS a tiempo Ohoras y GPTMS a tiempo oh y el resultado de la modelización de estos datos con el circuito equivalente de dos y tres constantes de tiempo, respectivamente. Se ha conseguido un buen ajuste del modelo en todo el intervalo de frecuencias y para todas las muestras ensayadas. 


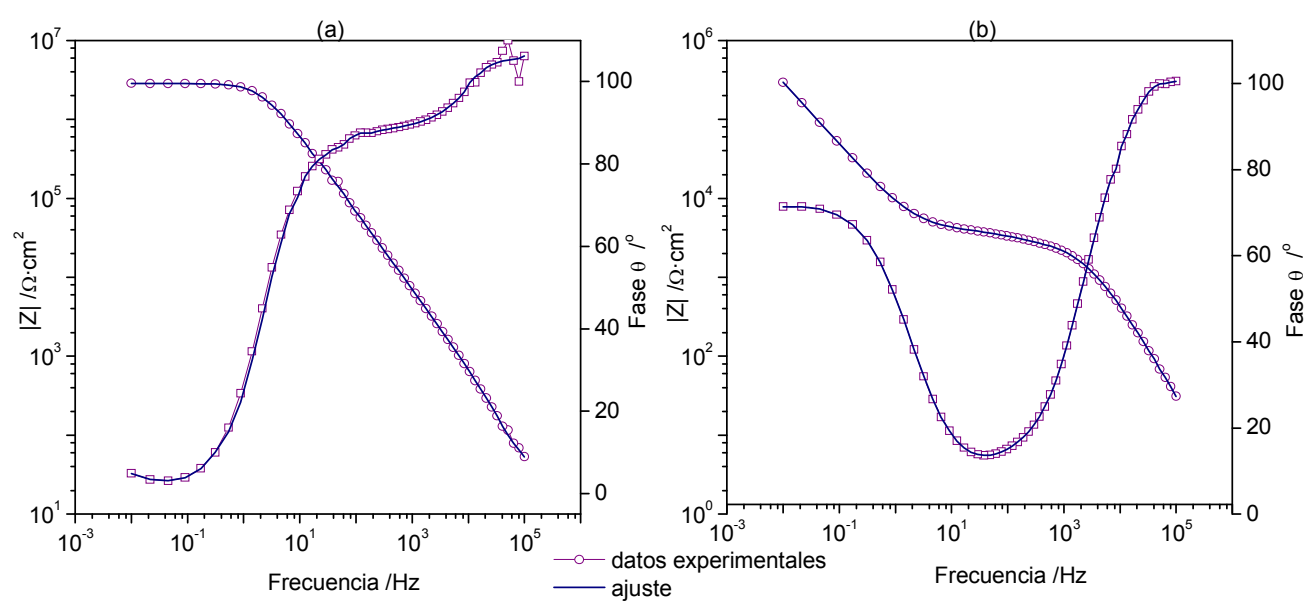

Figura. 4.21 Diagramas de Bode experimentales y simulados para: (a) el recubrimiento MTMOS y (b) el recubrimiento GPTMS, ambos a 0 h de exposición al electrolito.

Gracias a la modelización de los resultados electroquímicos se puede estudiar el comportamiento de los recubrimientos con mayor detalle, ya que se van a diferenciar los procesos que ocurren en el recubrimiento y en la interfase metal/recubrimiento. La Figura. 4.22 muestra la modelización a partir de los datos obtenidos de los parámetros del circuito equivalente asociados al recubrimiento, la resistencia de los poros del recubrimiento $\left(R_{p o}\right)$ y la capacidad del recubrimiento $\left(C P E_{c}\right)$, obtenidos a partir de la respuesta a alta frecuencia. 

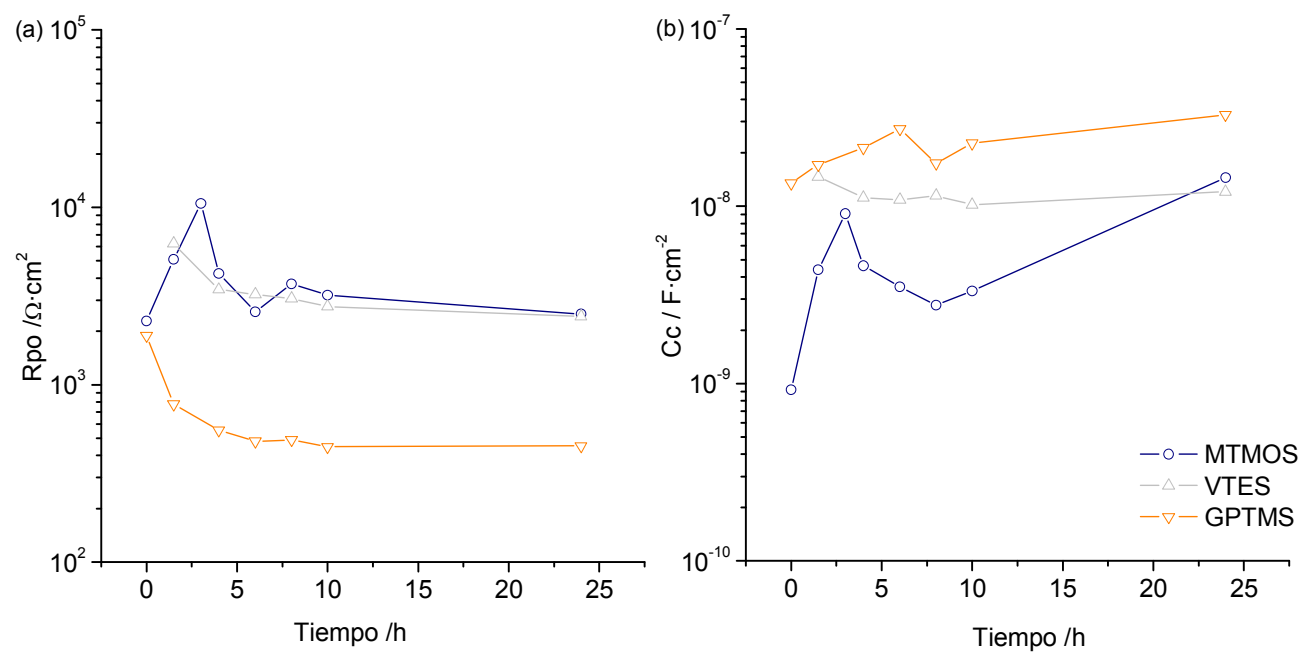

Figura. 4.22 Comparación de la evolución del valor de (a) resistencia al poro y (b) capacidad del recubrimiento con el tiempo de exposición a la disolución 3,5\% $\mathrm{NaCl}$ de los recubrimientos MTMOS, VTES y GPTMS.

El valor de $R_{p o}$ es una medida de la resistencia iónica a través de los poros de recubrimiento, y por tanto, es inversamente proporcional al número y extensión de defectos en el mismo. La evolución de $\mathrm{R}_{\mathrm{po}}$ con el tiempo de exposición al electrolito proporciona información acerca del comportamiento del recubrimiento sol-gel frente a la introducción del electrolito a través de sus canales o poros. El recubrimiento MTMOS tiene un valor de $R_{p o}$ inicial de $2300 \Omega \cdot \mathrm{cm}^{2}$, que evoluciona para mantenerse prácticamente constante con la exposición al electrolito con un valor entorno a 3000 $\Omega \cdot \mathrm{cm}^{2}$. El recubrimiento VTES tiene un valor de $R_{\mathrm{po}}$ prácticamente constante entorno a $3000 \Omega \cdot \mathrm{cm}^{2}$. El recubrimiento GPTMS tiene un valor inicial de $R_{p o}$ entono a 2000 $\Omega \cdot \mathrm{cm}^{2}$ y va disminuyendo su valor hasta alcanzar un valor entorno a $500 \Omega \cdot \mathrm{cm}^{2}$ a las 10 horas de exposición al electrolito. Se observa que los valores de esta resistencia para los recubrimientos MTMOS y VTES son un orden de magnitud mayores que los obtenidos para el recubrimiento basado en GPTMS. Adicionalmente el valor de la resistencia en el caso del recubrimiento de GPTMS registra una significativa disminución con el paso del tiempo de exposición al electrolito. Con estos datos, se puede concluir que el recubrimiento de GPTMS tiene una porosidad mayor que los correspondientes a MTMOS y VTES y además ésta aumenta con la exposición al electrolito. Esto se puede deber por un lado a su mayor carácter hidrófilo, por una 
mayor presencia de terminaciones $-\mathrm{OH}$ (silanoles y apertura del anillo epoxi) en su superficie y por otro lado por contar con una estructura de red más abierta.

En cuanto a la capacidad del recubrimiento, $\mathrm{CPE}_{\mathrm{c}}$, el valor inicial obtenido para el material basado en MTMOS es de $9,2 \cdot 10^{-10} \mathrm{~F} \cdot \mathrm{cm}^{-2}$, y este valor aumenta con el tiempo de exposición. Así a las 10horas de exposición al electrolito tiene un valor numérico de $3,3 \cdot 10^{-9} \mathrm{~F} \cdot \mathrm{cm}^{-2}$, siendo su valor final, después de 24 horas de exposición, de $1,45 \cdot 10^{-8} \mathrm{~F} \cdot \mathrm{cm}^{-2}$. La capacidad del recubrimiento VTES tiene un valor constante alrededor de $10^{-8} \mathrm{~F} \cdot \mathrm{cm}^{-2}$. El recubrimiento GPTMS tiene los valores más altos de $\mathrm{CPE}_{\mathrm{c}}$, presentando un valor inicial de la capacidad igual a $1,3 \cdot 10^{-8} \mathrm{~F} \cdot \mathrm{cm}^{-2}$, y siempre creciente con el tiempo de exposición, siendo el valor a 10 horas de exposición de $2,2 \cdot 10^{-8} \mathrm{~F} \cdot \mathrm{cm}^{-2}$ y llegando a $3,27 \cdot 10^{-8} \mathrm{~F} \cdot \mathrm{cm}^{-2}$.

Analizando estos datos, se puede observar que la capacidad del recubrimiento obtenido a partir del GPTMS es la mayor de los tres estudiados. Este hecho puede ser debido fundamentalmente a la entrada del electrolito en él por tener una red más abierta y un comportamiento más hidrófilo que el resto dado su mayor contenido de hidroxilos en superficie. En el caso del VTES nuevamente se constata que la red formada está más entrecruzada y que la entrada de electrolito se produce en mucha menor medida. Por otro lado, la capacidad en el caso del MTMOS presenta valores un orden de magnitud por debajo de los registrados para los otros dos recubrimientos a tiempos iniciales lo cual probablemente sea debido a que al menos inicialmente esta red es hidrófoba (como se vio en 4.4). Sin embargo, la capacidad aumenta con el tiempo de exposición rápidamente hasta valores intermedios entre el GPTMS y el VTES debido a la entrada del electrolito en el interior del recubrimiento. Esta evolución indica que la exposición al electrolito favorece la degradación del recubrimiento por hidrólisis, permitiendo así la entrada del medio electrolítico en el seno del recubrimiento y disminuyendo sus propiedades de protección frente a la corrosión electroquímica. 
La Figura. 4.23 muestra la modelización a partir de los datos obtenidos de los parámetros del circuito equivalente asociados a la resistencia a la polarización $\left(R_{p}\right)$ y la capacidad de la doble capa $\left(\mathrm{CPE}_{\mathrm{dl}}\right)$, correspondiente a la respuesta a baja frecuencia. Estos procesos corresponden a aquellos que necesitan tiempos largos de respuesta frente a la perturbación de una señal eléctrica para poder ser registrados y están relacionados con la evolución de la interfase metal/electrolito en la base de los poros del recubrimiento.

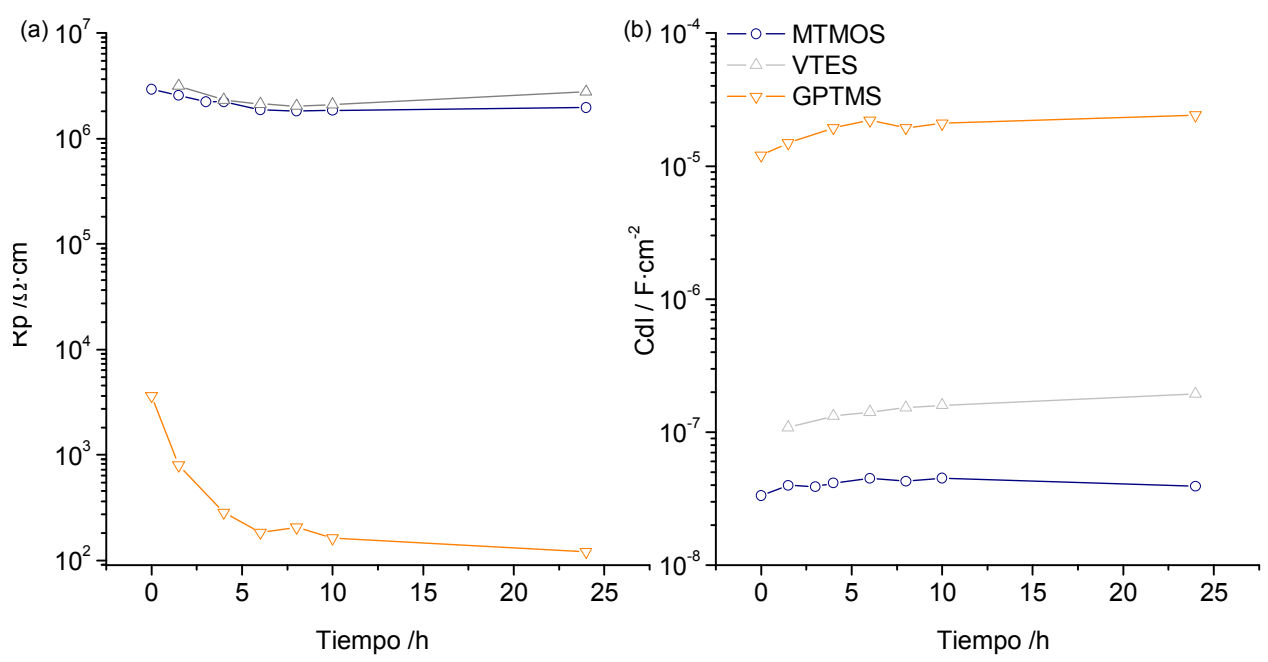

Figura. 4.23 Comparación de la evolución del valor de (a) resistencia a la polarización y (b) capacidad de la doble capa con el tiempo de exposición a la disolución $3,5 \% \mathrm{NaCl}$ de los recubrimientos MTMOS, VTES y GPTMS.

La resistencia de polarización, $R_{p}$, es una medida del grado de actividad ánodocátodo de la interfase, de forma que cuanto menor es este valor la interfase es más activa $\mathrm{y}$, por tanto se pueden generar procesos de corrosión más fácilmente. Los recubrimiento MTMOS y VTES tienen valores de $R_{p}$ muy constantes durante el tiempo de exposición al electrolito, con valores entorno a $2.3 \cdot 10^{6} \Omega \cdot \mathrm{cm}^{2}$. El recubrimiento GPTMS presenta valores mucho menores desde el instante inicial, con un valor de $3641 \Omega \cdot \mathrm{cm}^{2}$, y decreciente con el tiempo de exposición, con un valor a 24 horas de exposición de $120 \Omega \cdot \mathrm{cm}^{2}$. 
El recubrimiento GPTMS presenta valores de $R_{p} 4$ ordenes de magnitud por debajo de los registrados para los basados en MTMOS y en VTES. El recubrimiento GPTMS tiene una alta permeabilidad (valores de $R_{p o}$ bajos y valores crecientes de $\mathrm{CPE}_{\mathrm{c}}$ ) por lo que se favorece la entrada de electrolito y especies activas a su través, provocando una mayor actividad en la interfase. Los recubrimientos MTMOS y VTES muestran un valor de $R_{p}$ constante durante el tiempo de exposición, estos recubrimientos protegen frente a fenómenos de corrosión, teniendo una interfase muy estable.

Los valores de $\mathrm{CPE}_{d l}$ son muy constantes con el tiempo de exposición al electrolito para todos los recubrimientos. El recubrimiento MTMOS tiene un valor inicial de $3,3 \cdot 10^{-8} \mathrm{~F} \cdot \mathrm{cm}^{-2}$ y se mantiene constante con un valor a las 24 horas de $3,9 \cdot 10^{-8} \mathrm{~F} \cdot \mathrm{cm}^{-2}$. El recubrimiento VTES tiene un valor inicial de $1,1 \cdot 10^{-7} \mathrm{~F} \cdot \mathrm{cm}^{-2}$ y al final del tiempo de exposición es de $1,9 \cdot 10^{-7} \mathrm{~F} \cdot \mathrm{cm}^{-2}$. El recubrimiento GPTMS tiene un valor inicial de $1,2 \cdot 10^{-5} \mathrm{~F} \cdot \mathrm{cm}^{-2}$ y a tiempo 24 horas es de $2,4 \cdot 10^{-5} \mathrm{~F} \cdot \mathrm{cm}^{-2}$.

El recubrimiento GPTMS tiene un valor de $\mathrm{CPE}_{\mathrm{dl}}$ dos ordenes de magnitud superior a los registrados por MTMOS y VTES debido posiblemente a procesos de deslaminación entre el recubrimiento y el metal que hacen aumentar el valor de este condensador. Los recubrimientos MTMOS y VTES no presentan procesos de deslaminación.

Los elementos pasivos del circuito equivalente correspondientes a la tercera constante de tiempo (aquella que aparece a las menores frecuencias) describen la capa de óxido formada en el sustrato metálico. Esta tercera constante de tiempo sólo aparece en el caso del GPTMS debido a una mayor entrada de electrolito y especies activas (valores de $R_{p o}$ bajos y valores crecientes de $C P E_{c}$ ) y la presencia de una interfase más activa (valores $\mathrm{R}_{\mathrm{p}}$ bajos), respecto a los otros recubrimientos. En el caso del VTES y MTMOS no se aprecia el fenómeno de aparición de la capa de óxido y de ahí la existencia de únicamente dos constantes de tiempo. La tercera constante de tiempo, que se describe a frecuencias bajas, no está definida claramente dentro del intervalo de frecuencias utilizado para realizar las medidas. Los puntos que describen la tercera constante de tiempo no son suficientes para poder realizar una modelización de los valores de la resistencia $R_{o x}$ y la capacidad $C P E_{o x}$, pudiéndose sólo señalar su existencia. 
De los resultados electroquímicos se puede concluir que el recubrimiento MTMOS inicialmente es poco permeable al electrolito, es decir, tiene un carácter hidrófobo como se evaluó con las medidas de ángulo de contacto. Con el tiempo de exposición tiende a absorber electrolito rápidamente, tiene un comportamiento muy variable con el paso del tiempo de exposición, lo que puede deberse a una degradación hidrolítica del recubrimiento en contacto con el electrolito. A pesar de la entrada de electrolito la interfase es estable y no se producen fenómenos de deslaminación.

El recubrimiento VTES es poco permeable al electrolito y mantiene esta impermeabilidad durante todo el tiempo de exposición, sin verse afectada por el contacto con electrolito. Al igual que el recubrimiento MTMOS las especies activas no llegan a la interfase, y no se producen fenómenos de deslaminación. Los recubrimientos VTES y MTMOS tienen una red bastante tupida que impide el paso de especies activas hasta la superficie, mostrando una prometedora protección frente a los procesos corrosivos.

El recubrimiento GPTMS es un recubrimiento con una red abierta que permite la entrada de electrolito, registrándose desde el instante inicial una mayor cantidad de agua absorbida en su interior ( $\mathrm{CPE}_{\mathrm{c}}$ superior al obtenido para MTMOS y VTES), y con el paso del tiempo de exposición al electrolito va aumentando la cantidad de agua y especies activas que entran a través de los canales existentes en la red. Además cuenta con una interfase activa donde se llegan a producir procesos corrosivos por lo que llega a detectarse la presencia de una tercera constante de tiempo.

\section{6 Degradación hidrolítica}

Como hipótesis de trabajo, en función de la aplicación final de estos recubrimientos, se ha decidido contemplar que deben degradarse en contacto con el fluido biológico a tiempos menores a dos meses. Se ha seleccionado este tiempo debido a que el titanio en tiempos largos (menor a 2 meses) como material de implantes dentales muestra un buen comportamiento. Estos materiales en los primeros dos meses deben aumentar la biocompatibilidad y promover los procesos de osteointegración del implante. Los recubrimientos sol-gel pueden degradarse en contacto con agua, tanto por erosión como por hidrólisis de las películas. El 
mecanismo por el cual se produce la degradación hidrolítica de los films está extensamente descrito en bibliografía [67-71] y se esquematiza en la (ec.4.1).

$$
\mathrm{SiO}_{2}+2 \mathrm{H}_{2} \mathrm{O} \rightarrow \mathrm{Si}(\mathrm{OH})_{4}
$$

Se ha evaluado la degradación por hidrólisis de los recubrimientos sumergiéndolos en un buffer fosfato (PBS) durante un tiempo total de 6 semanas y registrando la pérdida de peso de los mismos. Los materiales para realizar este estudio se obtuvieron en película libre y se dispusieron dentro de unas "cestas" para permitir la entrada del medio (PBS) y, a su vez, impedir la pérdida de parte del material. Los resultados de la pérdida de peso en tanto por ciento para cada recubrimiento se muestran en la Figura. 4.24.

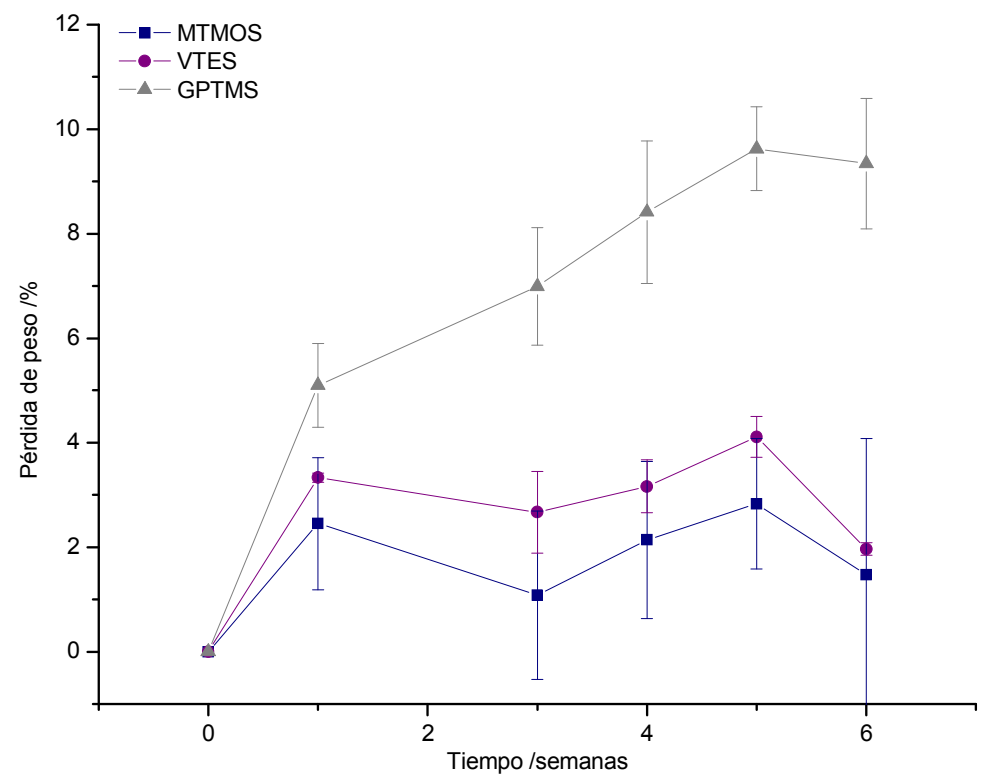

Figura. 4.24 Degradación hidrolítica por pérdida de peso de los recubrimientos MTMOS, VTES y GPTMS sumergidos en PBS a $37^{\circ} \mathrm{C}$.

El recubrimiento con una mayor tasa de degradación es el GPTMS. Este resultado era de esperar a la vista de los obtenidos en EIS. Al tratarse de una red abierta, el medio entra a través de los canales de la red y favorece la degradación del film por hidrólisis. 
Los recubrimientos MTMOS y VTES experimentan toda la degradación en la primera semana de estudio y mantienen su peso con el paso del tiempo de inmersión en el período estudiado, es decir no se registra una pérdida de peso significativa por encima de la primera semana de ensayo.

De los resultados obtenidos en el ensayo de degradación se concluye que los materiales obtenidos con los tratamientos de curado optimizados mediante la técnica ${ }^{29}$ Si-RMN para la obtención de un máximo entrecruzamiento no presentan una degradación significativa en los tiempos estudiados, alcanzándose un $10 \%$ en el caso de GPTMS y, tan solo, un 3\% en VTES y MTMOS.

En la metodología planteada para la realización de la presente Tesis Doctoral se plantearon distintas opciones para mejorar las tasas de degradación. Dichas alternativas se presentan en capítulos posteriores.

\section{7 Liberación de agentes terapéuticos}

Los recubrimientos sintetizados pueden servir como medio para la liberación localizada de agentes terapéuticos como antiinflamatorios o antibióticos, ya que se pueden dopar fácilmente y, gracias a los procesos de absorción de agua por parte del film y su degradación, se produce la liberación de los agentes al entorno.

Se han dopado los recubrimientos con procaína que es un fármaco utilizado como modelo en estudios de liberación, se trata de un fármaco muy soluble en agua. El fármaco se introdujo en la síntesis disolviéndolo en el agua de hidrólisis. Los materiales se obtuvieron en film libre, pero en este caso no se extrajeron del molde (en este caso de aluminio en vez de teflón) para simular mejor el comportamiento final del recubrimiento, ya que en la aplicación final solo se libera por una cara. Los estudios se realizaron sumergiendo las muestras junto con el molde y manteniendo en agitación dentro de PBS con $\mathrm{pH}=6,8$ a una temperatura de $37^{\circ} \mathrm{C}$. En la Figura. 4.25 se muestran las curvas de liberación de los materiales MTMOS, VTES y GPTMS hasta 3 días de ensayo. En las gráficas se representa $M_{t} / M_{\infty}$ donde $M_{t}$ es la cantidad de fármaco detectada a un tiempo determinado $t$ y $M_{\infty}$ es la cantidad de fármaco incorporado en el recubrimiento sintetizado. 


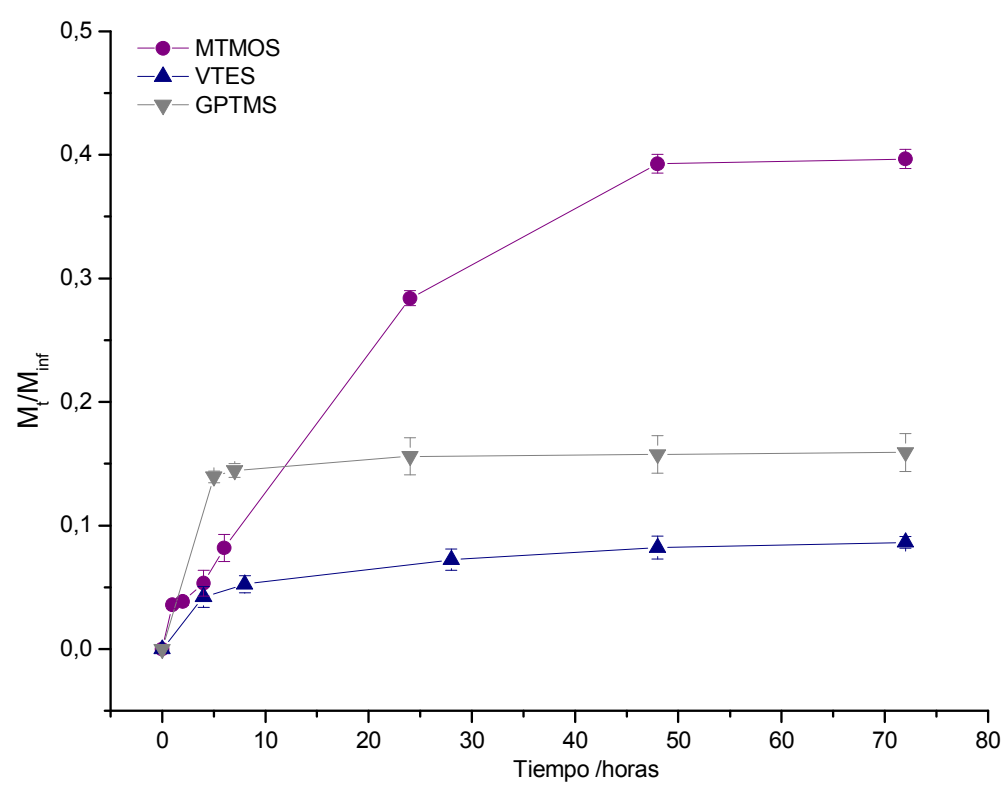

Figura. 4.25 Curvas de liberación de agente terapéutico de los recubrimientos MTMOS, VTES y GPTMS dopados con un $5 \%$ procaína.

Las curvas obtenidas tienen el perfil de liberación esperado, mostrando una primera liberación rápida proveniente del fármaco que está albergado en los poros que se encuentran en contacto con el medio, seguida de una liberación más lenta proveniente de los poros internos [80]. En el gráfico se observa como la cinética de liberación de los materiales es distinta en función de la composición. El material con una mayor tasa de liberación es el MTMOS, que llega a liberar un $40 \%$ del fármaco incorporado. Esto probablemente se debe a la mayor absorción de agua que experimenta este recubrimiento (analizada mediante la técnica EIS, apartado 4. 5) en contacto con un electrolito, el agua entra en la red y favorece la difusión del agente incorporado a través del recubrimiento de forma que se libera en el entorno.

El recubrimiento VTES no absorbe agua y se ve inalterado con el tiempo de inmersión en el electrolito. Por este motivo se produce una liberación acusada en las primeras horas de contacto con el medio, por liberación de los agentes en superficie (valor registrado de un 10\%) y luego se estabiliza.

El recubrimiento GPTMS a pesar de contar con una red abierta donde el agua entra fácilmente como se analizó con las técnicas electroquímicas, no se registra la 
liberación esperada. Este recubrimiento libera en las primeras 8 horas un $15 \%$ y a tras este tiempo no libera el resto de agentes incorporados. Este hecho se debe a la formación de un enlace químico entre el grupo amina del fármaco incorporado y el grupo epoxi del precursor GPTMS que impide que la procaína incorporada se libere al entorno. El grupo epoxi es un enlace muy reactivo, la amina presente en el fármaco ataca al carbono más deficiente de electrones y se crea un enlace entre éste y el nitrógeno de la amina. La forma en la que reacciona el grupo GPTMS con la amina del fármaco se esquematiza en la Figura. 4.26.<smiles>CCN(CC)CCOC(=O)c1ccc(N)cc1</smiles>

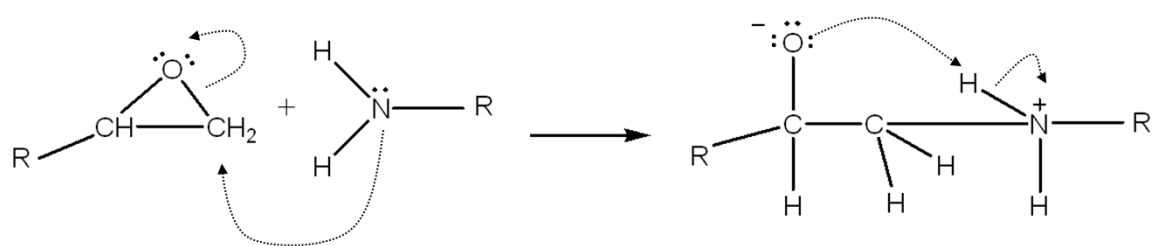<smiles>[R]N[CH]C([2H])([2H])O</smiles>

Figura. 4.26 Reacción de enlace del grupo epoxi del precursor GPTMS y grupo amina del fármaco procaína. 


\section{8 Comportamiento celular}

Dada la aplicación final de estos nuevos materiales, otro estudio importante a realizar consiste en la determinación de la presencia o ausencia de carácter tóxico de los mismos a las células, es decir, definir si son materiales citotóxicos, y en caso afirmativo, en qué grado. Para ello, se han realizado ensayos de viabilidad celular por extracción basados en la Norma ISO 10993 [119]. Los resultados del ensayo de citotoxicidad de los controles se presentan en $\%$ de viabilidad celular.

Con el fin de comparar los resultados obtenidos de los recubrimientos desarrollados con el material que actualmente se utiliza en implantes dentales, se ha realizado el ensayo sobre titanio puro grado 4 liso (sin topografía). Sobre este mismo material se han depositado los distintos recubrimientos. En la Figura. $4.27 \mathrm{se}$ muestran las curvas de viabilidad celular obtenidas en los ensayos con células L-929 en contacto con los extractos de los materiales.

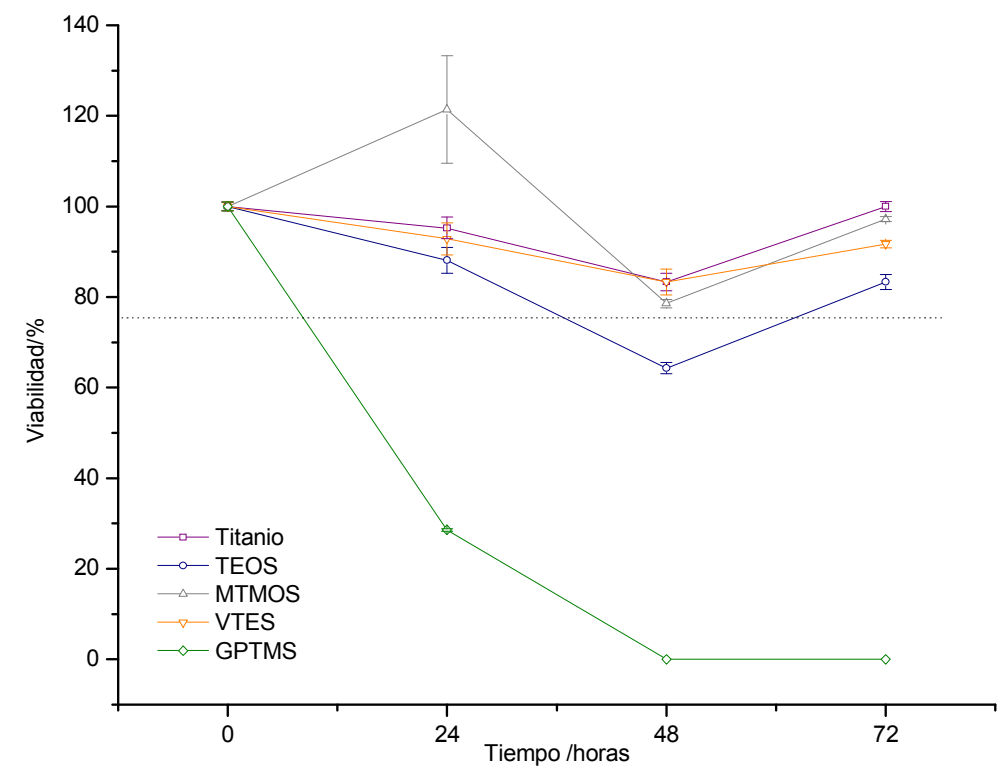

Figura. 4.27. Curva de viabilidad celular de las células L929 en contacto con los extractos del material de referencia Titanio puro grado 4 y los recubrimientos TEOS, MTMOS, VTES y GPTMS. Viabilidad celular en \% de DO de las muestras frente al DO control. 
El material de referencia seleccionado, titanio puro, tiene una ligera disminución de actividad mitocondrial celular, disminuyendo su viabilidad celular hasta alcanzar un $83 \%$ a 48 horas de ensayo, posteriormente a tiempos mayores a 48 horas comienza a mejorar su comportamiento, aumentando el número de células activas hasta alcanzar un valor de $\sim 92 \%$ a las 72 horas de ensayo.

El recubrimiento VTES, MTMOS y TEOS tienen un comportamiento similar en cuanto a viabilidad celular. EI MTMOS muestra un aumento del número de células viables a las 24 horas, mientras el VTES y TEOS tienen una tendencia ligeramente descendente. EI TEOS cruza ligeramente la barrera de citotoxicidad ( 64\%) a las 48 horas, reponiéndose hasta alcanzar un valor superior al $80 \%$ a las 72 horas. El GPTMS tiene un comportamiento considerablemente peor en comparación con el resto de materiales, con un carácter potencialmente citotóxico, como muestra el hecho de que a las 24 horas del inicio del ensayo la viabilidad celular sea del $28 \%$. Transcurridas las 48 horas de ensayo no se detecta actividad metabólica de las células.

El estudio de citotoxicidad demuestra que el MTMOS, TEOS, VTES y el titanio puro no tienen potencial citotóxico ya que el porcentaje de viabilidad celular no se reduce por debajo de un $75 \%$ respecto al valor control. Solamente el GPTMS presenta citotoxicidad ya que dicho material supera el $30 \%$ de reducción de la proliferación celular en relación al control.

Una vez estudiada la citotoxicidad, con el fin de evaluar el anclaje celular con distintas líneas celulares, se estudió la proliferación de fibroblastos de ratón de la línea celular L-929 Figura. 4.28 y osteoblastos humanos Figura. 4.30 sobre los materiales y sobre el Titanio puro.

Es importante recordar que el anclaje de células sobre la superficie de los materiales se ve influenciado por distintos parámetros del material como son la topografía, estructura química (que media en la hidrofilia) o propiedades mecánicas. De ellas la hidrofilia es un factor determinante en la absorción de proteínas en la superficie y en consecuencia de la adhesión celular [74, 120-121]. De hecho, superficies hidrófobas (superficies con alto ángulo de contacto) no favorecen las interacciones entre el medio biológico y el material, impidiendo la absorción de 
proteínas en la superficie. Por otro lado, superficies muy hidrófilas tampoco favorecen en anclaje celular [122]. Por tanto, existe un intervalo de hidrofilias óptimas, se ha reportado en bibliografía que superficies con una hidrofilia moderada mejoran la absorción de proteína y, por tanto, mejoran el anclaje celular [123-124].

De los resultados presentados de ángulo de contacto en el apartado 4. 5 , se extraía que el material más hidrófilo es el GPTMS y el TEOS con ángulos de contacto de $61^{\circ}$ y $66^{\circ}$ respectivamente. EI MTMOS y VTES tienen un carácter más hidrófobo, con un valor del ángulo de contacto de $82^{\circ}$ y $80^{\circ}$ respectivamente.

En la Figura. 4.28 se representan las curvas de proliferación celular de fibroblastos de ratón de la línea celular L-929 a 1, 2, 3 y 4 días desde la siembra de las células sobre los distintos materiales y sobre titanio puro liso.

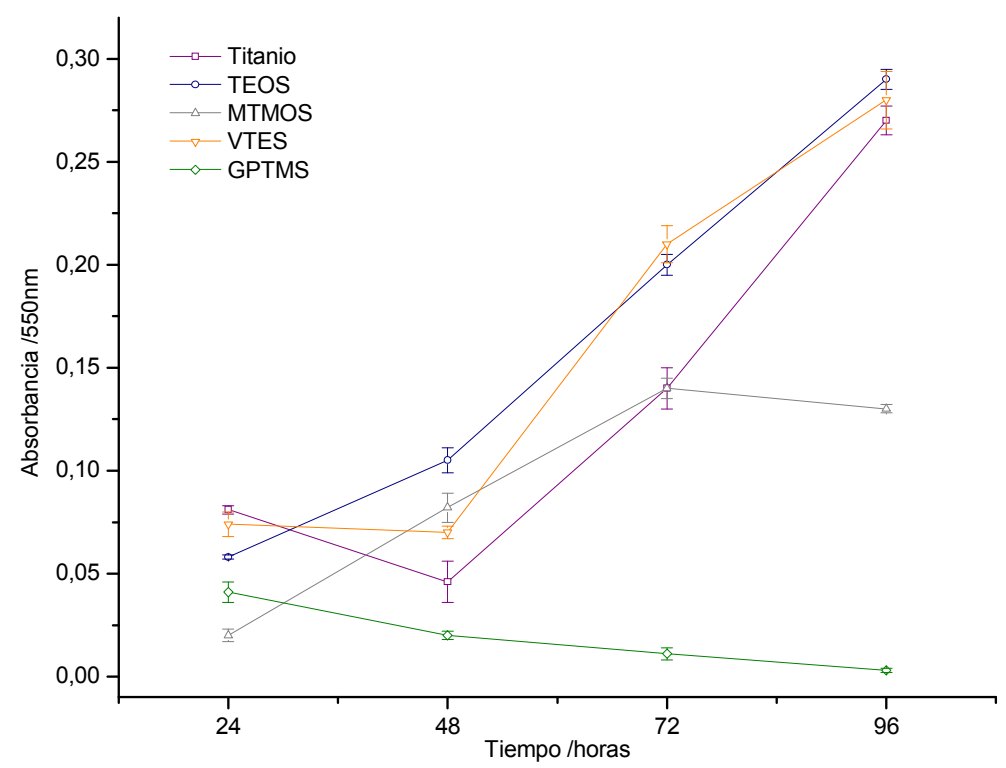

Figura. 4.28. Curva de proliferación de células L929 sobre el material de referencia Titanio puro grado 4 y los recubrimientos TEOS, MTMOS, VTES y GPTMS. Absorbancia medida a $550 \mathrm{~nm}$.

El material de referencia seleccionado para el estudio, Titanio puro, tiene una ligera disminución de actividad mitocondrial en las primeras horas que se registra hasta las 48 horas de ensayo. A tiempos mayores tiene una mejora progresiva del anclaje y proliferación celular de las L-929. 
El recubrimiento VTES y TEOS tienen una proliferación de fibroblastos similar. El VTES no presenta en las primeras 48 horas un incremento de la adhesión celular, pero tiene un mayor número de células ancladas en su superficie si se compara con el Titanio. A mayores tiempos de cultivo la proliferación celular se mejora notablemente respecto a la referencia. EI TEOS tiene una proliferación celular siempre creciente en el tiempo, con unos valores de actividad mitocondrial sobre el material muy semejantes a los obtenidos en VTES. EI MTMOS tiene una proliferación celular creciente con el tiempo de ensayo hasta las 72 horas donde no se estabiliza la proliferación celular. Como era de esperar el recubrimiento GPTMS tiene un mal comportamiento que se debe a su carácter citotóxico (Figura. 4.27).

Es importante estudiar la proliferación de osteoblastos en los materiales estudiados ya que dada su aplicación final, el reclutamiento de células osteoprogenitoras será importante para la regeneración del tejido circundante. En primer lugar se estudió la capacidad de reclutamiento de osteoblastos humanos del titanio (Figura. 4.29).

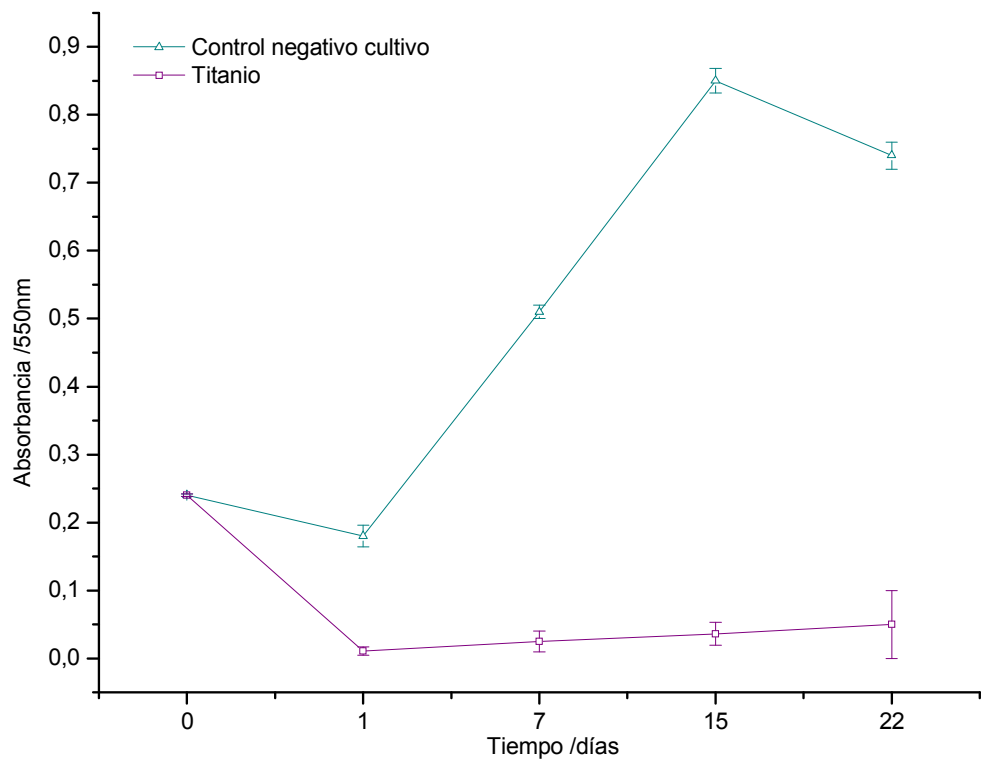

Figura. 4.29 Curva de proliferación de osteoblastos humanos sobre el material de referencia Titanio puro grado 4 y el control negativo del cultivo (medio para osteoblastos). Absorbancia medida a $550 \mathrm{~nm}$. 
El titanio en comparación con el control negativo tiene un reclutamiento y proliferación de osteoblastos humanos muy pobre. Registra una caída drástica, llegando casi a no detectarse actividad mitocondrial, en el primer día de cultivo y no consigue recuperar la adhesión celular con el paso del tiempo de cultivo hasta un tiempo de 22 días.

Es importante mejorar este funcionamiento deficiente del titanio y por este motivo se ha estudiado in vitro la capacidad para la proliferación de osteoblastos humanos de los recubrimientos obtenidos. En la Figura. 4.30 se representan las curvas de proliferación celular de osteoblastos humanos a 1, 7 y 15 días desde la siembra de las células sobre los distintos materiales y sobre titanio puro liso.

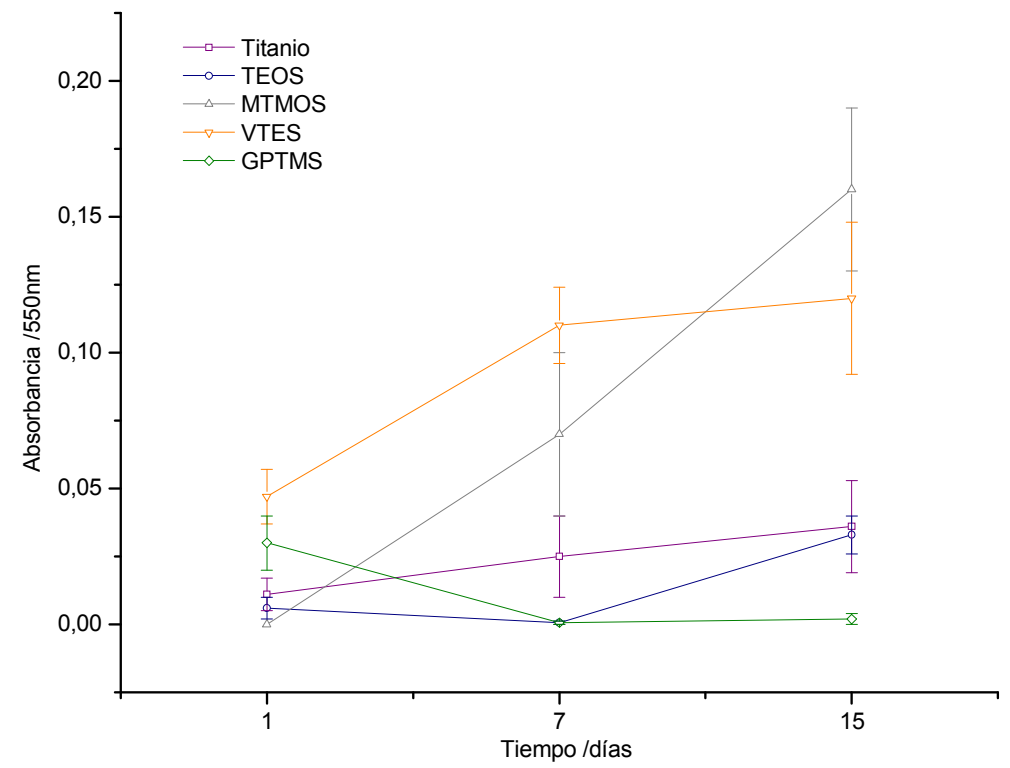

Figura. 4.30. Curva de proliferación de osteoblastos humanos sobre el material de referencia Titanio puro grado 4 y los recubrimientos TEOS, MTMOS, VTES y GPTMS. Absorbancia medida a $550 \mathrm{~nm}$.

El recubrimiento con peor comportamiento, como era de esperar dada su citotoxicidad, es el GPTMS no detectándose actividad mitocondrial a partir de 7 días de cultivo. El recubrimiento TEOS también muestra un mal comportamiento con una mala adhesión inicial que se recupera a partir de los 7 días. Este comportamiento era de esperar debido a que se trata de un material con una alta hidrofilia, como se comentó anteriormente, no favorece los procesos de anclaje celular. El material VTES 
tiene el mejor anclaje celular a tiempos cortos (1 día) y experimenta una buena proliferación celular en todos los tiempos estudiados, mucho superior a la registrada por el titanio. El material MTMOS tiene un mal anclaje inicial (1día) sin embargo es el que mejor proliferación de osteoblastos experimenta con el paso del tiempo de cultivo.

En comparación con el titanio estos dos últimos materiales presentan un reclutamiento de células osteogénicas excelente, consiguiéndose una actividad mitocondrial superior en todos los tiempos de ensayo.

\section{9 Selección del precursor óptimo}

Se han sintetizado y estudiado recubrimientos a base de TEOS, MTMOS, VTES y GPTMS. Se han obtenido para todos los casos recubrimientos homogéneos, sin grietas y con buenas propiedades superficiales. Los recubrimientos cuentan con una red inorgánica tipo Si-O-Si y una parte orgánica que varía dependiendo del precursor utilizado. Los recubrimientos con una parte orgánica pequeña, como MTMOS y VTES no presentan $T_{g}$, sin embargo, cuando se aumenta la proporción de parte orgánica, como es el caso del GPTMS, se detecta $T_{g}$ con un valor aproximado de $-52^{\circ} \mathrm{C}$. Por otro lado, se ha comprobado que las temperaturas utilizadas para la síntesis de los recubrimientos no degradan los materiales, ya que los fenómenos de degradación comienzan por encima de $200^{\circ} \mathrm{C}$ y las temperaturas de curado no superan los $140^{\circ} \mathrm{C}$.

Las propiedades anticorrosivas de los materiales se han evaluado y gracias a ella se ha podido evaluar la cantidad de agua que absorben los materiales en contacto con un electrolito. El material con mayor absorción es el GPTMS, seguido de MTMOS y VTES. Los materiales obtenidos se degradan en contacto con el medio líquido, el que mayor degradación experimenta es el GPTMS, seguido de VTES y MTMOS.

Se han dopado los recubrimientos con un fármaco modelo y se ha estudiado la cinética de liberación del agente incorporado. El material que libera mayor cantidad de fármaco es el MTMOS. EI VTES debido a su estabilidad en contacto con el electrolito libera pequeñas cantidades de fármaco. Se ha detectado que el material GPTMS reacciona con el fármaco introducido y tan solo se consigue liberar aquel que no ha reaccionado. 
Se ha estudiado la citotoxicidad de los materiales y se ha detectado que tan sólo el GPTMS presenta un carácter marcadamente citotóxico, el resto de recubrimientos TEOS, MTMOS y VTES a todos los tiempos estudiados $(0,24,48,72$ horas) se encuentran por encima del umbral de citotoxicidad fijado, en la normativa UNE, en un $75 \%$ de absorbancia frente a la absorbancia control, es decir, el material ha de tener al menos un $75 \%$ de las células que tiene el control en su superficie.

Adicionalmente, se han incubado in vitro sobre los recubrimientos fibroblastos L929 detectándose que el recubrimiento GPTMS tiene mal comportamiento en el anclaje celular. El resto de materiales y el titanio tienen una buena proliferación de fibroblastos L-929.

En el caso de estudiar el anclaje y proliferación de células osteogénicas como osteoblastos humanos se ha detectado que el titanio tiene un comportamiento deficiente sobre todo en los primeros días de cultivo. Todos los recubrimientos sintetizados, exceptuando el GPTMS, mejoran el anclaje y proliferación celular en comparación al titanio. El mejor comportamiento se ha detectado para los recubrimientos VTES y MTMOS.

Del análisis de las propiedades estudiadas se ha decidido tomar como precursor de partida para la preparación de distintos materiales y el posterior estudio de sus propiedades el precursor VTES. 

Capítulo 5 Síntesis y optimización de series de recubrimientos sol-gel con propiedades diferenciadas 

Tras haber seleccionado en el Capítulo 4 el precursor VTES como uno de los posibles precursores óptimos para la realización de distintos recubrimientos, en este capítulo se plantea la posibilidad de sintetizar series de materiales a partir de VTES y mezclando con otros precursores con el fin de modular las propiedades del recubrimiento. Por un lado, se busca disminuir las temperaturas de curado de los recubrimientos, el ángulo de contacto y aumentar la degradabilidad de los sistemas. Por otro lado, se busca variar la cantidad de grupos funcionales en la superficie del material de forma que se favorezca la adhesión de proteínas o péptidos a la superficie del recubrimiento. Se confía en que todos estos cambios contribuyan a mejorar el anclaje celular y, por tanto, el comportamiento del implante.

Se ha reportado en bibliografía que la adición de distintas cantidades de TEOS (precursor puramente inorgánico) como mezcla de otros precursores (en concreto MTMOS) se consigue disminuir la temperatura de curado, disminuir el ángulo de contacto y aumentar la degradación [67] de los materiales.

Por otro lado, la adición de distintas cantidades de GPTMS aumenta la cantidad de grupos funcionales epoxi en el material, además se incorpora un mayor carácter orgánico al recubrimiento que le confiere unas propiedades diferenciadas.

La metodología a llevar a cabo consiste en sintetizar dos series de materiales a partir del material base VTES, una de las series basada en la adición de distintas cantidades de TEOS y otra adicionando distintas cantidades de GPTMS. Se realiza la caracterización fisicoquímica, mecánica y biológica y se analizan los resultados en función de la composición química a fin de optimizar la formulación en cuanto a su capacidad de osteointegración definida a priori por características como: osteoinducción, capacidad de reabsorción, adherencia al sustrato, posibilidad de ser funcionalizados, etc. Se comprueba en primer lugar la morfología de los recubrimientos obtenidos sobre la superficie metálica a nivel macrométrico, así como a nivel micrométrico por medio de SEM. Se caracteriza la formación de red en función de los parámetros de síntesis utilizados por medio de ${ }^{29} \mathrm{Si}-\mathrm{RMN}$ de líquidos y se caracteriza químicamente la red formada por medio de FTIR y ${ }^{29}$ Si-RMN de sólidos. Con el fin de profundizar en el conocimiento de la estructura de las redes formadas se realiza un estudio de DSC para obtener $T_{g}$ y se caracteriza la degradación térmica por TGA. 
Para evaluar la biocompatibilidad de estas series de materiales a aplicaciones biomédicas se realizaron ensayos de proliferación de células madre mesenquimales y se estudió su diferenciación hacia osteoblastos.

Una vez optimizado el recubrimiento se seleccionará el óptimo para la aplicación final. Partiendo de este recubrimiento se intentará mejorar su comportamiento adicionando partículas bioactivas (HAp), se variará el grado de entrecruzamiento de la red por medio de cambios en el tratamiento de curado y se hará un estudio en profundidad de la liberación de fármacos desde el mismo.

\section{1 Recubrimientos con distinto contenido inorgánico}

En este apartado se sintetiza y caracteriza la serie de materiales obtenidos a partir del "precursor base seleccionado" VTES y distintas cantidades de TEOS. Se decide introducir TEOS y variar su proporción en la formulación fundamentalmente para reducir las temperaturas de curado y aumentar el carácter hidrófilo porque, como describe la bibliografía, el grado de hidrofilia del recubrimiento es un factor importante en la adhesión celular. Por otro lado, también se ha documentado en bibliografía que por medio de la degradación de las redes de silicio se liberan compuestos de silicio que pueden favorecer la osteoinducción [68-72] . La hipótesis de partida es que redes con un mayor contenido inorgánico degradarán más rápido, por tanto, liberarán mayores cantidades de compuestos de silicio al entorno. Además, es interesante que el recubrimiento desaparezca con el paso del tiempo (menos de 2 meses), dejando la superficie del implante de titanio expuesta, ya que a largos tiempos esta superficie tiene un buen comportamiento en cuanto al anclaje del implante se refiere.

\subsubsection{Síntesis de la serie de materiales VTES-TEOS}

Se ha sintetizado una serie de materiales partiendo de VTES y añadiendo distintas cantidades de TEOS utilizando las condiciones de síntesis descritas en 3.1.2.

El sol presenta unas buenas propiedades de viscosidad, siendo homogéneo y transparente, para todo el intervalo de formulaciones (desde 0\%TEOS hasta $100 \%$ TEOS). Sin embargo, el contenido máximo de TEOS está marcado por la formación o no de una película continua cuando el sol se aplica sobre metal. Se han 
aplicado sobre metal los recubrimientos en etapa sol preparados y se ha detectado que para una relación molar VTES:TEOS por encima de 7:3 no se consiguen obtener recubrimientos homogéneos y adheridos sobre la superficie metálica con las condiciones de síntesis utilizadas (apartado 3.1.2). Para relaciones molares VTES:TEOS por encima de 7:3 el recubrimiento obtenido es frágil y no presenta una buena adherencia al metal en toda la superficie por lo que se descarta la síntesis de estas formulaciones. Por tanto, se han sintetizado recubrimientos con una relación molar VTES:TEOS 9:1, 8:2 y 7:3.

Estos recubrimientos una vez depositados sobre el metal son transparentes, homogéneos y no presentan poros ni imperfecciones (Figura. 5.1(izq.)). Tienen un acabado brillante en todos los casos, que disminuye con el aumento del contenido en TEOS (Figura. 5.1(dcha.)).
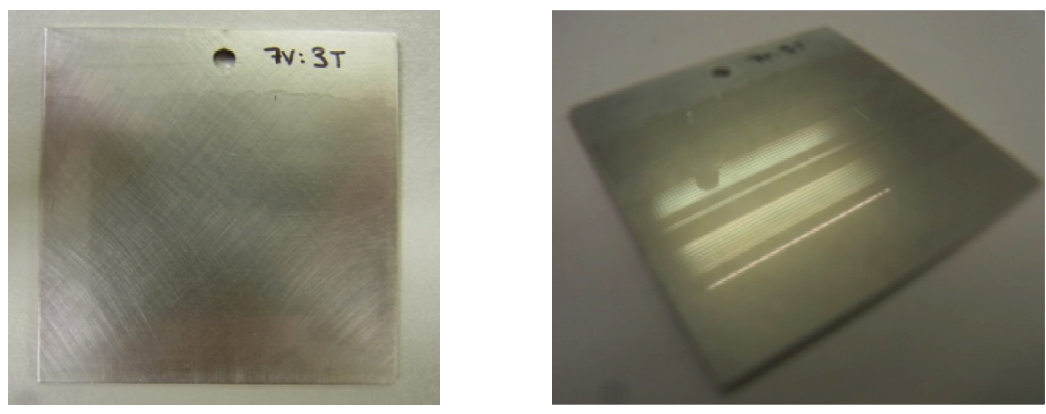

Figura. 5.1 (Izq.) Ejemplo de plancha recubierta con el recubrimiento 7V:3T mediante la técnica dip-coating. (Dcha.) reflejo tipo espejo sobre la superficie del recubrimiento 7V:3T.

Como en casos anteriores, se ha comprobado la adherencia del recubrimiento al sustrato metálico por medio de la técnica de corte enrejado obteniéndose para todos los casos recubrimientos adherentes.

Como se ha comentado la adicción de TEOS puede originar en los recubrimientos un exceso de fragilidad al verse aumentada la carga inorgánica y, por tanto, pueden aparecer grietas en los recubrimientos. Por este motivo, se ha evaluado por medio de SEM el acabado superficial a nivel micrométrico de los recubrimientos con distintas cantidades de TEOS hasta un $30 \%$ aplicados sobre acero AISI 316L (Figura. 5.2) con el fin de confirmar la usencia de grietas a todos los niveles. 

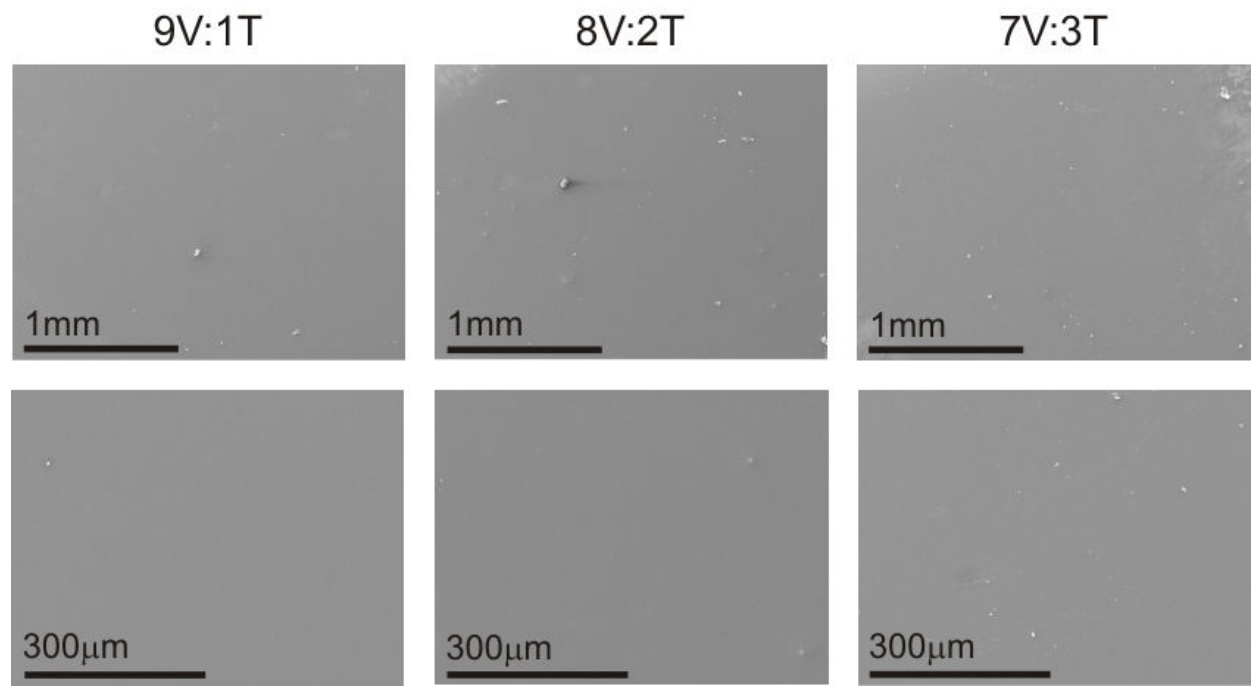

Figura. 5.2 Micrografías obtenidas por SEM de a los recubrimientos 9V:1T, 8V:2T, 7V:3T aplicados sobre acero $316 \mathrm{~L}$. En la primera fila a 50X aumentos y en la segunda a $200 \mathrm{X}$ aumentos.

La serie de materiales tienen un buen acabado superficial y no se observan imperfecciones como grietas o poros. Además no se aprecian agregados procedentes de posibles separaciones de fase entre los componentes utilizados.

Se han conseguido obtener el material sin aplicarlo en sustrato en forma de película libre con un espesor aproximado de $1 \mathrm{~mm}$ como se muestran en la Figura. 5.3. Estas películas libres se obtienen vertiendo la cantidad apropiada de sol (especificada en 3.1.3c) en moldes de teflón, para a continuación introducirlos en la estufa durante 1 hora a $50^{\circ} \mathrm{C}$. Posteriormente se extraen, se desmoldan y se vuelven a introducir en la estufa otra hora a $50^{\circ} \mathrm{C}$, si bien en esta ocasión la película se coloca entre dos planchas de teflón con una cierta compresión para concluir el proceso de curado y evitar la curvatura de la película. Las películas son consistentes y no presentan grietas ni poros. Este tipo de muestra se utilizará para realizar la caracterización del material en aquellos ensayos donde no se pueda utilizar como recubrimiento sobre metal sino como película libre (propiedades térmicas, químicas o mecánicas). 


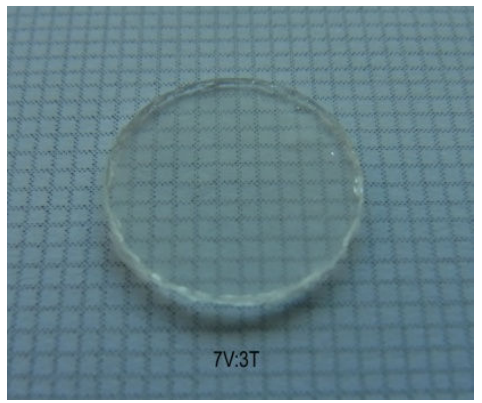

Figura. 5.3 Ejemplo de los recubrimientos en película libre obtenidos a partir de VTES con distintas cantidades de TEOS, 7V:3T.

\subsubsection{Caracterización química de la serie de recubrimientos VTES-TEOS}

Se han caracterizado los procesos de formación de red durante las reacciones de hidrólisis/condensación cuando intervienen los precursores VTES y TEOS. Estas reacciones pueden estudiarse por medio de ${ }^{29} \mathrm{Si}-\mathrm{RMN}$ de líquidos y sólidos, así como por FTIR. Se han utilizado estas técnicas para fijar parámetros de síntesis como pueden ser el tiempo de reacción para la hidrólisis y condensación de los precursores, o las condiciones de curado óptimas para la formación de la red polisiloxánica. Al tratarse de una formulación mixta, es importante comprobar que se ha producido la correcta hidrólisis de los dos precursores y que las reacciones de condensación se producen para todo el intervalo de formulaciones.

Por otro lado, las técnicas de caracterización química permiten caracterizar la cadena vinílica presente en el precursor VTES así como su posible modificación durante la reacciones de síntesis de la red sol-gel.

Se presentan en este apartado los resultados para dos técnicas: ${ }^{29}$ Si-RMN y FTIR.

\section{a) Resonancia magnética nuclear}

Cada alcóxidos de silicio tiene su velocidad de hidrólisis y condensación, por este motivo, cuando se introducen dos alcóxidos distintos dentro de una misma formulación es necesario comprobar que, con los parámetros de síntesis utilizados ( $\mathrm{pH}$, cantidad de agua estequiométrica, tiempo de hidrólisis), se consigue la mayor hidrólisis posible de ambos alcóxidos. Para ello, se ha realizado un estudio por RMN en líquidos del núcleo ${ }^{29} \mathrm{Si}$ que nos permite analizar el grado de hidrólisis y condensación de cada precursor en cada mezcla VTES:TEOS con las condiciones 
establecidas. En este caso el pH seleccionado es 1, y la cantidad de agua adicionada es la estequiométrica para la hidrólisis de los grupos alcoxi del VTES y TEOS. Además se pretende optimizar el tiempo de hidrólisis/condensación para obtener el máximo entrecruzamiento de la red.

Para realizar el estudio a cada formulación (con distintas cantidades de TEOS) se ha realizado, en primer lugar, un RMN a ambos precursores disueltos en isopropanol. Posteriormente, se añadió el agua estequiométrica para la completa hidrólisis de los precursores VTES y TEOS y se registraron espectros en el instante en el que se añadió el agua acidificada (20 minutos tras la adición) y tras 1 y 2 horas de la adición. Se muestra en la Figura. 5.4 los espectros obtenidos para la formulación $7 \mathrm{~V}: 3 \mathrm{~T}$ a modo de ejemplo, en el resto de formulaciones el comportamiento registrado fue el mismo.

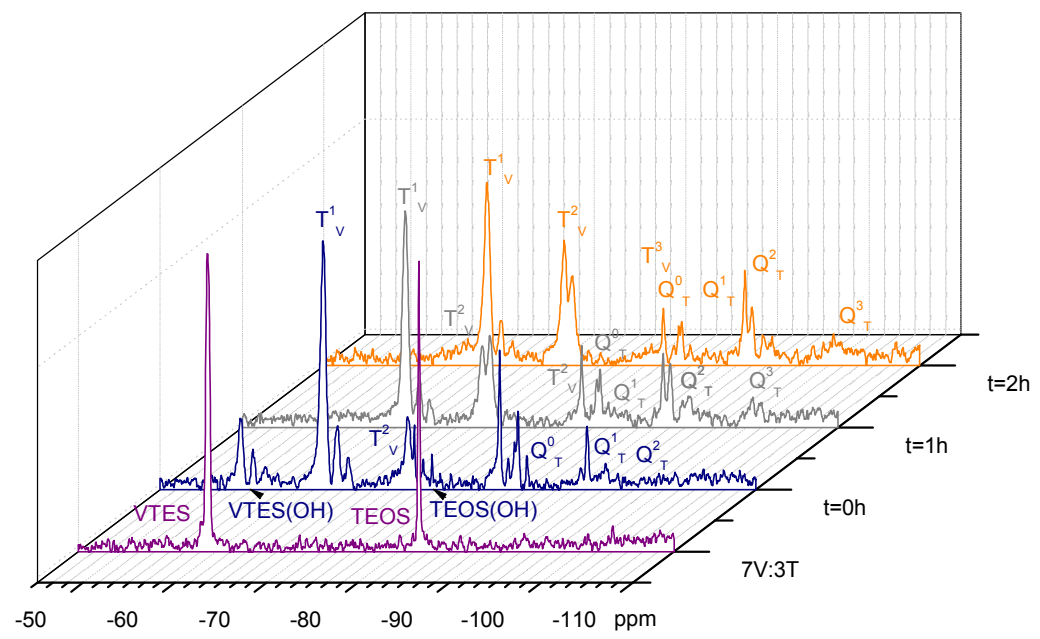

Figura. 5.4 Espectro de ${ }^{29}$ Si-RMN líquidos de 7VTES:3TEOS

El espectro de la mezcla de ambos precursores en alcohol muestra un desplazamiento químico a $-82 \mathrm{ppm}$ asociado al precursor TEOS y otro a $-59 \mathrm{ppm}$ asociado al VTES. Al adicionar el agua acidificada $(\mathrm{t}=0)$ se detectan picos asociados a especies hidrolizadas de ambos precursores -72ppm correspondiente al TEOS y 53ppm al VTES. También se detectan picos asociados a átomos de silicio de 
entornos $T^{1}$ y $T^{2}$ de VTES y $Q^{0}, Q^{1}, Q^{2}$ de TEOS. Después de una hora desde la adición del agua acidificada, los picos asociados a especies hidrolizadas desaparecen y aumenta la intensidad relativa de los picos $T^{2}$ y $Q^{2}$, además aparece $Q^{3}$. El pico $T^{3}$ puede existir pero se encuentra solapado por la señal $Q^{0}$. Tras 2 horas, aumenta la intensidad relativa de los picos $T^{2}, T^{3}, Q^{2}$ y $Q^{3}$. Los picos de desplazamientos químicos correspondientes a cada especie se recopilan en la Tabla 5.1.

Tabla 5.1 Valores del desplazamiento químico de las señales de ${ }^{29} \mathrm{Si}-\mathrm{RMN}$ líquidos 7VTES:3TEOS, asociadas a cada precursor.

\begin{tabular}{|c|c|c|c|c|c|c|c|c|c|}
\hline 7VTES:3TEOS & \multicolumn{8}{|c|}{ Desplazamiento químico $\delta /$ ppm } \\
\hline Precursor & $\mathrm{OH}$ & $\mathrm{T}^{1}$ & $\mathrm{~T}^{2}$ & $\mathrm{~T}^{3}$ & $\mathrm{Q}^{\mathrm{U}}$ & $\mathrm{Q}^{1}$ & $\mathrm{Q}^{2}$ & $\mathrm{Q}^{3}$ & $\mathrm{Q}^{4}$ \\
\hline VTES & -82 & -53 & -63 & -72 & -81 & - & - & - & - \\
\hline TEOS & -59 & -72 & - & - & - & -82 & -84 & -91 & -100 \\
\hline
\end{tabular}

En esta serie de materiales se ha utilizado una hidrólisis ácida, como cuando se preparan recubrimientos de un único precursor. Se produce por tanto una hidrólisis rápida de uno de los grupos alquil, detectándose en el instante inicial especies hidrolizadas que no han condensado TEOS(OH) y VTES(OH). Este alcóxido tiene una mayor tendencia a condensar que ha hidrolizar de nuevo por lo que la intensidad de especies $T^{1}$ y $Q^{1}$ asociadas a silicios con un puente siloxano formado es la más elevada. Con el paso del tiempo las reacciones de hidrólisis y condensación se van sucediendo y se va formando la cadena polisiloxánica, detectándose un aumento en las especies $T^{2}, T^{3}, Q^{2}$ y $Q^{3}$.

Con estos resultados se puede concluir que con la adición de hasta un $30 \%$ de TEOS en el VTES, las reacciones de hidrólisis y condensación de los dos precursores no están afectadas. Se observa como la adición de TEOS no altera las reacciones del precursor VTES. Como en el caso en el que se hidroliza VTES solo, se produce rápidamente especies $\mathrm{T}^{1}$ y $\mathrm{T}^{2}$, aumentando la intensidad de $\mathrm{T}^{2}$ con el tiempo de hidrólisis. En el caso del precursor TEOS cuando se sintetiza junto con VTES, sí ve alterado su velocidad de hidrólisis/condensación. En este caso el TEOS no hidroliza y condensa tan rápido como cuando se dispone solo, los picos asociados a la especie $Q^{3}$ se empiezan a detectar a partir de una hora después de la adición de agua. 
El proceso de hidrólisis se establece en todos los sistemas $9 \mathrm{~V}: 1 \mathrm{~T}, 8 \mathrm{~V}: 2 \mathrm{~T}$ y $7 \mathrm{~V}: 3 \mathrm{~T}$ a un tiempo fijo de una hora ya que no se aprecian cambios significativos en las intensidades relativas de los picos registrados a 1 hora y 2 horas. Se aprecia en todos los sistemas como después del proceso de hidrólisis el avance de la condensación es muy pequeño (señales de entornos tipo $T^{2}, T^{3}, Q^{2}, Q^{3}$ ) siendo necesaria la aplicación de un proceso de secado/curado con temperatura para asegurar la formación de la red.

Después de realizar el estudio de las reacciones de hidrólisis y condensación con ${ }^{29}$ Si-RMN de líquidos, los materiales obtenidos tras la aplicación del tratamiento de curado han sido estudiados por RMN de sólidos del núcleo ${ }^{29} \mathrm{Si}$. El tratamiento de curado se aplica con el fin de permitir la evaporación de los disolventes incorporados así como promover las reacciones de condensación. Se ha registrado en los espectros ${ }^{29} \mathrm{Si}-\mathrm{RMN}$ de líquidos que durante la primera etapa de hidrólisis aunque han tenido lugar reacciones de condensación, éstas no han sido suficientes para que se logre el máximo entrecruzamiento de la red, ya que no se detectan señales tipo $T^{3}$ (VTES) $\circ Q^{4}$ (TEOS). En este estudio se pretende comprobar si el tratamiento térmico aplicado consistente en una isoterma a $50^{\circ} \mathrm{C}$ durante 2 horas consigue el mayor grado de condensación de los precursores empleados, por tanto, un máximo entrecruzamiento de la red. Como consecuencia se detallará una caracterización de la red obtenida con las condiciones de síntesis aplicadas.

En la Figura. 5.5 se representa a modo de ejemplo el espectro de ${ }^{29} \mathrm{Si}-\mathrm{RMN}$ de sólidos del recubrimiento $7 \mathrm{~V}$ :3Ttras haberle aplicado el tratamiento de secado y curado consistente en una isoterma a $50^{\circ} \mathrm{C}$ durante 120 minutos. Las muestras ensayadas se obtienen en película libre y posteriormente se trituran para permitir una correcta adquisición de los espectros. 


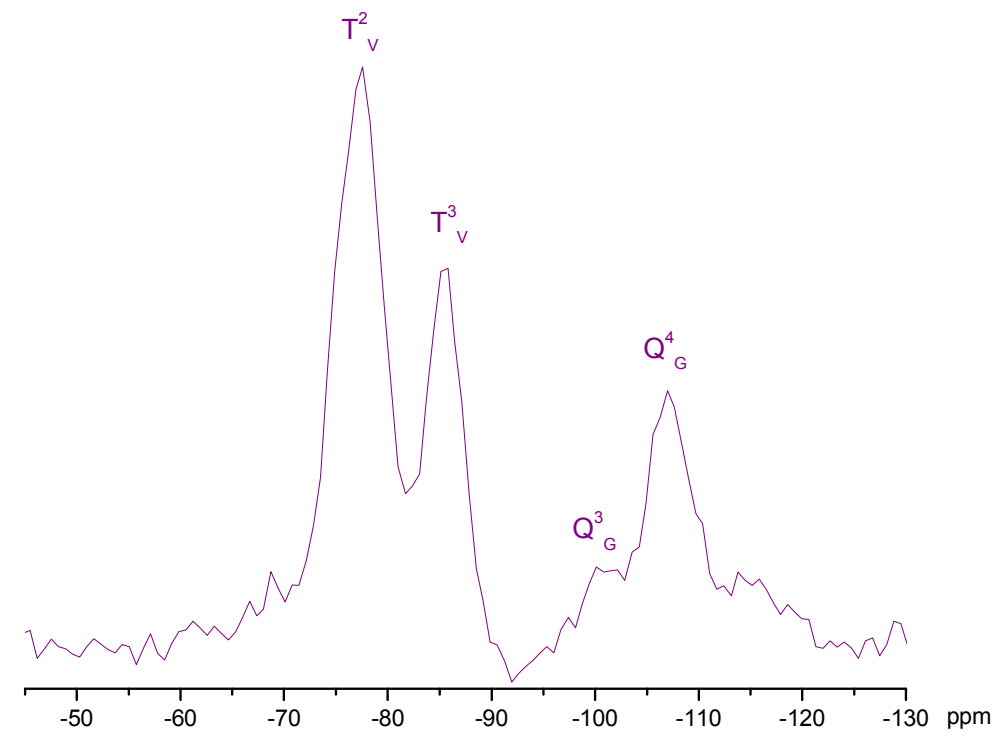

Figura. 5.5 Espectro ${ }^{29} \mathrm{Si}-\mathrm{RMN}$ de sólidos del 7VTES:3TEOS.

El espectro de la formulación $7 \mathrm{~V}: 3 \mathrm{~T}$ muestra picos asociados a silicios de entorno $T^{2}$ y $T^{3}$ del precursor VTES y $Q^{3}$ y $Q^{4}$ del precursor TEOS, no existen especies $T^{0}, T^{1}$, $Q^{0}, Q^{1}$ y $Q^{2}$, por lo que, se puede asumir que se ha producido una buena condensación de los precursores con el tratamiento de curado aplicado. El precursor VTES tiene una relación de intensidades de los picos $\mathrm{T}^{2} / \mathrm{T}^{3}$ de 61/39, por tanto quedan posibilidades de enlaces siloxano por formar. Tener una relación de intensidades $Q^{3} / Q^{4}$ es $17 / 83$ indica que este precursor ha alcanzado una condensación muy alta con las condiciones de curado aplicadas (Tabla 5.2).

Tabla 5.2 Valores del desplazamiento químico de las señales de ${ }^{29} \mathrm{Si}-\mathrm{RMN}$ sólidos VTES-TEOS.

\begin{tabular}{|c|c|c|c|c|c|c|}
\hline Form. 7V:3T & \multicolumn{7}{|c|}{ Desplazamiento químico, $\delta / p p m$} \\
\hline Precursor & $\mathrm{T}^{2}$ & $\mathrm{~T}^{3}$ & $\mathrm{~T}^{2} / \mathrm{T}^{3}$ & $\mathrm{Q}^{3}$ & $\mathrm{Q}^{4}$ & $\mathrm{Q}^{3} / \mathrm{Q}^{4}$ \\
\hline VTES & -77 & -85 & $61 / 39$ & & & \\
\hline TEOS & - & - & & -101 & -107 & $17 / 83$ \\
\hline
\end{tabular}

Por tanto, se puede concluir que se ha conseguido obtener una red entrecruzada, en la que se han hidrolizado y condensado la mayor parte de los enlaces posibles y en la que, no solo no existen especies sin hidrolizar, si no que se ha alcanzado un alto nivel de condensación (no hay bandas $T^{0}, T^{1}, Q^{0}, Q^{1}$ y $Q^{2}$ ). El grado de 
entrecruzamiento podría aumentarse mediante la aplicación de condiciones más severas de curado en cuanto a tiempo y temperatura, si bien, no podría darse un entrecruzamiento total debido al tamaño de la cadena orgánica del VTES que impediría que grupos silanoles contiguos se pusieran en contacto para condensar. No obstante, criterios adicionales como la fragilidad encontrada en los materiales sintetizados en forma de recubrimiento y película libre, e incluso la selección de tiempos que fueran factibles de poder ser utilizados en futuras aplicaciones de tipo industrial han jugado un papel fundamental a la hora de seleccionar el tratamiento final a aplicar. Los tratamientos de curado optimizados tras este estudio se recogen en la Tabla 5.3.

Tabla 5.3 Tratamiento de curado optimizado para la serie VTES:TEOS.

\begin{tabular}{|c|c|c|c|}
\hline & \multicolumn{4}{|c|}{ VTES : TEOS } \\
\hline Temperatura $/{ }^{\circ} \mathbf{C}$ & $\mathbf{9 : 1}$ & $\mathbf{8 : 2}$ & $\mathbf{7 : 3}$ \\
\hline Tiempo $/ \mathbf{m i n}$ & 50 & 50 & 50 \\
\hline *Tratamiento de secado común en todas las muestras: $50^{\circ} \mathrm{C} / 15 \mathrm{~min}+$ rampa $\mathrm{V}=3^{\circ} \mathrm{C} / \mathrm{min}$ hasta Tc
\end{tabular}

\section{b) Espectroscopia infrarroja}

Se ha estudiado por medio de FTIR las diferencias en la estructura química de los materiales en función de las cantidades de TEOS adicionada. Esta adición hace que la red tenga un carácter más inorgánico, es decir, tenga una red polisiloxánica (Si-O$\mathrm{Si})$ más preponderante frente al contenido orgánico que existía en el material únicamente formulado a partir de VTES. Esto se verifica con el estudio comparativo por FTIR de toda la serie de materiales (VTES:TEOS) obtenida (Figura. 5.6). Como en casos anteriores, con este estudio también se puede comprobar el nivel de condensación de la cadena por medio de la detección de grupos silanoles no condensados, y comprobar si las condiciones de síntesis aplicadas $(\mathrm{pH}$, temperatura de curado) han afectado a la parte orgánica del VTES. Las muestras para realizar este ensayo se obtienen en película libre aplicándoles los tratamientos de curado optimizados tras el estudio de Si-RMN. Una vez obtenidos los materiales se trituraron y se prepararon cápsulas de $\mathrm{KBr}$, manteniendo en todas las muestra la proporción muestra/ $\mathrm{KBr}$ a un $5 \%$ en peso de muestra. En la Figura. 5.6 se muestran los espectros de infrarrojos adquiridos para el precursor VTES y para formulaciones con 
cantidades crecientes de TEOS $10 \%, 20 \%$ y $30 \%$ correspondientes a $9 \mathrm{~V}: 1 \mathrm{~T}, 8 \mathrm{~V}: 2 \mathrm{~T}$ y $7 \mathrm{~V}: 3 \mathrm{~T}$, respectivamente.

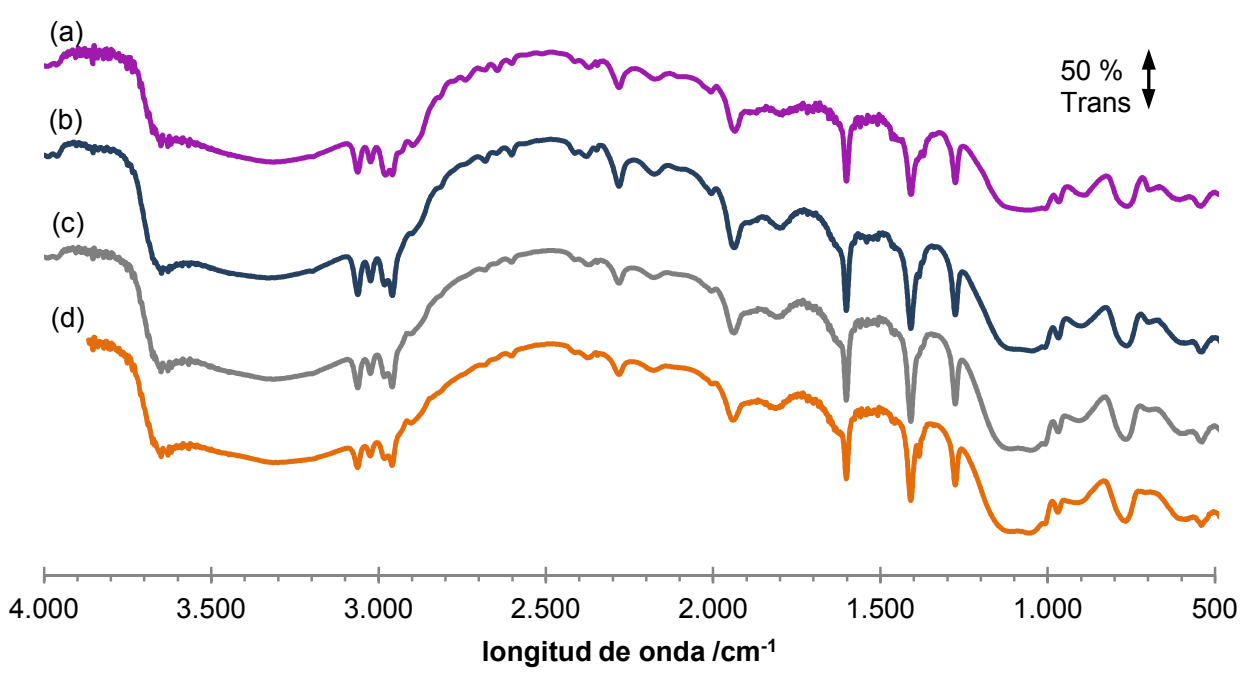

Figura. 5.6. Espectros infrarrojos (región $4000-500 \mathrm{~cm}^{-1}$ ) de la serie de materiales VTES-TEOS: (a) VTES, (b) 9V:1T, (c) 8V:2T, (d) 7V:3T.

Se observa como el análisis por FTIR de esta serie de materiales basada en VTES y adicionando distintas cantidades de TEOS no revela cambios significativos en los nuevos materiales. Todos ellos presentan bandas asociadas a la vibración de enlaces Si-O-Si alrededor de $1075 \mathrm{~cm}^{-1}, 1163 \mathrm{~cm}^{-1}$ y $800 \mathrm{~cm}^{-1}$ características de la formación de la red polisiloxánica [52, 108]. Con el incremento de la cantidad de TEOS únicamente se aprecia un ligero incremento en la intensidad relativa de estos picos. Se detectan en todos los espectros bandas asociadas a la vibración de especies $\mathrm{OH}$ entre $3300-3500 \mathrm{~cm}^{-1}$, y Si-OH terminales $3740 \mathrm{~cm}^{-1}$. Por otro lado, se detectan las bandas asociadas al grupo vinil del VTES a longitudes de onda $3060 \mathrm{~cm}^{-1}, 1600 \mathrm{~cm}^{-1}$ y $1450 \mathrm{~cm}^{-1}$ asociadas a $=\mathrm{CH}_{2}, \mathrm{C}=\mathrm{C}$ y $\mathrm{Si}-\mathrm{C}$, respectivamente.

La ausencia de diferencias significativas entre los espectros se debe a que esta técnica de caracterización es cualitativa y su mayor potencial radica en detectar diferencias en la composición de los recubrimientos. En este caso, la adición de distintas cantidades de TEOS no varía la composición química ya que tan solo introduce una mayor cantidad de enlaces Si-O-Si en la red, detectándose un incremento en la intensidad relativa de las bandas asociadas a este enlace. Mediante 
la técnica FTIR se ha determinado que con las condiciones de síntesis aplicadas ( $\mathrm{pH}=1$, cantidad de agua estequimétrica, duración de reacciones de hidrólisis), así como los tratamiento de curado aplicados, se han conseguido obtener redes polisiloxánicas en todos los casos, así como la presencia de una cadena orgánica vinílica.

\subsubsection{Comportamiento térmico}

El estudio de las propiedades térmicas del material, como son la determinación de $\mathrm{T}_{\mathrm{g}}$ o el estudio de los procesos de degradación, son valiosos para profundizar en el conocimiento de la estructura de red formada. Por ello se estudia la existencia de $T_{g} y$ su evolución por medio de DSC. Adicionalmente se estudian los fenómenos de degradación con la temperatura con la intención de valorar la influencia de la cantidad de carga inorgánica (no degradable en el intervalo de temperaturas estudiado) añadida.

Las muestras a ensayar en calorimetría se han obtenido en película libre y, posteriormente, se han triturado para permitir una correcta distribución del flujo de calor a través de la muestra. La Figura. 5.7 representa las curvas calorimétricas de un barrido de temperaturas entre $-100^{\circ} \mathrm{C}$ hasta $200^{\circ} \mathrm{C}$ bajo flujo de nitrógeno de la serie de muestras con distintas cantidades de TEOS. El criterio seguido en los termogramas representados conlleva que los picos hacia arriba corresponden a procesos exotérmicos. 


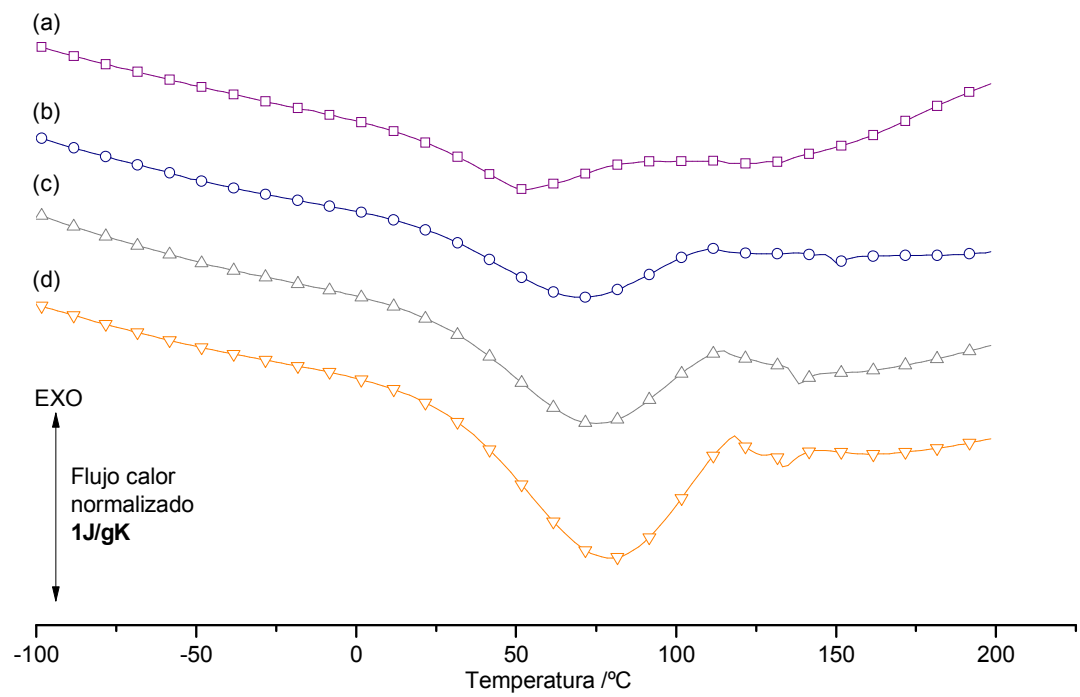

Figura. 5.7 Curvas DSC (a) VTES, (b) 9v:1T, (c) 8V:2T, (d) 7V:3T. Velocidad de calentamiento $10^{\circ} \mathrm{C}$ con un flujo de $\mathrm{N}_{2}$ de $30 \mathrm{ml} / \mathrm{min}$.

En el apartado 4. 3 se discutió que $T_{g}$ es una propiedad que está relacionada con la movilidad molecular de las cadenas y que sólo se detectará en aquellos sistemas donde el peso molecular asociado sea suficiente para que la señal sea registrada. Se detectó que el precursor VTES no presenta $T_{g}$ debido a que las posibilidades de movimientos conformacionales son muy pequeñas por la formación de la red polisiloxánica y al pequeño peso molecular de la cadena vinil lateral. También se detecto la existencia de un pico endotérmico entre $50^{\circ} \mathrm{C}-100^{\circ} \mathrm{C}$ que se asocia a la evaporación de especies volátiles remanentes en los recubrimientos, como agua y alcohol [114-115].

La incorporación de TEOS en la formulación no incorpora cambios significativos en los termogramas, al no introducir un mayor carácter orgánico, si no por el contrario, se forma una red polisiloxánica más densa, las posibilidades de movimientos conformacionales se ven más restringidos y sigue sin detectarse $T_{g}$. Los cambios se observan en la intensidad del pico endotérmico que aumenta conforme aumenta el contenido en TEOS, este hecho se puede deber a una mayor cantidad de especies volátiles atrapadas dentro de la red, ya que las temperaturas de curado 
utilizadas son bajas y no favorecen la salida de disolventes como agua y alcohol sobrante de las reacciones.

Por otro lado, se han estudiado los fenómenos de degradación con la temperatura que sirve para valorar la influencia de la cantidad de TEOS añadido, es decir, la carga inorgánica que no es degradable en el intervalo de temperaturas estudiado. Para ello se ha realizado un estudio de degradación térmica por TGA. Los materiales se han obtenido en película libre $y$, posteriormente, se han triturado para favorecer la correcta dispersión de calor por la muestra. En la Figura. 5.8 se representan las curvas de pérdida de peso por degradación térmica así como la derivada de la pérdida de peso de la serie de materiales VTES-TEOS obtenidas desde temperatura ambiente y $700^{\circ} \mathrm{C}$ a $10^{\circ} \mathrm{C} / \mathrm{min}$ en flujo de nitrógeno.

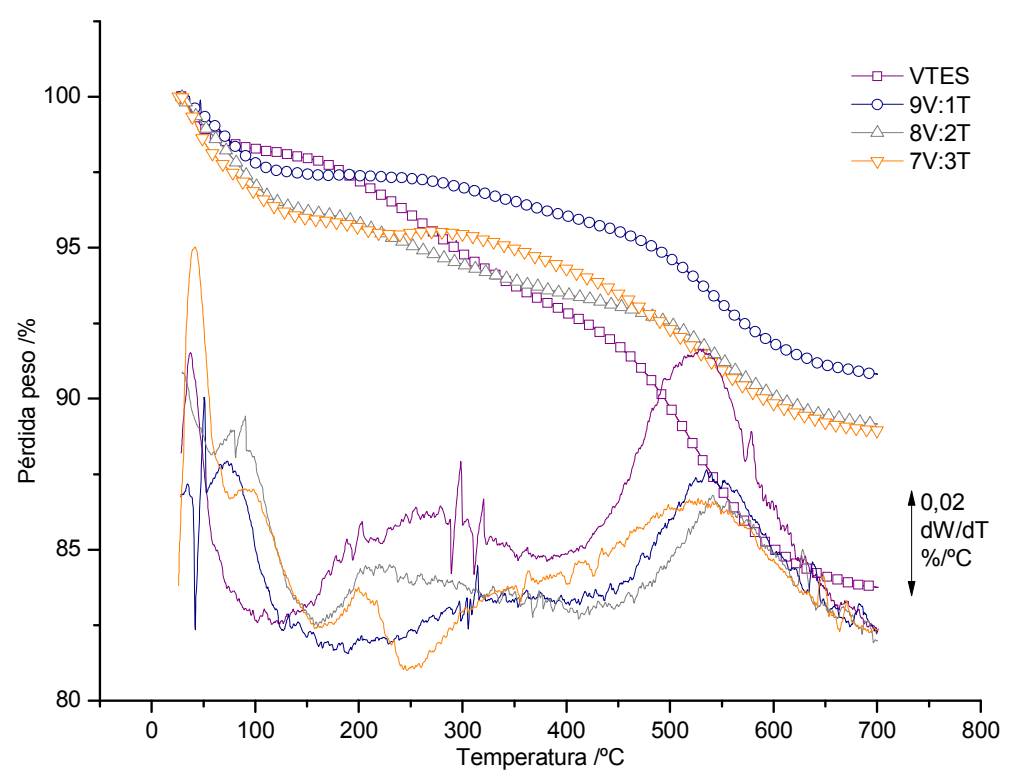

Figura. 5.8 Curvas TGA y la derivada de la pérdida de peso de las muestras VTES, 9V:1T, 8V:2T y 7V:3T. Velocidad de calentamiento $10^{\circ} \mathrm{C} / \mathrm{min}$ bajo atmosfera de $\mathrm{N}_{2}$.

Tal y como se presentó en el apartado 4.3 el recubrimiento VTES presenta tres pérdidas de peso. La primera (por debajo de $100^{\circ} \mathrm{C}$ ) debida posiblemente a la evaporación de componentes volátiles (alcohol y agua) presentes en el material, siendo estos componentes residuales del proceso de curado. La segunda registrada entre $180^{\circ} \mathrm{C}$ y $350^{\circ} \mathrm{C}$ que se puede deber a la existencia de las reacciones de curado 
conforme aumenta la temperatura por encima de la utilizada en la síntesis ya que el tratamiento de curado ha dejado grupos silanol no condensados. La pérdida de peso se debería en este caso a la evaporación del agua creada en la condensación de dos grupos silanol. El pico de degradación que aparece a altas temperaturas $\left(550^{\circ} \mathrm{C}\right)$ con una mayor pérdida de peso se relaciona con la degradación del grupo vinil del precursor.

Al añadir un $10 \%$ TEOS (9V:1T) se detecta una pérdida de peso por debajo de $100^{\circ} \mathrm{C}$ de un $2,5 \%$, seguida de otra segunda degradación entre $240^{\circ} \mathrm{C}$ y $300^{\circ} \mathrm{C}$ con poca pérdida de peso asociada a ésta y una pérdida final a altas temperaturas $\left(550^{\circ} \mathrm{C}\right)$ con una mayor pérdida de peso. Al añadir mayor cantidad de TEOS (20\% y $30 \%$ ) se observa como la pérdida de peso por debajo de $100^{\circ} \mathrm{C}$ es mayor a la registrada en la muestra con un $10 \%$. Esto es debido posiblemente a una mayor presencia de disolventes y agua residuales de las reacciones de hidrólisis y condensación. De nuevo se registra una ligera pérdida de peso a temperaturas entre $180^{\circ} \mathrm{C}$ y $350^{\circ} \mathrm{C}$ y la mayor pérdida de peso se registra su máximo a $550^{\circ} \mathrm{C}$.

Con la adición de TEOS a la red formada por VTES se observa una disminución del valor de la derivada de la pérdida de peso respecto a la temperatura en la pérdida de peso registrada entre $410^{\circ} \mathrm{C}$ y $650^{\circ} \mathrm{C}$. Este fenómeno permite corroborar que la degradación registrada en este intervalo se debe a la pérdida del grupo vinilo del VTES, ya que cuanto mayor es el contenido en TEOS menor es el contenido en VTES, por tanto, menor cantidad de cadenas vinílicas susceptibles a degradarse.

Por otro lado, el registro de pérdidas de peso a bajas temperaturas creciente con la cantidad de TEOS se puede deber a una mayor continuación de las reacciones de curado por condensación de grupos silanoles procedentes del TEOS. Al condensar se produce agua que se evapora, registrándose pérdida de peso.

El estudio de las propiedades térmicas de la serie de materiales basada en VTES y con adición de distintas cantidades de TEOS permite llegar a concluir que con las cantidades adicionadas (hasta un $30 \%$ ) las propiedades térmicas no se han variado de forma importante. Este hecho se debe, como se ha concluido del estudio de la estructura química que la introducción de TEOS varía la red en cuanto a la formación de un mayor número de enlaces siloxano, por tanto, crea una red más entrecruzada e 
inorgánica. En cuanto a la estabilidad térmica, se ha producido una menor pérdida de peso debido a la menor cantidad de cadenas orgánicas en los sistemas, ya que presentan contenidos mayores de TEOS.

\subsubsection{Propiedades mecánicas}

La variación en el contenido de carga inorgánica en la formulación del recubrimiento provoca cambios en la respuesta mecánica del material, debido a la formación de una red con una mayor densidad de entrecruzamiento. La incorporación de un precursor con cuatro posibilidades de enlace como el TEOS trae consigo un aumento en la densidad de enlaces, formándose una red más compacta. En este apartado se caracterizan las variaciones en las propiedades mecánicas con los cambios en la cantidad de TEOS adicionado en la formulación.

Para la realización de este ensayo se obtuvieron muestras en película libre de un espesor de $1 \mathrm{~mm}$. Se cortaron en forma circular con un diámetro de $12 \mathrm{~mm}$ de forma que la muestra fuera lo suficientemente grande para que el vástago que aplica la carga de 3,6mm de diámetro actuara en la zona central de la muestra evitando efectos de borde. Se aplicaron sobre todas las muestras un primer ciclo de cargas desde 0 a $1400 \mathrm{mN}$ (compresión) a una velocidad de $50 \mathrm{mN} / \mathrm{min}$, seguido de un ciclo de descarga a la misma velocidad. Se realizaron tres réplicas para cada muestra estudiada. Para todas las muestras se detectó que las deformaciones registradas correspondían a deformaciones elásticas ya que tras la descarga no se detectaron deformaciones residuales.

En la Figura. 5.9 se muestran las curvas de tensión-deformación a compresión de los materiales hasta un $30 \%$ de TEOS (VTES, 9V:1T, $8 \mathrm{~V}: 2 \mathrm{~T}, 7 \mathrm{~V}: 3 \mathrm{~T}$ ) a las que se ha aplicado un ciclo de carga de 0 a $1400 \mathrm{mN}$ a $50 \mathrm{mN} / \mathrm{min}$. Se muestra además una ampliación de la zona de bajas deformaciones. 


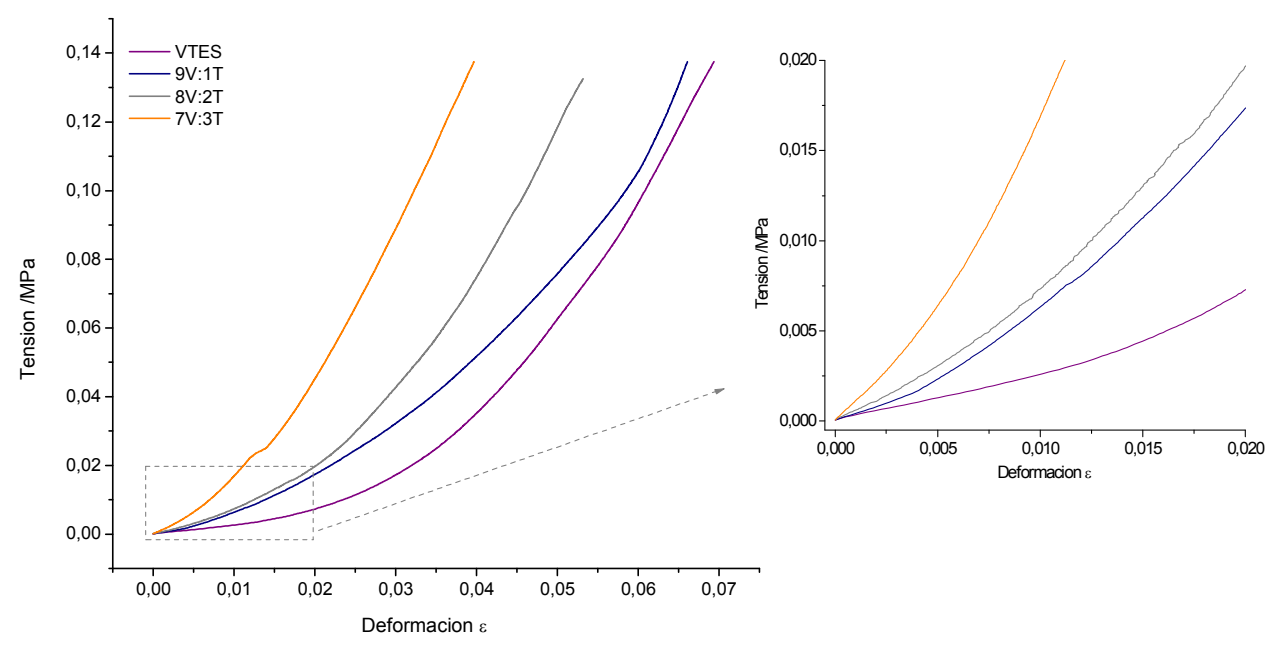

Figura. 5.9 (Izq.) Curvas tensión deformación a compresión de los recubrimientos VTES, 9V:1T, $8 \mathrm{~V}: 2 \mathrm{~T}, 7 \mathrm{~V}: 3 \mathrm{~T}$. Velocidad de carga $50 \mathrm{mN} / \mathrm{min}$ hasta una carga máxima de $1400 \mathrm{mN}$. (Dcha.) Ampliación de la primera zona elástica.

Los materiales obtenidos tienen dos comportamientos elásticos (aunque no lineales) diferenciados. Uno en el que se obtienen grandes deformaciones para una carga baja, seguido de una deformación con una rigidez mayor que se registra por un cambio en la pendiente de la curva. Si se calcula el módulo de Young de la primera zona elástica (obtenido a partir de la pendiente de la tangente a la curva desde el origen) se obtiene un valor numérico de $0,23 \mathrm{MPa}$ para el recubrimiento VTES. Conforme se aumenta el contenido en TEOS el módulo elástico crece hasta valores 0,27 MPa, 0,54 MPa y 0,87 MPa para el 9V:1T, 8V:2T y 7V:3T, respectivamente.

Se ha calculado la tensión y la deformación a la cual se registra el cambio en la pendiente de la curva, y por tanto el cambio en la respuesta mecánica del material (Tabla 5.4). Este cálculo se ha realizado extrapolando una línea de la primera zona elástica y otra de la segunda zona elástica y calculando el punto de intersección de ambas líneas. El recubrimiento VTES registra el cambio de pendiente a una tensión 0,0062MPa y una deformación de 0,035u.. Con la adición de un 10\% de TEOS se produce un aumento en la tensión necesaria para que se produzca el cambio en la rigidez a un valor de $0,0125 \mathrm{MPa}$, del mismo modo que se produce un ligero aumento de la deformación registrada $(0,041 \mathrm{u}$.). Para aumentos del $20 \%$ y $30 \%$ en el contenido en TEOS la tensión no experimenta un cambio significativo en el valor 
obtenido $(0,0115 \mathrm{MPa}$ y $0,0106 \mathrm{MPa}$, respectivamente), sin embargo, las deformaciones se desplazan a menores valores con el incremento en TEOS dando valores numéricos de 0,028u. y $0,012 u$. para un $20 \%$ y $30 \%$, respectivamente. Del análisis de estos datos se extrae que a mayor contenido en TEOS la tensión necesaria para que se produzca el cambio en la rigidez del material es mayor que para VTES, ocupando la primera zona elástica un intervalo de deformaciones más pequeño conforme se aumenta el contenido de TEOS.

El módulo de Young (obtenido a partir de la pendiente de la tangente para un intervalo de tensiones de $0,06 \mathrm{MPa}$ a $0,08 \mathrm{MPa}$ ) tras el cambio en la rigidez del material es mucho más elevado que el obtenido en la primera zona de deformaciones. En este caso el recubrimiento VTES presenta un módulo de elástico de $2,97 \mathrm{MPa}$. Con un aumento del $10 \%$ de TEOS el módulo se reduce dando un valor de $1,83 \mathrm{MPa}$. Para aumentos por encima del $10 \%$ se aumenta la rigidez del material con valores de $3,27 \mathrm{MPa}$ y $3,60 \mathrm{MPa}$ para un $20 \%$ y $30 \%$, respectivamente.

En la Figura. 5.10 se ha representado la evolución de la tensión necesaria para obtener una deformación dentro de la primera zona de bajas tensiones $(\varepsilon=0,005 \mathrm{u}$.) y en la segunda zona de mayores deformaciones $(\varepsilon=0,04 \mathrm{u}$.) en función del contenido en TEOS. 


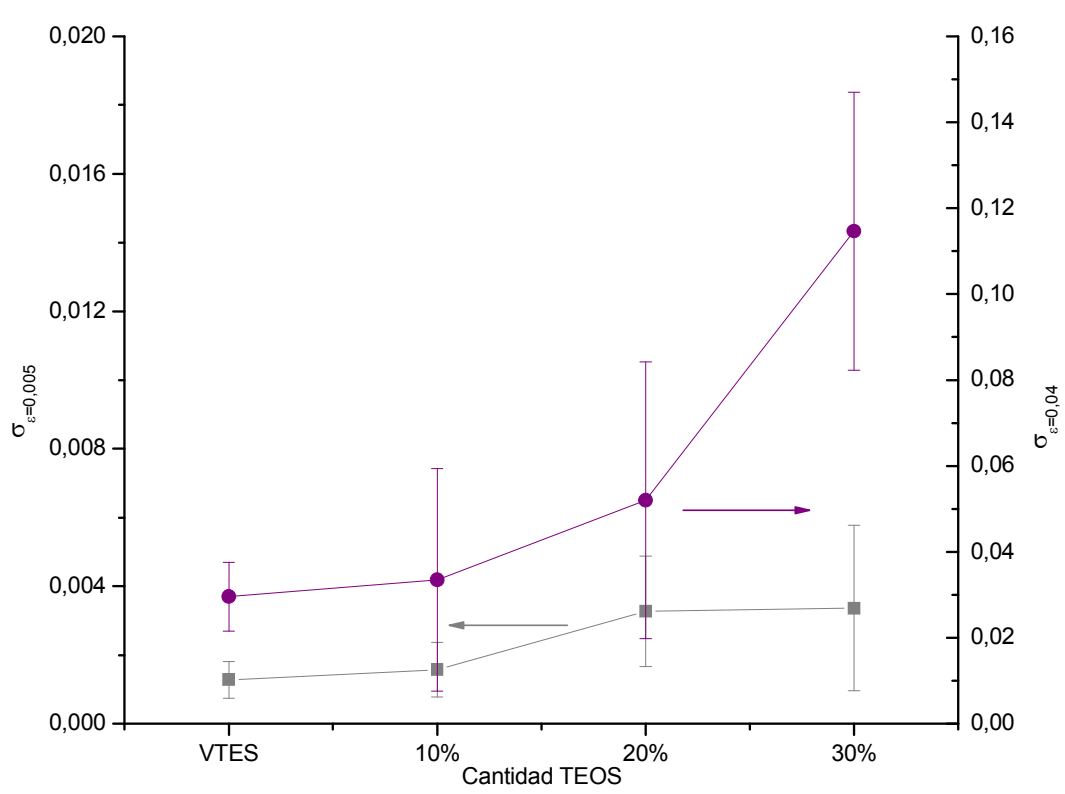

Figura. 5.10 Evolución con el contenido de TEOS de las tensiones para obtener un 0,005 unidades de deformación y un 0,04 unidades de deformación.

Los cambios registrados en la tensión para obtener una deformación dentro de la primera zona elástica no son significativos, aunque se aprecia un ligero aumento de la tensión necesaria para obtener una deformación de 0,005u. con el aumento en el contenido en TEOS. En la segunda zona elástica las variaciones de tensión entre las distintas formulaciones son mucho mayores. El material que necesita mayores tensiones para obtener una deformación de $0,04 \mathrm{u}$. es aquel con un $30 \%$ de TEOS (7V:3T), que necesita una tensión de $0,115 \mathrm{MPa}$. El material que necesita menor tensión es el VTES, con un valor de 0,029MPa. Las composiciones intermedias necesitan tensiones intermedias, $0,033 \mathrm{MPa}$ y $0,052 \mathrm{MPa}$ para un $10 \%$ y $20 \%$, respectivamente (Tabla 5.4). 
Tabla 5.4 Parámetros obtenidos de las curvas de tensión deformación de los materiales VTES, 9V:1T, 8V:2T, 7V:3T.

\begin{tabular}{|c|c|c|c|c|c|c|}
\hline Form. & $\begin{array}{c}\text { Módulo } \\
\text { Young } 1^{\mathrm{a}} \\
\text { zona /MPa }\end{array}$ & $\begin{array}{c}\text { Módulo } \\
\text { Young } 2^{\mathrm{a}} \\
\text { zona /MPa }\end{array}$ & $\varepsilon$ inflexión & $\delta$ inflexión & $\delta_{\varepsilon=0.005^{*}}$ & $\delta_{\varepsilon=0.04}{ }^{* *}$ \\
\hline VTES & $0,23 \pm 0,10$ & $2,97 \pm 0,12$ & $\begin{array}{c}0,035 \pm \\
0,004\end{array}$ & $\begin{array}{c}0,0062 \pm \\
0,0017\end{array}$ & $\begin{array}{c}0,0013 \pm \\
0,0005\end{array}$ & $\begin{array}{c}0,029 \pm \\
0,007\end{array}$ \\
\hline $9 \mathrm{~V}: 1 \mathrm{~T}$ & $0,27 \pm 0,13$ & $1,83 \pm 0,82$ & $\begin{array}{c}0,041 \pm \\
0,024\end{array}$ & $\begin{array}{c}0,0125 \pm \\
0,0046\end{array}$ & $\begin{array}{c}0,0016 \pm \\
0,0008\end{array}$ & $\begin{array}{c}0,033 \pm \\
0,026\end{array}$ \\
\hline $8 V: 2 T$ & $0,54 \pm 0,22$ & $3,27 \pm 1,37$ & $\begin{array}{c}0,028 \pm \\
0,007\end{array}$ & $\begin{array}{c}0,0115 \pm \\
0,0015\end{array}$ & $\begin{array}{c}0,0033 \pm \\
0,0016\end{array}$ & $\begin{array}{c}0,052 \pm \\
0,032\end{array}$ \\
\hline $7 V: 3 T$ & $0,87 \pm 0,24$ & $3,60 \pm 1,15$ & $\begin{array}{c}0,012 \pm \\
0,002\end{array}$ & $\begin{array}{c}0,0106 \pm \\
0,0048\end{array}$ & $\begin{array}{c}0,0034 \pm \\
0,0024\end{array}$ & $\begin{array}{c}0,115 \pm \\
0,032\end{array}$ \\
\hline
\end{tabular}

La incorporación de mayor carga inorgánica, por aumentos en la cantidad de TEOS, trae consigo la formación de una red más compacta. Esto se produce ya que el precursor TEOS cuenta con cuatro posibilidades de enlaces, por tanto, actúa como entrecruzador de la red que forma el VTES, favoreciendo la formación de una red polisiloxánica densa, en la que las cadenas laterales del precursor VTES se disponen aleatoriamente. Como se comentó anteriormente, la sustitución de grupos orgánicos (grupos vinil del precursor VTES) sin capacidad para establecer enlaces en la red, por grupo reactivos $\left(-\mathrm{OCH}_{2} \mathrm{CH}_{3}\right.$ del TEOS que hidrolizan y condensan para establecer enlaces siloxano) posibilita un aumento del grado de condensación del material. Así la red con un mayor carácter inorgánico es más rígida, registrándose valores mayores del módulo de Young, resultados que concuerdan con lo obtenidos en distintas publicaciones [106-107, 125].

\subsection{5 Ángulo de contacto}

Como hipótesis de trabajo, y tomando como base varios trabajos en los que se ha reportado que un aumento en el contenido de TEOS consigue disminuir el ángulo de contacto de los recubrimientos [67], se adiciona TEOS a la formulación con el fin de aumentar su hidrofilia y así aumentar su degradabilidad y potenciar la liberación de fármacos. La medida del ángulo de contacto de los materiales es una manera fácil de caracterizar esta propiedad.

La medida del ángulo de contacto se realizó sobre planchas de acero AISI 316L recubiertas por dip-coating con cada una de las formulaciones (VTES, 9V:1T, 8V:2T y 
$7 \mathrm{~V}: 3 \mathrm{~T}$ ), a las que se ha aplicado el tratamiento de curado estándar descrito en 3.1.3. Los valores de los ángulos de contacto obtenidos se presentan en la Tabla 5.5.

Tabla 5.5 Medida de ángulo de contacto de agua extrapura sobre la superficie de los materiales VTES, 9V:1T, 8V:2T y 7V:3T aplicado por dip-coating a 100mm/min sobre acero AISI 316L.

\begin{tabular}{|c|c|c|c|c|}
\hline Nomenclatura & VTES & $9 \mathrm{~V}: 1 \mathrm{~T}$ & $8 \mathrm{~V}: 2 \mathrm{~T}$ & $7 \mathrm{~V}: 3 \mathrm{~T}$ \\
\hline $\begin{array}{l}\text { Angulo de } \\
\text { contacto } /\end{array}$ & $80,1 \pm 0,5$ & $80,4 \pm 1,4$ & $69,4 \pm 0,5$ & $55,5 \pm 1,0$ \\
\hline
\end{tabular}

EI VTES tiene un carácter hidrófobo con un ángulo de contacto de $80^{\circ}$. Al añadir un 10\% de TEOS (9V:1T) no se aprecian diferencias notables en su ángulo de contacto manteniéndose entorno a $80^{\circ}$. Con adiciones del $20 \%$ y $30 \%$ se produce una disminución del ángulo de contacto, obteniéndose valores alrededor de $70^{\circ}$ y $55^{\circ}$ respectivamente.

La presencia de la cadena vinil hace que el recubrimiento tenga un carácter hidrófobo. La adición de TEOS a la formulación a favorecido la hidrofilia de los recubrimientos, tal y como se ha reportado en bibliografía [67], consiguiendo recubrimientos mucho más hidrófilos para contenidos por encima del $20 \%$ de TEOS.

\subsubsection{Propiedades anticorrosivas}

Se ha evaluado la capacidad de los recubrimientos de la serie VTES-TEOS para proteger frente a la corrosión electroquímica a los sustratos metálicos sobre los que se aplica. Como se citó en 4.5 una de las funciones a conseguir en los recubrimientos es la protección del entorno celular frente a la liberación de iones metálicos por parte del sustrato y debido a procesos corrosivos del implante, sobre todo en los momentos iniciales, a fin de que éstos no interfieran en la adhesión y proliferación de células osteoinductoras y, por tanto, en la regeneración del tejido óseo.

Las muestras para la realización de este ensayo se han obtenido recubriendo planchas de acero AISI 316L mediante la técnica dip-coating con los materiales VTES, 9V:1T, 8V:2T y 7V:3T. Se han realizado ensayos EIS, siendo las condiciones del ensayo las mismas que las descritas en el apartado 4.5 . 
En la Figura. 5.11 y Figura. 5.12 se representan los diagrama de Nyquist y de Bode, respectivamente, obtenidos de la realización de un ensayo EIS nada más ser expuestos al electrolito (tiempo $0 \mathrm{~h}$ ) para los recubrimientos VTES, 9V:1T, 8V:2T y $7 \mathrm{~V}: 3 \mathrm{~T}$.

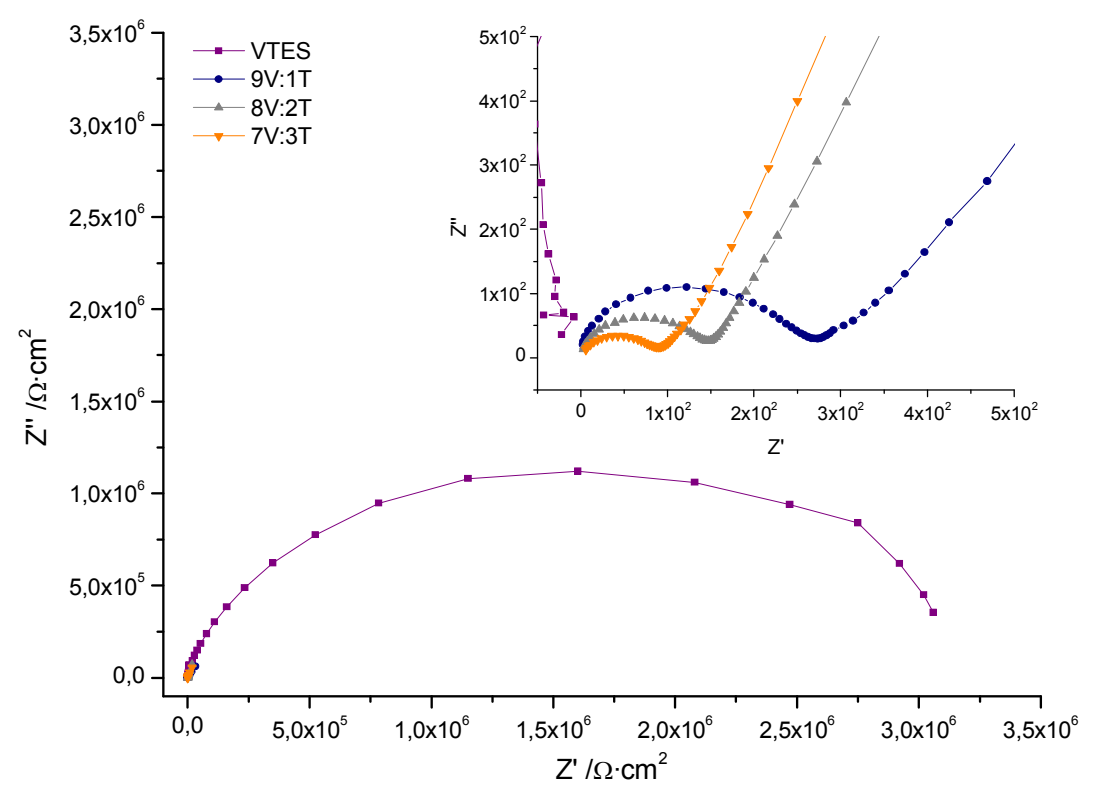

Figura. 5.11 Diagrama de Nyquist de los recubrimientos VTES, 9V:1T, 8V:2T y 7V:3T aplicados sobre acero AISI $316 \mathrm{~L}$ al comienzo del ensayo EIS (0 horas) en una disolución acuosa $3,5 \% \mathrm{NaCl}$. 


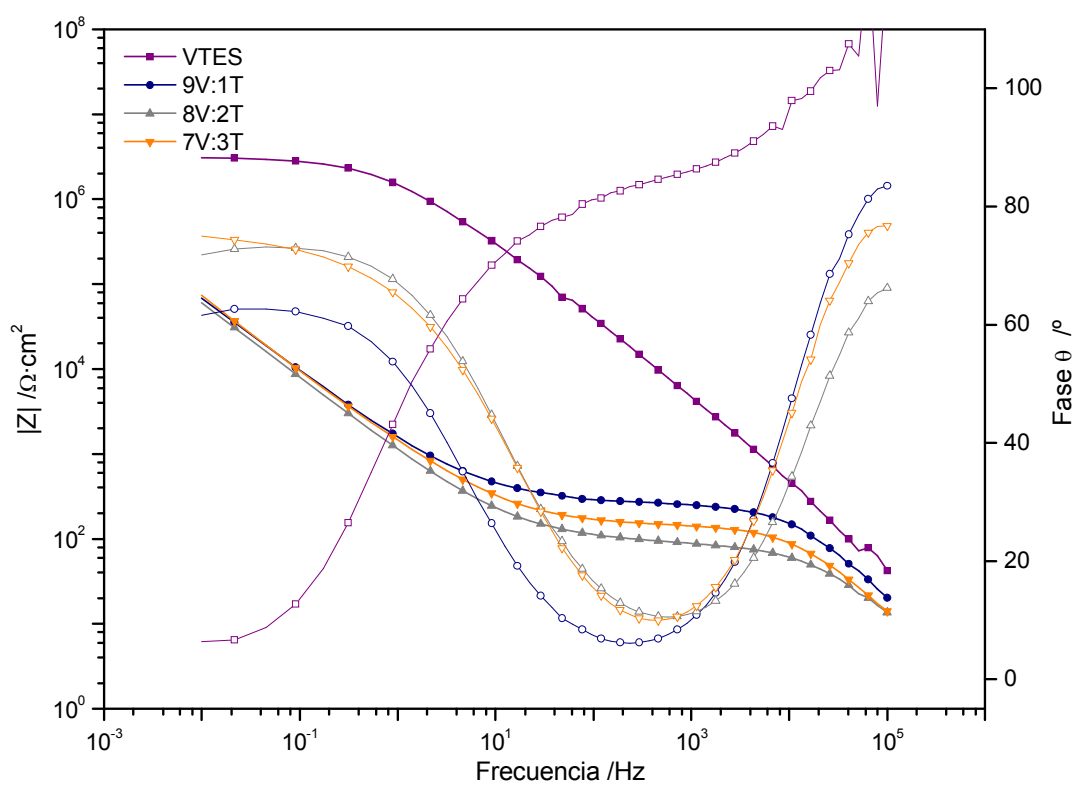

Figura. 5.12 Diagrama de Bode de los recubrimientos VTES, 9V:1T, 8V:2T y 7V:3T aplicados sobre acero AISI $316 \mathrm{~L}$ al comienzo del ensayo EIS (0 horas) en disolución acuosa $3,5 \% \mathrm{NaCl}$.

A la vista de los espectros obtenidos, se distinguen dos comportamientos electroquímicos diferenciados. Por un lado, el comportamiento del recubrimiento VTES y por otro, el obtenido en la evaluación de los recubrimientos con distintas cantidades de TEOS en su formulación.

El recubrimiento VTES, como se describió en el apartado 4.5, presenta un único arco achatado y asimétrico en el diagrama de Nyquist. El diagrama de Bode muestra claramente la existencia de dos constantes de tiempo en la respuesta de la impedancia frente a la frecuencia. La primera se desarrolla a altas frecuencias y se asocia a las propiedades dieléctricas del recubrimiento sol-gel y la segunda tiene lugar a bajas frecuencias y se asocia a procesos electroquímicos que tiene lugar en la interfase (fenómenos de respuesta mucho más lenta que los procesos de relajación dieléctrica que tienen lugar en el recubrimiento).

Los espectros de impedancia de los recubrimientos con contenido en TEOS en su formulación (9V:1T, 8V:2T y $7 \mathrm{~V}: 3 \mathrm{~T})$ tienen entre sí un aspecto similar y totalmente diferenciado de la respuesta del recubrimiento denominado VTES cuando se encuentra solo. Los tres muestran, en el diagrama de Nyquist al menos dos arcos. 
Cuando se analiza el diagrama de Bode, se distingue una respuesta de la impedancia en tres procesos diferenciados con tres constantes de tiempo. La primera a altas frecuencias que se relaciona con la respuesta del recubrimiento en contacto con el electrolito (fenómenos de respuesta rápida al estímulo eléctrico aplicado) y, por tanto, proporciona da información acerca de las propiedades del recubrimiento; otra asociada a la respuesta de la interfase, con valores de frecuencia intermedios; y la tercera con valores de frecuencia bajos asociada a la formación de una capa de óxido en la superficie del metal. Este arco no está totalmente definido dentro del intervalo de frecuencias estudiado. Se trata de fenómenos que necesitan tiempos de respuesta demasiado grandes (señales de potencial de frecuencias muy bajas) para el ensayo realizado, por lo que la información sobre estos procesos es muy limitada.

Los valores del módulo de impedancia y los ángulos de fase registrados en los ensayos EIS del recubrimiento VTES son superiores a aquellos recubrimientos con contenido en TEOS en su formulación en una amplia región del espectro de frecuencias, teniendo por tanto el recubrimiento VTES un comportamiento más dieléctrico y capacitivo. Con el aumento del contenido en TEOS las impedancias obtenidas disminuyen drásticamente, así para frecuencias altas e intermedias, la impedancia disminuye al aumentar el contenido en TEOS en la formulación. Este hecho probablemente se debe a la formación de una red con un carácter más hidrófilo cuando se introduce TEOS en la red de VTES. El valor de la impedancia a baja frecuencia está en el mismo orden de magnitud como se aprecia en el diagrama de Bode y se asocia a la presencia de óxido en la superficie del metal.

Se ha analizado el comportamiento de los recubrimientos con el paso del tiempo de exposición al electrolito hasta las 24 horas. En la Figura. 5.13 se muestra la evolución de los diagramas de impedancia (representación de Nyquist) de los recubrimientos VTES, en la Figura. 5.14 se muestra la evolución del recubrimiento 9V:1T, en la Figura. 5.15 la de $8 \mathrm{~V}: 2 \mathrm{~T}$ y en la Figura. 5.16 la de $7 \mathrm{~V}: 3 \mathrm{~T}$. 


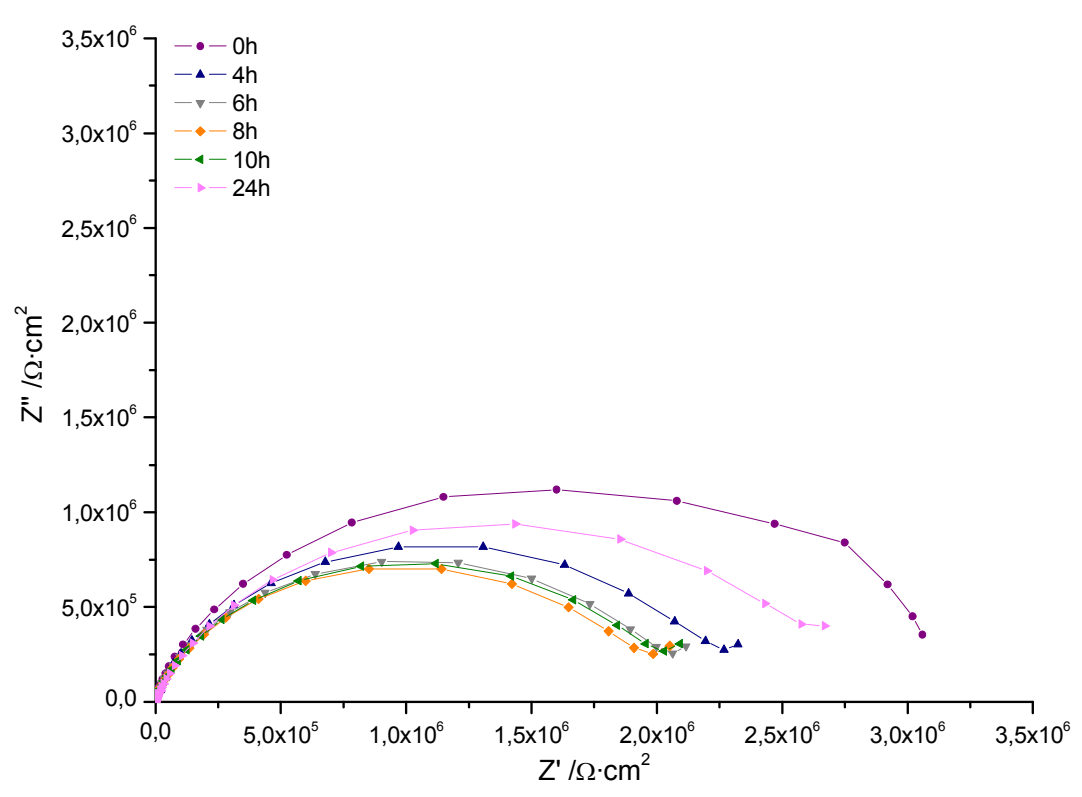

Figura. 5.13 Evolución de los diagramas de Nyquist obtenidos para el recubrimiento VTES durante 24 horas de exposición a una disolución acuosa de $\mathrm{NaCl}$ al 3,5\% en peso.

El recubrimiento VTES tiene un comportamiento muy estable con el paso del tiempo de exposición al electrolito. Se observa un descenso progresivo en los valores de impedancia a medida que aumenta el tiempo de exposición durante las primeras 10 horas y a las 24 horas se observa una ligera recuperación de las impedancias del sistema 


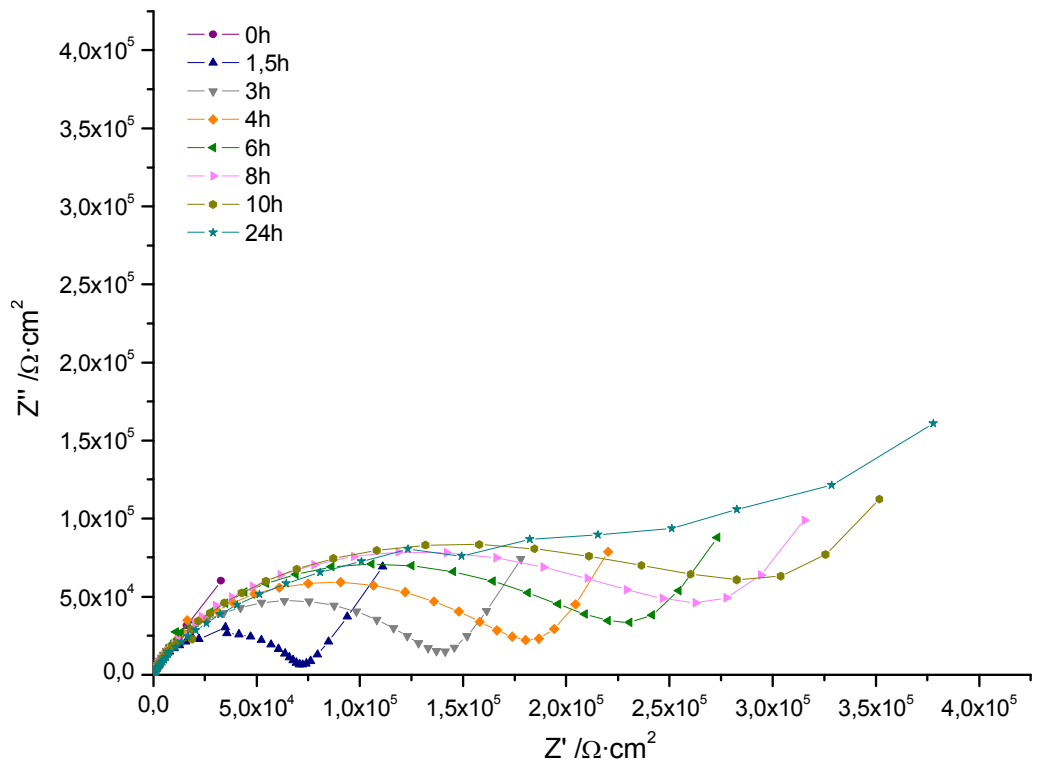

Figura. 5.14 Evolución de los diagramas de Nyquist obtenidos para el recubrimiento 9V:1T durante 24 horas de exposición a una disolución acuosa de $\mathrm{NaCl}$ al $3,5 \%$ en peso.

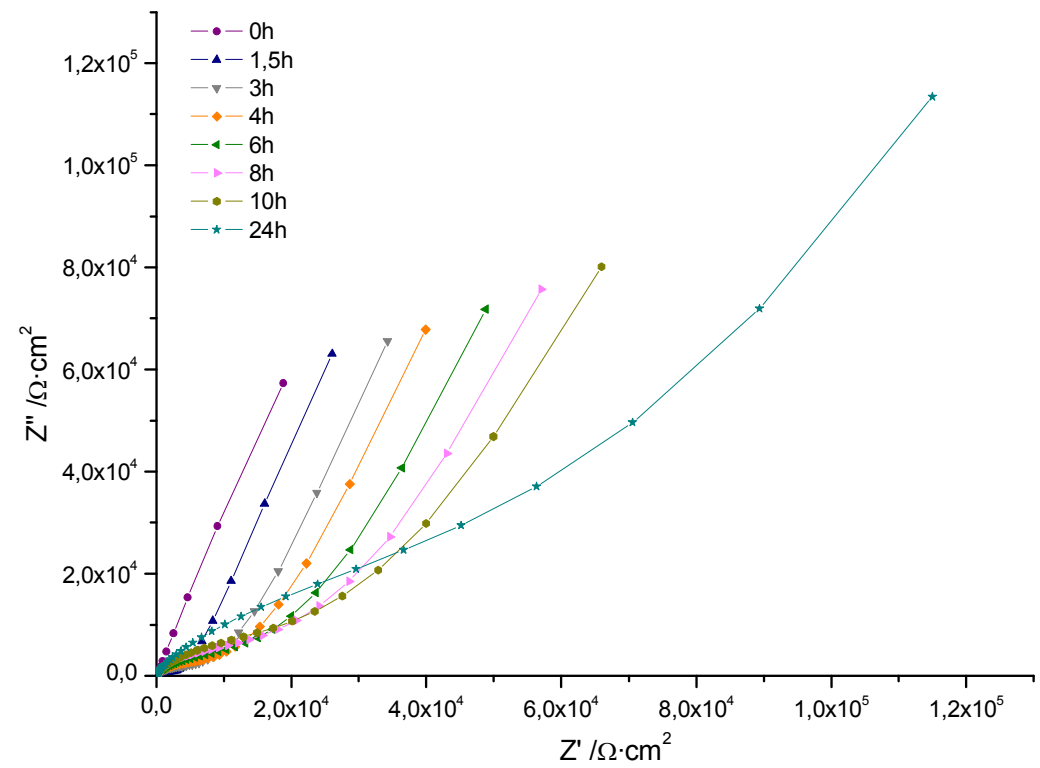

Figura. 5.15 Evolución de los diagramas de Nyquist obtenidos para el recubrimiento 8V:2T durante 24 horas de exposición a una disolución acuosa de $\mathrm{NaCl}$ al $3,5 \%$ en peso. 


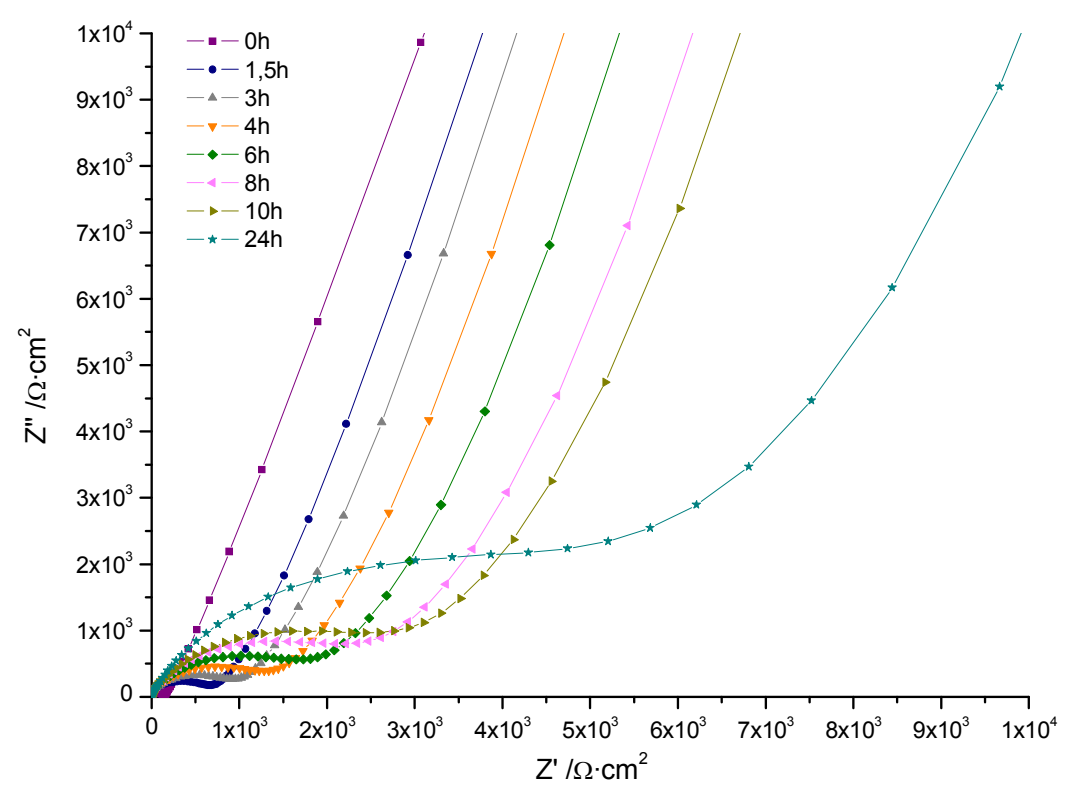

Figura. 5.16 Evolución de los diagramas de Nyquist obtenidos para el recubrimiento 7V:3T durante 24 horas de exposición a una disolución $\mathrm{NaCl}$ al 3,5\% en peso.

Los valores de las impedancias de los recubrimientos con TEOS, aumentan de valor durante la exposición al electrolito. Este fenómeno se podrá analizar en profundidad con los resultados de la modelización de los datos con circuito equivalente.

Se realiza la modelización de los valores de impedancia compleja mediante circuitos equivalentes. La modelización de los resultados obtenidos para VTES se presentó en el capítulo 4.5, y se realizó con un circuito de dos constantes de tiempo. Para los recubrimiento $9 \mathrm{~V}: 1 \mathrm{~T}, 8 \mathrm{~V}: 2 \mathrm{~T}$ y $7 \mathrm{~V}: 3 \mathrm{~T}$ se propone un circuito compuesto por tres constantes de tiempo formado por los elementos pasivos $R_{p o}$ (resistencia del electrolito dentro de los poros del recubrimiento), $\mathrm{CPE}_{\mathrm{c}}$ (capacidad de las zonas intactas del recubrimiento), ambos característicos del recubrimiento. Por otro lado, se encuentran $R_{p}$ (resistencia a la polarización) y $C P E_{d l}$ (capacidad de doble fase), que guardan relación con las propiedades electroquímicas de la interfase metal/electrolito en la base de los poros del recubrimiento. Por último, y en los recubrimientos con tres constantes de tiempo, se encuentran $\mathrm{CPE}_{\mathrm{ox}}$ (capacidad de la capa de óxido) y $\mathrm{R}_{\mathrm{ox}}$ (resistencia a la capa de óxido) característicos de la capa de óxido [117-118]. La representación de los circuitos se puede ver en el apartado 4.5. 
En la Figura. 5.17 se representan, a modo de ejemplo, los datos experimentales obtenidos para el recubrimiento $7 \mathrm{~V}: 3 \mathrm{~T}$ a tiempo oh y el resultado de la modelización de estos datos con el circuito equivalente de tres constantes de tiempo. Se ha conseguido un buen ajuste del modelo en todo el intervalo de frecuencias y para todos los recubrimientos estudiados.

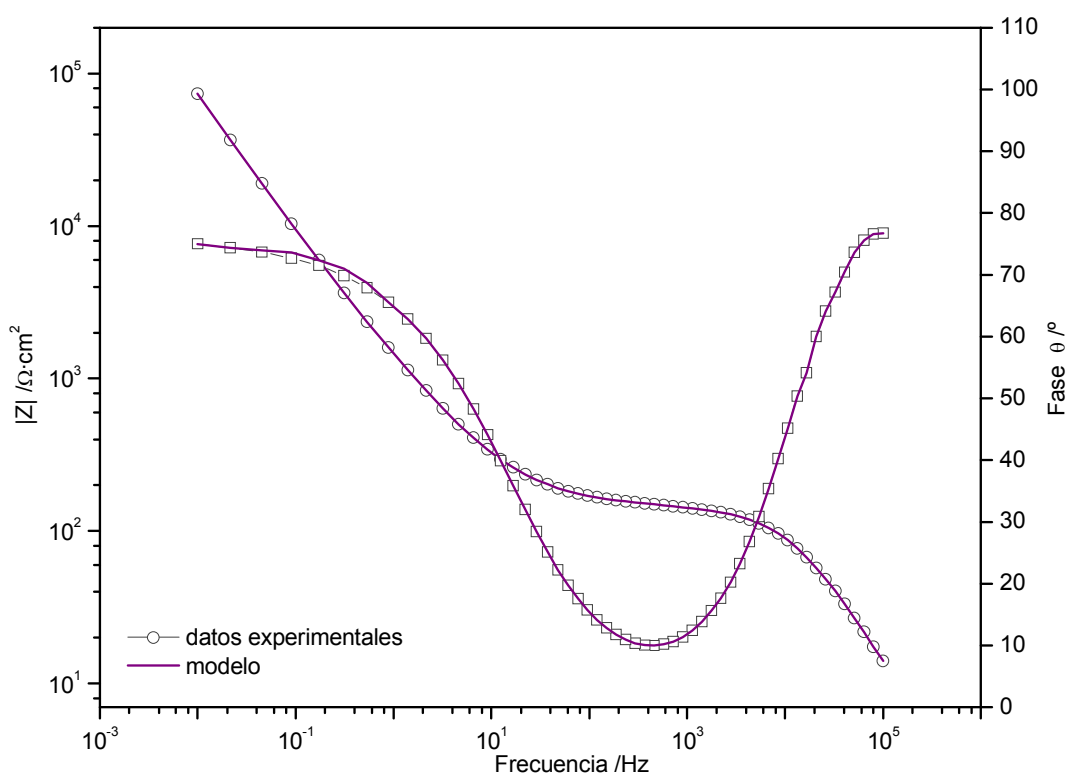

Figura. 5.17 Diagramas de Bode experimentales y simulados para el recubrimiento $7 \mathrm{~V}: 3 \mathrm{~T}$ a $0 \mathrm{~h}$ de exposición al electrolito.

Con ayuda de la modelización de los datos experimentales, se puede estudiar el comportamiento de los recubrimientos con mayor detalle, ya que se van a diferenciar los procesos que ocurren en el recubrimiento y en la interfase metal/recubrimiento. La Figura. 5.18 muestra la modelización a partir de los datos obtenidos de los parámetros del circuito equivalente asociados al recubrimiento, la resistencia al poro $\left(R_{p o}\right)$ y la capacidad del recubrimiento $\left(C P E_{c}\right)$, obtenidos a partir de la respuesta a alta frecuencia. 


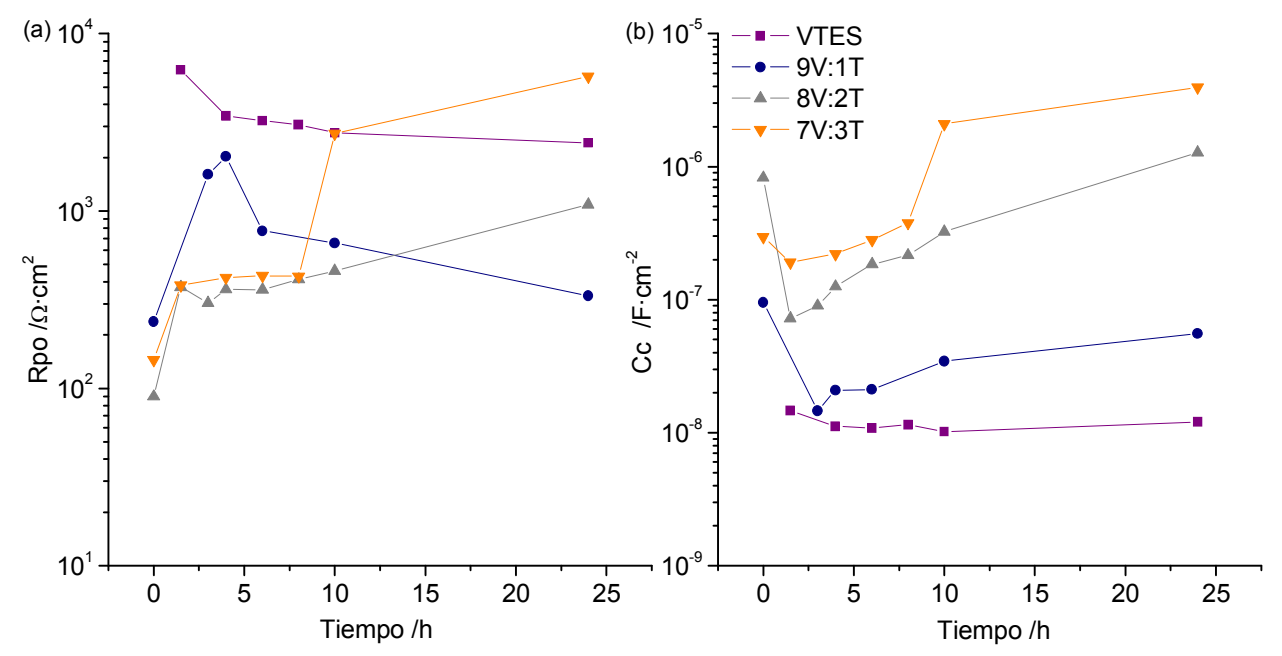

Figura. 5.18 Comparación de la evolución del valor de (a) resistencia al poro y (b) capacidad del recubrimiento con el tiempo de exposición a la disolución acuosa $3,5 \% \mathrm{NaCl}$ de los recubrimientos VTES, 9V:1T, 8V:2T y 7V:3T.

El valor de $R_{p o}$ es una medida de la resistencia iónica a través de los poros de recubrimiento y, por tanto, es inversamente proporcional al número y extensión de defectos en la película. La evolución de $\mathrm{R}_{\mathrm{po}}$ con el tiempo de exposición al electrolito proporciona información acerca del comportamiento del recubrimiento sol-gel para evitar la formación de poros a su través. El recubrimiento VTES tiene un valor de $R_{p o}$ inicial de $6200 \Omega \cdot \mathrm{cm}^{2}$ y a las 4 horas se mantiene prácticamente constante entorno a $3000 \Omega \cdot \mathrm{cm}^{2}$. El recubrimiento $9 \mathrm{~V}: 1 \mathrm{~T}$ tiene un valor inicial de $R_{\mathrm{po}}$ de $238 \Omega \cdot \mathrm{cm}^{2}$ que crece durante las primeras horas de exposición registrándose a 4horas un valor de $2031 \Omega \cdot \mathrm{cm}^{2}$. Para tiempos superiores, la tendencia es a la baja, alcanzando valores de $657 \Omega \cdot \mathrm{cm}^{2}$ y $332,7 \Omega \cdot \mathrm{cm}^{2}$ a 10 y 24 horas, respectivamente. El recubrimiento $8 \mathrm{~V}: 2 \mathrm{~T}$ tiene un valor inicial de $\mathrm{R}_{\mathrm{po}}$ de $89,7 \Omega \cdot \mathrm{cm}^{2}$, la tendencia de este parámetro con el paso del tiempo de exposición es creciente, obteniéndose a 10horas un valor de $460 \Omega \cdot \mathrm{cm}^{2}$ y a 24 horas $1085 \Omega \cdot \mathrm{cm}^{2}$. El recubrimiento $7 \mathrm{~V}: 3 T$ tiene un valor inicial de $145 \Omega \cdot \mathrm{cm}^{2}$, como en el caso del $8 \mathrm{~V}: 2 \mathrm{~T}$ este valor crece con el paso del tiempo de exposición para alcanzar a 10 horas un valor de $2725 \Omega \cdot \mathrm{cm}^{2}$ y a 24 horas 5734 $\Omega \cdot \mathrm{cm}^{2}$.

Se observa que los valores iniciales de $R_{p o}$ de los recubrimientos que incorporan TEOS son dos ordenes de magnitud inferiores a los obtenidos para VTES. Los 
recubrimientos $9 \mathrm{~V}: 1 \mathrm{~T}, 8 \mathrm{~V}: 2 \mathrm{~T}$ y $7 \mathrm{~V}: 3 \mathrm{~T}$ tienen una gran hidrofilia (como se ha documentado en el apartado anterior) que hace que el recubrimiento formado no ofrezca resistencia al paso de electrolito y especies activas a través de sus canales. Con el paso del tiempo los valores de $R_{p o}$ para el recubrimiento VTES permanecen prácticamente constantes, tan solo se observa una ligera disminución de este valor, por lo que el recubrimiento VTES es estable durante los tiempos estudiados. Los recubrimientos con contenidos en TEOS tienen valores crecientes de $R_{p o}$, este fenómeno se puede deber al taponamiento de los canales existentes en estos recubrimientos tal y como aumenta el tiempo de exposición al electrolito.

La capacidad del recubrimiento basado en VTES tiene un valor constante alrededor de $10^{-8} \mathrm{~F} \cdot \mathrm{cm}^{-2}$. El recubrimiento $9 \mathrm{~V}: 1 \mathrm{~T}$ tiene una capacidad inicial un orden de magnitud por encima de la obtenida en VTES, $9,54 \cdot 10^{-8} \mathrm{~F} \cdot \mathrm{cm}^{-2}$, que disminuye pasada una hora y media hasta un $1,5 \cdot 10^{-8} \mathrm{~F} \cdot \mathrm{cm}^{-2}$, y posteriormente va aumentando ligeramente su valor hasta alcanzar un valor final de $5,5 \cdot 10^{-8} \mathrm{~F} \cdot \mathrm{cm}^{-2}$ a las 24 horas de exposición al electrolito. El recubrimiento $8 \mathrm{~V}: 2 \mathrm{~T}$ tiene un valor de la capacidad inicial del recubrimiento dos ordenes de magnitud mayor que el obtenido para VTES, con un valor numérico de $7,97 \cdot 10^{-7} \mathrm{~F} \cdot \mathrm{cm}^{-2}$. Disminuye en la primera hora de exposición al electrolito $\left(7,15 \cdot 10^{-8} \mathrm{~F} \cdot \mathrm{cm}^{-2}\right)$ y posteriormente aumenta su valor progresivamente para alcanzar un valor final a las 24 horas de exposición de $1,27 \cdot 10^{-6} \mathrm{~F} \cdot \mathrm{cm}^{-2}$. El recubrimiento $7 \mathrm{~V}: 3 \mathrm{~T}$, como el resto de recubrimientos de la serie, tiene un valor inicial de la capacidad mayor que el obtenido en VTES $\left(2,88 \cdot 10^{-7} \mathrm{~F} \cdot \mathrm{cm}^{-2}\right)$, que disminuye en las primeras horas de ensayo $1,98 \cdot 10^{-7} \mathrm{~F} \cdot \mathrm{cm}^{-2}$, y que aumenta gradualmente con el tiempo de exposición alcanzando un valor final de $4,11 \cdot 10^{-6} \mathrm{~F} \cdot \mathrm{cm}^{-2}$ a las 24 horas.

En el recubrimiento VTES, debido a su carácter hidrófilo y a la estructura de red formada, la entrada de electrolito es muy pequeña. Conforme se aumenta el contenido en TEOS en la red, el valor de $\mathrm{CPE}_{\mathrm{c}}$ inicial aumenta en varios ordenes de magnitud, hecho que indica una mayor absorción de agua en los primeros instantes de contacto electrolito/recubrimiento. Con el paso del tiempo de exposición al electrolito se observa como los recubrimientos con TEOS va aumentando el valor de $\mathrm{CPE}_{c}$, por tanto aumenta el contenido de agua absorbida dentro de la red. El recubrimiento con un mayor contenido en TEOS, el 7V:3T, es el que mayor valor de 
$\mathrm{CPE}_{\mathrm{c}}$ registra, lo que se traduce en una mayor absorción de agua de este recubrimiento.

La Figura. 5.19 muestra la modelización a partir de los datos obtenidos de los parámetros del circuito equivalente asociados a la resistencia a la polarización $\left(R_{p}\right)$ y la capacidad de la doble capa $\left(\mathrm{CPE}_{\mathrm{dl}}\right)$, correspondiente a la respuesta a baja frecuencia. Estos procesos corresponden a aquellos que necesitan tiempos largos de respuesta frente a la perturbación de una señal electrica para poder ser registrados y están relacionados con la evolución de la interfase metal/electrolito en la base de los poros del recubrimiento.
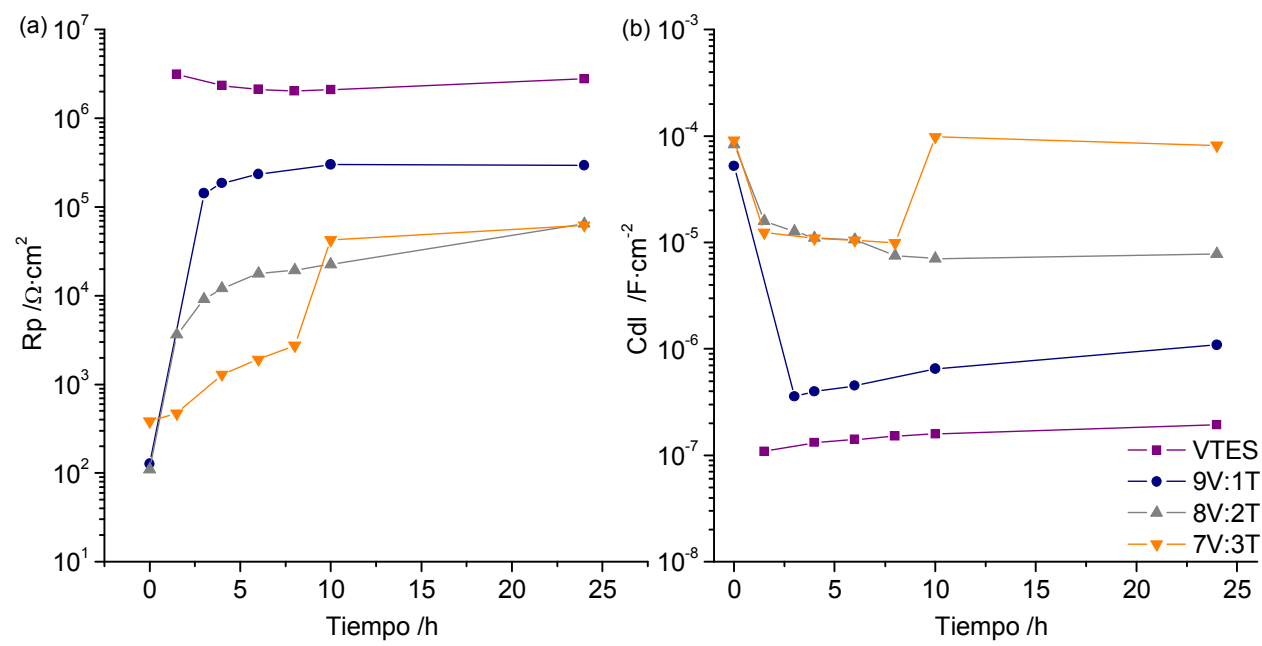

Figura. 5.19 Comparación de la evolución del valor de (a) resistencia a la polarización y (b) capacidad de la doble capa con el tiempo de exposición a la disolución acuosa $3,5 \% \mathrm{NaCl}$ de los recubrimientos VTES, 9V:1T, 8V:2T y $7 \mathrm{~V}: 3 \mathrm{~T}$.

La resistencia de polarización, $\mathrm{R}_{\mathrm{p}}$, es una medida del grado de actividad ánodocátodo de la interfase, de forma que cuanto menor es este valor la interfase es más activa $\mathrm{y}$, por tanto se pueden generar procesos de corrosión más fácilmente. No obstante el desarrollo de capas de óxido pasivantes da lugar a un aumento de valor de este parámetro con el tiempo de exposición. En general valores constantes de este parámetro se asocian con interfases poco activas y altas propiedades anticorrosivas del recubrimiento, mientras que si existen variaciones la interfase es activa y se asocia con baja protección frente a la corrosión del recubrimiento. 
recubrimiento VTES tiene valores de $R_{p}$ muy constantes durante el tiempo de exposición al electrolito, con valores entorno a $2,3 \cdot 10^{6} \Omega \cdot \mathrm{cm}^{2}$. Los recubrimientos $9 \mathrm{~V}: 1 \mathrm{~T}, 8 \mathrm{~V}: 2 \mathrm{~T}$ y $7 \mathrm{~V}: 3 \mathrm{~T}$ tienen valores de $\mathrm{R}_{\mathrm{p}}$ varios ordenes de magnitud por debajo de los obtenidos para VTES. El recubrimiento $9 \mathrm{~V}: 1 \mathrm{~T}$ inicialmente tiene un calor de Rp 5 ordenes de magnitud por debajo de VTES, con un valor de $129 \Omega \cdot \mathrm{cm}^{2}$, pero a las tres horas de exposición alcanza un valor de $1,4 \cdot 10^{5} \Omega \cdot \mathrm{cm}^{2}$, que permanece prácticamente constante con el paso del tiempo de exposición (a 24 horas se obtiene un valor de $2,9 \cdot 10^{5} \Omega \cdot \mathrm{cm}^{2}$ ). El recubrimiento $8 \mathrm{~V}: 2 \mathrm{~T}$ tiene un comportamiento similar, en el instante inicial tiene un valor de $R_{p}$ muy bajo de $129 \Omega \cdot \mathrm{cm}^{2}$, que rápidamente se recupera, dando en este caso un valor de $R_{p}$ a 3 horas de $9 \cdot 10^{4} \Omega \cdot \mathrm{cm}^{2}$ (un orden de magnitud por debajo de 9V:1T). Con el paso del tiempo de exposición este valor va aumentando hasta alcanzar un valor final de $6,4 \cdot 10^{4} \Omega \cdot \mathrm{cm}^{2}$. El recubrimiento $7 \mathrm{~V}: 3 T$ tiene un valor inicial de $R_{p}$ de $404 \Omega \cdot \mathrm{cm}^{2}$, en este caso no se produce un aumento drástico de $R_{p}$ como en los casos anteriores, siendo el valor de $R_{p}$ a las 3 horas de ensayo $1370 \Omega \cdot \mathrm{cm}^{2}$. Este recubrimiento tiene un aumento drástico de $R_{p}$ a las 10 horas y posteriormente se mantiene constante con un valor a 24 horas de $6,4 \cdot 10^{4}$ $\Omega \cdot \mathrm{cm}^{2}$.

El recubrimiento VTES muestra un valor de $R_{p}$ constante durante el tiempo de exposición y varios ordenes de magnitud por encima de los obtenidos para el resto de la serie. El recubrimiento VTES protege frente a fenómenos de corrosión, teniendo una interfase muy estable. Los recubrimientos con contenido en TEOS tienen una alta permeabilidad (valores de $R_{p o}$ bajos y valores crecientes de $C P E_{c}$ ), por tanto la entrada de electrolito, así como especies activas hasta la interfase se produce fácilmente. Cuando las especies activas alcanzan la interfase favorecen las reacciones ánodo-cátodo dando lugar a interfases activas (por tanto valores de $R_{p}$ por debajo de los obtenidos para VTES). Se observan interfases más activas cuanto mayor es el contenido en TEOS, por tanto, cuanto más permeable es el recubrimiento.

El valor de la capacidad de la doble capa es una medida de la tendencia a la deslaminación del recubrimiento (valores crecientes de la capacidad) o de la generación de óxido (valores decrecientes). Los valores de $\mathrm{CPE}_{\mathrm{dl}}$ del recubrimiento VTES son muy constantes con el tiempo de exposición al electrolito, teniendo un valor 
inicial de $1,1 \cdot 10^{-7} \mathrm{~F} \cdot \mathrm{cm}^{-2}$ y al final del tiempo de exposición es de $1,9 \cdot 10^{-7} \mathrm{~F} \cdot \mathrm{cm}^{-2}$. Un aumento en el contenido en TEOS de los recubrimientos, conlleva un incremento de la capacidad a la doble capa en su valor inicial. El recubrimiento 9V:1T tiene un valor inicial alto $5,22 \cdot 10^{-5} \mathrm{~F} \cdot \mathrm{cm}^{-2}$ que disminuye durante las primeras horas, para registrar un valor de $3,56 \cdot 10^{-7} \mathrm{~F} \cdot \mathrm{cm}^{-2}$ a las 3 horas, posteriormente permanece prácticamente constante con el tiempo de exposición con un valor a las 10 horas y 24 horas de $6,48 \cdot 10^{-7} \mathrm{~F} \cdot \mathrm{cm}^{-2}$ y $1,08 \cdot 10^{-6} \mathrm{~F} \cdot \mathrm{cm}^{-2}$, respectivamente. El recubrimiento $8 \mathrm{~V}: 2 \mathrm{~T}$ tiene un valor inicial próximo al obtenido para $9 \mathrm{~V}: 1 \mathrm{~T}, 8,34 \cdot 10^{-5} \mathrm{~F} \cdot \mathrm{cm}^{-2}$. Disminuye durante las primeras horas (pero en menor medida que $9 \mathrm{~V}: 1 \mathrm{~T}$ ) obteniéndose un valor a 3 horas de $1,26 \cdot 10^{-5} \mathrm{~F} \cdot \mathrm{cm}^{-2}$, con el paso del tiempo de exposición no se observan cambios significativos en este valor, para 10 horas se obtiene un valor de $7,08 \cdot 10^{-7} \mathrm{~F} \cdot \mathrm{cm}^{-2}$ y para 24 horas $7,78 \cdot 10^{-6} \mathrm{~F} \cdot \mathrm{cm}^{-2}$. El recubrimiento $7 \mathrm{~V}: 3 \mathrm{~T}$ tiene un valor inicial de $9,12 \cdot 10^{-5} \mathrm{~F} \cdot \mathrm{cm}^{-2}$. Con el paso del tiempo de exposición disminuye a $1,09 \cdot 10^{-5} \mathrm{~F} \cdot \mathrm{cm}^{-2}$ para 3 horas. A las 10 horas vuelve a aumentar a $9,8 \cdot 10^{-5} \mathrm{~F} \cdot \mathrm{cm}^{-2}$ para mantenerse constante hasta las 24 horas de inmersión en el electrolito $8,14 \cdot 10^{-5} \mathrm{~F} \cdot \mathrm{cm}^{-2}$.

Los recubrimientos con distintas cantidades de TEOS tienen un valor de CPE varios ordenes de magnitud superior a los registrados por VTES debido probablemente a procesos de deslaminación entre el recubrimiento y el metal que hacen aumentar la capacidad de este condensador. A mayor contenido en TEOS, más activo es el proceso de deslaminación del recubrimiento, mientras que el recubrimiento VTES no presenta procesos de esta naturaleza. No obstante, el decrecimiento con el tiempo de exposición al electrolito de esta capacidad puede ser indicativo de un proceso de formación de capa de óxido en la superficie por la llegada de especies activas a ésta.

Los recubrimientos con TEOS donde la entrada de electrolito y especies activas es mayor y muestran una interfase activa, describen un tercer proceso a frecuencias muy bajas. Este tercer proceso está asociado, como se mencionó anteriormente, con la formación de una capa de óxido en la superficie metálica, lo que es coherente con los resultados electroquímicos ya presentados. Los elementos pasivos del circuito equivalente correspondientes a esta tercera constante de tiempo son nuevamente una resistencia $R_{\text {ox }}$ y una capacidad representada por un elemento de fase constante $\mathrm{CPE}_{o x}$ en paralelo. Los datos que describen este proceso no son suficientes para 
poder realizar una buena modelización de los valores de la resistencia $R_{\text {ox }}$ y la capacidad $\mathrm{CPE}_{\mathrm{ox}}$, pudiéndose sólo señalar su existencia.

De los resultados electroquímicos se puede concluir que el recubrimiento VTES es poco permeable al electrolito y mantiene esta propiedad durante todo el tiempo de exposición, sin verse afectada por el contacto con el electrolito. Las especies activas no llegan a la interfase, y no se producen fenómenos de deslaminación, debido posiblemente a la formación de una red más tupida que impide el paso de especies activas hasta la superficie, protegiendo mejor frente a los procesos corrosivos. La incorporación de tan solo un $10 \%$ en la formulación provoca que las propiedades barrera del recubrimiento se vean empeoradas en gran medida. Puede establecerse, a modo genérico, que las propiedades protectoras frente a la corrosión electroquímica del recubrimiento son peores cuanto mayor es el contenido en TEOS. Estos recubrimientos tienen una red con canales a través de los que el electrolito y las especies activas pasan fácilmente, y los recubrimientos absorben mayor cantidad de agua con el tiempo de exposición al electrolito. Además cuenta con una interfase activa y se detectan fenómenos de deslaminación donde se llegan a producir procesos corrosivos por lo que llega a detectarse la presencia de una tercera constante de tiempo asociada a la formación de una capa de óxido.

\subsubsection{Degradación hidrolítica}

Se detectó en el estudio de la degradación hidrolítica de los precursores por separado (apartado 4.6) que el recubrimiento VTES es muy estable en medios acuosos, no viéndose afectado en cuanto a degradación con el paso del tiempo de inmersión y no favoreciendo la liberación de los agentes incorporados. Como se ha mencionado anteriormente, es aconsejable que los recubrimientos se degraden en tiempos inferiores a 2 meses, ya que se ha detectado que el titanio muestra un buen comportamiento biológico a tiempos mayores. Por este motivo, se ha adicionado TEOS con el fin de aumentar la hidrofilia del material y así aumentar su degradabilidad. Además, gracias al aumento de la degradabilidad y, al contar con una cadena inorgánica mayor, se favorecerá la liberación de compuestos de silicio que se han detectado promueven procesos de osteointegración. 
Para la realización de este ensayo se obtuvieron los materiales en película libre y se ha evaluado su degradación por hidrólisis sumergiéndolos en disolución de fosfato PBS durante un tiempo total de 6 semanas y registrando la pérdida de peso de los mismos. Los materiales se dispusieron dentro de unas "cestas" para permitir la entrada del medio (PBS) y, a su vez, impedir la pérdida de parte del material. Los resultados de la pérdida de peso en tanto por ciento para cada recubrimiento se muestran en la Figura. 5.20.

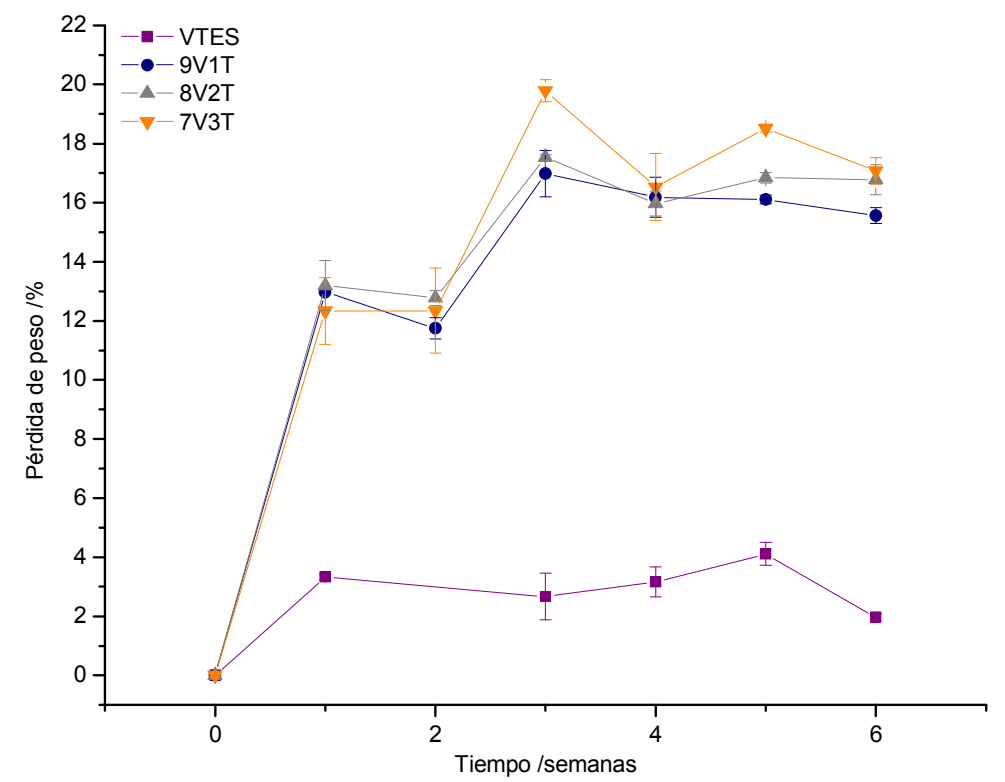

Figura. 5.20 Degradación hidrolítica por pérdida de peso del recubrimiento VTES y VTES con un $10 \%$ TEOS (9V:1T), $20 \%$ TEOS (8V:2T) y $30 \%$ TEOS (7V:3T) sumergidos en PBS a $37^{\circ} \mathrm{C}$.

Como se describió en el apartado 4.6 el recubrimiento VTES registra toda la degradación (aproximadamente un $3 \%$ ) dentro de la primera semana de exposición al medio y posteriormente no registra mayores pérdidas, dentro del intervalo de tiempos estudiado. Los recubrimientos $9 \mathrm{~V}: 1 \mathrm{~T}, 8 \mathrm{~V}: 2 \mathrm{~T}$ y $7 \mathrm{~V}: 3 \mathrm{~T}$ muestran un comportamiento entre ellos muy similar durante las primeras semanas. Durante la primera semana de exposición experimentan una degradación severa, degradándose alrededor de un $13 \%$ del total. A partir de la tercera semana de exposición el recubrimiento con un $30 \%$ de TEOS (7V:3T) tiene una degradación ligeramente superior (alrededor de 20\% del peso) en comparación al 8V:2T y 9V:1T (aproximadamente un 17\%). Para 
tiempos superiores a 3 semanas no se registran cambios significativos en la pérdida de peso.

A la vista de los resultados se ha conseguido aumentar la degradabilidad del material por hidrólisis de la cadena inorgánica Si-O-Si adicionando cantidades crecientes de TEOS, de un 3\% de pérdida de peso registrado en el VTES hasta un $20 \%$ obtenido para el $7 \mathrm{~V}: 3 \mathrm{~T}$. Este fenómeno se ve favorecido por una mayor hidrofilia de los recubrimientos con el aumento del contenido en TEOS.

\subsubsection{Liberación de agentes terapéuticos}

Una de las propiedades más importantes con las que se quiere dotar esta serie de recubrimientos hechos a medida es la capacidad de liberación de agentes terapéuticos en el momento necesario. Los recubrimientos de VTES con contenido en TEOS degradan fácilmente, por lo que se puede diseñar el perfil de liberación por medio de la adición de TEOS, favoreciendo así la liberación de fármacos. En este apartado se estudia la liberación de un fármaco modelo (procaína) en función del contenido en TEOS.

La procaína es un fármaco muy soluble en agua que se utiliza ampliamente como modelo. El fármaco se introdujo durante la síntesis de la fase sol, disolviéndolo en el agua de hidrólisis tal y como se detalló en el apartado 3.1.2. Los materiales para la realización de este ensayo se obtuvieron en película libre pero no se extrajeron del molde, que en este caso es de aluminio en vez de teflón, en un intento de obtener el comportamiento lo más parecido a la situación final, donde el recubrimiento está en contacto con el medio acuoso por una única cara. Para la realización del ensayo las muestras se introdujeron en PBS a pH 6,8 manteniendo la muestra con agitación suave y a una temperatura constante de $37^{\circ} \mathrm{C}$. En la Figura. 5.21 se muestran las curvas de liberación hasta 3 días de ensayo de la serie de materiales con distintas cantidades de TEOS $0 \%, 10 \%, 20 \%$ y $30 \%$ correspondiente a las muestras VTES, $9 \mathrm{~V}: 1 \mathrm{~T}, 8 \mathrm{~V}: 2 \mathrm{Ty}$ 7V:3T, respectivamente. En las gráficas se representa $\mathrm{M}_{t} / \mathrm{M}_{\infty}$ donde $\mathrm{M}_{t}$ es la cantidad de fármaco detectada a un tiempo determinado $t$ y $\mathrm{M}_{\infty}$ es la cantidad de fármaco incorporado en el recubrimiento sintetizado. 


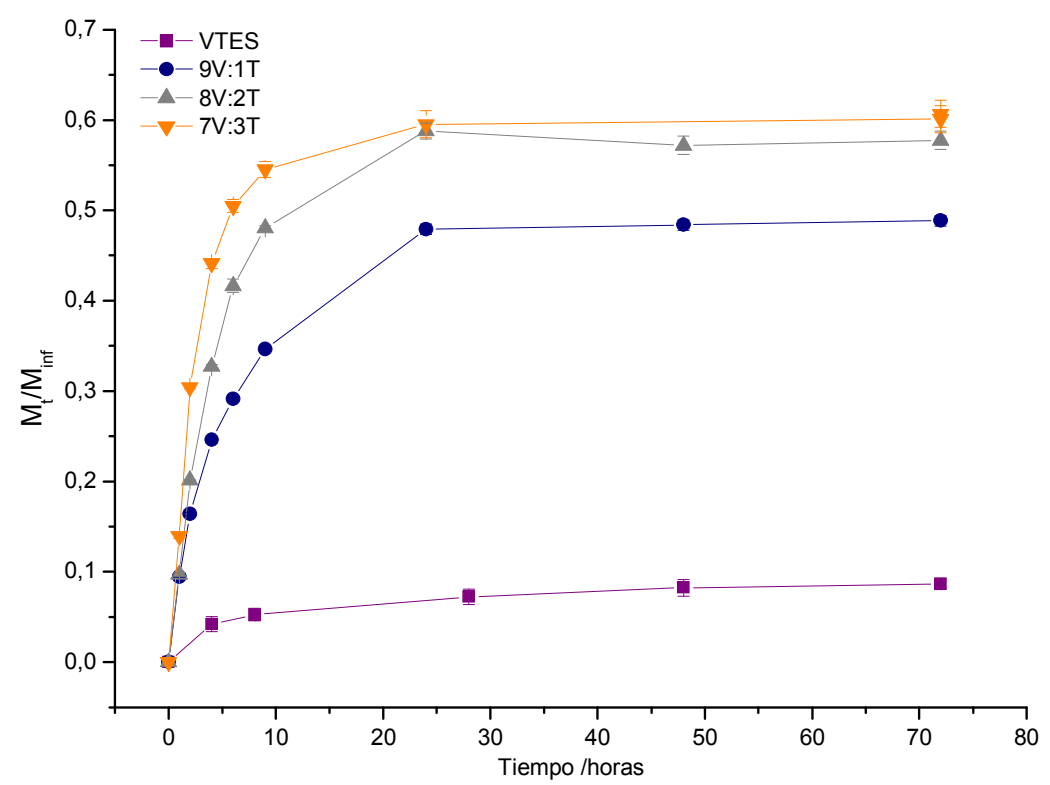

Figura. 5.21 Curvas de liberación de agente terapéutico de los recubrimientos hasta un $30 \%$ de TEOS (VTES, 9V:1T, 8V:2T, 7V:3T) dopados con un 5\% procaína.

EI VTES tiene una liberación pequeña en las primeras horas de ensayo, liberándose un $5 \%$ en las primeras 5 horas. A mayores tiempos tiene una liberación lenta pero creciente con el tiempo. La máxima liberación detectada a las 72 horas de ensayo no alcanza al $10 \%$ del total de fármaco introducido.

La incorporación de TEOS en la formulación hace que se acelere la cinética de degradación, se libera más cuanto mayor contenido en TEOS. En las primeras 24 horas de ensayo es donde se detecta la mayor tasa de liberación en todos los casos, la muestra $9 \mathrm{~V}: 1 \mathrm{~T}$ libera cerca del $50 \%$ de fármaco introducido, $8 \mathrm{~V}: 2 \mathrm{~T}$ y $7 \mathrm{~V}: 3 \mathrm{~T}$ alcanza hasta $60 \%$. A tiempos por encima de 24 horas la liberación se estabiliza y es más lenta, no aumentándose de manera significativa la cantidad de procaína detectada en el PBS.

Las curvas de liberación tienen el perfil esperado, mostrando una primera liberación rápida, dentro de las primeras 24 horas proveniente del fármaco albergado en los poros que se encuentran en contacto con el medio, seguida de una liberación más lenta de aquel fármaco que se alberga en las capas más internas del recubrimiento [80]. 
Se puede concluir que la incorporación de TEOS ha favorecido notablemente la liberación de fármacos desde el recubrimiento, aumentándose desde un $5 \%$, en el caso del VTES, hasta un $60 \%$ en el caso del 7V:3T.

\subsubsection{Comportamiento celular}

La adhesión celular depende de diversos factores, tal y como se mencionó en la introducción, como la rugosidad, la composición química o la hidrofilia. En este apartado se ha estudiado la adhesión celular en función de la composición química, si bien la composición tiene un efecto notable en parámetros como la hidrofilia. La hidrofilia es un factor clave, como se ha documentado en diversos trabajos [74, 120121], ya que de él depende la absorción de proteínas en superficie y su conformación, y por tanto, un mayor o menor anclaje de células. Superficies hidrófobas (con alto ángulo de contacto) tienden a decelerar las reacciones iniciales de absorción de proteínas en contacto con el medio de cultivo y, por tanto, conllevan un mal anclaje celular. Por otro lado, se ha detectado que superficies muy hidrófilas (como hidrogeles) no mejoran la adhesión celular. Son superficies con hidrofilias intermedias (alrededor $70^{\circ}$ ) las que mejoran la adhesión celular, aunque como se ha comentado anteriormente es la contribución de muchos factores la que media la adhesión celular. Por otro lado, esta serie de materiales con contenido creciente en TEOS, tienen una degradación mucho mayor que el recubrimiento obtenido a partir de VTES. Durante la degradación de los recubrimientos se liberan al entorno compuestos de silicio que se ha demostrado favorecen la osteoinducción [67-71].

En el apartado 4.8 se estudió la citotoxicidad de los precursores por separado y se detectó que no eran citotóxicos. En este apartado el estudio biológico va un paso más allá. Estos recubrimientos deben favorecer los procesos de osteoinducción de forma que favorezcan la osteointegración del implante, sobre todo en los primeros instantes tras la implantación. Tal y como se relató en el capítulo de introducción estos procesos están mediados inicialmente por células madre mesenquimales (AMSCs) provenientes del torrente sanguíneo que se activan por diversos factores para diferenciarse a células osteoprogenitoras. Las células osteoprogenitoras a su vez son capaces de diferenciarse a osteoblastos hecho esencial para la formación de hueso. Por este motivo, en este apartado se ha decido estudiar la adhesión y proliferación 
celular de las AMSCs sobre los materiales en función de su composición química (mezcla de VTES y TEOS en las proporciones ya descritas).

Se ha evaluado la capacidad osteogénica de las AMSCs dispuestas sobre los biomateriales mediante la cuantificación de los depósitos de calcio formados por las AMSCs diferenciadas a células óseas en un medio de diferenciación osteogénico. La formación de depósitos de calcio se produce por la secreción de matriz extracelular mineralizada cuando las AMSCs se han diferenciado a osteoblastos, lo que puede poner de manifiesto una buena diferenciación y osteoinducción de los materiales. Para realizar el ensayo se incuban las AMSCs utilizando el medio de cultivo de esta línea celular durante siete días. Posteriormente se adiciona un medio de diferenciación osteogénico y se cuantifican los depósitos de calcio mediante tinción con rojo alizarina a los 7 y 14 días desde la incorporación del nuevo medio.

Para este estudio se decidió recubrir en vez de discos de titanio puro, portas de vidrio que son totalmente inertes y se utilizan extensamente como controles para la realización de cultivos in vitro. Se recubrieron portas de vidrio de $12 \mathrm{~mm}$ de diámetro con cada una de las formulaciones. El método de aplicación fue por evaporación de una gota de sol sobre el porta de vidrio en posición horizontal y aplicando en la misma posición el tratamiento de curado estándar establecido para cada formulación.

Para la realización del estudio se sembraron sobre los materiales las AMSCs y se midió mediante un kit colorimétrico tipo MTT la actividad mitocondrial de las células. Sólo se detectará actividad mitocondrial de aquellas células que estén adheridas al material y que se encuentren vivas, por esto, la medida de la absorbancia será directamente proporcional al número de células viables sobre el material. En la Figura. 5.22 se representan las curvas de proliferación de células mesenquimales del tejido adiposo humano sobre la serie de materiales VTES-TEOS aplicados sobre vidrio en comparación con el material utilizado como soporte (vidrio) durante 14 días de cultivo. 


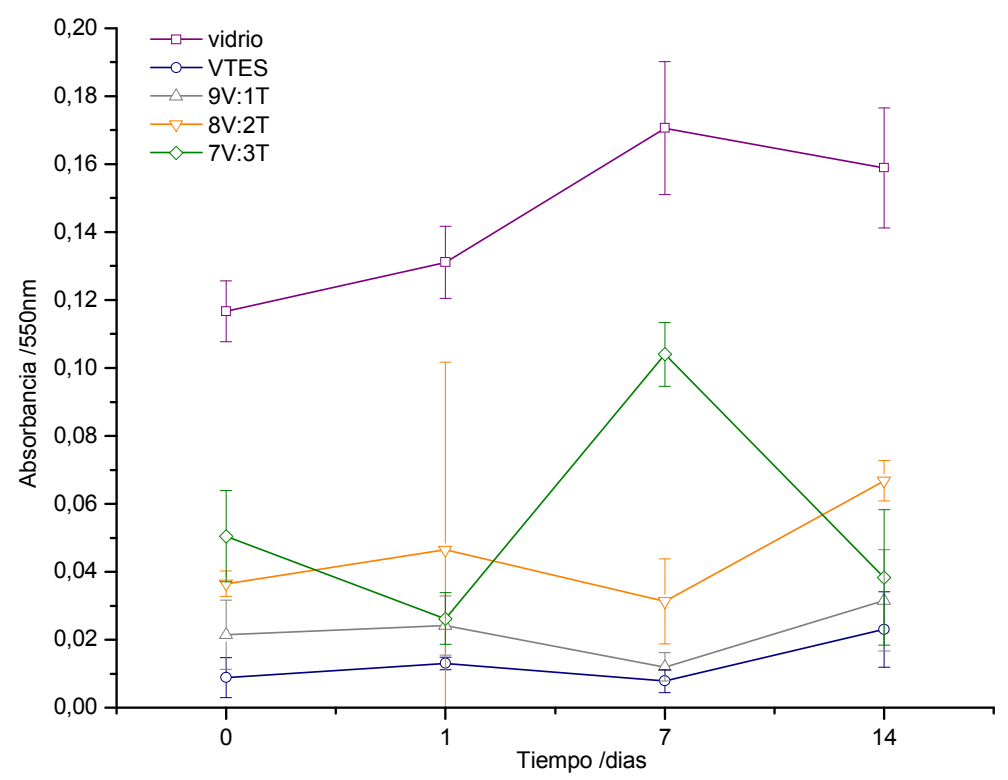

Figura. 5.22 Curva de proliferación de células mesenquimales del tejido adiposo humano AMSCs sobre el material de referencia vidrio y los recubrimientos VTES, 8V:2G, 5V:5G, 2V:8G y GPTMS. Absorbancia medida a $550 \mathrm{~nm}$.

El recubrimiento VTES tiene una baja adhesión de AMSCs sobre su superficie, ya que la actividad mitocondrial que se detecta es baja en todos los tiempos de ensayo. Se detecta una ligera recuperación para tiempos superiores a 7 días.

La adición de un $10 \%$ de TEOS mejora ligeramente la adhesión y proliferación de las AMSCs sobre su superficie, midiéndose una absorbancia entorno a 0,02 DO para 1 día de ensayo y manteniéndose constante para tiempos superiores, es decir, el número de células viables se mantiene prácticamente constante en todos los tiempos estudiados, con una ligera recuperación para tiempos superiores a 7 días.

El recubrimiento $8 \mathrm{~V}: 2 \mathrm{~T}$ tiene una mayor adhesión celular, detectándose en el ensayo una absorbancia por encima de 0,04 DO para 1 día de ensayo. Como en el caso anterior se produce un incremento en la proliferación para tiempos mayores a 7 días.

El recubrimiento $7 \mathrm{~V}: 3 \mathrm{~T}$ tiene un comportamiento cambiante en el tiempo. Es el que mejor adhesión inicial tiene, con una absorbancia cercana a 0,05 DO, mientras el $8 \mathrm{~V}: 2 \mathrm{~T}$ o el 9V:1T tienen 0,04 DO y 0,02 DO respectivamente. Sin embargo, tiene una 
bajada en la absorbancia medida a 1 día de ensayo, que se recupera a los 7 días para dar un valor cercano a 0,11 DO muy por encima de los registrados para los otros materiales. A 14 días se produce un descenso drástico en la detección de actividad mitocondrial, quedando el valor medido de absorbancia por debajo del registrado para la muestra $8 \mathrm{~V}: 2 \mathrm{~T}$.

El vidrio utilizado de base para la deposición de los recubrimientos y utilizado como control negativo en muchos ensayos (por tener una alta adhesión celular) tiene un anclaje celular mucho mayor al obtenido en nuestros materiales. Tiene desde el inicio un mayor número de células viables en su superficie y con el paso del tiempo el número aumenta hasta alcanzar el máximo a 7 días. A 14 días se produce una ligera disminución del valor registrado de absorbancia.

La serie de materiales VTES-TEOS tiene una proliferación celular por debajo del material de referencia vidrio para todos los tiempos estudiados. No obstante, los recubrimientos con distintas cantidades de TEOS muestran que se mejora la adhesión celular con el aumento en el contenido de TEOS para todos los tiempos, del mismo modo que se reduce el ángulo de contacto. Este hecho se puede deber a una mayor absorción de proteínas en la superficie de los recubrimientos por contar con una mayor hidrofilia al incrementar el contenido en TEOS. A los 7 días de cultivo el film con un $30 \%$ de TEOS destaca frente al resto, al detectarse una mayor cantidad de células adheridas, sin embargo a 14 días se produce un descenso significativo en la adhesión.

Se ha evaluado la adhesión de las AMSCs sobre la serie de materiales, pero si es importante determinar la viabilidad y adherencia a la superficie de las células, es más importante determinar si estas células tienen capacidad para diferenciarse a osteoblastos y segregar matriz extracelular mineralizada. Por este motivo, se ha evaluado la capacidad osteogénica de las AMSCs dispuestas sobre los biomateriales mediante la cuantificación de los depósitos de calcio formados por las AMSCs diferenciadas a células óseas en un medio de diferenciación osteogénico a los 7 y 14 días de cultivo diferenciador. En la Figura. 5.23 se muestran los valores de densidad óptica normalizados frente a los valores obtenidos en el material de control (vidrio). 


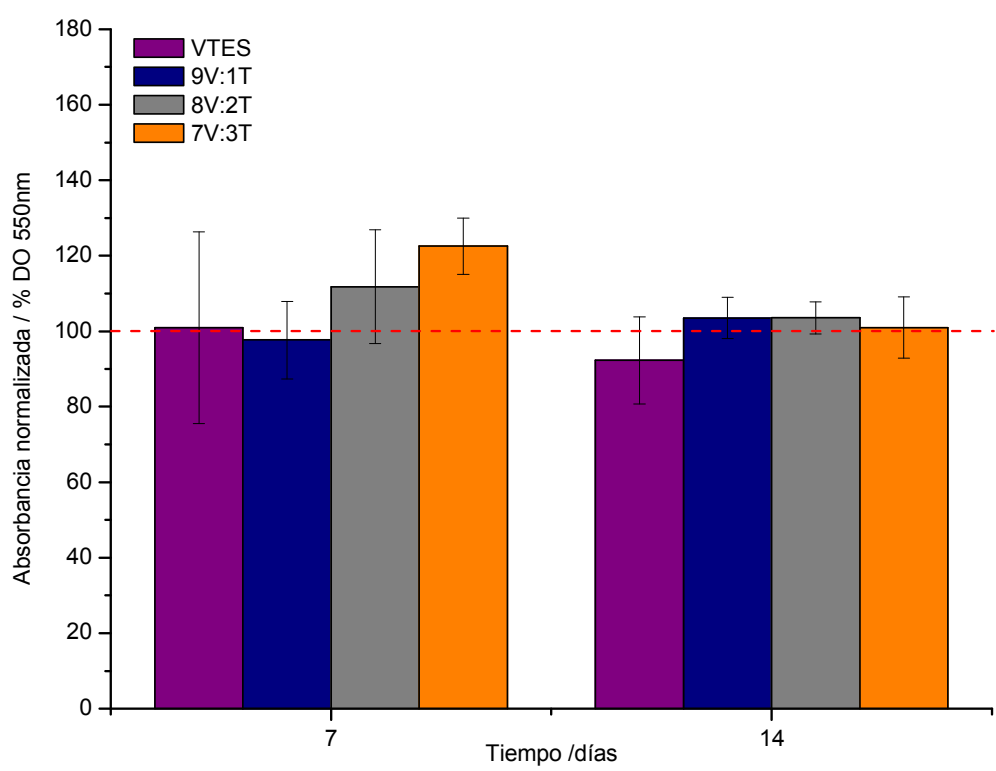

Figura. 5.23 Cuantificación de los depósitos de calcio formados por las AMSCs en medio de diferenciación osteogénico a los 7 y 14 días de cultivo sobre los materiales VTES, 9V:1T, 8V:2T y $7 \mathrm{~V}: 3 \mathrm{~T}$ normalizados frente al control vidrio.

Cuando se evalúa la capacidad osteogénica de la serie de materiales, se observa como las diferencias que se encontraban en proliferación con el material de referencia vidrio no se detectan aquí. La medida de absorbancia para los depósitos de calcio se encuentra cercana o por encima de los niveles medidos para el vidrio.

El recubrimiento VTES tiene una absorbancia relativa al control a los 7 días de $100,95 \%$, y a los 14 días disminuye hasta $92,30 \%$. El 9V:1T a los 7 días registra una absorbancia de $97,64 \%$, el $8 \mathrm{~V}: 2 \mathrm{~T}$ de $111,78 \%$ y $7 \mathrm{~V}: 3 \mathrm{~T}$ de $122,52 \%$. A los 14 días los valores de absorbancia relativa al control son de $103,48 \%, 103,54 \%$ y $100,98 \%$ para el $9 \mathrm{~V}: 1 \mathrm{~T}, 8 \mathrm{~V}: 2 \mathrm{~T}$ y $7 \mathrm{~V}: 3 \mathrm{~T}$, respectivamente.

Del análisis de los datos se puede concluir que el recubrimiento VTES tiene, a pesar de tener una adhesión celular muy por debajo del resto de materiales, tiene una capacidad para promover la diferenciación a osteoblastos semejante a la registrada por el vidrio control, que tenía mejor adhesión celular. A 7 días se detecta que con el incremento en el contenido en TEOS se mejora la osteoinducción de los materiales, aumentándose la cantidad de depósitos de calcio. Este fenómeno probablemente se debe a una mayor liberación de compuestos de silicio desde el recubrimiento por 
degradación del sistema. A los 14 días de cultivo las diferencias entre las distintas composiciones no son tan acusadas, el VTES es el que menor cantidad de depósitos de calcio presenta, el resto $9 \mathrm{~V}: 1 \mathrm{~T}, 8 \mathrm{~V}: 2 \mathrm{~T}$ y $7 \mathrm{~V}: 3 \mathrm{~T}$ tienen una producción semejante a la del vidrio.

Se ha conseguido mejorar la adhesión celular de las AMSCs sobre los recubrimientos incrementando el contenido en TEOS en la formulación VTES. Esta mejora se puede deber a que un aumento en la hidrofilia del recubrimiento favorezca la absorción de proteínas en la superficie y, por tanto, las células puedan anclarse a través de ellas a la superficie del material.

Cuando se promueve la diferenciación de las AMSCs a osteoblastos mediante la adición del medio de diferenciación osteogénico se detecta que los materiales inducen la diferenciación y se detecta la producción de matriz extracelular mineralizada por detección de depósitos de calcio. Todos los materiales alcanzan el nivel del material control. Dentro de la serie de materiales se detecta como el aumento de la cantidad de TEOS mejora la osteoinducción, probablemente debido a una mayor liberación de compuestos de silicio por una mayor degradación del material.

\section{2 Recubrimientos con grupo funcional epoxi}

En este apartado se sintetiza y caracteriza una serie de materiales obtenidos a partir del "precursor base seleccionado" VTES y distintas cantidades de GPTMS. El GPTMS es un precursor de silicio que como se describió en el Capítulo 4 cuenta con una cadena orgánica con un carboxilo y un grupo epoxi terminal. Se parte de la hipótesis que la introducción de un grupo epoxi al recubrimiento nos permitirá obtener una superficie con un grupo activo en el cual puedan unirse fácilmente agentes orgánicos como péptidos o proteínas, hecho que potenciará el anclaje celular y, por tanto, la osteoinducción y osteointegración. Además la introducción de un carácter más orgánico a la red hará que ésta tenga unas propiedades totalmente distintas a las obtenidas en la anterior serie, y que tienen interés para la aplicación final, como pueden ser la formación de una red más abierta y la obtención de una menor fragilidad del recubrimiento. 


\subsubsection{Síntesis de la serie de materiales VTES-GPTMS}

Se ha sintetizado la serie de materiales partiendo de VTES y añadiendo distintas cantidades de GPTMS. Se ha podido abarcar todo el intervalo de formulaciones desde un 100\% VTES hasta 0\% VTES (con incrementos de $2 \%$ entre formulación). En todos los casos se ha obtenido una fase sol transparente y sin precipitados, con una viscosidad adecuada para obtener una correcta aplicación sobre el metal.

Es importante que los recubrimientos tengan una buena aplicación y sean homogéneos en toda su superficie. Se ha evaluado el acabado superficial de los recubrimientos una vez depositados sobre el metal acero AISI 316L y aplicado el tratamiento de curado (descrito en 3.1.3), mediante la prueba de reflexión de un rayo luminoso. La serie de materiales obtenida tienen un buen acabado superficial, se han aplicado homogéneamente en toda la superficie del metal y no se observan imperfecciones como grietas o poros a escala macrométrica (Figura. 5.24(izq.)). Todos los recubrimientos son transparentes y tienen un acabado brillante en todos los casos, con una reflexión tipo espejo nítida (Figura. 5.24(dcha.)).
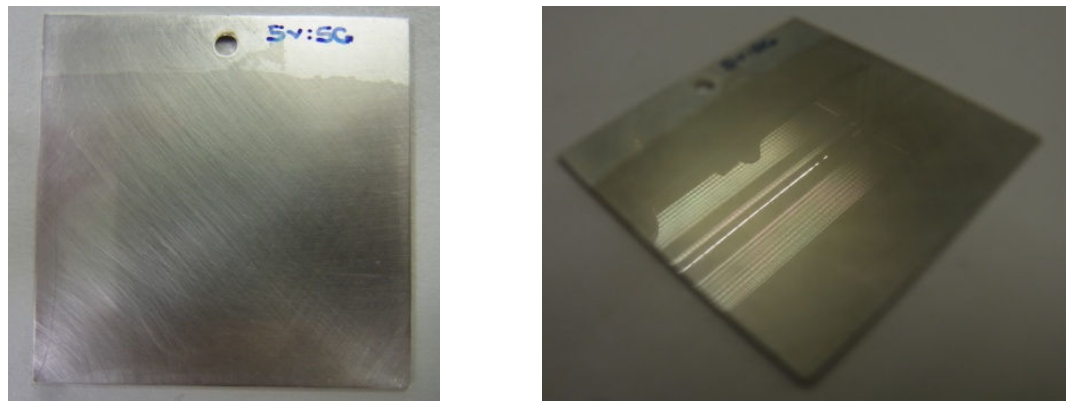

Figura. 5.24 (Izq.) Ejemplo de plancha recubierta con el recubrimiento 5V:5G mediante la técnica dip-coating. (Dcha.) reflejo tipo espejo sobre la superficie del recubrimiento 5V:5G.

También se ha comprobado la adherencia de los recubrimientos al sustrato metálico por medio de la técnica de corte enrejado. Se han obtenido para todos los casos recubrimientos adherentes, ya que no se ha detectado desprendimiento del recubrimiento en ningún caso.

A parte del acabado macrométrico es importante caracterizar el recubrimiento a nivel micrométrico. En la Figura. 5.25 se muestran las imágenes de SEM de los recubrimientos aplicados de la serie VTES-GPTMS. 
$2 \mathrm{~V}: 8 \mathrm{G}$
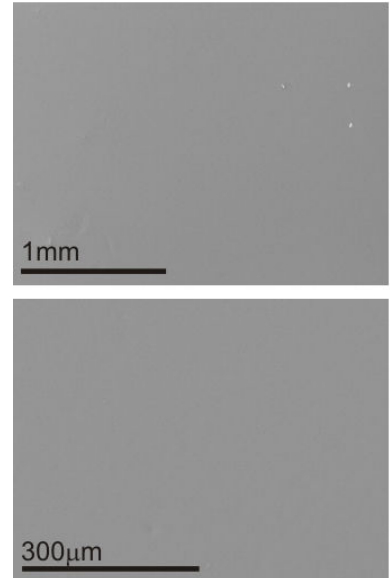

$5 V: 5 G$

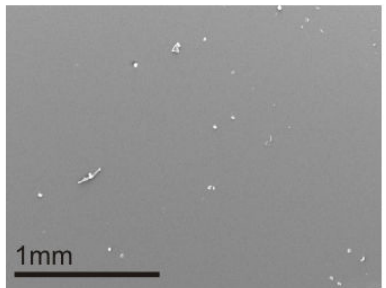

300 um
$8 V: 2 G$

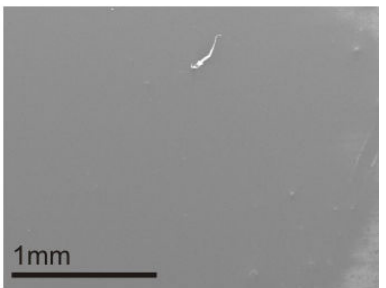

$300 \mu \mathrm{m}$

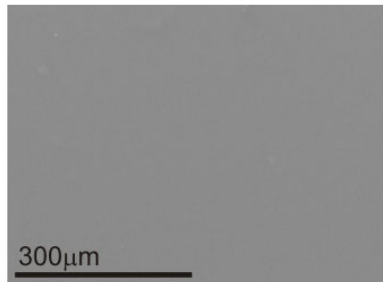

Figura. 5.25 Micrografías obtenidas con SEM de a los recubrimientos 8V:2G, 5V:5G, 2V:8G aplicados sobre acero $316 \mathrm{~L}$, en la primera fila a $50 \mathrm{X}$ aumentos y en la segunda a $200 \mathrm{X}$ aumentos.

Las imágenes de SEM muestran que se han obtenido para todas las composiciones recubrimientos homogéneos, continuos, sin grietas ni poros. Además no se aprecian agregados procedentes de posibles separaciones de fase entre los componentes utilizados.

Además, se han conseguido obtener el material sin aplicarlo en sustrato en forma de película libre con un espesor aproximado de $1 \mathrm{~mm}$ como se muestran en la Figura. 5.26. Estas películas libres se obtienen vertiendo una cantidad apropiada de fase sol (especificada en 3.1.3.c) en moldes de teflón y se aplica el mismo tratamiento de curado que el aplicado en las planchas metálicas. Posteriormente se desmoldan y se obtienen películas consistentes que no presentan grietas ni poros. Como en anteriores estudios, estas películas se utilizan para la caracterización del material en aquellos experimentos en los que no se pueda utilizar el material como recubrimiento aplicado en metal, como por ejemplo en técnicas calorimétricas o en propiedades mecánicas. 


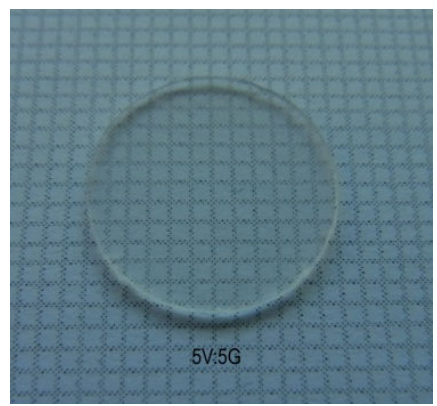

Figura. 5.26 Ejemplo de recubrimiento en película libre obtenidos a partir de VTES y GPTMS, 5V:5G.

\subsubsection{Caracterización química}

Se ha caracterizado los procesos de formación de red durante las reacciones de hidrólisis/condensación cuando intervienen los precursores VTES y GPTMS. La introducción de GPTMS, que es un precursor de silicio de gran tamaño, en la red de VTES puede impedir que las reacciones de hidrólisis y condensación se den en la misma medida que cuando se dispone del precursor VTES solo. Para analizar esta posibilidad, se realiza un estudio por ${ }^{29} \mathrm{Si}-\mathrm{RMN}$ de líquidos en el que analiza la reacción de hidrólisis y condensación con el tiempo, adicionalmente se realiza un RMN de sólidos para comprobar el estado final de la red de silicio. Estas reacciones también pueden estudiarse por medio de FTIR. Se han utilizado estas técnicas para fijar parámetros de síntesis como pueden ser el tiempo de reacción para la hidrólisis/condensación de los precursores, y las condiciones de curado óptimas para la formación de la red polisiloxánica en cuanto a parámetros de temperatura y tiempo. Además estas técnicas proporcionarán información valiosa sobre el tipo y estado de la red formada.

Se presentan en este apartado los resultados para dos técnicas: ${ }^{29}$ Si-RMN y FTIR.

a) Resonancia magnética nuclear ( ${ }^{29}$ Si-RMN).

Los alcóxidos de silicio tienen distinta velocidad de hidrólisis y condensación, por este motivo, cuando se introducen dos alcóxidos distintos dentro de una misma formulación es necesario comprobar que, con los parámetros de síntesis utilizados $(\mathrm{pH}$, cantidad de agua estequiométrica, tiempo de hidrólisis), se consigue la mayor hidrólisis posible de ambos alcóxidos. Para ello, se ha realizado un estudio por RMN 
en líquidos del núcleo ${ }^{29} \mathrm{Si}$ que nos permite analizar el grado de hidrólisis y condensación de cada precursor con las condiciones establecidas. En este caso el $\mathrm{pH}$ seleccionado es 1 , y la cantidad de agua adicionada es la estequiométrica para la hidrólisis de los grupos alcoxi del VTES y del GPTMS. Además se pretende optimizar el tiempo de hidrólisis/condensación para obtener el máximo entrecruzamiento de la red.

Para realizar el estudio a cada formulación (con distintas cantidades de GPTMS) se ha llevado a cabo, en primer lugar, un ${ }^{29} \mathrm{Si-RMN}$ de líquidos a ambos precursores disueltos en isopropanol. Posteriormente, se añadió el agua estequiométrica para la completa hidrólisis de los precursores VTES y GPTMS y se registraron espectros en el instante en el que se añadió el agua acidificada (20 minutos tras la adición) y tras 1 y 2 horas de la adición.

Se muestra en la Figura. 5.27 los espectros obtenidos para la formulación 5V:5G a modo de ejemplo, en el resto de formulaciones el comportamiento registrado fue semejante.

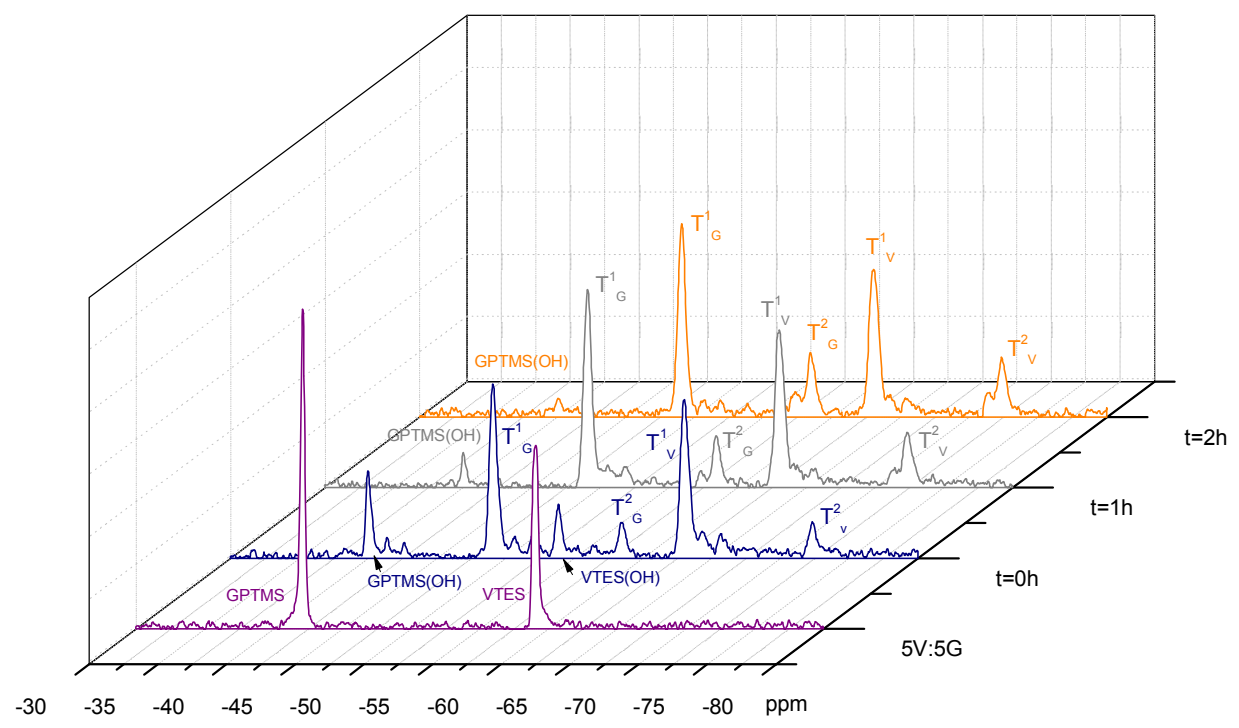

Figura. 5.27 Espectro de ${ }^{29}$ Si-RMN líquidos del 50VTES:50GPTMS 
El espectro de la mezcla de ambos precursores en alcohol muestra un desplazamiento químico a $-41 \mathrm{ppm}$ asociado al precursor GPTMS y otro a $-59 \mathrm{ppm}$ asociado al VTES. Al adicionar el agua acidificada $(\mathrm{t}=0)$ se detectan picos asociados a especies hidrolizadas de ambos precursores $-40 \mathrm{ppm}$ correspondiente al GPTMS y -53ppm al VTES. También se detectan picos asociados a átomos de silicio de entornos $\mathrm{T}^{1}$ y $\mathrm{T}^{2}$ de GPTMS y VTES. Pasada 1 hora desde la adición del agua acidificada los picos asociados a especies hidrolizadas desaparecen y aumenta la intensidad relativa de los picos $\mathrm{T}^{2}$, disminuyendo la de $\mathrm{T}^{1}$.Tras 2 horas, aumentan ligeramente la intensidad relativa de los pico $\mathrm{T}^{2}$ de GPTMS y VTES. Los picos de desplazamientos químicos correspondientes a cada especie se recopilan en la Tabla 5.6.

\begin{tabular}{|c|c|c|c|c|c|}
\hline 5VTES:5GPTMS & \multicolumn{5}{|c|}{ Desplazamiento químico $\delta / p p m$} \\
\hline & Precursor & $\mathrm{OH}$ & $T^{1}$ & $T^{2}$ & $T^{3}$ \\
\hline VTES & -59 & -53 & -63 & -72 & -81 \\
\hline GPTMS & -41 & -40 & -49 & -58 & - \\
\hline
\end{tabular}

En esta serie de materiales, como en las demás, se ha utilizado hidrólisis ácida. Se produce por tanto una hidrólisis rápida de uno de los alquil, detectándose en el instante inicial especies que tienen un $-\mathrm{OH}$ y que no han condensado GPTMS $(\mathrm{OH})$ y VTES $(\mathrm{OH})$. Este alcóxido tiene una mayor tendencia a condensar que ha hidrolizar de nuevo por lo que la intensidad de especies $\mathrm{T}^{1}$ asociadas a silicios con un puente siloxano formado es más elevada que la correspondiente a $\mathrm{T}^{2}$. Con el paso del tiempo las reacciones de hidrólisis y condensación se van sucediendo y se va formando la cadena polisiloxánica, detectándose un ligero aumento en las especies $\mathrm{T}^{2}$.

Cuando se estudió las reacciones de hidrólisis/condensación de los precursores por separado (apartado 4.2.a) se detectó que durante el tiempo que duran las reacciones el precursor GPTMS no se detectaban especies tipo $\mathrm{T}^{3}$, es decir, durante la etapa sol no se detectaban átomos de silicio (del GPTMS) con tres puentes siloxano establecidos. Sin embargo, cuando se analizó las reacciones del precursor VTES sí se detectaban especies tipo $\mathrm{T}^{3}$, es decir, existían átomos de silicio (del VTES) que habían alcanzado el máximo entrecruzamiento ya en la etapa sol. En el caso de la formulación $5 \mathrm{~V}: 5 \mathrm{G}$ no se detectan especies tipo $\mathrm{T}^{3}$ de los átomos de silicio 
del VTES, esto puede ser debido a que la adición de GPTMS afecta a la hidrólisis y condensación del precursor VTES en la etapa sol.

El proceso de hidrólisis se establece en todos los sistemas $8 \mathrm{~V}: 2 \mathrm{G}, 5 \mathrm{~V}: 5 \mathrm{G}$ y $2 \mathrm{~V}: 8 \mathrm{G}$ a un tiempo fijo de una hora ya que no se aprecian cambios significativos en las intensidades relativas de los picos registrados. Se aprecia en todos los sistemas como después del proceso de hidrólisis el avance de la condensación es muy pequeño, no detectándose silicios con entorno $\mathrm{T}^{3}$, siendo necesaria la aplicación de un proceso de secado/curado con temperatura para asegurar la formación de la red.

Tras el estudio de optimización del proceso de hidrólisis donde se ha evaluado las reacciones de hidrólisis y condensación en estado sol, se ha estudiado por ${ }^{29} \mathrm{Si}-\mathrm{RMN}$ de sólidos, los materiales obtenidos tras la aplicación del tratamiento de curado. El tratamiento de curado se aplica con el fin de permitir la evaporación de los disolventes incorporados así como para promover las reacciones de condensación. Como se describió en los espectros de líquidos durante la reacción de hidrólisis y condensación no se ha llegado al máximo de entrecruzamiento ya que no se detectan señales tipo $\mathrm{T}^{3}$ en ninguno de los precursores. Es por ello que se necesita la etapa de curado donde se promueven las reacciones de condensación de la futura red. Con este estudio se pretende comprobar este hecho y optimizar los tratamientos térmicos aplicados para conseguir un mayor grado de condensación de la futura red, por tanto, un máximo entrecruzamiento de la red. Los tratamientos de curado aplicados a cada una de las muestras se recogen en la Tabla 5.7. Con esta técnica también se consigue una caracterización de la red obtenida con las condiciones de curado aplicadas. Las muestras ensayadas se obtienen en película libre y posteriormente se trituran para permitir una correcta adquisición de los espectros.

Tabla 5.7 Tratamiento de curado aplicados para la serie VTES:GPTMS.

\begin{tabular}{|cccc|} 
& \multicolumn{4}{c|}{ VTES : GPTMS } \\
\hline Temperatura $/{ }^{\circ} \mathbf{C}$ & $\mathbf{8 : 2}$ & $\mathbf{5 : 5}$ & $\mathbf{2 : 8}$ \\
\hline Tiempo $/ \mathbf{m i n}$ & 100 & 140 & 140 \\
*Tratamiento de secado común en todas las muestras: $50^{\circ} \mathrm{C} / 15 \mathrm{~min}+$ rampa $\mathrm{V}=3^{\circ} \mathrm{C} / \mathrm{min}$ hasta Tc
\end{tabular}


En la Figura. 5.28 se representa el espectro Si-RMN de sólidos de la formulación 5V:5G a modo de ejemplo.

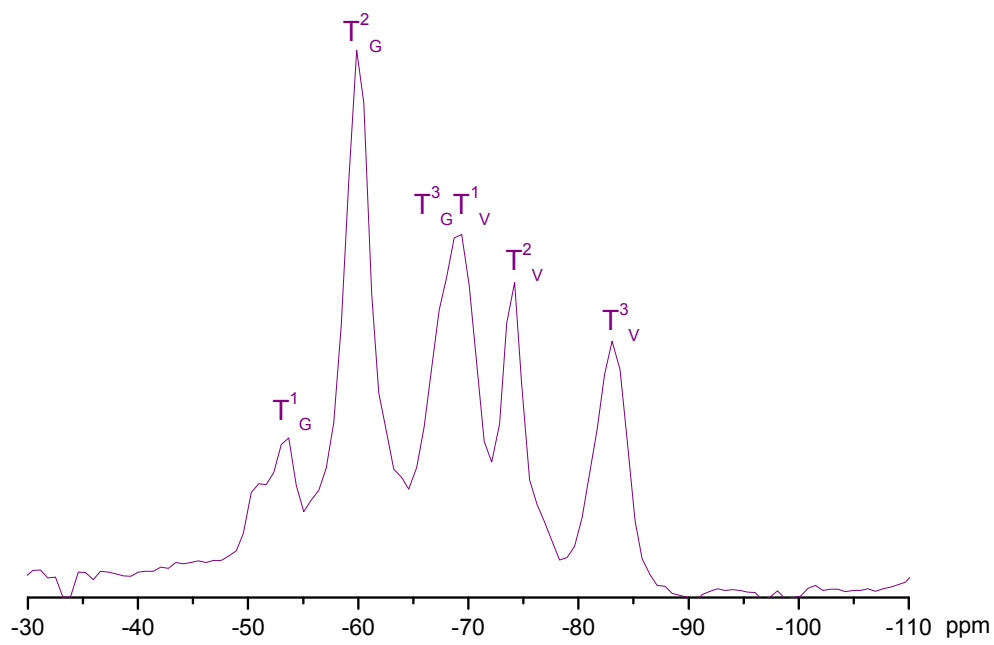

Figura. 5.28 Espectro ${ }^{29}$ Si-RMN de sólidos del 5VTES:5GPTMS

El espectro de la formulación $5 \mathrm{~V}: 5 \mathrm{G}$ muestra picos asociados a silicios de entorno $\mathrm{T}^{1}, \mathrm{~T}^{2}$ y $\mathrm{T}^{3}$ de los precursores GPTMS y VTES. Es importante señalar que en este caso los picos de entornos $\mathrm{T}^{3}$ del precursor GPTMS y $\mathrm{T}^{1}$ del VTES se solapan, por lo que la discusión acerca de la intensidad del pico $\mathrm{T}^{1}$ del VTES no se puede hacer. Además, los valores de relación de intensidades tabulados no son reales, al no poder distinguir la altura del pico $\mathrm{T}^{1}$ del VTES. Los picos de mayor intensidad son los $\mathrm{T}^{2} \mathrm{y} \mathrm{T}^{3}$, es decir, existen moléculas completamente hidrolizadas y condensadas y otras a las que les falta condensar por uno de sus posibles enlaces. Se detecta una baja intensidad relativa de especies tipo $\mathrm{T}^{1}$, por tanto, son pocas las moléculas en las que falta establecer dos de sus tres posibilidades de enlace (Tabla 5.8).

Tabla 5.8 Valores del desplazamiento químico de las señales de ${ }^{29}$ Si-RMN sólidos VTES-GPTMS.

\begin{tabular}{|c|c|c|c|c|}
\hline Form. 5V:5G & \multicolumn{4}{|c|}{ Desplazamiento químico, $\boldsymbol{\delta} / \mathbf{p p m}$} \\
\hline Precursor & $\mathrm{T} 1$ & $\mathrm{~T} 2$ & $\mathrm{~T} 3$ & $\mathrm{~T} 1 / \mathrm{T} 2 / \mathrm{T} 3$ \\
\hline VTES & -69 & -74 & -83 & $39^{*} / 34 / 27$ \\
\hline GPTMS & -53 & -59 & 968 & $14 / 52 / 34^{*}$ \\
* existe solapamiento de picos, el valor calculado no es real. & &
\end{tabular}


Por tanto, se puede concluir que con el tratamiento de curado utilizado se ha conseguido obtener una red parcialmente entrecruzada, en la que se han hidrolizado y condensado la mayor parte de los enlaces posibles y en la que no existen especies sin hidrolizar (no hay bandas $\mathrm{T}^{0}$ ). El grado de entrecruzamiento podría aumentarse mediante la aplicación de condiciones más severas de curado en cuanto a tiempo y temperatura, si bien, no podría darse un entrecruzamiento total debido al gran tamaño de la cadena orgánica del GPTMS que impediría estéricamente la condensación de grupos silanoles contiguos. No obstante ha jugado un papel fundamental a la hora de seleccionar el tratamiento final la aplicación de criterios adicionales como la fragilidad encontrada en las redes tanto al aplicar los recubrimientos como al ser obtenidos como película libre, e incluso la selección de tiempos que fueran susceptibles de ser utilizados en futuras aplicaciones de tipo industrial. Los tratamientos de curado optimizados tras este estudio se recogen en la Tabla 5.9.

Tabla 5.9 Tratamiento de curado optimizado para la serie VTES:GPTMS.

\begin{tabular}{|c|c|c|c|}
\hline & \multicolumn{3}{|c|}{ VTES : GPTMS } \\
\hline & $8: 2$ & $5: 5$ & $2: 8$ \\
\hline Temperatura $/{ }^{\circ} \mathrm{C}$ & 100 & 140 & 140 \\
\hline Tiempo /min & 90 & 90 & 90 \\
\hline
\end{tabular}

\section{b) Espectroscopia infrarroja}

Se han formulado materiales partiendo de VTES y adicionando distintas cantidades de GPTMS, 20\%, 50\%, 80\% y 100\% (VTES, 8V:2G, 5V:5G, 2V:8G y GPTMS, respectivamente). Para comprobar que la adicción de distintas cantidades de GPTMS durante la hidrólisis hace que se obtengan redes con distinta cantidad de grupos epoxi en superficie, se lleva a cabo ensayos FTIR. Además, se ha contrastado gracias a bibliografía que dependiendo de distintos factores de síntesis, como puede ser el $\mathrm{pH}$ utilizado y el precursor que acompañe al GPTMS, se puede producir la apertura del anillo epoxi [112], hecho que se puede comprobar con este ensayo.

Las muestras para realizar este ensayo se obtienen en film libre aplicándoles el tratamiento de curado optimizado en el estudio de RMN, posteriormente se trituran y se prepararon cápsulas de $\mathrm{KBr}$ con un $5 \%$ de muestra en $\mathrm{KBr}$. En la Figura. 5.29 se representan los espectros obtenidos para la serie de materiales VTES-GPTMS. 


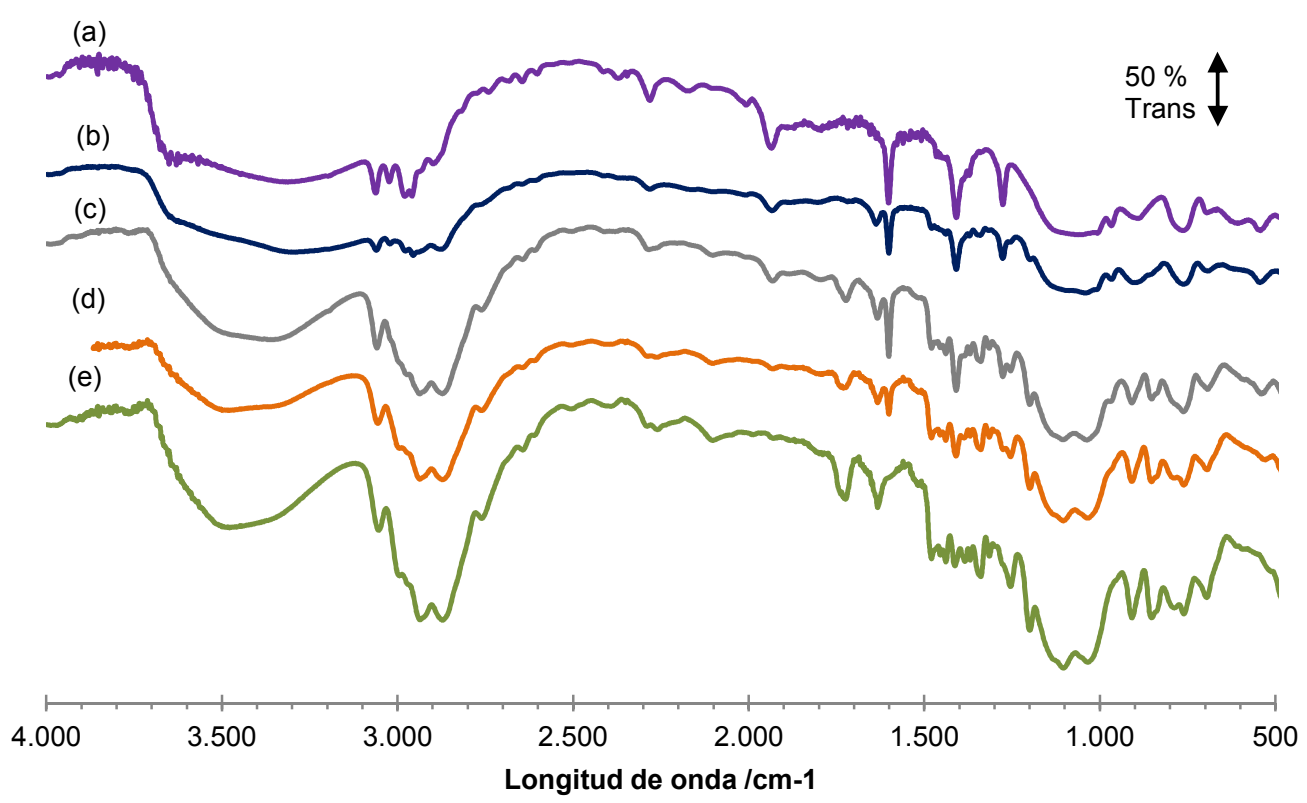

Figura. 5.29 Espectros FTIR de los materiales (a) VTES, (b) 8V:2G, (c) 5V:5G, (d) 2V:8G y (e) GPTMS al $5 \%$ en $\mathrm{KBr}$.

El espectro de VTES y GPTMS se analizaron en el capítulo 4, donde se documentó que las bandas características del VTES se detectan en una longitud de onda alrededor de $3060 \mathrm{~cm}^{-1}$ correspondiente a $\mathrm{CH}_{2}$ terminal y que el doble enlace vibra a $1600 \mathrm{~cm}^{-1}$ [111]. Por otro lado, el GPTMS tiene las bandas características del grupo epoxi a $3050 \mathrm{~cm}^{-1}, 2955 \mathrm{~cm}^{-1}$ y $2758 \mathrm{~cm}^{-1}$, y el grupo éter tiene una vibración asociada a la banda $1200 \mathrm{~cm}^{-1}$. Como se mencionó en el apartado 4.2.b el GPTMS sufre una apertura parcial de los grupos epoxi presentes, debido al aumento de la banda asociada a la vibración $\mathrm{OH}$, y no se produce en todos los grupos epoxi debido a la detección de bandas características de este grupo. Este hecho se corroboró comparando los resultados obtenidos en FTIR con los de RMN y con los de calorimetría. En los RMN se mostraba que en el recubrimiento GPTMS no hay una mayor presencia de especies $\mathrm{T}^{1}$ y $\mathrm{T}^{2}$ que en otros precursores por lo que la banda de $\mathrm{OH}$ no se debe a grupos silanoles terminales. En las curvas calorimétricas donde se detectó que el GPTMS no cuenta con un contenido mayor de alcoholes ni agua residuales de las reacciones de síntesis en su interior que el resto de materiales de la serie. 
Las composiciones intermedias muestran bandas características de los dos precursores que varían en intensidad en función de la relación molar existente entre los mismos. Conforme se aumenta el contenido de GPTMS, las bandas asociadas a la vibración del grupo epoxi, así como la del grupo éter aumentan en intensidad relativa. Está documentado en bibliografía que en función de las condiciones de síntesis, así como el precursor que acompañe al GPTMS se puede producir o no la apertura del anillo epoxi [52, 113]. En este caso la presencia del precursor VTES probablemente impide la apertura de los grupos epoxi, ya que la intensidad relativa de la banda asociada a grupos $\mathrm{OH}\left(3300-3500 \mathrm{~cm}^{-1}\right)$ para las composiciones intermedias no es tan elevada como la obtenida para la formulación basada en el precursor GPTMS solo. Esta banda de OH más pronunciada en GPTMS se puede deber a la apertura por hidrólisis de parte de los anillos epoxi presentes en la formulación, ya que a la vista de los resultados de RMN no se debe a un menor grado de condensación. Se detecta en las composiciones intermedias (8V:2G, 5V:5G, 2V:8G) las bandas características del grupo epoxi (3050, 2955 y $\left.2758 \mathrm{~cm}^{-1}\right)$.

Todas las muestras han formado red polisiloxánica ya que presentan las bandas características de la vibración de enlaces Si-O-Si alrededor de $1075 \mathrm{~cm}^{-1}, 1163 \mathrm{~cm}^{-1}$ y $800 \mathrm{~cm}^{-1}[52,108]$. Se detectan en todos los espectros bandas asociadas a la vibración Si-OH terminales $3740 \mathrm{~cm}^{-1}$.

A la vista de los resultados se puede concluir que la formulación basada en el precursor GPTMS presenta apertura de parte de los anillos epoxi presentes en su formulación. En el caso de composiciones con VTES y GPTMS, la presencia del precursor VTES probablemente provoca la no apertura de los anillos epoxi, no detectándose un aumento en la intensidad relativa de la banda $\mathrm{OH}$ en estas formulaciones. Las bandas $\mathrm{OH}$ detectadas en las formulaciones intermedias se deben a la presencia de grupos silanoles terminales que no han condensado, así como la presencia de restos de disolvente o agua.

Mediante el análisis de los espectros FTIR, se observa que con las condiciones de síntesis aplicadas ( $\mathrm{pH}=1$, cantidad de agua estequimétrica, duración de reacciones de hidrólisis) así como con los tratamiento de curado aplicados (Tabla 5.9) se han obtenido redes polisiloxánicas en todos los casos. Se confirma mediante esta técnica que existen grupos reactivos silanoles por condensar (detectados también mediante 
la técnica RMN), debido probablemente a los tratamientos de curado aplicados, así como al tamaño de las cadenas orgánicas de los precursores seleccionados GPTMS y VTES.

\subsubsection{Comportamiento térmico}

En este apartado se estudia las propiedades térmicas de los materiales obtenidos en función del contenido en GPTMS que dependerá por tanto de la carga orgánica introducida, más concretamente se estudia la existencia de $T_{g}$. Esta temperatura sólo se registrará en aquellas formulaciones donde la parte amorfa de la carga orgánica introducida sea suficientemente grande para que se pueda registrar la movilidad de sus cadenas. Adicionalmente, se analizan los procesos de de degradación que sufren los materiales con la temperatura, que nos permitirán determinar la cantidad de carga inorgánica de los recubrimientos. Además nos permitirán evaluar si la temperatura de síntesis es la adecuada para no degradar las cadenas orgánicas presentes en la formulación.

La $T_{g}$ de cada uno de los recubrimientos de la serie se ha determinado por medio de medidas DSC. Para la realización del experimento se prepararon muestras en film libre aplicándoles el tratamiento optimizado en el estudio de RMN y se trituraron para permitir una distribución homogénea del calor por la muestra. Se realizó un barrido de temperaturas desde $-100^{\circ} \mathrm{C}$ hasta $200^{\circ} \mathrm{C}$ con flujo de nitrógeno. En la Figura. 5.30 se representan las curvas de DSC de la serie de materiales VTES-GPTMS. El criterio seguido en los termogramas representados conlleva que los picos hacia arriba corresponden a procesos exotérmicos. 


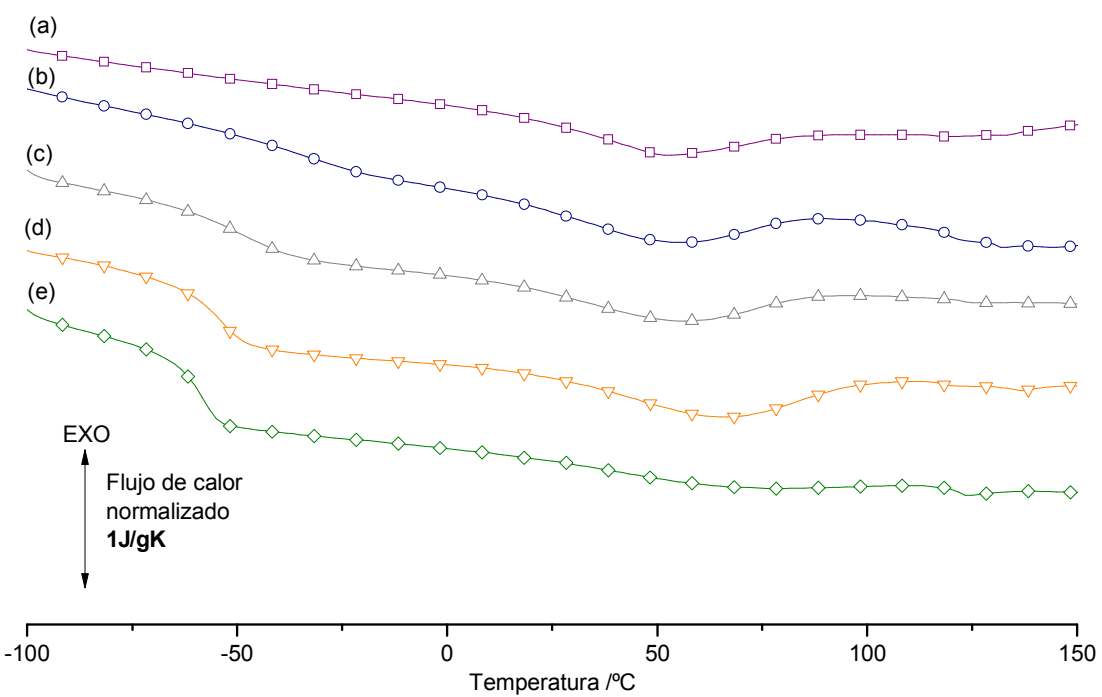

Figura. 5.30 Curvas DSC de los recubrimientos (a) VTES, (b) 8V:2G, (c) 5V:5G, (d) 2V:8G, (e) GPTMS. Velocidad de calentamiento $10^{\circ} \mathrm{C} / \mathrm{min}$ con un flujo de $\mathrm{N}_{2}$ de $30 \mathrm{ml} / \mathrm{min}$.

El recubrimiento VTES, como se observó en el apartado 4. 3, no registra $T_{g}$ debido al pequeño peso molecular de su cadena orgánica. Cuando se añade GPTMS a la formulación, que cuenta con una cadena molecular de mayor peso y, por tanto, con una posible mayor movilidad conformacional de sus cadenas, sí se registran valores de $T_{g}$, desplazándose a bajas temperaturas conforme aumenta el contenido en GPTMS. Este desplazamiento se produce probablemente a que con el aumento del contenido en GPTMS se necesita menos energía para que se produzca el movimiento de las cadenas. Por el mismo motivo $\Delta \mathrm{Cp}$ va aumentando con el incremento del contenido en GPTMS (Tabla 5.10).

Tabla 5.10 Datos calorímetros extraídos de las curvas DSC de los materiales VTES, 8V: 8V:2G, 5V:5G, 2V:8G, GPTMS.

\begin{tabular}{|c|c|c|}
\hline Composición & $\mathbf{T}_{\mathbf{g}} /{ }^{\circ} \mathbf{C}$ & $\Delta \mathbf{C}_{\mathbf{p}} / \mathbf{J g}^{-1} \mathbf{K}^{-\mathbf{1}}$ \\
\hline VTES & - & - \\
\hline $8 \mathrm{~V}: 2 \mathrm{G}$ & $-28,75$ & 0,207 \\
\hline $5 \mathrm{~V}: 5 \mathrm{G}$ & $-45,91$ & 0,349 \\
\hline $2 \mathrm{~V}: 8 \mathrm{G}$ & $-54,16$ & 0,439 \\
\hline GPTMS & $-57,01$ & 0,512 \\
\hline
\end{tabular}


El estudio del pico endotérmico detectado entre $50^{\circ} \mathrm{C}-100^{\circ} \mathrm{C}$, nos permite evaluar la cantidad de especies volátiles presentes en cada formulación. Los recubrimientos VTES, $8 \mathrm{~V}: 2 \mathrm{G}, 5 \mathrm{~V}: 5 \mathrm{G}$ y $2 \mathrm{~V}: 8 \mathrm{G}$ presentan este pico endotérmico entre $50^{\circ} \mathrm{C}$ y $100^{\circ} \mathrm{C}$, por lo que retienen en su red compuestos volátiles derivados de las reacciones de condensación (agua) o bien del disolvente introducido durante la síntesis. El recubrimiento GPTMS no presenta este pico, por lo que la cantidad de especies volátiles atrapadas en la red es menor.

Este resultado se puede relacionar con el obtenido en las técnicas de caracterización química y puede ayudar a confirmar si la banda asociada a la vibración de $\mathrm{OH}$ detectada mediante la técnica FTIR en las formulaciones $2 \mathrm{~V}: 8 \mathrm{G}$, $5 \mathrm{~V}: 5 \mathrm{G}$ y $8 \mathrm{~V}: 2 \mathrm{G}$ se debe a una mayor cantidad de volátiles en la formulación [114-115] como se ha concluido anteriormente, o si bien, se puede debe a la apertura de parte de los grupos epoxi introducidos $[52,113]$. La presencia del pico endotérmico en las formulaciones $2 \mathrm{~V}: 8 \mathrm{G}, 5 \mathrm{~V}: 5 \mathrm{G}$ y $8 \mathrm{~V}: 2 \mathrm{G}$ se asocia a la presencia de especies volátiles en la red, por lo que la banda de $\mathrm{OH}$ que registran estas formulaciones en FTIR se puede atribuir a este hecho, así como a la presencia de grupos silanol no condensados (detectados en ${ }^{29}$ Si-RMN por presencia de especies $\mathrm{T}^{1}$ y $\mathrm{T}^{2}$ ), y no a la apertura (por reacción de hidrólisis) de alguno de los grupos epoxi presentes en la red. En el caso del recubrimiento obtenido a partir de GPTMS, no existe pico endotérmico, por lo que la cantidad de especies volátiles es muy reducida, sin embargo la intensidad relativa de la banda asociada a $\mathrm{OH}$ es mucho mayor que las otras formulaciones. Esto se puede deber a la apertura de parte de los grupos epoxi del recubrimiento.

Se ha realizado un estudio de degradación térmica por TGA. Este estudio nos permite cuantificar la carga inorgánica de los recubrimientos y asegurar que las temperaturas de curado son las óptimas, es decir, no se produce pérdida de la parte orgánica introducida con los alcoxisilanos. Para la realización de este ensayo se prepararon las muestras en las mismas condiciones que para el ensayo de DSC. Se aplica un barrido de temperaturas desde temperatura ambiente hasta $700^{\circ} \mathrm{C}$ a $10^{\circ} \mathrm{C} / \mathrm{min}$ con flujo de nitrógeno. En la Figura. 5.31 se representa las curvas de pérdida de peso y la derivada de la pérdida de peso de la serie de materiales VTESGPTMS. 


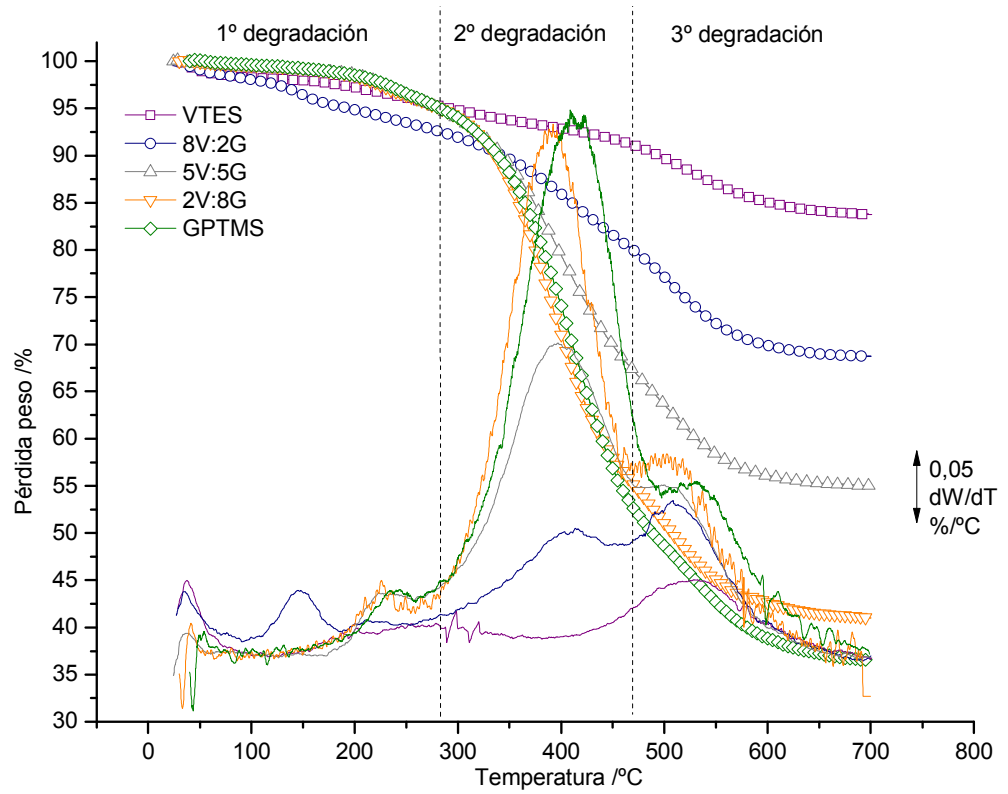

Figura. 5.31 Curva TGA y la derivada de la pérdida de peso de VTES, 8V:2G, 5V:5G, 2V:8G, GPTMS. Velocidad de degradación $10^{\circ} \mathrm{C} / \mathrm{min}$ bajo atmosfera de $\mathrm{N}_{2}$.

La Figura. 5.31 muestra como el proceso de degradación se puede dividir en tres zonas, una primera a bajas temperaturas que abarca aproximadamente de $0^{\circ} \mathrm{C}$ a $290^{\circ} \mathrm{C}$, una segunda de $290^{\circ} \mathrm{C}$ a $460^{\circ} \mathrm{C}$ y la última de $460^{\circ} \mathrm{C}$ a $700^{\circ} \mathrm{C}$. El recubrimiento VTES no muestra degradación dentro de la segunda zona definida $\left(290^{\circ} \mathrm{C}-460^{\circ} \mathrm{C}\right)$.

De las curvas obtenidas se pueden extraer datos cuantitativos interesantes a la hora de discutir los resultados obtenidos. En la Tabla 5.11 se recoge la temperatura a la cual se registra un $20 \%$ de pérdida de material, la temperatura a la cual se registra el máximo de pérdidas de la segunda y la tercera zona de degradación y el tanto por ciento de residuo sólido al final de la rampa de calentamiento.

Tabla 5.11 Datos termogravimétricos extraídos de las curvas TGA de los materiales VTES, 8V: 8V:2G, 5V:5G, 2V:8G, GPTMS.

\begin{tabular}{|c|c|c|c|c|}
\hline Composición & $\mathrm{T}_{\mathrm{c}}{ }^{\mathrm{a}} /{ }^{\circ} \mathrm{C}$ & $\mathrm{T}_{2}^{\mathrm{b}} /{ }^{\circ} \mathrm{C}$ & $\mathrm{T}_{3}{ }^{\mathrm{C}} /{ }^{\circ} \mathrm{C}$ & $\begin{array}{c}\text { Residuo solido } \\
/ \%\end{array}$ \\
\hline VTES & - & - & 526 & 83,8 \\
\hline $8 V: 2 G$ & 470 & 410 & 507 & 68,8 \\
\hline $5 V: 5 G$ & 397 & 400 & 503 & 55,1 \\
\hline $2 \mathrm{~V}: 8 \mathrm{G}$ & 373 & 391 & 503 & 41,1 \\
\hline GPTMS & 383 & 415 & 534 & 36,5 \\
\hline
\end{tabular}


El residuo sólido disminuye con el aumento del contenido en GPTMS, ya que al aumentar el contenido de GPTMS se aumenta la cantidad de cadenas orgánicas susceptibles a degradarse en el intervalo de temperaturas estudiadas.

En la curva de la derivada de pérdida de peso de GPTMS (apartado 4. 3) se detectan tres picos predominantes correspondientes a distintos procesos de degradación. Existe una pérdida de peso inicial a temperaturas entre $180^{\circ} \mathrm{C}-280^{\circ} \mathrm{C}$ debida probablemente a la existencia de reacciones de condensación, al existir grupos silanol por condensar, produciéndose agua que se evapora. Otras dos degradaciones cuyos máximos se detectan a $415^{\circ} \mathrm{C}$ y $534^{\circ} \mathrm{C}$ atribuidas a la pérdida de cadenas orgánicas.

El recubrimiento basado en el precursor VTES tiene procesos de degradación asociados a tres pérdidas de peso, dos de ellas se encuentran dentro de la primera zona de degradación y la última en la tercera zona. Existe una pequeña pérdida por debajo de $100^{\circ} \mathrm{C}$ asociada a la evaporación de restos de disolvente y agua atrapados en la red. Entre $180^{\circ} \mathrm{C}$ y $280^{\circ} \mathrm{C}$ se produce una pérdida de peso probablemente por la evaporación de agua derivada de reacciones de condensación entre silanoles residuales del tratamiento de curado aplicado. A altas temperaturas entre $460^{\circ} \mathrm{C}$ y $650^{\circ} \mathrm{C}$ se produce la degradación con mayor pérdida de peso y se atribuye a la pérdida del grupo vinil.

Las composiciones intermedias, dependiendo de la relación VTES:GPTMS, muestran picos en la derivada del peso frente a la temperatura en las tres zonas delimitadas en el gráfico, que se desplazan a mayores o menores temperaturas en función de la composición. Dentro de la primera zona de degradación los recubrimientos $8 \mathrm{~V}: 2 \mathrm{G}, 5 \mathrm{~V}: 5 \mathrm{G}$ y $2 \mathrm{~V}: 8 \mathrm{G}$ presentan dos pérdidas de peso, la primera a temperaturas por debajo de $100^{\circ} \mathrm{C}$, con una pérdida de peso pequeña que se atribuye a la evaporación de restos de disolvente y agua atrapados en la red. Otra a temperaturas por encima de $140^{\circ} \mathrm{C}$ que se atribuye a pérdida de peso probablemente por la evaporación de agua derivada de reacciones de condensación entre silanoles residuales del tratamiento de curado aplicado. 
Como se ha recopilado en la Tabla 5.11, la intensidad de la derivada de la segunda pérdida de peso (de $290^{\circ} \mathrm{C}$ a $460^{\circ} \mathrm{C}$ ) es mayor cuanto mayor es el contenido en GPTMS. La temperatura a la cual se registra el pico máximo de degradación se desplaza ligeramente a menores temperaturas con el aumento del contenido en GPTMS (desde $410^{\circ} \mathrm{C}$ para $8 \mathrm{~V}: 2 \mathrm{G}$ hasta $391^{\circ} \mathrm{C}$ para $2 \mathrm{~V}: 8 \mathrm{G}$ ). Este pico se asocia a la degradación de parte de las cadenas orgánicas que aporta el GPTMS a la red de VTES:GPTMS. El tercer pico de degradación registrado entre $460^{\circ} \mathrm{C}$ y $650^{\circ} \mathrm{C}$ se atribuye a la degradación de las cadenas orgánicas que aporta el precursor VTES, así como las del precursor GPTMS.

Se han creado redes con distinto contenido orgánico en función de la cantidad de GPTMS adicionada, tanto más orgánica cuanto mayor es el contenido en GPTMS. Se han detectado tres regiones de degradación en las que ocurren procesos de descomposición distintos. Se ha detectado que existen restos de disolvente o agua en las formulaciones $8 \mathrm{~V}: 2 \mathrm{G}, 5 \mathrm{~V}: 5 \mathrm{G}$ y $2 \mathrm{~V}: 8 \mathrm{G}$, hecho que corrobora las hipótesis propuestas en el estudio calorimétrico. Se ha detectado que con las condiciones de curado aplicadas quedan grupos silanol por condensar que reaccionan durante el ensayo, registrándose una pérdida de peso por debajo de $240^{\circ} \mathrm{C}$ que se asocia a la evaporación de agua derivada del proceso de condensación. La degradación de las cadenas orgánicas se produce a una temperatura por encima de $290^{\circ} \mathrm{C}$ y hasta $650^{\circ} \mathrm{C}$.

De los estudios del comportamiento térmico se puede concluir que éste depende de la composición de la red formada. En las redes donde el contenido en VTES es mayor no se detecta la transición entre el estado gomoso y vítreo, debido a que: (1) las posibilidades de movimientos conformacionales están impedidos por la formación de la red de silicio, y (2) el peso molecular de la cadena vinil, en este estudio, se puede considerar pequeño. Conforme se aumenta el contenido en GPTMS, al introducir una cadena de mayor peso molecular, y por tanto una mayor carga orgánica (residuo sólido de TGA menor), las posibilidades de movimientos conformacionales aumentan y la cantidad de energía necesaria para producirlas disminuye, disminuyendo así $\mathrm{T}_{\mathrm{g}}$. Se ha detectado que la aplicación de temperatura por encima de $100^{\circ} \mathrm{C}$ promueve reacciones de condensación entre silanoles terminales en las redes obtenidas con los tratamientos de curado aplicados. Los 
procesos de degradación registrados entre $290^{\circ} \mathrm{C}$ y $650^{\circ} \mathrm{C}$ se deben a la degradación de las cadenas orgánicas introducidas por los precursores VTES y GPTMS en la red.

\subsubsection{Propiedades mecánicas}

El comportamiento mecánico tensión-deformación está influenciado por la incorporación de un carácter más orgánico, por medio de la introducción de GPTMS en la red híbrida. El precursor GPTMS introduce en la red una cadena orgánica de gran peso molecular que provoca una disminución en la conectividad de la red inorgánica dando lugar a una estructura abierta. Además, la introducción de GPTMS aumenta el carácter orgánico del recubrimiento provocando cambios en el comportamiento mecánico del material.

Para la realización de este ensayo se obtuvieron muestras en film libre de un espesor de $1 \mathrm{~mm}$. Se cortaron en forma circular con un diámetro de $12 \mathrm{~mm}$ de forma que la muestra fuera lo suficientemente grande para que el vástago que aplica la carga de $3,6 \mathrm{~mm}$ de diámetro actuara en la zona central de la muestra evitando efectos de borde. Se aplicaron sobre todas las muestras un primer ciclo de cargas desde 0 a $1400 \mathrm{mN}$ (compresión) a una velocidad de $50 \mathrm{mN} / \mathrm{min}$, seguido de un ciclo de descarga a la misma velocidad. Se realizaron tres réplicas para cada muestra ensayada. Para todas las muestras se detectó que las deformaciones registradas correspondían a deformaciones elásticas ya que tras la descarga no se obtuvieron deformaciones residuales.

En la Figura. 5.32 se muestran las curvas de tensión deformación de la serie de materiales con distintas cantidades de GPTMS 0\%, 20\%, 50\%, 80\% y $100 \%$ correspondientes a la nomenclatura VTES, 8V:2G, 5V:5G, 2v:8G y GPTMS, respectivamente. Se muestra además una ampliación de la zona de bajas deformaciones. 


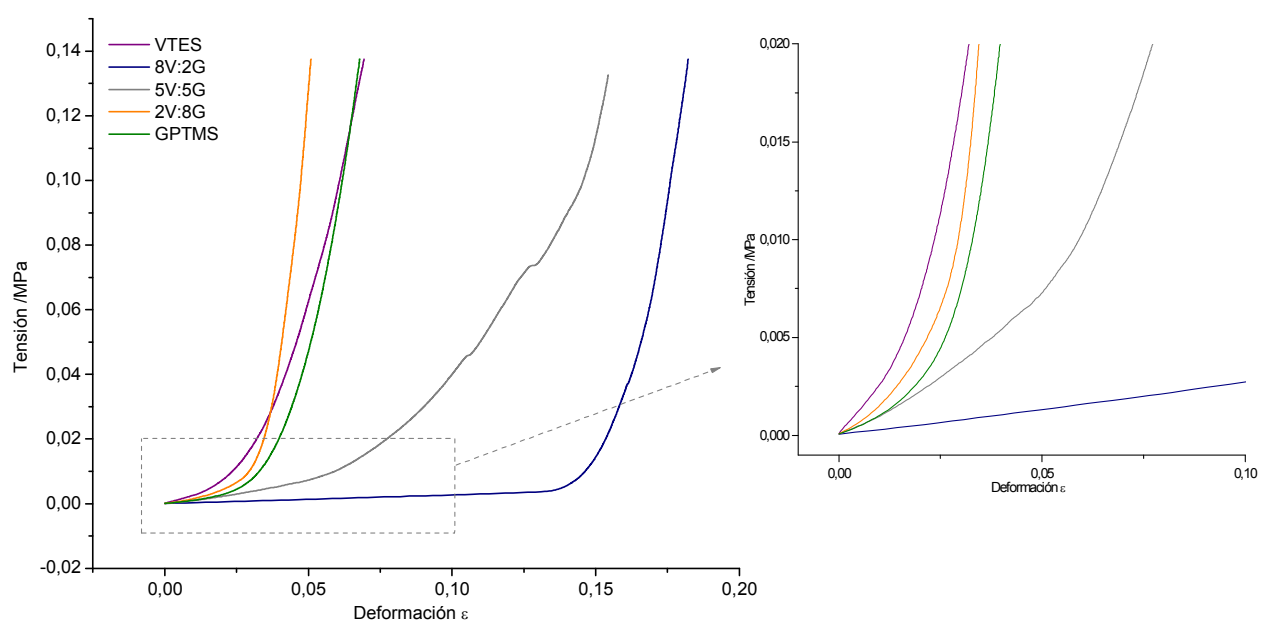

Figura. 5.32 Curvas tensión deformación a compresión de los recubrimientos VTES, 8V:2G, 5V:5G, 2V:8G y GPTMS. Velocidad de carga $50 \mathrm{mN} / \mathrm{min}$ hasta una carga máxima de $1400 \mathrm{mN}$. Ampliación de la primera zona de menor carga.

Se observa en la Figura. 5.32 que las curvas de tensión-deformación de todos los materiales tienen comportamiento elástico y no lineal para el intervalo de tensiones ensayado. Adicionalmente se observa que en las curvas existen dos comportamientos diferenciados, uno a baja tensión y otro a tensiones superiores claramente diferenciados por la existencia de un punto de inflexión en la respuesta del material. En la primera parte de la curva se observa que se obtienen grandes deformaciones elásticas por la aplicación de pequeñas cargas, mientras en la segunda ocurre lo contrario (por tanto una respuesta más rígida del material).

Se ha calculado el módulo de Young de la primera zona de menor carga. Así, el mayor módulo elástico se obtiene para el recubrimiento VTES y es de 0,23MPa. Con la adición de un $20 \%$ de GPTMS este valor disminuye drásticamente a 0,01MPa. Conforme se aumenta el contenido en GPTMS este valor va aumentando dando como valores para el $5 \mathrm{~V}: 5 \mathrm{G}$ 0,09MPa, para el $8 \mathrm{~V}: 2 \mathrm{G} 0,14 \mathrm{MPa}$ y para GPTMS $0,13 \mathrm{MPa}$.

Se ha calculado la tensión y la correspondiente deformación a la cual se produce el cambio de comportamiento mecánico para cada una de las formulaciones (Tabla 5.12). Este cálculo se ha realizado extrapolando una línea de la primera zona elástica y otra de la segunda zona elástica y calculando el punto de intersección de ambas 
líneas. Todas las curvas presentan el cambio de pendiente a una tensión semejante entorno a 0,005MPa, excepto el recubrimiento $2 \mathrm{~V}: 8 \mathrm{G}$. En éste la tensión necesaria para que se produzca un cambio en la rigidez del material es algo inferior al registrado en el resto de muestras $(0,003 \mathrm{MPa})$. Sin embargo, el valor de la deformación del cambio de comportamiento mecánico varía en función del contenido. El recubrimiento VTES registra el cambio de pendiente de la curva tensióndeformación a una deformación de $0,035 \mathrm{u}$., el valor más bajo calculado para la serie de materiales. El recubrimiento $2 \mathrm{~V}: 8 \mathrm{G}$ tiene un valor de $0,037 \mathrm{u}$., seguido de GPTMS con un valor de $0,048 \mathrm{u}$. y $5 \mathrm{~V}: 5 \mathrm{G}$ con un valor de $0,056 \mathrm{u}$.. El recubrimiento con el valor más alto es el 8V:2G con un valor de la deformación de 0,167u.. El recubrimiento que experimenta el cambio de rigidez a menor deformación es el VTES, seguido de 2V:8G, GPTMS, 5V:5G y 8V:2G.

Se ha calculado el módulo elástico tras el cambio en la rigidez del material, en la zona de grandes cargas. Los valores del módulo aumentan notablemente en esta zona. El recubrimiento con mayor rigidez es el $2 \mathrm{~V}: 8 \mathrm{G}$ con un valor de 7,41MPa. Los recubrimientos $8 \mathrm{~V}: 2 \mathrm{G}$ y GPTMS tienen un módulo parecido de $4,85 \mathrm{MPa}$ y $4,50 \mathrm{MPa}$, respectivamente. El recubrimiento VTES tiene un módulo de 2,97MPa y el material con menor módulo de Young es el 5V:5G con un valor de 1,21MPa.

En la Figura. 5.33 se ha representado la evolución de la deformación obtenida en las curvas tensión-deformación para una compresión de 0,003MPa y 0,04 MPa en función del contenido en GPTMS. 


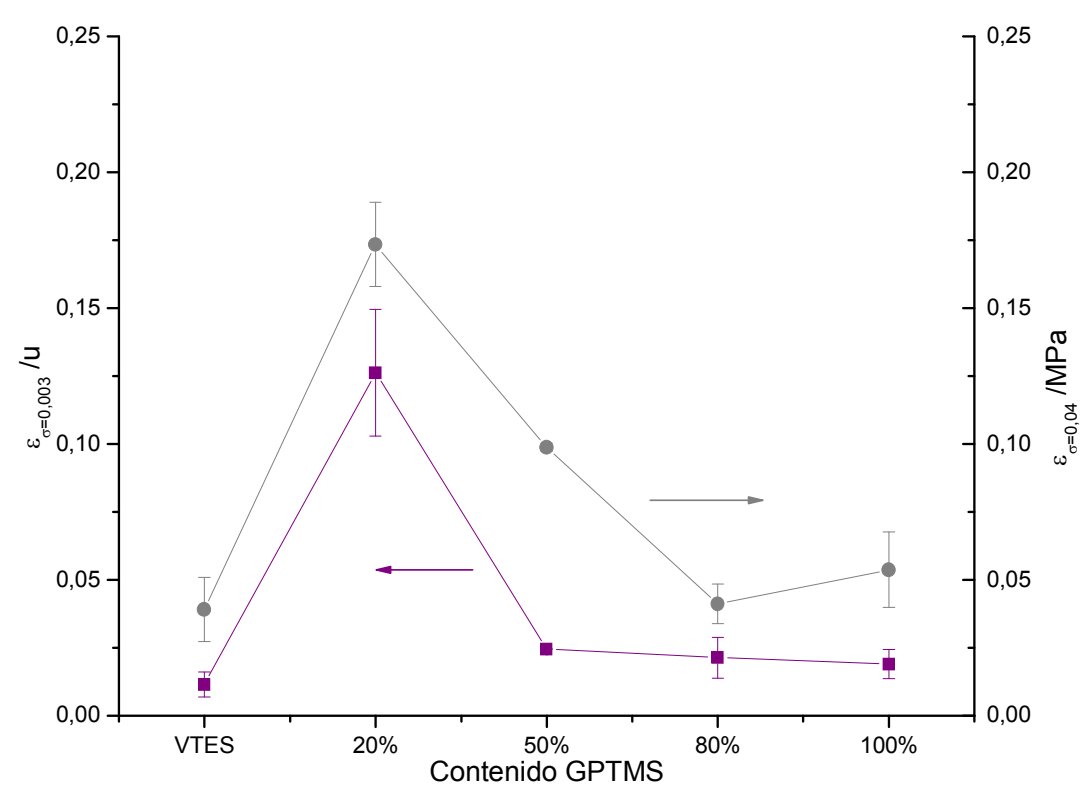

Figura. 5.33 Evolución con el contenido de GPTMS de las deformaciones registradas para una tensión de 0,003MPa y 0,04MPa.

Analizando los datos obtenidos en valor de deformación para una tensión determinada se observa un cambio en este valor en función de la composición de los recubrimientos y en función de la carga aplicada. Si la tensión aplicada se encuentra dentro del intervalo de las consideradas cargas bajas, las deformaciones obtenida son mucho menores que si se aplica una tensión dentro de la zona de las denominadas altas cargas.

Para una tensión aplicada de 0,003MPa (dentro de la zona de bajas cargas) todos los recubrimientos tienen una deformación semejante, excepto el recubrimiento $2 \mathrm{~V}: 8 \mathrm{G}$, que tiene una deformación mucho mayor. Para una tensión aplicada de $0,04 \mathrm{MPa}$ (dentro de la zona de altas cargas) las variaciones registradas en la deformación entre los recubrimientos con distinto contenido en GPTMS son mayores. El recubrimiento que se deforma en mayor medida es el $2 \mathrm{~V}: 8 \mathrm{G}(0,173$ unidades.). El recubrimiento $5 \mathrm{~V}: 5 \mathrm{G}$ se deforma $0,098 \mathrm{u}$.. Las otras composiciones registran deformaciones semejantes entorno a $0,04 \mathrm{u}$. Se detecta nuevamente como el recubrimiento con un $20 \%$ de GPTMS, $8 \mathrm{~V}: 2 \mathrm{G}$ es el material que presenta las deformaciones más elevadas para un mismo nivel de tensión. (Tabla 5.12) 
Tabla 5.12 Módulo elástico de la primera y segunda zona elástica calculado a partir de las curvas tensión deformación.

\begin{tabular}{|c|c|c|c|c|c|c|}
\hline Form. & $\begin{array}{c}\text { E } 1^{\mathrm{a}} \text { zona } \\
\text { /MPa }\end{array}$ & $\begin{array}{c}\text { E } 2^{\mathrm{a}} \text { zona } \\
/ \mathrm{MPa}\end{array}$ & $\varepsilon$ inflexión & $\begin{array}{c}\delta \text { inflexión } \\
\text { /MPa }\end{array}$ & $\begin{array}{c}\delta \varepsilon=0,003 \\
/ \mathrm{MPa}\end{array}$ & $\begin{array}{c}\delta \varepsilon=0,04 \\
/ \mathrm{MPa}\end{array}$ \\
\hline VTES & $0,23 \pm 0,10$ & $2,97 \pm 0,12$ & $\begin{array}{c}0,035 \pm \\
0,004\end{array}$ & $\begin{array}{c}0,006 \pm \\
0,002\end{array}$ & $\begin{array}{c}0,0116 \pm \\
0,0047\end{array}$ & $\begin{array}{c}0,0391 \pm \\
0,0117\end{array}$ \\
\hline $8 V: 2 G$ & $0,01 \pm 0,01$ & $4,85 \pm 1,00$ & $\begin{array}{c}0,167 \pm \\
0,013\end{array}$ & $\begin{array}{c}0,003 \pm \\
0,001\end{array}$ & $\begin{array}{c}0,1263 \pm \\
0,0233\end{array}$ & $\begin{array}{c}0,1735 \pm \\
0,0155\end{array}$ \\
\hline $5 V: 5 G$ & $0,09 \pm 0,01$ & $1,21 \pm 0,33$ & $\begin{array}{c}0,056 \\
\pm 0,021\end{array}$ & $\begin{array}{c}0,005 \pm \\
0,002\end{array}$ & $\begin{array}{c}0,0245 \pm \\
0,0001\end{array}$ & $\begin{array}{c}0,0988 \pm \\
0,0016\end{array}$ \\
\hline $2 V: 8 G$ & $0,14 \pm 0,02$ & $7,41 \pm 0,35$ & $\begin{array}{c}0,037 \pm \\
0,007\end{array}$ & $\begin{array}{c}0,005 \pm \\
0,001\end{array}$ & $\begin{array}{c}0,0214 \pm \\
0,0075\end{array}$ & $\begin{array}{c}0,0412 \pm \\
0,0073\end{array}$ \\
\hline GPTMS & $0.13 \pm 0.04$ & $4,50 \pm 0,15$ & $\begin{array}{c}0,048 \pm \\
0,014\end{array}$ & $\begin{array}{c}0,006 \pm \\
0,002\end{array}$ & $\begin{array}{c}0,0190 \pm \\
0,0053\end{array}$ & $\begin{array}{c}0,0537 \pm \\
0,0139\end{array}$ \\
\hline
\end{tabular}

Se han obtenido curvas de tensión-deformación con dos deformaciones elásticas diferenciadas. Metroke [106] explica que la introducción de cadenas orgánicas en la red de silicio induce la formación de dominios inorgánicos rodeados de dominios orgánicos. Atanacio [107], por su parte, expone que en la red formada a partir de VTES no se consiguen observar separaciones de fase al tener la cadena orgánica corta, aunque no descarta su existencia. Estas separaciones de fases entre dominios orgánicos e inorgánicos pueden dar respuesta a la existencia de estas dos zonas elásticas diferenciadas, la primera zona elástica registraría las propiedades mecánicas de los dominios orgánicos y la segunda zona elástica registraría las propiedades mecánicas de los dominios inorgánicos.

Por otro lado, se puede observar la respuesta mecánica en las mezclas VTES:GPTMS varía con la composición química de forma compleja. Cabe destacar que las muestras $8 \mathrm{~V}: 2 \mathrm{G}, 5 \mathrm{~V}: 5 \mathrm{G}$ y $2 \mathrm{~V}: 8 \mathrm{G}$ presentan una respuesta mucho más dúctil y menos resistente que la que presentan los materiales obtenidos a partir de los precursores solos. La estructura de la red con distintas relaciones molares de VTES:GPTMS pueden ser muy complejas, ya que pueden solaparse el efecto de la separación de dominios orgánicos e inorgánicos, así como la separación de fases entre los dos precursores utilizados. La introducción de un 20\% de GPTMS en la formulación ha provocado un empeoramiento en las propiedades mecánicas del 
recubrimiento, con una clara pérdida de la rigidez. Para la composición 5V:5G no hay una matriz predominante y la red se puede formar de manera interpenetrada de los dos precursores, GPTMS y VTES, y se obtiene un comportamiento más homogéneo, sin un cambio brusco en las propiedades mecánicas entre las dos zonas elásticas. Cuando se aumenta el contenido en GPTMS al $80 \%$ la matriz formada es predominantemente de GPTMS y por su lado el VTES, debido a su pequeño tamaño puede entrar a formar parte de la red actuando como entrecruzador. Este efecto puede explicar el aumento del módulo elástico de este material. El recubrimiento GPTMS tiene un módulo elástico de la primera zona semejante al registrado en $2 \mathrm{~V}: 8 \mathrm{G}$, sin embargo, al no contar con VTES como entrecruzador de la red el segundo módulo elástico es menor al obtenido en $2 \mathrm{~V}: 8 \mathrm{G}$.

\subsection{5 Ángulo de contacto}

La medida del ángulo de contacto de los materiales es una manera sencilla de determinar el carácter hidrófilo de las superficies de los recubrimientos. La medida del ángulo de contacto se realizó sobre planchas de acero AISI $316 \mathrm{~L}$ recubiertas por dip-coating con cada una de las formulaciones (VTES, 8V:2G, 5V:5G, 2V:8G y GPTMS), a las que se ha aplicado el tratamiento de curado estándar descrito en 3.1.3. Los valores de los ángulos de contacto obtenidos se presentan en la Tabla 5.13 .

Tabla 5.13 Medida ángulo de contacto de agua extrapura sobre recubrimientos VTES, 8V:2G, 5V:5G y 2V:8G aplicados sobre acero AISI 316L.

\begin{tabular}{c|c|c|c|c|c|}
\hline Nomenclatura & VTES & $8 \mathrm{~V}: 2 \mathrm{G}$ & $5 \mathrm{~V}: 5 \mathrm{G}$ & $2 \mathrm{~V}: 8 \mathrm{G}$ & GPTMS \\
\hline $\begin{array}{l}\text { Angulo de } \\
\text { contacto / }\end{array}$ & $80,1 \pm 0,5$ & $80,3 \pm 0,9$ & $83,9 \pm 1,2$ & $87,9 \pm 0,9$ & $61,5 \pm 1,0$ \\
\hline
\end{tabular}

El recubrimiento VTES tiene un carácter hidrófobo con un ángulo de contacto elevado de $80^{\circ}$. Por el contrario el recubrimiento GPTMS tiene un carácter más hidrófilo, determinándose un ángulo de contacto hasta $61^{\circ}$. Las composiciones intermedias van aumentando ligeramente el valor del ángulo de contacto con el aumento en el contenido en GPTMS. La adición de un $20 \%$ no revela cambios significativos en la medida del ángulo de contacto. La adición de un $80 \%$ hace aumentar el valor hasta $87.9^{\circ}$ 
Este fenómeno puede deberse a que, como se ha demostrado en apartados anteriores la presencia del VTES en la síntesis impide la apertura del anillo del GPTMS (apartado 5.2.2.a). Se ha reportado en bibliografía [52, 113] que en función de las condiciones de síntesis y en función de la presencia de otro precursor puede propiciarse la apertura o no de este anillo. Esta apertura de anillos epoxi trae consigo la formación de grupos $\mathrm{OH}$ por hidrólisis del anillo (apartado 4.2.b), provocando la presencia de grupos $\mathrm{OH}$ en la superficie del material lo que cambia la hidrofilia del recubrimiento, al tratarse de un grupo polar. Las composiciones $8 \mathrm{~V}: 2 \mathrm{G}, 5 \mathrm{~V}: 5 \mathrm{G}$ y $2 \mathrm{~V}: 8 \mathrm{G}$ no tendrían apertura del anillo epoxi, por lo que no se generarían grupos hidroxilo en la superficie y el ángulo de contacto medido es mayor que el obtenido para GPTMS, donde sí se produce la apertura del anillo epoxi.

\subsubsection{Propiedades anticorrosivas}

Se ha evaluado la capacidad de los recubrimientos de la serie VTES-GPTMS para proteger frente a la corrosión con la técnica EIS. Como se citó en 4.5 los materiales deben proteger frente a la liberación de iones metálicos al entorno celular, sobre todo en los momentos iniciales, a fin de que éstos no interfieran en la adhesión y proliferación de células osteoinductoras, y por tanto en la regeneración del tejido óseo.

Las muestras para la realización de este ensayo se han obtenido recubriendo planchas de acero AISI 316 L mediante la técnica dip-coating con los materiales VTES, 8V:2G, 5V:5G, 2V:8G y GPTMS. Las condiciones del ensayo EIS son las mismas que las descritas en el apartado 4.5.

En la Figura. 5.34 y Figura. 5.35 se representa los diagramas de Nyquist y de Bode, respectivamente, obtenidos de la realización de un ensayo EIS nada mas ser expuestos al electrolito (tiempo $0 \mathrm{~h}$ ) para los recubrimientos VTES, 8V:2G, 5V:5G, 2V:8G y GPTMS. 

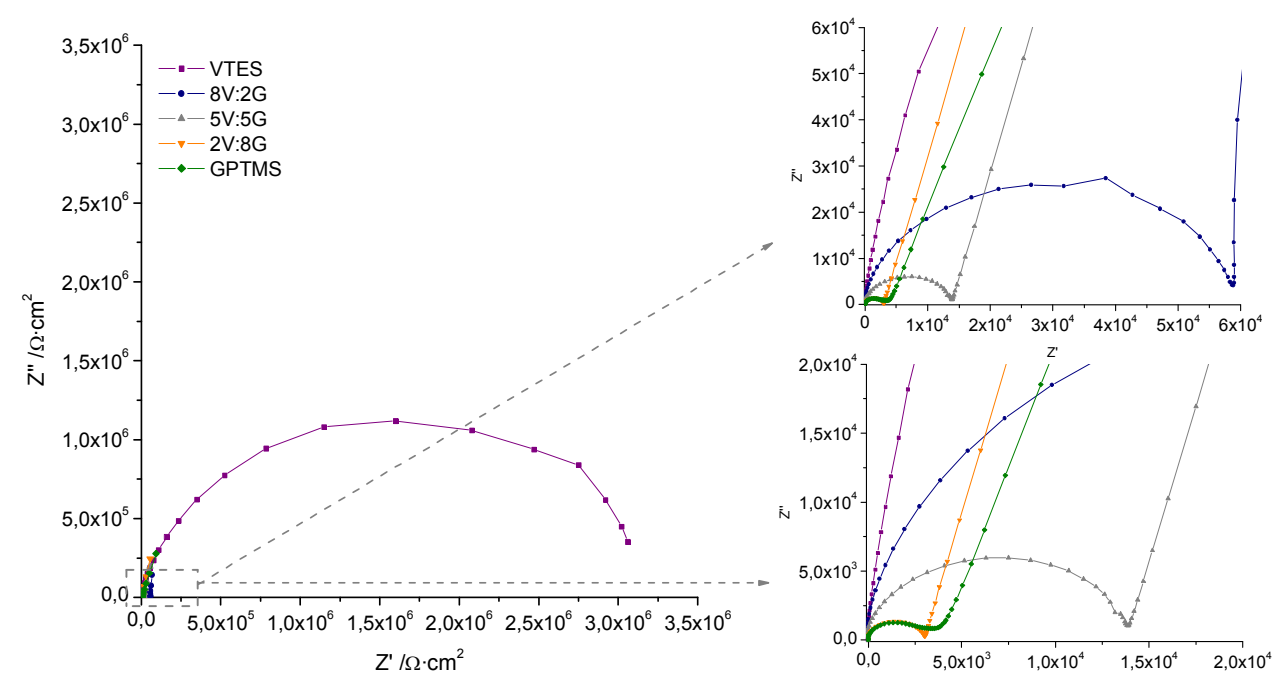

Figura. 5.34 (Izq.) Diagrama Nyquist de las muestras VTES, 8V:2G, 5V:5G, 2V:8G y GPTMS al comienzo del ensayo EIS (0 horas) en una disolución acuosa 3,5\% $\mathrm{NaCl}$. (Dcha.) Detalles del mismo.

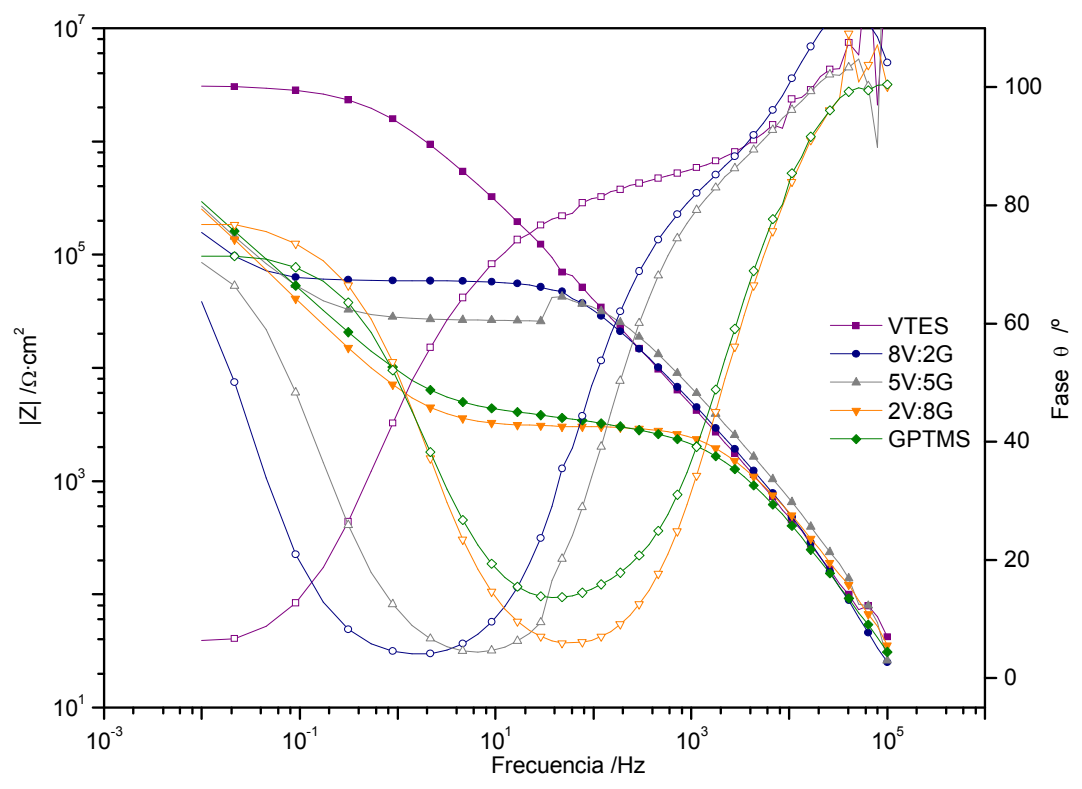

Figura. 5.35 Diagrama de Bode de las muestras VTES, 8V:2G, 5V:5G, 2V:8G y GPTMS al comienzo del ensayo EIS (0 horas) en una disolución acuosa $3,5 \% \mathrm{NaCl}$. 
Como se ha analizado anteriormente el recubrimiento VTES muestra en el diagrama de Bode (a pesar de distinguirse un único arco en el diagrama de Nyquist) la presencia de dos constantes de tiempo en la respuesta de la impedancia frente a la frecuencia, una a altas frecuencias asociada al comportamiento dieléctrico del recubrimiento y otra a bajas frecuencias asociada al comportamiento de la interfase.

Los espectros de impedancia de los recubrimientos con GPTMS tienen un aspecto totalmente diferenciado de la respuesta del VTES cuando se encuentra solo. Las cuatro formulaciones (8V:2G, 5V:5G, 2V:8G y GPTMS) muestran en el diagrama de Nyquist al menos dos arcos. Cuando se analiza el diagrama de Bode se distingue, en estas formulaciones, una respuesta de la impedancia de tres procesos diferenciados con tres constantes de tiempo distintas. La primera a altas frecuencias que se relaciona con la respuesta del recubrimiento en contacto con el electrolito y, por tanto, aporta información acerca de las propiedades del recubrimiento, otra asociada a la respuesta de la interfase (valores de frecuencia intermedios) y la tercera asociada a la capa de óxido formada en la superficie del metal (valores de frecuencia bajos). El arco descrito a bajas frecuencias y correspondiente a la capa de óxido formada no está totalmente definido dentro del intervalo de frecuencias estudiado. Se trata de fenómenos que necesitan tiempos de respuesta demasiado grandes (señales de potencial de frecuencias muy bajas) para el ensayo realizado, por lo que la información obtenida sobre estos procesos es muy limitada.

Se observa que los valores del módulo de impedancias y ángulo de fase registrados en el ensayo EIS de la formulación VTES son superiores a los obtenidos para la serie de recubrimientos con GPTMS en una amplia región del espectro de frecuencias, mostrando un comportamiento más dieléctrico y capacitivo, esto es, mayores valores de ángulo de fase y decrecimiento de éste a menores frecuencias. Las razones que pueden explicar este comportamiento desde el punto de vista del material, son fundamentalmente la formación de una red más compacta y menos permeable por parte del precursor VTES. Con la incorporación de GPTMS, que cuenta con una cadena orgánica de gran peso molecular se crea una red con canales a través de los que el electrolito puede pasar, reduciéndose así el comportamiento capacitivo registrado en los espectros de VTES, siendo este comportamiento más resistivo. Con el aumento del contenido en GPTMS los módulos de impedancias 
obtenidos disminuyen drásticamente, tanto más bajos cuanto mayor es el contenido en GPTMS para frecuencias altas e intermedias. El valor de la impedancia a baja frecuencia está en el mismo orden de magnitud y se asocia a la presencia de óxido en la superficie del metal.

Se ha analizado el comportamiento de los recubrimientos con el paso del tiempo de exposición al electrolito hasta 24 horas de ensayo. Se muestra la evolución de los diagramas de impedancias (representación de Bode) de los recubrimientos de la serie VTES:GPTMS. En la Figura. 5.36 se representan los resultados obtenidos para la muestra $8 \mathrm{~V}: 2 \mathrm{G}$, en la Figura. 5.37 para la muestra $5 \mathrm{~V}: 5 \mathrm{G}$ y en la Figura. 5.38 los obtenidos para $2 \mathrm{~V}: 8 \mathrm{G}$.

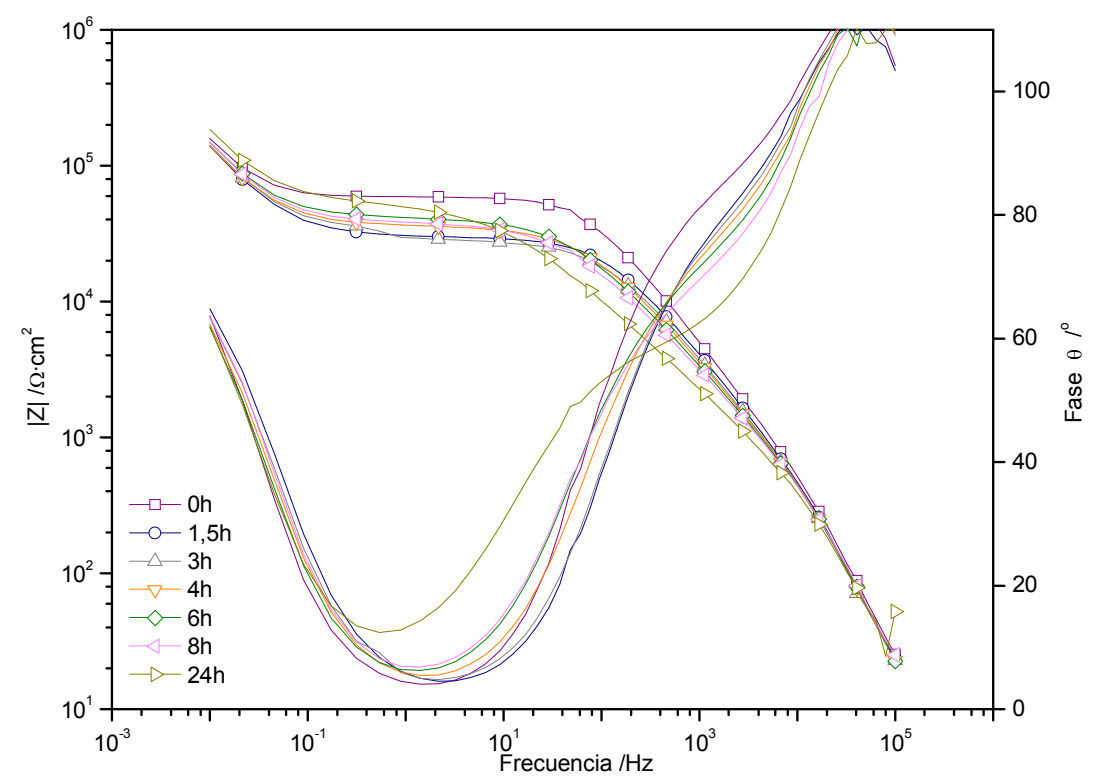

Figura. 5.36 Evolución de los diagramas de Bode obtenidos para el recubrimiento 8V:2G durante 24 horas de exposición a una disolución acuosa $\mathrm{NaCl}$ al 3,5\% en peso. 


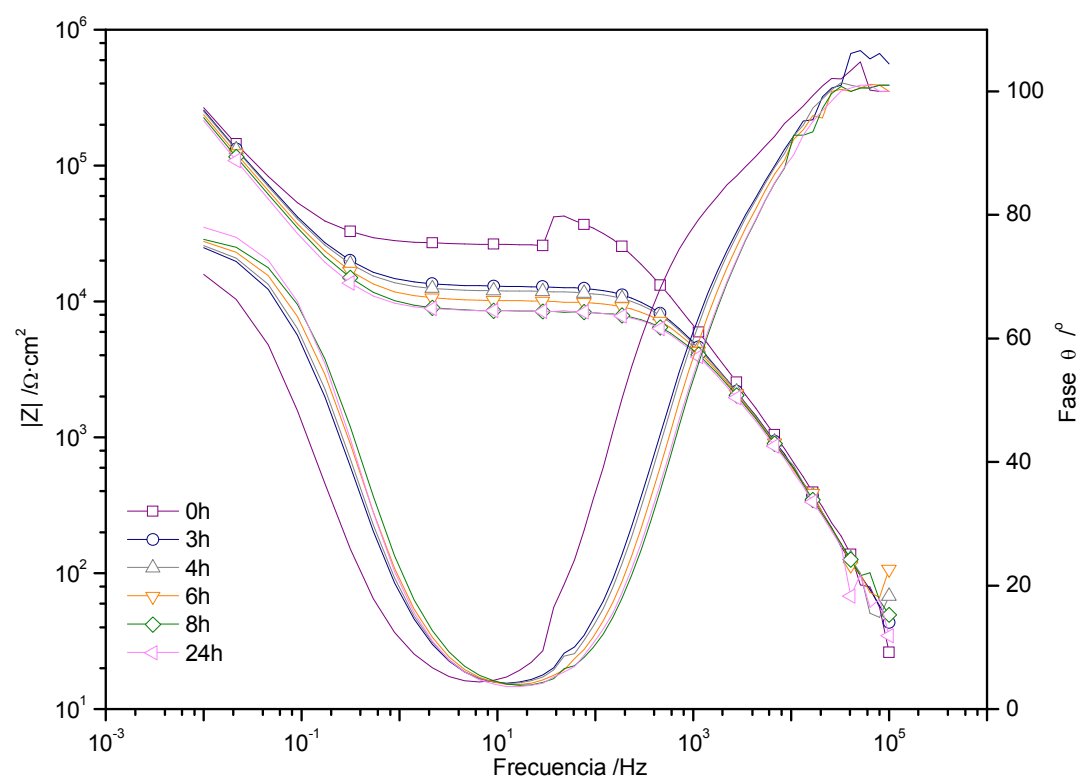

Figura. 5.37 Evolución de los diagramas de Bode obtenidos para el recubrimiento 5V:5G durante 24 horas de exposición a una disolución acuosa $\mathrm{NaCl}$ al 3,5\% en peso.

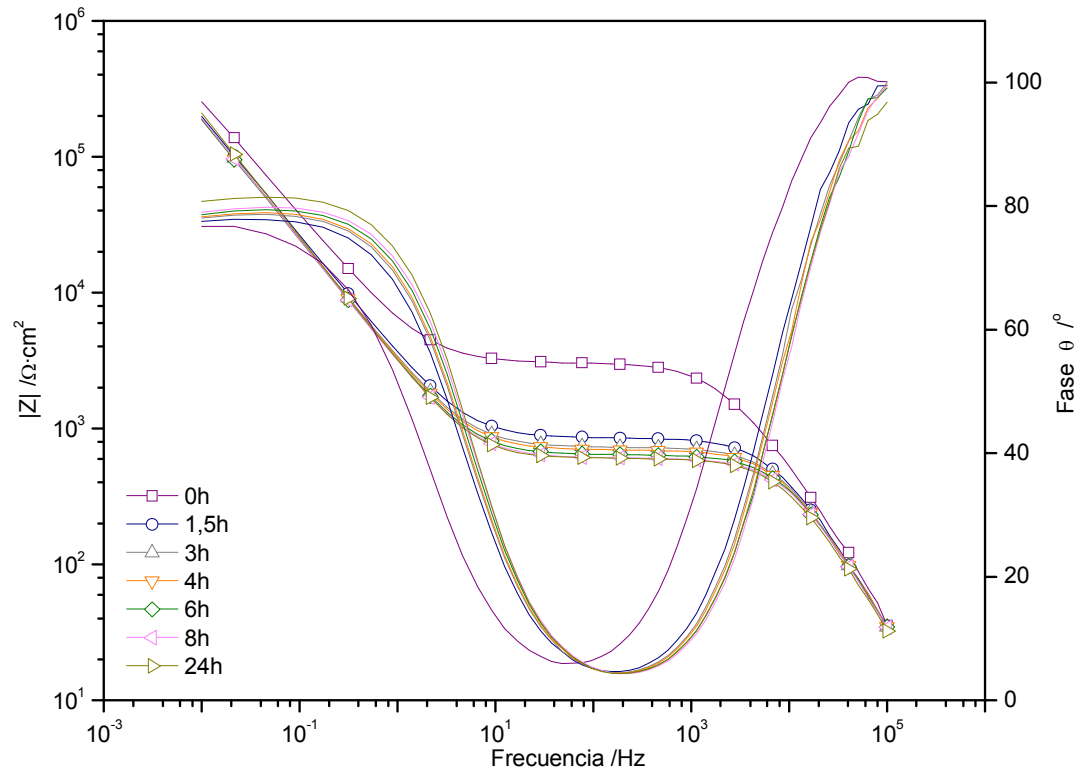

Figura. 5.38 Evolución de los diagramas de Bode obtenidos para el recubrimiento 2V:8G durante 24 horas de exposición a una disolución acuosa $\mathrm{NaCl}$ al 3,5\% en peso. 
Los recubrimientos $8 \mathrm{~V}: 2 \mathrm{G}, 5 \mathrm{~V}: 5 \mathrm{G}$ y $2 \mathrm{~V}: 8 \mathrm{G}$ tienen una evolución similar con el paso del tiempo de exposición al electrolito. Se detecta en todos los casos un descenso en los valores del módulo de impedancia en todo el intervalo de frecuencias estudiado, detectándose el mayor descenso en el intervalo de frecuencias intermedio. El recubrimiento $8 \mathrm{~V}: 2 \mathrm{G}$ tiene un descenso progresivo de los valores de impedancia con el tiempo de inmersión al electrolito, sin embargo el recubrimiento $2 \mathrm{~V}: 8 \mathrm{G}$ presenta una disminución drástica a tan solo 1,5 horas de exposición al electrolito. La incorporación de GPTMS hace que el recubrimiento tenga un comportamiento mucho más resistivo, tanto mayor cuanto mayor es el contenido en GPTMS. Este hecho se puede deber, como se ha comentado anteriormente, a la formación de una red con mayor número de canales, de forma que cuanto mayor es el contenido en GPTMS mayor es la facilidad de paso del electrolito a su través.

Se realiza la modelización de los valores de impedancia compleja mediante circuitos equivalentes. El recubrimiento obtenido a partir de VTES se utiliza un circuito con dos constantes de tiempo formado por los elementos pasivos $R_{p o}$ (resistencia del electrolito dentro de los poros del recubrimiento), $\mathrm{CPE}_{\mathrm{c}}$ (capacidad de las zonas intactas del recubrimiento), ambos característicos del recubrimiento. Por otro lado se encuentran $R_{p}$ (resistencia a la polarización) y $C P E_{d l}$ (capacidad de doble capa), que guardan relación con las propiedades electroquímicas de la interfase metal/electrolito en la base de los poros del recubrimiento. En los recubrimientos con composiciones VTES:GPTMS y GPTMS se utiliza un circuito con tres constantes de tiempo formado por dos elementos pasivos adicionales característicos de la capa de óxido $\mathrm{CPE}_{\mathrm{ox}}$ (capacidad de la capa de óxido) y $R_{o x}$ (resistencia a la capa de óxido)[117-118].

En la Figura. 5.39 se representan, a modo de ejemplo, los datos experimentales obtenidos para el recubrimiento $8 \mathrm{~V}: 2 \mathrm{G}$ a tiempo oh y el resultado de la modelización de estos datos con el circuito equivalente de tres constantes de tiempo. Se ha conseguido un buen ajuste del modelo en todo el intervalo de frecuencias y para todos los recubrimientos estudiados. 


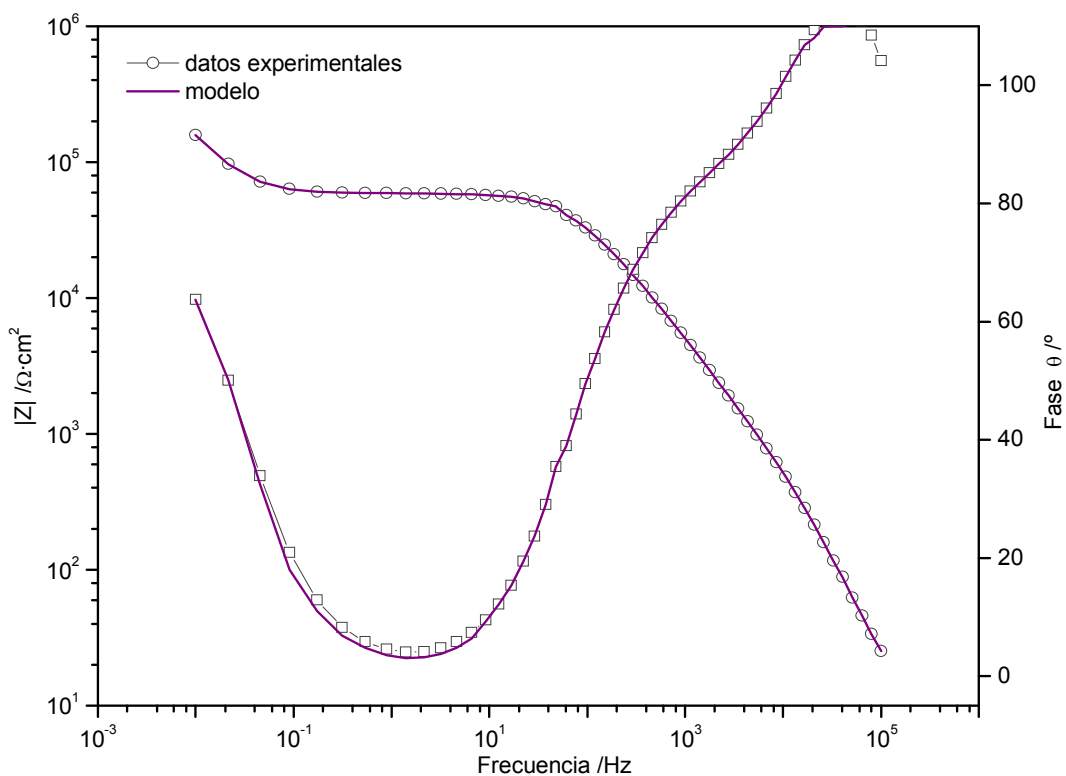

Figura. 5.39 Diagramas de Bode experimentales y simulados para el recubrimiento $8 \mathrm{~V}: 2 \mathrm{G}$ a $0 \mathrm{~h}$ de exposición al electrolito.

Gracias a la modelización de los resultados electroquímicos se puede estudiar el comportamiento de los recubrimientos con mayor detalle, ya que se van a diferenciar los procesos que ocurren en el recubrimiento y en la interfase metal/recubrimiento. La Figura. 5.40 muestra la modelización a partir de los datos obtenidos de los parámetros del circuito equivalente asociados al recubrimiento, la resistencia al poro $\left(R_{p o}\right)$ y la capacidad del recubrimiento $\left(C P E_{c}\right)$, obtenidos a partir de la respuesta a alta frecuencia. 


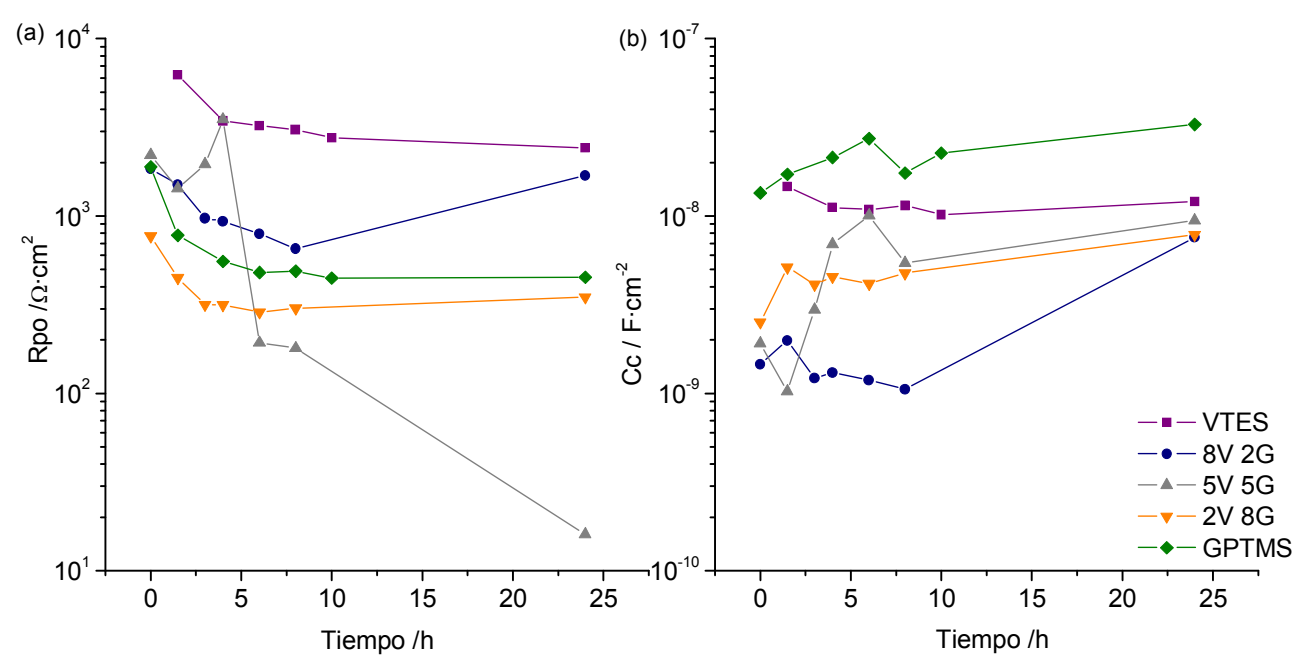

Figura. 5.40 Comparación de la evolución del valor de (a) resistencia al poro y (b) capacidad del recubrimiento con el tiempo de exposición a la disolución acuosa $3,5 \% \mathrm{NaCl}$ de los recubrimientos VTES,8V:2G, 5V:5G, 2V:8G y GPTMS.

La evolución de $\mathrm{R}_{\mathrm{po}}$ con el tiempo de exposición al electrolito proporciona información acerca del comportamiento del recubrimiento sol-gel. Todos los recubrimientos, excepto $5 \mathrm{~V}: 5 \mathrm{G}$, tienen una tendencia del valor de $R_{\mathrm{po}}$ frente al tiempo de exposición semejante. El recubrimiento VTES tiene un valor de $R_{p o}$ inicial de $6200 \Omega \cdot \mathrm{cm}^{2}$ y a las 4 horas se mantiene prácticamente constante entorno a $3000 \Omega \cdot \mathrm{cm}^{2}$. El recubrimiento con un $20 \%$ de GPTMS (8V:2G) tienen el valor de $R_{p o}$ por debajo del obtenido para VTES, con un valor inicial de $1852 \Omega \cdot \mathrm{cm}^{2}$, que disminuye con el paso del tiempo de exposición al electrolito, obteniéndose un valor a 8horas de $654 \Omega \cdot \mathrm{cm}^{2}$, a 24 horas se produce un aumento del valor a $1690 \Omega \cdot \mathrm{cm}^{2}$.El recubrimiento $2 \mathrm{~V}: 8 \mathrm{G}$ tiene un valor inicial de $769 \Omega \cdot \mathrm{cm}^{2}$ que disminuye progresivamente hasta las 8 horas de ensayo dando un valor de $300 \Omega \cdot \mathrm{cm}^{2}$ y se mantiene prácticamente constante a tiempos superiores, a 24 horas se obtiene un valor de $348 \Omega \cdot \mathrm{cm}^{2}$. El recubrimiento GPTMS tiene un valor inicial de $R_{p o}$ de $1890 \Omega \cdot \mathrm{cm}^{2}$, que disminuye progresivamente con la exposición hasta un valor de $488 \Omega \cdot \mathrm{cm}^{2}$ a las 8 horas y se mantiene constante para 24 horas con un valor de $452 \Omega \cdot \mathrm{cm}^{2}$. En la modelización del recubrimiento $5 \mathrm{~V}: 5 \mathrm{G}$ se ha obtenido un valor de $\mathrm{R}_{\mathrm{po}}$ muy cambiante con el tiempo de exposición al electrolito. El valor inicial es semejante al obtenido para $8 \mathrm{~V}: 2 \mathrm{G}$, a 4 horas aumenta a $3500 \Omega \cdot \mathrm{cm}^{2}$, y disminuye 
drásticamente su valor a $180 \Omega \cdot \mathrm{cm}^{2}$ para 8 horas de exposición y $16 \Omega \cdot \mathrm{cm}^{2}$ para 24 horas.

Se observa que los valores iniciales de $R_{p o}$ de los recubrimientos con GPTMS son inferiores a los obtenidos para VTES. El valor de $R_{p o}$ es una medida de la resistencia iónica a través de los poros de recubrimiento y por tanto es inversamente proporcional al número y extensión de defectos en la película. Con el paso del tiempo los valores de $R_{\mathrm{po}}$ para el recubrimiento VTES permanecen prácticamente constantes, tan solo se observa una ligera disminución de este valor, por lo que el recubrimiento VTES es estable durante los tiempos estudiados. Los recubrimientos con GPTMS tienen una mayor cantidad de canales a través de los que puede pasar el electrolito y especies activas. Entre los recubrimientos 8V:2G, 2V:8G y GPTMS no se observan diferencias significativas, siendo el $2 \mathrm{~V}: 8 \mathrm{G}$ el que tiene mayor número de canales.

La capacidad del recubrimiento VTES tiene un valor constante alrededor de $10^{-8} \mathrm{~F} \cdot \mathrm{cm}^{-2}$. El recubrimiento GPTMS tiene los valores más altos de $\mathrm{CPE}_{\mathrm{c}}$ con un valor inicial de $1,3 \cdot 10^{-8} \mathrm{~F} \cdot \mathrm{cm}^{-2}$, y siempre creciente con el tiempo de exposición, siendo el valor a 10horas de exposición de $2,2 \cdot 10^{-8} \mathrm{~F} \cdot \mathrm{cm}^{-2}$ y llegando a $3,27 \cdot 10^{-8} \mathrm{~F} \cdot \mathrm{cm}^{-2}$. Los recubrimientos con composiciones intermedias tienen capacidades por debajo de las obtenidas para VTES y GPTMS. El recubrimiento $8 \mathrm{~V}: 2 \mathrm{G}$ tiene una capacidad inicial de $1,46 \cdot 10^{-9} \mathrm{~F} \cdot \mathrm{cm}^{-2}$, y se mantiene prácticamente constante en las primeras 8 horas de ensayo, con un valor a las 8 horas de $1,06 \cdot 10^{-9} \mathrm{~F} \cdot \mathrm{cm}^{-2}$. A partir de las 8 horas se produce un aumento del valor de $\mathrm{CPE}_{\mathrm{c}}$ hasta $7,58 \cdot 10^{-9} \mathrm{~F} \cdot \mathrm{cm}^{-2}$ para 24 horas. La muestra $2 \mathrm{~V}: 8 \mathrm{G}$ tiene un valor inicial de $2,52 \cdot 10^{-9} \mathrm{~F} \cdot \mathrm{cm}^{-2}$ y conforme pasa el tiempo de exposición el valor de $\mathrm{CPE}_{\mathrm{c}}$ aumenta, a 8 horas tiene un valor de $4,76 \cdot 10^{-9} \mathrm{~F} \cdot \mathrm{cm}^{-2}$ y a 24 horas $7,87 \cdot 10^{-9} \mathrm{~F} \cdot \mathrm{cm}^{-2}$. El recubrimiento $5 \mathrm{~V}: 5 \mathrm{G}$ tiene un comportamiento menos uniforme, pero con valores de $\mathrm{CPE}_{\mathrm{c}}$ crecientes con el tiempo de exposición. Tiene un valor inicial de $1,91 \cdot 10^{-9} \mathrm{~F} \cdot \mathrm{cm}^{-2}$, a 8 horas tiene un valor de $5,43 \cdot 10^{-9} \mathrm{~F} \cdot \mathrm{cm}^{-2}$ y a 24 horas $9,45 \cdot 10^{-9} \mathrm{~F} \cdot \mathrm{cm}^{-2}$

Analizando estos datos, se puede observar que la capacidad del recubrimiento obtenido a partir del GPTMS es la mayor de los cinco estudiados y probablemente es debido a la entrada del electrolito en él por tener una red más abierta y un carácter más hidrófilo que el resto, dado su mayor contenido de hidroxilos en superficie (apartado 5.2.5). Por otro lado, el recubrimiento VTES tiene una entrada de electrolito 
inferior a la obtenida para el GPTMS debido, como se ha comentado anteriormente, a la formación de una red más entrecruzada e hidrófoba. Los recubrimientos con composiciones intermedias $8 \mathrm{~V}: 2 \mathrm{G}, 5 \mathrm{~V}: 5 \mathrm{G}$ y $2 \mathrm{~V}: 8 \mathrm{G}$ tienen valores de capacidad por debajo de los obtenidos para las composiciones puras. Esto se puede deber al menor carácter hidrófilo detectado para estos recubrimientos (apartado 5.2.5) que provoca que el electrolito no entre a través de sus canales y, por tanto, no absorban agua.

La Figura. 5.41 muestra la modelización a partir de los datos obtenidos de los parámetros del circuito equivalente asociados a la resistencia a la polarización $\left(R_{p}\right)$ y la capacidad de la doble capa $\left(\mathrm{CPE}_{\mathrm{dl}}\right)$, correspondiente a la respuesta a baja frecuencia en VTES y media frecuencia para $8 \mathrm{~V}: 2 \mathrm{G}, 5 \mathrm{~V}: 5 \mathrm{G}, 2 \mathrm{~V}: 8 \mathrm{G}$ y GPTMS. Estos procesos corresponden a aquellos que necesitan tiempos largos de respuesta frente a la perturbación de una señal eléctrica para poder ser registrados y están relacionados con la evolución de la interfase metal/recubrimiento.

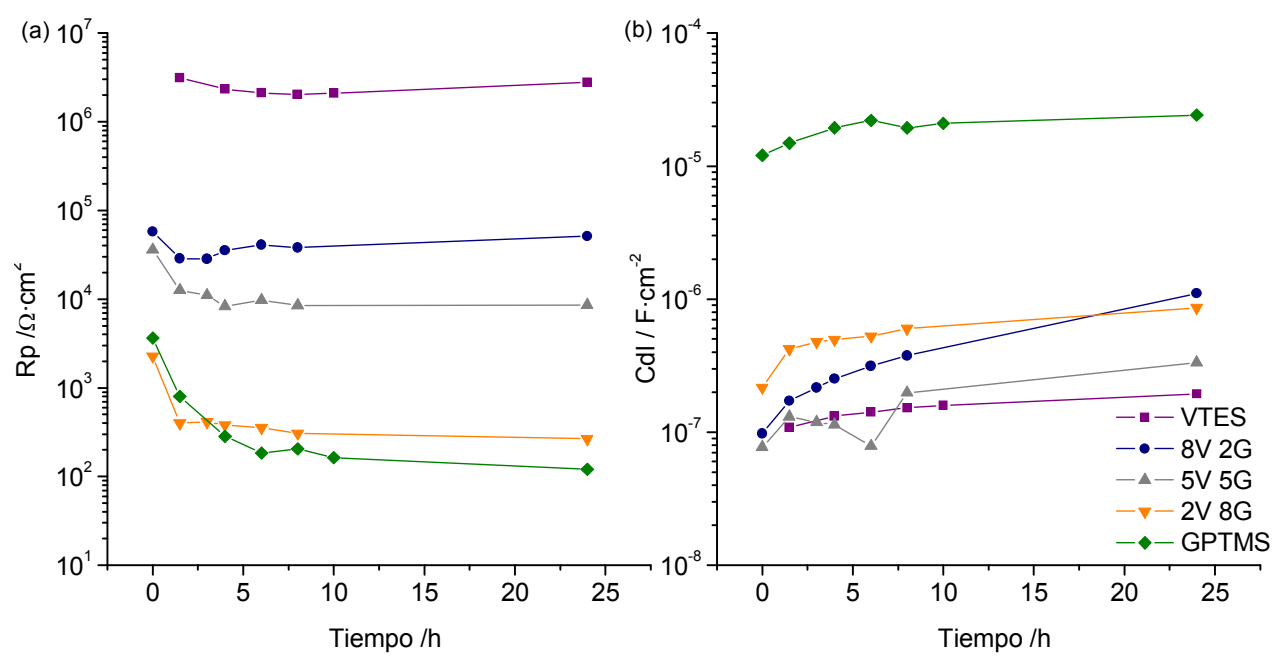

Figura. 5.41 Comparación de la evolución del valor de (a) resistencia a la polarización y (b) capacidad de la doble capa con el tiempo de exposición a la disolución acuosa $3,5 \% \mathrm{NaCl}$ de los recubrimientos VTES,8V:2G, 5V:5G, 2V:8G y GPTMS. 
La resistencia de polarización, $\mathrm{R}_{\mathrm{p}}$, es una medida del grado de actividad ánodocátodo de la interfase, de forma que cuanto menor es este valor la interfase es más activa y, por tanto se pueden generar procesos de corrosión más fácilmente. El recubrimiento VTES tiene los valores de $R_{p}$ más altos y son además constantes durante el tiempo de exposición, con valores entorno a $2,3 \cdot 10^{6} \Omega \cdot \mathrm{cm}^{2}$.

La adición de un $20 \%$ de GPTMS (8V:2G) hace bajar el valor de $R_{p}$ dos ordenes de magnitud, con un valor de $R_{p} 5,7 \cdot 10^{4} \Omega \cdot \mathrm{cm}^{2}$ y constante con el tiempo de exposición. El recubrimiento $5 \mathrm{~V}: 5 \mathrm{G}$ tiene un valor de $\mathrm{R}_{\mathrm{p}}$ inferior al registrado para $8 \mathrm{~V}: 2 \mathrm{G}$ con un valor inicial de $3,6 \cdot 10^{4} \Omega \cdot \mathrm{cm}^{2}$ que disminuye con el tiempo de exposición, dando un valor de $1,1 \cdot 10^{4} \Omega \cdot \mathrm{cm}^{2}$ para 3 horas y manteniéndose constante para tiempos mayores. Para un aumento en el contenido de GPTMS del $80 \%$ (2V:8G) el valor de $R_{p}$ sigue disminuyendo, dando un valor inicial de $2267 \Omega \cdot \mathrm{cm}^{2}$, que disminuye durante las primeras horas de exposición para dar un valor a las 3 horas de $410 \Omega \cdot \mathrm{cm}^{2}$, para tiempos superiores permanece constante. El recubrimiento GPTMS presenta un valor inicial de $3641 \Omega \cdot \mathrm{cm}^{2}$, y decreciente con el tiempo de exposición, con un valor a 3 horas de exposición de $284 \Omega \cdot \mathrm{cm}^{2}$ y a 24 horas de $120 \Omega \cdot \mathrm{cm}^{2}$.

El recubrimiento VTES muestra un valor de $R_{p}$ constante durante el tiempo de exposición y varios ordenes de magnitud por encima de los obtenidos para el resto de formulaciones, por lo que estos recubrimientos protegen frente a fenómenos de corrosión, teniendo una interfase muy estable. Conforme se aumenta el contenido en GPTMS la interfase se hace más activa. El recubrimiento con una interfase más activa es el GPTMS al presentar los menores valores de $R_{p}$.

Los valores de $\mathrm{CPE}_{\mathrm{dl}}$ del recubrimiento VTES son muy constantes con el tiempo de exposición, tiene un valor inicial de $1,1 \cdot 10^{-7} \mathrm{~F} \cdot \mathrm{cm}^{-2}$ y al final del tiempo de exposición es de $1,9 \cdot 10^{-7} \mathrm{~F} \cdot \mathrm{cm}^{-2}$. El recubrimiento $8 \mathrm{~V}: 2 \mathrm{G}$ tiene un valor inicial de $9,7 \cdot 10^{-8} \mathrm{~F} \cdot \mathrm{cm}^{-2}$ que crece ligeramente con el tiempo de exposición siendo para 8 horas $3,75 \cdot 10^{-7} \mathrm{~F} \cdot \mathrm{cm}^{-2}$ y para 24 horas $1,10 \cdot 10^{-6} \mathrm{~F} \cdot \mathrm{cm}^{-2}$. El recubrimiento $5 \mathrm{~V}: 5 \mathrm{G}$ tiene valores de $\mathrm{CPE}_{\mathrm{dl}}$ parecidos a los obtenidos en $8 \mathrm{~V}: 2 \mathrm{G}$, con un valor inicial de $7,7 \cdot 10^{-8} \mathrm{~F} \cdot \mathrm{cm}^{-2}$, a 8 horas $1,98 \cdot 10^{-7} \mathrm{~F} \cdot \mathrm{cm}^{-2}$ y a 24 horas $3,34 \cdot 10^{-7} \mathrm{~F} \cdot \mathrm{cm}^{-2}$. El recubrimiento $2 \mathrm{~V}: 8 \mathrm{G}$ tiene un valor inicial por encima de $8 \mathrm{~V}: 2 \mathrm{G}$ y $5 \mathrm{~V}: 5 \mathrm{G}$ de $2,16 \cdot 10^{-7} \mathrm{~F} \cdot \mathrm{cm}^{-2}$, a 8 horas es de $6,01 \cdot 10^{-7} \mathrm{~F} \cdot \mathrm{cm}^{-2}$ y a 24 horas $8,59 \cdot 10^{-7} \mathrm{~F} \cdot \mathrm{cm}^{-2}$. El 
recubrimiento GPTMS tiene unos valores de $\mathrm{CPE}_{\mathrm{dl}}$ constantes en el tiempo con un valor inicial varios ordenes de magnitud por encima del resto de recubrimientos con un valor de $1,2 \cdot 10^{-5} \mathrm{~F} \cdot \mathrm{cm}^{-2}$ y a tiempo 24 horas es de $2,4 \cdot 10^{-5} \mathrm{~F} \cdot \mathrm{cm}^{-2}$.

El recubrimiento VTES dada la estabilidad de su interfase no sufre procesos de deslaminación, teniendo un valor de $\mathrm{CPE}_{\mathrm{dl}}$ por debajo de los obtenidos para el resto de recubrimientos de la serie. Conforme se incorpora GPTMS a la formulación los procesos de deslaminación se suceden, debido al incremento en la actividad de la interfase. La presencia de una interfase activa puede ser indicativo de un proceso de formación de capa de óxido en la superficie metálica.

Los recubrimientos con GPTMS donde la entrada de electrolito y especies activas es mayor y muestran una interfase activa, describen un tercer proceso a frecuencias muy bajas. Este tercer proceso está asociado, como se mencionó anteriormente, con la formación de una capa de óxido en la superficie metálica, lo que es coherente con los resultados electroquímicos ya presentados. Los elementos pasivos del circuito equivalente correspondientes a esta tercera constante de tiempo son nuevamente una resistencia $R_{\text {ox }}$ y elemento capacitivo $C P E_{o x}$ en paralelo. Los datos que describen este proceso no son suficientes para poder realizar una buena modelización de los valores de la resistencia $R_{o x}$ y la capacidad $C P E_{o x}$, pudiéndose sólo señalar su existencia.

De los resultados electroquímicos se puede extraer que el recubrimiento VTES es poco permeable al electrolito y mantiene esta impermeabilidad durante todo el tiempo de exposición, sin verse afectada por el contacto con electrolito. Las especies activas no llegan a la interfase, y no se producen fenómenos de deslaminación. Esto, como se ha comentado en apartados anteriores se puede deber a la formación de una red más tupida que impide el paso de especies activas hasta la superficie, protegiendo mejor frente a los procesos corrosivos. Por otro lado, el recubrimiento GPTMS, que es un recubrimiento con una red abierta, permite la entrada de electrolito, registrándose desde el instante inicial una mayor cantidad de agua absorbida en su interior $\left(\mathrm{CPE}_{\mathrm{c}}\right.$ superior al obtenido para VTES). Con el paso del tiempo de exposición al electrolito va aumentando la cantidad de agua y especies activas que entran a través de sus canales. Además cuenta con una interfase activa donde se llegan a producir procesos corrosivos por lo que llega a detectarse la presencia de una tercera constante de 
tiempo correspondiente a la formación de una capa de óxido en la superficie del metal.

Partiendo del VTES y aumentando las cantidades de GPTMS (8V:2G, 5V:5G, $2 \mathrm{~V}: 8 \mathrm{G}$ ) se produce una disminución de $\mathrm{R}_{\mathrm{po}}$, por tanto, los recubrimientos cuentan con un mayor número de canales a través de los que puede entrar electrolito y especies activas. Sin embargo, estos recubrimientos absorben menor cantidad de agua que GPTMS y VTES, por tener valores de $\mathrm{CPE}_{\mathrm{c}}$ por debajo de los obtenidos para estos recubrimientos puros. Esto se puede deber al mayor carácter hidrófobo de estos recubrimientos, por no producirse la apertura del anillo epoxi, como en el caso del recubrimiento GPTMS puro. Por otro lado, conforme se aumenta el contenido en GPTMS se obtienen interfases con una mayor actividad ánodo-cátodo y procesos de deslaminación. Debido a la actividad en la interfase llegan a darse fenómenos de corrosión, detectándose en los diagramas de Bode la forma característica de la tercera constante de tiempo asociada a la formación de una capa de óxido.

\subsubsection{Degradación hidrolítica}

Se ha estudiado la degradación de estos recubrimientos en medio acuoso porque, como se introdujo anteriormente, es aconsejable que los recubrimientos se degraden en tiempos inferiores a 2 meses, ya que se ha detectado que el titanio muestra un buen comportamiento biológico a tiempos mayores.

Para la realización de este ensayo se obtuvieron los materiales en película libre y se ha evaluado su degradación por hidrólisis sumergiéndolos en PBS durante un tiempo total de 6 semanas y registrando la pérdida de peso de los mismos. Los materiales se dispusieron dentro de unas "cestas" para permitir la entrada del medio (PBS) y, a su vez, impedir la pérdida de parte del material. Los resultados de la pérdida de peso en tanto por ciento para cada recubrimiento se muestran en la Figura. 5.42 . 


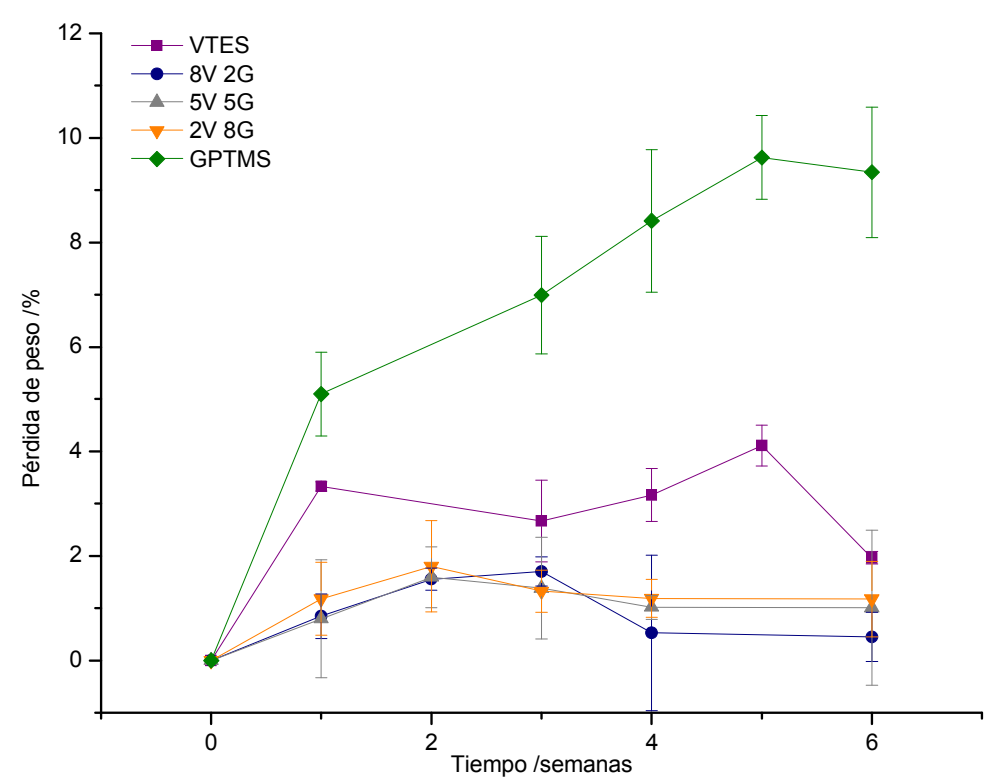

Figura. 5.42 Degradación hidrolítica por pérdida de peso del recubrimiento VTES,8V:2G, 5V:5G, 2V:8G y GPTMS sumergidos en PBS a $37^{\circ} \mathrm{C}$.

La degradación de los recubrimientos puros se estudió en el apartado 4.6. El recubrimiento con una mayor tasa de degradación es el GPTMS. Inicialmente registra una pérdida de peso rápida ( $5 \%$ del total) y con el paso del tiempo continua su degradación siempre creciente (máximo de $9,6 \%$ a 5 semanas). Esto se justificó porque cuanta con una red abierta, a través de la cual el medio entra y favorece la degradación del film por hidrólisis.

El recubrimiento VTES experimenta toda la degradación $(3,3 \%)$ en la primera semana de estudio y mantiene su peso con el paso del tiempo de inmersión en el período estudiado, es decir, no se registra una pérdida de peso significativa por encima de la primera semana de ensayo.

Las composiciones intermedias $(8 \mathrm{~V}: 2 \mathrm{G}, 5 \mathrm{~V}: 5 \mathrm{G}, 2 \mathrm{~V}: 8 \mathrm{G})$ presentan una tasa de degradación muy similar entre ellas e inferior a la registrada por los materiales obtenidos a partir de cada precursor por separado. Se ha observado que toda la degradación se produce en las 3 primeras semanas de estudio alcanzando valores entorno a $1,5 \%$ de pérdida de peso y tras este periodo no se registran cambios de peso significativos. 
Estos resultados concuerdan con aquellos obtenidos en las medidas de hidrofilia y propiedades anticorrosivas. En las composiciones donde están presentes los precursores GPTMS y VTES no se produce la apertura del anillo epoxi presente en el recubrimiento, por lo que no se produce un aumento de la hidrofilia del material con el aumento en el contenido en GPTMS. Al tratarse de materiales hidrófobos no se favorece la entrada de electrolito, como se observó en los resultados electroquímicos (valores de capacidad del recubrimiento bajos), y, por tanto, la red no se degrada hidrolíticamente. La red formada no es tan abierta como cuando se dispone el GPTMS solo haciendo los canales más pequeños y una red más estable hidroliticamente.

\subsubsection{Liberación de agentes terapéuticos}

Como en el caso de la serie VTES-TEOS se han dopado los recubrimientos con un fármaco modelo con el fin de estudiar la liberación desde los mismos. Una de las aplicaciones más importantes de los recubrimientos es que sirvan como medio para la liberación de agentes terapéuticos.

La procaína es un fármaco modelo, muy soluble en agua. El fármaco se introdujo durante la síntesis del sol, disolviéndolo en el agua de hidrólisis. Los materiales para la realización de este ensayo se obtuvieron en película libre pero no se extrajeron del molde, que en este caso de aluminio en vez de teflón, en un intento de obtener el comportamiento lo más parecido a la situación final. Para la realización del ensayo las muestras se introdujeron en PBS a pH 6,8 manteniendo la muestra en agitación y a una temperatura constante de $37^{\circ} \mathrm{C}$. En la Figura. 5.43 se muestran las curvas de liberación hasta 3 días de ensayo de la serie de materiales con distintas cantidades de GPTMS. En las gráficas se representa $M_{t} / M_{\infty}$ donde $M_{t}$ es la cantidad de fármaco detectada a un tiempo determinado $t$ y $\mathrm{M}_{\infty}$ es la cantidad de fármaco incorporado en el recubrimiento sintetizado. 


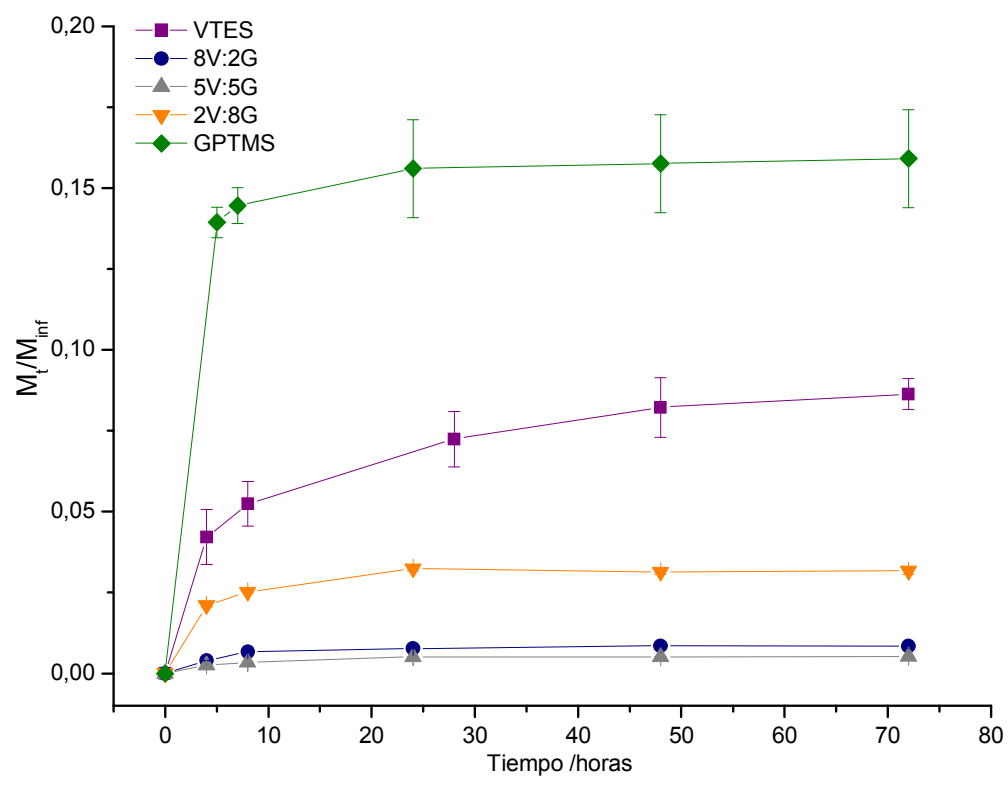

Figura. 5.43 Curvas de liberación de agente terapéutico de los recubrimientos VTES, 8V:2G, 5V:5G, 2V:8G y GPTMS dopados con un 5\% procaína

Como en los demás estudios de liberación desde este tipo de materiales las curvas obtenidas en esta serie VTES:GPTMS tienen el perfil de liberación esperado, mostrando una primera liberación rápida proveniente del fármaco que está albergado en los poros que se encuentran en contacto con el medio, seguida de una liberación más lenta proveniente de los poros internos [80].

El recubrimiento que presenta mayor liberación es el GPTMS, que libera en las primeras 8 horas un $15 \%$ y a tras este tiempo no libera el resto de agentes incorporados en su red. Como se describió en el apartado 4.7 este hecho probablemente se debe a la formación de un enlace químico entre el grupo amina del fármaco incorporado y el grupo epoxi del precursor GPTMS que impide que la procaína incorporada se libere al entorno.

El recubrimiento VTES no absorbe agua y se ve inalterado con el tiempo de inmersión en el electrolito. Por este motivo se produce una liberación acusada en las primeras horas de contacto con el medio, por liberación de los agentes en superficie (valor registrado de un 10\%) y luego se estabiliza. 
Las composiciones intermedias muestran una liberación por debajo de la obtenida para las composiciones puras. En el análisis del buffer donde están sumergidos los recubrimientos $8 \mathrm{~V}: 2 \mathrm{G}$ y $5 \mathrm{~V}: 5 \mathrm{G}$ apenas se detecta procaína en los 3 días de ensayo. El recubrimiento $2 \mathrm{~V}: 8 \mathrm{G}$ consigue liberar un $3 \%$ de la procaína introducida a los 3 días de ensayo. En estos casos, como en el caso de disponerse GPTMS solo, se produce unión química entre el grupo amina de la procaína y el grupo epoxi del GPTMS, lo que limita la cantidad de procaína que puede ser liberada al entorno. Por otro lado, no se favorece la liberación ya que el recubrimiento tiene un carácter hidrófobo que no favorece los procesos de liberación. Además estos recubrimientos se ha detectado que no degradan en medio hidrolítico por lo que la procaína que se encuentra sin reaccionar en el interior del recubrimiento no puede salir fácilmente al no producirse degradación del film. De entre las formulaciones intermedias la que mejor liberación presenta es $2 \mathrm{~V}: 8 \mathrm{G}$.

\subsubsection{Comportamiento celular}

Un factor clave en el estudio de esta serie de recubrimientos VTES:GPTMS es evaluar el comportamiento celular. Esta necesidad se debe a la detección del comportamiento citotóxico del precursor GPTMS cuando se dispone él solo en contacto con las células (apartado 4. 8). A pesar de haber detectado esta citotoxicidad se ha desarrollado esta serie de materiales debido al gran interés que despiertan sus propiedades, entre ellas las mecánicas, así como la introducción de grupos activos epoxi que aportan una gran versatilidad y funcionalidades a los recubrimientos desarrollados.

Como en el apartado 5.1.9 se ha estudiado la adhesión y proliferación de las AMSCs sobre la serie de materiales obtenida (VTES, 8V:2G, 5V:5G y 2V:8G), en este caso no se ha evaluado el comportamiento del GPTMS por su alto nivel citotóxico. Además, se ha estudiado la capacidad de los materiales para activar en las AMSCs los procesos de diferenciación a osteoblastos. Para ello, se han cultivado las AMSCs, se ha añadido un medio de diferenciación a osteoblastos y se han cuantificado los depósitos de calcio procedentes de la secreción de matriz extracelular mineralizada.

Para la realización del ensayo se han preparado las muestras sobre portas de vidrio de $12 \mathrm{~mm}$ de diámetro. El método de aplicación fue por evaporación de una gota 
de sol sobre el porta de vidrio en posición horizontal y aplicando en la misma posición el tratamiento de curado estándar establecido para cada formulación.

La evaluación de la proliferación de AMSCs sobre los recubrimientos de la serie GPTMS-VTES a 0, 1, 7 y 14 días de ensayo se representa en la Figura. 5.44. En este caso, las diferencias en proliferación celular se deberán a cambios en la química de la superficie, ya que no se han registrado cambios significativos en la hidrofilia de los films.

Para la realización del estudio se sembraron sobre los materiales las AMSCs y se midió la actividad mitocondrial de las células utilizando un kit MTT. Sólo se detectará actividad mitocondrial de aquellas células que estén adheridas al material y que se encuentren vivas, por esto, la medida de la absorbancia será directamente proporcional al número de células viables sobre el material. En la Figura. $5.44 \mathrm{se}$ representan las curvas de proliferación de células mesenquimales del tejido adiposo humano sobre la serie de materiales VTES-GPTMS aplicados sobre vidrio en comparación con el material utilizado como soporte (vidrio) durante 14 días de cultivo. 


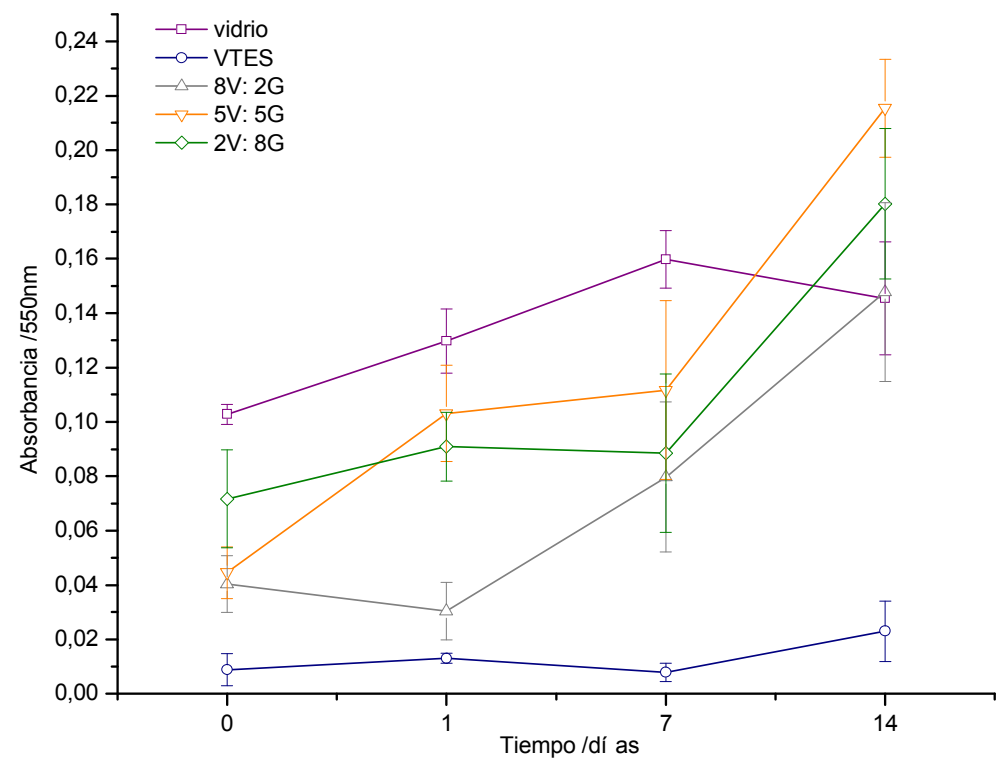

Figura. 5.44 Curva de proliferación de células mesenquimales del tejido adiposo humano AMSCs sobre el material de referencia vidrio y los recubrimientos VTES, 8V:2G, 5V:5G, 2V:8G y GPTMS. Tiempos de estudio 0, 1, 7 y 14 días. Absorbancia medida a 550nm.

El número de células viables en VTES es muy bajo, comparado con el control vidrio, desde el instante inicial (medido a las 3,5-4 horas de la siembra) y se mantiene bajo (alrededor 0,01 DO) durante los tiempos de cultivo ensayados. A 14 días se observa una leve recuperación con un incremento de la absorbancia de 0,01 DO, lo que significa un incremento en el número de células adheridas y viables sobre el recubrimiento.

Con la adición de un $20 \%$ de GPTMS (8V:2G) la adhesión y proliferación celular de AMSCs se mejora notablemente desde el instante inicial de la siembra $(0,04 \mathrm{DO})$, se produce un aumento progresivo del número de células viables en la superficie del material hasta alcanzar el máximo a 14 días de siembra con un 0,15 DO.

El recubrimiento con un 50\% de GPTMS (5V:5G) tiene inicialmente un anclaje celular semejante al obtenido en $8 \mathrm{~V}: 2 \mathrm{G}$ con un valor de absorbancia de 0,04 DO. Pasadas 24 horas desde la siembre el valor de densidad óptica medido aumenta notablemente a 0,103 DO, por tanto, existe una proliferación celular muy buena, llegándose a los 14 días a superar el nivel del material control, con un valor de 0,21 DO. 
El recubrimiento con un $80 \%$ de GPTMS (2V:8G) es el que muestra inicialmente un mejor anclaje celular, ya que se ha medido un valor de absorbancia de 0,07 DO. En los primeros 7 días de cultivo no se observa una aumento importante en la actividad mitocondrial, por lo que el número de células no aumenta, pero a partir de 7 días de cultivo se promueve la proliferación de las AMSCs y alcanza un valor próximo al obtenido para $5 \mathrm{~V}: 5 \mathrm{G}$ de $0,18 \mathrm{DO}$.

Se ha comprobado cómo, a pesar de introducir en la formulación inicial de VTES un precursor con un comportamiento citotóxico como el GPTMS, las mezclas han conseguido mejorar el anclaje y proliferación de las AMSCs sobre los recubrimientos respecto a los resultados obtenidos para el VTES. Con un contenido por encima del $50 \%$ de GPTMS (5V:5G y $2 \mathrm{~V}: 8 \mathrm{G}$ ) se ha detectado un numero de células viables sobre el material por encima del material control.

Adicionalmente al estudio de la proliferación celular, se ha estudiado la capacidad de los materiales para inducir la diferenciación de células madre a osteoblastos. Esta propiedad, como se ha visto anteriormente, es muy importante dada la aplicación final, ya que se busca que estos recubrimientos induzcan la formación de hueso alrededor del implante. Por este motivo, se ha evaluado la capacidad osteogénica de las AMSCs dispuestas sobre los biomateriales mediante la cuantificación de los depósitos de calcio formados por las AMSCs diferenciadas a células óseas en un medio de diferenciación osteogénico a los 7 y 14 días de cultivo diferenciador. En la Figura. 5.45 muestran los valores de densidad óptica normalizados frente a los valores obtenidos en el control vidrio. 


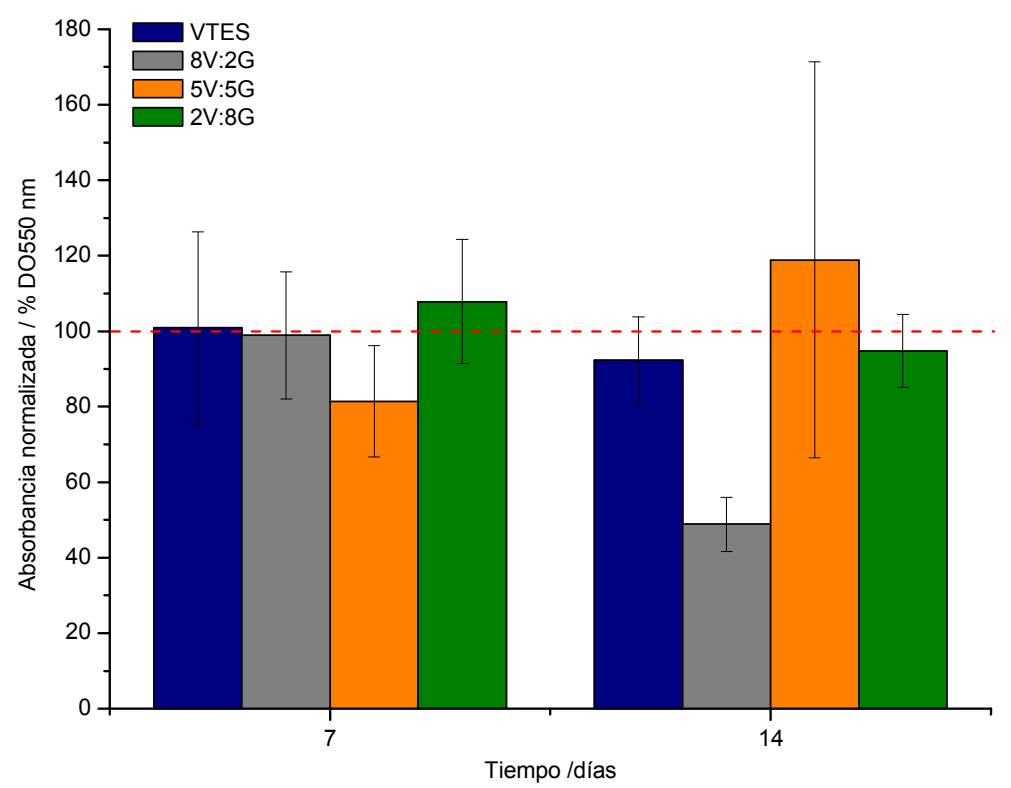

Figura. 5.45 Cuantificación de los depósitos de calcio formados por las AMSCs en medio de diferenciación osteogénico a los 7 y 14 días de cultivo sobre los materiales VTES, 8V:2G, 5V:5G: $2 \mathrm{~V}: 8 \mathrm{G}$ normalizados frente al control vidrio. .

Tras 7 días de cultivo diferenciador, las células dispuestas sobre la serie de materiales ensayados han formado depósitos de calcio. El recubrimiento VTES tiene una absobancia relativa al control de 100,95\%. El recubrimiento $8 \mathrm{~V}: 2 \mathrm{G}$ tiene una absorbancia de 98,88\%, el 5V:5G tiene una formación de depósitos de calcio por debajo del control con un valor relativo de $81,47 \%$. En el recubrimiento $2 \mathrm{~V}: 8 \mathrm{G}$ se detecta una mayor producción de matriz extracelular mineralizada alcanzando un valor de $107,83 \%$.

A los 14 días de cultivo el material VTES se produce un ligero descenso en los depósitos formados respecto al control vidrio $(92,30 \%)$ y el recubrimiento $8 \mathrm{~V}: 2 \mathrm{G}$ sufre una disminución significante quedando en un $48,86 \%$ respecto al vidrio. Los recubrimientos $5 \mathrm{~V}: 5 \mathrm{G}$ y $2 \mathrm{~V}: 8 \mathrm{G}$ tienen un aumento en la producción de calcio extracelular. Los valores relativos al control muestran que el recubrimiento $2 \mathrm{~V}: 8 \mathrm{G}$ tiene un valor de $94,80 \%$, muy próximo al vidrio y el recubrimiento $5 \mathrm{~V}: 5 \mathrm{G}$ tiene un valor de $118,88 \%$ respecto al vidrio. 
Del análisis de los datos se extrae que el recubrimiento VTES tiene, a pesar de tener una adhesión celular muy por debajo del resto de materiales, una capacidad para promover la diferenciación a osteoblastos semejante a la registrada por el vidrio control, que tenía mejor adhesión celular.

A 7 días se detecta que con la adición de un $80 \%$ de GPTMS (2V:8G) se mejora la osteoinducción de los materiales, aumentándose la cantidad de depósitos de calcio. A los 14 días de cultivo el recubrimiento con un 20\% de GPTMS tiene un mal comportamiento en cuanto a diferenciación. Los recubrimientos que mejor se comportan son el 5V:5G y 2V:8G teniendo una producción semejante, o por encima, del material tomado como referencia.

Se ha conseguido mejorar la adhesión celular de AMSCs sobre el recubrimiento VTES añadiendo GPTMS. Se consigue mejorar notablemente el comportamiento biológico con contenidos por encima del 50\% de GPTMS. Este comportamiento se puede deber a diversos factores superficiales de los recubrimientos. Como se ha citado anteriormente, son varios los factores que pueden influenciar en la adhesión celular como son topografía, hidrofilia, dureza de la superficie. Con la adición de GPTMS se han variado todos estos factores y gracias a ello, se ha conseguido mejorar el anclaje celular.

Cuando se promueve la diferenciación de las AMSCs a osteoblastos los materiales obtenidos con un $50 \%$ y $80 \%$ de GPTMS son unos soportes adecuados para que se produzca la diferenciación y las células secreten matriz extracelular mineralizada, detectándose niveles de producción de depósitos de calcio por encima del material control. Estos resultados evidencian la buena diferenciación celular que han sufrido las AMSCs a osteoblastos cuando se han dispuesto sobre estos materiales, indicador de una buena osteintegración y osteoinducción. 


\section{3 Selección del recubrimiento óptimo para la aplicación biomédica.}

En este capítulo se han sintetizado dos series de recubrimientos tomando como precursor de partida el VTES (seleccionado en el Capítulo 4). Una primera serie basada en la adición de distintas cantidades de TEOS y otra en las que se han añadido distintas cantidades de GPTMS. Con la elaboración de estas series de materiales se han modulado propiedades como la hidrofilia, la degradabilidad, la funcionalidad, el módulo elástico, etc.

Se han sintetizado y estudiado los recubrimientos obtenidos en las dos series VTES:TEOS y VTES:GPTMS. Partiendo del recubrimiento VTES puro se han obtenido formulaciones hasta un $30 \%$ en TEOS y hasta un $100 \%$ de GPTMS dando lugar a películas homogéneas, sin grietas y con buenas propiedades superficiales.

Se han optimizado las condiciones de síntesis para cada formulación mediante estudios de ${ }^{29} \mathrm{Si}-\mathrm{RMN}$ en líquidos, donde se ha fijado el tiempo óptimo de hidrólisis en 1 hora para todas las formulaciones. Las condiciones de temperatura y tiempo de curado se han optimizado por medio de ${ }^{29}$ Si-RMN RMN y FTIR y varían en función de la composición. En la serie VTES-TEOS la incorporación de TEOS ha hecho disminuir las temperaturas de curado a $50^{\circ} \mathrm{C}$. Por el contrario, la adición de GPTMS hace necesario un incremento de la temperatura de curado a $140^{\circ} \mathrm{C}$.

Se han caracterizado las redes formadas por medio de RMN y FTIR, confirmándose el carácter híbrido de los materiales. Todos ellos cuentan con una red polisiloxánica con cadenas orgánicas embebidas en ella. En la serie VTES-TEOS se ha aportado un mayor carácter inorgánico a la red con el incremento en la cantidad de TEOS, que es un precursor de silicio que reacciona por puente siloxano por sus cuatro posibilidades de enlace. La serie VTES:GPTMS aporta un carácter más orgánico por introducción de la cadena glicidoxipropil de gran peso molecular en comparación a la cadena vinil del VTES. Además, se ha detectado que esta cadena con grupo epoxi terminal, con las condiciones de curado ( $\mathrm{pH}$ y temperatura) se abre por hidrólisis, aunque no en todos los casos, quedando anillos epoxi sin hidrolizar en todas las formulaciones. 
Estas redes híbridas presentan $T_{g}$ en función de la carga orgánica, por este motivo solo se ha conseguido obtener $T_{g}$ en la serie VTES:GPTMS. Además, se ha visto como $T_{g}$ se desplaza a menores temperaturas con el aumento en el contenido en GPTMS. Por otro lado, se ha estudiado la degradación detectándose que hasta $700^{\circ} \mathrm{C}$ no se produce degradación de la red polisiloxánica. La parte orgánica del recubrimiento se degrada en el intervalo de temperaturas comprendido entre $240^{\circ} \mathrm{C}$ a $600^{\circ} \mathrm{C}$.

Se ha variado las propiedades mecánicas de los recubrimientos. Por un lado, la adición de TEOS trae consigo un aumento en la rigidez de los recubrimientos. Por otro lado, la adición de GPTMS aporta un carácter más dúctil, disminuyéndose el módulo elástico, aunque en este caso el comportamiento no es proporcional al contenido en GPTMS.

Se ha obtenido un gradiente de hidrofilias por medio de la adición de TEOS, a mayor contenido en TEOS mayor hidrofilia del recubrimiento. Con la adición de GPTMS no se han conseguido grandes variaciones en el ángulo de contacto, obteniéndose para todas las formulaciones un carácter hidrófobo.

Se ha modulado la degradación de los recubrimientos por medio de la composición. Los recubrimientos de la serie VTES:TEOS degradan rápidamente conforme se aumenta el contenido en TEOS, siendo el de mayor tasa de degradación el 7V:3T. Por el contrario, los recubrimientos de la serie VTES:GPTMS degradan menos que el VTES o el GPTMS solos. Dentro de la serie, los comportamientos son muy parecidos siendo el que mayor tasa de degradación presenta es el 2V:8G.

La liberación de fármacos se ha mejorado por medio de la adición de TEOS, a mayor contenido en TEOS mayor velocidad de liberación de fármacos. El recubrimiento con la tasa de liberación mayor es el 7V:3T. La cinética de liberación desde la serie de materiales VTES:GPTMS no es más rápida a la obtenida en VTES puro, la incorporación de GPTMS hace que la liberación sea más lenta y mantenida en el tiempo. El recubrimiento con una tasa de liberación mayor dentro de la serie es el 2V:8G. 
Se ha estudiado la adhesión celular de AMSCs sobre las dos series de materiales. En este caso, las dos series de materiales han conseguido mejorar el comportamiento del recubrimiento VTES. A mayor contenido en TEOS se ha conseguido una mayor adhesión celular de las AMSCs, al igual que con el incremento en GPTMS. Los recubrimientos con un mejor anclaje celular con el 7V:3T y el 5V:5G.

En el estudio de diferenciación de las AMSCs a osteoblastos se observa como la serie VTES:GPTMS induce la diferenciación, al producirse una mayor secreción de matriz extracelular mineralizada de las células dispuestas sobre estos materiales. Los recubrimientos donde se ha detectado un mayor número de depósitos de calcio son $5 \mathrm{~V}: 5 \mathrm{G}$ y $2 \mathrm{~V}: 8 \mathrm{G}$. La serie VTES:TEOS también muestra unos buenos niveles de diferenciación, pero se encuentra por debajo de los detectados para $5 \mathrm{~V}: 5 \mathrm{G}$ y $2 \mathrm{~V}: 8 \mathrm{G}$, siendo el mejor de la serie el $7 \mathrm{~V}: 3 \mathrm{~T}$.

El principal objetivo que han de cumplir estos recubrimientos es la mejora de la osteoinducción y osteointegración del implante. Por este motivo, la propiedad que ha tomado mayor peso a la hora de determinar el mejor recubrimiento para esta aplicación es el estudio de la diferenciación de las AMSCs a osteoblastos. Pero también son importantes a la hora de seleccionar el recubrimiento propiedades como el comportamiento mecánico, la protección frente a procesos corrosivos del implante, la facilidad para la liberación de fármacos y la reabsorción del recubrimiento, por lo que se han tenido en cuenta de manera conjunta.

Todos los recubrimientos estudiados en este capítulo de la presente Tesis Doctoral han mejorado la adhesión y proliferación de las AMSCs así como la diferenciación de las AMSCs a osteoblastos en comparación con los resultados obtenidos para el recubrimiento VTES. Los mejores resultados, en cuanto a diferenciación a osteoblastos, han sido los obtenidos para los recubrimientos $5 \mathrm{~V}: 5 \mathrm{G}$ y $2 \mathrm{~V}: 8 \mathrm{G}$. El recubrimiento $2 \mathrm{~V}: 8 \mathrm{G}$ tiene inicialmente una mayor secreción de matriz extracelular mineralizada, a los 14 días de ensayo los valores de depósitos de calcio obtenidos para el $2 \mathrm{~V}: 8 \mathrm{G}$ son menores que para el $5 \mathrm{~V}: 5 \mathrm{G}$, sin embargo, las desviaciones de este último son muy elevadas. 
Por tanto, la selección del mejor recubrimiento para la aplicación final, se centra entre el recubrimiento $5 \mathrm{~V}: 5 \mathrm{G}$ y $2 \mathrm{~V}: 8 \mathrm{G}$. Evaluando las propiedades mecánicas, el recubrimiento $2 \mathrm{~V}: 8 \mathrm{G}$ tiene una mayor rigidez que el $5 \mathrm{~V}: 5 \mathrm{G}$, lo que es de interés ya que los recubrimientos deberán soportar los esfuerzos derivados del proceso de atornillado en el hueso. En cuanto a las propiedades en medio acuoso, el recubrimiento $2 \mathrm{~V}: 8 \mathrm{G}$ tiene una tasa de degradación superior a la obtenida para el recubrimiento $5 \mathrm{~V}: 5 \mathrm{G}$, por lo que tenderá a reabsorberse con mayor facilidad una vez implantado. Por último, la liberación del fármaco introducido ha sido más fácil desde el recubrimiento $2 \mathrm{~V}: 8 \mathrm{G}$, detectándose una cantidad de fármaco en el medio superior que la obtenida para $5 \mathrm{~V}: 5 \mathrm{G}$.

De la evaluación ponderada de todas propiedades se ha seleccionado la formulación $2 \mathrm{~V}: 8 \mathrm{G}$ como óptima para posteriormente, realizar las mejoras que se plantean en el siguiente capítulo de la presente Tesis Doctoral. 

Capítulo 6 Diseño a medida del recubrimiento (nivel de bioactividad, control de la velocidad de degradación y de la liberación de fármacos) 

En este capítulo se presentan los resultados obtenidos del estudio en profundidad de la formulación óptima seleccionada en el capítulo anterior. Al tratarse de un material altamente versátil, permite realizarle variaciones tanto en la adición de distintos agentes, que puedan resultar de interés para la aplicación final, así como variaciones en la propia red por medio de modificaciones en los parámetros de síntesis con el fin de controlar el nivel de bioactividad, la velocidad de degradación y liberación de fármacos.

Se actúa sobre parámetros de curado de la red para regular el grado de entrecruzamiento de ésta, así como la adición de partículas bioactivas (hidroxiapatita) para intentar regular el nivel de bioactividad. En este capítulo se presentan los materiales obtenidos vía la modificación de los parámetros citados, así como la caracterización de éstos.

\section{1 Nivel de bioactividad}

\subsubsection{Síntesis de recubrimientos con HAp}

La incorporación de cargas inorgánicas en recubrimientos obtenidos vía sol-gel es una práctica común en el campo biomédico [126-128]. Entre las cargas más utilizadas se encuentran la hidroxiapatita, obtenida de muy diversas formas, y los fosfatos cálcicos. En este estudio se ha optado por la introducción de hidroxiapatita (HAp) comercial de la marca Sigma-Aldrich como partícula para regular la bioactividad.

Para introducir la mayor cantidad de partículas bioactivas, y a la vez seguir contando con una red con buenas propiedades, se probaron distintos protocolos de síntesis y se realizó un estudio de optimización del proceso a llevar a cabo. Finalmente, se introdujo hasta un $5 \%$ en peso de HAp respecto a los silanos dispersada por medio de ultrasonidos en isopropanol y se optó por añadirla en la etapa sol, tras la reacción de hidrólisis de los precursores (apartado 3.1.2).

El sol obtenido en este caso es blanco debido a la presencia de las partículas bioactivas y homogéneo. La viscosidad es mayor a la obtenida sin HAp, pero permite realizar una correcta aplicación del recubrimiento sobre las planchas metálicas. 
Los recubrimientos obtenidos sobre las planchas de acero AISI $316 \mathrm{~L}$ se han aplicado de manera homogénea por toda la superficie, obteniéndose una película continua y sin imperfecciones. Se aprecia una mayor rugosidad en la superficie de las planchas por la presencia de las partículas de HAp. Se comprueba el acabado de los recubrimientos aplicados sobre metal mediante una prueba que consiste en comparar visualmente la reflexión de un rayo luminoso y la formación de la imagen en la superficie, obteniéndose que los recubrimientos tienen buenas propiedades superficiales, son homogéneos y tienen un acabado menos brillante y blanquecino (Figura. 6.1).
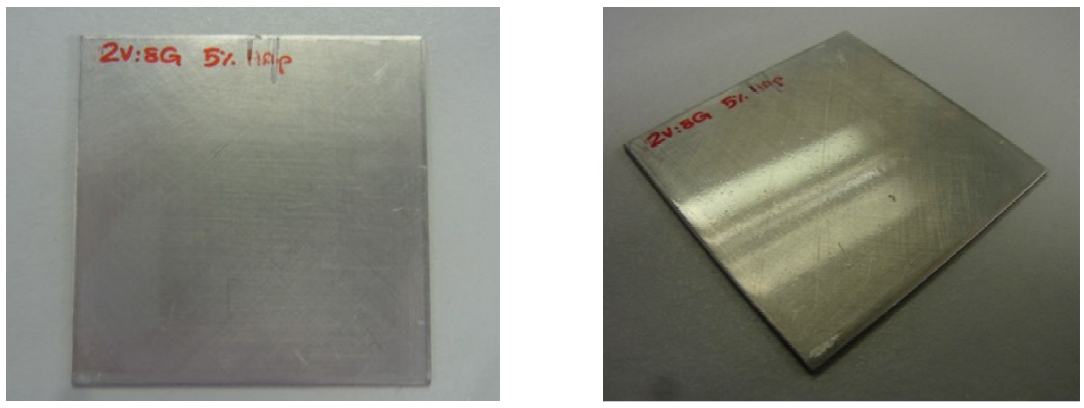

Figura. 6.1 (Izq.) Ejemplo de plancha recubierta con el recubrimiento $2 \mathrm{~V}: 8 \mathrm{G}$ dopado con un 5\% de HAp mediante la técnica dip-coating. (Dcha.) reflejo tipo espejo sobre la superficie de este mismo recubrimiento.

Por otro lado, se ha determinado la adherencia de los recubrimientos al metal por medio de la técnica de corte enrejado. Se han obtenido para todos los casos recubrimientos adherentes, sin desprendimiento del mismo en ningún caso.

Para comprobar las características superficiales micrométricas de los materiales obtenidos se evaluó con SEM la superficie de los recubrimientos aplicados sobre acero AISI 316L (Figura. 6.2). Se muestran las imágenes captadas con el detector de electrones secundarios y la imagen obtenida con el detector de electrones retrodispersados que permite evaluar la dispersión de las partículas dentro del recubrimiento. 

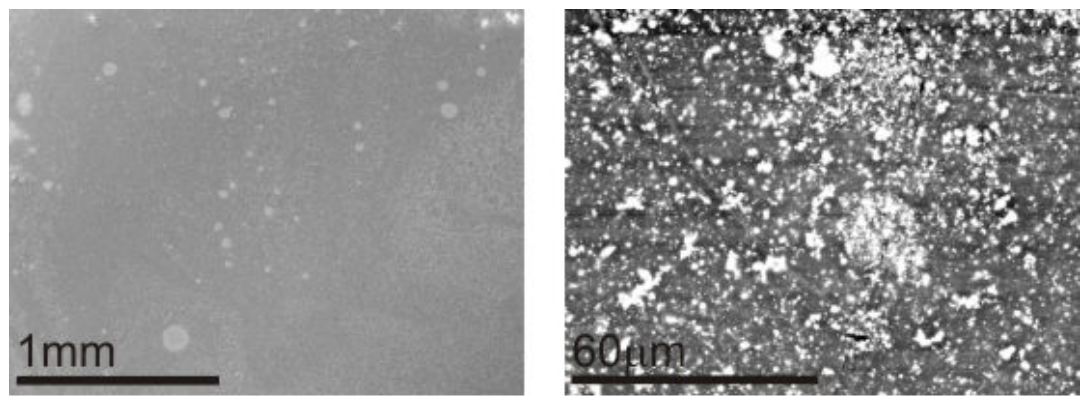

Figura. 6.2 Micrografías obtenidas con SEM mediante detector de (a) electrones secundarios $100 \mathrm{X}$ aumentos $\mathrm{y}$ (b) electrones retrodispersados $1000 \mathrm{X}$ aumentos.

Los recubrimientos dopados con HAp tienen un buen acabado superficial, no apreciándose agregados en la superficie, poros o grietas. Cuando se analiza la dispersión de las partículas mediante la detección de electrones retrodispersados se observa que existe una correcta distribución de las partículas dentro de la película de sol-gel creada. Es importante tener en cuenta, que con esta técnica en la imagen se muestran partículas que se encuentran a distinta profundidad del recubrimiento, aun así la presencia de aglomerados es baja. El tamaño de partícula medido oscila entre $600 \mathrm{~nm}$ a $800 \mathrm{~nm}$.

Es importante para conseguir una bioactividad adecuada que las partículas se encuentren correctamente dispersadas por toda la superficie del recubrimiento, gracias al procedimiento de síntesis se ha conseguido una buena dispersión de las mismas dentro del recubrimiento.

Además, se han obtenido muestras en forma de película libre (sin sustrato) con un espesor aproximado de $1 \mathrm{~mm}$ como se muestran en la Figura. 6.3. Estas películas se obtienen vertiendo una cantidad apropiada de sol (especificada en 3.1.3) en moldes de teflón y se aplica el mismo tratamiento de curado que el aplicado en las planchas metálicas. Posteriormente se desmoldan y se obtienen películas consistentes que no presentan grietas ni poros. Estas películas libres se utilizarán para la caracterización del material en aquellos experimentos en los que no se pueda utilizar el material como recubrimiento aplicado en metal, como por ejemplo en técnicas calorimétricas. 


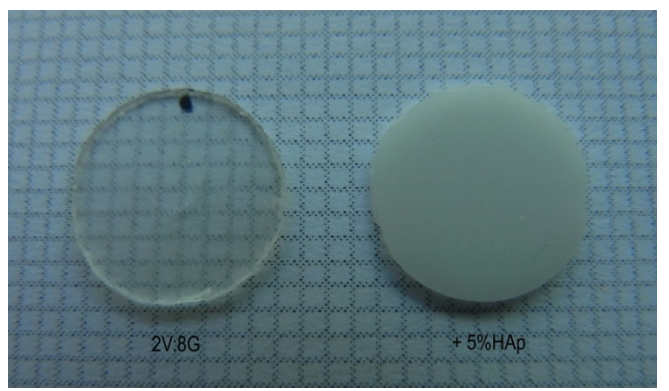

Figura. 6.3 Fotografía film libre recubrimiento $2 \mathrm{~V}: 8 \mathrm{G}$ y $2 \mathrm{~V}: 8 \mathrm{G}$ dopado con $5 \%$ en peso de HAp.

Los recubrimientos $2 \mathrm{~V}: 8 \mathrm{G}$ obtenido como película libre son homogéneos y transparentes. El recubrimiento dopado con un $5 \%$ en peso de HAp también es homogéneo pero, debido a la alta carga de HAp que contienen, presentan color blanco (Figura. 6.3).

Además se ha podido medir el espesor del recubrimiento (Figura. 6.4) obtenido por dip-coating. Se ha obtenido un espesor muy uniforme en toda la muestra, con un valor promedio de $3.2 \pm 0.7 \mu \mathrm{m}$. El espesor es semejante a los obtenidos en bibliografía [63] para este tipo de recubrimientos y es adecuada para la aplicación final objeto de esta Tesis Doctoral.

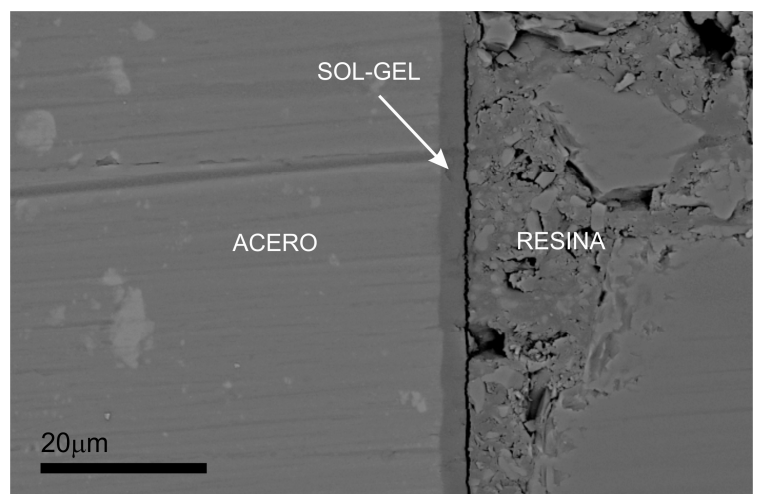

Figura. 6.4 Micrografía de la sección transversal del recubrimiento $2 \mathrm{~V}: 8 \mathrm{G}$ aplicado sobre metal por medio de dip-coating. 


\subsubsection{Comportamiento térmico con distintas cargas de HAp}

La incorporación de cargas orgánicas produce variaciones en la red y, por tanto, variaciones en la estabilidad térmica del material. Por este motivo, se realizó un estudio completo sobre degradación térmica variando el contenido de HAp en los recubrimientos. Este estudio nos permite además cuantificar la cantidad de carga inorgánica presente en el recubrimiento, que en este caso proviene de la red de silicio y de las cargas de HAp incorporadas. Se realizó además un estudio cinético de la degradación con el fin de obtener las curvas de degradación isoterma del material y el triplete cinético. El triplete cinético se compone por un factor pre-exponencial $A$, la energía de activación $E$, y la función integral del grado de conversión $g(\alpha)$ que describe la reacción de degradación, para ello se utilizó un análisis integral noisotérmico. La finalidad de este estudio es doble, por un lado se intenta determinar si el proceso de curado seleccionado provoca degradación en la red, y por otro lado establecer, en caso de querer en el futuro realizar procesos de sinterización, cuáles serían los parámetros del tratamiento térmico a aplicar.

Para la realización del experimento se prepararon muestras en film libre aplicándoles el tratamiento de curado descrito en el apartado 3.1.3 y se trituraron para permitir una distribución homogénea del calor por la muestra. Se aplica un barrido de temperaturas desde temperatura ambiente hasta $700^{\circ} \mathrm{C}$ a $10^{\circ} \mathrm{C} / \mathrm{min}$ con flujo de nitrógeno. En la Figura. 6.5 se representa las curvas de pérdida de peso y la derivada de la pérdida de peso de las muestras sin cargas $(2 \mathrm{~V}: 8 \mathrm{G})$, con un $2,5 \%$ de HAp (2v:8G+2,5\%HAp) y con un $5 \%$ de HAp (2V:8G+5\%HAp). 

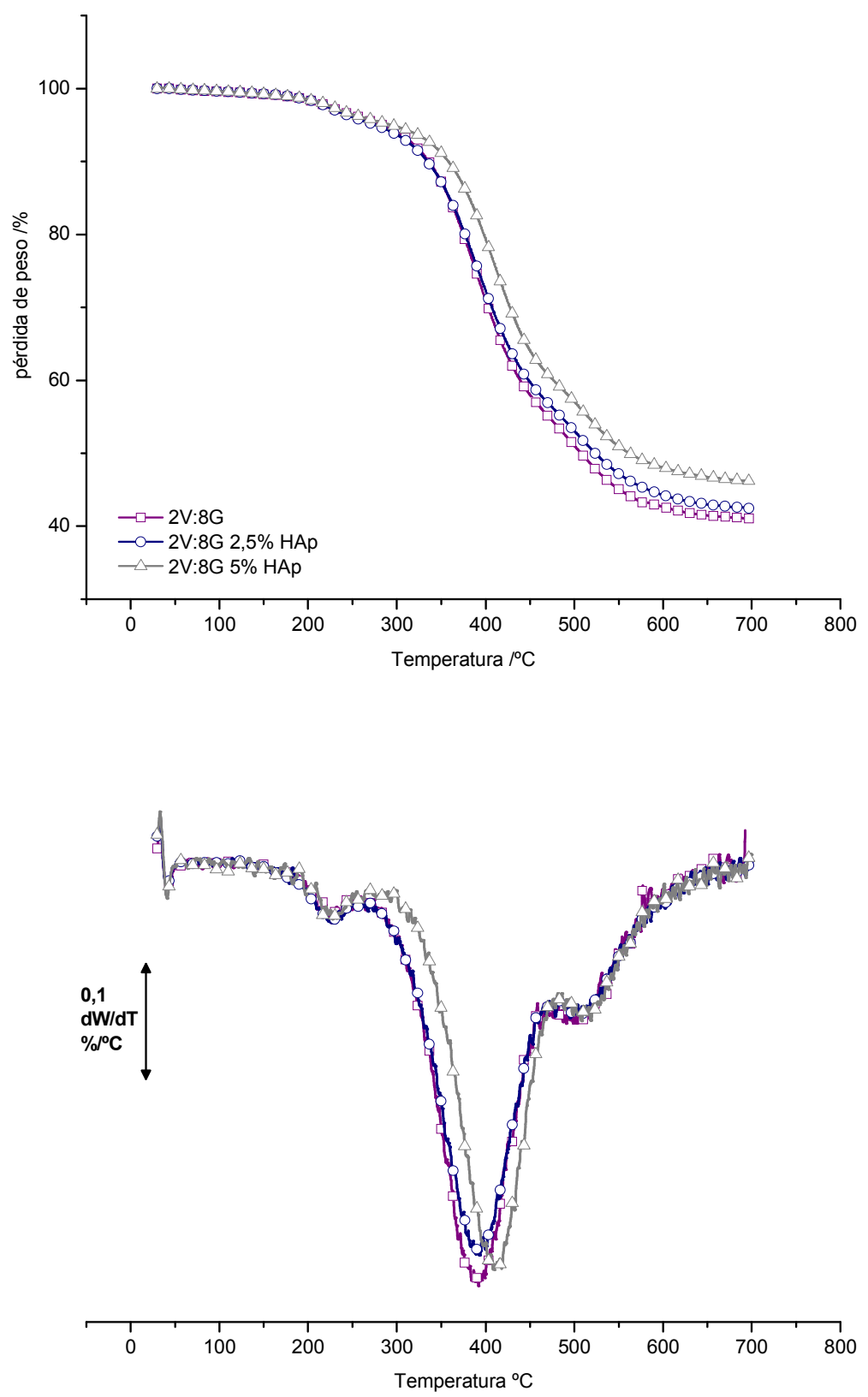

Figura. 6.5 Curvas TGA y la derivada de la pérdida de peso de las muestras $2 \mathrm{~V}: 8 \mathrm{G}$ con un $0 \%$ HAp, $2,5 \%$ HAp y $5 \%$ HAp. Velocidad de calentamiento $10^{\circ} \mathrm{C} / \mathrm{min}$ bajo atmosfera de $\mathrm{N}_{2}$. 
Los tres materiales tienen una curva de degradación semejante, en las que los procesos de degradación térmica son idénticos (descritos en detalle en el apartado 5.2.3). Se diferencian en la cantidad de residuo inorgánico que contienen a mayor carga de HAp, mayor es el residuo inorgánico. En la Tabla 6.1 se recogen los datos cuantitativos extraídos de los datos del ensayo TGA.

Tabla 6.1 Datos TGA para 2V:8G, $2.5 \%$ y $5 \%$ Hap.

\begin{tabular}{|c|c|c|c|}
\hline Formulación & $\mathbf{T}_{\mathbf{c}}{ }^{\mathbf{a}}$ & $\mathbf{T}_{\max }{ }^{\mathbf{b}}$ & Residuo (\%) \\
\hline $2 \mathrm{~V}: 8 \mathrm{G}$ & 283 & 387 & 41 \\
\hline $2 \mathrm{~V}: 8 \mathrm{G} \% 2.5 \mathrm{HAp}$ & 276 & 389 & 42 \\
\hline 2V:8G $\% 5 \mathrm{HAp}$ & 294 & 410 & 46 \\
${ }^{\mathrm{a}}$ Temperatura a la que se registra un $5 \%$ de pérdida de peso. ${ }^{\mathrm{b}}$ Temperatura a la que se detecta \\
el máximo de degradación. ${ }^{\mathrm{c}}$ Cantidad de residuo sólido a $700^{\circ} \mathrm{C}$
\end{tabular}

La adicción de HAp no deriva en cambios significativos en los procesos de degradación, la temperatura a la cual ha degradado un $5 \%$ del total del peso de la muestra no varía. La temperatura del pico de mayor pérdida se desplaza a mayores temperaturas conforme aumenta el contenido de HAp, debido posiblemente a la presencia de la carga inorgánica que absorbe parte del calor que se suministra a la muestra, y retrasando por tanto la degradación de la cadena principal orgánica. Los incrementos de residuo obtenidos son lógicos con las adiciones en peso efectuadas en HAp.

Al realizar la derivada de la curva de pérdida de peso representada en la Figura 30 se pueden distinguir los tres procesos de degradación distintos que se producen en el material. En la DTG se observa un pico a una temperatura de aproximadamente $200{ }^{\circ} \mathrm{C}$, el cual viene asociado a una pequeña pérdida de masa. La explicación de este fenómeno probablemente está relacionada con la pérdida de componentes volátiles (disolventes utilizados en la reacción o alcoholes formados durante las reacciones de hidrólisis y condensación). Según algunos autores [115-116], entre 375 y $600^{\circ} \mathrm{C}$ se produce la degradación del radical orgánico, con la consecuente pérdida de peso detectada con TGA. Se descompone la cadena orgánica del GPTMS y VTES (para mayor detalle apartado 4. 3).

Adicionalmente, se realizó el estudio cinético de la degradación con el fin de obtener las curvas de degradación isoterma del material y el triplete cinético que 
describe la reacción de degradación. Para ello se utilizó el análisis integral noisotérmico.

El triplete cinético se compone por un factor pre-exponencial $A$, la energía de activación $E$, y la función integral del grado de conversión $g(\alpha)$.

El grado de conversión de la pérdida de masa se define como:

$$
\alpha=\frac{m_{0}-m}{m_{0}-m_{\infty}}
$$

Donde $m$ es la masa correspondiente a la temperatura $T, m_{0}$ es la masa inicial y $m_{\infty}$ es la masa residual al final del experimento.

Si se acepta que el ratio de pérdida de masa en función del tiempo sigue una ecuación tipo Arrhenius, el análisis no-isotermo comienza con la siguiente ecuación:

$$
\frac{d \alpha}{d t}=\beta \frac{d \alpha}{d T}=A \exp \left(-\frac{E}{R T}\right) f(\alpha)
$$

Donde $\beta$ es la velocidad de degradación (a la que se ha realizado el experimento), $d \alpha / d t$ es el ratio de conversión, $R$ es la constante universal de los gases, $T$ es la temperatura y $f(\alpha)$ es la función diferencial de la conversión.

La solución que da para esta ecuación diferencial el método de Coats-Redfern es:

$$
\ln \frac{g(\alpha)}{T^{2}}=\ln \left[\frac{A R}{\beta E}\right]-\frac{E}{R T}
$$

Otra solución que corresponde al método Kissinger-Akahira-Sunose (KAS) conlleva a la siguiente ecuación:

$$
\ln \frac{\beta}{T^{2}}=\ln \left[\frac{A R}{g(\alpha) E}\right]-\frac{E}{R T}
$$

Para cada grado de conversión, la representación lineal de $\ln \left[\beta / T^{2}\right]$ frente a $T^{1}$ permite la obtención de $E$ y $\ln [A R / g(\alpha) E]$ a partir de la pendiente y de la ordenada en el origen. Si el modelo $g(\alpha)$ se conoce, se puede calcular el factor preexponencial. La integración de la ecuación en condiciones isotermas da la expresión isoconversional: 


$$
\ln t=\ln \left[\frac{g(\alpha)}{A}\right]+\frac{E}{R T}
$$

donde $t$ es el tiempo de degradación.

A través de los dos métodos se puede obtener los parámetros isotermos y simular el comportamiento isotermo sin conocer $g(\alpha)$ ya que la constante isoterma $\ln g(\alpha) / A$ (Coats-Redfern) está directamente relacionada para cada valor de $\alpha$ con $\ln [A R / g(\alpha) E](\mathrm{KAS})$ a través de $R / E$.

Para poder realizar este estudio se realizaron varias medidas a distintas velocidades de degradación y se representó el grado de conversión frente a la temperatura de degradación (Figura. 6.6).

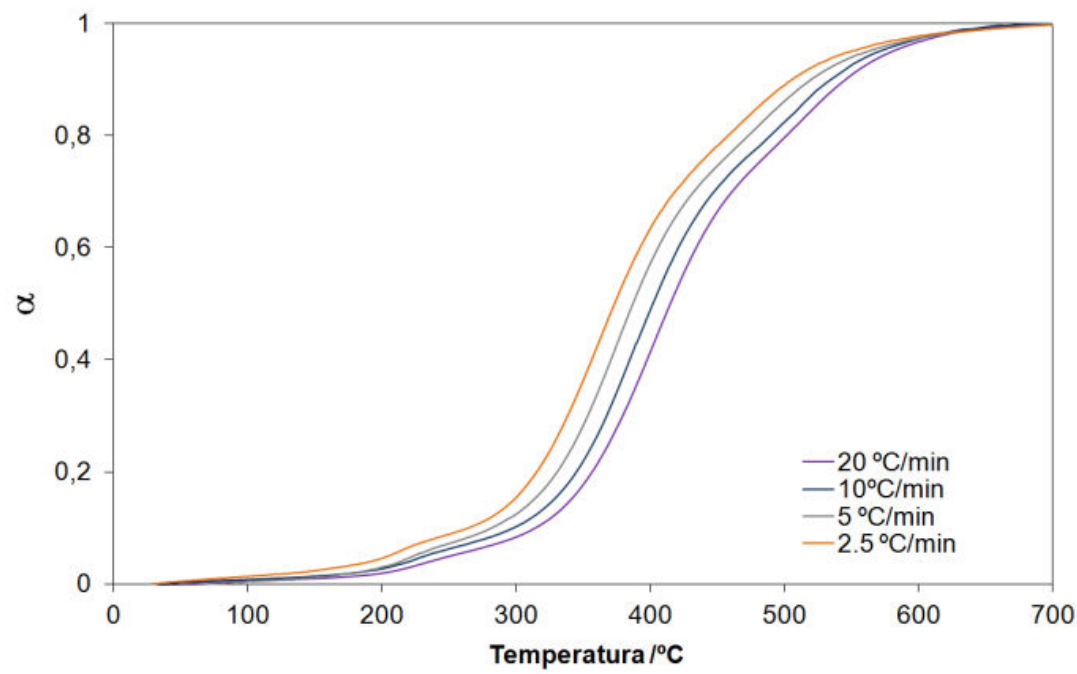

Figura. 6.6 Comparación del grado de conversión a distinta velocidad de degradación $(2,5,5,10$ y $20^{\circ} \mathrm{C} / \mathrm{min}$ ) para $2 \mathrm{~V}: 8 \mathrm{G}$.

De los cálculos realizados siguiendo la metodología descrita anteriormente (que se pueden consultar en un artículo publicado y recogido en el anexo I) se obtienen los parámetros cinéticos que se detallan en la Tabla 6.2.

Tabla 6.2 Parámetros cinéticos del recubrimiento 2V:8G y dopado con 2,5\% y 5\% HAp.

\begin{tabular}{|c|c|c|c|}
\hline Formulación & $\begin{array}{c}\text { Energía activación } \mathrm{E} \\
(\mathrm{KJ} / \mathrm{mol})\end{array}$ & Ln A & modelo \\
\hline $\mathbf{8 V}: \mathbf{2 G}$ & 176,7 & 32,6 & $\mathrm{n}=6$ \\
\hline $\mathbf{2 , 5 \%}$ HAp & 164,2 & 30,1 & $g(\alpha)=\frac{1-(1-\alpha)^{-5}}{-5}$ \\
\hline $\mathbf{5 \%}$ HAp & 207,0 & 37,0 & \\
\hline
\end{tabular}


Aplicando el procedimiento isoconversional se puede predecir el tiempo necesario para alcanzar una determinada pérdida de peso a una temperatura seleccionada. En la Figura. 6.7 se representan las curvas del grado de conversión frente al tiempo de las muestras estudiadas para una temperatura constante de $300^{\circ} \mathrm{C}$ y $400^{\circ} \mathrm{C}$.
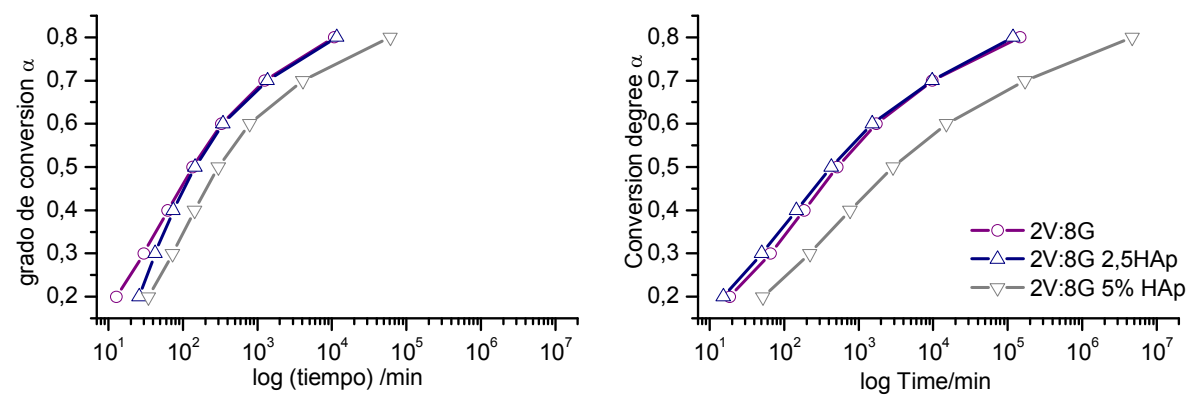

Figura. 6.7 Predicción de la evolución del grado de conversión en el tiempo por degradación a una temperatura constante de $300^{\circ} \mathrm{C}$ (izq.) y $400^{\circ} \mathrm{C}$ (dcha.) para la muestra $2 \mathrm{~V}: 8 \mathrm{G}$ y dopada con $2,5 \%$ y $5 \%$ de HAp.

Se puede realizar un estudio comparativo del proceso de degradación isoterma para la serie completa de muestras. Se puede observar que el comportamiento térmico del material cargado con un 2,5\% HAp apenas se distingue del comportamiento isotermo del $2 \mathrm{~V}: 8 \mathrm{G}$. El proceso de degradación de la muestra 2,5\% HAp comienza más tarde y en los instantes iniciales se aprecia una mayor pendiente, por tanto una mayor velocidad en la degradación. Por otro lado, en el material dopado con un $5 \% \mathrm{HAp}$ el proceso de degradación se produce a tiempos mayores. Si se observan las energías de activación medias (Tabla 6.2) se distingue que el sistema con un $5 \%$ HAp tiene una energía más alta, hecho que respalda esta tendencia.

Por tanto, se puede concluir que el sistema cargado con 2,5\% HAp apenas varía la estabilidad térmica del material respecto al 8V:2G. El material con 5\% HAp produce materiales más estables térmicamente, por tanto con una energía de activación sensiblemente mayor al resto. Esto se puede deber a que la adición de HAp estabiliza la red formada.

Tras la modelización numérica del proceso de degradación se podría optimizar el tratamiento de sinterización (tiempo y temperatura) óptimo si se quisiera obtener una red puramente inorgánica. Por ejemplo, con temperaturas de curado por debajo de 
$200^{\circ} \mathrm{C}$ sólo se obtendrán redes híbridas. Para la obtención de redes inorgánicas es necesario obtener las curvas de degradación isotermas como las mostradas en la Figura. 6.7. Si se aplicara una temperatura de sinterización de $300^{\circ} \mathrm{C}$, el tiempo necesario para la obtención de una red totalmente inorgánica del recubrimiento $2 \mathrm{~V}: 8 \mathrm{G}$ sería de $10^{5}$ minutos y para el recubrimiento dopado con un $5 \%$ de HAp el tiempo necesario sería superior a $10^{6}$ minutos.

\subsection{3 Ángulo de contacto}

Se ha comprobado si la adición de partículas de HAp ha variado el grado de hidrofilia de los recubrimientos. Para ello se ha medido el ángulo de contacto que es una técnica sencilla para caracterizar esta propiedad.

La medida del ángulo de contacto se realizó sobre planchas de acero AISI 316L recubiertas por dip-coating con cada una de las formulaciones, sin HAp 2V:8G y con distintas cantidades de HAp $(2,5 \% \mathrm{HAp}$ y $5 \% \mathrm{HAp})$, a las que se ha aplicado el tratamiento de curado estándar descrito en 3.1.3. Los valores de los ángulos de contacto obtenidos se presentan en la Tabla 6.3.

Tabla 6.3 Valores del ángulo de contacto de agua extrapura sobre el recubrimiento $2 \mathrm{~V}: 8 \mathrm{G}$ y dopado con $2,5 \%$ y $5 \%$ de HAp aplicados sobre acero AISI $316 \mathrm{~L}$.

\begin{tabular}{|c|c|c|c|}
\hline Formulación & $2 V: 8 G$ & $2,5 \% 2 \mathrm{~V}: 8 \mathrm{G}$ & $5 \% 2 V: 8 G$ \\
\hline Valor ángulo / ${ }^{\circ}$ & $87,9 \pm 0,9$ & $87,0 \pm 2,7$ & \\
\hline
\end{tabular}

Comparando los resultados obtenidos para la serie de materiales se puede observar que no hay un cambio del ángulo de contacto apreciable entre las muestras con contenido de HAp y el $2 \mathrm{~V}: 8 \mathrm{G}$, todas las muestras tienen un ángulo alrededor de $85^{\circ}$. Sin embargo, sí se puede apreciar un error de medida más elevado en las muestras con contenido de HAp, debido posiblemente a la irregularidad en la topografía de la superficie por contener éstas partículas de HAp. 


\section{2 Control de la velocidad de degradación y la liberación de fármacos}

Para realizar el control de la velocidad de degradación y la liberación de fármacos del material seleccionado en el Capítulo 5 se ha decidido actuar sobre parámetros de curado (temperatura y tiempo del proceso) que regulan el grado de entrecruzado de la red. El comportamiento del material varía mucho en función de la densidad de la red (con un alto grado de entrecruzamiento o redes poco entrecruzadas). Esto es importante ya que como se ha mencionado anteriormente es conveniente que los recubrimientos desaparezcan con el tiempo para dejar el titanio al descubierto, y se ha detectado que el recubrimiento $2 \mathrm{~V}: 8 \mathrm{G}$ con las condiciones de síntesis y curado estándar no degrada lo suficientemente rápido.

En este apartado se presenta un estudio para determinar el efecto de la temperatura y tiempo de curado en el grado de entrecruzado de la red, además se estudia las condiciones de curado óptimas para obtener distintos tipos de red y cómo estas condiciones afectan a las características del recubrimiento en cuanto a ángulo de contacto, degradación hidrolítica y la influencia de ésta característica en la liberación de agentes terapéuticos.

Por otro lado, se ha realizado un estudio para evaluar la influencia de la cantidad de fármaco introducida en la red sobre las propiedades superficiales del recubrimiento y la cinética de liberación de las mismas.

\subsubsection{Estudio mediante FTIR del efecto de las condiciones (tiempo y} temperatura) de curado del recubrimiento $2 \mathrm{~V}: 8 \mathrm{G}$.

En primer lugar se ha realizado un estudio del proceso de condensación por medio de FTIR para analizar la cinética de curado. Para ello se ha realizado el estudio del proceso de curado con medidas "in situ" con temperatura controlada.

Para la realización de este ensayo se obtuvo el sol del recubrimiento $2 \mathrm{~V}: 8 \mathrm{G}$ y se precalentó el accesorio ATR con control de temperatura y cristal de diamante a la temperatura de curado $140^{\circ} \mathrm{C}$ del equipo FTIR-680PLUS de la marca JASCO. Se dispuso una gota de material sobre el ATR y se registraron espectros a lo largo del tiempo. En la Figura. 6.8 se muestran los espectros registrados a lo largo del tiempo, cada 50 segundos. En la Figura. 6.9 se ha representado la evolución de la intensidad 
relativa de los picos formadores de red inorgánica Si-O-Si $\left(1075\right.$ y $1163 \mathrm{~cm}^{-1}$ ) así como de la evolución de los silanoles Si-OH $\left(850\right.$ y $\left.894 \mathrm{~cm}^{-1}\right)$ a lo largo del tiempo de curado.

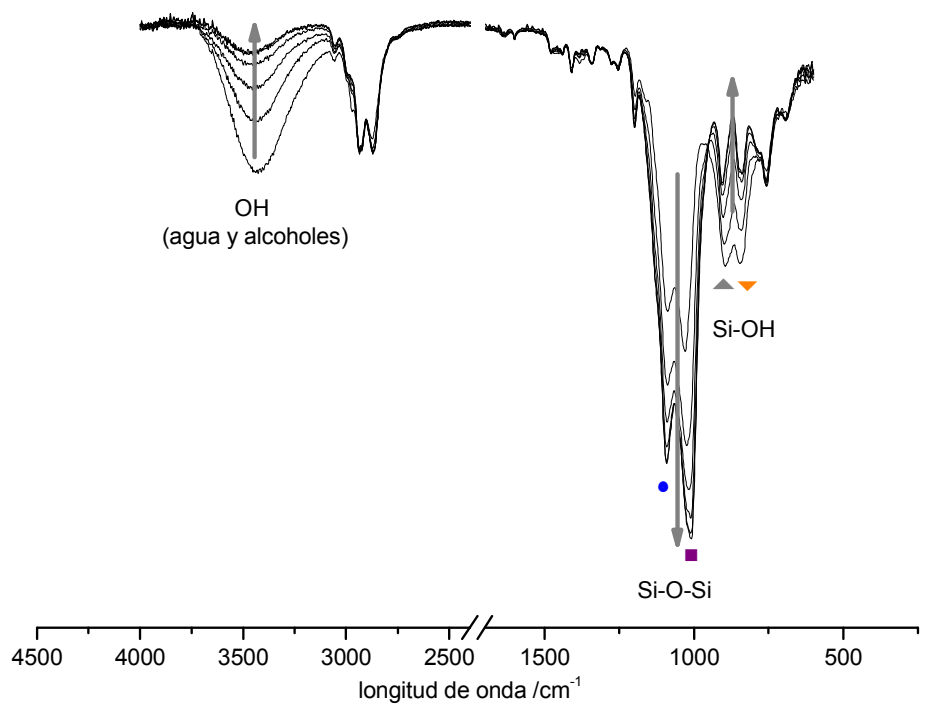

Figura. 6.8 Evolución de los espectros FTIR-ATR medidas "in situ" con el tiempo de curado a temperatura de $140^{\circ} \mathrm{C}$. 


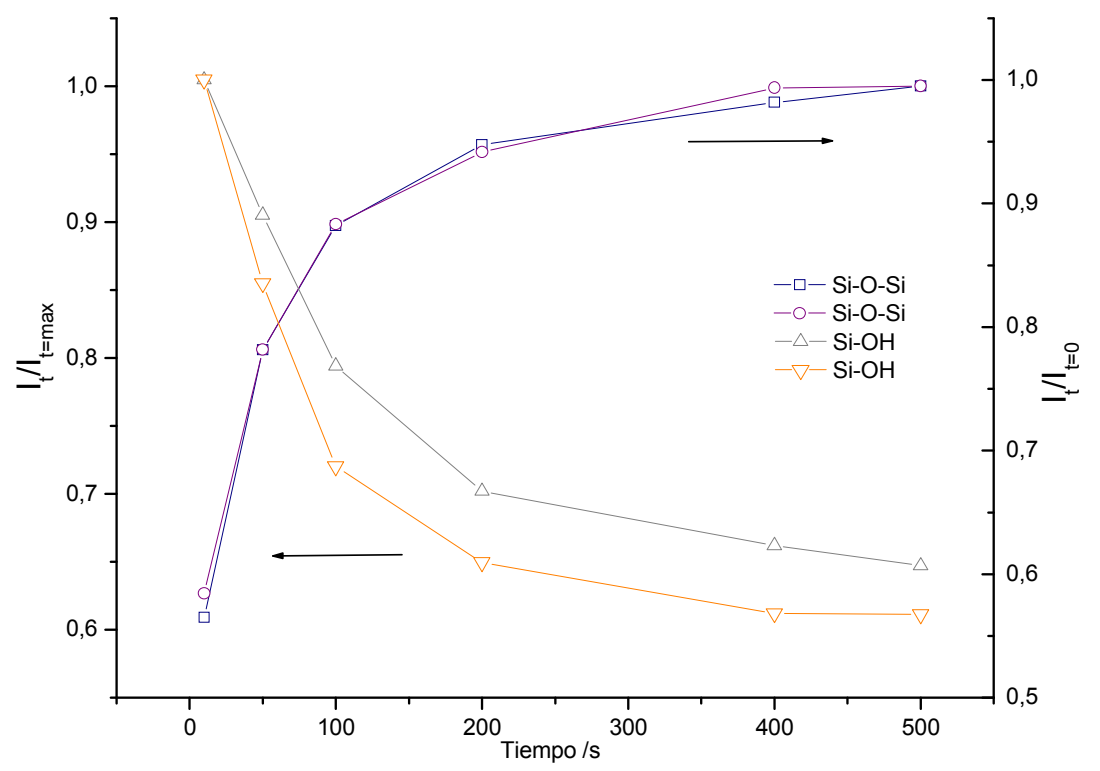

Figura. 6.9 Gráficos de evolución de enlaces formadores de red Si-O-Si $\left(1075\right.$ y $\left.1163 \mathrm{~cm}^{-1}\right)$ y SiOH $\left(850\right.$ y $\left.894 \mathrm{~cm}^{-1}\right)$.

Durante el curado de la red se forman enlaces Si-O-Si por condensación de los grupos $\mathrm{Si}-\mathrm{OH}$ formados durante la hidrólisis. Si se analiza las curvas obtenidas cuando se representa la intensidad relativa de estos picos se puede observar que conforme se forman enlaces Si-O-Si desaparecen los enlaces $\mathrm{Si}-\mathrm{OH}$, hasta que se produce la estabilización en la curva debido probablemente a la culminación del proceso de condensación de los grupos hidroxilo.

Comparando la evolución en la formación de enlaces Si-O-Si entre distintas temperaturas de curado se puede analizar la influencia que tiene ésta en el fenómeno de formación de red. En la gráfica de la Figura. 6.10 queda representada la curva de formación de enlaces Si-O-Si para dos temperaturas de curado concretas, $140^{\circ} \mathrm{C}$ y $120^{\circ} \mathrm{C}$. 


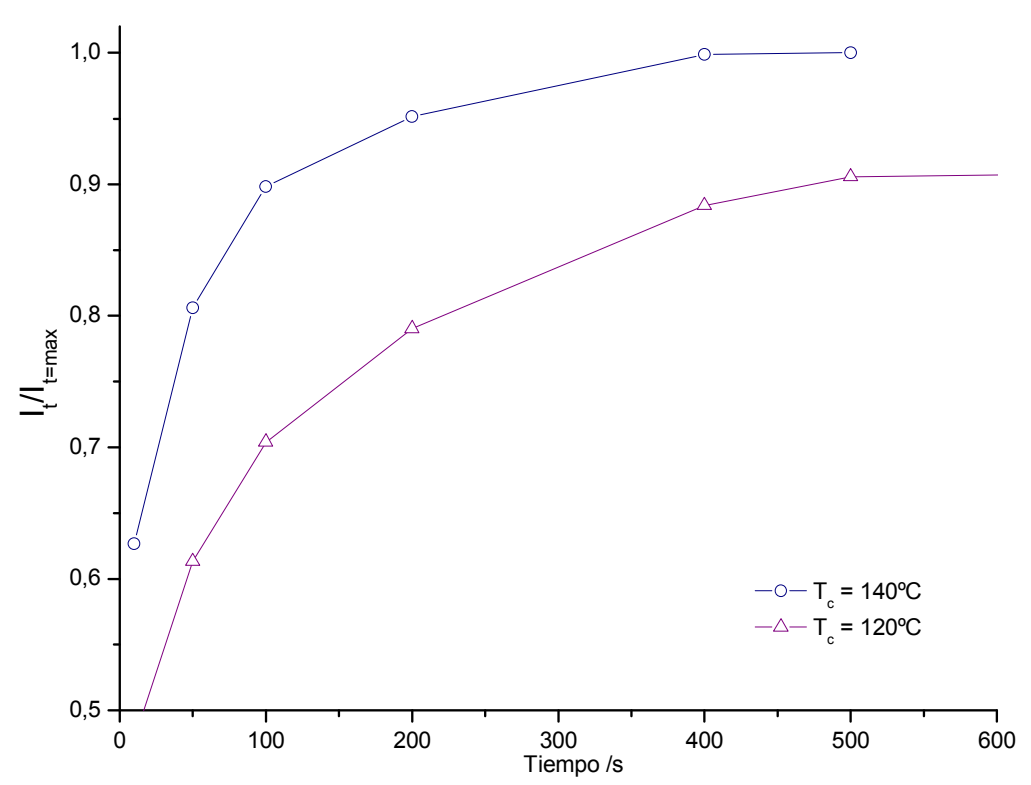

Figura. 6.10 Comparación de la evolución de formación de enlaces Si-O-Si $\left(1075 \mathrm{~cm}^{-1}\right)$ con la temperatura de curado $140^{\circ}$ y $120^{\circ}$ de la muestra $2 \mathrm{~V}: 8 \mathrm{G}$.

Con esta representación se evidencia que, para un mismo tiempo de curado, tratando el material con una menor temperatura $120^{\circ} \mathrm{C}$ el número de enlaces $\mathrm{Si}-\mathrm{O}-\mathrm{Si}$ es menor que cuando se utiliza una alta temperatura $140^{\circ} \mathrm{C}$.

Por tanto, se puede concluir que la cinética de formación de red depende de forma muy significativa de la temperatura, así como del tiempo de curado.

\subsubsection{Caracterización de la formación de red mediante DSC}

La caracterización del grado de entrecruzamiento de la red puede ser realizado de forma sencilla mediante ensayos DSC. En este apartado se ha estudiado la evolución de la temperatura de transición vítrea, $\mathrm{T}_{\mathrm{g}}$, durante la etapa de curado de la red. Se efectuaron medidas sobre materiales tratados a distintos tiempos de curado para una temperatura seleccionada $140^{\circ} \mathrm{C}$.

Para la realización de este ensayo se preparó el sol del recubrimiento $8 \mathrm{~V}: 2 \mathrm{G}$ y se dispuso una cantidad igual en distintos viales. Estos viales se introdujeron un la estufa a la temperatura de ensayo $\left(140^{\circ} \mathrm{C}\right)$ y se fueron extrayendo cada 5 minutos, de forma que se tienen materiales curados a distintos tiempos para una misma temperatura de 
curado. Se prepararon las cápsulas de DSC con muestras obtenidas de cada vial y se realizó un barrido de temperaturas entre $-100^{\circ} \mathrm{C}$ hasta $200^{\circ} \mathrm{C}$ a $10^{\circ} \mathrm{C} / \mathrm{min}$ bajo flujo de nitrógeno.

En la Figura. 6.11 se representa la evolución de $T_{g}$ durante el tiempo de curado para una temperatura de $140^{\circ} \mathrm{C}$. El criterio seguido en los termogramas representados conlleva que los picos hacia arriba corresponden a procesos exotérmicos.

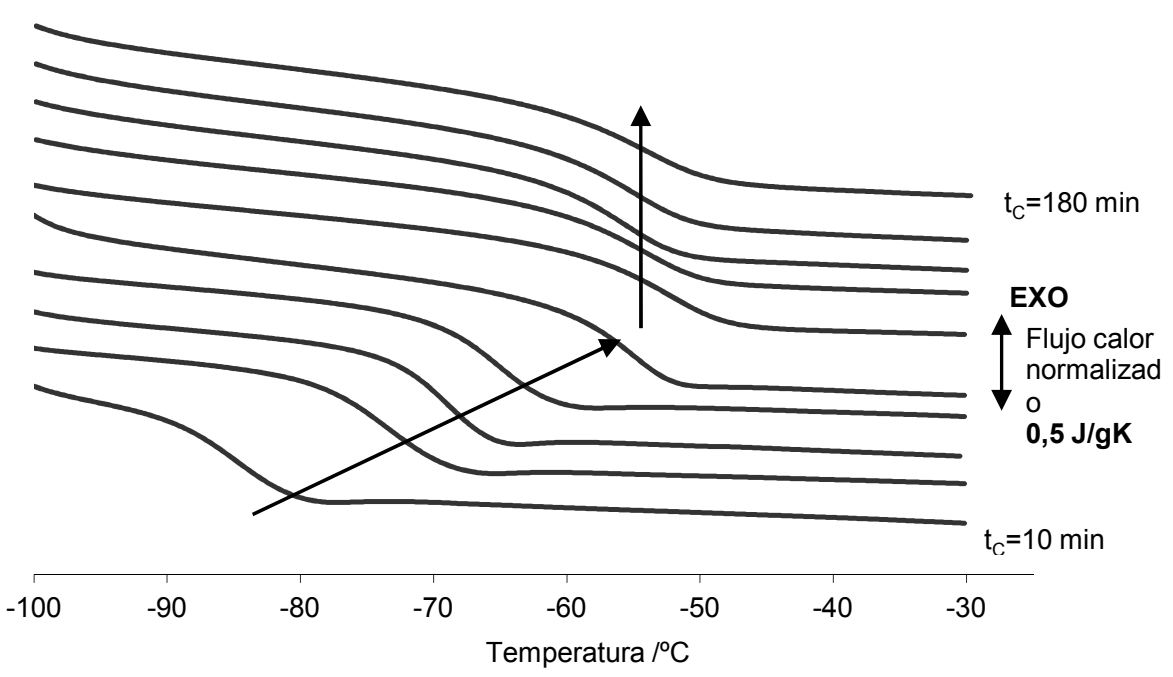

Figura. 6.11 Curvas DSC a distintos tiempos de curado del recubrimiento 2V:8G. Temperatura de curado $140^{\circ} \mathrm{C}$.

La $T_{g}$ evoluciona a lo largo del tiempo de curado desde temperaturas bajas $\left(-85^{\circ} \mathrm{C}\right)$ hasta obtener un valor en el cual permanece estable $\left(-55^{\circ} \mathrm{C}\right)$, tal y como muestra la Figura. 6.12 obtenida a partir de las curvas DSC anteriores. Este hecho se debe a que tal y como se forma la red inorgánica por medio de enlaces Si-O-Si las posibilidades de movimientos conformacionales se reducen $\mathrm{y}$, por tanto, se produce un aumento en la energía necesaria para que se den, en definitiva se produce un aumento en la transición vítrea del material.

En la Figura. 6.12 se representa la evolución de $T_{g}$ con el tiempo de curado para dos temperaturas distintas, $140^{\circ} \mathrm{C}$ y $120^{\circ} \mathrm{C}$ obtenidas a partir de los datos de DSC para la muestra $2 \mathrm{~V}: 8 \mathrm{G}$. 


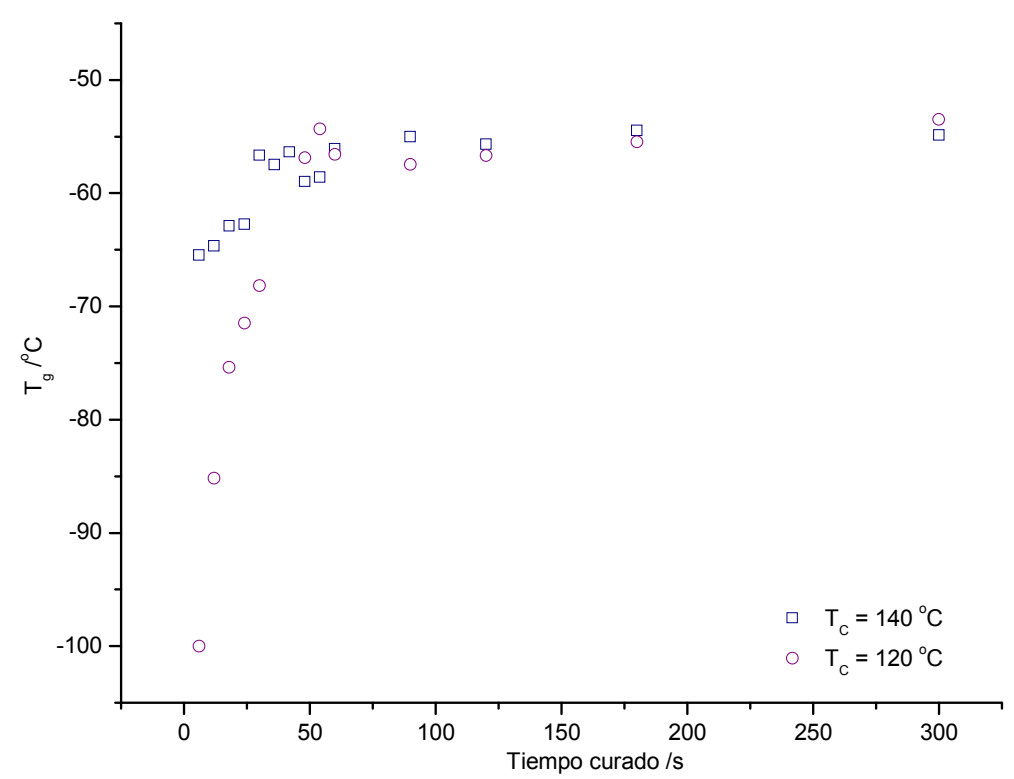

Figura. 6.12 Evolución de $\mathrm{T}_{\mathrm{g}}$ con el tiempo de curado. Comparación para distintas temperaturas de curado $\left(120^{\circ} \mathrm{C}\right.$ y $\left.140^{\circ} \mathrm{C}\right)$ para el recubrimiento $2 \mathrm{~V}: 8 \mathrm{G}$

En esta gráfica se aprecia la evolución de $\mathrm{T}_{\mathrm{g}}$ con el tiempo de curado, por tanto, la cinética de formación de red. Se puede analizar la influencia de la temperatura de curado en la formación de red. Así, para mayores temperaturas de curado la cinética de reacción es más rápida, obteniéndose para un mismo tiempo de curado valores de $T_{g}$ superiores antes de llegar al Plateau (zona de estabilización del valor de $T_{g}$ ). Se puede concluir que la cinética de curado es más rápida cuanto mayor es la temperatura de curado.

A partir de las representaciones de las temperaturas de transición vítrea frente al tiempo de curado (Figura. 6.12), se distinguen dos zonas bien diferenciadas, que se pueden denominar como zona de "curado no severo" (CNS) (a la izquierda del gráfico) y zona de "curado severo" (CS) (a la derecha del gráfico), señaladas en la Figura. 6.13. 


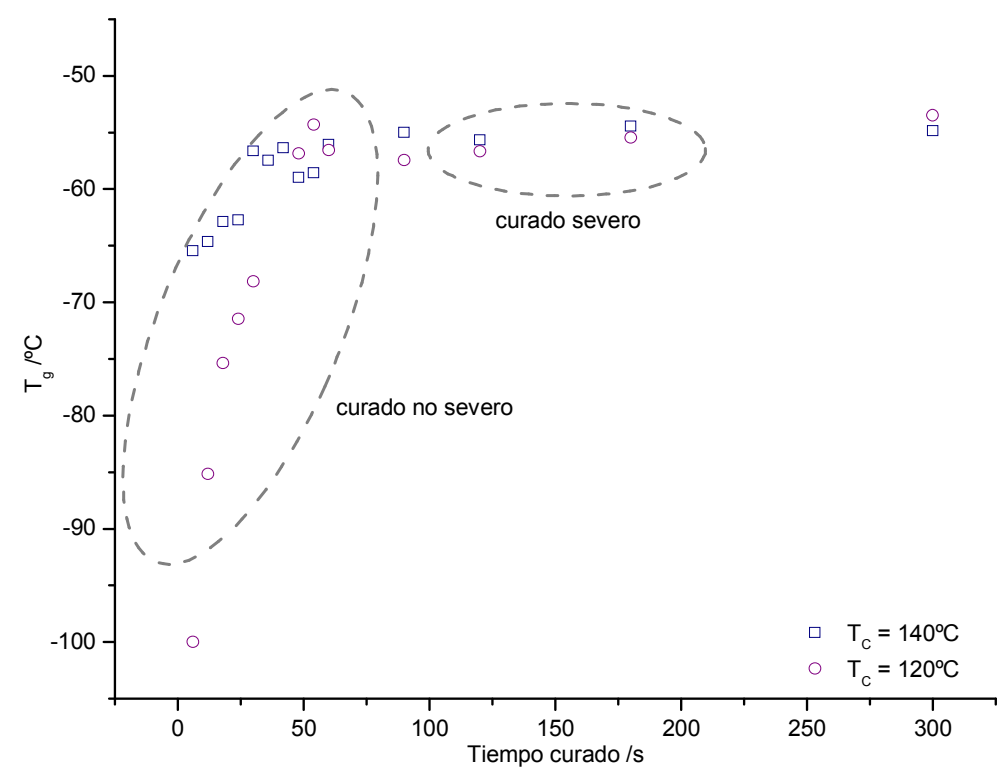

Figura. 6.13 Determinación de los tratamientos de "curado severo" y "curado no severo" en la grafica de evolución de $\mathrm{T}_{\mathrm{g}}$ con el tiempo de curado.

En el caso del tratamiento de "curado no severo" el material formado tiene una red poco entrecruzada, es decir, la densidad de enlaces Si-O-Si no es alta y quedan grupos $\mathrm{Si}-\mathrm{OH}$ sin reaccionar. En esta situación, la $\mathrm{T}_{\mathrm{g}}$ está en su zona de no estabilización (bajos valores de $\mathrm{T}_{\mathrm{g}} \mathrm{y}$ en aumento con el tiempo de curado). Si se selecciona un tratamiento de "curado severo" se obtiene una red fuertemente entrecruzada gracias a la formación de enlaces $\mathrm{Si}-\mathrm{O}-\mathrm{Si}$, donde la $\mathrm{T}_{\mathrm{g}}$ ha alcanzado un valor estable con el tiempo para el sistema.

En función de la red formada (dependiendo de su densidad de entrecruzamiento) se obtendrán recubrimientos en los que se pueda controlar de forma efectiva su velocidad de degradación y de liberación de distintos agentes (un material poco entrecruzado será altamente degradable y con velocidad de liberación elevada como se discutirá en el apartado 4.2.3). Así se puede seleccionar el tratamiento de curado "a medida" en función de las características finales que se quieran obtener. 
Para el recubrimiento objeto de estudio $2 \mathrm{~V}: 8 \mathrm{G}$ se han determinado los intervalos de las temperaturas y tiempos de curado que darán redes con "curado no severo" (CNS) y "curado severo" (CS) y finalmente se han seleccionado las condiciones del curado a realizar que se recogen en la Tabla 6.4.

Tabla 6.4 Determinación de las temperaturas y tiempos de curado para "curado severo" y "curado no severo".

\begin{tabular}{|c|c|c|}
\hline & Tratamiento secado & Tratamiento curado \\
\hline Curado no severo & $50^{\circ} \mathrm{C} / 15 \mathrm{~min}+$ rampa $\mathrm{V}=3^{\circ} \mathrm{C} / \mathrm{min}$ & $140^{\circ} \mathrm{C} / 30 \mathrm{~min}$ \\
\hline Curado severo & hasta $140^{\circ} \mathrm{C}$ (total $\left.30 \mathrm{~min}\right)$ & $140^{\circ} \mathrm{C} / 90 \mathrm{~min}$ \\
\hline
\end{tabular}

\subsection{3 Ángulo de contacto con distintos tratamientos de curado}

Las variaciones en la red formada pueden modificar algunas propiedades de las mismas como su carácter hidrófilo. La medida del ángulo de contacto de los materiales es una manera sencilla de caracterizar esta propiedad de los materiales.

Los materiales aquí estudiados parten de la formulación $2 \mathrm{~V}: 8 \mathrm{G}$ y se han aplicado sobre planchas de acero AISI $316 \mathrm{~L}$ por medio de dip-coating. El tratamiento de curado aplicado se describe en la Tabla 6.4.

Los valores del ángulo de contacto para estos dos materiales con distintas condiciones de curado del recubrimiento $2 \mathrm{~V}: 8 \mathrm{G}$ se recogen en la Tabla 6.5 .

Tabla 6.5 Medida ángulo de contacto de agua extrapura con los materiales TEOS, MTMOS, VTES y GPTMS aplicados por dip-coating a $100 \mathrm{~mm} / \mathrm{min}$ sobre acero AISI 316L.

\begin{tabular}{|c|c|c|}
\hline Nomenclatura & $2 \mathrm{~V}: 8 \mathrm{G}$ curado no severo CNS & 2V:8G curado severo CS \\
\hline Angulo de contacto $/^{\circ}$ & $77,1 \pm 2,0$ & $87,9 \pm 0,9$ \\
\hline
\end{tabular}

Los resultados muestran que el recubrimiento más hidrófilo es el que tiene un tratamiento de "curado no severo", resultado que probablemente se debe a una mayor presencia de grupos - $\mathrm{OH}$ terminales en la superficie del material y a la formación de una red más abierta por no haberse producido una condensación total de la red. Estas conclusiones concuerdan con las obtenidas después de analizar los resultados de los espectros FTIR (apartado 6.2.1) y del estudio calorimétrico con DSC (apartado 6.2.2). 
6.2.4 Degradación hidrolítica con distinto tratamiento de curado

Una de las finalidades más importantes de la variación en el grado de entrecruzado de la red, por medio del cambio en las condiciones de curado es la variación en la cinética de degradación del material. En el apartado 5.2.7 se analizó la cinética de degradación hidrolitica del recubrimiento $2 \mathrm{~V}: 8 \mathrm{G}$ en condiciones de "curado severo" y se detectó que este material tenía una degradación reducida de alrededor de $1,5 \%$ en peso a las 6 semanas de inmersión en PBS. Como se citó anteriormente es aconsejable que los recubrimientos se degraden en tiempos inferiores a 2 meses, ya que se ha detectado que el titanio muestra un buen comportamiento biológico a tiempos mayores. Por medio de la variación de las condiciones de curado se busca aumentar la degradación de este recubrimiento en contacto con medio acuoso.

Para la realización de este ensayo se han obtenido los materiales en película libre y se ha evaluado su degradación por hidrólisis sumergiéndolos en PBS durante un tiempo total de 9 semanas y registrando la pérdida de peso de los mismos. Los materiales se dispusieron dentro de unas "cestas" para permitir la entrada del medio (PBS) y, a su vez, impedir la pérdida de parte del material en caso de rotura. Los resultados de la pérdida de peso en tanto por ciento para el recubrimiento $2 \mathrm{~V}: 8 \mathrm{G}$ con "curado severo" y "curado no severo" se muestran en la Figura. 6.14. 


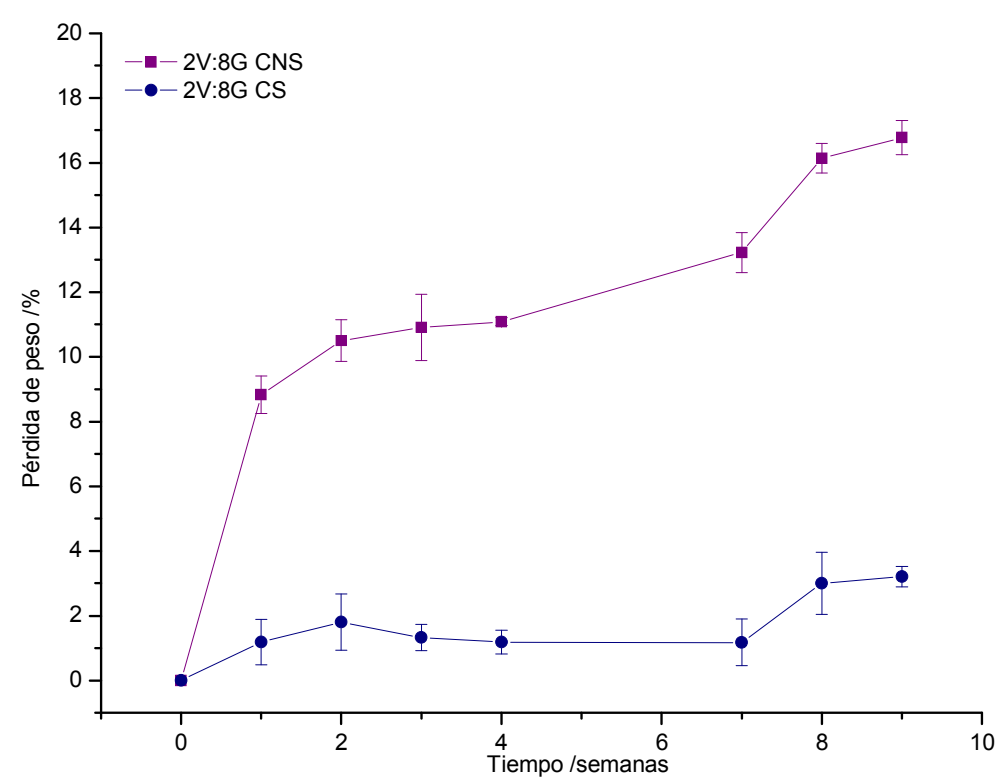

Figura. 6.14 Degradación hidrolítica por pérdida de peso del recubrimiento $2 \mathrm{~V}: 8 \mathrm{G}$ CNS ("curado no severo", $140^{\circ} \mathrm{C} / 90 \mathrm{~min}$ ) y $2 \mathrm{~V}: 8 \mathrm{G} \mathrm{CS}$ ("curado severo" $140^{\circ} \mathrm{C} / 30 \mathrm{~min}$ ) sumergidos en PBS a $37^{\circ} \mathrm{C}$.

El recubrimiento 2V:8G CS ("curado severo") tiene una degradación hidrolítica reducida, tal y como se observó en el apartado correspondiente. Después de una semana de exposición al medio se obtuvo una degradación del 1,18\% en peso que se mantiene constante durante las primeras 7 semanas, a partir de este tiempo se produce un ligero aumento de la degradación obteniéndose un valor final a las 9 semanas de $3,2 \%$ en peso del total de muestra introducida.

El recubrimiento $2 \mathrm{~V}: 8 \mathrm{G}$ CNS ("curado no severo") registra en la primera semana una degradación muy por encima de la obtenida para $2 \mathrm{~V}: 8 \mathrm{G} \mathrm{CS}$, degradándose un $8,83 \%$ en peso del total de la muestra. A partir de la primera semana, la velocidad de degradación se ralentiza y a las 4 semanas se obtiene una pérdida de $11,09 \%$ en peso. A partir de las 7 semanas se aumenta de nuevo la velocidad de degradación, obteniéndose a 9 semanas de exposición una pérdida del 16,78\% en peso del total de muestra introducida.

Suavizando las condiciones de curado (en tiempo y temperatura) se consigue obtener redes con un grado de entrecruzamiento menor (con valores de $T_{g}$ inferiores, apartado 6.2.2) y con un carácter menos hidrófilo que aplicando un tratamiento de 
"curado severo". Se puede concluir que es posible aumentar la velocidad de degradación hidrolítica así como la cantidad de material que se degrada con el tratamiento de curado adecuado.

6.2.5 Estudio de la influencia del grado de entrecruzado en la liberación de agentes terapéuticos

Se ha estudiado el efecto del grado de entrecruzado de la red en la liberación de agentes terapéuticos. Se ha conseguido variar las propiedades de las redes formadas, y por tanto las propiedades del material por medio de cambios en los tratamientos de curado del material. Se obtienen variaciones en el tipo de red formada, con mayor o menor densidad de enlaces siloxano (Si-O-Si), lo que provoca cambios en las propiedades finales del material que pueden ser de interés para la aplicación final como son la hidrofilia del material o su degradación. A la vista de los resultados de estudios anteriores, se parte de la hipótesis de que las redes poco entrecruzadas, con tratamientos de "curado no severo", tengan una liberación mayor a la obtenida en redes con un alto grado de entrecruzamiento.

Los materiales para la realización de este ensayo se obtuvieron en película libre pero no se extrajeron del molde, que en este caso fue de aluminio en vez de teflón, en un intento de simular un caso real. Para la realización del ensayo las muestras se introdujeron en PBS a pH 6,8 manteniendo la muestra en agitación y a una temperatura constante de $37^{\circ} \mathrm{C}$. En la Figura. 6.15 se representan las gráficas de liberación para el material $2 \mathrm{~V}: 8 \mathrm{G}$ dopado con $5 \%$ procaína con distintas condiciones de curado, "curado no severo" y "curado severo". En la Tabla 6.6 se recogen las condiciones de curado de los dos tratamientos de curado aplicados en estas muestras ( $2 \mathrm{~V}: 8 \mathrm{G}$ CNS y $2 \mathrm{~V}: 8 \mathrm{G}$ CS). En la Figura. 6.15 se representa $\mathrm{M}_{\mathrm{t}} / \mathrm{M}_{\infty}$ donde $M_{t}$ es la cantidad de fármaco detectada a un tiempo determinado $t$ y $M_{\infty}$ es la cantidad de fármaco incorporado en el recubrimiento sintetizado ( $y$ es la misma en ambos recubrimientos)

Tabla 6.6 Definición de tratamiento de "curado severo" y no severo para la muestra 2V:8G.

\begin{tabular}{|c|c|c|}
\hline 2V:8G & Tratamiento secado & Tratamiento curado \\
\hline $\begin{array}{c}\text { Curado no severo CNS } \\
\text { Curado severo CS }\end{array}$ & $50^{\circ} \mathrm{C} / 15 \mathrm{~min}+$ rampa $\mathrm{V}=3^{\circ} \mathrm{C} / \mathrm{min}$ & $140^{\circ} \mathrm{C} / 30 \mathrm{~min}$ \\
\hline
\end{tabular}




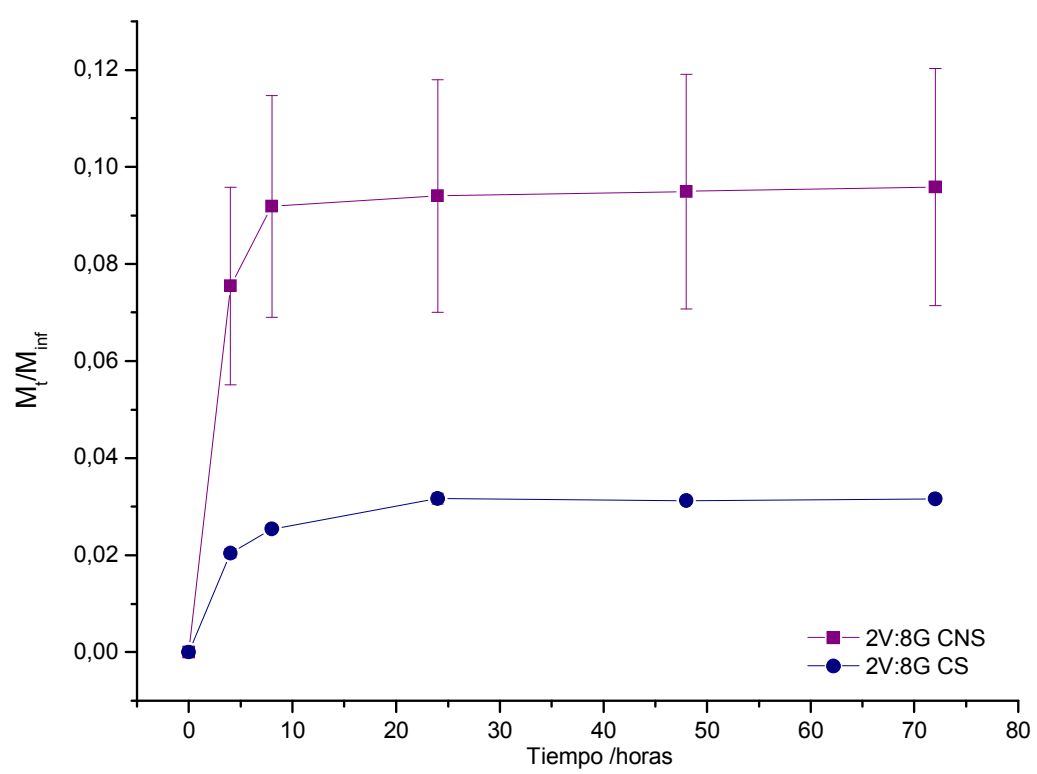

Figura. 6.15 Curvas de liberación de agente terapéutico de los recubrimientos 2V:8G CNS (curado no severo, $140^{\circ} \mathrm{C} / 90 \mathrm{~min}$ ) y $2 \mathrm{~V}: 8 \mathrm{G} \mathrm{CS}$ (curado severo, $140^{\circ} \mathrm{C} / 30 \mathrm{~min}$ ) dopados con un $5 \%$ procaína.

El recubrimiento 2V:8G CNS ("curado no severo") registra toda la liberación en las primeras 8 horas de ensayo, a las 4 horas libera un 7,5\% del fármaco incorporado y a las 8 horas se detecta que ha liberado un 9,2\%. Para tiempos superiores no se detecta mayores liberaciones. El recubrimiento 2V:8G CS (ya estudiado en el apartado 5.2.8) tiene una cinética de liberación más lenta, y se liberan cantidades crecientes de procaína hasta 24 horas de ensayo. A las 4 horas ha liberado un $2 \%$, a 8 horas un $2,5 \%$. A las 72 horas de ensayo ha liberado un $3,2 \%$ del total introducido.

En las gráfica se observan diferencias en las cinéticas de liberación respecto al tratamiento de curado utilizado. Cuanto más curado está el recubrimiento obtenido vía sol-gel se obtiene una pendiente de la curva de liberación menor, por tanto la liberación del fármaco es más lenta. Ambos sistemas muestran una liberación muy rápida inicialmente (casi instantánea) debido principalmente a que la procaína es un fármaco soluble en agua y, por tanto, aquella que se encuentra en la superficie se libera rápidamente al medio.

Se han obtenido distintas cinéticas de degradación por medio del control del curado de la red. El sistema en estado "curado severo" forma una red más densa que 
impide la liberación de los agentes que tiene en su interior, produciéndose la liberación por difusión. Además, la procaína, al ser un fármaco muy soluble en agua, presenta dificultades para su dosificación controlada, ya que muestra una liberación casi instantánea en contacto con el agua. Por otro lado, es importante recordar que se produce un enlace químico entre la procaína y el grupo epoxi del recubrimiento lo que conlleva que parte de la procaína incorporada no se pueda liberar al medio y, por tanto, los niveles liberados no superen el $10 \%$ de procaína incorporada.

6.2.1 Estudio de la influencia en la cantidad de fármaco incorporado en la liberación

Se han incorporado distintas cantidades de fármaco $(5 \%, 7,5 \%$ y $10 \%$ en peso respecto a los silanos), con el fin de evaluar si la variación en el contenido del mismo provoca cambios en la cinética de liberación de éstos.

Nuevamente, los materiales para la realización de este ensayo se obtuvieron en película libre pero no se extrajeron del molde, que en este caso fue de aluminio en vez de teflón, en un intento de simular un caso real. Para la realización del ensayo las muestras se introdujeron en PBS a pH 6.8 manteniendo la muestra en agitación y a una temperatura constante de $37^{\circ} \mathrm{C}$. En la Figura. 6.16 se muestran las curvas de liberación hasta 3 días de ensayo de la serie de materiales dopadas con distintas cantidades de procaína $(5 \%, 7,5 \%, 10 \%$ en peso respecto a silanos) en el recubrimiento $2 \mathrm{~V}: 8 \mathrm{G}$ al que se ha aplicado el tratamiento de "curado severo" $\left(140^{\circ} \mathrm{C} / 90 \mathrm{~min}\right)$. En la Figura. 6.16 (a) se representa $M_{t}$ que es el valor absoluto de procaína detectada en el medio, medido en miligramos. En la Figura. 6.16 (b) se representa $M_{t} / M_{\infty}$ donde $M_{t}$ es la cantidad de fármaco detectada a un tiempo t y $M_{\infty}$ es la cantidad de fármaco que tiene cada recubrimiento sintetizado (en este caso varía entre las muestras). 

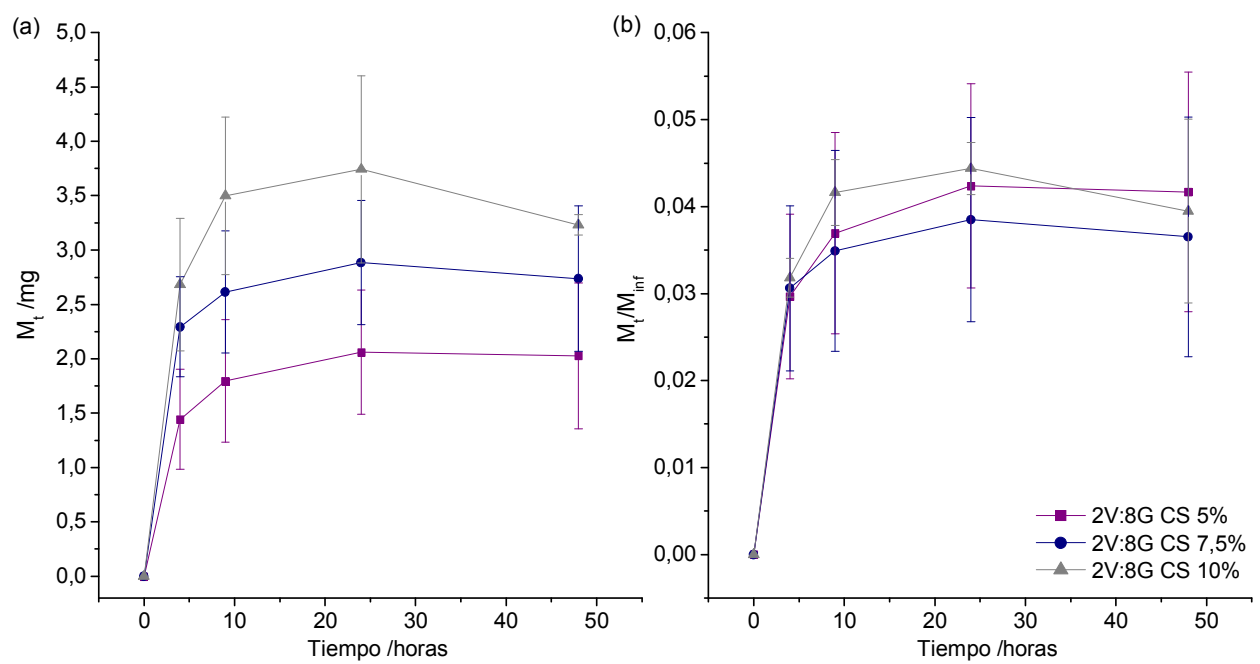

Figura. 6.16 Curvas de liberación de agente terapéutico (a) en valor absoluto y (b) valor relativo a la cantidad total de procaína incorporada, del recubrimiento $2 \mathrm{~V}: 8 \mathrm{G}$ CS dopado con un $5 \%, 7,5 \%$ y $10 \%$ de procaína.

Si se analiza las curvas de liberación obtenidas en valores absolutos de procaína liberada al medio $\left(\mathrm{M}_{\mathrm{t}}\right)$ (Figura. $6.16(\mathrm{a})$ ) se observa diferencias entre los materiales. En el estudio del recubrimiento con un $10 \%$ de procaína se detecta a 4 horas un valor de $2,68 \mathrm{mg}$ y este valor aumenta hasta las 24 horas de ensayo, para dar un valor de $3,74 \mathrm{mg}$ de procaína en el medio quedando aproximadamente estable. El recubrimiento con un $7,5 \%$ es de $2,29 \mathrm{mg}$ a las 4 horas, a 24 horas es de $2,88 \mathrm{mg}$ momento a patir del cual queda estable. El recubrimiento con $5 \%$ registra los valores más bajos de procaína detectada en el medio, dando un valor a las 4 horas de 1,44 $\mathrm{mg}$, a 24 horas de $2,06 \mathrm{mg}$ y a 48 horas de $2,02 \mathrm{mg}$. Se observa que a mayor contenido en procaína incorporada en el recubrimiento, mayor es la cantidad liberada al medio.

Sin embargo, si se representa el valor relativo de procaína liberada al medio respecto a la procaína añadida $\left(\mathrm{M}_{\mathrm{t}} / \mathrm{M}_{\infty}\right)$ se observa que los valores obtenidos para cada tiempo no muestran diferencias significativas entre ellos, encontrándose todos dentro de la barra de error de la medida, es decir, la cinética de liberación es constante con la variación en el contenido de procaína. 
De este estudio se concluye que la cantidad de fármaco introducido no produce cambios en la cinética de liberación del agente incorporado, aunque se detecta una mayor cantidad de procaína cuanto mayor es el contenido de ésta en el recubrimiento.

\section{3 Discusión del diseño a medida del recubrimiento $2 \mathrm{~V}: 8 \mathrm{G}$}

El recubrimiento $2 \mathrm{~V}: 8 \mathrm{G}$ tiene unas buenas propiedades para la aplicación final, sin embargo, se puede mejorar aplicando variaciones que permitan modular la bioactividad o la degradación y liberación de fármacos. En este capítulo se han presentado los resultados obtenidos en estos intentos de mejora.

Por un lado, se han introducido partículas bioactivas en un intento de mejorar la osteointegración del implante, se ha optimizado el procedimiento de síntesis y se ha conseguido introducir hasta un $5 \%$ de $\mathrm{HAp}$ en peso respecto a silanos. La incorporación de cargas inorgánicas varía la estabilidad del material, por lo que se ha realizado un estudio en profundidad sobre la estabilidad térmica del mismo. Se ha detectado que la energía de activación del proceso de degradación térmica es mayor cuanto mayor es el contenido en HAp. Se han evaluado otras propiedades del recubrimiento, como el ángulo de contacto, y se ha detectado que no varía el carácter hidrófobo del material.

Por otro lado, se han modulado la velocidad de degradación y de liberación de fármacos por medio del control del proceso de curado. Para ello, se ha desarrollado un estudio que permite variar el grado de entrecruzamiento de la red de forma controlada y repetitiva, de forma que se obtienen redes con distintas densidad de enlaces Si-O-Si.

En primer lugar se ha analizado el efecto del tiempo y temperatura de curado en la formación de la red polisiloxánica. Se ha detectado que la formación de red de silicio está directamente relacionada con el tiempo y temperatura de curado. Se ha obtenido que para un mismo tiempo de curado, aplicando dos temperaturas de curado distintas, se obtiene una mayor cantidad de enlaces siloxano Si-O-Si (detectados por FTIR) cuanto mayor es la temperatura de curado. Además gracias al estudio de la evolución de $T_{g}$ con el tiempo de curado se obtiene que para mayores temperaturas 
de curado la cinética de reacción es más rápida. Por otro lado durante el curado de la red se produce una evolución de $T_{g}$, creciente con el tiempo de curado, hasta que se alcanza un valor donde permanece constante. Gracias a este ensayo se ha podido determinar el tratamiento de "curado severo" (CS), donde $T_{g}$ es estable, ya no se producen más enlaces $\mathrm{Si}-\mathrm{O}-\mathrm{Si}$ para el recubrimiento $2 \mathrm{~V}: 8 \mathrm{G}$ y el tratamiento de "curado no severo" (CNS), donde $\mathrm{T}_{\mathrm{g}}$ se encuentra en evolución quedando grupos Si$\mathrm{OH}$ por reaccionar.

Se han definido los tiempos y temperaturas de curado para la obtención de los dos tipos de red, por un lado redes densas, con un alto grado de entrecruzamiento y, por otro lado, redes poco entrecruzadas, con pocos enlaces formados. Posteriormente, se han evaluado el ángulo de contacto, la degradación hidrolítica y la liberación de agentes desde estos dos tipos de redes.

Se ha podido concluir que el recubrimiento $2 \mathrm{~V}: 8 \mathrm{G}$ con tratamiento de "curado no severo" tiene menores ángulos de contacto ( $10^{\circ}$ menos) que aquel con tratamiento de "curado severo". Se ha conseguido aumentar la degradación de los mismos mediante la aplicación de un "curado no severo", consiguiendo degradar un 14\% más para este tipo de red. Por otro lado, se ha conseguido aumentar la liberación del fármaco introducido en un $6,4 \%$ en comparación a la liberación desde el recubrimiento con tratamiento de "curado severo".

En un intento de mejorar la liberación de fármacos desde el recubrimiento, se optó por cargar con una mayor cantidad de fármaco el recubrimiento. La cantidad de fármaco liberada al entorno es mayor cuanto mayor es la cantidad de fármaco introducido en el recubrimiento, sin embargo, no se producen cambios en la cinética de liberación de la procaína. 

Capítulo 7 Conclusiones 

De la investigación realizada en el desarrollo de esta Tesis Doctoral se pueden extraer las siguientes conclusiones:

1. Se han sintetizado recubrimientos sol-gel aplicados sobre superficies metálicas de forma homogénea y reproducible a partir de los precursores de silicio VTES, MTMOS y GPTMS utilizándolos de manera individual y como distintas mezclas (VTES:TEOS y VTES:GPTMS).

2. El comportamiento físico-químico de los recubrimientos varía en función de la composición química. Los recubrimientos obtenidos a partir de mezclas VTES:TEOS están formados por una red con mayor densidad de enlaces $\mathrm{Si}-\mathrm{O}-\mathrm{Si}$, por lo tanto, mayor rigidez respecto del recubrimiento obtenidos a partir de VTES solo. Los recubrimientos obtenidos a partir de mezclas VTES:GPTMS están formados por una red más abierta, con un marcado carácter orgánico y un comportamiento más dúctil respecto del recubrimiento obtenidos a partir de VTES solo .

3. La degradación de los recubrimientos se ha modulado por medio de la composición y del grado de curado de la red. La adición de TEOS en la red de VTES provoca un incremento en la hidrofilia y en la velocidad de degradación. La incorporación de GPTMS en la red de VTES aumenta la estabilidad del recubrimiento en contacto con medio líquido produciéndose una degradación menor. El recubrimiento GPTMS tiene una tasa de degradación alta por el marcado carácter hidrófilo de éste.

4. Se ha introducido satisfactoriamente un fármaco modelo (procaína) en las redes sintetizadas. La liberación del agente se ha modulado por medio de la composición y del grado de curado de la red. Se puede concluir que redes con contenido en TEOS muestran una liberación rápida, tanto más, cuanto mayor es el contenido en TEOS. Además, el grupo epoxi presente en la cadena orgánica el precursor GPTMS reacciona con el grupo amina del fármaco lo que impide la liberación desde la redes con contenido en GPTMS. 
5. Las redes con poco grado de entrecruzamiento, obtenidas con tratamientos de "curado no severo", son hidrofílicas y tienen una tasa de liberación mayor que aquellas con redes con alto grado de entrecruzamiento.

6. El recubrimiento obtenido a partir de VTES y MTMOS proporciona una buena protección al entorno celular en cuanto a posible salida de iones procedentes de procesos corrosivos del implante.

7. La incorporación de TEOS o GPTMS en la red de VTES empeora la protección frente a fenómenos corrosivos del implante.

8. Los recubrimientos obtenidos a partir de MTMOS y VTES no presentan citotoxicidad. El recubrimiento basado en GPTMS es potencialmente citotóxico. La proliferación de osteoblastos sobre los recubrimientos MTMOS y VTES se ha mejorado respecto a la obtenida sobre titanio sin recubrimiento.

9. La introducción de TEOS o GPTMS en la red de VTES mejora la proliferación de células madre mesenquimales respecto a VTES.

10. Los recubrimientos VTES:GPTMS tienen una buena osteoinducción, ya que se ha detectado una buena secreción de matriz extracelular mineralizada cuando se induce la diferenciación a osteoblastos.

Como conclusión final de esta Tesis Doctoral cabe resaltar que se han sintetizado nuevos recubrimientos híbridos tipo sol-gel diseñados "a medida", para la mejora de la osteointegración de implantes dentales metálicos. De todos ellos, el material que ha ofrecido un mejor comportamiento ha sido el obtenido a partir de VTES:GPTMS con una relación molar 2:8. 
Glosarios 



\section{ABREVIATURAS}

$\triangle \mathrm{Cp} \quad$ Incremento del calor específico

AMSCs Células madre mesenquimales del tejido adiposo humano

ATR

Accesorio de reflexión atenuada del FTIR

BPO

Benzoil peróxido

CNS

Curado no severo

CS

Curado severo

DSC

Calorimetría diferencial de barrido

EIS

Espectroscopia de impedancia electroquímica

FTIR

Espectroscopia de infrarrojos por transformada de Fourier

GPTMS

Glicidoxipropil-trimetoxisilano

HAp

Hidroxiapatita

MSCs

Células madre mesenquimales

MTMOS

Metil-trimetoxisilano

MTT

Ensayos colorimétricos

PBS

Buffer fosfato salino

$\operatorname{Pr}$

Procaína

RMN

Resonancia magnética nuclear

SBF

Fluido humano simulado

SEM

Microscopía electrónica de barrido

TEOS

Tetraetil- ortosilicato

$\mathrm{Tg}$

Temperatura de transición vítrea

TGA

Análisis termogravimétrico

TMA

Análisis termo-mecánico

TMOS

Tetrametil- ortosilicato

UV

Ultravioleta

VTES

Vinil-trietoxisilano 



\section{FIGURAS}

Figura. 1.1 Composición y estructura de hueso maduro[4] .................................................30

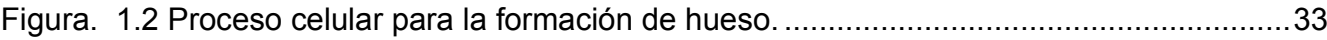

Figura. 1.3 Esquema de regeneración ósea tras fractura [10]..........................................34

Figura. 1.4 Cascada de reacciones que se dan el cuerpo humano cuando se introduce un

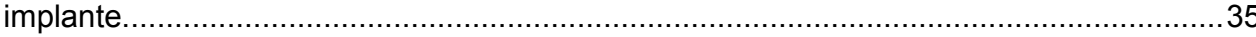

Figura. 1.5 Esquema de fijación de implante dental y orientación de las cargas [19]...............39

Figura. 1.6 Ejemplo de silanización para el anclaje de RGD en la superficie del titanio[32] ....43

Figura. 1.7 Esquema influencia del pH en la formación de red .......................................50

Figura. 1.8 Esquema de obtención de recubrimientos híbridos orgánico-inorgánico sol-gel. ...52

Figura. 1.9 Representación esquemática de la formación de enlace covalente entre el sustrato metálico y el film sol-gel antes y después de la densificación producido durante el curado.

Figura. 1.10 Esquema formación de red sol-gel sobre metal (a) inmediatamente después de la aplicación y (b) después del tratamiento de curado (adaptada de [58])............................54

Figura. 1.11 Esquema deposición por inmersión o dip-coating............................................55

Figura. 1.12 Esquema deposición por giro o spin-coating. ..............................................56

Figura. 2.1 Esquema de la metodología desarrollada para la obtención de los objetivos y su correspondencia con los capítulos de la presente Tesis Doctoral......

Figura. 3.1 Diagrama del plan de trabajo seguido en la presente Tesis Doctoral para la selección de un recubrimiento óptimo.

Figura. 3.2 Esquema de la estructura molecular de los precursores de silicio (a) TEOS (b)

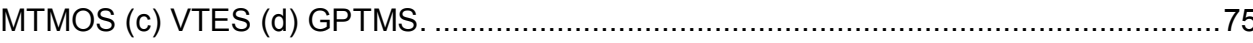

Figura. 3.3 Esquema de la estructura molecular de la procaína. ........................................76

Figura. 3.4 Esquema implante Phoenix-3. (1) rosca interior, (2) hexágono externo, (3) plataforma, (4) rosca exterior, (5) fresadas autoroscantes..........................................76

Figura. 3.5 Esquema de síntesis de sol-gel. ................................................................. 78

Figura. 3.6 Esquema del método de obtención de las distintos tipos de materiales. ...............79

Figura. 3.7 Esquema de método de recubrimiento de superficies mediante la técnica "Dip-

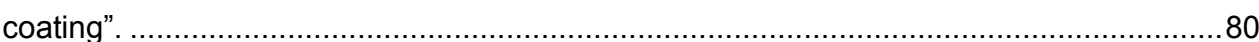

Figura. 3.8 Variaciones de la impedancia con la frecuencia. Diagrama de Nyquist.................89

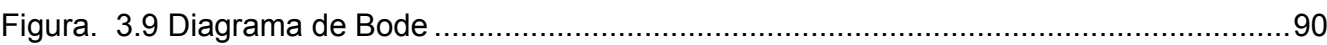

Figura. 3.10 Diagrama de Bode (izquierda) y diagrama de Nyquist (derecha) de una resistencia de $10^{4} \Omega$. 
Figura. 3.11 Diagrama de Bode (izquierda) y diagrama de Nyquist (derecha) de una capacidad de $1 \mu \mathrm{F}$. 92

Figura. 3.12 Diagrama de Bode (izquierda) y diagrama de Nyquist (derecha) de un circuito RC

en paralelo. 92

Figura. 3.13 Modelo del circuito equivalente simplificado propuesto por Randles.................. 93

Figura. 3.14 Modelo del circuito equivalente general para metales pintados.......................... 94

Figura. 3.15 Modelo de circuito equivalente para un sistema dominado por el proceso de transferencia de carga. .95

Figura. 3.16 Celda electroquímica de tres electrodos. Electrodo de referencia $(\mathrm{Ag} / \mathrm{AgCl})$, contraelectrodo (hoja grafito) y electrodo de trabajo (sustrato metálico). ....................... 97

Figura. 3.17 Esquema de medida del ángulo de contacto entre un líquido y un material.........98

Figura. 4.1 (a) Ejemplo de plancha recubierta con el recubrimiento VTES mediante la técnica dip-coating. (b) reflejo tipo espejo sobre la superficie del recubrimiento VTES. 108

Figura. 4.2 Micrografías obtenidas con SEM de los recubrimientos VTES, MTMOS y GPTMS aplicados sobre acero $316 \mathrm{~L}$ (primera fila a 50X aumentos, segunda fila a 200X aumentos). 109

Figura. 4.3 Ejemplo de los recubrimientos en película libre obtenidos a partir de los precusores VTES y GPTMS. 109

Figura. 4.4 Nomenclatura seguida en RMN para el estudio de los precursores GPTMS, VTES y MTMOS.

Figura. 4.5 Nomenclatura seguida en RMN para el estudio del precursor TEOS................. 112

Figura. 4.6 Espectro ${ }^{29}$ Si-RMN liquido de TEOS .......................................................... 112

Figura. 4.7 Espectro ${ }^{29} \mathrm{Si}-\mathrm{RMN}$ liquido de MTMOS .......................................................... 113

Figura. 4.8 Espectro ${ }^{29}$ Si-RMN liquido de VTES .......................................................... 114

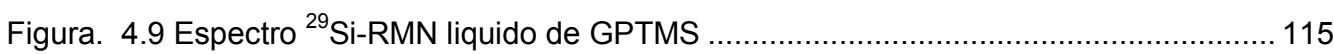

Figura. 4.10 Espectro RMN de ${ }^{29} \mathrm{Si}$ de TEOS, MTMOS, VTES y GPTMS............................ 118

Figura. 4.11 Espectros infrarrojos (región 4000-500 $\mathrm{cm}^{-1}$ ) de los materiales basado en: (a)

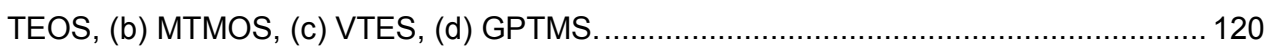

Figura. 4.12 Apertura por hidrólisis de anillo epoxi en GPTMS. ....................................... 123

Figura. 4.13 Curvas DSC de los materiales MTMOS, VTES y GPTMS. Velocidad de calentamiento $10^{\circ} \mathrm{C}$ con un flujo de $\mathrm{N}_{2}$ de $30 \mathrm{ml} / \mathrm{min}$.

Figura. 4.14 Curvas TGA y derivada de la pérdida de peso de los materiales TEOS, MTMOS, VTES y GPTMS, Velocidad de calentamiento $10^{\circ} \mathrm{C} / \mathrm{min}$ en atmosfera $\mathrm{N}_{2}$. 125

Figura. 4.15 Diagrama de Nyquist de los recubrimientos MTMOS, VTES y GPTMS aplicados sobre acero AISI 316-L a tiempo cero, en una disolución de $\mathrm{NaCl}$ al 3,5\% en peso. 
Figura. 4.16 Diagrama de Bode de los recubrimientos MTMOS, VTES y GPTMS aplicados sobre acero AISI 316-L a tiempo cero, en una disolución de $\mathrm{NaCl}$ al 3,5\% en peso. 129

Figura. 4.17 Evolución de los diagramas de Nyquist obtenidos para el recubrimiento MTMOS durante 24 horas de exposición a una disolución $\mathrm{NaCl}$ al 3,5\% en peso.

Figura. 4.18 Evolución de los diagramas de Nyquist obtenidos para el recubrimiento VTES durante 24 horas de exposición a una disolución $\mathrm{NaCl}$ al 3,5\% en peso.

Figura. 4.19 Evolución de los diagramas de Nyquist obtenidos para el recubrimiento GPTMS durante 24 horas de exposición a una disolución $\mathrm{NaCl}$ al 3,5\% en peso.

Figura. 4.20 Circuito equivalente de (izq.) con constantes de tiempo y (dcha.) contres constantes de tiempo usado en la modelización de los datos electroquímicos [116]

Figura. 4.21 Diagramas de Bode experimentales y simulados para: (a) el recubrimiento MTMOS y (b) el recubrimiento GPTMS, ambos a Oh de exposición al electrolito

Figura. 4.22 Comparación de la evolución del valor de (a) resistencia al poro y (b) capacidad del recubrimiento con el tiempo de exposición a la disolución $3,5 \% \mathrm{NaCl}$ de los recubrimientos MTMOS, VTES y GPTMS.

Figura. 4.23 Comparación de la evolución del valor de (a) resistencia a la polarización y (b) capacidad de la doble capa con el tiempo de exposición a la disolución 3,5\% $\mathrm{NaCl}$ de los recubrimientos MTMOS, VTES y GPTMS.

Figura. 4.24 Degradación hidrolítica por pérdida de peso de los recubrimientos MTMOS, VTES y GPTMS sumergidos en PBS a $37^{\circ} \mathrm{C}$.

Figura. 4.25 Curvas de liberación de agente terapéutico de los recubrimientos MTMOS, VTES y GPTMS dopados con un $5 \%$ procaína.

Figura. 4.26 Reacción de enlace del grupo epoxi del precursor GPTMS y grupo amina del fármaco procaína.

Figura. 4.27. Curva de viabilidad celular de las células L929 en contacto con los extractos del material de referencia Titanio puro grado 4 y los recubrimientos TEOS, MTMOS, VTES y GPTMS. Viabilidad celular en \% de DO de las muestras frente al DO control. 145

Figura. 4.28. Curva de proliferación de células L929 sobre el material de referencia Titanio puro grado 4 y los recubrimientos TEOS, MTMOS, VTES y GPTMS. Absorbancia medida a $550 \mathrm{~nm}$.

Figura. 4.29 Curva de proliferación de osteoblastos humanos sobre el material de referencia Titanio puro grado 4 y el control negativo del cultivo (medio para osteoblastos). Absorbancia medida a 550 $\mathrm{nm}$.

Figura. 4.30. Curva de proliferación de osteoblastos humanos sobre el material de referencia Titanio puro grado 4 y los recubrimientos TEOS, MTMOS, VTES y GPTMS. Absorbancia medida a 550nm. 
Figura. 5.1 (Izq.) Ejemplo de plancha recubierta con el recubrimiento 7V:3T mediante la técnica dip-coating. (Dcha.) reflejo tipo espejo sobre la superficie del recubrimiento $7 \mathrm{~V}: 3 \mathrm{~T}$.

Figura. 5.2 Micrografías obtenidas por SEM de a los recubrimientos 9V:1T, 8V:2T, 7V:3T aplicados sobre acero $316 \mathrm{~L}$. En la primera fila a 50X aumentos y en la segunda a $200 \mathrm{X}$ aumentos.

Figura. 5.3 Ejemplo de los recubrimientos en película libre obtenidos a partir de VTES con distintas cantidades de TEOS, 7V:3T.

Figura. 5.4 Espectro de ${ }^{29}$ Si-RMN líquidos de 7VTES:3TEOS .......................................... 160

Figura. 5.5. Espectros infrarrojos (región $4000-500 \mathrm{~cm}^{-1}$ ) de la serie de materiales VTESTEOS: (a) VTES, (b) $9 \mathrm{~V}: 1 \mathrm{~T}$, (c) $8 \mathrm{~V}: 2 \mathrm{~T}$, (d) $7 \mathrm{~V}: 3 \mathrm{~T}$. 165

Figura. 5.6 Curvas DSC (a) VTES, (b) $9 \mathrm{v}: 1 \mathrm{~T}$, (c) $8 \mathrm{~V}: 2 \mathrm{~T}$, (d) $7 \mathrm{~V}: 3 \mathrm{~T}$. Velocidad de calentamiento $10^{\circ} \mathrm{C}$ con un flujo de $\mathrm{N}_{2}$ de $30 \mathrm{ml} / \mathrm{min}$.

Figura. 5.7 Curvas TGA y la derivada de la pérdida de peso de las muestras VTES, 9V:1T, $8 \mathrm{~V}: 2 \mathrm{~T}$ y $7 \mathrm{~V}: 3 \mathrm{~T}$. Velocidad de calentamiento $10^{\circ} \mathrm{C} / \mathrm{min}$ bajo atmosfera de $\mathrm{N}_{2}$. 168

Figura. 5.8 (Izq.) Curvas tensión deformación a compresión de los recubrimientos VTES, $9 \mathrm{~V}: 1 \mathrm{~T}, 8 \mathrm{~V}: 2 \mathrm{~T}, 7 \mathrm{~V}: 3 \mathrm{~T}$. Velocidad de carga $50 \mathrm{mN} / \mathrm{min}$ hasta una carga máxima de 1400 $\mathrm{mN}$. (Dcha.) Ampliación de la primera zona elástica.

Figura. 5.9 Evolución con el contenido de TEOS de las tensiones para obtener un 0.005 y un 0.04 de deformación.

Figura. 5.10 Diagrama de Nyquist de los recubrimientos VTES, 9V:1T, 8V:2T y 7V:3T aplicados sobre acero AISI 316L al comienzo del ensayo EIS (0 horas) en una disolución acuosa $3,5 \% \mathrm{NaCl}$.

Figura. 5.11 Diagrama de Bode de los recubrimientos VTES, 9V:1T, 8V:2T y 7V:3T aplicados sobre acero AISI 316 L al comienzo del ensayo EIS (0 horas) en disolución acuosa 3,5\% $\mathrm{NaCl}$

Figura. 5.12 Evolución de los diagramas de Nyquist obtenidos para el recubrimiento VTES durante 24 horas de exposición a una disolución acuosa de $\mathrm{NaCl}$ al 3,5\% en peso....... 179

Figura. 5.13 Evolución de los diagramas de Nyquist obtenidos para el recubrimiento 9V:1T durante 24 horas de exposición a una disolución acuosa de $\mathrm{NaCl}$ al 3,5\% en peso....... 180

Figura. 5.14 Evolución de los diagramas de Nyquist obtenidos para el recubrimiento 8V:2T durante 24 horas de exposición a una disolución acuosa de $\mathrm{NaCl}$ al 3,5\% en peso....... 180

Figura. 5.15 Evolución de los diagramas de Nyquist obtenidos para el recubrimiento 7V:3T durante 24 horas de exposición a una disolución $\mathrm{NaCl}$ al 3,5\% en peso.

Figura. 5.16 Diagramas de Bode experimentales y simulados para el recubrimiento $7 \mathrm{~V}: 3 \mathrm{~T}$ a $0 \mathrm{~h}$ de exposición al electrolito. 
Figura. 5.17 Comparación de la evolución del valor de (a) resistencia al poro y (b) capacidad del recubrimiento con el tiempo de exposición a la disolución acuosa 3,5\% $\mathrm{NaCl}$ de los recubrimientos VTES, $9 \mathrm{~V}: 1 \mathrm{~T}, 8 \mathrm{~V}: 2 \mathrm{~T}$ y $7 \mathrm{~V}: 3 \mathrm{~T}$.

Figura. 5.18 Comparación de la evolución del valor de (a) resistencia a la polarización y (b) capacidad de la doble capa con el tiempo de exposición a la disolución acuosa $3,5 \% \mathrm{NaCl}$ de los recubrimientos VTES, 9V:1T, 8V:2T y $7 \mathrm{~V}: 3 \mathrm{~T}$

Figura. 5.19 Degradación hidrolítica por pérdida de peso del recubrimiento VTES y VTES con un $10 \%$ TEOS (9V:1T), $20 \%$ TEOS (8V:2T) y $30 \%$ TEOS (7V:3T) sumergidos en PBS a $37^{\circ} \mathrm{C}$.

Figura. 5.20 Curvas de liberación de agente terapéutico de los recubrimientos hasta un 30\% de TEOS (VTES, 9V:1T, 8V:2T, 7V:3T) dopados con un 5\% procaína

Figura. 5.21 Curva de proliferación de células mesenquimales del tejido adiposo humano AMSCs sobre el material de referencia vidrio y los recubrimientos VTES, 8V:2G, 5V:5G, 2V:8G y GPTMS. Absorbancia medida a 550 $\mathrm{nm}$.

Figura. 5.22 Cuantificación de los depósitos de calcio formados por las AMSCs en medio de diferenciación osteogénico a los 7 y 14 días de cultivo sobre los materiales VTES, 9V:1T, $8 \mathrm{~V}: 2 \mathrm{~T}$ y $7 \mathrm{~V}: 3 \mathrm{~T}$ normalizados frente al control vidrio.

Figura. 5.23 (Izq.) Ejemplo de plancha recubierta con el recubrimiento 5V:5G mediante la técnica dip-coating. (Dcha.) reflejo tipo espejo sobre la superficie del recubrimiento 5V:5G.

Figura. 5.24 Micrografías obtenidas con SEM de a los recubrimientos 8V:2G, 5V:5G, 2V:8G aplicados sobre acero $316 \mathrm{~L}$, en la primera fila a $50 \mathrm{X}$ aumentos y en la segunda a $200 \mathrm{X}$ aumentos.

Figura. 5.25 Ejemplo de recubrimiento en película libre obtenidos a partir de VTES y GPTMS, $5 \mathrm{~V}: 5 \mathrm{G}$ 200

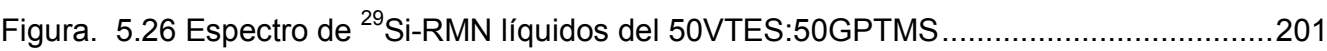

Figura. 5.27 Espectro ${ }^{29} \mathrm{Si}-\mathrm{RMN}$ de sólidos del 5VTES:5GPTMS ......................................204

Figura. 5.28 Espectros FTIR de los materiales (a) VTES, (b) 8V:2G, (c) 5V:5G, (d) 2V:8G y (e) GPTMS al $5 \%$ en $\mathrm{KBr}$. 206

Figura. 5.29 Curvas DSC de los recubrimientos (a) VTES, (b) 8V:2G, (c) 5V:5G, (d) 2V:8G, (e) GPTMS. Velocidad de calentamiento $10^{\circ} \mathrm{C} / \mathrm{min}$ con un flujo de $\mathrm{N}_{2}$ de $30 \mathrm{ml} / \mathrm{min}$. 209

Figura. 5.30 Curva TGA y la derivada de la pérdida de peso de VTES, 8V:2G, 5V:5G, 2V:8G, GPTMS. Velocidad de degradación $10^{\circ} \mathrm{C} / \mathrm{min}$ bajo atmosfera de $\mathrm{N}_{2}$.

Figura. 5.31 Curvas tensión deformación a compresión de los recubrimientos VTES, 8V:2G, $5 \mathrm{~V}: 5 \mathrm{G}, 2 \mathrm{~V}: 8 \mathrm{G}$ y GPTMS. Velocidad de carga $50 \mathrm{mN} / \mathrm{min}$ hasta una carga máxima de 1400 $\mathrm{mN}$. Ampliación de la primera zona de menor carga. 
Figura. 5.32 Evolución con el contenido de GPTMS de las deformaciones registradas para una tensión de 0.003MPa y 0.04MPa. 217

Figura. 5.33 (Izq.) Diagrama Nyquist de las muestras VTES, 8V:2G, 5V:5G, 2V:8G y GPTMS al comienzo del ensayo EIS (0 horas) en una disolución acuosa 3,5\% NaCl. (Dcha.) detalles del mismo 221

Figura. 5.34 Diagrama de Bode de las muestras VTES, 8V:2G, 5V:5G, 2V:8G y GPTMS al comienzo del ensayo EIS (0 horas) en una disolución acuosa $3,5 \% \mathrm{NaCl}$.

Figura. 5.35 Evolución de los diagramas de Bode obtenidos para el recubrimiento 8V:2G durante 24 horas de exposición a una disolución acuosa $\mathrm{NaCl}$ al 3,5\% en peso...... 223

Figura. 5.36 Evolución de los diagramas de Bode obtenidos para el recubrimiento 5V:5G durante 24 horas de exposición a una disolución acuosa $\mathrm{NaCl}$ al 3,5\% en peso.

Figura. 5.37 Evolución de los diagramas de Bode obtenidos para el recubrimiento 2V:8G durante 24 horas de exposición a una disolución acuosa $\mathrm{NaCl}$ al 3,5\% en peso.

Figura. 5.38 Diagramas de Bode experimentales y simulados para el recubrimiento $8 \mathrm{~V}: 2 \mathrm{G}$ a $0 \mathrm{~h}$ de exposición al electrolito.

Figura. 5.39 Comparación de la evolución del valor de (a) resistencia al poro y (b) capacidad del recubrimiento con el tiempo de exposición a la disolución acuosa 3,5\% $\mathrm{NaCl}$ de los recubrimientos VTES,8V:2G, 5V:5G, 2V:8G y GPTMS

Figura. 5.40 Comparación de la evolución del valor de (a) resistencia a la polarización y (b) capacidad de la doble capa con el tiempo de exposición a la disolución acuosa $3,5 \% \mathrm{NaCl}$ de los recubrimientos VTES,8V:2G, 5V:5G, 2V:8G y GPTMS

Figura. 5.41 Degradación hidrolítica por pérdida de peso del recubrimiento VTES,8V:2G, $5 \mathrm{~V}: 5 \mathrm{G}, 2 \mathrm{~V}: 8 \mathrm{G}$ y GPTMS sumergidos en PBS a $37^{\circ} \mathrm{C}$

Figura. 5.42 Curvas de liberación de agente terapéutico de los recubrimientos VTES,8V:2G, $5 \mathrm{~V}: 5 \mathrm{G}, 2 \mathrm{~V}: 8 \mathrm{G}$ y GPTMS dopados con un 5\% procaína 235

Figura. 5.43 Curva de proliferación de células mesenquimales del tejido adiposo humano AMSCs sobre el material de referencia vidrio y los recubrimientos VTES, 8V:2G, 5V:5G, 2V:8G y GPTMS. Tiempos de estudio 0, 1, 7 y 14 días. Absorbancia medida a 550nm. 238

Figura. 5.44 Cuantificación de los depósitos de calcio formados por las AMSCs en medio de diferenciación osteogénico a los 7 y 14 días de cultivo sobre los materiales VTES, 8V:2G, 5V:5G: $2 \mathrm{~V}: 8 \mathrm{G}$ normalizados frente al control vidrio. 240

Figura. 6.1 (a) Ejemplo de plancha recubierta con el recubrimiento $2 \mathrm{~V}: 8 \mathrm{G}$ dopado con un $5 \%$ de HAp mediante la técnica dip-coating. (b) reflejo tipo espejo sobre la superficie de este mismo recubrimiento.

Figura. 6.2 Micrografías obtenidas con SEM mediante detector de (a) electrones secundarios 100X aumentos y (b) electrones retrodispersados $1000 \mathrm{X}$ aumentos. 251 
Figura. 6.3 Fotografía film libre recubrimiento $2 \mathrm{~V}: 8 \mathrm{G}$ y $2 \mathrm{v}: 8 \mathrm{G}$ con $5 \%$ en peso de HAp.

Figura. 6.4 Micrografía de la sección transversal del recubrimiento $2 \mathrm{~V}: 8 \mathrm{G}$ aplicado sobre metal por medio de dip-coating.

Figura. 6.5 Curvas TGA y la derivada de la pérdida de peso de las muestras $2 \mathrm{~V}: 8 \mathrm{G}$ con un $0 \% \mathrm{HAp}, 2,5 \% \mathrm{HAp}$ y $5 \% \mathrm{HAp}$. Velocidad de calentamiento $10^{\circ} \mathrm{C} / \mathrm{min}$ bajo atmosfera de $\mathrm{N}_{2}$.

Figura. 6.6 Comparación del grado de conversión a distinta velocidad de degradación (2,5, 5, 10 y $20^{\circ} \mathrm{C} / \mathrm{min}$ ) para $2 \mathrm{~V}: 8 \mathrm{G}$.

Figura. 6.7 Predicción de la evolución del grado de conversión en el tiempo por degradación a una temperatura constante de $300^{\circ} \mathrm{C}$ (izq.) y $400^{\circ} \mathrm{C}$ (dcha.) para la muestra $2 \mathrm{~V}: 8 \mathrm{G}$ y dopada con $2,5 \%$ y $5 \%$ de HAp.

Figura. 6.8 Evolución de los espectros FTIR-ATR medidas "in situ" con el tiempo de curado a temperatura de $140^{\circ} \mathrm{C}$.

Figura. 6.9 Gráficos de evolución de enlaces formadores de red Si-O-Si $\left(1075\right.$ y $\left.1163 \mathrm{~cm}^{-1}\right)$ y $\mathrm{Si}-\mathrm{OH}\left(850\right.$ y $\left.894 \mathrm{~cm}^{-1}\right)$.

Figura. 6.10 Comparación de la evolución de formación de enlaces Si-O-Si (1075 y $\left.1163 \mathrm{~cm}^{-1}\right)$ con la temperatura de curado $140^{\circ}$ y $120^{\circ}$ de la muestra $2 \mathrm{~V}: 8 \mathrm{G}$.

Figura. 6.11 Curvas DSC a distintos tiempos de curado del recubrimiento $2 \mathrm{~V}: 8 \mathrm{G}$. Temperatura de curado $140^{\circ} \mathrm{C}$.

Figura. 6.12 Evolución de $T_{g}$ con el tiempo de curado. Comparación para distintas temperaturas de curado $\left(120^{\circ} \mathrm{C}\right.$ y $\left.140^{\circ} \mathrm{C}\right)$ para el recubrimiento $2 \mathrm{~V}: 8 \mathrm{G}$ 265

Figura. 6.13 Determinación de los tratamientos de "curado severo" y "curado no severo" en la grafica de evolución de $T_{g}$ con el tiempo de curado

Figura. 6.14 Degradación hidrolítica por pérdida de peso del recubrimiento $2 \mathrm{~V}: 8 \mathrm{G} \mathrm{CNS}$ ("curado no severo", $140^{\circ} \mathrm{C} / 90 \mathrm{~min}$ ) y $2 \mathrm{~V}: 8 \mathrm{G} \mathrm{CS}$ ("curado severo" $140^{\circ} \mathrm{C} / 30 \mathrm{~min}$ ) sumergidos en PBS a $37^{\circ} \mathrm{C}$

Figura. 6.15 Curvas de liberación de agente terapéutico de los recubrimientos $2 \mathrm{~V}: 8 \mathrm{G}$ CNS (curado no severo, $140^{\circ} \mathrm{C} / 90 \mathrm{~min}$ ) y $2 \mathrm{~V}: 8 \mathrm{G} \mathrm{CS}$ (curado severo, $140^{\circ} \mathrm{C} / 30 \mathrm{~min}$ ) dopados con un $5 \%$ procaína.

Figura. 6.16 Curvas de liberación de agente terapéutico (a) en valor absoluto y (b) valor relativo a la cantidad total de procaína incorporada, del recubrimiento $2 \mathrm{~V}: 8 \mathrm{G}$ CS dopado con un $5 \%, 7,5 \%$ y $10 \%$ de procaína. 



\section{TABLAS}

Tabla 1.1 Composición química de los distintos grados de Titanio puro.

Tabla 3.1 Relaciones volumétricas alcohol:precursor cuando se utiliza un solo precursor para la síntesis del nuevo material (tabla superior) y cuando se parte de distintas mezclas molares de dos precursores distintos (tabla inferior). La relación precursor:agua de hidrólisis siempre es la estequiométrica.

Tabla 3.2 Volumen de material incorporado al molde de teflón para la obtención de films libres homogéneos de cada formulación

Tabla 3.3 Cuadro de muestras y tratamientos de curado estándar...................................... 82

Tabla 4.1 Valores del desplazamiento químico de las señales de ${ }^{29}$ Si-RMN líquidos............. 115

Tabla 4.2 Tratamiento de curado aplicado para cada recubrimiento. ....................................117

Tabla 4.3 Valores del desplazamiento químico de las señales de ${ }^{29} \mathrm{Si}$-RMN sólidos..............119

Tabla 4.4 Tratamiento de curado aplicado para cada recubrimiento. .....................................120

Tabla 4.5 Tabla asignación bandas representativas de cada formulación.............................121

Tabla 4.6 Medida ángulo de contacto de agua extrapura con los materiales TEOS, MTMOS, VTES y GPTMS aplicados por dip-coating a $100 \mathrm{~mm} / \mathrm{min}$ sobre acero AISI $316 \mathrm{~L}$.

Tabla 4.7 Elementos pasivos del circuito equivalente y su interpretación física dentro de los procesos del sistema recubrimiento/metal.

Tabla 5.1 Valores del desplazamiento químico de las señales de ${ }^{29} \mathrm{Si}-\mathrm{RMN}$ líquidos

7VTES:3TEOS, asociadas a cada precursor

Tabla 5.3 Valores del desplazamiento químico de las señales de ${ }^{29} \mathrm{Si}-\mathrm{RMN}$ sólidos VTESTEOS

Tabla 5.4 Tratamiento de curado optimizado para la serie VTES:TEOS 164

Tabla 5.5 Parámetros obtenidos de las curvas de tensión deformación de los materiales VTES, $9 \mathrm{~V}: 1 \mathrm{~T}, 8 \mathrm{~V}: 2 \mathrm{~T}, 7 \mathrm{~V}: 3 \mathrm{~T}$

Tabla 5.6 Medida de ángulo de contacto de agua extrapura sobre la superficie de los materiales VTES, 9V:1T, 8V:2T y 7V:3T aplicado por dip-coating a $100 \mathrm{~mm} / \mathrm{min}$ sobre acero AISI $316 \mathrm{~L}$

Tabla 5.7 Valores del desplazamiento químico de las señales de ${ }^{29} \mathrm{Si}-\mathrm{RMN}$ líquidos 5VTES:5GPTMS

Tabla 5.8 Tratamiento de curado aplicados para la serie VTES:GPTMS. 203

Tabla 5.9 Valores del desplazamiento químico de las señales de ${ }^{29} \mathrm{Si}-\mathrm{RMN}$ sólidos VTESGPTMS. 204

Tabla 5.10 Tratamiento de curado optimizado para la serie VTES:GPTMS 205 
Tabla 5.11 Datos calorímetros extraídos de las curvas DSC de los materiales VTES, 8V:

$8 \mathrm{~V}: 2 \mathrm{G}, 5 \mathrm{~V}: 5 \mathrm{G}, 2 \mathrm{~V}: 8 \mathrm{G}$, GPTMS

Tabla 5.12 Datos termogravimétricos extraídos de las curvas TGA de los materiales VTES, 8V:

$8 \mathrm{~V}: 2 \mathrm{G}, 5 \mathrm{~V}: 5 \mathrm{G}, 2 \mathrm{~V}: 8 \mathrm{G}$, GPTMS.

Tabla 5.13 Módulo elástico de la primera y segunda zona elástica calculado a partir de las curvas tensión deformación.

Tabla 5.14 Medida ángulo de contacto de agua extrapura sobre recubrimientos VTES, 8V:2G, $5 \mathrm{~V}: 5 \mathrm{G}$ y $2 \mathrm{~V}: 8 \mathrm{G}$ aplicados sobre acero AISI $316 \mathrm{~L}$

Tabla 6.1 Datos TGA para 2V:8G, $2.5 \%$ y $5 \%$ Hap. 255

Tabla 6.2 Parámetros cinéticos del recubrimiento $2 \mathrm{~V}: 8 \mathrm{G}$ y dopado con $2,5 \%$ y $5 \%$ HAp. ..... 257

Tabla 6.3 Valores del ángulo de contacto de agua extrapura sobre el recubrimiento $2 \mathrm{~V}: 8 \mathrm{G}$ y dopado con $2,5 \%$ y $5 \%$ de HAp aplicados sobre acero AISI $316 \mathrm{~L}$.

Tabla 6.4 Determinación de las temperaturas y tiempos de curado para "curado severo" y "curado no severo". 267

Tabla 6.5 Medida ángulo de contacto de agua extrapura con los materiales TEOS, MTMOS, VTES y GPTMS aplicados por dip-coating a $100 \mathrm{~mm} / \mathrm{min}$ sobre acero AISI $316 \mathrm{~L}$.

Tabla 6.6 Definición de tratamiento de "curado severo" y no severo para la muestra 2V:8G. . 270 
Referencias 

1. Monteiro, F.J. and J. San Román, Biomateriales: Introducción y desarrollo histórico, in Biomateriales, R. Sastre, S. de Aza, and J. San Román, Editors. 2004, Faenza Editrice iberica. p. 17-26.

2. West, J.L., Wound Healing, in Frontiers in Tissue Engineering, C.W. Patrick, A.G. Mikos, and L.V. McIntire, Editors. 1998, Pergamon: Houston. p. 138-151.

3. Olszta, M.J., et al., Bone structure and formation: A new perspective. Materials Science \& Engineering R-Reports, 2007. 58(3-5): p. 77-116.

4. http://sabanet.unisabana.edu.co/.

5. Ramzi S. Cotran, M., M. Vinay Kumar, and M. Tucker Collins, Patología estructural y funcional. $6^{\mathrm{a}}$ ed, ed. M. Graw-Hill. 2006.

6. Anselme, K., Osteoblast adhesion on biomaterials. Biomaterials, 2000. 21(7): p. 667-681.

7. Bruder, S.P. and A.I. Caplan, Bone regeneration through cellular engineering, in Principles of tissue Engineering. Second Edition., R.P. Lanza, R. Langer, and J. Vacanti, Editors. 2000, Academic Press. p. 683-696.

8. Kraus, K.H. and C. Kirker-Head, Mesenchymal stem cells and bone regeneration. Veterinary Surgery, 2006. 35(3): p. 232-242.

9. Hollinger, J. and M.E.K. Wong, The integrated processes of hard tissue regeneration with special emphasis on fracture healing. Oral Surgery, Oral Medicine, Oral Pathology, Oral Radiology, and Endodontology, 1996. 82(6): p. 594-606.

10. Carano, R.A.D. and E.H. Filvaroff, Angiogenesis and bone repair. Drug Discovery Today, 2003. 8(21): p. 980-989.

11. Anderson, J.M., Biological responses to materials. Annual Review of Materials Research, 2001. 31: p. 81-110.

12. Sastre, R., S. Aza de, and J. San Román, Biomateriales. 2004 Faenza Editrice iberica. p.517-518

13. Vallet-Regi, M. and L. Munuera, Biomateriales: Aqui y ahora, ed. Dykinson. 2000: Dykinson.

14. Anderson, J.M., et al., Host reactions to biomaterials and their evaluation, in Biomaterials Science, B.D. Ratner, Editor. 1996, Elsevier Academic Press: San Diego. p. 165-173.

15. Balamurugan, A., et al., Corrosion aspects of metallic implants - An overview. Materials and Corrosion-Werkstoffe Und Korrosion, 2008. 59(11): p. 855-869.

16. Gil, F.J., et al., Biometales, in Biomateriales, R. Sastre, S. de Aza, and J. San Román, Editors. 2004, faenza Editrice iberica. p. 17-26.

17. Implates, S.E.d., Libro Blanco de la Implantología Dental en España. 2008, Madrid: Sociedad Española de Implantes.

18. Spiekermann, H., Atlas de implantología, ed. S. Manson. 1995.p. 11-56 
19. Gottlow, J., The implant design and biological response, in Osseointegration and dental implants, A. Jokstad, Editor. 2008, Wiley-Blackwell: Toronto. p. 225-234.

20. Sahin, S., M.C. Cehreli, and E. Yalcin, The influence of functional forces on the biomechanics of implant-supported prostheses - a review. Journal of Dentistry, 2002. 30(7-8): p. 271-282.

21. Le Guéhennec, L., et al., Surface treatments of titanium dental implants for rapid osseointegration. Dental Materials, 2007. 23(7): p. 844-854.

22. Ong, J.L., D.L.D.L. Carnes, and K. Bessho, Evaluation of titanium plasmasprayed and plasma-sprayed hydroxyapatite implants in vivo. Biomaterials, 2004. 25(19): p. 4601-4606.

23. Aparicio, C., et al., Corrosion behaviour of commercially pure titanium shot blasted with different materials and sizes of shot particles for dental implant applications. Biomaterials, 2003. 24(2): p. 263-273.

24. Zinger, O., et al., Time-dependent morphology and adhesion of osteoblastic cells on titanium model surfaces featuring scale-resolved topography. Biomaterials, 2004. 25(14): p. 2695-2711.

25. Cho, S.-A. and K.-T. Park, The removal torque of titanium screw inserted in rabbit tibia treated by dual acid etching. Biomaterials, 2003. 24(20): p. 36113617

26. Sul, Y.-T., et al., Qualitative and quantitative observations of bone tissue reactions to anodised implants. Biomaterials, 2002. 23(8): p. 1809-1817.

27. Sivakumar, B., S. Kumar, and T.S.N. Sankara Narayanan, Fretting corrosion behaviour of Ti-6Al-4V alloy in artificial saliva containing varying concentrations of fluoride ions. Wear, 2011. 270(3-4): p. 317-324.

28. Bozzini, B., et al., An electrochemical impedance investigation of the behaviour of anodically oxidised titanium in human plasma and cognate fluids, relevant to dental applications. Journal of Materials Science. Materials in Medicine, 2008. 19: p. 3443-3453.

29. Paital, S.R. and N.B. Dahotre, Calcium phosphate coatings for bio-implant applications: Materials, performance factors, and methodologies. Materials Science and Engineering: R: Reports, 2009. 66(1-3): p. 1-70.

30. Liu, X., P.K. Chu, and C. Ding, Surface modification of titanium, titanium alloys, and related materials for biomedical applications. Materials Science and Engineering: R: Reports, 2004. 47(3-4): p. 49-121.

31. Xue, W., et al., In vivo evaluation of plasma sprayed hydroxyapatite coatings having different crystallinity. Biomaterials, 2004. 25(3): p. 415-421.

32. Hoffmann, B., M. Feldmann, and G. Ziegler, Sol-gel and precursor-derived coatings with cover function on medical alloys. Journal of Materials Chemistry, 2007. 17(38): p. 4034-4040. 
33. Xiao, S.J., et al., Immobilization of the cell-adhesive peptide Arg-Gly-Asp-Cys (RGDC) on titanium surfaces by covalent chemical attachment. Journal of Materials Science-Materials in Medicine, 1997. 8(12): p. 867-872.

34. Erdtmann, M., R. Keller, and H. Baumann, Photochemical immobilization of heparin, dermatan sulphate, dextran sulphate and endothelial cell surface heparan sulphate onto cellulose membranes for the preparation of athrombogenic and antithrombogenic polymers. Biomaterials, 1994. 15(13): $\mathrm{p}$. 1043-1048.

35. Mani, G., et al., Interaction of Endothelial Cells with Self-Assembled Monolayers for Potential Use in Drug-Eluting Coronary Stents. Journal of Biomedical Materials Research Part B-Applied Biomaterials, 2009. 90B(2): p. 789-801.

36. Wright, J.D. and N. Sommerdijk, Sol-Gel Materials Chemistry and Applications. Advanced Chemistry Text, ed. D. Phillips. Vol. 4. 2001, London: CRC Press.

37. Jimenez-Morales, A., Sensores electroquímicos y membranas de separación iónica basados en materiales organopolisiloxánicos que incorporan compuestos ionóforos o enzimas, in Ciencia de los materiales e ingenieria metalurgica. Tesis Doctoral. 1999, Universidad Carlos III Madrid: Madrid.

38. Wei, Y., A fast convenient method to prepare hybrid sol-gel materials with low volume-shrinkages. JOURNAL OF SOL-GEL SCIENCE AND TECHNOLOGY, 1996. 7(3): p. 191-201.

39. Brinker, C.J. and G.W. Scherer, Sol-Gel Science: The Physics and Chemistry of Sol-Gel Processing, ed. A.P. Limited. 1990, London.

40. Lira-Cantú, M. and P. Gómez-Romero, The polyaniline-V2O5 system:: improvement as insertion electrode in lithium batteries. International Journal of Inorganic Materials, 1999. 1(1): p. 111-116.

41. Rabinovich, L., et al., Sol-gel-derived carbon ceramic electrodes: A new lithium intercalation anode. Advanced Materials, 1998. 10(8): p. 577-587.

42. Levy, D. and L. Esquivias, Sol-Gel Processing of Optical and Electrooptical Materials. Advanced Materials, 1995. 7(2): p. 120-129.

43. Cheben, P., et al., A photorefractive organically modified silica glass with high optical gain. Nature, 2000. 408(6808): p. 64-67.

44. Gonzalez, A., et al., Oriented growth of sol-gel-modified PbTiO3 thin films on Si-based substrates. Surface and Interface Analysis, 2000. 29(5): p. 325-329.

45. Morales, M.P., et al., Coercivity enhancement in gamma-Fe2O3 particles dispersed at low-volume fraction. Journal of Magnetism and Magnetic Materials, 1998. 183(1-2): p. 232-240.

46. Liu, Q., et al., A Novel Two-Step Silica-Coating Process for Engineering Magnetic Nanocomposites. Chemistry of Materials, 1998. 10(12): p. 39363940. 
47. Jiménez-Morales, A., J.C. Galván, and P. Aranda, A new silver-ion selective sensor based on a polythiacrown-ether entrapped by sol-gel. Electrochimica Acta, 2002. 47(13-14): p. 2281-2287.

48. Jiménez-Morales, A., P. Aranda, and J.C. Galván, Nanocomposite materials based on organopolysiloxane/macrocyle systems for electrochemical sensors. Journal of Materials Processing Technology, 2003. 143-144: p. 5-10.

49. Dedamborenea, J., et al., Electrochemical-Behavior of Sio2 Sol-Gel Coatings on Stainless-Steel. Journal of Sol-Gel Science and Technology, 1995. 4(3): p. 239-244.

50. Galliano, P., et al., Sol-gel coatings on 316L steel for clinical applications. Journal of Sol-Gel Science and Technology, 1998. 13(1-3): p. 723-727.

51. Schottner, G., Hybrid sol-gel-derived polymers: Applications of multifunctional materials. Chemistry of Materials, 2001. 13(10): p. 3422-3435.

52. Innocenzi, P., et al., Structural Characterization of Hybrid Organic-Inorganic Materials, in Sol-gel Science and Technology. Processing, Characterization and Applications, S. Sumio, Editor. 2005, Kluwer Academic Publishers: Lisboa. p. 139-157.

53. Sanchez, C., et al., Applications of hybrid organic-inorganic nanocomposites. Journal of Materials Chemistry, 2005. 15(35-36): p. 3559-3592.

54. Wang, D. and G.R. Bierwagen, Sol-gel coatings on metals for corrosion protection. Progress in Organic Coatings, 2009. 64(4): p. 327-338.

55. Barranco, V., et al., Electrochemical study of tailored sol-gel thin films as pretreatment prior to organic coating for AZ91 magnesium alloy. Progress in Organic Coatings.

56. Garcia-Heras, M., et al., Preparation and electrochemical study of ceriumsilica sol-gel thin films. Journal of Alloys and Compounds, 2004. 380(1-2): p. 219-224.

57. Chico, B., et al., Electrochemical impedance spectroscopy study of the effect of curing time on the early barrier properties of silane systems applied on steel substrates. Progress in Organic Coatings, 2007. 60(1): p. 45-53.

58. El hadad, A., et al., Preparation of sol-gel hybrid materials from $y$ methacryloxypropyltrimethoxysilane and tetramethyl orthosilicate: study of the hydrolysis and condensation reactions. Colloid \& Polymer Science, 2011. 289(17): p. 1875-1883.

59. Palanivel, V., D. Zhu, and W.J. van Ooij, Nanoparticle-filled silane films as chromate replacements for aluminum alloys. Progress in Organic Coatings, 2003. 47(3-4): p. 384-392.

60. Brinker, C.J., et al., Fundaments of sol-gel dip coating. Thin Solid Films, 1991. 201(1): p. 97-108.

61. Strawbridge, I. and P.F. James, Thin silica films prepared by dip coating. Journal of Non-Crystalline Solids, 1986. 82(1-3): p. 366-372. 
62. Sanctis, O., et al., Rescubrimientos protectores sobre acero inoxidable producidos por sol-gel., C.S.d.I. Científicas, Editor. 1993: Spain.

63. Sayilkan, H., et al., The sol-gel synthesis and application of some anticorrosive coating materials. Materials Science, 2003. 39(5): p. 733-739.

64. Joshua Du, Y., et al., Inorganic/organic hybrid coatings for aircraft aluminum alloy substrates. Progress in Organic Coatings, 2001. 41(4): p. 226-232.

65. Khramov, A.N., et al., Hybrid organo-ceramic corrosion protection coatings with encapsulated organic corrosion inhibitors. Thin Solid Films, 2004. 447448: p. 549-557.

66. Garcia-Heras, M., et al., Preparation and electrochemical study of ceriumsilica sol-gel thin films. Journal of Alloys and Compounds, 2004. 380(1-2): p. 219-224.

67. Zolkov, C., D. Avnir, and R. Armon, Tissue-derived cell growth on hybrid solgel films. Journal of Materials Chemistry, 2004. 14(14): p. 2200-2205.

68. Reiner, T., S. Kababya, and I. Gotman, Protein incorporation within Ti scaffold for bone ingrowth using Sol-gel SiO2 as a slow release carrier. Journal of Materials Science-Materials in Medicine, 2008. 19(2): p. 583-589.

69. Reffitt, D.M., et al., Orthosilicic acid stimulates collagen type 1 synthesis and osteoblastic differentiation in human osteoblast-like cells in vitro. Bone, 2003. 32(2): p. 127-135.

70. Hench, L.L., Stimulation of bone repair by gene activating glasses, in Bioceramics, Vol 16, M.A. Barbosa, et al., Editors. 2004, Trans Tech Publications Ltd: Zurich-Uetikon. p. 3-6.

71. Patel, N., et al., A comparative study on the in vivo behavior of hydroxyapatite and silicon substituted hydroxyapatite granules. Journal of Materials ScienceMaterials in Medicine, 2002. 13(12): p. 1199-1206.

72. Gupta, R. and A. Kumar, Bioactive materials for biomedical applications using sol-gel technology. Biomedical Materials, 2008. 3(3): p. 1-15.

73. Peon, E., et al., Recubrimientos de hidroxiapatita preparados mediante un proceso sol-gel. Revista de metalurgia, 2005: p. 479-482.

74. Advincula, M.C., et al., Osteoblast adhesion and matrix mineralization on solgel-derived titanium oxide. Biomaterials, 2006. 27(10): p. 2201-2212.

75. García, C., S. Ceré, and A. Durán, Bioactive coatings prepared by sol-gel on stainless steel 316L. Journal of Non-Crystalline Solids, 2004. 348: p. 218-224.

76. Ballarre, J., et al., Protective hybrid sol-gel coatings containing bioactive particles on surgical grade stainless steel: Surface Characterization. Applied Surface Science, 2007. 253(17): p. 7260-7264.

77. García, C., S. Ceré, and A. Durán, Bioactive coatings deposited on titanium alloys. Journal of Non-Crystalline Solids, 2006. 352(32-35): p. 3488-3495. 
78. García, C., A. Duran, and R. Moreno, Stability of Suspensions of bioactive particles using hybrid organic-inorganic solutions as dispersing media. Journal of Sol-Gel Science and Technology, 2005. 34: p. 211-217.

79. Gallardo, J., P. Galliano, and A. Duran, Biactive and protective Sol-Gel coatings on metals for orthopaedic protheses. Journal of Sol-Gel Science and Technology, 2001. 21: p. 65-74.

80. Bottcher, H., Bioactive sol-gel coatings. Journal Fur Praktische ChemiePractical Applications and Applied Chemistry, 2000. 342(5): p. 427-436.

81. Santos, E.M., S. Radin, and P. Ducheyne, Sol-gel derived carrier for the controlled release of proteins. Biomaterials, 1999. 20(18): p. 1695-1700.

82. Jin, W. and J.D. Brennan, Properties and applications of proteins encapsulated within sol-gel derived materials. Analytica Chimica Acta, 2002. 461(1): p. 1-36.

83. Radin, S., et al., Silica sol-gel for the controlled release of antibiotics. I. Synthesis, characterization, and in vitro release. Journal of Biomedical Materials Research, 2001. 57(2): p. 313-320.

84. Radin, S., et al. In vitro and in vivo bactericidal effect of sol-gel/antibiotic thin films on fixation devices. in 19th International Symposium on Ceramics in Medicine. 2006. Chengdu.

85. Radin, S. and P. Ducheyne, Controlled release of vancomycin from thin solgel films on titanium alloy fracture plate material. Biomaterials, 2007. 28(9): p. 1721-1729.

86. Livage, J., Sol-gel processes. Current Opinion in Solid State and Materials Science, 1997. 2(2): p. 132-138.

87. Beganskiene, A. and et al., Modified sol-gel coatings for biotechnological applications. Journal of Physics: Conference Series, 2007. 93(1): p. 012050.

88. Manso-Silvan, M., et al., Hybrid titania-aminosilane platforms evaluated with human mesenchymal stem cells. Journal of Biomedical Materials Research Part B-Applied Biomaterials, 2007. 83B(1): p. 232-239.

89. Tsuru, K., et al., Sol-gel synthesis and in vitro cell compatibility analysis of silicate-containing biodegradable hybrid gels, in Bioceramics, Vol 20, Pts 1 and 2, G. Daculsi and P. Layrolle, Editors. 2008. p. 447-450.

90. Hosseinalipour, S.M., et al., Characterization of sol-gel coated 316L stainless steel for biomedical applications. Progress in Organic Coatings, 2010. 67(4): p. 371-374.

91. Shirosaki, Y., et al., In vitro cytocompatibility of MG63 cells on chitosanorganosiloxane hybrid membranes. Biomaterials, 2005. 26(5): p. 485-493.

92. Bottcher, H., P. Slowik, and W. Suss, Sol-gel carrier systems for controlled drug delivery. Journal of Sol-Gel Science and Technology, 1998. 13(1-3): $p$. 277-281. 
93. Radin, S., J. Parvizi, and P. Ducheyne. Thin sol-gel films on fracture fixation material for the controlled release of antibiotics. in 18th International Symposium on Ceramics in Medicine. 2005. Kyoto, Japan.

94. Böttcher, H., et al., Sol-gel composite films with controlled release of biocides. Journal of Controlled Release, 1999. 60(1): p. 57-65.

95. Morpurgo, M., et al., Influence of synthesis and processing conditions on the release behavior and stability of sol-gel derived silica xerogels embedded with bioactive compounds. II Farmaco, 2005. 60(8): p. 675-683.

96. Unger, K., et al., The use of porous and surface modified silicas as drug delivery and stabilizing agents. Drug Development and Industrial Pharmacy, 1983. 9(1-2): p. 69-91.

97. Kortesuo, P., et al., In vitro evaluation of sol-gel processed spray dried silica gel microspheres as carrier in controlled drug delivery. International Journal of Pharmaceutics, 2000. 200(2): p. 223-229.

98. Kortesuo, P., et al., Alkyl-substituted silica gel as a carrier in the controlled release of dexmedetomidine. Journal of Controlled Release, 2001. 76(3): p. 227-238.

99. Kortesuo, P., et al., In vitro release of dexmedetomidine from silica xerogel monoliths: effect of sol-gel synthesis parameters. International Journal of Pharmaceutics, 2001. 221(1-2): p. 107-114.

100. Radin, S., et al., In vitro bioactivity and degradation behavior of silica xerogels intended as controlled release materials. Biomaterials, 2002. 23(15): p. 31133122.

101. Brasack, I., H. Böttcher, and U. Hempel, Biocompatibility of Modified SilicaProtein Composite Layers. Journal of Sol-Gel Science and Technology, 2000. 19(1): p. 479-482.

102. G.W, W., A review of impedance plot methods used for corrosion performance analysis of painted metals. Corrosion Science, 1986. 26(9): p. 681-703.

103. Bonora, P.L., F. Deflorian, and L. Fedrizzi, Electrochemical Impedance Spectroscopy as a tool for investigating underpaint corrosion. Electrochimica Acta, 1996. 41(7-8): p. 1073-1082.

104. Amirudin, A. and D. Thieny, Application of electrochemical impedance spectroscopy to study the degradation of polymer-coated metals. Progress in Organic Coatings, 1995. 26(1): p. 1-28.

105. Smith, M.E. and D. Holland, Atomic Scale Structure of Gel Materials by Solid State NMR, in Sol-gel Science and Technology. Processing, Characterization and Applications, S. Sumio, Editor. 2005, Kluwer Academic Publishers: Lisboa. p. 35-63.

106. Metroke, T.L., R.L. Parkhill, and E.T. Knobbe, Passivation of metal alloys using sol-gel-derived materials -- a review. Progress in Organic Coatings, 2001. 41(4): p. 233-238. 
107. Atanacio, A.J., et al., Mechanical properties and adhesion characteristics of hybrid sol-gel thin films. Surface and Coatings Technology, 2005. 192(2-3): p. 354-364.

108. Almeida, R.M. and A.C. Marques, Characterization of Sol-Gel Materials by Infrared Spectroscopy, in Sol-gel Science and Technology. Processing, Characterization and Applications, S. Sumio, Editor. 2005, Kluwer Academic Publishers: Lisboa. p. 65-89.

109. Han, Y.-H., et al., Sol-gel-derived organic-inorganic hybrid materials. Journal of Non-Crystalline Solids, 2007. 353(3): p. 313-320.

110. Cholewa-Kowalska, K., et al., Coloured inorganic-organic films on glass, in Physica Status Solidi C - Current Topics in Solid State Physics, Vol 4, No 3, M. Stutzmann, Editor. 2007, Wiley-V C H Verlag Gmbh: Weinheim. p. 11301133.

111. Li, Y.-S., et al., Vibrational spectroscopic studies of vinyltriethoxysilane sol-gel and its coating. Spectrochimica Acta Part A: Molecular and Biomolecular Spectroscopy, 2004. 60(12): p. 2759-2766.

112. Alonso, B., et al., Design of hybrid organic-inorganic materials through their structure control: The case of epoxy bearing alkoxides. Journal of NonCrystalline Solids, 2008. 354(15-16): p. 1615-1626.

113. Zheludkevich, M.L., I.M. Salvado, and M.G.S. Ferreira, Sol-gel coatings for corrosion protection of metals. Journal of Materials Chemistry, 2005. 15(48): p. $5099-5111$.

114. Pathak, S.S. and A.S. Khanna, Synthesis and performance evaluation of environmentally compliant epoxysilane coatings for aluminum alloy. Progress in Organic Coatings, 2008. 62(4): p. 409-416.

115. Chattopadhyay, D.K., A.D. Zakula, and D.C. Webster, Organic-inorganic hybrid coatings prepared from glycidyl carbamate resin, 3-aminopropyl trimethoxy silane and tetraethoxyorthosilicate. Progress in Organic Coatings, 2009. 64(2-3): p. 128-137.

116. Hernández-Escolano, M., et al., Study of the thermal degradation of bioactive sol-gel coatings for the optimization of its curing process. Journal of Thermal Analysis and Calorimetry: p. 1-10.

117. García, S.J. and J. Suay, Anticorrosive properties of an epoxy-Meldrum acid cured system catalyzed by erbium III trifluromethanesulfonate. Progress in Organic Coatings, 2006. 57(4): p. 319-331.

118. García, S.J. and J. Suay, Optimization of deposition voltage of cataphoretic automotive primers assessed by EIS and $A C / D C / A C$. Progress in Organic Coatings, 2009. 66(3): p. 306-313.

119. Normalización, C.E.d., Evaluación biológica de productos sanitarios. Parte 5: Ensayos de citotoxicidad in vitro 2009, AENOR. p. 44.

120. Zhu, X.L., et al., Effects of topography and composition of titanium surface oxides on osteoblast responses. Biomaterials, 2004. 25(18): p. 4087-4103. 
121. Hao, L., J. Lawrence, and K.S. Chian, Osteoblast cell adhesion on a laser modified zirconia based bioceramic. Journal of Materials Science-Materials in Medicine, 2005. 16(8): p. 719-726.

122. Janssen, M.I., et al., Promotion of fibroblast activity by coating with hydrophobins in the beta-sheet end state. Biomaterials, 2004. 25(14): p. 27312739.

123. Baier, R.E., Surface behaviour of biomaterials: The theta surface for biocompatibility. Journal of Materials Science-Materials in Medicine, 2006. 17(11): p. 1057-1062.

124. Avnir, D., et al., Recent bio-applications of sol-gel materials. Journal of Materials Chemistry, 2006. 16(11): p. 1013-1030.

125. Wei, Y., et al., Organic-inorganic hybrid materials: relations of thermal and mechanical properties with structures. Materials Science \& Engineering CBiomimetic and Supramolecular Systems, 1998. 6(2-3): p. 91-98.

126. A. P. Tomsia, E.S.J.S.C.R.B., Biomimetic Bonelike Composites and Novel Bioactive Glass Coatings. 2005. p. 999-1004.

127. Fathi, M.H. and A. Doostmohammadi, Bioactive glass nanopowder and bioglass coating for biocompatibility improvement of metallic implant. Journal of Materials Processing Technology, 2009. 209(3): p. 1385-1391.

128. Kim, H.M., Ceramic bioactivity and related biomimetic strategy. Current Opinion in Solid State and Materials Science, 2003. 7(4-5): p. 289-299. 

ANEXO I 



\title{
Study of the thermal degradation of bioactive sol-gel coatings for the optimization of its curing process
}

\author{
M. Hernández-Escolano $\cdot$ X. Ramis . \\ A. Jiménez-Morales · M. Juan-Díaz · \\ J. Suay
}

Received: 21 January 2011/Accepted: 31 March 2011

C) Akadémiai Kiadó, Budapest, Hungary 2011

Abstract A set of materials has been prepared by sol-gel process containing different quantities of hydroxyapatite $(0,2.5$ and $5 \% \mathrm{HAp} w / \mathrm{w})$ using as silica precursors glycidyloxypropyltrimethoxysilane (GPTMS) and triethoxyvinylsilane (VTES). In order to optimize the curing process to obtain sintherized systems (inorganic network) or hybrid systems (organic-inorganic) a TG and FTIR studies have been developed and degradation kinetic triplet parameters were obtained (the activation energy, preexponential factor, and function of degree of conversion). The kinetic study was analyzed by means of an integral isoconversional non-isothermal procedure (model free), and the kinetic model was determined by the Coats-Redfern method and through the compensation effect (IKR). All the systems followed the $n=6$ kinetic model. The addition of HAp increases the thermal stability of the systems. The isothermal degradation was simulated from non-isothermal data, and the curing process could be

M. Hernández-Escolano (丣) - J. Suay

Centre for Biomaterials and Tissue Engineering, Univ. Politec Valencia, CIngeniro Fausto Elio S/N, 46021 Valencia, Spain e-mail: miheres@ doctor.upv.es URL: http://www.upvesich/

$\mathrm{X}$. Ramis

Laboratory of Thermodynamics, Univ. Politec. Cataluña Av. Diagonal 647, 08028 Barcelona, Spain

A. Jiménez-Morales

Universidad Carlos III, Av. Universidad 30, 28911 Leganés. Madrid, Spain

M. Juan-Díaz - J. Suay

Universidad Jaume I, Vicent Sos Baynat, sín, 12071 Castelló de la Plana, Spain

defined to obtain the two types of materials. Temperature under $250^{\circ} \mathrm{C}$ allows the formation of hybrids networks.

Keywords Sol gel - HAp - VTES - GPTMS - Kinetics

\section{Introduction}

The sol-gel process is a chemical synthesis method initially used for the preparation of inorganic materials such as glasses and ceramics [1]. This process can be described as the creation of an oxide network by progressive condensation reactions of molecular precursors in a liquid medium [2]. Generally, material formation occurs in four stages: (a) hydrolysis, (b) condensation and polymerization of precursors to form chains and particles, (c) growth of the particles, (d) agglomeration of the structures followed by the formation of [3,4]. Steps b, c, d need to be performed with a thermal treatment that can be named as curing process. Since liquid precursors are used, it is possible to cast coatings in complex shapes and to produce thin films without the need for machining or melting and this method is waste-free and excludes the stage of washing [1-9].

The most widely used metal-organic precursors for the preparation of materials by sol-gel processing are the alkoxysilanes, including tetraoxy silicate $\left(\mathrm{Si}(\mathrm{OR})_{4}\right)$ and organically modified silicates $\left(\mathrm{R}^{\prime} n \mathrm{Si}(\mathrm{OR})_{4-n}\right.$ or $(\mathrm{RO})_{3} \mathrm{Si}$ $\mathbf{R}^{\prime} \mathrm{Si}(\mathrm{OR})_{3}$, where $\mathbf{R}$ is typically an alkyl) [10]. As it is shown in Fig. 1 the sol-gel process of derived silica materials involved the formation of a $\mathrm{Si}-\mathrm{O}-\mathrm{Si}$ network.

Depending on the curing treatment different types of coatings are possible: (a) inorganic $\left(\mathrm{SiO}_{2}\right)$ coatings using high temperatures in order to sintherized the film and to degrade the organic compounds and (b) hybrid

Q Springer 

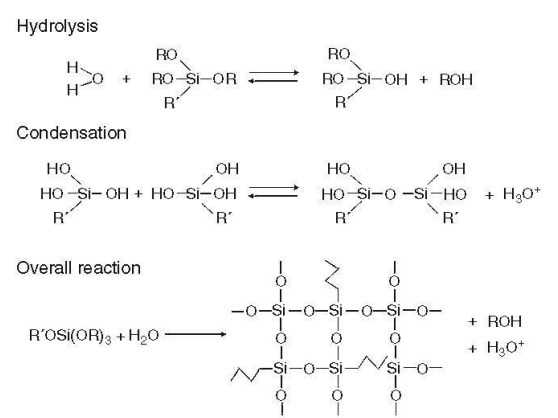

Fig. 1 Hydrolysis and condensation involved in making sol-gel derived silica materials

organic-inorganic sol-gel coatings, in this case we use much lower temperatures.

Inorganic $\mathrm{SiO}_{2}$ coatings can improve the oxidation and acidic corrosion resistance of metals under different temperatures due to its high heat resistance and chemical resistance [11]. Durán et al. made $\mathrm{SiO}_{2}$ coating on galvanized steel using tetraethylorthosilicate (TEOS) and methyltriethoxysilane (MTES) precursors to improve the corrosion behaviour of the substrate [6]. Vasconcellos et al. found that the inorganic $\mathrm{SiO}_{2}$ coating obtained through TEOS was homogeneous, free of cracks and improved the anti-corrosion performance of stainless steel substrate [5]. While inorganic coatings can provide good protection on metal substrates, the drawback of these coatings are brittleness, low thicker and the difficulty to achieve without cracking [1].

To overcome the limitation of pure inorganic sol-gel coatings much works introduce organic chains into the precursors to form the organic-inorganic hybrid coating. Sayilkan et al. developed an organic-inorganic coating on aluminium and iron plates using different alkoxysilanes and they show that in most cases the durability of the coating was satisfactory [7]. Parkhill et al applied water based epoxide ormosil coatings on aluminium panels using 3-glycidoxypropyl trimethoxysilane (GPTMS) and TEOS as precursors, they characterized film thickness and morphology and evaluated the overall corrosion performance [8]. Chan et al. obtained three kinds of hybrids using TEOS, MTES, vinyltriethoxysilane (VTES) and GPTMS, they demonstrated that the introduction of unhydrolizable organic groups increased the module and the hardness [9]. The group of J.C. Galván have develop hybrid organicinorganic sol-gel coatings using $\alpha$-methacryloxypropyltrimethoxysilane (MAP) and tetramethoxysilane (TMOS) loaded with inorganic particles such as titania or cerium that enhance the corrosion properties of sol-gel [12, 13]

On the other hand, one of the most important properties of the silica-based sol-gel system is that they usually have a high content of surface silanol groups, which have been reported to be bone growth inductors because they promote in vitro and in vivo mucleation of apatite. Therefore, they can be used as a coating of orthopaedic metallic implants to overcome the limitations of these materials $[10,11]$ such as, a limited corrosion resistance in the human body and the lack of bioactivity [14]. The combination of this property with the ability of organic-inorganic systems to embed different bioactive compounds has opened the field of bioactive sol-gel coatings. One way of improving the bioactivity of the sol-gel coatings is adding hydroxyapatite to the sol-gel system (hydroxyapatite particles increase the quality and the bond to the living bone [15]). Most of the works reported around these materials use a high process temperature so the system loses its organic part. Durán et al. have made numerous studies of sol-gel coatings with hydroxyapatite applying sinterization thermal process and they demonstrated the improvement of the corrosion resistance of the substrate and bioactivity [16-18]. Nevertheless, it is possible to use HAp particles in the coating maintaining its organic part, in this case the curing process has to avoid the degradation and of course the sinterization of the film.

In the present study, we report a thermal degradation study of an sol-gel material obtained from glycidyloxypropyltrimethoxysilane (GPTMS) and triethoxyvinylsilane (VTES) with different hydroxyapatite (HAp) particles content. The main objective of this study is to understand thermal degradation kinetics of these materials. Controlling the chemical nature of the initial formulation (precursors and particles), and the curing process we will be able to obtain materials with different organic-inorganic compositions. Moreover, the thermal degradation at high temperatures will be studied and the kinetic model calculated in order to define optimal curing process depending if a hybrid or an inorganic film want to be obtained.

\section{Experimenta}

Materials

The silica precursors used were glycidyloxypropyltrimethoxysilane (GPTMS) and triethoxyvinylsilane (VTES) from Sigma-Aldrich (used as received). Their chemical structure is shown in Fig. 2.

Isopropanol (Sigma-Aldrich) was used as a co-solvent without further purification. 


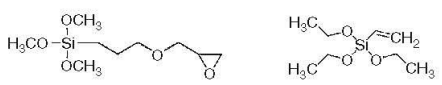

Fig. 2 Chemical strucuture of glycidyloxypropyltrimethoxysilane (GPTMS) and triethoxyvinylsilane (VTES), respectively

$0.1 \mathrm{M}$ nitric acid $\left(\mathrm{HNO}_{3}\right)$ was used in order to obtain acidic $\mathrm{pH}$ as the catalytic of the hydrolysis and condensation reactions.

The bioactive particles were hydroxyapatite (HAp) particles $(>200 \mathrm{~nm}$ ) from Sigma-Aldrich

Synthesis of the materials

Synthesis of the inorganic-organic hybrid materials

The GPTMS/VTES sols were prepared by acid catalysi method in one stage. The volume ratio of GPTMS/VTES was $80: 20$. The precursors were dissolved into isopropanol. The hydrolysis of the alcoxy groups presented in the precursors was carried out by addiction of the stoichiometric quantity of acidified water while stirring at room temperature. The solution were stirred for about $1 \mathrm{~h}$ and set for another hour at room temperature before use. The materials were cured at $50{ }^{\circ} \mathrm{C}$ for $15 \mathrm{~min}, 100{ }^{\circ} \mathrm{C}$ for $15 \mathrm{~min}$ and $140{ }^{\circ} \mathrm{C}$ for $90 \mathrm{~min}$ (Table 1 ).

Synthesis of bone grow inductor materials

The bone growth inductors coatings were prepared by the addition of HAp to the organic-inorganic sol-gel coatings. In order to ensure a proper dispersion of the particles in the coating the HAp particles were ultrasonicated Sonoplus HD 3200 in isopropanol before adding to the sol solution. The addition was made after the sol solution was stirring for $1 \mathrm{~h}$ and then it was set for another hour at room temperature before use. In this case two materials were prepared 2.5 and $5 \%$ HAp wt respect to the precursors. The materials were cured at $50^{\circ} \mathrm{C}$ for $15 \mathrm{~min}, 100^{\circ} \mathrm{C}$ for $15 \mathrm{~min}$ and $140^{\circ} \mathrm{C}$ for $90 \mathrm{~min}$ (Table 1 ).

Characterization and measurements

The Fourier Transform Infrared (FTIR) spectra were recorded with a Thermo Nicolet NEXUS FTIR spectrophotometer in the transmittance mode.

Thermogravimetric analysis (TG) was carried out with Mettler-Toledo TG-50 thermobalance. Cured samples with an approximate mass of $7 \mathrm{mg}$ were degraded between 30 and $700^{\circ} \mathrm{C}$ at a heating rate of $10^{\circ} \mathrm{C} / \mathrm{min}$ in $\mathrm{N}_{2}(100 \mathrm{~mL} / \mathrm{min})$ measured under normal conditions. Non-isothermal thermogravimetric tests were carried out at rates of 2, 5, 10 and $20^{\circ} \mathrm{C} / \mathrm{min}$ to evaluate the kinetic parameters.
The degradation of the materials was performed at the same conditions as TG essays. The residues produced maintaining the materials in different temperatures ( 240 , 450 and $700{ }^{\circ} \mathrm{C}$ ) were investigated by FTIR spectra in order to follow the degradation of the materials.

Kinetics analysis

Integral non-isothermal kinetic analysis was used to determine the kinetic triplet ( $A$-pre-exponential factor, $E$-activation energy and $g(\alpha)$-integral function of degree of conversion). The degree of conversion as the mass loss is defined as:

$\alpha=\frac{m_{0}-m}{m_{0}-m_{\infty}}$

where $m$ is the mass corresponding to temperature $T, m_{0}$ is the initial mass and $m_{\infty}$ is the mass of the substance at the end of the experiment.

If we accept that the dependence of the rate constant on the temperature follows the Arrhenius equation, kinetic analysis may start with the kinetic equation:

$\frac{\mathrm{d} \alpha}{\mathrm{d} t}=A \exp \left(-\frac{E}{R T}\right) f(\alpha)$

where $\mathrm{d} \alpha / \mathrm{d} t$ is the rate of conversion, $R$ the universal gas constant, $T$ the temperature and $f(\alpha)$ is the differential conversion function.

Kinetic analysis has generally been performed with an isoconversional method [19]. The basic assumption of such method is that the reaction rate at a constant conversion is solely a function of temperature [20].

Isothermal methods

By integrating the rate equation (Eq. 2) we obtain:

$\ln t=\ln \left[\frac{g(\alpha)}{A}\right]+\frac{E}{R T}$

where $g(\alpha)$ is the integral conversion function and is defined as follows:

$g(\alpha)=\int_{0}^{\alpha} \frac{\mathrm{d} \alpha}{f(\alpha)}$

According to Eq. 3, $E$ and the constant $\ln (g(\alpha) / A)$ can be obtained from the slope and the intercept, respectively, of the linear relationship $\ln t=f\left(T^{-1}\right)$ for a constant value of $\alpha$.

Isothermal methods require long times to be performed and give problems with the data acquisition. Firstly, if the degradation is evaluated isothermally at high temperature the reactions take place very fast, the TG equipment was not able to detect the initial mass loss signal because 
stabilization time is needed and the initial part of the degradation is lost. Secondly, isothermal experiments at low temperature needs very long time to be performed so, probably non-isothermal data could give more accurate results and easier to obtain than those given by isothermal experiments.

Non-isothermal methods

When non-isothermal methods are applied, the integration of rate equation (Eq. 2) and its reordering gives place to the so-called temperature integral:

$g(\alpha)=\int_{0}^{\alpha} \frac{\mathrm{d} \alpha}{f(\alpha)}=\frac{A}{\beta} \int_{0}^{T} e^{-(E / R T)} \mathrm{d} T$

where, $\beta$ is the heating rate

By using the Coats-Redfern [21] approximation for the resolution of Eq. 5 and considering $2 R T / E \ll 1$, we can rewrite this equation as follows:

$\ln \frac{g(\alpha)}{T^{2}}=\ln \left[\frac{A R}{\beta E}\right]-\frac{E}{R T}$

For a given kinetic model, the linear representation of $\ln \left[g(\alpha) / T^{2}\right]$ versus $T^{-1}$ makes it possible to determine $E_{\mathrm{ap}}$ and $A$ from the slope and the ordinate at the origin

In this study, the kinetic model that had the best linear correlation in the Coats-Redfern equation and that had an $E$ value $\left(E_{\mathrm{ap}}\right)$ similar to that obtained isoconversionally (considered to be the effective $E$ value, $E_{\text {ef }}$ ) was selected.

By reordering Eq. 6 the Kissinger-Akahira-Sunose (KAS) equation can be written:

$\ln \frac{\beta}{T^{2}}=\ln \left[\frac{A R}{g(\alpha) E}\right]-\frac{E}{R T}$

The linear representation of $\ln \left[\beta / T^{2}\right]$ versus $1 / T$ makes i possible to determine $E_{\text {ap }}$ (apparent $E$ value) and the kinetic parameter $\ln [A R / g(\alpha) E]$ for every value of $\alpha$. The constant $\ln [A R / g(\alpha) E]$ is directly related by the $R / E$
to the constant $\ln [g(\alpha) / A]$ of the isothermal adjustment. Thus, taking the dynamic data $\ln [A R / g(\alpha) E]$ and $E$ from Eq. 7, we can determine the isothermal parameters of Eq. 3 and simulate isothermal curing without knowing $g(\alpha)$ $[22,23]$.

Compensation effect and isokinetic relationship (IKR)

Complex processes are characterized by the dependences of $E$ on $A$ and $\alpha$. This generally reflects the existence of a compensation effect through the following equation:

$\ln A_{\alpha}=a E_{\alpha}+b=\frac{E_{\alpha}}{R T}+\ln \left[\frac{(\mathrm{d} \alpha / \mathrm{d} t)_{\alpha}}{f(\alpha)}\right]$ where $a$ and $b$ are constants and the subscript $\alpha$ represents the degree of conversion that produces a change in the Arrhenius parameters.

The slope $a=1 / R T_{\text {iso }}$ is related to the isokinetic temperature $\left(T_{\text {iso }}\right)$, and the intercept $b=\ln k_{\text {iso }}$ is related to the isokinetic rate constant $\left(k_{\text {iso }}\right)$. Equation 8 represents an IKR and can be deduced by the reordering of Eq. 2. The appearance of the IKR shows that there is only one model, whereas the existence of parameters that do not meet the IKR (meaning that for a given $\alpha$ the relation between $A$ and $E$ changes) implies that there are several models [24], because $f(\alpha)$ is not constant in all the process.

The kinetic model whose IKR had the best linear correlation between $E$ and $A$ and in which the associated $T_{\text {iso }}$ value was near the experimental temperature range was selected [25].

\section{Results and discussion}

FTIR analysis

The FTIR analysis provides evidence for the formation of the sol-gel network. Figure 3 shows the FTIR spectra of the GPTMS-VTES hybrid material and Table 2 reports the

Table 1 Materials used in this study their formulation and abbreviation

\begin{tabular}{lll}
\hline Material & Formulation & Abbreviation
\end{tabular}

Inorganic

hybrid

Bone grow inductor GPTMS-VTES\%2.5HAp G-V2.5HAp

systems GPTMS-VTES\%5HAp G-V5HAp

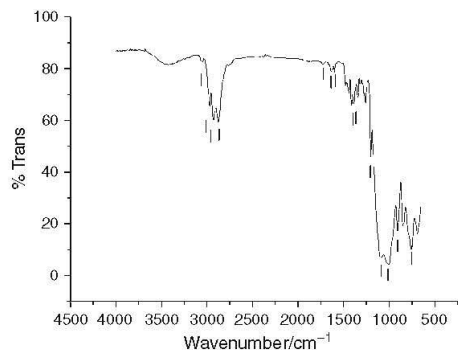

Fig. 3 FTIR spectra of GPTMS-VTES (the wavenumber of marks on the figure are listed in Table 2) 
Table 2 Assigniment of the FTIR peaks in Fig. 4

\begin{tabular}{lll}
\hline Peak position $/ \mathrm{cm}^{1}$ & Precursor assignment & Peak assignment \\
\hline 3500 & GPTMS and VTES & $\mathrm{OH}$ \\
3061 & VTES & $\mathrm{CH}_{2}$ \\
2989 & GPTMS & $\mathrm{CH}$ epoxy ring \\
2939 & GPTMS and VTES & Aliphatic \\
2866 & GPTMS & $\mathrm{CH}_{2}$ \\
1730 & GPTMS & $\mathrm{C}-\mathrm{O}$ epoxy ring \\
1638 & GPTMS & $\mathrm{C}-\mathrm{C}$ epoxy ring \\
1594 & VTES & $\mathrm{Si}-$ Vinyl \\
1400 & VTES & $\mathrm{CH} 2$ \\
1384 & GPTMS & $\mathrm{CH}_{\text {epoxy ring }}$ \\
1205 & GPTMS & $\mathrm{CH}_{2}-\mathrm{O}-\mathrm{CH}_{2}$ \\
$1070 ; 1010$ & GPTMS and VTES & $\mathrm{Si}-\mathrm{O}-\mathrm{Si}$ \\
912 & GPTMS and VTES & $\mathrm{Si}-\mathrm{OH}$ \\
763 & GPTMS and VTES & $\mathrm{Si}-\mathrm{O}-\mathrm{Si}$ \\
\hline
\end{tabular}

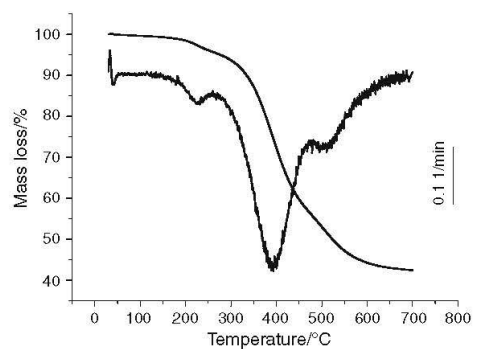

Fig. 4 TG and DTG curves under $\mathrm{N}_{2}$ atmosphere at $10^{\circ} \mathrm{C} / \mathrm{min}$ of the G-V material

assignment of the FTIR peaks marked in the spectra with the vibration of the characteristics bonds.

The silica network is characterized by the strong absorptions at 1,070 and $1,010 \mathrm{~cm}^{-1}$ corresponding to the
$\mathrm{Si}-\mathrm{O}-\mathrm{Si}$ bond. The organic part of the hybrid is characterized by the peaks around $2,500-3,000 \mathrm{~cm}^{-1}$. The epoxy ring reacts partially during the cured process, the main peak 1384 persists but with low intensity. The addition of hydroxiapatite does not change the FTIR spectra, so similar chemical structure it is expected.

Thermal degradation of organic-inorganic hybrid

Figure 4 shows the thermal degradation curve of GPTMSVTES materials. Three overlapped degradation processes are shown. The first one around $200^{\circ} \mathrm{C}$, the highest mass loss associated with approximately $65 \%$ of mass loss is near $400{ }^{\circ} \mathrm{C}$ and the last one almost at $550^{\circ} \mathrm{C}$.

In order to understand the degradation process and assign the peaks detected with TG with a specific degradation reaction, a study combining FTIR and TG was carried out. All films were tested in TG at $10^{\circ} \mathrm{C} / \mathrm{min}$ first until $240^{\circ} \mathrm{C}$ (just after first DTG peak), second until $450{ }^{\circ} \mathrm{C}$ (after second DTG peak) and third until $700^{\circ} \mathrm{C}$ (after third DTG peak). After TG tests the produced residues were investigated by FTIR in order to study the degradation process (Fig. 5).

FTIR analysis of $240^{\circ} \mathrm{C}$ sample shows that the intensity of the $\mathrm{Si}-\mathrm{OH}$ band assign at $912 \mathrm{~cm}^{-1}$ compared to FTIR analysis of non-degraded sample has been reduced significatively probably due to the continuation of the condense process and the consequent liberation of the produced alcohols $\mathrm{R}-\mathrm{OH}$, so the peaks associated to $\mathrm{CH}_{2}$ also slightly decrease.

The study of FTIR spectra of $450^{\circ} \mathrm{C}$ sample shows that the main loss of mass is due to the degradation of the organic chains of the precursors GPTMS and VTES. All peaks associated to the organic chains (and principally $\mathrm{CH}_{2}$ and $\mathrm{CH}$ ) has almost disappeared. Finally FTIR spectra of sample someted to $700^{\circ} \mathrm{C}$ shows the decrease of the intensity of the peaks at 1010,1070 and $763 \mathrm{~cm}^{-1}$ that means there has been a degradation of the $\mathrm{Si}-\mathrm{O}-\mathrm{Si}$ network.
Fig. 5 FTIR spectra of an

GPTMS-VTES sample and the residues of same type of sample the temperatures of 240,450 the temperat
and $700{ }^{\circ} \mathrm{C}$

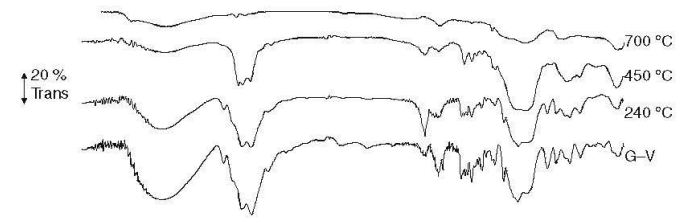

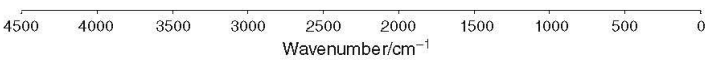


Comparison of the thermal degradation of inorganicorganic hybrid and bone growth inductor systems

Figure 6 shows the TG and DTG curves versus temperature curves of the materials GPTMSVTES and those containing HAp (G-V2.5HAp and G-V5HAp). Table 3 collects some quantitative parameters for these samples obtained directly from the TG raw data.
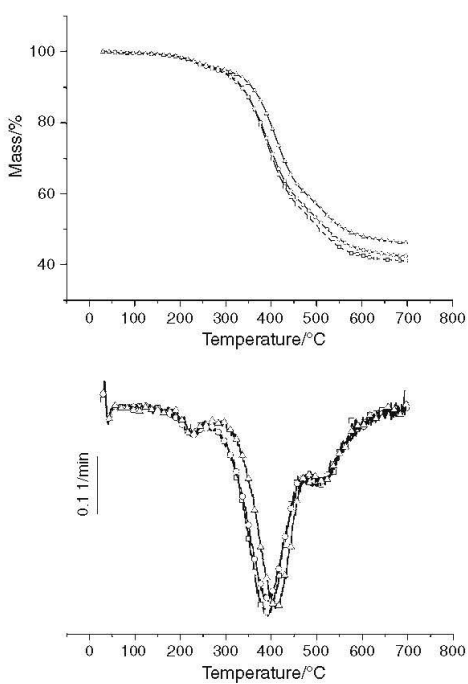

Fig. $6 \mathrm{TG}$ and DTG curves at $10^{\circ} \mathrm{C} / \mathrm{min}$ in $\mathrm{N} 2$ atmosphere of $\mathrm{G}-\mathrm{V}$ (filled square), G-V2.5Hap (filled circle) and G-V5Hap (filled triangle) samples

Table 3 Thermogravimetric data under N2 atmosphere of G-V G-V2.5Hap and G-V5Hap

\begin{tabular}{lllcll}
\hline Entry & Formulation & Abbreviation & $T_{c}^{\mathrm{a}}$ & $T_{\max }^{\mathrm{b}}$ & $\begin{array}{l}\text { Char } \\
\text { yield } / \%^{\circ}\end{array}$ \\
\hline 1 & GPTMS:VTES & G-V & 373 & 387 & 41 \\
2 & GPTMS:VTES & G-V2.5HAp & 378 & 389 & 42 \\
3 & $\% 2.5$ HAp \\
& $\begin{array}{c}\text { GPTMS:VTES } \\
\% 5 \text { HAp }\end{array}$ & G-V5HAp & 399 & 410 & 46 \\
& & & & \\
\hline
\end{tabular}

${ }^{a}$ Temperature of a $20 \%$ of weight loss calculated by thermogravimetry

bemperature of the maximum degradation rate calculated by thermogravimetr

${ }^{\circ}$ Char yield at $700^{\circ} \mathrm{C}$

黑 Springer
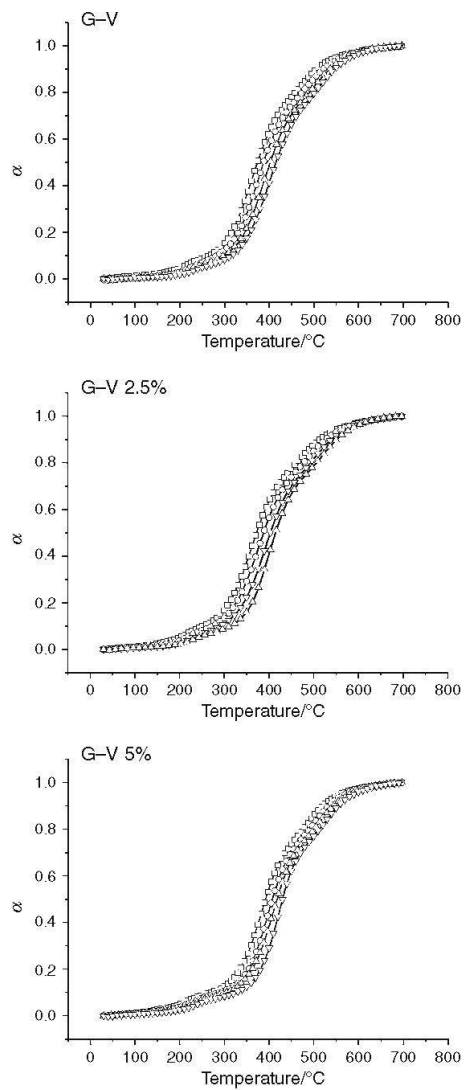

Fig. 7 Thermogravimetric curves at different heating rates (2.5 (filled square), 5 (filled circle), 10 (filled triangle) and 20 (inverted filled triangle ${ }^{\circ} \mathrm{C} / \mathrm{min}$ ) for each studied material

As it can be seen in Fig. 6, the addition of HAp do not change significantly the degradation process at temperatures lower to $250^{\circ} \mathrm{C}$ but modified the thermal degradation process over this temperature. The temperature of maximum degradation rate shifts towards higher temperatures with HAp content, although deeper analysis has to be done to obtain detail analysis.

Data obtained by the thermogravimetric analysis (Fig. 6) was standardized by means of Eq. 1 to find the degree of conversion $\alpha$ versus temperature (Fig. 7) at 
different heating rates. The non-isothermal isoconversional kinetic parameters were calculated from $\alpha-T$ curves by the application of the isoconversional KAS equation, Eq. 7, to different conversions, and from these, the isothermal parameter $\ln (g(\alpha) / A)$, with which the studied degradation process would subsequently be simulated. The kinetic analysis was only applied to the main loss peak associate to the degradation of the organic chains of the precursors GPTMS and VTES.

Table 4 shows the kinetic parameters of non-isothermal curing obtained from Eq. 7 for the samples type G-V. The process was repeated with the other two samples containing HAp. Figure 8 shows the experimental relationship between $\ln \left(\beta / T^{2}\right)$ and the inverse of temperature, with the adjustment made with Eq. 7 .

In Table 5 it can be seen that activation energy $E$ is modified during the degradation, strongly increasing with the advance of the reaction, probably due to the bigger stability of the bonds as the material degradation proceeds (i.e., $\mathrm{Si}-\mathrm{O}-\mathrm{Si}$ is more stable than $\mathrm{Si}-\mathrm{C}$ bond). As it can be seen in Table 5 an high increase of HAp content ( $5 \% \mathrm{GV}$ ) produces an increase of the activation energy $E$ for a given conversion value, whereas a low increase of HAp content $(2.5 \% \mathrm{GV})$ produces a slightly no regular modification of

Table 4 Kinetic parameters of non-isothermal for GV sample, using the model $n=6$

\begin{tabular}{llllll}
\hline$\alpha$ & $E / \mathrm{kJ} / \mathrm{mol}$ & $\ln [A R / g(\alpha) E]$ & $\ln [g(\alpha) / A]$ & $\ln A / \min { }^{1}$ & $R^{2}$ \\
\hline 0.2 & 143.3 & 17.38 & -27.13 & 26.24 & 0.9927 \\
0.3 & 156.5 & 18.81 & -28.66 & 28.65 & 0.9943 \\
0.4 & 166.1 & 19.72 & -29.62 & 30.48 & 0.9981 \\
0.5 & 174.4 & 20.39 & -30.34 & 32.17 & 0.9998 \\
0.6 & 184.3 & 21.22 & -31.22 & 34.19 & 0.9996 \\
0.7 & 197.2 & 22.13 & -32.20 & 36.61 & 0.9978 \\
0.8 & 215.3 & 23.11 & -33.27 & 39.70 & 0.9980 \\
\hline
\end{tabular}

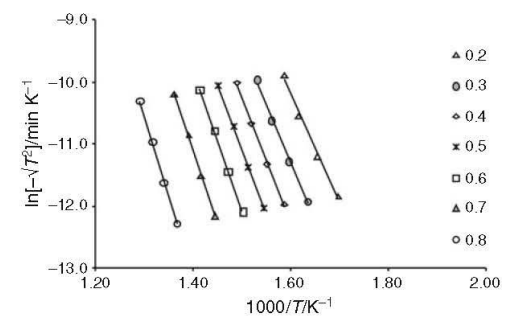

Fig. 8 Parameter $\ln \left(\beta / T^{2}\right)$ versus the inverse of temperature for sample $\mathrm{G}-\mathrm{V}$ between 0.2 and 0.8 conversion degree
E. The parameters $\ln (A R /(g(\alpha) E))$ and the associated $A$ value exhibits similar trend.

To establish the kinetic model for system $\mathrm{G}-\mathrm{V}$, the isoconversional kinetic parameters (Table 4) and the equation (Eq. 8) were used (the same process was done for the other two formulations with HAp). Different kinetic models were studied: diffusion (D1, D2, D3 and D4), Avrami-Erofeev (A3/2, A2, A3 and A4), power law (P2), phase-boundarycontrolled reaction ( $\mathrm{R} 2$ and $\mathrm{R} 3$ ), reaction-order $/ \mathrm{n} /(\mathrm{n} /=6$, $5,3,2,1.5$ and 1 denominated $\mathbf{F} 1)$ and autocatalytic $(/ \mathbf{n} /+1$ $\mathrm{m} /=2$ with $/ \mathrm{n} /=1.5$, and $/ \mathrm{n} /+/ \mathrm{m} /=3$ with $/ \mathrm{n} /=2.1$, $2.3,2.4,2.9)[26]$.

From the parameters $\ln (A R /(g(\alpha) E))$ and $E$ shown in Table 4 and the $g(\alpha)$ functions, $A$ values were calculated for all different kinetics models used. Subsequently, by plotting $E$ versus $\ln A$ (Eq. 8), we determined the IKRs for all models used. Table 6 shows the obtained results, as well as the $T_{\text {iso }}$ values determined from the slope of the IKRs [27]. The model considered that it is the best one describing the sol-gel material degradation is $n=6$ because this model shows a good regression and $T_{\mathrm{jso}}$ values closer to the experimental procedures. Model $n=5$ also has a good regression $\left(R^{2}\right)$ and values of $T_{\text {iso }}$ close to those found in the isoconversional method, nevertheless, model $n=6$ correlate better when all the systems are considered globally. In agreement with Vyazovkin and Linert [25], a $T_{\text {iso }}$ value close to the range of experimental temperatures indicates that the kinetic model accurately describes the reactive process. The same conclusion was reached for systems with HAp.

To confirm the methodology used with the IKR, we determined $E_{\mathrm{ap}}$ and $\ln A$ for each tested model with the Coats-Redfern method (Eq. 6) [27, 28]. The results Coats-Redfern method (Eq. 6)
obtained for the sample G-V when Eq. 6 was applied to the conversions related to the high mass loss conversions, are shown in Table 6 (similar results were obtained for the other two samples with HAp and for other heating rates) Some of the models exhibit very good regressions, and so from these data alone, it is not possible to establish the reaction mechanism. To determine the kinetic model, it

Table 5 Variation of the activation energy with the conversion of the samples GV and with different (2.5 and 5\%) contents of HAp

\begin{tabular}{llll}
\hline Conversion & GV & $2.5 \% \mathrm{GV}$ & $5 \% \mathrm{GV}$ \\
\hline 0.2 & 143.3 & 114.4 & 144.4 \\
0.3 & 156.5 & 136.6 & 167.2 \\
0.4 & 166.1 & 153.2 & 185 \\
0.5 & 174.4 & 166.4 & 204.2 \\
0.6 & 184.3 & 179 & 226.3 \\
0.7 & 197.2 & 194 & 251.2 \\
0.8 & 215.3 & 205.5 & 270.8 \\
\hline
\end{tabular}

S) Springer 
M. Hernández-Escolano et al

Table 6 Arrhenius parameters determined by the Coats-Redfern method and isokinetic parameters for a G-V sample at a heating rate of $10^{\circ} \mathrm{C} / \mathrm{min}$

\begin{tabular}{|c|c|c|c|c|c|c|c|}
\hline \multirow[t]{2}{*}{ Models } & \multicolumn{3}{|c|}{ Coats-Redfern } & \multicolumn{4}{|l|}{ IKR } \\
\hline & $\bar{E}$ & $\ln A / \min { }^{1}$ & $R^{2}$ & $\bar{a}$ & $b$ & $T_{\mathrm{iso}} / / \mathrm{C}$ & $R^{2}$ \\
\hline $\mathrm{A} 3 / 2$ & 24.6 & 1.33 & 0.9476 & 0.103 & 11.772 & 889.0 & 0.9828 \\
\hline A2 & 15.6 & -0.65 & 0.9259 & 0.099 & 12.664 & 943.5 & 0.9833 \\
\hline $\mathrm{A} 3$ & 6.6 & -3.04 & 0.8241 & 0.094 & 13.555 & 1003.4 & 0.9838 \\
\hline A4 & 2.1 & -4.95 & 0.4393 & 0.092 & 14.000 & 1035.6 & 0.9840 \\
\hline $\mathrm{R} 2$ & 33.4 & 2.17 & 0.9312 & 0.110 & 9.322 & 824.1 & 0.9801 \\
\hline R3 & 36.3 & 2.43 & 0.9429 & 0.108 & 9.924 & 838.9 & 0.9793 \\
\hline D1 & 62.6 & 7.73 & 0.9213 & 0.124 & 6.934 & 700.2 & 0.9711 \\
\hline D2 & 83.5 & 13.08 & 0.9562 & 0.128 & 5.612 & 663.9 & 0.9734 \\
\hline D3 & 84.0 & 10.09 & 0.9582 & 0.134 & 3.307 & 622.5 & 0.9767 \\
\hline D4 & 76.1 & 8.42 & 0.9471 & 0.130 & 3.844 & 649.8 & 0.9746 \\
\hline F1 & 42.6 & 4.93 & 0.9616 & 0.113 & 9.990 & 793.4 & 0.9819 \\
\hline Power & 7.1 & -3.12 & 0.6851 & 0.095 & 13.236 & 998.3 & 0.9809 \\
\hline$n=1.5$ & 53.2 & 7.24 & 0.9800 & 0.118 & 9.250 & 745.1 & 0.9848 \\
\hline$n=2$ & 65.3 & 9.80 & 0.9904 & 0.124 & 8.402 & 695.4 & 0.9878 \\
\hline$n=3$ & 93.1 & 15.56 & 0.9979 & 0.138 & 6.417 & 597.3 & 0.9931 \\
\hline$n=5$ & 159.3 & 28.93 & 0.9964 & 0.171 & 1.673 & 428.6 & 0.9985 \\
\hline$n=6$ & 195.4 & 36.14 & 0.9947 & 0.189 & -0.913 & 361.6 & 0.9992 \\
\hline$n=2.1, m=0.9$ & 4.1 & -1.40 & 0.9516 & 0.093 & 16.355 & 1021.8 & 0.9891 \\
\hline$n=2.3, m=0.7$ & 28.2 & 3.86 & 0.9968 & 0.105 & 13.236 & 870.6 & 0.9917 \\
\hline$n=2.4, m=0.6$ & 38.7 & 5.78 & 0.9979 & 0.110 & 12.063 & 815.7 & 0.9922 \\
\hline$n=2.9, m=0.1$ & 84.5 & 14.04 & 0.9980 & 0.134 & 7.274 & 625.6 & 0.9931 \\
\hline
\end{tabular}

was also used the average value of $E$ obtained isoconversionally shown in Table 5 . This value of $E$ is considered the effective value because it was obtained without the necessity of determining the model. In addition to the good regression, the correct kinetic model must also possess a value of $E$ similar to the effective value. According to these criteria model $n=6$, with good regression and $E$ value closer to the $E_{\text {ef }}$ in the three samples, is considered the correct one for samples with and without HAp. Other similar models such $n=5$ can also describe the curing.

All the samples investigated showed that the two methodologies (IKR and Coats-Redfern) lead to the same result, and in both cases, it is necessary to know the effective $E$ (isoconversional) value to determine the complete kinetic triplet $(E, A$ and $f(\alpha))$ [23].

If we compare the activation energies (Table 5), a simple analysis would conclude that the fastest system considering degradation is that with the minor $E$, but this is not always true because a compensation effect between $E$ and $\ln A$ exists [29]. Then, to know which is the most efficient system it should be compared the rate constant, $k$ (because samples fit the same kinetic model $g(\alpha)$ ). Eq. 9 shows the Arrhenius relation between $k$ (rate constant), $A$ and $E$.

$k=A \cdot \exp \left(-\frac{E}{R T}\right) \rightarrow \ln k=\ln A-\frac{E}{R T}$

Introducing in Eq. 9 values of $E, A$ and $\alpha$ with the chosen kinetic model $n=6$ and for a given conversion degree $(\alpha=0.5)$ we can obtain a graphic like Fig. 9 $(\ln k=f(1 / T))$

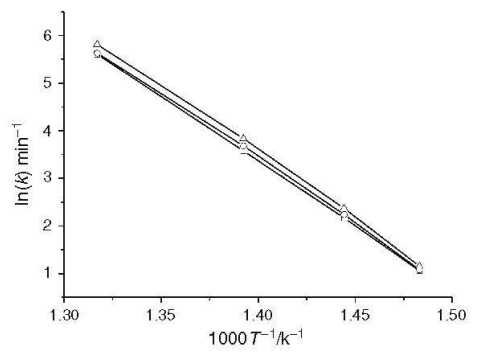

Fig. 9 Rate constant, $\ln k$, versus the inverse of temperature $(1000 / \mathrm{T})$ for G-V (filled square), G-V2.5HAp (filled circle) and G-V5HAp (filled triangle) samples

黑 Springer 

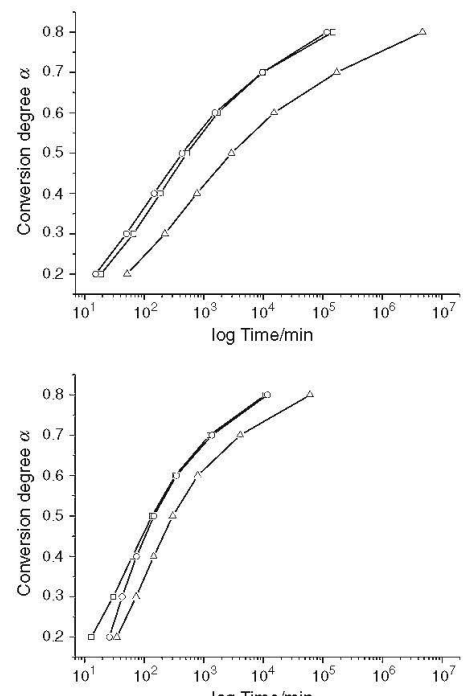

$\log$ Time/min

Fig. 10 Predicted evolution of weight loss against time at 300 and $400^{\circ} \mathrm{C}$ of inotranic-otganic hybrid system with and without $\mathrm{Hap}$ $\mathrm{G}-\mathrm{V}$ (filled square), G-V2.5Hap (filled circle) and G-V5Hap (filled triangle $)$ samples

In this figure, it can be observed that the addition of HAp decrease the rate constant which means that these systems are more stable with a reduction of the degradation rate with temperature. These results corroborate that in order to know which system could be more stable at determined temperature it is appropriate to consider not only $E$ but also the parameter $\ln A$ if they fit the same kinetic model $[27,28]$.

Finally, by applying the isoconversional procedure, Eq. 3, we can predict the time necessary to reach a determined degree of mass loss at a selected temperature. Figure 9 shows the plot of mass loss against time at 300 and $400{ }^{\circ} \mathrm{C}$ for the different formulations. We have found that the simulated time are similar to those obtained isothermally. These results suggest that the methodology used in this study is correct and could be used to simulate isothermal degradation at other temperatures (Fig. 10).

As it can be seen in Fig. 10, the more thermal stable systems are those with higher HAp content (at a specific temperature the mass losses at a time is less as hydroxyapatite increase). The reason for this procedure can be that the addition of HAp stabilizes the network formed by solgel process specially when its content is $5 \% \mathrm{wt}$.

Conclusions

In order to optimize the curing procedure for hybrid systems to obtain Si networks with or without organic chains, a thermal degradation TG test has been developed. Different types of samples were prepared by sol-gel process with the alkoxysilanes GPTMS and VTES, with different amount of HAp $(0,2.5$ and $5 \% \mathrm{w} / \mathrm{w})$.

Combining FTIR and TG tests it was possible to obtain better description of the degradation mechanism. Degradation process starts with the loss of low molecular mass polymer chains as $\mathrm{CH} 2$ around $200{ }^{\circ} \mathrm{C}$, continuing after $250^{\circ} \mathrm{C}$ with the main degradation process with total loss of the organic chains and finally after $450{ }^{\circ} \mathrm{C}$ the degradation of the Si-O-Si network

Two methods (Coats-Redfern and IKR) that allows the determination of the complete kinetic triplet $(E, A, g(\alpha))$ have been applied. The effective $E$ value has to be known, which can be determined with an isoconversional procedure (model-free).

All systems showed that the reaction mechanism followed an $n=6$ model, showing no dependence of the HAp quantity. Degradation rates for all the systems were obtained and the results showed that adding HAp, systems are more thermal stable.

After the numerical modelization of the degradation process, with the knowing of the kinetic triplet, it is possible to optimize de curing treatment. It is possible to determine the temperature and time conditions to obtain total inorganic material or hybrids ones. For example, curing temperatures under $200^{\circ} \mathrm{C}$ will lead to an hybrids network. In order to obtain an inorganic network, it will be necessary to calculate isothermal degradation curves as those showed in Fig. 10. If we apply curing temperatures around $300{ }^{\circ} \mathrm{C}$, the time needed to obtain the inorganic network will be $10^{5}$ min for samples without HAp or $2.5 \%$ HAp, and more than $10^{6}$ for samples with 5\% HAp.

\section{References}

1. Wen JY, Wilkes GL. Organicfinorganic hybrid network materials by the sol-gel approach. Chem Mater. 1996;8:1667-81.

Brinker CJ, Scherer GW. Sol-gel science: the physics and chemistry of sol-gel processing. London: Academic Press; 1990. 1997;8:443-9.

4. Wright J, Sommerdijk N. Sol-gel materials chemistry and applications. London: CRC Press; 2001 
5. Vasconcelos DCL, Carvalho JAN, Mantel M, Vasconcelos WL Corrosion resistance of stainless steel coated with sol-gel silica Corrosion resistance of stainless sted

6. Conde A, De Damborenea J, Duran A, Menning M. Protective Conde A, De Damborenea J, Duran A, Menning M. Protective
properties of a sol-gel coating on zinc coated steel. J Sol-Gel Sci Technol. 2006;37:79-85.

7. Sayilkan $H$, Sener S, Sener E, Sulu M. The sol-gel synthesis and application, 2003:39:733-9.

8. Parkhill RL, Krobbe ET, Donley MS. Application and evaluation of environmentally compliant spray-coated ormosil films as Coat. 2001:41:261-5.

9. Chan Z, Ai'mei L, Xiao Z, Miao F, Juan H, Hongbing Z Microstructures and properties of ORMOSIL comprising methyl. vinyl, and [gamma]-glycidoxypropyl-substitued silica. Opt Mater. 2007;29:1543-7.

10. Li PJ, Ohtsuki C, Kokubo T, Nakanishi K, Soga N, Nakamura T, Yamamuro T. Apatite formation induced by silica-gel in a simulated body-fluid. J Am Ceram Soc. 1992;75:2094-7.

11. Kawashita M, Nakao M, Minoda M, Kin HM, Beppu T, Miyamoto T, Kokubo T, Nakamura T. Apatite-forming ability of carboxyl group-containing polymer gels in a simulated body fluid. Biomaterials. 2003;24:2477-84.

12. Chico B, Galvăn JC, de la Fuente D, Morcillo M. Electrochemcal impedance spectroscopy study of the effect of curing time on the early barrier properties of silane systems applied on steel substrates. Prog Org Coat. 2007;60:45-53

13. Garcia-Heras M, Jimenez-Morales A, Casal B, Galvan JC, Radzki S, Villegas MA. Preparation and electrochemical study of cerium-silica sol-gel thin films. J Alloys Compd. 2004;380 19-24.

14. Galliano P, De Damborenea JJ, Pascual MJ, Duran A. Sol-gel coatings on 316L steel for clinical applications. J Sol-Gel Sci Technol. 1998;13:723-7.

15. Ohtsuki C, Miyazaki T, Tanihara M. Development of bioactive organic-inorganic hybrid for bone substitutes. Mater Sci Eng C

2002;22:27-34. gel on stainless steel 316L. J Non-Cryst Solids. 2004;348:218-24.
17. García C, Ceré S, Durán A. Bioactive coatings deposited on titanium alloys. J Non-Cryst Solids. 2006;352:3488-95.

18. Balarte J, Loper DA, Rosero NC, Duran A, Aparicio M, Cere SM. Electrochemical evaluation of multilayer silica-metacrylate (atings containing bioactive particles on surgical grade stainless steel. Surf Coat Technol. 2008;203:80-6.

19. Salla JM, Cadenato A, Ramis X, Morancho JM. Thermoset cure kinetics by isoconversional methods. J Therm Anal Calorim. 1999;56:771-81.

20. Vyazovkin S, Wight CA. Kinetics in solids. Annu Rev Phys Chem. 1997:48:125-49.

21. Coats AW, Redfern JP. Kinetic parameters from thermogravimetric data. Nature. 1964;201:68

22. Ramis X, Salla IM, Cadenato A, Motancho JM. Simulation of isothermal cure of a powder coating-non-isothermal DSC experiments. J Therm Anal Calorim. 2003;72:707-18.

23. Ramis X, Cadenato A, Salla JM, Morancho JM, Valles A, Conta L, Ribes A. Thermal degradation of polypropylene/starch-based materials with enhanced biodegradability. Polym Degrad Stab. 2004;86:483-91

24. Vyazovkin S, Linert $W$. The application of isoconversional methods for analyzing isokinetic relationships occuring at thermal-decomposition of solids. J Solid State Chem. 1995;114: $392-8$

25. Vyazovkin S, Linert W. False isokinetic relationships found in the nonisothermal decomposition of solids. Chem Phys. 1995; 193:109-18

26. Chrissafis K. Kinetics of thermal degradation of polymers. J Thern Anal Calorim. 2009;95:273-83

27. Garcia SJ, Serra A, Ramis X, Suay J. Influence of the addition of erbium and ytterbium triflates in the curing kinetics of a DGEBA/ $o$-tolybiguanide powder mixture. J Therm Anal Calorim. 2007;89:223-31.

. Garcia SJ, Ramis X, Serra A, Suay J. Cationic crosslinking of solid DGEBA resins with ytterbium(III) trifluoromethanesulfonate as 2006:83:429-38.

. Salla JM, Morancho JM, Cadenato A, Ramis X. Non-isothermal degradation of a thermoset powder coating in inert and oxidan 